\title{
BROMIDE CHARACTERISTICS AND \\ DEFORMATION MECHANISMS OF NATURALLY \\ DEFORMED ROCK SALT OF THE GERMAN \\ ZECHSTEIN BASIN
}

\author{
Dissertation \\ zur Erlangung des Doktorgrades \\ der Mathematisch-Naturwissenschaftlichen Fakultät \\ der Georg-August-Universität zu Göttingen
}

vorgelegt von

YVONNE KÜSTER

aus Görlitz 
D 7

Referent: PD Dr. Helmut Klein

1. Korreferent: Prof. Dr. Bent Hansen

2. Korreferent: Dr. Bernd Leiss

Tag der mündlichen Prüfung: 30. Juni 2011 


\section{Abstract}

This dissertation includes four studies that were concerned with geochemical characteristics and deformation mechanisms of rock salt. The studies focused especially on the rock salt of the Stassfurt Formation (Zechstein 2) and samples were taken from different salt deposits of Germany and the Netherlands.

The first study investigated the relationship between deformation intensity and bromide characteristics of the rock salt. For this, the bromide distribution of a defined stratigraphic section (Hauptsalz) of the Stassfurt Formation (Zechstein 2) was investigated in three salt deposits, with bedded salt (Teutschenthal) compared to domal salts (Morsleben, Gorleben). The comparison between the locations yielded the following findings: (1) The characteristic trend of the bromide profile can be observed in both the bedded and the more intensely deformed domal salts. (2) The dispersion of bromide contents along the running average curve is lower in Morsleben and Gorleben than in Teutschenthal, especially in the lower half of the Hauptsalz. (3) The Kristallbrocken are absent in the lower half of the Hauptsalz of Morsleben and Gorleben. On the one hand, the lower dispersion of the bromide contents in the domal salts and the absence of the Kristallbrocken are clear indications for the influence of salt migration-related processes on the bromide distribution characteristics. It shows that these processes are associated with a redistribution of bromide, which eventually results in a homogenisation of the originally varying bromide contents. On the other hand, preservation of the characteristic trend in all bromide profiles indicates that large-scale brecciation, folding processes, or circulating bromide-rich fluids could play only a minor role during the formation of the salt domes.

The topic of the second and third study of this work was the laminated halite type Kristallbrocken that is characteristic for the Stassfurt Formation (Z2) rock salt. The investigations of both studies contributed to the understanding of the structure, the formation and the deformation mechanisms of this halite type. X-ray texture analyses on 4 Kristallbrocken samples from the salt deposit Teutschenthal demonstrated that the Kristallbrocken are single crystals and that they can be regarded as relics of formerly larger 'single crystal-layers'. Microscopic investigations showed that the internal lamination of the Kristallbrocken consists of several types of sulfate inclusions (anhydrite, polyhalite). Especially characteristic are anhydrite aggregates with surrounding brine. The original size of the monocrystalline beds, their high amount of relatively large solid inclusions as well as the characteristic sedimentary features make it unlikely that these laminated single crystals were grown directly from a solution. A more probable scenario is that an originally fine-grained, 
laminated halite sediment was converted into monocrystalline Kristallbrocken in a postsedimentary grain growth process. A plausible explanation for the formation of the characteristic anhydrite aggregates is that, initially, gypsum crystals were incorporated in the halite sediment, which converted into anhydrite within the later formed Kristallbrocken. The solid volume reduction as well as the release of water in consequence of a complete gypsumanhydrite conversion explains the present appearance of the characteristic solid inclusions within the Kristallbrocken. The brittle deformational behavior of the monocrystalline Kristallbrocken can be explained by the originally large size and the high amount of solid inclusions forming the internal lamination, since these features make this halite type behave rheologically more competent compared to the surrounding fine- to coarse-grained polycrystalline rock salt.

The aims of the fourth study were the investigation of textures in naturally deformed rock salt and their correlation with micro- and macrostructures as well as large scale salt structures. This dissertation presents the results of first neutron texture measurements on four samples from the salt deposits Teutschenthal, Morsleben, and Gorleben. The samples from Morsleben and Gorleben show a clear grain shape anisotropy, whereas the samples from Teutschenthal display only a weak grain elongation. The pole figures of all samples show no crystallographic preferred orientation (texture). The lack of texture indicates that Intracrystalline deformation mechanisms played no or only a minor role during the deformation of the salts. So, alternative deformation mechanisms have to be taken into account such as solution precipitation processes, diffusion creep, or fluid assisted grain boundary migration. 


\section{Kurzfassung}

Die vorliegende Dissertation beinhaltet die Ergebnisse von vier Studien, die sich mit geochemischen Charakteristika und Deformationsmechanismen von Steinsalz befassten. Die Studien konzentrierten sich vor allem auf das Steinsalz der Staßfurt-Folge (Zechstein 2) und die Proben stammen aus verschiedenen Salzlagerstätten Deutschlands und der Niederlande.

Die erste Studie untersuchte den Zusammenhang zwischen Deformationsintensität und Bromidcharakteristika im Steinsalz. Dazu wurde die Bromidverteilung eines definierten stratigraphischen Abschnitts (Hauptsalz) der Staßfurt-Folge (Zechstein 2) in drei Salzlagerstätten untersucht, wobei Salz aus flacher Lagerung (Teutschenthal) mit Salzen aus Salzdomen (Morsleben, Gorleben) verglichen wurden. Der Vergleich der verschiedenen Lokalitäten ergab folgende Ergebnisse: (1) Der charakteristische Verlauf des Bromidprofils ist sowohl in flach gelagerten Salzen als auch im stärker deformierten Salz der Salzdome zu erkennen. (2) Die Streuung der Bromidgehalte entlang der gleitenden Durchschnittskurve ist in den Salzen aus Morsleben und Gorleben geringer als in Teutschenthal, insbesondere im unteren Bereich des Hauptsalzes. (3) Im unteren Bereich des Hauptsalzes von Morsleben und Gorleben wurden keine Kristallbrocken beobachtet. Die geringere Streuung der Bromidgehalte im Salz von Salzdomen sowie das Fehlen von Kristallbrocken sind einerseits klare Anzeichen für den Einfluss von Verformungsprozessen während der Salzdomentstehung. Es zeigt, dass diese Prozesse mit einer Umverteilung von Bromid verbunden sind, was schließlich $\mathrm{zu}$ einer Homogenisierung der ursprünglich stärker variierenden Bromidgehalte führte. Andererseits zeigt der charakteristische Verlauf des Bromidprofils in allen drei Lokalitäten, dass großmaßstäbliche Brekziierung, Faltungsprozesse oder zirkulierende bromidreiche Fluide während der Entstehung der Salzdome nur eine untergeordnete Rolle gespielt haben können.

Das Thema der zweiten und dritten Studie dieser Arbeit war der für die StaßfurtFormation (Z2) charakteristische, laminierte Halit-Typ Kristallbrocken. Die Untersuchungen der beiden Studien sollten dazu beitragen, diesen Halit-Typ besser zu verstehen und bisher ungeklärte Fragen bezüglich Struktur, Bildung und Deformation beantworten zu können. Röntgentexturmessungen an 4 Kristallbrocken-Proben aus der Salzlagerstätte Teutschenthal zeigten, dass es sich bei diesem Halit-Typ um Einkristalle handelt und sie als Relikte von vormals größeren Einkristalllagen angesehen werden können. Detaillierte mikroskopische Untersuchungen zeigten, dass die Internlamination der Kristallbrocken aus verschiedenen Arten von Sulfateinschlüssen (Anhydrit, Polyhalit) besteht. Besonders charakteristisch sind dabei Anhydritaggregate, die von Lösung umgeben sind. Durch die ursprüngliche Größe der 
Einkristalllagen, deren hohen Anteil an relativ großen Festeinschlüssen sowie ihre charakteristischen sedimentären Merkmale erscheint es sehr unwahrscheinlich, dass die laminierten Einkristalle direkt aus der Lösung gebildet worden sind. Viel wahrscheinlicher ist, dass ursprünglich ein feinkörniges, laminiertes Halitsediment vorhanden war, welches in einem postsedimentären Kornwachstumsprozess $\mathrm{zu}$ monokristallinen Kristallbrocken umgewandelt wurde. Eine plausible Erklärung für die Entstehung der charakteristischen Anhydritaggregate ist, dass zunächst Gipskristalle im Halitsediment eingeschlossen wurden, welche sich im später gebildeten Kristallbrocken in Anhydrit umwandelten. Die Volumenreduktion sowie die Freisetzung von Wasser bei einer vollständigen Gips-AnhydritUmwandlung erklären das heutige Aussehen dieser Festeinschlüsse im Kristallbrocken. Das bruchhafte Deformationsverhalten der monokristallinen Kristallbrocken kann durch die ursprüngliche Größe sowie die große Anzahl von Festeinschlüssen erklärt werden, denn dadurch verhält sich dieser Halittyp gegenüber der umgebenden fein- bis grobkörnigen Steinsalzmatrix rheologisch kompetenter.

Die Ziele der vierten Studie waren die Untersuchung von Texturen in natürlich deformierten Salzgesteinen und deren Korrelation mit Mikro- und Makrostrukturen sowie der gesamten Salzstruktur. Die vorliegende Dissertation präsentiert die Ergebnisse der ersten Neutronentexturanalysen von vier Proben aus den Salzlagerstätten Teutschenthal, Morsleben und Gorleben. Die Proben aus Morsleben und Gorleben zeigen eine deutliche Kornformanisotropie, während die Proben aus Teutschenthal nur eine schwache Kornlängung aufweisen. Die Polfiguren aller Proben zeigen keine kristallographische Vorzugsorientierung (Textur). Das Fehlen einer Textur deutet darauf hin, dass intrakristalline Deformationsmechanismen keine oder nur eine untergeordnete Rolle bei der Deformation dieser Salze gespielt haben können. Es müssen daher alternative Deformationsmechanismen in Betracht gezogen werden wie z.B. Drucklösungsprozesse, Diffusionskriechen oder flüssigkeitsgestützte Korngrenzmigration. 


\section{Contents}

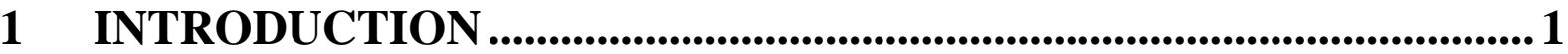

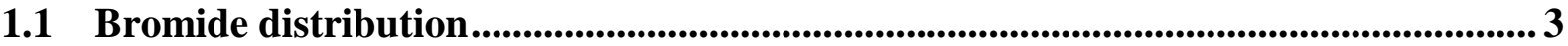

1.2 Deformation mechanisms in naturally deformed rock salt ..........................................5

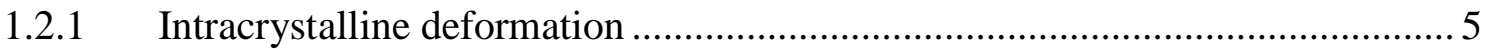

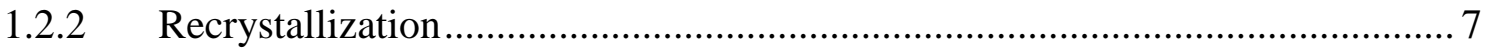

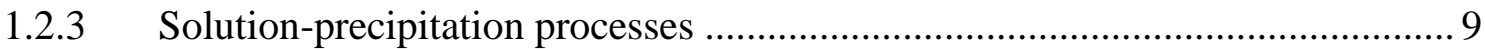

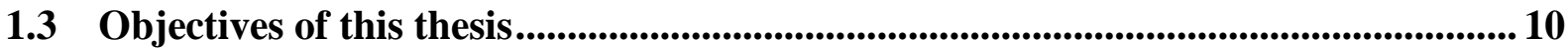

1.4 Organization of this thesis ..................................................................................................... 11

2 SAMPLES AND METHODS ..................................................................13

2.1 Study locations and sample material ........................................................................... 13

2.2 Methodology and sample preparation................................................................... 16

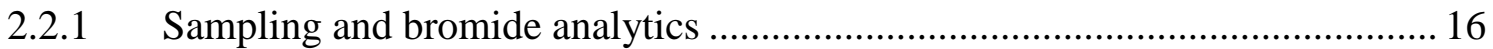

2.2.2 Scanning electron microscopy (SEM) of solid inclusions .............................. 18

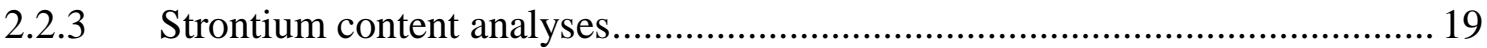

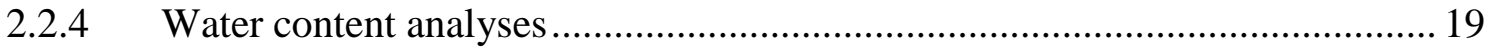

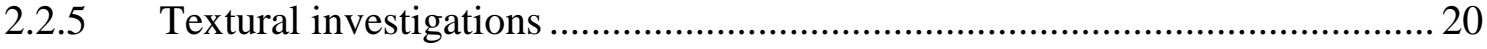

2.2.6 Sample preparation for microstructural investigations ................................. 25

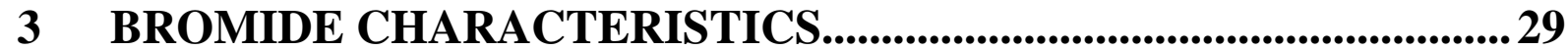

3.1 Bromide distribution characteristics of different Zechstein 2 rock salt sequences of the Southern Permian Basin: a comparison between bedded and domal salts ....... 29

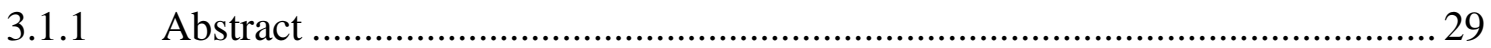

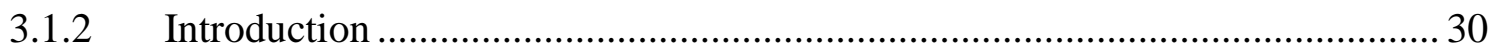

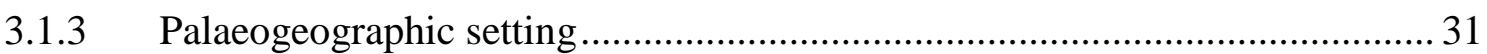

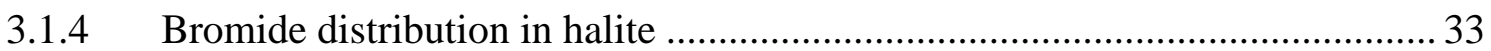

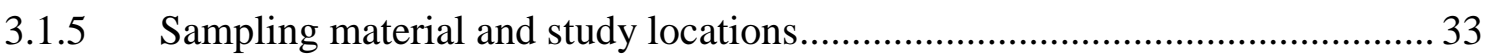

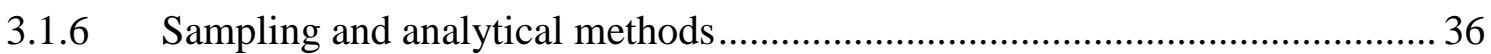

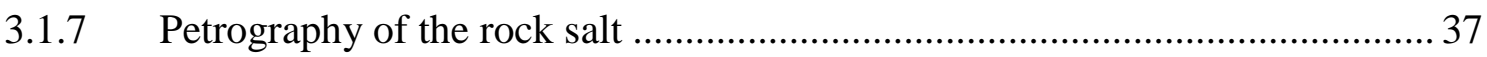

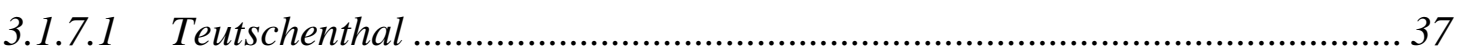

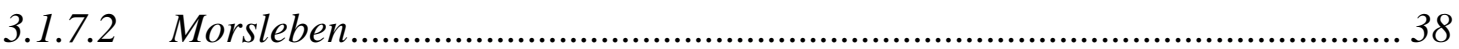

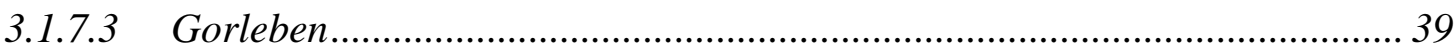




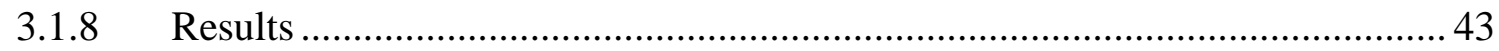

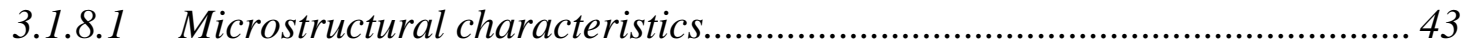

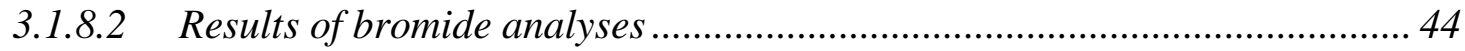

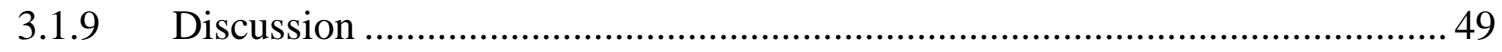

3.1.9.1 Characteristics of the bromide profiles....................................................... 49

3.1.9.2 Implications for the influence of salt migration-related processes............... 53

3.1.9.3 Bromide contents in different halite types ..................................................56

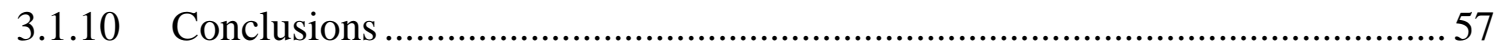

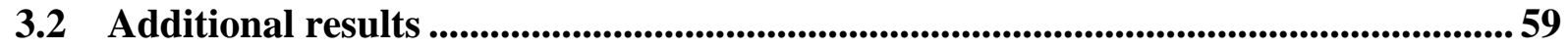

3.2.1 Detailed sampling of Kristallbrocken samples............................................. 59

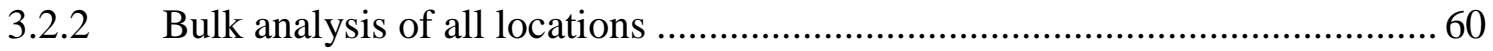

3.2.3 Electron microprobe analysis of a Kristallbrocken sample ............................. 62

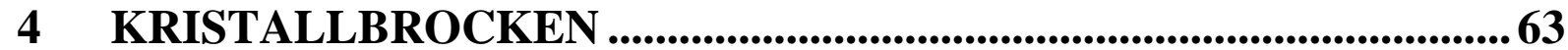

4.1 Structural characteristics of the halite fabric type 'Kristallbrocken' from the Zechstein Basin with regard to its development....................................................... 63

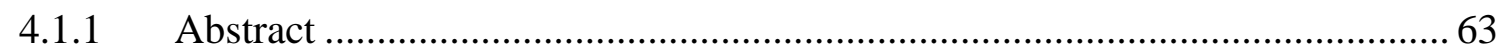

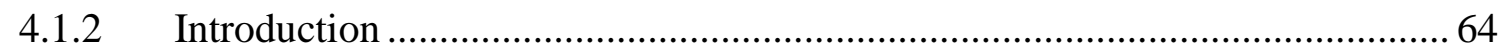

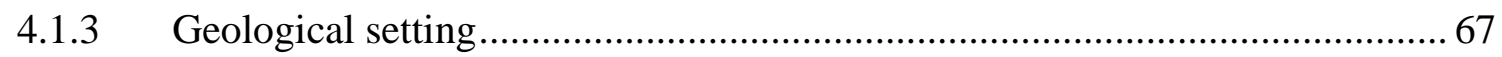

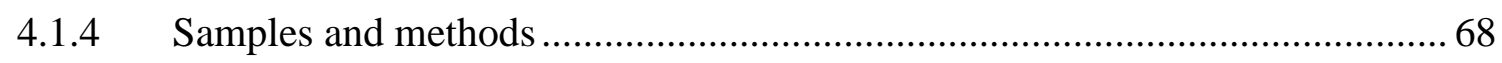

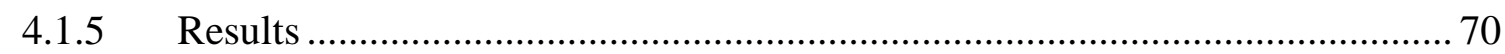

4.1.5.1 Microstructural characteristics.............................................................. 70

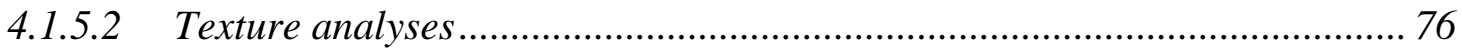

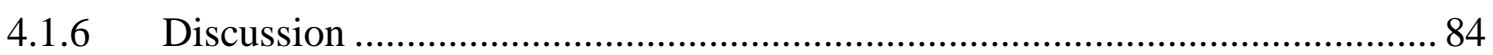

4.1.6.1 Texture analysis - methodical aspects ....................................................... 84

4.1.6.2 Texture analysis - microstructural aspects............................................... 86

4.1.6.3 Deformation mechanisms of Kristallbrocken.......................................... 87

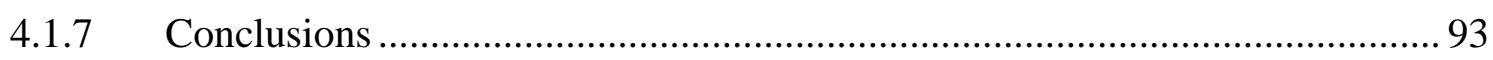

4.2 Compositional and microstructural characterization of solid inclusions in the laminated halite type 'Kristallbrocken' with regard to its formation in the Central European Zechstein Basin..........................................................................................95

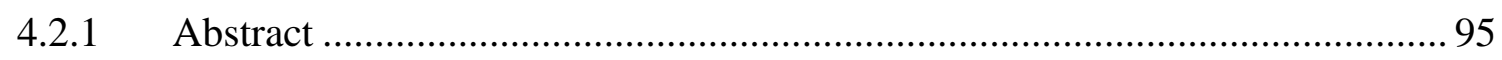

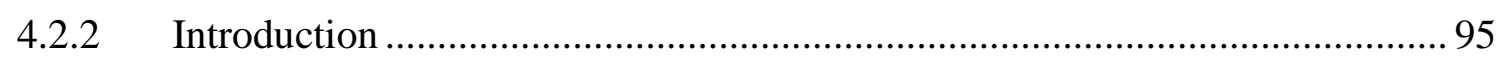

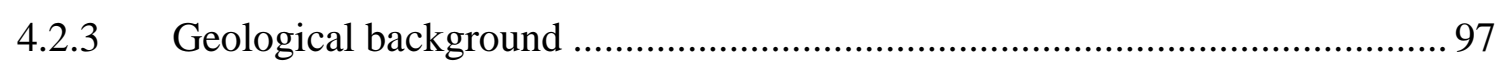

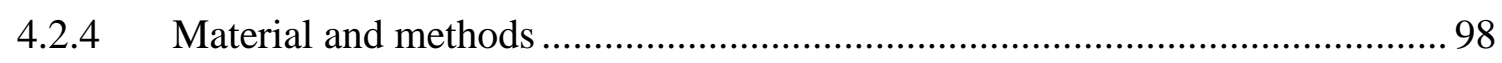

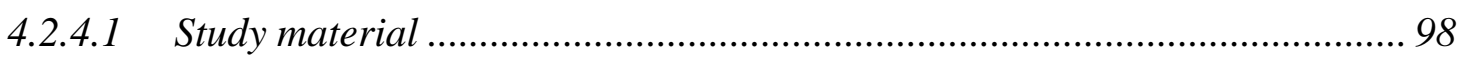




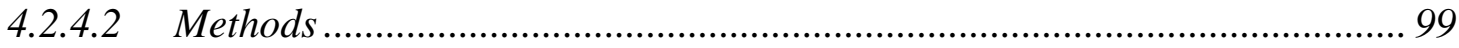

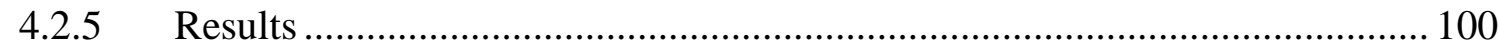

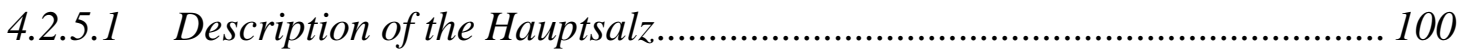

4.2.5.2 Petrography of the halite type Kristallbrocken ........................................ 102

4.2.5.3 SEM analyses of the solid inclusions ......................................................... 104

4.2.5.4 Strontium content of the anhydrite inclusions ............................................ 108

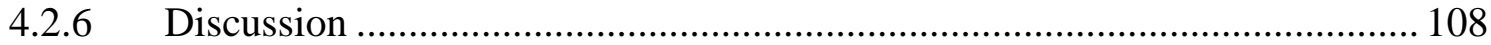

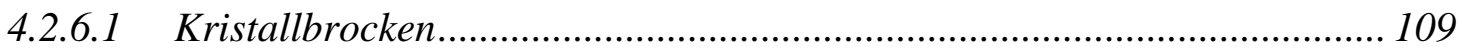

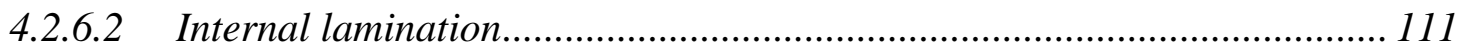

4.2.6.3 Propositions for a post-sedimentary formation process .......................... 114

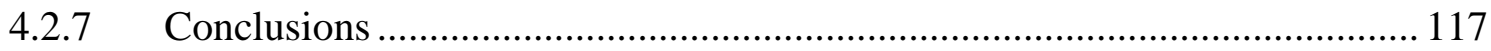

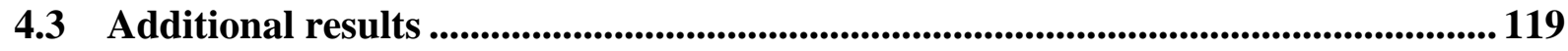

4.3.1 Sample Lt62-6-125 - comparison of M1, M2, and M3 .............................. 119

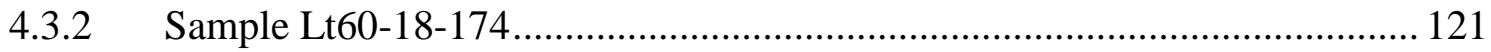

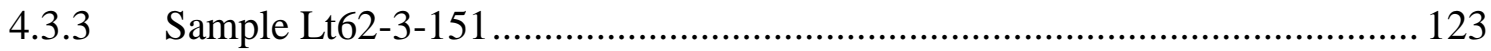

$5 \quad$ DEFORMATION MECHANISMS …..................................................125

5.1 Neutron texture analyses of naturally deformed halite rocks - Implications for

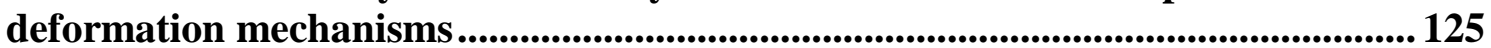

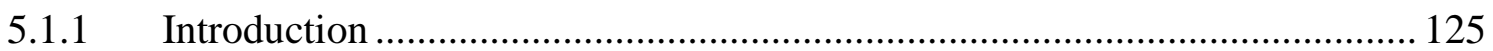

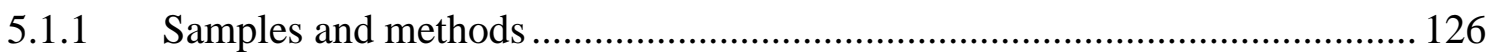

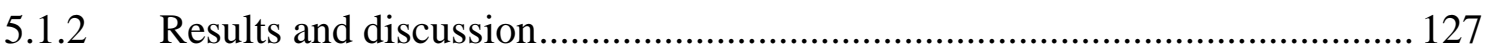

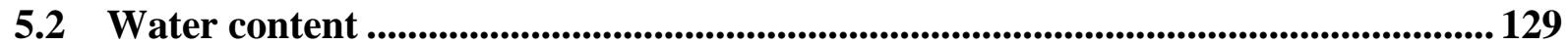

6 OVERALL RESULTS, CONCLUSIONS, AND OUTLOOK ........... 131

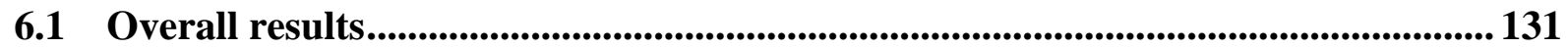

6.1.1 Summary and discussion of chapter 3 ..................................................... 131

6.1.2 Summary and discussion of Chapter 4 ......................................................... 134

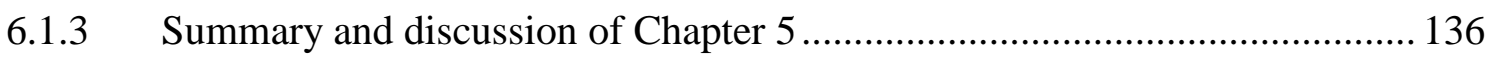

6.1.3.1 Texture measurements....................................................................... 137

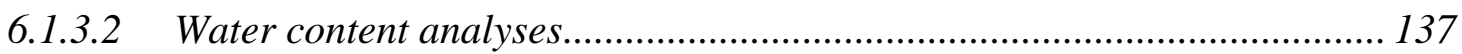

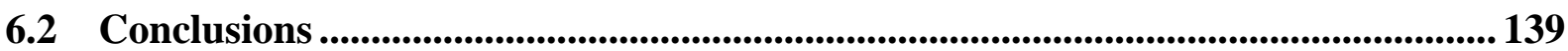

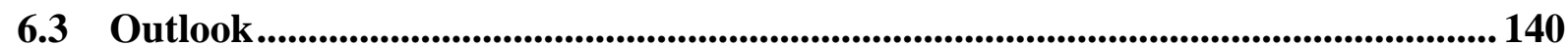

7 BIBLIOGRAPHY ........................................................................... 143

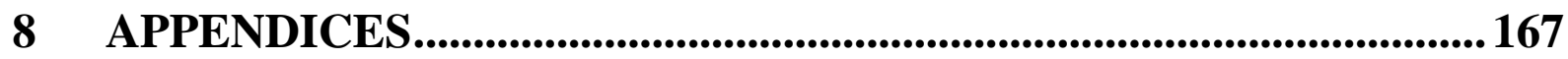





\section{INTRODUCTION}

Rock salt has a large economic and scientific significance. On the economic side, rock salt is traditionally used for the food industries and plays an important role in the chemical industry, e.g. for the production of diverse substances such as sodium hydroxide, chlorine, and hydrochloric acid; it can be used for the fabrication of glass, pottery, textile dyes and soaps, or plainly as de-icing material on streets and pavements. Apart from these direct uses as a raw material, the salt deposits themselves have become increasingly relevant for the interim storage of liquid or gaseous hydrocarbons (e.g., Richter-Bernburg 1970; Hofrichter 1972; Hofrichter 1974; Jagsch \& Theylich 1999; Thoms \& Gehle 2000; Wilke et al. 2002). Additionally, for decades, salt deposits are objects of research (Herrmann 1980; Albrecht \& Hunsche 1980; Schneider 1988; Jaritz 1993; Hunsche \& Hampel 1999; Schulze \& Popp 2002; Wallner et al. 2002) as both the industry and politics look for possibilities for the safe final storage of all kinds of radioactive waste as well as for the storage of $\mathrm{CO}_{2}$ (e.g., Plötz 2003; Bachu \& Rothenburg 2003; Dusseault et al. 2004; Shi \& Durucan 2005). From the viewpoint of today's knowledge, it is therefore impossible to predict the full scale of future applications of salt as a host rock - and in consequence, the specific characteristics required from potential host rocks cannot yet be fully specified. This calls for thorough basic research into the deformation characteristics and physical properties of rock salt, as such knowledge is important for predicting the long-term behavior of rock salt in storage caverns or potential radioactive waste repositories, as well as for questions regarding the area of technical engineering.

On the scientific side, evaporites in general play an important role as climate indicators - directly through indication of warm climate periods and thus also for the reconstruction of 
paleoenvironmental distribution of land masses; indirectly through fluid and gaseous inclusions that provide data about paleoenvironmental conditions such as temperatures, sea water compositions, and atmosphere compositions (e.g., Hardie 1991; Horita et al. 1991; Lowenstein et al. 1998, 2001, 2005; Benison \& Goldstein 1999; Bobst et al. 2001; Siemann \& Ellendorf 2001; Timofeeff et al. 2001; Horita et al. 2002; Satterfield et al. 2005). In any of these studies, it is crucial for evaporite sedimentologists and geochemists to be able to distinguish depositional evaporite features from diagenetic features (Hardie et al. 1983). It is important to have knowledge about the depositional environment, the genetic history of the rock salt, and the corresponding different halite types (e.g., Wardlaw \& Schwerdtner 1966; Shearman 1970; Schreiber et al. 1976; Gornitz \& Schreiber 1981; Kendall 1992; Schreiber \& El Tabakh 2000; Pape et al. 2002; Warren 2006).

The determination of the bromide content in the halite facies of rock salt sequences is a standard tool for investigating marine evaporite deposits. The knowledge about its concentration in halite is critical for providing information about the geochemical environment of deposition (e.g., Kühn 1955; Es-Said 1974; Fisher \& Hovorka 1987; Smith et al. 1995; Raup \& Hite 1996; Kirkland et al. 2000). Bromide is therefore an excellent tool for the reconstructions of paleosalinities in evaporite basins and the exploration of potash deposits. The distribution of the bromide content in salt deposits is useful for their stratigraphic classification (e.g., Valyashko 1956; Baar 1963, Haltenhof \& Hofrichter 1972; Simon 1972; Käding 2003). For solution mining projects in salt domes, bromide content analyses of cuttings provide detailed information about the current stratigraphic location during drilling and complement geophysical data obtained by gamma-ray and density measurements (Schramm et al. 2002; Wilke et al. 2002).

This thesis represents a compilation of four studies concerning primarily the rock salt of the Stassfurt Formation (Z2), which is the second main depositional cycle of the German Zechstein group. The studies focus on the geochemical and deformational characteristics of this stratigraphic unit, which is especially a target unit for radioactive waste disposal (e.g., Asse, Morsleben etc.). This formation is widely distributed over the former Zechstein Basin and was extensively studied in the last decades (e.g., Jung 1968; Simon \& Haltenhof 1970; Simon 1972; Bachmann 1985; Popp et al. 1999; Herrmann 2000; Schlechter 2004). These studies focused on the petrography, the stratigraphy, the microstructural variability, and the bromide distribution of distinct deposits. In the drilling core storage facility of the Federal Institute for Geosciences and Natural Resources (BGR, Germany), a large number of drilling cores from several salt sites exists that represent the Stassfurt Formation rock salt completely 
or almost completely. This salt unit thus provides the possibility to compare rock salt originating from the same stratigraphic unit - but from different tectonic settings.

The first study is the systematic investigation of the bromide distributions in three wellpreserved drilling cores of the Stassfurt Formation rock salt, which were taken from salt deposits of different tectonic settings (bedded, domal). This approach aims to show a possible relationship between deformation intensity and bromide characteristics of the rock salt. Additionally, microstructural investigations are carried out to show to what extent the different deformation history of the salt deposits is reflected in the microstructural characteristics of the rock salt. The second and third study of the thesis examines a special halite type that occurs in the Stassfurt Formation rock salt, because there are many open questions concerning its nature as well as the formation and deformation mechanisms. In a fourth study, detailed texture measurements on naturally deformed rock salt from different salt structures in northern Germany are carried out via neutron texture goniometry. This study aims to correlate textures with micro-, macro- as well as large scale salt structures.

The following sections of this introduction give an overview of basic geochemical and deformational mechanisms of rock salt relevant for the understanding of the studies compiled in this thesis.

\subsection{Bromide distribution}

Bromide is the most important component in chemically precipitated marine chloride sediments, as it is not very reactive and has a long residence time of about 100 million years (Holland 1978; Chester 2000) in the oceans. It is therefore likely that the bromide concentration has not changed significantly during the Phanerozoic (Horita et al. 1991, 2002). Bromide does not form bromide minerals during the evaporation of sea water, but partially substitutes chloride in the crystal lattice of halite and other chloride minerals (e.g., Boeke 1908; Fig. 1.1).

The amount of bromide in halite is proportional to the bromide content in the parent brine. This relationship between bromide in halite and bromide in evaporating sea water is expressed by the partition coefficient

$$
{ }^{\text {halite }} D_{\mathrm{Br}}=\text { wt } \% \mathrm{Br}_{\text {halite }} / \mathrm{wt} \% \mathrm{Br}_{\text {sea water. }}
$$

It ranges from about 0.14 at the beginning of halite precipitation to approximately 0.07 at precipitation of first potash salts (Braitsch \& Herrmann 1963). Since the partition coefficient for bromide in halite is always less than one (Boeke 1908; Schobert 1912, quoted by Schulze 1958; D’Ans \& Kühn 1940, 1944; Braitsch \& Herrmann 1963), the parent brine becomes 
progressively enriched in bromide. This enrichment is also reflected in progressively increasing bromide contents in the chloride sediments with continuous sea water evaporation and chloride salt precipitation.

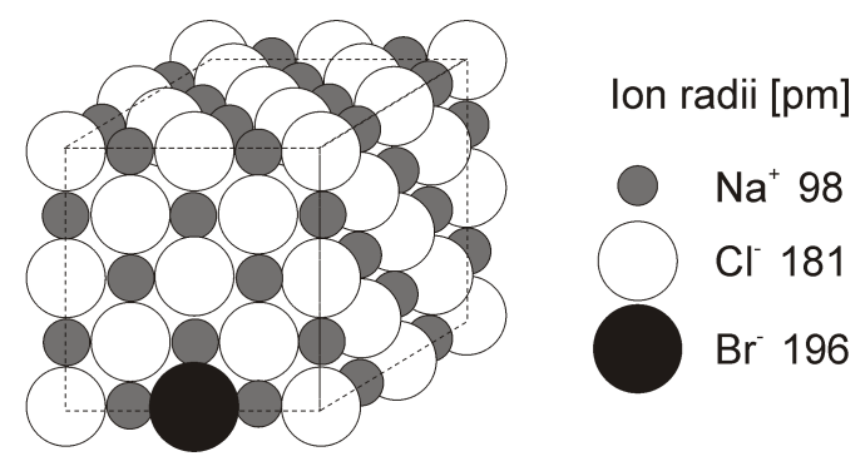

Fig. 1.1: Unit cell drawing of the sodium chloride $(\mathrm{NaCl})$ crystal structure showing the space filling representation of the ions. Due to similar ion radii, bromide can partially substitute chloride in the halite crystal lattice.

The composition of modern sea water is quite similar to that of Permian sea water (e.g., Horita et al. 1991; Lowenstein et al. 2001; Horita et al. 2002; Lowenstein et al. 2005). Modern sea water contains approximately 67 ppm bromide (Bruland 1983). Under ideal (theoretic) conditions, the bromide content increases during progressive evaporation to about $540 \mathrm{ppm}$ at the beginning of halite precipitation and the first halite is expected to contain $75 \mathrm{ppm}$. The bromide content of both the parent brine and halite increases with progressive sea water evaporation and halite precipitation, and reaches values of about $280 \mathrm{ppm}$ in halite prior to the precipitation of first potash salts (Braitsch 1962). This spectrum from $75 \mathrm{ppm}$ to $280 \mathrm{ppm}$ also applies only for ideal conditions (Fig. 1.2), which is not observed in nature, where significant variations can be observed between higher and lower values (Holser 1966a). Evaporation experiments revealed that the partition coefficient for bromide in halite depends especially on the bromide concentration and the major element composition of the brine (Siemann \& Schramm 2002) and, to a minor degree, on the temperature of the brine (Herrmann et al. 1973; Herrmann 2000).

Plotting the bromide content against the cumulative thickness of the sediment leads to characteristic curves that provide genetic and stratigraphic information as well as indication about secondary processes. For example, bromide profiles that closely resemble the trend of an "ideal" profile (Fig. 1.2) indicate gradual salinity increase in the evaporite basin. The regularity of such profiles is interpreted as being the result of deposition from a large brine volume that was only little affected by changes of the influx-reflux balance of the basin (Raup \& Hite 1978). In turn, a more irregular bromide distribution is interpreted as being produced 
in halite deposited in shallow water or small basins with small brine volumes. The variability in bromide concentration may result either from frequent fluctuations in brine concentration during deposition or from recrystallization processes of the halite during diagenesis (Raup \& Hite 1978).

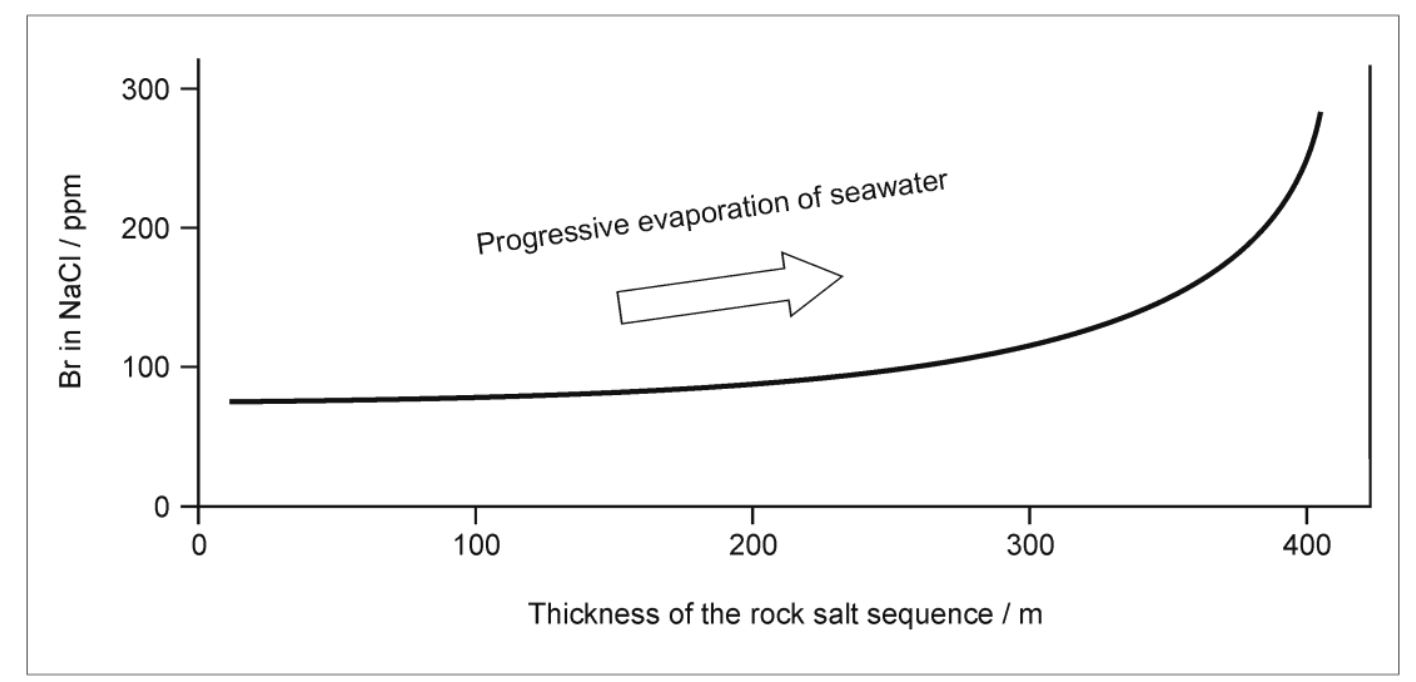

Fig. 1.2: Sketch of an "ideal" bromide profile showing a smooth gradual increase in bromide content from the base of the rock salt section to the top.

\subsection{Deformation mechanisms in naturally deformed rock salt}

Under natural conditions, rock salt generally deforms in the ductile regime, i.e. without crack formation (e.g., Guillopé \& Poirier 1979; Carter \& Hansen 1983; Carter et al. 1993; Hunsche $\&$ Schulze 1994). Depending on the geological and tectonic setting, the strain rates for natural in situ deformation of rock salt range from $10^{-16}$ to $10^{-8} \mathrm{~s}^{-1}$ (e.g., Jackson \& Talbot 1986; Watanabe \& Peach 2002). According to Skrotzki (1984), for the formation of cracks in rock salt, short-term tectonic movements with strain rates higher than $10^{-11} \mathrm{~s}^{-1}$ have to be assumed, or the crack formation develops in weak zones like anhydrite-rich layers.

The principle deformation mechanisms in rock salt are intracrystalline deformation, recrystallisation, and solution-precipitation processes (e.g., Urai et al. 1987, Spiers et al. 1986; Schenk \& Urai 2004; Schléder \& Urai 2005).

\subsubsection{Intracrystalline deformation}

Intracrystalline deformation includes the processes of dislocation glide, dislocation creep, solution-precipitation creep and diffusion creep. During these processes, crystals deform internally by the migration of lattice defects through the crystal lattice. Lattice defects can be point defects and line defects (= dislocations). Dislocations can move only in specific crystal 
planes (= slip planes) and directions (= slip direction), and the combination of slip plane and direction is known as a slip system (e.g., Passchier \& Trouw 2005).

According to Carter \& Heard (1970), three slip systems are known in halite $(\{110\}<110\rangle$; $\{111\}<110\rangle$; $\{100\}<011>$; Fig. 1.3, 1.4). Which of the slip systems is activated depends on the critical resolved shear stress (CRSS) that can be very different depending on the temperature, the strain rate or the differential stress (Fig. 1.5; cf. Passchier \& Trouw 2005). The slip system $\{110\}<110\rangle$ shows the lowest CRSS in halite at all temperatures (e.g., Carter \& Heard 1970; Skrotzki \& Haasen 1981, Skrotzki et al. 1981). At room temperature, other slip systems in halite such as $\{111\}<110\rangle$ and $\{100\}<011>$ have CRSS that are several times higher than required for the activation of the slip system $\{110\}<110>$ (cf. Scheffzük 1999). At temperatures of up to $200^{\circ} \mathrm{C}$, the slip systems $\{110\}<110>$ and $\{100\}<011>$ are active during deformation (cf. Scheffzük 1999).

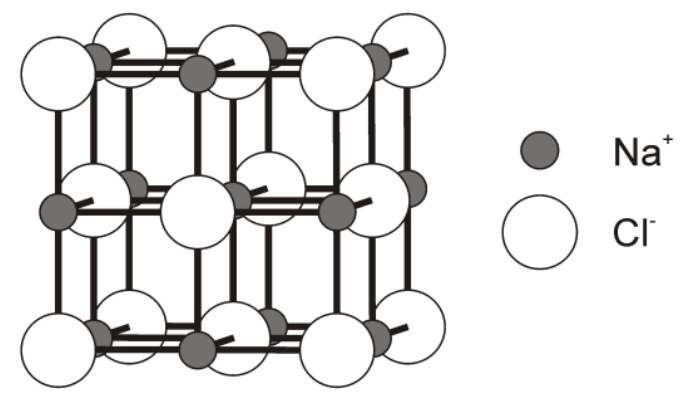

Fig. 1.3: Unit cell drawing of the halite crystal structure. The lattice of halite is cubic-face-centered. The unit cell has an edge length of $5.6402 \AA$. In the crystal lattice, positively charged sodium ions (grey) and negatively charged chloride ions (white) alternate. Each sodium ion is surrounded by six chloride ions forming a perfect symmetrical crystal.
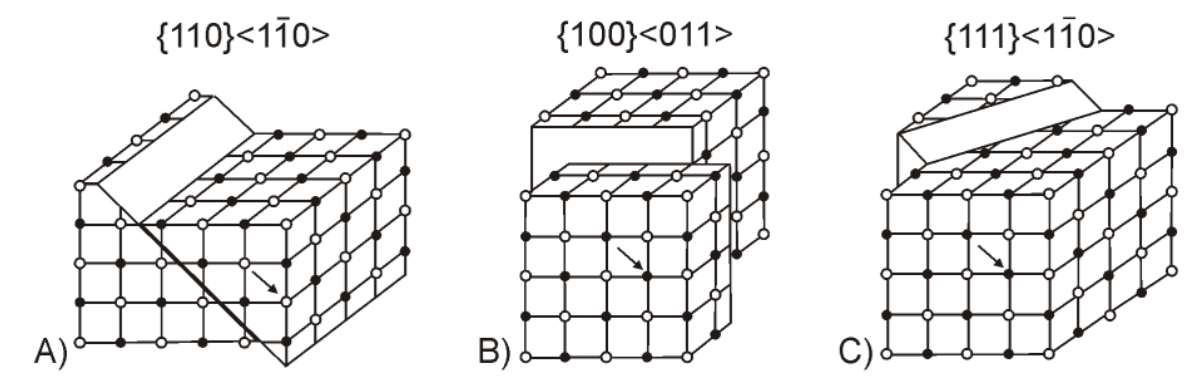

Fig. 1.4: Slip systems for cubic halite lattice. Halite can deform by slip on the slip planes A) (110), B) (100), and C) (111) in the slip direction [110]. Black arrow indicates slip direction. Slip systems are: A) $\{110\}<110>$; B) $\{100\}<011>$; C) $\{111\}<110>$ (Figure from Scheffzük 1999).

Experimental work and microstructural observations indicate that dislocation creep is the most important deformation mechanism in rock salt (e.g., Urai et al. 1986b, 1987; Skrotzki \& Welch 1983; Carter \& Hansen 1983). The presence of subgrains and slip bands is characteristic for this process (Senseny et al. 1992). 
Intracrystalline deformation can result in the development of a crystallographic preferred orientation of the grains. The observation of such a crystallographic preferred orientation $(\mathrm{CPO}=$ texture; chapter 2.2.4) can help identifying the deformation mechanism, which is important for interpreting the formation of a rock. Textural analyses in naturally deformed rock salt were carried out only exemplarily (Clabaugh 1962; Schwerdtner 1966; Goeman \& Schumann 1976, 1977; Kämpf et al. 1987; Kern \& Richter 1985; Scheffzük 1999). In these studies, generally a $\{100\}$ maximum perpendicular to the foliation $(=(100)$ fiber texture) is documented, but also the (110) fiber texture as well as the $\{001\}<100\rangle$ cube texture is described.
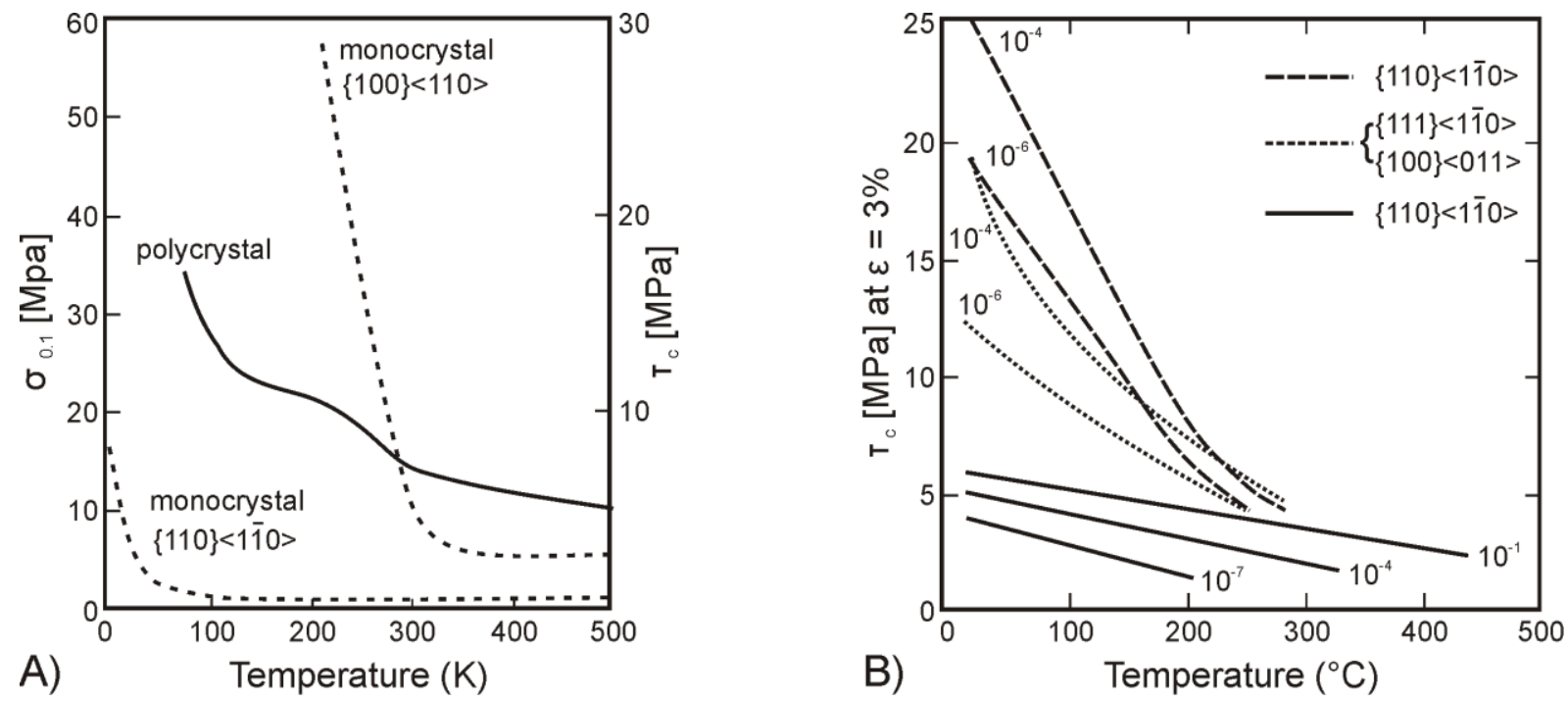

Fig. 1.5: A) Temperature dependence of the flow stress of polycrystalline $\mathrm{NaCl}$ at $0.1 \%$ strain. The dashed lines represent the temperature dependence of the critical resolved shear stresses for slip on $\{110\}$ and $\{100\}$ planes (modified from Skrotzki et al. 1981) B) Critical resolved shear stress of slip systems in halite as a function of temperature at different strain rates (after Carter \& Heard 1970).

\subsubsection{Recrystallization}

When a crystal lattice is free of dislocations, the internal strain energy is at its minimum.

During deformation, the internal strain energy of a crystal increases. An increase in internal strain energy is proportional to an increase of the dislocation density. Several processes can take place for reducing the internal energy of a crystal. During the so-called recovery process, the dislocation density is reduced by concentrating the dislocations in planar zones and finally forming subgrain boundaries. Another process that contributes to the reduction of dislocation density in deformed crystals is recrystallisation. This process means a reorganization of material with a change in grain size, shape, and orientation (cf. Passchier \& Trouw 2005).

If recrystallization takes place during deformation, the process is called dynamic recrystallisation (Guillopé \& Poirier 1979). Depending on temperature and/or flow stress, three different recrystallisation mechanisms can be active during deformation (cf. Passchier \& 
Trouw 2005). These are, with increasing temperature and decreasing flow stress: bulging (BLG), subgrain rotation (SGR) and grain boundary migration (GBM) recrystallisation (Guillopé \& Poirier 1979; Urai et al. 1986a; cf. Twiss \& Moores 1992, Passchier \& Trouw 2005). There are transitions between the three mechanisms and, under certain conditions, they can operate simultaneously. During BLG, grain boundaries migrate into grains with higher dislocation densities and new, strain-free grains can be formed. This process is a kind of GBM that takes place at low temperatures and generally results in a finer grain size of the material. Old, deformed grains are surrounded by recrystallized, strain free grains (= coreand-mantle structure). During SGR recrystallisation, progressive rotation of subgrains can result in the development of high angle grain boundaries and thus of a new grain. At higher temperatures, GBM recrystallisation is active, because then grain boundaries become highly mobile and can sweep through the material in any directions and remove dislocations and subgrain boundaries. GBM results in lobate grain boundaries and a variable grain size distribution.

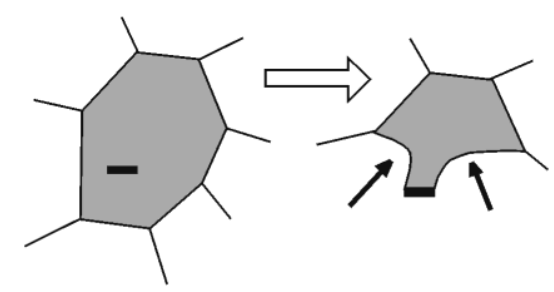

'Pinning' microstructure

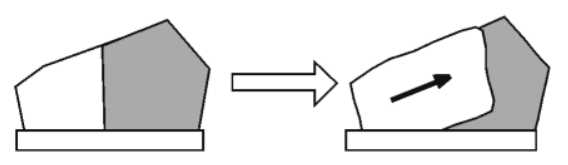

'Dragging' microstructure

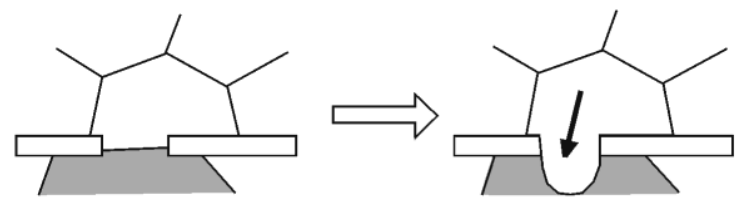

'Window' microstructure

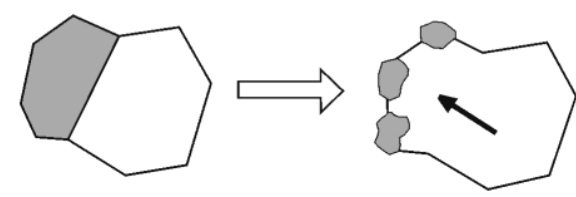

'Left-over grains'

Fig. 1.6: Sketch of four microstructures indicating the movement direction (solid arrows) of a migrating grain boundary during GBM (from Passchier \& Trouw 2005).

Recrystallization processes in rock salt are strongly influenced by the presence of impurities (Skrotzki \& Welch 1983, Skrotzki et al. 1995). In the presence of such secondary phases, several microstructures can be indicative for the movement direction of grain boundaries and thus for GBM as recrystallization mechanism: 'pinning'-, 'window'-, and 'dragging'-microstructures as well as 'left-over-grains' (Fig. 1.6; Passchier \& Trouw 2005). The presence of lobate grain boundaries and core-and-mantle structures in naturally deformed rock salt is characteristic for dynamic recrystallisation processes and indicates GBM as the most important mechanism (Urai et al. 1987). 
Static recrystallisation is the combined process of recovery, recrystallisation and grain boundary area reduction (GBAR) that take place in absence of deformation to reduce the internal energy of the deformed material (Passchier \& Trouw 2005). The principal mechanism, GBAR, is a kind of GBM, during which irregular grain boundaries formed during deformation and dynamic recrystallisation are straightened to a polygonal shape (Fig. 1.7). This process decreases the total surface area of grain boundaries and thus the internal energy of the rock. GBAR is especially active at high temperatures.

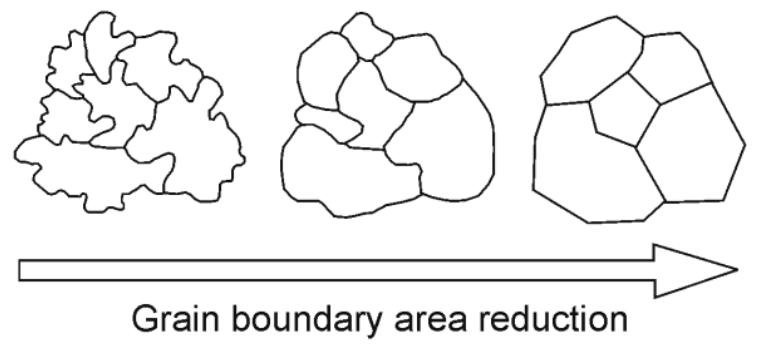

Fig. 1.7: Sketch of the process of grain boundary area reduction (GBAR). Irregular grain boundaries are straightened to a polygonal shape resulting in a decrease of the grain boundary energy (from Passchier \& Trouw 2005).

\subsubsection{Solution-precipitation processes}

Natural rock salts always contain small amounts of water that may be present in the form of intergranular pore water and as intragranular fluid inclusions (e.g., Roedder \& Bassett 1981; Roedder 1984). During solution-precipitation processes, highly stressed parts of a grain go into solution and precipitate on the less stressed part. Due to the high solubility of halite, the presence of only small amounts of brine can change the deformation mechanism from dislocation to solution-precipitation creep (Urai et al. 1986b, Spiers et al. 1990; Peach et al. 2001; Pennock et al. 2006). In rock salt with grain sizes of up to $2 \mathrm{~mm}$, traces of water can cause diffusion effects or solution-precipitation processes (Urai et al. 1986b; Spiers et al. 1986). Intergranular brine can be transformed into subcontinuous brine films that strongly enhance the grain boundary mobility. Such dynamic recrystallisation by fluid-assisted GBM could be observed in rock salt containing 500-1000 ppm brine (Urai et al. 1986b; Spiers et al. 1990). These studies demonstrate that GBM can take place in rock salt under natural deformation conditions at low temperatures (around $100^{\circ} \mathrm{C}$ ) and not only above temperatures of $500^{\circ} \mathrm{C}$ as suggested by experimental work of Guillopé \& Poirier (1979). 


\subsection{Objectives of this thesis}

One of the main objectives of this thesis is to illuminate a possible relationship between deformation and geochemistry, e.g. what influence the deformation intensity has on the bromide distribution of rock salt. For this purpose, the bromide distributions of three stratigraphically equivalent rock salt sequences (Hauptsalz) from different locations in the Zechstein Basin are compared, with bedded salt on the one hand and domal salt on the other hand. Furthermore, the two different halite types of this rock salt sequence (matrix, Kristallbrocken) are distinguished and separately sampled. Based on these well-standardized sets of bromide profiles of a definite stratigraphic section, the following questions can be clarified:

1. What are the characteristics of the bromide profiles in the three studied locations? How do the three bromide profile trends differ from each other?

2. What are the microstructural characteristics of halite in the studied locations?

3. Does the different deformation history have an influence on the bromide distribution of the different locations?

4. Are the petrographic differences between the two halite types reflected in the bromide content, and if so, does this considerably influence the trend of the bromide profile?

Another topic of this thesis is focused on the nature, the formation and the deformation of a laminated halite type (Kristallbrocken) that appears to occur only in the Stassfurt Formation rock salt of the Zechstein Basin. For this purpose, the following questions are to be answered:

1. What is the nature of the Kristallbrocken? Are they relics of very fine-grained, polycrystalline halite beds or clasts of 'single crystal-layers', or can they be regarded as postdeformational blasts?

2. Which kinds of inclusions build up the internal lamination of this halite type and how did they form?

3. What are the deformation mechanisms of the Kristallbrocken?

4. When and how did this halite type form and deform?

To address these questions, microstructural investigations are carried out on samples of the salt deposit Teutschenthal. Specifically, the deformational characteristics of the Kristallbrocken are investigated and their local crystallographic preferred orientations (CPOs $=$ textures) are determined by X-ray texture goniometry. Furthermore, based on samples from 
different locations of the Zechstein Basin, the internal lamination of the Kristallbrocken halite type is studied in detail by optical microscopy and scanning electron microscopy (SEM).

A last objective of this thesis concerns the textural characteristics of naturally deformed rock salt and a correlation of the textures with micro-, macro- as well as large scale salt structures. Texture analyses are carried out on samples from the salt deposits Teutschenthal, Morsleben, and Gorleben, using neutron texture goniometry. The samples are taken from drill core segments that show significant grain shape preferred orientations and relatively small grain sizes (long axis max. several $\mathrm{mm}$ ), implying that they represent mylonitic shear zones.

\subsection{Organization of this thesis}

Chapter 1 gives an overview of the scope and the objectives of this thesis as well as background information of thesis-relevant topics such as bromide distribution in rock salt and deformation mechanisms of naturally deformed rock salt.

In chapter 2, general information about the studied locations and the samples is provided. Furthermore, the sample preparation and the methods used in this thesis are described in detail.

Chapter 3 deals with the bromide characteristics of the studied Stassfurt Formation rock salt. It consists of two parts. In the first part, chapter 3.1, a bromide data set of a defined stratigraphic section (Hauptsalz) of the Stassfurt Formation is presented for three salt deposits, with bedded salt (Teutschenthal) compared to domal salts (Morsleben, Gorleben). The bromide data set also includes a distinction in bromide content between the two different halite types (Kristallbrocken, matrix) of the rock salt sequence. Additionally, the results of microstructural investigations by reflected light microscopy are discussed in context with the bromide data. In the second part, chapter 3.2, the results of additional bromide samplings are presented. For a closer look at the bromide characteristics of the Kristallbrocken, nine drilling core slabs were chosen for detailed sampling of several Kristallbrocken in each of the drilling core slab. Additionally, a bulk analysis of the drilling cores of the three salt deposits was carried out. To do this, samples were taken by a drill bit (diameter $10 \mathrm{~mm}$ ) in regular, smallscaled intervals throughout the drilling core. A relatively new approach was the determination of the bromide content via electron microprobe by using laboratory-grown halite crystals with a definite concentration of bromide as standards.

Chapter 4 contains three parts and presents the results of a set of investigations related to the Kristallbrocken, a laminated halite type that is typical for the Stassfurt Formation rock salt of the Zechstein Basin. In the first part, chapter 4.1, the results of X-ray texture measurements are presented in order to explain the nature of this halite type, i.e. if it is 
monocrystalline or polycrystalline. The second part, chapter 4.2 , concerns the formation of the Kristallbrocken and presents the results of SEM investigations of the solid inclusions in this halite type for microstructural and compositional characteristics. In chapter 4.3, further results of X-ray texture measurement of the Kristallbrocken samples are presented that are not included in chapter 4.1 .

Chapter 5 consists of two parts. In the first part, chapter 5.1, the first results of a detailed textural characterization of naturally deformed rock salts are presented. In the second part, chapter 5.2, the results of water content determinations are presented, which were carried out on Stassfurt Formation rock salt samples from the three salt deposits Teutschenthal, Morsleben, and Gorleben.

In the final chapter 6 , the results of this thesis are summarized and discussed. Furthermore, it provides an outlook on possible future research topics.

The chapters 3.1, 4.1, 4.2, and 5.1 are presented as self-standing units that have been published or intended to be published as separate papers. For that reason, repetitions of some parts were unavoidable. 


\section{SAMPLES AND METHODS}

\subsection{Study locations and sample material}

The former Zechstein Basin extended from Eastern England and the Southern North Sea in the west to Poland and Lithuania in the east (Fig. 2.1). Today, Zechstein sediments occur in

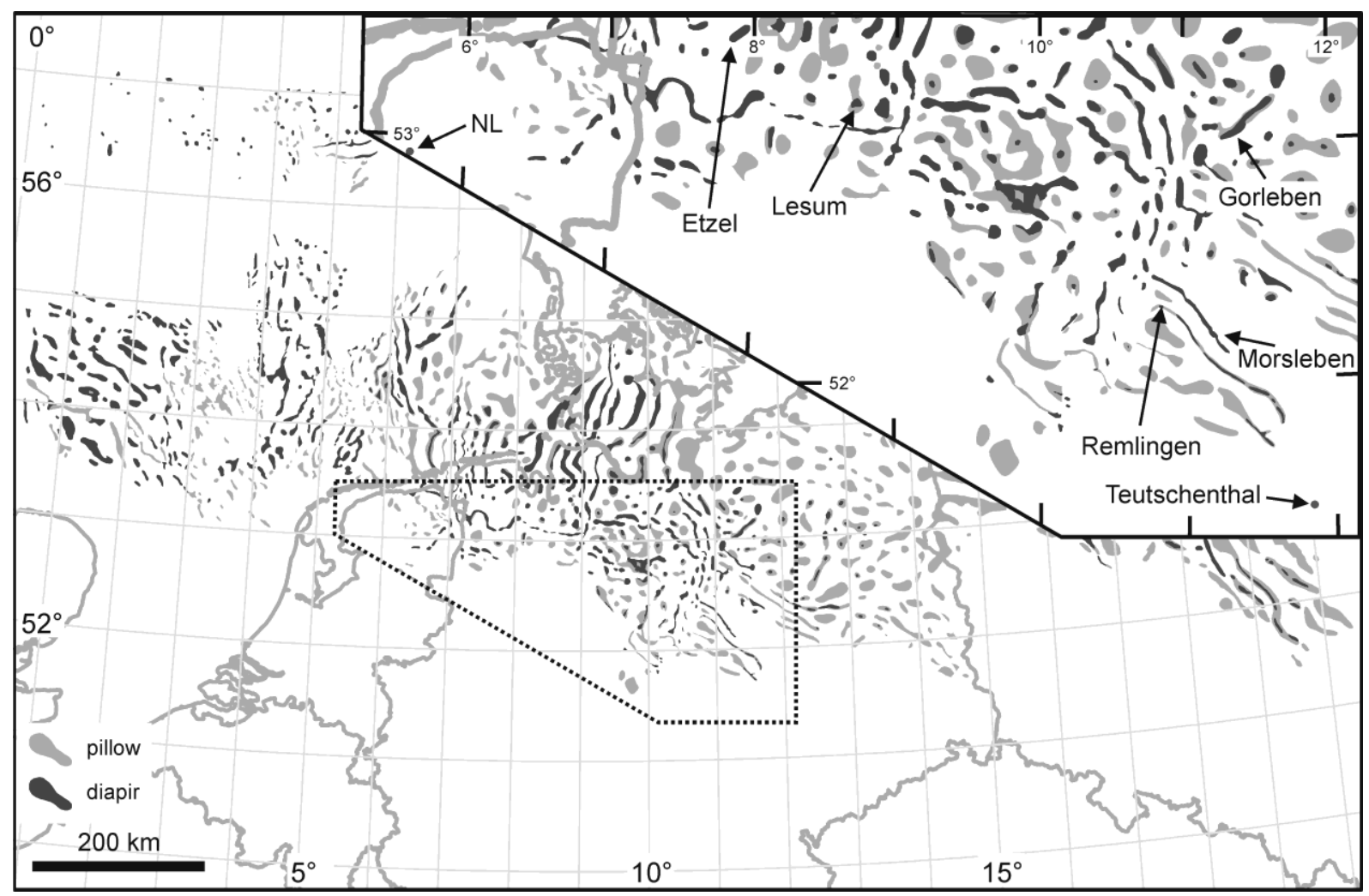

Fig. 2.1: Map showing the Zechstein Basin (after Lokhorst 1998). Inserted rectangle shows the position of the salt structures investigated in this study. 
both flat-lying, apparently undisturbed settings, and in the form of pillows, diapirs, and salt walls formed by salt tectonics (Trusheim 1960; Jaritz 1973; Kockel 1998; Fig. 2.1). The German Zechstein group comprises 4 main evaporation cycles referred to as the Werra (Z1), Stassfurt (Z2), Leine (Z3), and Aller (Z4) Formations (Richter-Bernburg 1955a; Fig. 2.2) and 3 rudimentary and only regionally occurring cycles referred to as the Ohre (Z5), Friesland (Z6), and Fulda (Z7) Formations (Käding 1978, 2000; Fig. 2.2). In Germany, the rock salt of the Stassfurt Formation is most widespread, with an estimated original thickness of $500 \mathrm{~m}$ and more (cf., Zharkov 1984). The present thickness, however, is highly variable due to different post-depositional processes like diapirism, leaching or erosion.

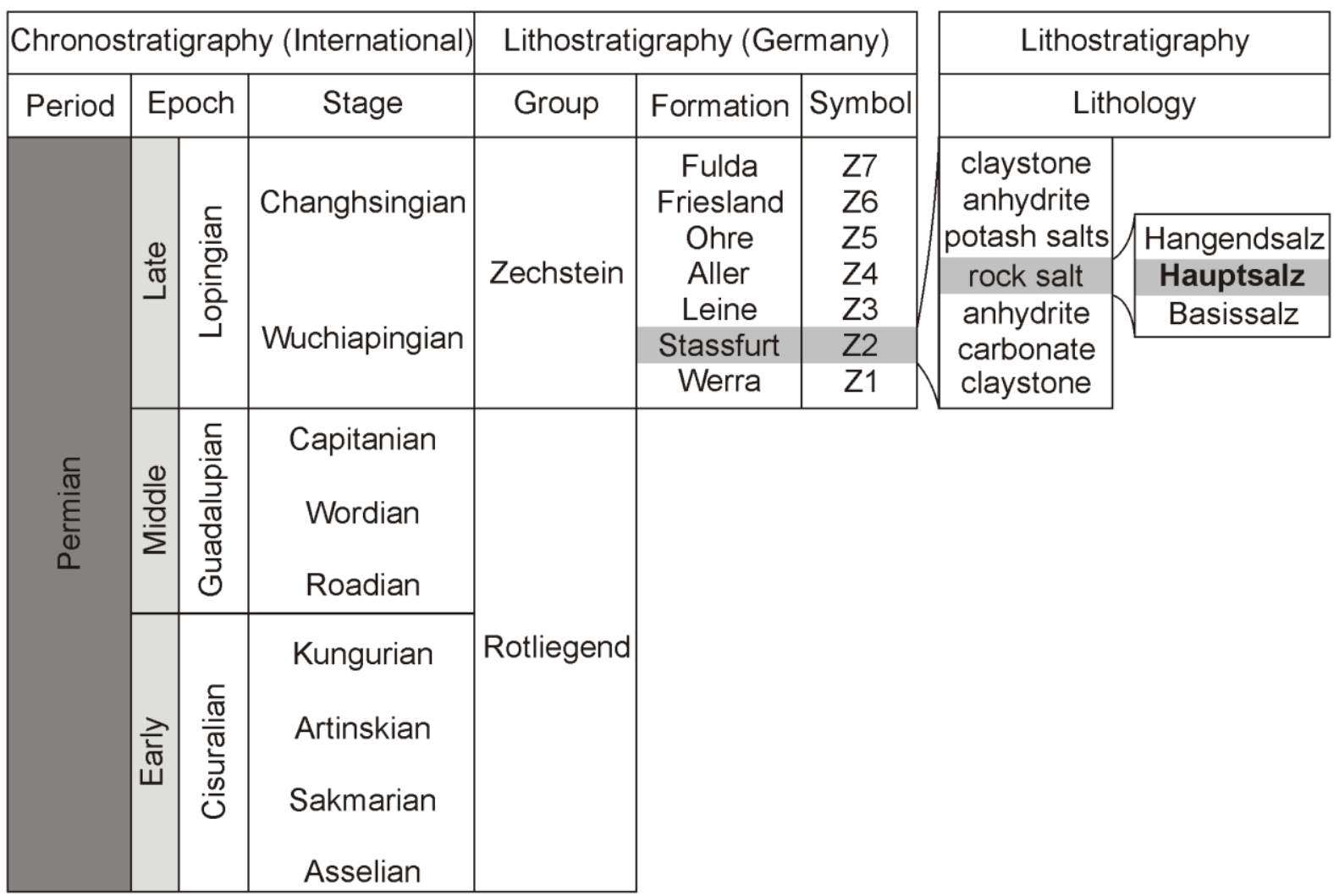

Fig. 2.2: Stratigraphic table of the German Zechstein group (according to Richter-Bernburg 1955a and Käding 1978, 2000).

For bromide analyses and detailed examination on Kristallbrocken, the rock salt of the Stassfurt Formation (Z2) was used and samples were obtained from drilling cores of different locations in the former Zechstein Basin (Fig. 2.1). The Stassfurt Formation can be subdivided into three stratigraphic units (Richter-Bernburg 1955a). These are (from base to top): Basissalz, Hauptsalz, and Hangendsalz (Fig. 2.2). In this study, the main focus was on the Hauptsalz (German: "Hauptsalz" = main salt) of the salt deposits Teutschenthal, Morsleben, and Gorleben, which is the thickest part of the Stassfurt rock salt and is almost completely exposed by drilling cores in each of these locations. The three deposits belong to different 
tectonic settings, with Teutschenthal consisting of bedded salt and Morsleben and Gorleben consisting of domal salts (Fig. 2.3). The Hauptsalz of the Stassfurt formation (Z2) consists of rock salt and anhydrite. In the rock salt horizons, two characteristic halite types can be distinguished: (1) clear, equigranular halite also referred to as matrix halite, and (2) the socalled Kristallbrocken (German: "Kristallbrocken" = crystal fragments; Simon 1972), halite crystals with an internal lamination made up by variations in sulphate inclusion content. More detailed information about these locations is given in chapter 3.1.5. In addition to bromide analyses as well as detailed investigations on the Kristallbrocken of Teutschenthal, Morsleben, and Gorleben, supplementary examinations were carried out on Kristallbrocken belonging to the Stassfurt salt rocks of Lesum, Remlingen (Asse salt mine), Etzel, and the Netherlands (Fig. 2.1). For neutron texture investigations, samples were also taken from Teutschenthal, Morsleben, and Gorleben (Fig. 2.3). Information about the position of the investigated wells in the salt deposits and sampling depths in drilling cores is given in chapter 3.1.7.
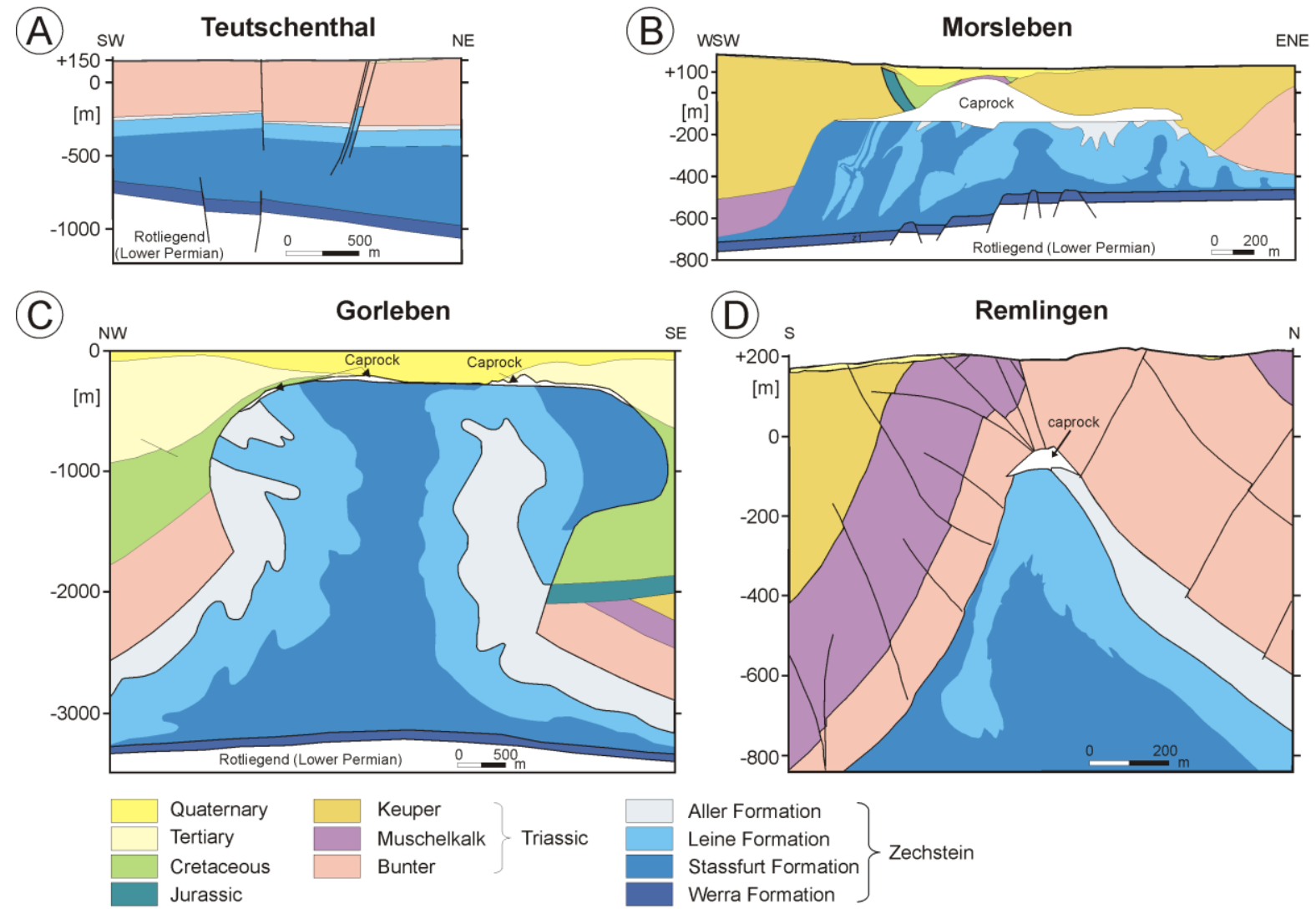

Fig. 2.3: Cross sections of the studied locations. Drilling cores from Teutschenthal, Morsleben, and Gorleben were sampled for bromide analytics (chapter 3). For neutron texture measurements (chapter 5.1), samples were taken from drilling cores of all locations represented in this figure. A) Teutschenthal salt pillow (modified from Jagsch \& Theylich 1999). B) Morsleben salt structure (after BfS 2001). C) Gorleben salt dome (modified from Bornemann 1991). D) Remlingen (Asse salt mine). 


\subsection{Methodology and sample preparation}

\subsubsection{Sampling and bromide analytics}

For sampling, $2 \mathrm{~cm}$ thick slabs were cut from the cores of the 3 locations in regular intervals of about $1 \mathrm{~m}$ in Morsleben, $3 \mathrm{~m}$ in Teutschenthal, and $5 \mathrm{~m}$ in Gorleben. After grinding and polishing, the sections were examined with transmitted light using a Wild M3 stereomicroscope (Wild, now Leica Geosystems AG, Heerbrugg, Switzerland) and prepared for sampling. During sampling, it was distinguished between the different halite types (Kristallbrocken and matrix; chapter 3.1) and tried to avoid sampling of fluid inclusion-rich areas and anhydrite laminations. In addition to these samples, 9 drilling core slabs of Teutschenthal were selected for detailed sampling of Kristallbrocken (chapter 3.2.1; Table A4). Samples for bromide analyses were taken by drilling small holes (diameter $=1 \mathrm{~mm}$ ) into previously marked points on the thick sections using a bench drilling machine (Proxxon $\mathrm{GmbH}$, Niersbach, Germany). Prior to each new sample, the drill bit was cleaned to avoid contamination by previously drilled material. A total of 785 samples have been taken: 264 from Teutschenthal, 344 from Morsleben, and 177 from Gorleben. From each sample, mostly $100 \mathrm{mg}$, partly only $50 \mathrm{mg}$ of the material has been weighed in for analysis. For the Hauptsalz bulk composition of the 3 locations, the corresponding drilling cores were sampled by a power drill, with the bit having a diameter of $10 \mathrm{~mm}$. In Morsleben and Gorleben, the whole Hauptsalz was sampled in regular intervals of some meters (chapter 3.2.2). In Teutschenthal, several drilling core sections were selected and sampled in small intervals of 1 or $2 \mathrm{~cm}$, because the rhythmic stratification of rock salt and anhydrite layers has been largely preserved and thus sampling in larger intervals would not have been sufficiently representative for the bulk composition (chapter 3.2.2). After sampling, the drilled material of definite stratigraphic sections (lower, middle, and upper Hauptsalz) was collected and comminuted in a vibration disc mill. Then, sample material was mixed and divided into several equal parts in order to get multiple representative samples. From each sample, $250 \mathrm{mg}$ material has been weighed in for analysis.

The sampled material was analyzed for major cations, including potassium, sodium, magnesium, and calcium, and major and trace anions, including chloride, sulphate, and bromide (Tables A.1-A.3). The determination of the cations was conducted by inductively coupled plasma optical emission spectrometry (ICP-OES), using a Spectro CIROS (Spectro Analytical Instruments $\mathrm{GmbH} \& \mathrm{Co}$. KG, Kleve, Germany). Anion analysis was performed on a Dionex DX500 ion chromatograph (IC; Dionex GmbH, Idstein, Germany). The limit of detection for bromide is approximately $10 \mathrm{ppm}$. The accuracy as well as reproducibility for 
bromide was better than 5\% measured against an in-house halite reference sample. The difference in the anion-cation balance was generally less than $1 \%$. Based on the chemical analyses, the quantitative mineral composition of the sample was calculated. As samples contained no potash-bearing salt minerals, the analyzed bromide content could be directly related to the calculated halite content of the sample.

In addition to the above described wet chemical analyses of drilled sample material, it was tried to measure the bromide distribution across one Kristallbrocken by means of an electron microprobe (Cameca SX100), as this more detailed method may reveal small-scaled differences in the bromide distribution in Kristallbrocken (chapter 3.2.3). For electron microprobe analyses, a standard for bromide is necessary. The formerly used house-intern standard $\mathrm{AgBr}$ is in an insufficient state and could not be used for this purpose; therefore, laboratory-grown halite crystals with a definite concentration of bromide have been used instead. Two nearly saturated solutions with specific proportions of $\mathrm{NaCl}, \mathrm{NaBr}$, and distilled water were synthesized and placed in Erlenmeyer flasks that were sealed with stretchable laboratory plastic tape. To allow for slow evaporation rates of no more than $3 \mathrm{~g} \mathrm{H}_{2} \mathrm{O}$ loss per day, the plastic tape was punctured with small holes (diameter $\sim 5 \mathrm{~mm}$ ), and the flasks were placed for several weeks in the oven at a constant temperature of $27^{\circ} \mathrm{C}$. The halite crystals were sampled with a plastic sieve, immediately dried with a tissue, and examined under the microscope (Fig. 2.4). For the application of a bromide containing halite crystal as a standard for microanalytic methods, it is very important that the crystal has low fluid inclusion content, as an opening of the fluid inclusion by the electron beam would impair the measurement. Two
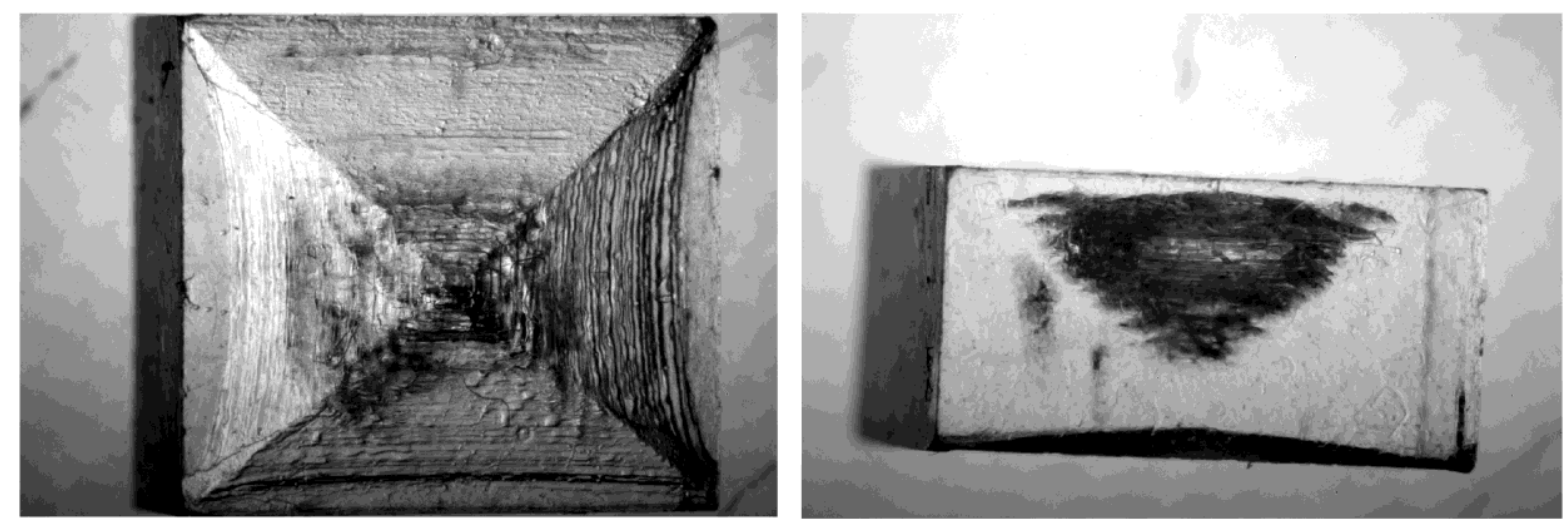

Fig. 2.4: Laboratory grown halite crystals used as standards for the bromide content determination via electron microprobe.

large halite crystals (length $\sim 6 \mathrm{~mm}$ ) with few fluid inclusions were selected and cut by a diamond saw into two pieces. One half of each crystal was wet chemically analyzed by IC. For this, the crystal halves were pulverized, and the material was separated into 2 or 3 
subspecimens in order to perform a multiple analysis for an internal quality control. Halite crystals have bromide contents of about $150 \mathrm{ppm}$ and $1 \%$ respectively. The other half was embedded in resin, and after drying, the microsection was polished with diamond spray. For the microprobe analysis, a $6 \times 3 \mathrm{~cm}$ large slab with a bent Kristallbrocken was cut from the drilling core of Teutschenthal. From the same Kristallbrocken, sample material was drilled for wet chemical analysis to get an internal control. Before the measurements, the slab was dryground, polished with diamond spray, and coated with carbon. The bromide concentration was determined at 18 measuring points via a Cameca SX100 electron microprobe. The measurements were performed at an accelerating voltage of $10 \mathrm{kV}$ and a beam current of $40 \mathrm{nA}$. The detection limit for bromide was $57 \mathrm{ppm}$.

\subsubsection{Scanning electron microscopy (SEM) of solid inclusions}

For a more detailed examination of the halite type Kristallbrocken, the solid inclusions within the Kristallbrocken were investigated by scanning electron microscopy (SEM) using a FEI Quanta 600 FEG ESEM. One advantage of this environmental scanning electron microscope (ESEM) is that it allows samples to be examined at near atmospheric pressures and humidities that approach normal laboratory conditions (e.g., Donald 2003). For that reason, samples do not need to be coated with a conductive layer (e.g., carbon, gold).
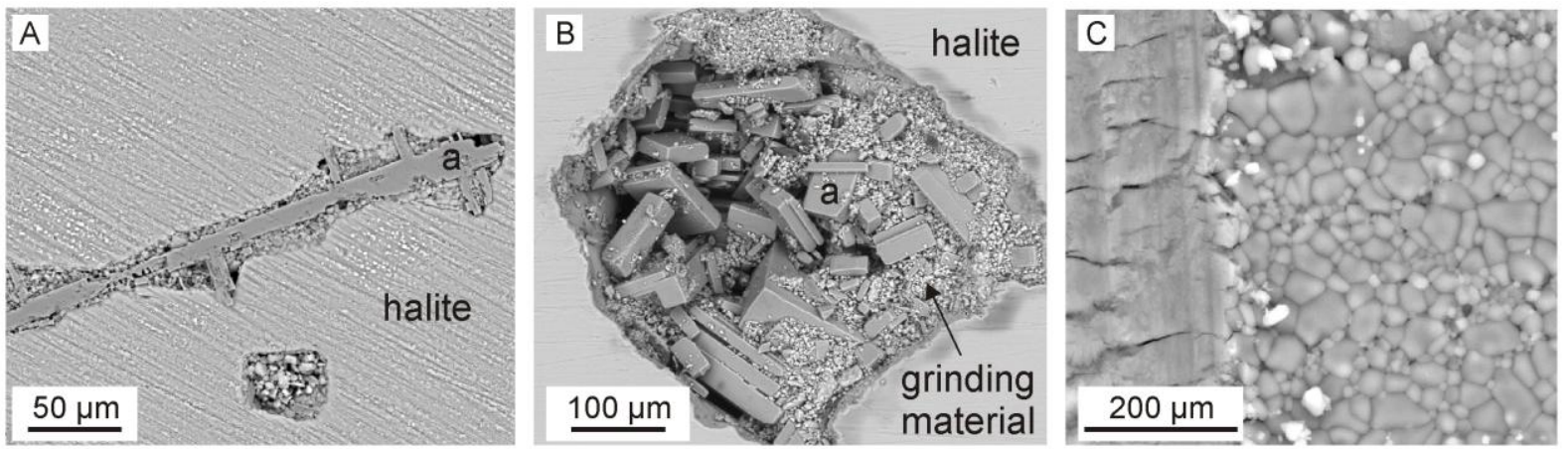

Fig. 2.5: A) SEM photomicrograph showing an anhydrite crystal (a) included in halite. Note the polishing marks on the sample surface and grinding material within the circular inclusion in the lower middle. B) SEM photomicrographs with anhydrite aggregates in an opened inclusion. Due to grinding, the inclusion was filled with abraded material. C) SEM photomicrograph showing minute halite precipitated on the sample surface. On the left hand, the sample surface was scratched with a knife in order to confirm that the small halite crystals are secondary.

For SEM analyses, fracture surfaces of Kristallbrocken were primarily used, because the internal structure and the composition of the inclusions could be studied very well, whereas in polished samples the surface quality is impaired by polishing marks (Fig. 2.5A), and the inclusions opened by the grinding process are partially filled with grinding material (Fig. 2.5B). To prevent absorption of moisture by the halite, the Kristallbrocken were carefully 
split immediately before SEM analysis. Otherwise, the halite crystal surfaces could be slightly etched by moisture, which would result in numerous minute halite precipitates and impairs the quality of the SEM images (Fig. 2.5C). All samples were imaged in low vacuum mode. Qualitative element analysis was carried out by energy dispersive X-ray analysis (EDX) attached to the SEM.

\subsubsection{Strontium content analyses}

The thick sections prepared for bromide sampling were also used for strontium content analyses of the anhydrite inclusions in the studied rock salt sequence from Teutschenthal, Morsleben, and Gorleben. For this purpose, $6 \times 3 \mathrm{~cm}$ large slabs were prepared. The slabs were dry-ground, polished with diamond spray, and coated with carbon. Before the measurements, suitable measuring points were chosen by means of reflected light microscopy. The strontium content was measured via the Cameca SX100 electron microprobe using natural standards (Celestine (strontium content $\approx 2000 \mathrm{ppm}$ ) and anhydrite (strontium content $\approx 300 \mathrm{ppm}$ ). The measurements were performed at an accelerating voltage of $15 \mathrm{kV}$ and a beam current of $20 \mathrm{nA}$. The detection limit for strontium was $163 \mathrm{ppm}$.

\subsubsection{Water content analyses}

Rock salt formations always contain small amounts of water that may be present in three forms: as chemically combined water in hydrous minerals, as intergranular pore water, and as intragranular fluid inclusions (e.g., Jockwer 1981; Roedder \& Bassett 1981; Roedder 1984). The water content of rock salt can be determined by different methods (Roedder \& Basset 1981), for example thermal gravimetric analysis (TGA; e.g., Jockwer 1980; De Las Cuevas \& Pueyo 1995), differential thermal analysis (DTA), a combination of the two, or the KarlFischer titration (KFT; e.g. Jockwer 1981; Roedder \& Basset 1981; Sell 1988, as cited in Gies et al. 1990). To allow for comparability to earlier investigations on German rock salt samples, the water content was determined with the Karl-Fischer titration (Jockwer 1981; Gies et al. 1990), a widely used analytical method for the quantitative determination of water in a variety of substances and products. The principle of this method is based on a chemical reaction between iodine and sulphur dioxide in an aqueous medium (Wieland 1985). This reaction is specific for water, and it is independent of the presence of other volatile substances, which is an important advantage over conventional thermal methods of moisture determination that are based on loss on drying. Depending on the amount of water to be determined, the analysis can be performed by volumetric or coulometric titration (Wieland 1985). The Karl-Fischer reagent (titrant) consists of an alcohol, a base, sulphur dioxide $\left(\mathrm{SO}_{2}\right)$ and a known 
concentration of iodine $\left(\mathrm{I}_{2}\right)$. One mole of $\mathrm{I}_{2}$ is consumed for each mole of $\mathrm{H}_{2} \mathrm{O}$. The water content of the sample is calculated on the basis of the amount of Karl-Fischer reagent consumed in the titration. The end-point of titration is revealed by the presence of excess iodine and can be detected visually, photometrically, or potentiometrically (Wieland 1985).

Water content analyses were performed at the Gesellschaft für Anlagen- und Reaktorsicherheit mbH (GRS) in Braunschweig, Germany. For the analysis, $5 \mathrm{~cm}$-long sections were cut from drilling cores of Teutschenthal, Morsleben, and Gorleben and put into hermetically sealed PE foils immediately after sampling. The sections were divided into three (Gorleben) or five (Teutschenthal, Morsleben) parts in order to check the homogeneity of water content distribution. Prior to analysis, each sample was crushed into small pieces inside the PE foils to avoid loss of water. The intergranular pore water of the rock salt samples was first extracted with water-free 1,4-dioxane and then volumetrically determined according to Karl-Fischer. Three analyses have been made on each sample.

\subsubsection{Textural investigations}

In material science, partially in geosciences, and also in the present study, the term texture is used as a synonym for crystallographic preferred orientation (CPO), which describes the distribution of crystallographic orientations in a polycrystalline aggregate. Samples can be described as having a weak, moderate, or strong texture, which depends on the percentage of the volume that has a preferred orientation. One extreme case is a rock with a perfectly random orientation of its crystal constituents, and the opposite extreme is a perfect single crystal. Texture investigations are very important for understanding and reconstructing the processes by which the texture formed, including crystallization, sedimentation, plastic deformation, recrystallisation, and metamorphism (cf., Skrotzki 1994). Furthermore, the texture of a rock provides information about anisotropies of its physical properties such as elastic, thermal and magnetic properties, and this anisotropy needs to be considered in, e.g., interpreting seismic data, developing geophysical models, and geophysical prospecting (e.g., Raymer \& Kendall 1998; Raymer et al. 2000).

The texture of a mineral phase of a rock can be quantitatively described by the threedimensional orientation distribution (or density) function (ODF)

$$
\mathrm{f}(\mathrm{g}) \mathrm{dg}=1 / \mathrm{V} \mathrm{dV} / \mathrm{dg}
$$

which is defined as the volume fraction of grains having a certain orientation $\mathrm{g}$. The orientation $\mathrm{g}$ is described by the rotation that transforms the sample-fixed coordinate system into the crystal-fixed coordinate system of the crystallite in question. The geometrical 
relationship between both coordinate systems is usually identified using the three Euler angles $\varphi_{1}, \Phi$, and $\varphi_{2}$. The ODF cannot be measured directly, but can be calculated from experimental pole figures that are obtained from electron, X-ray, or neutron diffraction techniques by measuring the orientation distributions of certain crystallographic directions.

Two distinct ways of orientation measurements can be distinguished. One way is to measure the complete orientation of individual crystals in the sample $(=$ single grain measurements), which can be performed by electron backscatter diffraction (EBSD) in the scanning electron microscope (SEM). This method is especially suited for questions on local textures, since the location of a grain can be determined and relationships between neighboring grains can be evaluated (e.g., Wenk \& van Houtte 2004), and thus provides information on deformation, recrystallisation, and growth mechanisms. To allow for good statistics, a large number of grains need to be measured, which is enabled by automated measurements in modern instruments (e.g., Kunze et al. 1994). The second way is to average over a large volume of a polycrystalline aggregate (= volume texture measurements). As radiation sources, X-rays and neutrons are applied most commonly. The difference between $\mathrm{X}$-rays and neutrons is their absorption or penetration depth in matter. X-rays penetrate less than $100 \mu \mathrm{m}$ into a rock, whereas the absorption of neutrons in matter is very low and thus the penetration depth is $10^{2}$ to $10^{4}$ times higher for most minerals (Table 2.1). Therefore, neutron diffraction enables measurements of larger sample volumes (several cubic centimeters), which is especially important for coarse-grained or inhomogeneous samples. Neutron diffraction is thus well suited for global texture analyses with regard to the correlation of texture characteristics with anisotropic physical properties of rocks. Another advantage is that for the measurements, almost no sample preparation is necessary. However, disadvantages of neutrons compared to X-rays are the expensive generation with a nuclear reactor and the limited accessibility of such instruments.

Table 2.1: Penetration depth $\mathrm{d}_{0.5}$ for $\mathrm{X}$-rays and neutrons of some rock-forming minerals; the parameter $\mathrm{d}_{0.5}$ characterizes the sample thickness, at which the incoming intensity is reduced to the half (data from Brokmeier 1994).

\begin{tabular}{lcc}
\hline Mineral & $\begin{array}{c}\mathrm{d}_{0.5}(\mu \mathrm{m}) \\
\text { X-rays }\end{array}$ & $\begin{array}{c}\mathrm{d}_{0.5}(\mu \mathrm{m}) \\
\text { neutrons }\end{array}$ \\
\hline Quartz & 75.9 & 24300 \\
Albite & 81.0 & 24800 \\
Calcite & 36.0 & 19800 \\
Biotite & 18.1 & 6410 \\
Muscovite & 57.9 & 7940 \\
Halite & 42.0 & 8140 \\
Amphibole & 25.0 & 9690 \\
\hline
\end{tabular}




\subsubsection{X-ray texture goniometry}

When a monochromatic X-ray beam with the wavelength $\lambda$ is projected onto a crystalline material at an angle $\theta$, diffraction and constructive interference occurs when the distance traveled by the rays reflected from successive planes differs by an integer number $n$ of wavelengths. By varying the angle $\theta$, the Bragg's law conditions (Fig. 2.6A) are satisfied by different lattice spacings $d_{h k l}$ in polycrystalline materials.

$$
n \lambda=2 d_{h k l} \sin \theta
$$

The orientation distribution of a certain lattice plane in a crystal is determined by setting the detector to the Bragg angle $2 \theta$ of the diffraction peak of interest and rotating the sample around the axes $\varphi$ and $\psi$ (Fig. 2.6B) by using an Eulerian cradle. The sample is rotated several times around the $\varphi$-axis by $360^{\circ}$, and tilted once around the $\psi$-axis by $90^{\circ}$. In a polycrystalline sample, the recorded intensity of the reflected beam is directly proportional to the volume fraction of crystals with their lattice planes in reflection. The pole figure is the twodimensional stereographic projection of the intersections of the crystal lattice plane normal with the surface of a sphere.

In this study, the X-ray texture measurements were carried out on a PANalytical (PW 3040) X-ray texture goniometer at the Geoscience Centre of the University of Göttingen (Fig. 2.7A). This instrument is particularly modern as it provides a number of new features, compared to conventional goniometers (Leiss 2005; Leiss \& Ullemeyer 2006). One new feature is the large beam size of up to $7 \mathrm{~mm}$, which enables investigation of coarser-grained samples. The cross slit system allows adopting the beam size in height and width independently from each other. So, the beam size can be adopted in dependence of the sample size, the grain size of the sample, the size of homogeneous areas, and the influence of defocusing effects. Another new feature is the XYZ-table that allows measuring large sample areas in scanning mode (Fig. 2.7B). High X-ray intensities, an automatic sample changer and a completely computer-controlled sample movement enable automated measurements and short measuring times. The parallel beam optics avoids problems with depth of focus and degradation of the 2 theta resolution during tilting. The size of the samples can be up to $200 \mathrm{~mm}$ in diameter and $24 \mathrm{~mm}$ in height, and their weight can be up to $500 \mathrm{~g}$.

For the measurements of the Kristallbrocken, the beam size was 1x1 mm. Pole figures were measured with an equidistant raster of $5 \times 5^{\circ}$ The rotation angle $(\varphi)$ was $360^{\circ}$ and the tilting angle $(\psi)$ was $85^{\circ}$, which yields an incomplete raster with 1296 measuring points. From the measured reflections $\{111\},\{220\},\{400\}$, and $\{420\}$, pole figures were calculated and presented by the programs XTexCor 1.0 (written by Ullemeyer in 2006) and PFPlot 2.2 
(written by Umlauf \& Ullemeyer in 2006), respectively. To check the compatibility

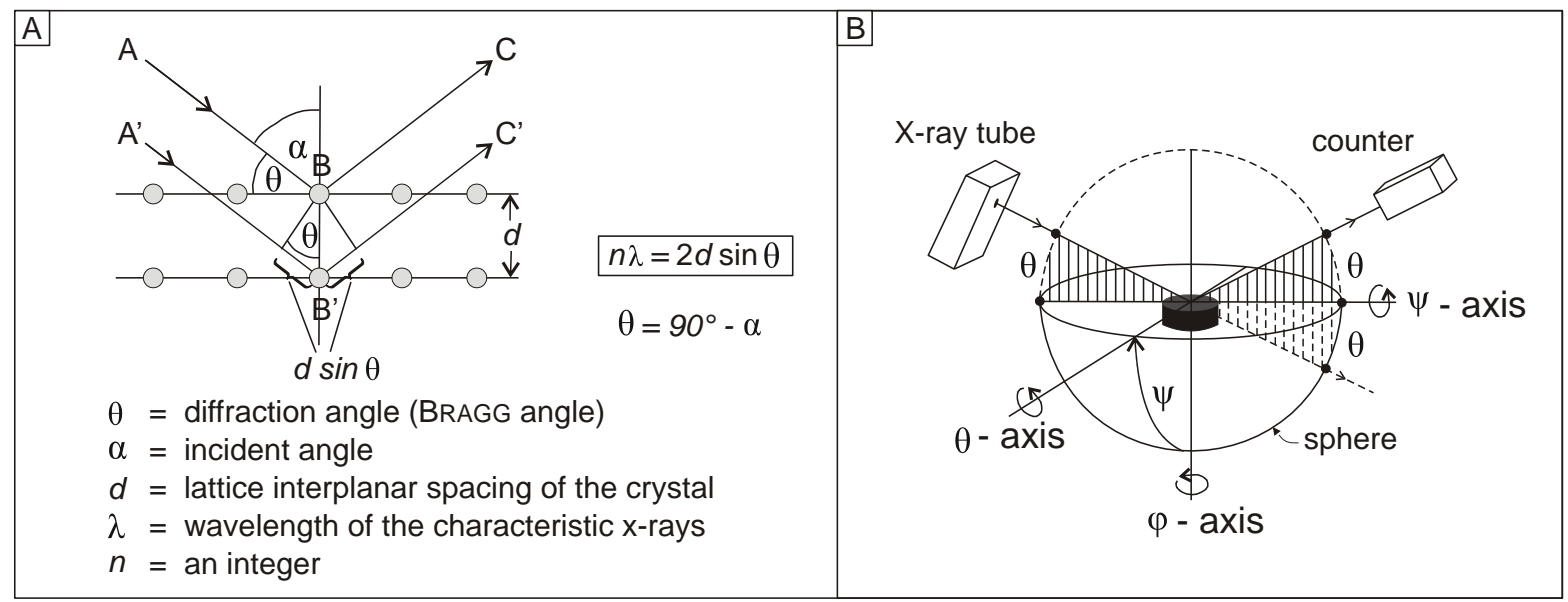

Fig. 2.6: A) Bragg's Law reflection. The diffracted $X$-rays exhibit constructive interference when the distance between paths $\mathrm{ABC}$ and $\mathrm{A}^{\prime} \mathrm{B}^{\prime} \mathrm{C}^{\prime}$ differs by an integer number $n$ of wavelengths $(\lambda)$. B) Schematic representation of an X-ray texture goniometer (after Ullemeyer \& Weber 1994, as cited in Leiss 1996).

between pole figures and crystallography, the so-called component method (Helming \& Eschner 1990; Eschner 1993; Helming 1995) was applied for a quantitative description of the texture. By this method, Gaussian-shaped texture components are fitted in the experimental pole figures, with each component representing a crystallographic preferred orientation locally restricted in the orientation space. The component determination was carried out with the program MulTex (DOS version, 1987, 1995) written by K. Helming (1995, 2000).

\subsubsection{Neutron texture goniometry}

For the texture analyses of the polycrystalline rock salt samples, neutron diffraction was used. This technique is particularly suitable for the investigation of this kind of sample, since their grain size is more than $1 \mathrm{~mm}$, and as due to low absorption of neutrons in matter measurements of large sample volumes are possible, this allows for good statistics even in coarser-grained samples. Neutron texture measurements were carried out at the SKAT diffractometer in Dubna (Russia) (Ullemeyer et al. 1998). For the analyses, cube-shaped, cylindrical and spherical samples with dimensions up to five centimeters were prepared.

\subsubsection{Electron backscatter diffraction (EBSD)}

In this work, electron backscatter diffraction was used for measuring the orientation of a set of grains in a rock salt shear zone of Morsleben, with the grains showing a significant shapepreferred orientation. In this context, and as there are only few EBSD studies focusing on natural rock salts (e.g., Schléder \& Urai 2007), this technique was used to test which sample preparation technique yields high-quality EBSD patterns (Kikuchi-patterns). EBSD data were 
recorded using the software Channel of HKL coupled to a Zeiss Leo 1455VP scanning electron microscope. Prior to the measurements, samples needed to be
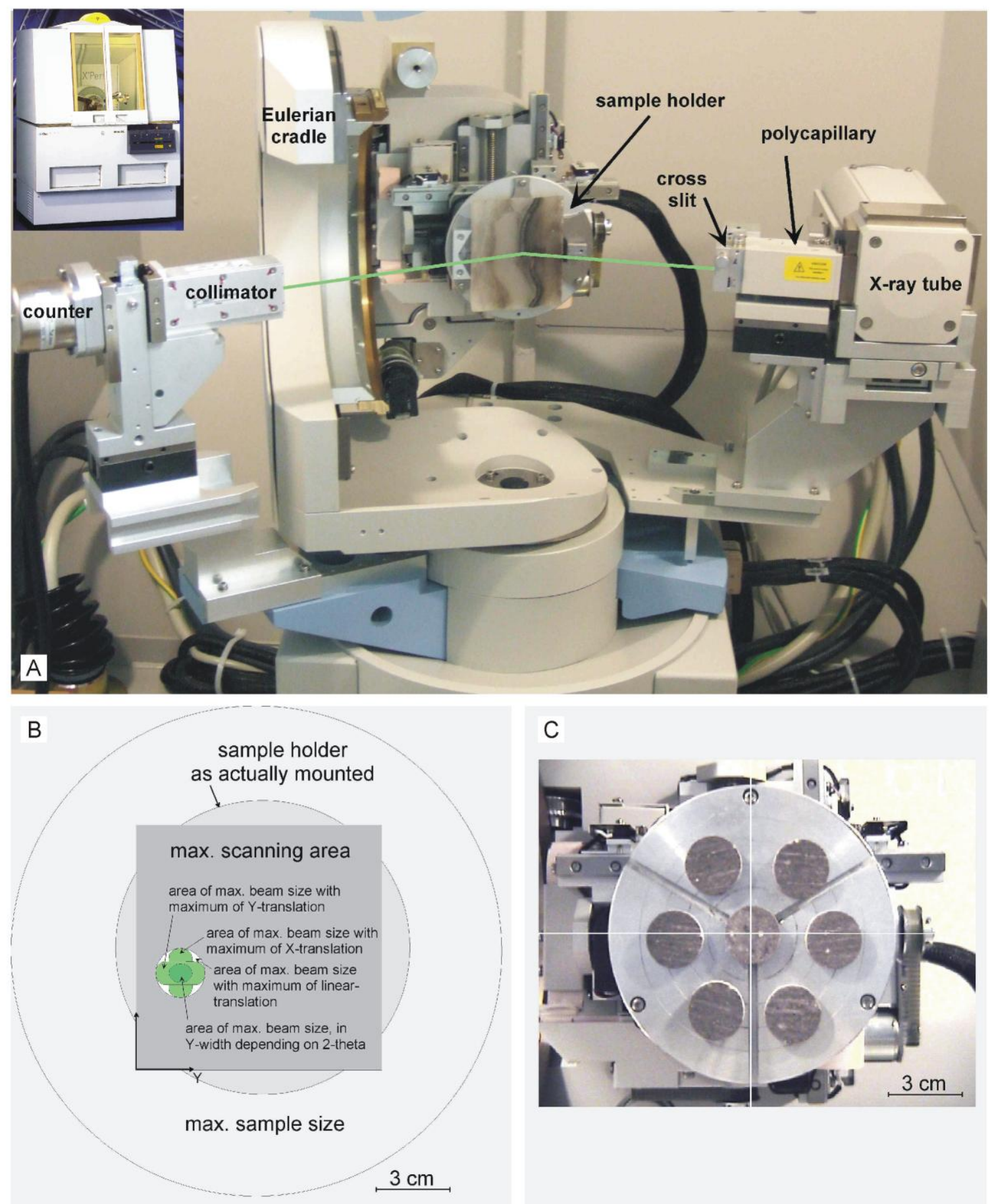

Fig. 2.7: A) Configuration of the X-ray texture goniometer at the Geoscience Centre of the University of Göttingen. Tilt angle of the sample holder is at $0^{\circ}$. In this figure, a sample of the Stassfurt Formation rock salt is fixed on the sample holder. B) Size of the primary beam considering XYtranslation of $\pm 10 \mathrm{~mm}$, size of the sample holder and maximum size of the sample. C) XYZ-table that provides a full scanning area of $100 \times 100 \mathrm{~mm}$. In this configuration, the table is used as automatic sample changer for 7 samples. Figure from Leiss \& Ullemeyer (2006). 
prepared in a special way (see section 2.2.6) and coated with carbon. Working conditions were: $20 \mathrm{kV}$ acceleration voltage, $4 \mathrm{nA}$ beam current, and $25 \mathrm{~mm}$ working distance.

\subsubsection{Sample preparation for microstructural investigations}

For microstructural analyses via EBSD, reflected light microscopy, or geochemical analyses by means of electron microprobe, samples need to have a special preparation procedure.

Initially, a representative sample is dry-sectioned from the drilling core by means of a diamond saw. After sectioning, the samples were ground in order to produce a planar surface and to remove the deformation layer at the surface induced during sectioning. For this study, samples were manually ground (dry) on a grinding instrument, using 60-, 120-, 500-, and 1000-grit $\mathrm{SiC}$ abrasive papers. Then, the samples were polished with diamond spray (3.0 and $1.0 \mu \mathrm{m}$ ) on a low-napped synthetic cloth. For the final polishing step, a low-napped synthetic velvet cloth was selected, and a $0.25 \mu \mathrm{m}$ diamond spray was used as polishing medium. The time required for polishing depends on the particular sample, but was generally quite short, with each abrasive size being used not longer than 2 minutes to minimize effects of preferential polishing and etching rates of halite compared to anhydrite. The polished samples were used for the bromide and strontium content determinations by means of electron microprobe described in sections 2.2.2 and 2.2.4.

For microstructural investigations via EBSD and reflected light microscopy, samples need to be etched after polishing. This procedure reveals grain boundaries and dislocation substructures within the grains in an excellent way. Especially for EBSD, etching is necessary to remove abrasive damage induced by polishing, as the crystal lattice of the top 1050 nanometers needs to be strain-free and clean from contamination. Otherwise, the resulting EBSD patterns will be of poor quality or not visible at all. Several etching mediums were tested to find out, which of them provides optimal results. These include slightly undersaturated $\mathrm{NaCl}$ solution, $0.2 \mu \mathrm{m}$ water-free silica suspension, distilled water, and diluted $\mathrm{HCl}$, with a mixture ratio of $\mathrm{H}_{2} \mathrm{O}: \mathrm{HCl}=5: 1$. In general, etching has to be very short (not more than $10 \mathrm{~s}$ ), as otherwise topographical differences on the surface will be generated due to preferential etching of halite compared to anhydrite, which would impair the quality of EBSD patterns. After etching, the samples need to be rinsed with a substance that has a relatively high evaporation rate. This enables quick removal of the etching medium and normally avoids the precipitation of new halite crystals on the sample surface. In this study, samples were rinsed with either butanol or methanol, with the latter having produced higher quality surfaces, presumably due to its higher evaporation rate. Finally, the samples were dried in a jet of warm air and stored under dry conditions. 
For microstructural investigations, rock salt samples from various locations (Morsleben, Teutschenthal, Remlingen, and Gorleben) and different stratigraphic units (Muschelkalk (Middle Triassic); Stassfurt rock salt, Leine rock salt, and Aller rock salt (Zechstein, Upper Permian) were prepared.
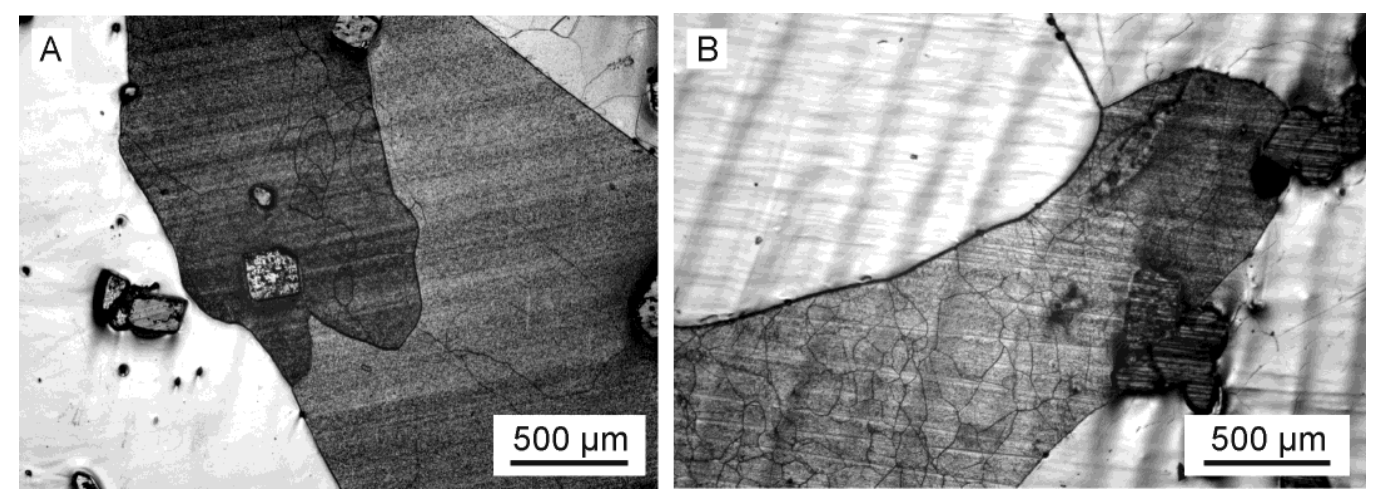

Fig. 2.8: Examples of etched sample surfaces with high quality in respect to the visualization of grain boundaries and substructures.
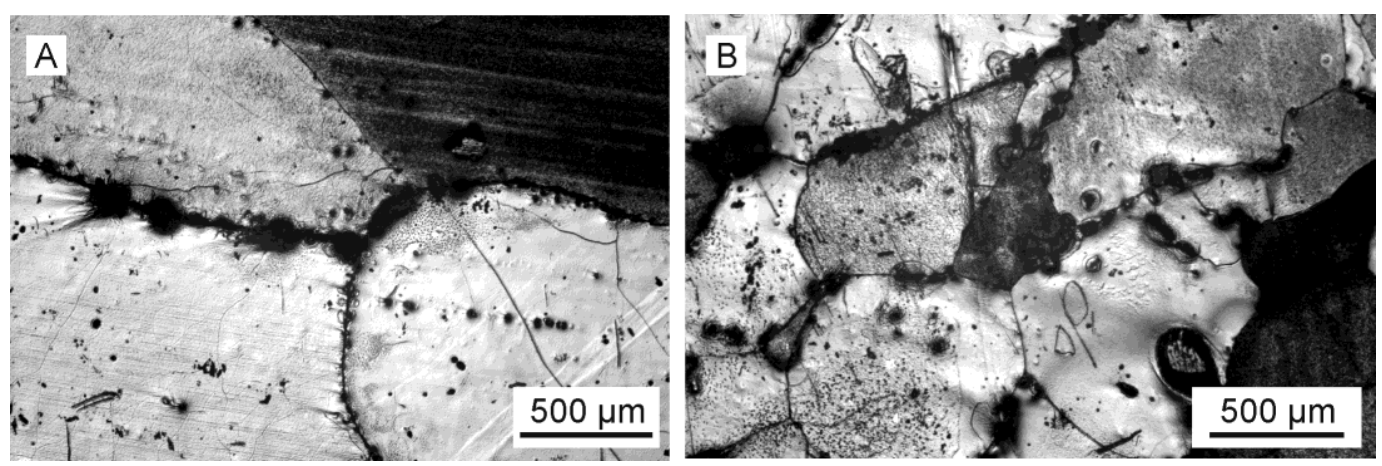

Fig. 2.9: Examples of etched sample surfaces with lower quality showing fluid inclusion-rich grain boundaries and impurities within the grains. Due to evaporation of the fluids released during etching, the surface is partly coated with minute halite crystals, and thus substructures are less visible.

Etching with distilled water and rinsing with methanol generally yields very good results in respect to the visualization of grain boundaries and substructures (Fig. 2.8). However, the sample surface quality is strongly dependent on two factors: (1) the specific properties of the investigated rock salt samples, and (2) the quality of grinding and polishing. One major problem related to the sample itself seems to be the presence of impurities or fluid inclusions within the grains or at the grain boundaries, respectively (Fig. 2.9). For example, grain boundaries are opened by the etching procedure and cannot be sealed quickly enough; consequently, some fluids will remain at the boundaries and evaporate later. Because of this, parts of the sample surface will be covered by a layer of minute halite crystals, or by droplets of released fluids around the grain boundaries (Fig. 2.9). Some samples show open grain boundaries (Fig. 2.9), which is probably due to partial breaking-up of the rock salt as a consequence of the drilling procedure or through the stress relief of the sample that is caused 
by the uplift of the core. The preparation of the Kristallbrocken was especially problematic due to the inclusions within this halite type. Most of these inclusions are filled with sulphate crystals and brine (Fig. 2.10A). During polishing, the sulphate crystals fall off and scratch the sample surface, and the brine released during etching leads to minute halite crystals on the surface (Fig. 2.10B). Another problem presumably concerns manual grinding and polishing. If the sample surface is not perfectly flat, a pattern of ridges can be observed after rinsing with methanol (Fig. 2.11).
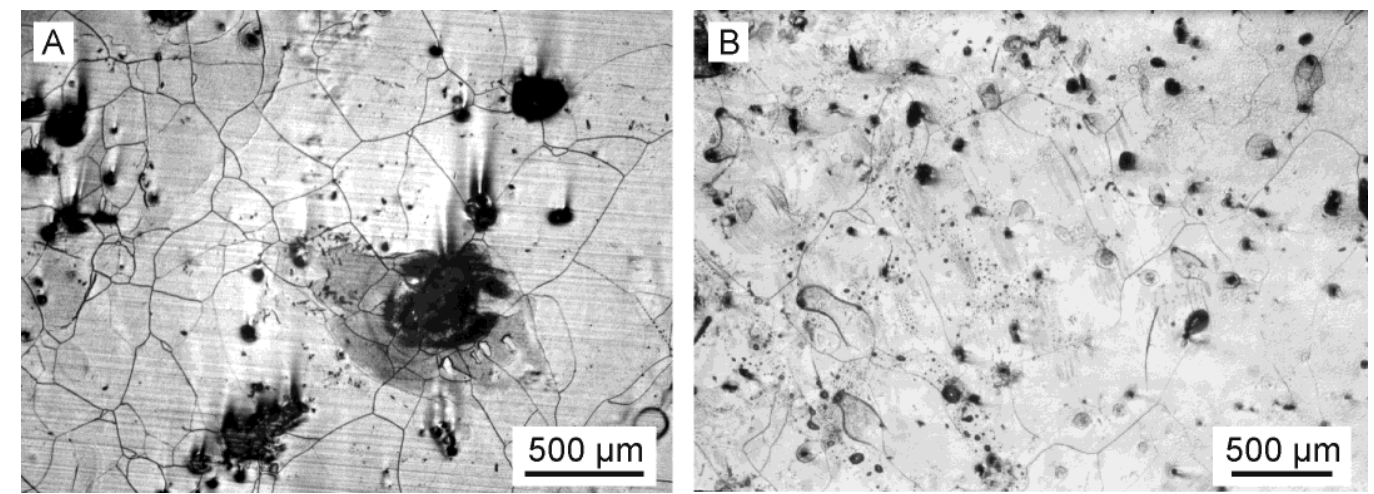

Fig. 2.10: Photomicrographs of Kristallbrocken surfaces after etching showing substructures and solid inclusions. Areas around the inclusions can be coated with minute halite crystals (Fig. 2.10A) or droplets of released fluids (Fig. 2.10B). Both features impair the surface quality and make EBSD measurements difficult.
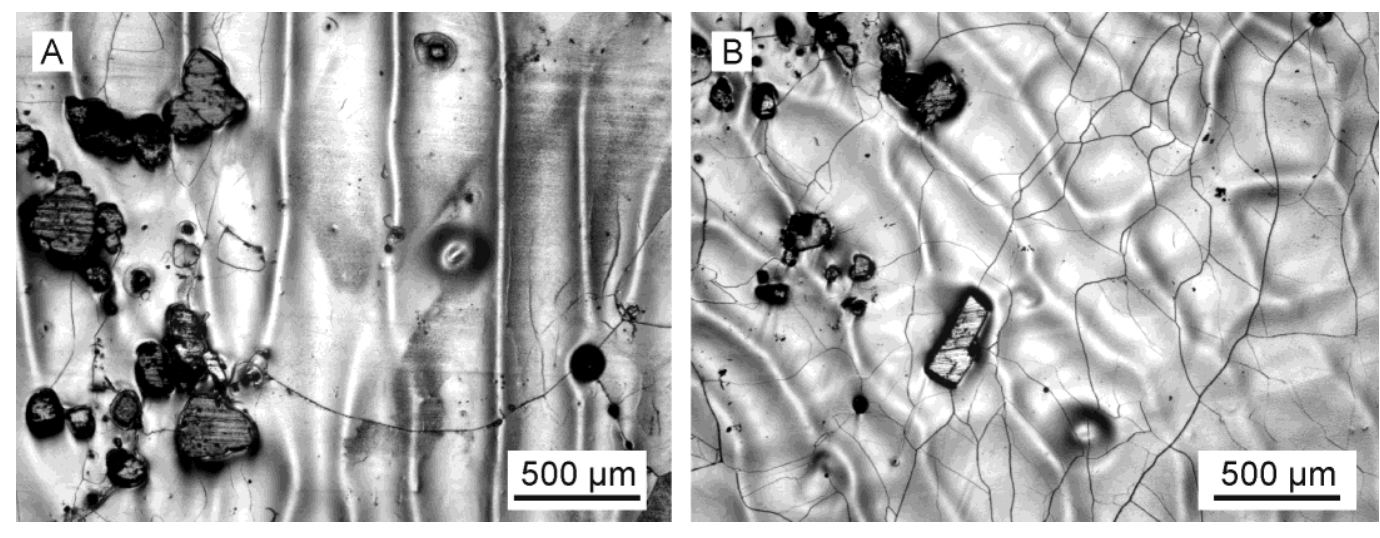

Fig. 2.11: Photomicrographs of sample surfaces after etching showing a pattern of ridges.

Despite all these phenomena, the microstructures of the samples can be studied quite well via reflected light microscopy, but for EBSD investigations they are very problematic, since it is very difficult to get good EBSD patterns and nearly impossible to enable automated measurements. Furthermore, the quality of etching and thus EBSD analysis seems to be highly dependent on the sample provenance and its specific properties rather than the etching procedure. Such problems have not been reported from other studies concerned with EBSD analyses on rock salt samples; however, most of these studies dealt with synthetic rock salts 
(e.g., Trimby et al. 2000a, b; Pennock et al. 2005, 2006), and these have generally lower water contents and fewer impurities than natural rock salts.

Another technique to visualize grain boundaries and deformation-related microstructures is gamma-irradiation (Urai et al. 1987; Garcia Celma \& Donker 1996, as cited in Schléder 2006). This technique involves gamma-irradiation of the sample slabs at constantly elevated temperatures (e.g., at $100^{\circ} \mathrm{C}$ ), with dose rates varying between $1 \mathrm{kGy} / \mathrm{h}$ and $4 \mathrm{kGy} / \mathrm{h}$ and up to a total dose of about $4 \mathrm{MGy}$ (cf. Schléder 2006). After this procedure, thin sections are prepared from these samples, which are then etched using slightly undersaturated $\mathrm{NaCl}$ solution following the method of Urai et al. (1987). Due to the irradiation with high doses of gamma ray, the internal structure (grain boundaries, subgrain boundaries, growth bands, and zonations) of the samples is revealed, which can be used for the investigation of deformation mechanisms. For technical reasons, it was not possible to use this technique for this thesis.

In this study, EBSD was used to measure the orientation of a set of grains in a rock salt shear zone sample from the Morsleben salt mine (see Fig. 5.2C in chapter 5.1.2). To allow for a good statistical basis, the aim was to measure a lot of grains, because although the sample is from a shear zone, the grain sizes are still in the range of $\mathrm{mm}$. Unfortunately, automatic measurements were hardly possible due to the poor sample surface quality and thus insufficient EBSD pattern quality. A total of 150 measurements could be carried out on about 30 grains. The results show no crystallographic preferred orientation in this sample. 


\section{BROMIDE CHARACTERISTICS}

\subsection{Bromide distribution characteristics of different Zechstein 2 rock salt sequences of the Southern Permian Basin: a comparison between bedded and domal salts}

Yvonne Küster, Michael Schramm, Otto Bornemann, Bernd Leiss, Sedimentology 56 (2009), 1368-1391.

\subsubsection{Abstract}

The bromide profile of the bedded Zechstein 2 rock salts in the Southern Permian Basin is characterized by a continuous increase in the bromide contents from base to top, indicating progressive evaporation of sea water. Former studies suggested that the bromide distribution in domal salts is more irregular, raising such questions as if there is a causal relationship between bromide distribution and deformation-related processes, or if various halite types with different primary bromide contents account for such irregularities. In this study, the bromide distribution of a defined stratigraphic section (Hauptsalz) of the Zechstein 2 was investigated in three salt deposits, with bedded salt (Teutschenthal) compared to domal salts (Morsleben, Gorleben). Furthermore, two different halite types (Kristallbrocken, matrix) were distinguished during sampling. The comparison between the locations reveals that (i) the characteristic trend of the bromide profile was generally preserved in both the bedded and the more intensely deformed domal salts, (ii) the dispersion of bromide contents along the running average curve is lower in domal salt, especially in the lower half of the Hauptsalz, and (iii) the Kristallbrocken are absent in the lower half of the Hauptsalz of Morsleben and Gorleben. The absence of the Kristallbrocken and the lower dispersion of the bromide 
contents in the domal salts are clear indications for the influence of salt migration-related processes on the bromide distribution characteristics. It shows that these processes are associated with a redistribution of bromide, which eventually results in a homogenization of the originally varying bromide contents. On the other hand, preservation of the characteristic trend in the bromide profiles indicates that large-scale brecciation, folding processes, or circulating bromide-rich fluids played only a minor role during the formation of the salt domes. Selective sampling of the Kristallbrocken and matrix halite displays a disparity in bromide content that is not consistent between the studied locations. These specific phenomena might be related to different depositional locations in the Zechstein Basin or to post-depositional processes.

\subsubsection{Introduction}

During the sedimentation of marine salt deposits, bromide is incorporated into the crystal lattice of chloride salts instead of chloride, with a partition coefficient always less than one (Boeke 1908; Schobert 1912, quoted by Schulze 1958; D’Ans \& Kühn 1940, 1944; Braitsch \& Herrmann 1963). The bromide content of both the parent brine and the chloride salts increases with continuous sea water evaporation and chloride salt precipitation. The bromide content of halite is therefore a useful indicator for the degree of evaporation and can be used as a stratigraphic marker (Valyashko 1956; Baar 1963; Haltenhof \& Hofrichter 1972; Simon 1972; Käding 2003) as well as a genetic marker (Kühn 1955; Es-Said 1974; Fisher \& Hovorka 1987; Smith et al. 1995; Raup \& Hite 1996; Kirkland et al. 2000) in salt deposits. Furthermore, bromide analyses of salt deposits are helpful in potash exploration, repository research and solution mining projects, especially in salt domes. In the latter case, bromide analyses of cuttings provide detailed information about the current stratigraphic location during drilling and complement geophysical data obtained by gamma-ray and density measurements (Schramm et al. 2002; Wilke et al. 2002).

In Germany, a substantial number of studies investigated the stratigraphy and the bromide distribution of various Zechstein salt deposits (Baar 1954; Schulze 1958; Schulze 1960a; Simon \& Haltenhof 1970; Haltenhof \& Hofrichter 1972; Simon 1972; Käding 2003). These studies have been particularly focused on the rock salt of the Stassfurt Formation (Z2; Fig. 3.1). The bromide profile of the rock salt of the Stassfurt Formation is characterized by a continuous upward increase in the bromide content reflecting progressive evaporation of sea water (Schulze 1960a; Simon 1972). Some of the bromide profiles of the Stassfurt rock salt can be regarded as relatively regular or even ideal (Holser 1966a; Kühn 1968). However, detailed investigations of various Stassfurt rock salt profiles in the Gorleben salt dome 
3.1 Bromide distribution characteristics of different Zechstein 2 rock salt sequences of the Southern Permian Basin: a comparison between bedded and domal salts

showed surprising differences in bromide contents between profiles of the same stratigraphic intervals, especially in the upper parts of the Stassfurt rock salt (Bornemann et al. 2008). Previous studies, by Simon (1972), Herrmann (2000), and Bornemann et al. (2000), attributed the disparity in bromide content between different halite fabric types within the Stassfurt rock salt to deformation processes during salt migration. However, since more detailed systematic investigations on the bromide distributions are missing, the controlling parameters causing distribution disparities remain uncertain.

The approach of this study is threefold: (1) The bromide distribution of three stratigraphically equivalent rock salt sequences from different locations in the Southern Permian Zechstein Basin was compared, with two locations situated near the basin edge and one location situated close to the basin centre. (2) Based on these three salt deposits with different deformation histories, well-standardized and coherent sets of bromide profiles of a definite stratigraphic section were generated in order to illuminate a possible relationship between the bromide distribution and the intensity of deformation. (3) Based on two different salt fabric types, this study aimed to determine whether petrographic differences are reflected in the bromide content, and if so, to what extent does this contribute to the previously observed difference.

\begin{tabular}{|c|c|c|c|c|c|c|}
\hline \multicolumn{2}{|c|}{$\begin{array}{c}\text { Chrono- } \\
\text { stratigraphy }\end{array}$} & \multicolumn{3}{|c|}{ Lithostratigraphy } & \multirow{2}{*}{\multicolumn{2}{|c|}{$\begin{array}{c}\text { Lithostratigraphy } \\
\text { Lithology }\end{array}$}} \\
\hline Period & Epoch & Group & Formation & Symbol & & \\
\hline \multirow[t]{2}{*}{$\begin{array}{l}\frac{c}{\frac{D}{\sigma}} \\
\frac{\frac{1}{d}}{0} \\
0\end{array}$} & \multirow{2}{*}{ 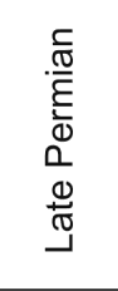 } & \multirow[t]{2}{*}{$\begin{array}{l}\frac{5}{\bar{D}} \\
\frac{1}{0} \\
\frac{C}{0} \\
\mathbb{D} \\
N\end{array}$} & $\begin{array}{l}\text { Fulda } \\
\text { Friesland } \\
\text { Ohre } \\
\text { Aller } \\
\text { Leine }\end{array}$ & $\begin{array}{l}\mathrm{Z7} \\
\mathrm{Z6} \\
\mathrm{Z} 5 \\
\mathrm{Z} 4 \\
\mathrm{Z} 3\end{array}$ & \multirow{2}{*}{$\begin{array}{c}\begin{array}{c}\text { claystone } \\
\text { anhydrite } \\
\text { potash salts }\end{array} \\
\text { rock salt } \\
\begin{array}{c}\text { anhydrite } \\
\text { carbonate } \\
\text { claystone }\end{array}\end{array}$} & \begin{tabular}{|c} 
Hangendsalz \\
Hauptsalz \\
Basissalz
\end{tabular} \\
\hline & & & $\begin{array}{l}\text { Stassfurt } \\
\text { Werra }\end{array}$ & $\begin{array}{l}\mathrm{Z} 2 \\
\mathrm{Z1} \\
\end{array}$ & & \\
\hline
\end{tabular}

Fig. 3.1: Stratigraphic table of the German Zechstein group (according to Richter-Bernburg 1955a; Käding 1978, 2000).

\subsubsection{Paleogeographic setting}

During the Permian, two east-west aligned depositional basins developed in north-western Europe: the Northern and the Southern Permian basin (Fig. 3.2). The Northern Permian basin extended from Scotland to Northern Denmark, the Southern Permian basin extended from Eastern England and the Southern North Sea in the west to Poland and Lithuania in the east. These basins were partly separated by the Mid-North Sea High and the Ringkøbing-Fyn High. 
With the beginning of the Late Permian (Zechstein), both basins were repeatedly transgressed by sea water coming from the Arctic Sea. The cyclicity of these marine transgressions was presumably caused by glacio-eustatic fluctuations in sea level as well as tectonic processes (Smith 1979; Ziegler 1981, 1990; Strohmenger et al. 1996; Taylor 1998). The high evaporation rates due to the arid climatic conditions during the Zechstein, combined with cyclic restriction of sea water influx into the basins, resulted in the deposition of the Zechstein carbonates and evaporites.

In Germany, the Zechstein group comprises four main evaporation cycles referred to as the Werra (Z1), Stassfurt (Z2), Leine (Z3) and Aller (Z4) Formations (Richter-Bernburg 1955a; Fig. 3.1) and three rudimentary and only regionally occurring cycles referred to as the Ohre (Z5), Friesland (Z6) and Fulda (Z7) Formations (Käding 1978, 2000; Fig. 3.1). Each cycle is characteristic for a progressive evaporation phase, starting with clastic sediments like mudstones and followed by carbonates, anhydrites, rock salt and potash salts. Today, Zechstein sediments occur in both flat-lying, apparently undisturbed settings, and in the form of pillows, diapirs, and salt walls formed by salt tectonics (Trusheim 1960; Jaritz 1973; Kockel 1998). In Germany, the rock salt of the Stassfurt Formation is most widespread, with an estimated original thickness of $500 \mathrm{~m}$ and more (cf. Zharkov 1984). The present thickness, however, is highly variable due to different post-depositional processes like diapirism, leaching or erosion.

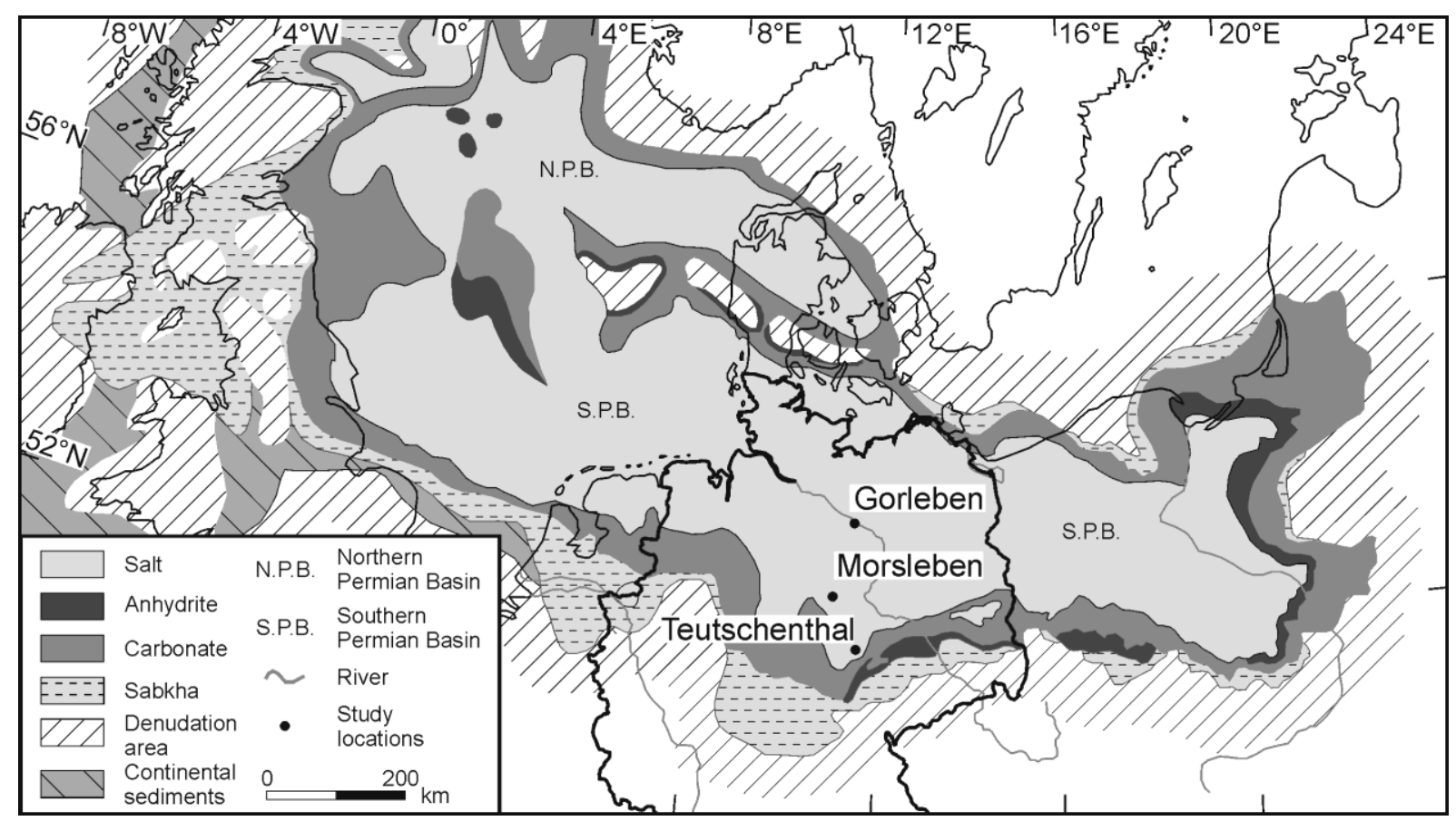

Fig. 3.2: Map of the Late Permian Zechstein Basin showing the position of the studied locations in context with the paleogeographic situation during the deposition of the Stassfurt Formation (modified from Best 1989). 
3.1 Bromide distribution characteristics of different Zechstein 2 rock salt sequences of the

\subsubsection{Bromide distribution in halite}

Bromide does not form bromide minerals during the evaporation of sea water, but partially substitutes chloride in the crystal lattice of halite and other chloride minerals (Boeke 1908). The amount of bromide in halite is proportional to the bromide content in the parent brine. This relationship between bromide in halite and bromide in evaporating sea water is expressed by the partition coefficient

$$
{ }^{\text {halite }} D_{\mathrm{Br}}=\mathrm{wt} \% \mathrm{Br}_{\text {halite }} / \mathrm{wt} \% \mathrm{Br}_{\text {sea water }}
$$

that ranges from about 0.14 at the beginning of halite precipitation to approximately 0.07 at precipitation of the first potash salts (Braitsch \& Herrmann 1963). Modern sea water contains approximately $67 \mathrm{ppm}$ bromide (Bruland 1983). During evaporation, the bromide content increases to about $540 \mathrm{ppm}$ at the beginning of halite precipitation and the first halite is expected to contain 75 ppm (D’Ans \& Kühn 1940, 1944; Braitsch \& Herrmann 1963; Holser 1966a). The bromide content of both the parent brine and halite increases with progressive sea water evaporation and halite precipitation, and reaches values of about $280 \mathrm{ppm}$ in halite prior to the precipitation of first potash salts (Braitsch 1962). The composition of modern sea water is assumed to be quite similar to that of Permian sea water (Horita et al. 1991; Lowenstein et al. 2001; Horita et al. 2002; Lowenstein et al. 2005). Bromide has a long residence time of about 100 Myr in the world oceanic waters (Holland 1978; Chester 2000), and it is therefore likely that the bromide concentration has not changed significantly during the Phanerozoic (Horita et al. 1991; Horita et al. 2002).

\subsubsection{Sampling material and study locations}

The studied drill core material was obtained from salt deposits located in the central to southern part of the former Southern Permian Basin (Fig. 3.2). For comparison, three salt deposits were chosen whose present structure varies from a bedded salt in Teutschenthal to a domal salt in Morsleben and Gorleben (Fig. 3.3).

The investigated rock salts belong to the Stassfurt Formation which can be subdivided into three stratigraphic units. These are (from base to top): Basissalz, Hauptsalz, and Hangendsalz (Richter-Bernburg 1955a; Fig. 3.1). The Basissalz is a very thin sequence between the overlying Hauptsalz and the underlying anhydrite sequence, which generally consists of very clear rock salt zones and frequently interbedded anhydrite layers. The Hauptsalz (German: "Hauptsalz" = main salt) is the thickest part of the Stassfurt rock salt and has been exposed almost completely by drilling cores in each location. Therefore, sampling of the drilling cores focused on the Hauptsalz unit to allow systematic comparisons between the 
different bromide profiles. Originally, the Hauptsalz unit is characterized by a rhythmic stratification composed of anhydrite and rock salt layers. The latter typically consists of two halite fabric types, namely (1) clear, granular halite that is also referred to as matrix halite, and (2) blocks of laminated halite, the so-called "Kristallbrocken" (German: "Kristallbrocken" = crystal fragments; Simon 1972). This halite fabric type appears to be characteristic for the Stassfurt Formation rock salt of the German Zechstein Basin (RichterBernburg 1955b; Lotze 1957; Simon \& Haltenhof 1970; Simon 1972) and the Oldest and Older Halite of the Polish Zechstein Basin (Czapowski 1986, 1987, Czapowski et al. 1990, 1993), where it is described as "C-halite" type. The original sedimentary fabric of the Hauptsalz has been largely preserved in Teutschenthal, whereas in Morsleben and Gorleben, it was destroyed and homogenized by halokinetic processes. The Hangendsalz can be distinguished from the Hauptsalz by a generally lower sulphate content and the presence of polyhalite as the predominant sulphate mineral. In addition, it is mainly composed of clear granular rock salt and characterized by an absence of the Kristallbrocken halite type.

Teutschenthal, the former potash and rock salt mine, is situated about $15 \mathrm{~km}$ south-west of the city of Halle in Saxony-Anhalt. The salt mine belongs to the NW-SE trending Teutschenthal anticline, a salt pillow formed by the accumulation of salt migrating from adjacent areas (Fig. 3.3A). The original thickness of the Stassfurt rock salt in this area is estimated to range between about $300 \mathrm{~m}$ and $400 \mathrm{~m}$. Due to halokinesis, the present thickness varies considerably, with a maximum of about $1000 \mathrm{~m}$ (Jagsch \& Theylich 1999).

The salt structure Morsleben is located about $30 \mathrm{~km}$ south-east of the city of Wolfsburg near the border of Lower Saxony and Saxony-Anhalt. The salt structure (Fig. 3.3B) belongs to the NW-SE trending Allertal Fault Zone, a major structural element of the Subherzynian Basin (Schulze 1962). During the Late Triassic, Zechstein salt migrated into the Allertal Fault Zone, forming a salt diapir in this area (Jubitz et al. 1991). Since the Late Cretaceous, regional uplift and erosion of overlying sediments led to intense subrosion of the upper parts of the folded Zechstein sediments resulting in an up to $200 \mathrm{~m}$ thick cap rock (Balzer 1992; Best \& Zirngast 1999). The present salt structure is the relict of a diapiric structure, in which approximately $73 \%$ of the original salt diapir has been subjected to subrosion (Best \& Zirngast 1999). The thickness of the salt body ranges between $380 \mathrm{~m}$ and $580 \mathrm{~m}$, with the top at about $140 \mathrm{~m}$ below sea level and the base ranging between $500 \mathrm{~m}$ and $710 \mathrm{~m}$ below sea level (Behlau \& Mingerzahn 2001). The Stassfurt rock salts of the Allertal Fault Zone generally have less original thicknesses (ca. 100 to 200 m; Löffler \& Schulze 1962) than those 
3.1 Bromide distribution characteristics of different Zechstein 2 rock salt sequences of the Southern Permian Basin: a comparison between bedded and domal salts

of the other investigated deposits. Due to intense salt migration and subrosion, the present thickness is highly variable, ranging from less than 50 to up to $400 \mathrm{~m}$ (Fig. 3.3B).
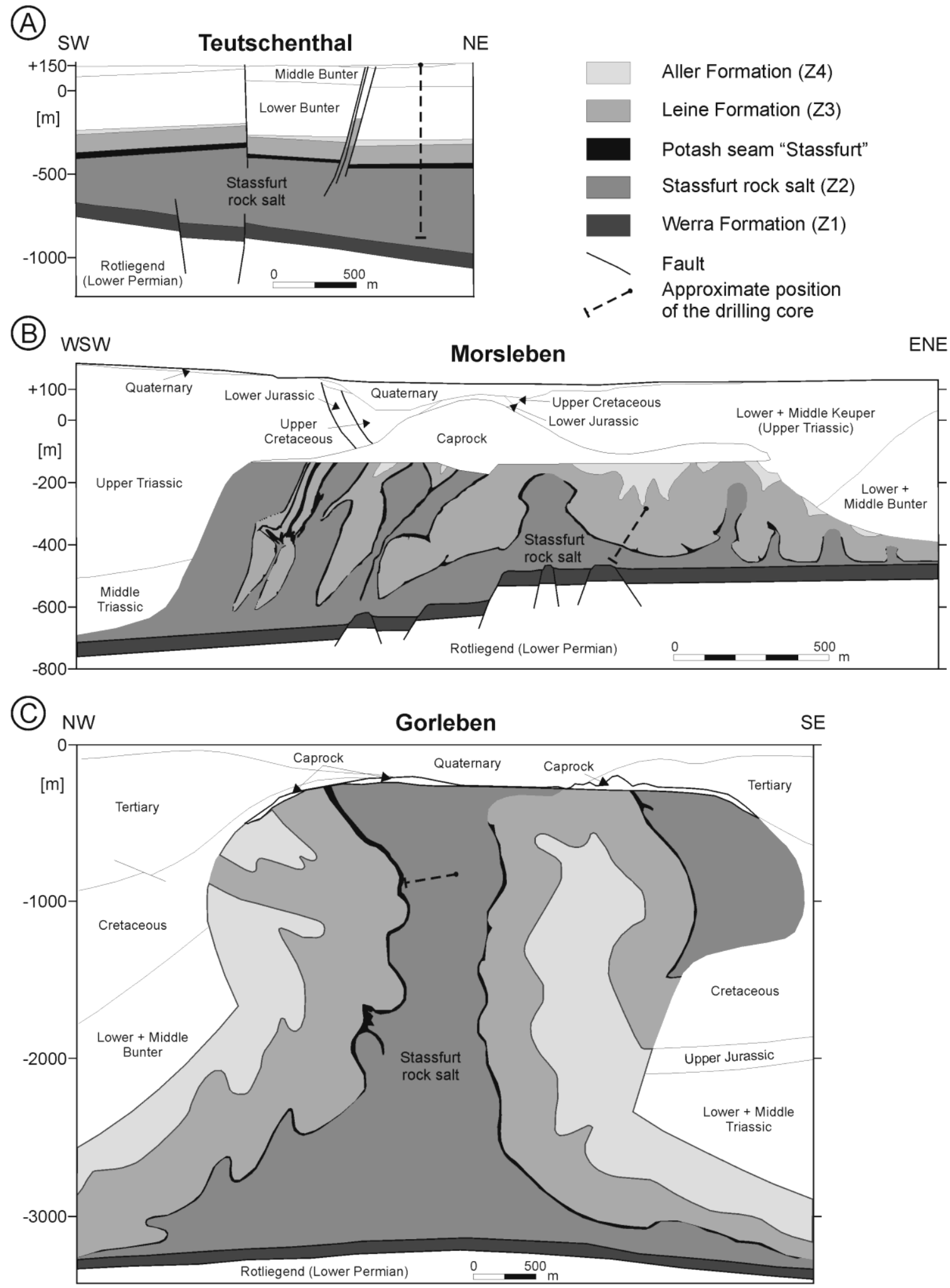

Fig. 3.3: Cross sections of the salt deposits showing the approximate position of the investigated wells (dashed line). A) Teutschenthal salt pillow (modified from Jagsch \& Theylich 1999). B) Morsleben salt structure (after BfS 2001). C) Gorleben salt dome (modified from Bornemann 1991). 
The NE-SW trending Gorleben salt dome (Fig. 3.3C) is situated about $100 \mathrm{~km}$ southeast of the city of Hamburg, in Lower Saxony. Its approximate extent is $14 \mathrm{~km}$ in length and $4 \mathrm{~km}$ in width, with the top at $250 \mathrm{~m}$ and the base at about $3 \mathrm{~km}$ depth (Bornemann 1991). The salt dome formed by the upward migration of Zechstein salts initiated in the Late Bunter (Early Triassic) and the diapiric stage was reached in the Early Cretaceous (Zirngast 1991; Jaritz 1993). The active part during diapirism was presumably the thick Stassfurt rock salt, especially the Hauptsalz, which forms the core of the present salt dome (Bornemann et al. 2000). Therefore, the original sedimentary fabric of the Hauptsalz, namely the rhythmic stratification of anhydrite layers and rock salt sequences, was extensively destroyed. In contrast, the younger Zechstein sequences were dragged upwards more passively, and thus their sedimentary fabric could be largely preserved (Bäuerle 2000; Bornemann et al. 2000).

\subsubsection{Sampling and analytical methods}

For sampling, $2 \mathrm{~cm}$ thick slabs were cut from the cores collected at the three locations in regular intervals of about $1 \mathrm{~m}$ in Morsleben, $3 \mathrm{~m}$ in Teutschenthal and $5 \mathrm{~m}$ in Gorleben. After grinding and polishing, the sections were examined with transmitted light using a Wild M3 stereomicroscope (WILD, now Leica Geosystems AG, Heerbrugg, Switzerland) and prepared for sampling. The different halite fabric types (Kristallbrocken and matrix) were segregated during sampling, and attempts were made to avoid sampling of fluid inclusion-rich areas and anhydrite laminations. Samples for bromide analyses were taken by drilling small holes ( $1 \mathrm{~mm}$ ) into previously marked points on the thick sections using a bench drilling machine (Proxxon). Prior to each new sample, the drill bit was cleaned to avoid contamination by previously drilled material. Each sample contained approximately $100 \mathrm{mg}$ of halite.

In this study, a total of 785 samples have been sampled and analyzed: 264 from Teutschenthal, 344 from Morsleben, and 177 from Gorleben. The sampled material was analyzed for major cations, including potassium, sodium, magnesium and calcium, and major and trace anions, including chloride, sulphate and bromide. The determination of the cations was conducted by inductively coupled plasma optical emission spectrometry (ICP-OES), using a Spectro CIROS. Anion analysis was performed on a Dionex DX500 ion chromatograph (IC). The limit of detection for bromide is approximately $10 \mathrm{ppm}$. The accuracy as well as reproducibility for bromide was better than 5\% measured against an inhouse halite reference sample. The difference in the anion-cation balance was generally less than $1 \%$. Based on the chemical analyses, the quantitative mineral composition of the sample was calculated. As samples contained no potash-bearing salt minerals, the analyzed bromide content could be directly related to the calculated halite content of the sample. 
3.1 Bromide distribution characteristics of different Zechstein 2 rock salt sequences of the

In addition to the samples for bromide analyses, several samples of each location were prepared for microstructural investigations by reflected light microscopy. Thick sections were cut from the core slabs of different parts of the Hauptsalz. After dry grinding and polishing, thick sections were etched with distilled water for $5 \mathrm{sec}$, then rinsed for some seconds with methanol, and finally dried in a jet of warm air. This procedure reveals grain boundaries and dislocation substructures within the grain.

\subsubsection{Petrography of the rock salt}

\subsubsection{Teutschenthal}

The studied rock salt was obtained from two wells drilled for hydrocarbon storage caverns, in which the Hauptsalz of the Stassfurt Formation reaches a total thickness of up to nearly 480 $\mathrm{m}$. The diameter of the drilling core is $10 \mathrm{~cm}$. The Hauptsalz is even bedded, and consists of differently developed rock salt horizons and thin, regularly interbedded layers of anhydrite (Fig. 3.4A). The rock salt horizons generally have a thickness of 1 to $15 \mathrm{~cm}$, occasionally up to $20 \mathrm{~cm}$, and contain mostly two characteristic types of halite (Fig. 3.4, A-C): (1) Clear, granular halite that is also referred to as matrix halite, with grain sizes ranging from $0.2 \mathrm{~cm}$ to $1 \mathrm{~cm}$. (2) The Kristallbrocken, with grain sizes ranging from about $2 \mathrm{~cm}$ to up to $10 \mathrm{~cm}$ in the drilling core. The appearance of this laminated halite type is sometimes clear and transparent and sometimes white and opaque due to different amounts of solid inclusions. The characteristic lamination within the Kristallbrocken is defined by variations in sulphate inclusion content (Simon 1972; Czapowski 1986; Küster et al. 2007b), i.e. light-colored zones with few solid inclusions alternate with grey-colored zones containing many solid inclusions. In Teutschenthal, the solid inclusions of the laminae are made up of anhydrite aggregates and individual anhydrite crystals. The lamination suggests that the Kristallbrocken are relics of former continuous sedimentary halite beds and can thus be regarded as an unaltered, quasi primary component of the Hauptsalz. The interbedded, massive anhydrite layers can be usually traced throughout the sediment, with a thickness ranging from some millimeters at the base of the Hauptsalz up to $2 \mathrm{~cm}$ in its upper parts. Locally, anhydrite layers are slightly folded (Fig. 3.4B-C) or boudinaged, which illustrates the high competence contrast between halite and anhydrite during salt migration processes. Individual anhydrite crystals or aggregates of some hundred micrometers, dispersed within the rock salt horizons, occur at the grain boundaries of the halite or within the halite grains as solid inclusions (Fig. 3.4D, E, H and I). 


\subsubsection{Morsleben}

The studied rock salt was obtained from a well drilled for investigative purposes; drilling was started from the second level of the mine, at about $280 \mathrm{~m}$ below sea level (Fig. 3.3B).
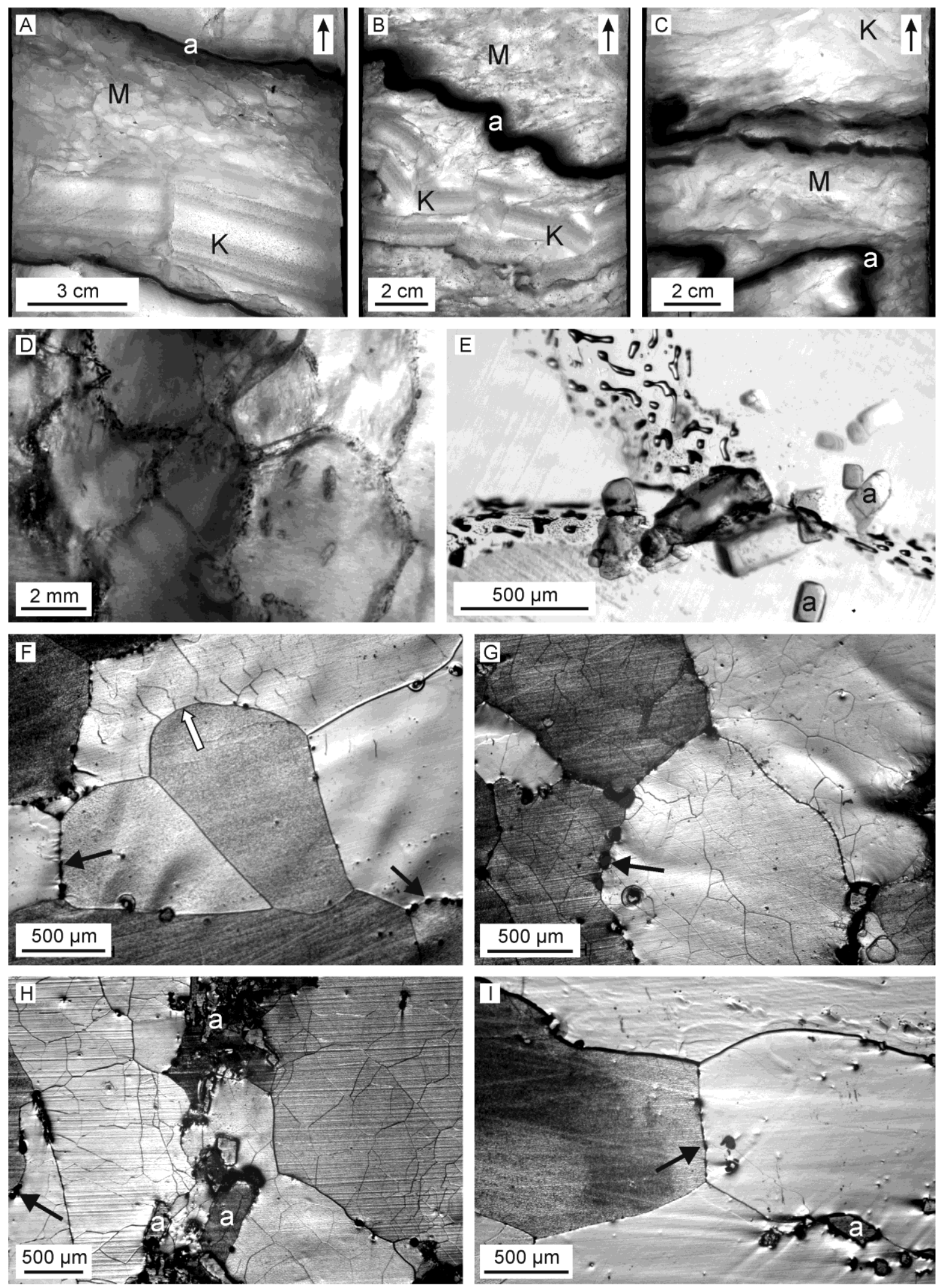
The thickness of the Hauptsalz in this core $(\varnothing 6 \mathrm{~cm})$ is comparatively low (ca. $71 \mathrm{~m})$ and, possibly, points to intense thinning processes due to diapirism. In general, the rock salt is more homogeneous than in Teutschenthal, because the original sedimentary fabric, namely the rhythmic bedding of rock salt and anhydrite layers, has been destroyed as a consequence of deformation processes during salt migration The Hauptsalz is predominantly composed of fluid inclusion-poor matrix halite (Fig. 3.5A and B). The grain size distribution is quite heterogeneous, ranging from some millimeters up to more than $2 \mathrm{~cm}$. The Kristallbrocken are only locally preserved, mainly in the upper parts of the Hauptsalz (Fig. 3.5C), and their grain size ranges between $1 \mathrm{~cm}$ and $4 \mathrm{~cm}$. In some parts of the Hauptsalz, matrix halite grains are elongated (Fig. 3.5D). The Hauptsalz ranges from light-grey to dark-grey in color because of different amounts of finely dispersed anhydrite crystals in the matrix halite. In addition, the Hauptsalz contains anhydrite in the form of fragments or nodules that originated from previously continuous anhydrite layers by deformation-related processes like fracturing and folding. Although the average anhydrite content of 4 to $5 \%$ is nearly constant throughout the entire Hauptsalz, its appearance varies from bottom to top. The lower and the middle parts of the Hauptsalz are dominated by rock salt zones that are rich in finely dispersed anhydrite crystals alternating with anhydrite-poor zones (Fig. 3.5A and B), whereas the upper parts consist of relatively clear rock salt zones with anhydrite occurring as layer fragments or nodules (Fig. 3.5C). In the uppermost parts of the Hauptsalz, polyhalite can be observed in addition to anhydrite.

\subsubsection{Gorleben}

The studied rock salt was obtained from an exploration well drilled nearly horizontally within the upper central part of the salt diapir, at about $840 \mathrm{~m}$ below ground level (Fig. 3.3C). The

\section{$\leftarrow$}

Fig. 3.4: A-C) Core slab photographs of the Hauptsalz of Teutschenthal. Arrow in white box indicates stratigraphic up direction. A) Rock salt sample with medium-grained to coarse-grained matrix halite (M), the Kristallbrocken (K), and interbedded, thin anhydrite layers (a). Note the well developed internal lamination of the Kristallbrocken. B-C) Rock salt samples containing matrix halite, the Kristallbrocken, and slightly to considerably folded anhydrite layers. D-E) Transmitted light photomicrographs of matrix halite grains showing worm-like fluid or gaseous inclusions and some anhydrite crystals (a) at the grain boundaries. F-I) Reflected light photomicrographs of etched sample surfaces. F) Sample showing sub-structure free grains in the middle and a sub-grain rich grain above. Note the lobate grain boundary (white arrow) in the upper part of the middle grain indicating the migration direction. The black spots visible at the grain boundaries (black arrow) represent fluid inclusions liberated during sample preparation. G) Sample with sub-grain rich grains containing considerable amounts of fluid inclusions at the grain boundaries. H) Sample showing substructure-rich grains and parts of an anhydrite layer consisting of many small-sized anhydrite crystals (a). Few fluid inclusions can be observed at the grain boundary or within the grains. I) Largely substructure-free grains with smooth grain boundaries and only few amounts of fluid inclusions. 
thickness of the Hauptsalz exposed in that core $(\varnothing 6 \mathrm{~cm})$ is about $440 \mathrm{~m}$, but, due to intense folding and the homogeneity of the rock salt, it is unclear to what extent this reflects its original thickness. Additionally, in contrast to Teutschenthal and Morsleben, the Hauptsalz
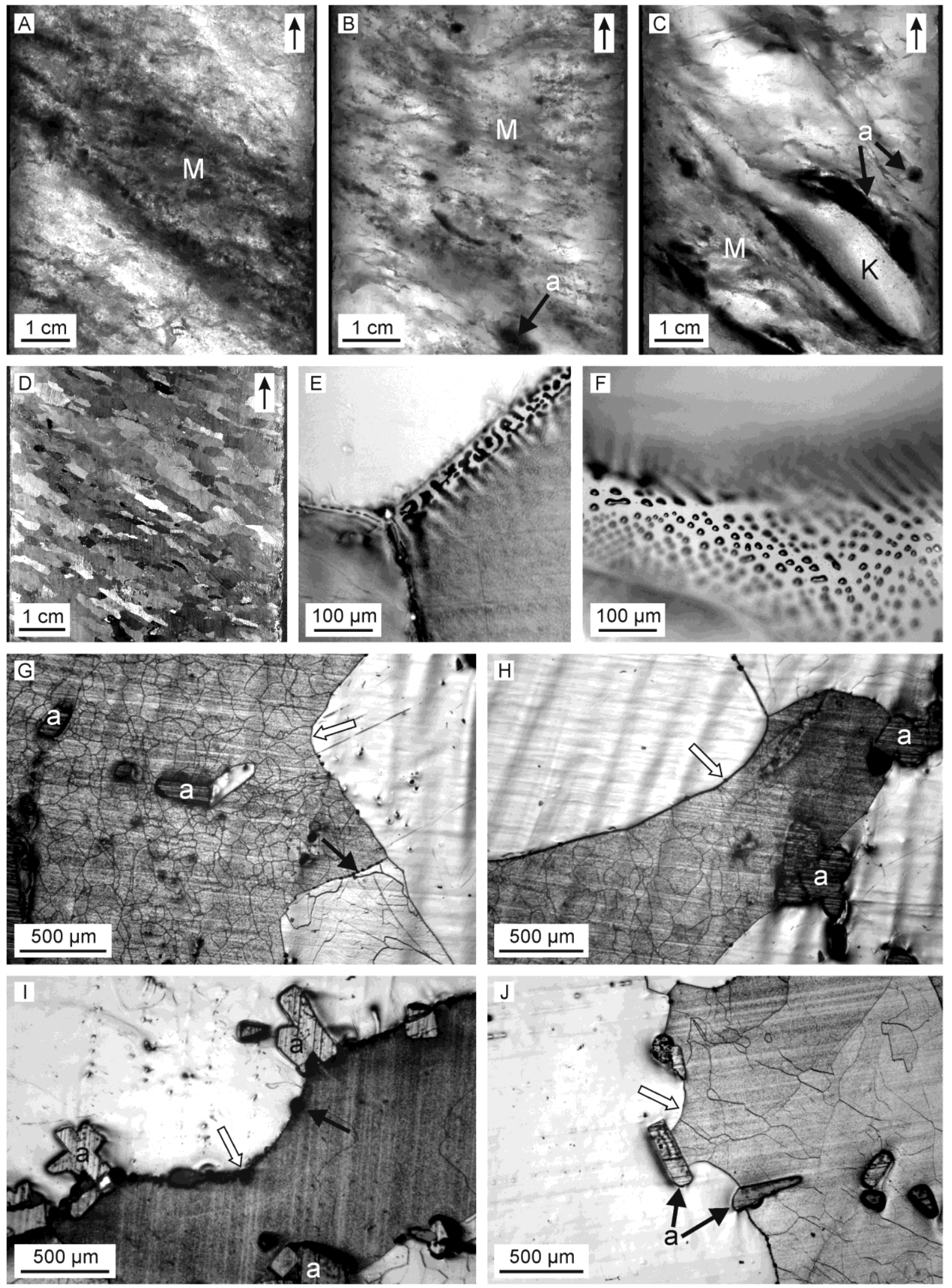
cannot be distinguished from the underlying Basissalz, as either this section looks similar to the Hauptsalz due to homogenization processes during salt migration or it was actually not involved in the origin of the salt dome and remained at its base. As the original sedimentary fabric of the Hauptsalz was destroyed and homogenized during diapirism, the fabric of the Hauptsalz is similar to that of Morsleben. Based on petrographic aspects, the Hauptsalz of the Stassfurt rock salt in Gorleben can be subdivided into three subunits. These are (from bottom to top): Knäuelsalz, Streifensalz and Kristallbrockensalz (Bornemann 1991). The lower part (Knäuelsalz) predominantly consists of matrix halite with a grain size of some millimeters up to more than $1 \mathrm{~cm}$. The rock salt is grey to dark-grey in color, due to uniformly dispersed anhydrite crystals within the matrix, and, additionally, contains a large amount of anhydrite layer relics in the form of nodules (Fig. 3.6A). The middle part (Streifensalz) is characterized by anhydrite-rich rock salt zones alternating with anhydrite-poor zones, which give this subunit its banded appearance (Fig. 3.6B). Anhydrite-rich zones can be composed of relics of anhydrite layers or finely dispersed anhydrite crystals. Anhydrite nodules are not as frequent in the middle part as in the lower part. In addition to the equigranular rock salt, some Kristallbrocken can be observed. The upper part (Kristallbrockensalz) consists of matrix halite and a considerable amount of the Kristallbrocken, with a grain size ranging from $1 \mathrm{~cm}$ up to more than $6 \mathrm{~cm}$ (Fig. 3.6C). The Kristallbrocken have a milky appearance because of high amounts of relatively small solid inclusions. In contrast to Teutschenthal and Morsleben, the inclusions are mostly not macroscopically visible. Besides, the Kristallbrocken in this upper part predominantly contain polyhalite aggregates as solid inclusions. Due to less finely

\section{$\leftarrow$}

Fig. 3.5: A-C) Core slab photographs of the Hauptsalz of Morsleben. Arrow in white box indicates stratigraphic up direction. Samples are from the lower (A), middle (B), and upper $(\mathbf{C})$ part of the Hauptsalz. The light-grey to dark-grey color of the rock salt is due to low or high amounts of finely dispersed anhydrite, respectively. Anhydrite (a) occurs as layer relics or nodules or finely dispersed in the matrix halite. In the upper part of the Hauptsalz, rock salt has a larger grain size spectrum and contains the Kristallbrocken (K). D) Core slab photograph (reflected light) of etched surface showing elongated matrix grains. E-F) Thick section photographs of matrix halite (transmitted light) showing fluid inclusion arrays at the grain boundaries. Note that near the surface inclusions are worm-like, whereas in deeper parts they occur isolated from each other and are circular. G-J) Reflected light photomicrographs of etched sample surfaces. G) Sample showing a sub-structure free grain on the right replacing (white arrow) the highly sub-structured grain on the left. Fluid inclusions occur as black spots at the grain boundaries and within the grain. H) Sample with a sub-structure rich grain in the middle being consumed by the surrounding sub-grain free grains. Note the lobate grain boundary (white arrow) that indicates the migration direction. I) A grain with relatively little sub-structure on the upper left grows at the expense of the moderately sub-structured grain below. The migrating grain boundary (white arrow) is pinned by anhydrite crystals. J) A moderately sub-structured grain (darkgrey) surrounded by largely sub-structure free grains. The rather smooth grain boundaries contain few fluid inclusions. 
dispersed anhydrite, the rock salt is grayish to white in color. In addition to anhydrite, polyhalite can be observed in the uppermost sections of the Hauptsalz. The average anhydrite content decreases from about $6 \%$ in the lower part of the Hauptsalz to about $2 \%$ in the upper part.
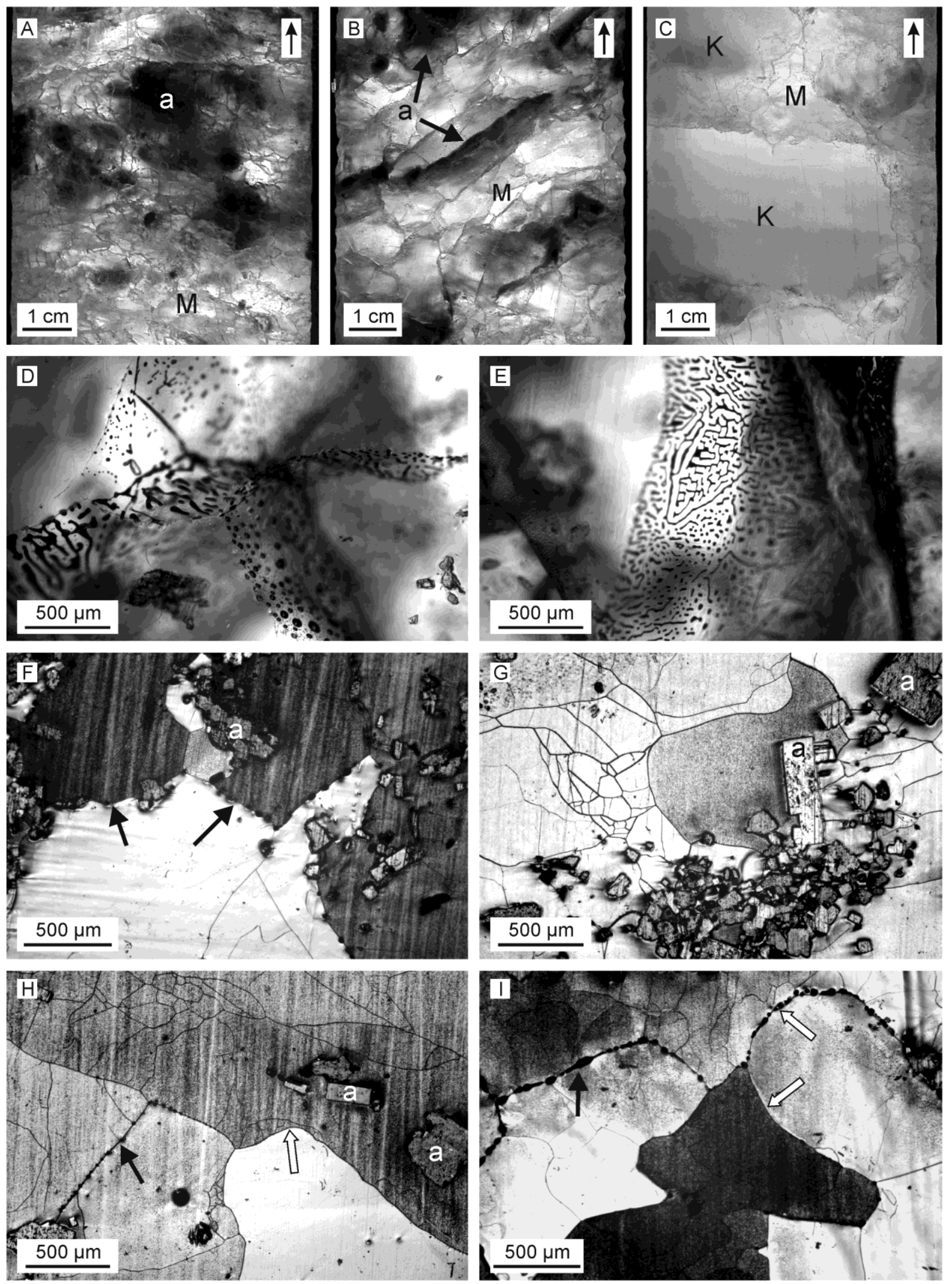


\subsubsection{Results}

\subsubsection{Microstructural characteristics}

In all studied locations, matrix halite does not show any primary fluid inclusions within the grains, but exhibits fluid or gaseous inclusions at the grain boundaries (Figs 3.4D and E, 3.5E and F, 3.6D and E). In etched samples, these fluid inclusions are worm-like or tube-like near the surface (Fig. 3.5E). This is presumably due to suction effects as a consequence of etching processes that opened the grain boundary. Farther away from the surface, the fluid inclusions are circular and occur isolated from each other (Fig. 3.5F). Reflected light examination of etched sample surfaces revealed in all samples of all studied locations that the matrix halite contains highly sub-structured grains as well as sub-structure poor and sub-structure free grains (Figs 3.4F-I, 3.5G-J, 3.6F-I). The sub-grain size distribution is rather heterogeneous in two locations, with sizes ranging between about $40 \mu \mathrm{m}$ and $500 \mu \mathrm{m}$ in samples from Teutschenthal and between about $20 \mu \mathrm{m}$ and $350 \mu \mathrm{m}$ in those of Gorleben, whereas in samples from Morsleben, the sub-grains are rather equant, with sizes ranging from about $40 \mu \mathrm{m}$ to $200 \mu \mathrm{m}$. In samples from Gorleben, many of the halite grains contain relatively high amounts of fluid inclusions at their boundaries (Fig. 3.6D-F, I). In addition, a noticeable amount of individual anhydrite crystals can be observed within the matrix halite, especially in the sub-structured grains (Fig. 3.6F and G). Some boundaries of sub-grain-free grains show lobate shapes in relation to sub-grain-rich grains (Figs 3.4F, 3.5G-J, 3.6H and I) indicating the direction of the migrating boundary (Urai et al. 1986a; Passchier \& Trouw 1998). During such grain boundary migration recrystallisation (GBM), highly sub-structured grains are consumed by less sub-structured grains. Migrating grain boundaries are partially pinned due to anhydrite crystals finely dispersed in the matrix halite (Fig. 3.5I and J).

\section{$\leftarrow$}

Fig. 3.6: A-C) Core slab photographs of the Hauptsalz of Gorleben. Arrow in white box indicates stratigraphic up direction. Samples are from the lower $(\mathbf{A})$, middle $(\mathbf{B})$, and upper $(\mathbf{C})$ part of the Hauptsalz. Anhydrite (a) occurs in the form of nodules or finely dispersed in the matrix halite. The upper part of the Hauptsalz contains matrix halite and the Kristallbrocken (K). D-E) Thick section photomicrographs showing fluid inclusions at the grain boundaries of matrix halite grains. Fluid inclusions are partly interconnected or occur isolated from each other. F-I) Reflected light photomicrographs of etched sample surfaces. F) Sample showing a less sub-structured, anhydrite-poor grain in the lower left with fluid inclusion-rich grain boundaries (black arrow). The more substructured grain above contains many anhydrite crystals (a) finely dispersed within the grain. G) A sub-structure free grain in the middle of a highly sub-structured grain. H) Sample showing a sub-grain and inclusion-free grain in the lower right, a moderately sub-structured grain in the lower left, and a sub-structure rich grain above. I) Sample with differently intensive sub-structured grains and high amounts of fluid inclusions at the grain boundaries (black arrow). The less sub-structured grain in the upper right grows at the expense of the sub-grain richer grains above and below (white arrow). 


\subsubsection{Results of bromide analyses}

The results of the bromide analyses are presented for all studied locations as (1) rough profiles with the data of the Kristallbrocken and matrix plotted together (Fig. 3.7) and as (2) rough profiles with the Kristallbrocken and matrix plotted separately with a running average of five points for each halite type (Fig. 3.8). All profiles were plotted on the same horizontal and vertical scale. For comparisons of bulk bromide contents across locations, as well as comparisons between the Kristallbrocken and matrix within each location, Table 1 presents average bromide contents for all locations and both halite types. To enable direct comparison of the different bromide profiles, the analytical results of all locations are presented together in Fig. 3.9, with the Hauptsalz thickness having been normalized to $100 \mathrm{~m}$.

In all locations, the bromide profiles of the Hauptsalz show a similar general pattern insofar as the profile starts with constantly low bromide values ranging between $40 \mathrm{ppm}$ and $60 \mathrm{ppm}$ on average (Fig. 3.9), and, from about the middle of the Hauptsalz, continues with increasing bromide values up to more than $200 \mathrm{ppm}$. In detail, however, variation in bromide content can be observed both within and between the bromide profiles. These differences mainly concern the trend of the bromide curve, the average bromide content, and the dispersion of the bromide contents along the running average curve (Fig. 3.9). Furthermore, the nature of disparity in bromide contents between the different halite types differs, i.e. whether the bromide content in the Kristallbrocken is higher or lower than that of the matrix halite (Fig. 3.8).

In Teutschenthal, the bromide profile is rather constant within the lower half of the Hauptsalz (Fig. 3.7A). In this range, both the average bromide content and the standard deviation are higher (statistically significant at $\mathrm{p}<0.001$ ) compared to the same section in the Hauptsalz of Morsleben and Gorleben (Table 1). In the upper half of the Hauptsalz, the bromide content continues to increase slightly until about $8 \mathrm{~m}$, and then terminates with rapidly increasing values near the top. The average bromide content of the whole profile is $66 \mathrm{ppm}$. The comparison between different halite types shows that, throughout the entire profile, the average bromide content of the Kristallbrocken is significantly lower $(\mathrm{p}<0.001)$ than that of the associated matrix halite (Table 1; Fig. 3.8A). In the lower half of the Hauptsalz, the average bromide contents of both the Kristallbrocken and matrix are consistently low. From the middle of the Hauptsalz upwards, the bromide content of the matrix halite increases more or less continuously up to a maximum value of $189 \mathrm{ppm}$, whereas that of the Kristallbrocken increases only slightly. Matrix halite crystals show relatively high bromide contents at the top of the profile; the Kristallbrocken do not occur in 


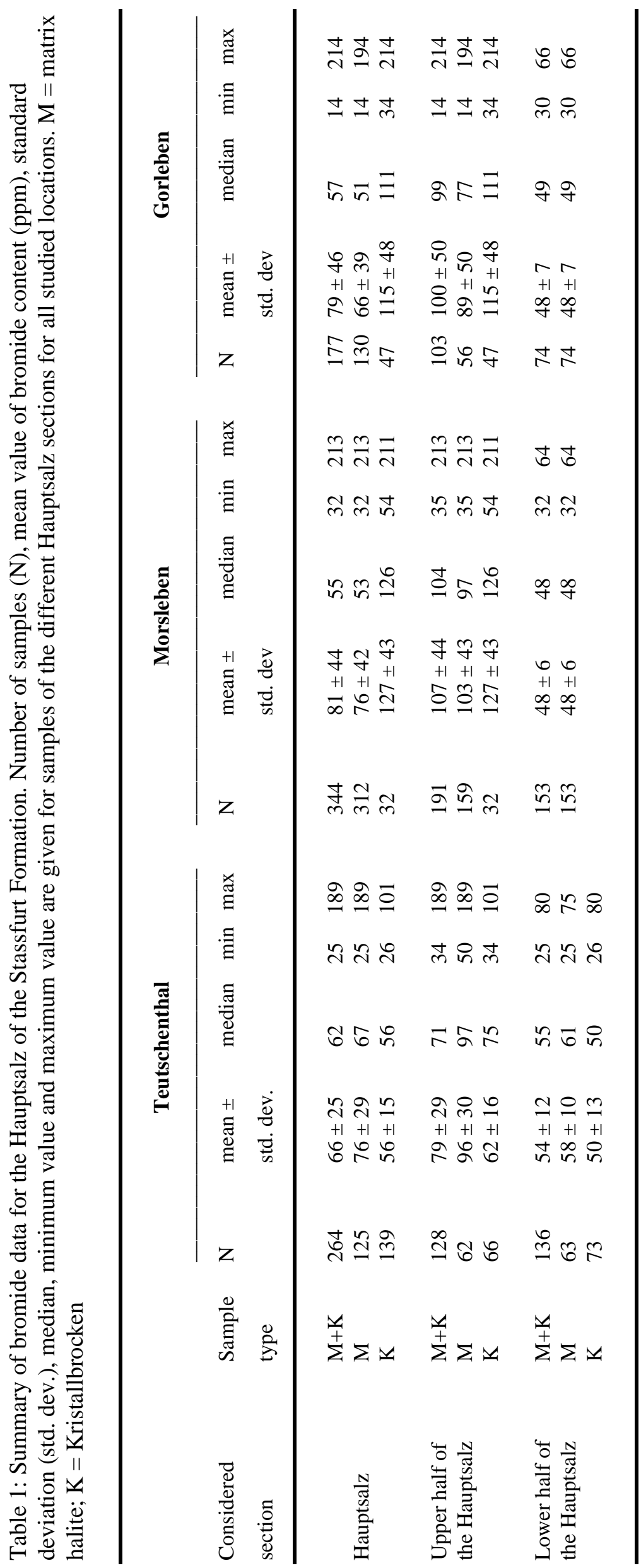


this uppermost part of the Hauptsalz. The dispersion of bromide contents along the running average curve in both the Kristallbrocken and matrix halite is quite high, in particular in the upper part of the Hauptsalz (Fig. 3.8A). For comparison of the dispersion of the bromide data between the different locations, the standard deviation of the mean is not a good measure, at least in the upper half of the Hauptsalz, because the bromide curves show a more or less strong inclination. This means that the stronger the inclination the higher the standard deviation of average bromide contents in this section, although the dispersion along the running average curve might be low. A better approach is the determination coefficient $\mathrm{R}^{2}$ $\left(0<R^{2}<1\right)$ that estimates the goodness of the fit of an exponential regression model to the data in the upper half of the Hauptsalz. The higher $\mathrm{R}^{2}$ the better the model, and the better the model the lower the dispersion of the bromide data along the running average curve. In Teutschenthal, determination coefficients for this section are quite low (Matrix: $\mathrm{R}^{2}=0.50$; Kristallbrocken: $\left.\mathrm{R}^{2}=0.03\right)$.

In Morsleben, the bromide profile trend is in principle quite similar to that of Teutschenthal and Gorleben, but the Hauptsalz thickness is strongly reduced. In the lower half, the profile is quite regular, with bromide contents varying within a narrow range of less than $20 \mathrm{ppm}$ from one sample to the next (Fig. 3.7C). The average bromide content and standard deviation in this area is $48 \pm 6 \mathrm{ppm}$ (Table 1). Then, from the middle of the Hauptsalz upwards, the bromide content increases unusually abruptly to a maximum value of 213 ppm (Fig. 3.7C). The mean bromide content of the whole profile is $81 \mathrm{ppm}$. Comparing the different halite types within the profile section in which both types occur, the average bromide content of the Kristallbrocken $(127 \mathrm{ppm})$ is higher than that of matrix halite (105 ppm) (Fig. 3.8C). It should be noted that there were less Kristallbrocken (32 samples; Table 1) to sample, and thus the statistical significance is limited. The relatively low number obtained for the Kristallbrocken, however, is an interesting result in itself (discussed further below). Compared with Teutschenthal, the average bromide content (matrix halite + Kristallbrocken) is significantly higher $(\mathrm{p}<0.001)$ in the upper part of the profile (Table 1; Fig. 3.8C). In addition, the dispersion of the bromide contents along the running average curve in that section is lower than that of Teutschenthal (Matrix: $\mathrm{R}^{2}=0.87$; Kristallbrocken: $\left.\mathrm{R}^{2}=0.70\right)$.

In Gorleben, the bromide content of the whole profile is $79 \mathrm{ppm}$ on average (Fig. 3.7B). The bromide profile in the lower half of the Hauptsalz is, like in Morsleben, rather smooth, with an average bromide content and standard deviation of $48 \mathrm{ppm} \pm 7 \mathrm{ppm}$ (Table 1). Near the base, the profile displays a slight increase and decrease in the bromide values (Figs 3.7B, 
3.1 Bromide distribution characteristics of different Zechstein 2 rock salt sequences of the Southern Permian Basin: a comparison between bedded and domal salts

8b). From the middle part upwards, the bromide content first decreases slightly from a mean of $48 \mathrm{ppm}$ to values below $40 \mathrm{ppm}$, and then increases continuously up to a maximum value of 214 ppm near the top.
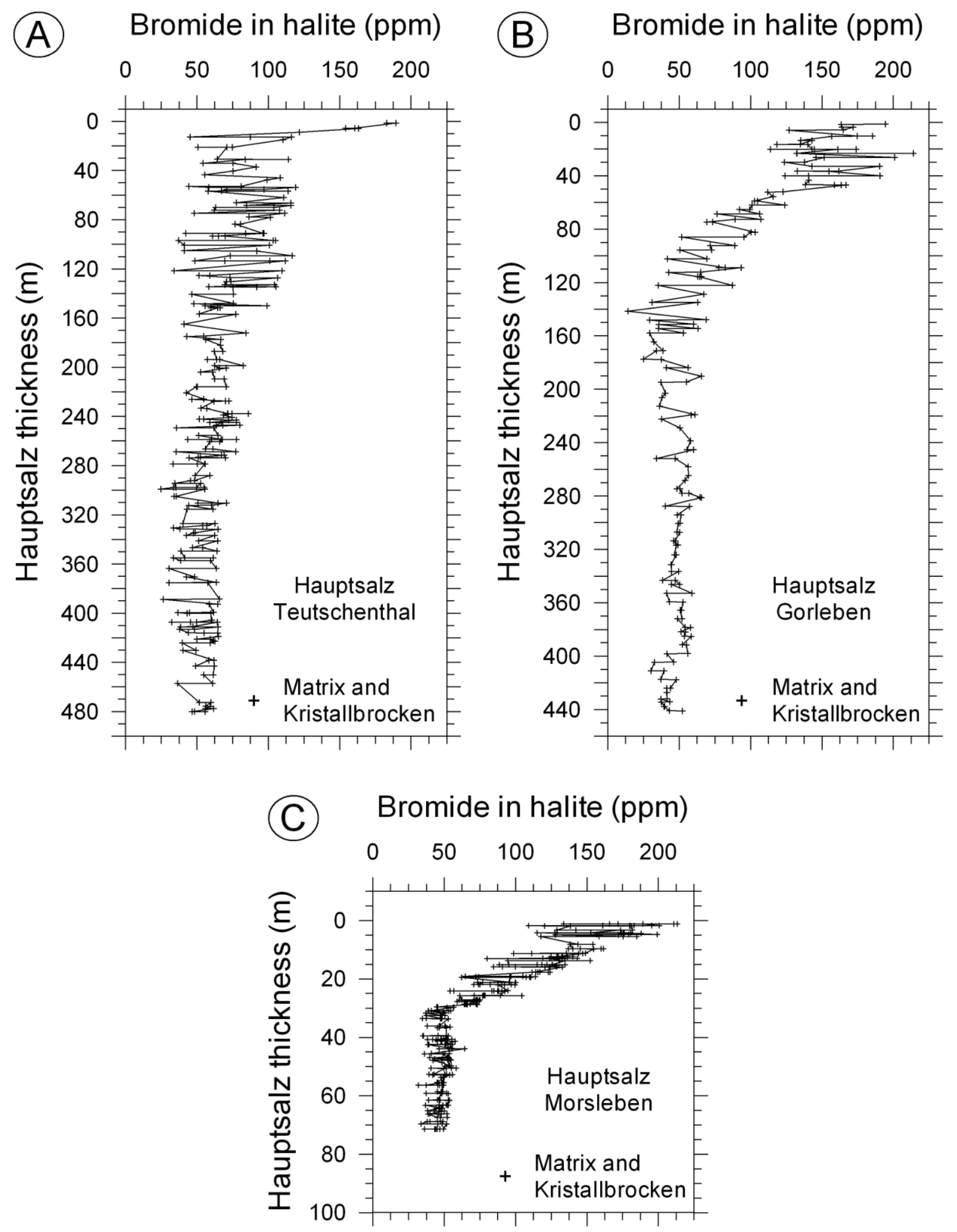

Fig. 3.7: Plots of bromide content versus thickness of the cored Hauptsalz with the data of the Kristallbrocken and matrix plotted together for all samples in (A) Teutschenthal, (B) Gorleben, and (C) Morsleben. 

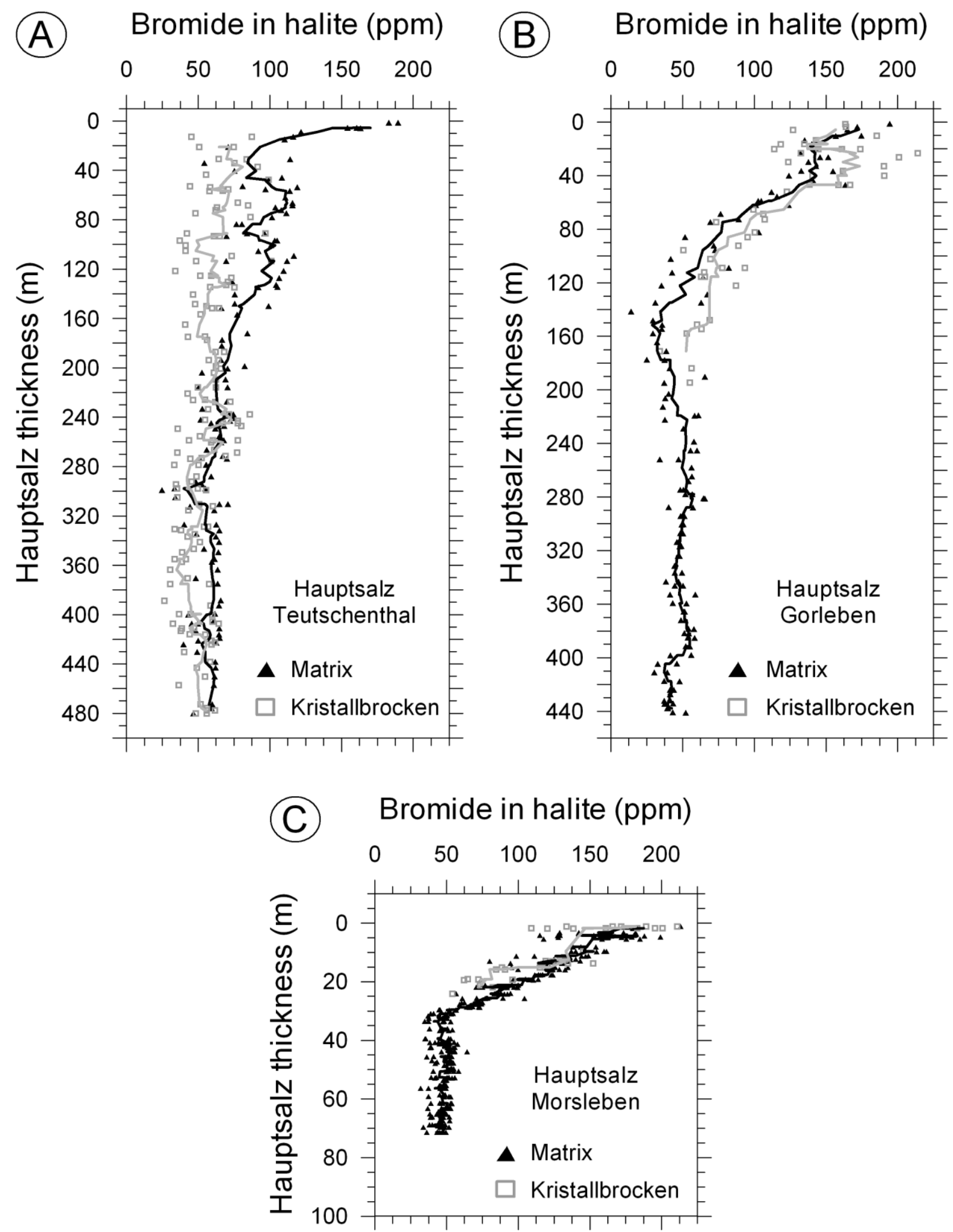

Fig. 3.8: Plots of bromide content versus thickness of the cored Hauptsalz for the Kristallbrocken and matrix plotted separately with a running average of 5 points for both of the two halite types in (A) Teutschenthal, (B) Gorleben, and (C) Morsleben. Solid triangles represent the bromide content of matrix halite, and open squares represent the bromide content of the Kristallbrocken. 
3.1 Bromide distribution characteristics of different Zechstein 2 rock salt sequences of the Southern Permian Basin: a comparison between bedded and domal salts

The Kristallbrocken only occur in the upper half of the Hauptsalz, and the running average curve of the Kristallbrocken bromide contents exhibits higher values than the curve of associated matrix halite (Fig. 3.8B). The dispersion of the bromide contents along the running average curves of matrix halite and the Kristallbrocken in this section is lower compared to that of Teutschenthal (Matrix: $\mathrm{R}^{2}=0.72$; Kristallbrocken: $\mathrm{R}^{2}=0.79$ ).

\subsubsection{Discussion}

\subsubsection{Characteristics of the bromide profiles}

The results of this comparative investigation between locations with different deformation backgrounds reveal a similar general shape to the bromide profile in all investigated locations. This bromide profile is characterized by low bromide values in the lower half of the Hauptsalz and more or less steeply increasing bromide values in the upper half. However, in detail, differences can be observed between the locations, concerning the dispersion of the bromide values along the running average curve, the average bromide content, and partially the inclination of the curve in the upper part of the profile.

\section{Minimum bromide contents and variance}

In all studied locations, the bromide values in the lower half of the Hauptsalz predominantly range between $40 \mathrm{ppm}$ and $60 \mathrm{ppm}$ (Figs 3.7 and 3.9) and thus lie considerably below the value of $75 \mathrm{ppm}$ expected for the first halite to precipitate from evaporating sea water. Such low bromide contents were also reported from basal halite in other Stassfurt rock salt deposits (Schulze 1958, 1960a; Kühn 1968). The most plausible explanation for such discrepancy between theoretical and observed values is that the bromide content of the brine at the beginning of halite precipitation was lower than the bromide content of concentrated normal sea water. Such decreased bromide content was probably the result of recycling processes of already precipitated halite due to an influx of either sea water or meteoric water, as, for example, suggested by Wardlaw \& Schwerdtner (1966) or Hovorka et al. (1993). Meteoric water influence is not very likely for the Hauptsalz of the studied locations, as in that case bromide values would be far below the observed 40 to 60 ppm (Hovorka et al. 1993). During recycling, sea water partly reaches saturation by the dissolution of already precipitated halite and, consequently, the bromide content of the first halite that crystallizes from such saturated brine will be lower than that of concentrated normal sea water. Such dissolution processes would preferentially occur at a stage of evaporation in which sea water concentration fluctuated about the point of saturation of sodium chloride (Wardlaw \& Schwerdtner 1966). These fluctuations are in line with the rhythmic stratification of rock salt sequences and 
anhydrite layers characteristic of the Hauptsalz of the Stassfurt Formation (Z2). Another possibility would be that the bromide content of the Permian sea water was lower than that of modern sea water. However, due to its high residence time of about $100 \mathrm{Myr}$ in the world oceanic waters (Holland 1978; Chester 2000), the bromide concentrations are assumed to have not changed significantly during the Phanerozoic. A decrease of the partition coefficient due to reduced crystal growth rates as discussed, for example, by Herrmann et al. (1973) and Herrmann (2000) seems unlikely, because recent evaporation experiments revealed that the partition coefficient more strongly depends on the bromide concentration or the major element composition of the brine than on the evaporation rate (Siemann \& Schramm 2002).

The comparatively high dispersion of the bromide contents in the bedded rock salt of Teutschenthal (Figs 3.7A and 3.9a) can be most satisfactorily explained with rhythmic changes in sea water concentrations. Such changes result from evaporation and dilution that alternate due to periodic influxes of sea water or meteoric water into the basin and indicate that the basin was connected to the open sea at that time. Similar observations have been made by Kühn (1955) and Wardlaw \& Schwerdtner (1966), who generated detailed bromide profiles through halite-anhydrite seasonal layers. In comparison, the bromide profile of the Hauptsalz of Morsleben and Gorleben is more regular, especially in the lower half (Figs 3.7B and c, 3.9a and b; Table 1). Given that the Hauptsalz of the studied locations formed under similar conditions, the smoother curve in Morsleben and Gorleben, combined with the absence of the Kristallbrocken halite type in these locations, suggests an influence of postdepositional, presumably deformation-related processes (discussed further below).

\section{Average bromide content}

In Morsleben and Gorleben, the average bromide contents in the upper half of the Hauptsalz are higher than that of the same stratigraphic intervals in Teutschenthal (Fig. 3.7). The comparatively higher bromide values can especially be observed in the Kristallbrocken. As this halite type has not yet disintegrated during deformation, their high bromide concentration has been present since their formation, i.e. post-depositional alteration of the bromide contents by secondary, bromide-rich brines cannot account for the comparatively increased bromide values. The varying amounts of bromide in the studied locations can be better explained by their different paleogeographic positions in the Zechstein basin (Fig. 3.2), as different parameters like water depth, the proximity to the influx of the basin, or the proximity to the basin edge influence the bromide content of precipitating halite (Fisher \& Hovorka 1987; Hovorka et al. 1993; Raup \& Hite 1996). Similar observations were made in several earlier studies showing that the bromide content of stratigraphically equivalent rock salt beds 
3.1 Bromide distribution characteristics of different Zechstein 2 rock salt sequences of the

increases generally from deposits close to the basin margin to those near the basin centre (Schulze 1958; Haltenhof \& Hofrichter 1972; Raup \& Hite 1996). The reason for this lateral bromide gradient may be a stratified brine column representing a vertical salinity gradient (Raup \& Hite 1996). At the deepest point of the basin, high-density brines would be near the sediment surface, whereas in more upslope positions like the basin edge, less dense brines would be close to the sediment surface.

\section{Inclination of the profile in its upper half}

The bromide profile of the Hauptsalz is generally inclined in its upper part indicating that the basin conditions changed towards increasing salinity (Raup \& Hite 1996). In Teutschenthal, the profile has a gentle increase from the middle, and shows rapidly increasing bromide concentrations just below the overlying potash salt unit (Figs 3.7A and 3.8A), while in Gorleben the profile shows a more gradually progressive increase from the middle of the Hauptsalz upwards (Figs 3.7B and 3.8B). In contrast, the profile in Morsleben is strongly inclined, with bromide values increasing from $50 \mathrm{ppm}$ to $150 \mathrm{ppm}$ in only about $40 \mathrm{~m}$ (Figs 3.7C and 3.8C). On the one hand, these different inclinations might be a result of rapid changes in sea water concentrations, induced by relative positions in the evaporation basin. On the other hand, it has to be considered that processes related to salt migration may also cause deviations from the original bromide profile trend. For example, during salt migration, rock salt beds are subjected to intense folding, which results in thickening or thinning of salt beds. Even though the Hauptsalz unit appears to be completely preserved between the overlying and underlying stratigraphic sections, parts of the Hauptsalz may have been thinned, thickened, or doubled by salt migration. In case of Morsleben and Gorleben, however, this would not be visible in the cores due to the homogeneous fabric of the rock salt. For example, as the studied rock salt of Morsleben was obtained from a well drilled into the flank of an anticline (Fig. 3.3B), it is very likely that the rock salt sequence has been thinned out during salt migration, altering the original thickness. The abrupt rise of the bromide profile from the middle part upwards might be a consequence of such a process. In addition, the slight fluctuations in the trend of the bromide profile that can be observed to some extent in the lower third of the Hauptsalz of Gorleben may be caused by sampling of folded areas. Therefore, when comparing the bromide content of various rock salt profiles of diapirs, changes in the original profile thickness (multiplication or reduction) due to halokinesis should be considered. These changes in thickness influence the trend or slope of bromide profiles and thus may lead to genetic misinterpretations when comparing them with each other (Fig. 3.9). Accordingly, variations in the trend of bromide profiles from the same 

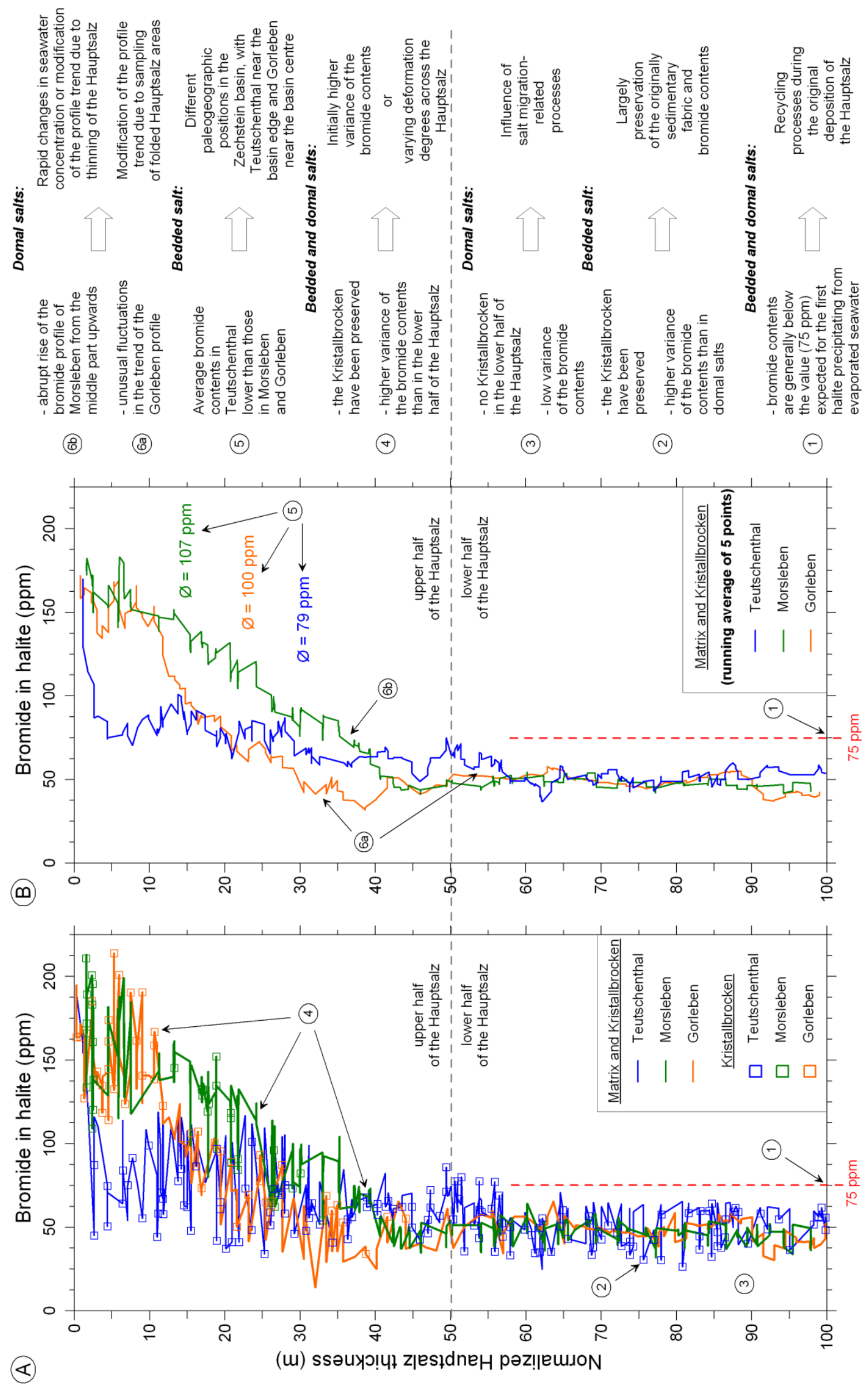
3.1 Bromide distribution characteristics of different Zechstein 2 rock salt sequences of the Southern Permian Basin: a comparison between bedded and domal salts

stratigraphic intervals, as observed in Gorleben (Bornemann et al. 2008), may also partially be due to comparing different thicknesses of otherwise equivalent stratigraphic intervals.

\subsubsection{Implications for the influence of salt migration-related processes}

Former studies implied that the bedded Stassfurt rock salt yields a very regular bromide profile that resembles almost a theoretical profile (Schulze 1958, 1960a). A comparison of these profiles with that of domal salt (Herrmann 2000; Simon \& Haltenhof 1970; Bornemann et al. 2008) suggests that diapirism-related processes result in irregular bromide profiles, either due to bromide-rich fluids involved in such processes (Baar 1963; Simon \& Haltenhof 1970; Simon 1972), or by brecciation and mixing of rock salt layers (Bornemann et al. 2000, 2008). For that reason, one aim of the present study was to illuminate the relationship between the bromide content and the intensity of deformation of the studied salt by means of a well-standardized and coherent set of bromide profiles. The comparison of the bromide distribution between bedded (Teutschenthal) and domal salt (Morsleben, Gorleben) shows that the classic trend of the bromide profile of a stratigraphically equivalent rock salt sequence was principally preserved in all three studied locations (Fig. 3.9). Therefore, a contribution from bromide-rich fluids that potentially circulated through the Hauptsalz during salt migration and significantly altered the bromide contents for either Morsleben or Gorleben is highly unlikely. In addition, although the fabric of the Hauptsalz in these two locations is most likely a result of brecciation, folding, and homogenization of different layers and halite types (Bornemann et al. 2000, 2008), these processes must have been restricted to formationparallel units, since the general stratigraphic sequence has been preserved. On the one hand, this is demonstrated by the bromide profiles and, on the other hand, by geological sections that are based on excellent subsurface outcrops and cores from wells.

Typical original depositional features, such as primary fluid inclusions or growth zones like in chevron crystals (Hardie et al. 1983; Lowenstein \& Hardie 1985), are only present in very rare cases in the Hauptsalz of the Stassfurt Formation (Pape et al. 2002). Nevertheless, the characteristic lamination within the Kristallbrocken indicates that they are relics of former continuous sedimentary layers. Furthermore, results of a preliminary study showed that,

\section{$\leftarrow$}

Fig. 3.9: Compilation of bromide analyses and interpretation of the observed findings. Bromide contents are plotted versus the thickness of the Hauptsalz section normalized to $100 \mathrm{~m}$. A) Plot showing for all studied locations the curve through the data of the Kristallbrocken and matrix plotted together as well as the bromide values of the Kristallbrocken. B) Plot showing for each location the running average of five points through the data of the Kristallbrocken and matrix. 
within the Kristallbrocken, the bromide content of these laminae increases upward reflecting progressive evaporation and precipitation (Schlechter 2004). Consequently, the Kristallbrocken can be regarded as an unaltered, quasi primary component of the Hauptsalz. In Teutschenthal, they are arranged in layers and occur throughout the whole Hauptsalz, whereas in Gorleben and Morsleben they are restricted to the upper half of the Hauptsalz and occur more separated from each other surrounded by matrix halite.

In contrast to the Kristallbrocken, the matrix halite can be regarded as secondary, presumably a dynamically recrystallised component of the Hauptsalz. In all locations, matrix halite is mostly composed of clear, fluid inclusion-poor halite, with fluid inclusions and anhydrites arranged at its boundaries. The presence of fluid inclusions at the grain boundaries suggests that the matrix halite of all three locations has been largely recrystallised (Roedder 1984). Reflected light examination of etched sample surfaces revealed a quite similar microfabric of matrix halite for the three locations. In all studied samples, both sub-structure free and sub-structure rich grains could be observed in different parts of the Hauptsalz. The presence of less sub-structured grains replacing highly sub-structured grains as well as lobate grain boundaries and pinning structures points to grain boundary migration recrystallisation (Urai et al. 1987; Drury \& Urai 1990; Passchier \& Trouw 1998; Schléder \& Urai 2005). Grains with well developed, equidimensional sub-grains indicate intracrystalline deformation (Passchier \& Trouw 1998). In all samples from each location, evidence for intracrystalline deformation and recrystallisation can be observed. The microstructural investigations revealed no significant differences within the Hauptsalz and between the three studied locations, although they belong to different tectonic settings. The clearly different regional deformation intensities at the various locations are not reflected in the microfabrics. Only the macrofabric of the Hauptsalz in Morsleben and Gorleben differs considerably from the one in Teutschenthal, as deformation-related processes have destroyed the original sedimentary fabric during salt migration. As a consequence, the Hauptsalz contains less Kristallbrocken and higher amounts of matrix halite, the grain size distribution is more homogeneous, and anhydrite mainly occurs as a fine dispersion in the rock salt or as layer fragments and nodules. As the bromide characteristics of the Hauptsalz in Morsleben and Gorleben before salt migration are assumed to be similar to that of Teutschenthal at present, the absence of the Kristallbrocken in the lower part of the profile and the low dispersion of bromide contents along the running average curve is interpreted to be the result of deformation related processes. The assumption of comparable bromide characteristics seems plausible because the 
3.1 Bromide distribution characteristics of different Zechstein 2 rock salt sequences of the Southern Permian Basin: a comparison between bedded and domal salts

investigated profiles belong to equivalent stratigraphic intervals precipitated in analogous time intervals.

The following, presumably deformation-related features in the domal salt of Morsleben and Gorleben can be determined: (1) The absence of the Kristallbrocken in the lower half of the Hauptsalz (Fig. 3.9). (2) A lower dispersion of bromide contents along the running average curve, especially in the lower half of the Hauptsalz (Fig. 3.9). The absence of the laminated Kristallbrocken in the lower half of the domal salt indicates that this halite type was deformed and recrystallised during salt migration, forming clear, medium to coarse grained matrix halite. The comparatively lower dispersion of bromide contents along the running average curve is expected to be associated with a redistribution of bromide, which eventually results in homogenization of the varying bromide contents and smoothing of the bromide profile (Figs 3.7B and C, 3.8B and C). However, the exact process of bromide redistribution and homogenization cannot be satisfactorily explained. This is because it is not yet well understood, what effect deformation-related processes such as dislocation creep, diffusion creep, dynamic recrystallisation, or combinations of these processes (Guillopé \& Poirier 1979; Carter \& Hansen 1983; Skrotzki \& Welch, 1983; Spiers et al. 1986; Urai et al. 1986a, 1986b, 1987; Spiers et al. 1990; Carter et al. 1993; Spiers \& Carter 1998) may have on the behavior of trace elements, especially bromide. In any case, the presence of brine is supposed to be crucial, as deformation or recrystallisation would influence the bromide content only if brines are present that have bromide contents different from that of the original brine (Raup \& Hite 1996).

In the upper part of the bromide profiles of Morsleben and Gorleben, the Kristallbrocken are still present and the dispersion of bromide contents is considerably higher than that in the lower part of the profile. Two explanations for this finding are conceivable: first, the original dispersion of bromide contents may likewise have been higher in the upper half than in the lower half of the Hauptsalz (similar to the profile in Teutschenthal). In this case, due to such initially different dispersions, homogenization of the varying bromide contents and smoothing of the bromide profile would require more time in the upper half. Second, halite beds of the upper half may have behaved more passively during salt migration, and thus may have been subjected to less intense deformation than the lower half. This explanation would also be in line with the observation that the sedimentary fabric of younger Zechstein sequences of Gorleben could be largely preserved (Bäuerle 2000; Bornemann et al. 2000). Another possibility could be that the kind of deformation mechanism was affected by varying amounts of fluids or impurities in the Hauptsalz. However, this explanation would 
only apply for the Hauptsalz of Gorleben, because in Morsleben, there is no significant difference between the anhydrite content of the upper part (ca. 4.1\%) and that of the lower part (ca. $4.3 \%$ ) of the Hauptsalz.

\subsubsection{Bromide contents in different halite types}

The results of the present study reveal a disparity in bromide content between the Kristallbrocken and matrix halite. This disparity is not consistent, i.e. the bromide content of the Kristallbrocken is higher in Gorleben and lower in Teutschenthal compared to that of the associated matrix halite (Fig. 3.8A and C). The phenomenon of a noticeable disparity in bromide content between the different halite types has also been mentioned in other publications (Simon 1972; Czapowski 1986; Herrmann 2000), but the disparity is likewise not consistent between these studies. For example, the Kristallbrocken studied by Simon (1972) and Czapowski (1986) revealed, like in Teutschenthal, comparatively lower bromide contents, whereas Hermann (2000) determined the Kristallbrocken with both higher and lower values compared to the bromide content of the surrounding matrix halite.

Effects of differences due to sampling, i.e. through accidental sampling of brine in fluid inclusions, can be excluded as an explanation because the same standardized sampling procedure was used for each halite type and each location.

One explanation may be that the formation of the Kristallbrocken and matrix halite took place at different evaporation levels. The lower bromide content in the Kristallbrocken is caused by early precipitation, when sea water contains less bromide, whereas the comparatively higher bromide values in matrix halite are due to precipitation at later stages, when sea water was more concentrated. As a result, the Kristallbrocken would generally have lower bromide contents than matrix halite crystals. This hypothesis was also suggested by Czapowski (1986), but it applies only to the situation in Teutschenthal and would not explain the presence of the Kristallbrocken with comparatively higher bromide values occurring in Gorleben. It might be assumed that in Gorleben the reverse situation applied, with matrix halite and the Kristallbrocken being precipitated from bromide-poor and bromide-richer sea water brines, respectively, but due to the similar appearance of the Kristallbrocken, their formation is assumed to be comparable. Nevertheless, the locations were situated at different positions in the former Zechstein Basin making different origin parameters probable.

Herrmann (2000) suggested that the different bromide contents of the two halite types in domal salts are related to deformation and local mixing of the former rhythmically bedded rock salt sequence that result in a salt breccia (Bornemann et al. 2000). This hypothesis does 
3.1 Bromide distribution characteristics of different Zechstein 2 rock salt sequences of the Southern Permian Basin: a comparison between bedded and domal salts

not seem very likely because the disparity in bromide content can also be observed in Teutschenthal, where the original sedimentary fabric has been largely preserved.

According to Simon (1972), the large, laminated Kristallbrocken were originally uniform and continuous halite layers that formed by a kind of accumulation (grain growth by grain boundary area reduction) of normal-grained rock salt, a recrystallisation process that is comparable with the formation of sparite from micrite in carbonate rocks. He explained the lower bromide content of the Kristallbrocken with a contribution from bromide-poor fluids during this formation process. Consequently, a contribution from bromide-rich fluids during the formation of the Kristallbrocken would result in comparatively higher values. Such a scenario is conceivable for the Kristallbrocken of Gorleben, as the polyhalite crystals observed in the Kristallbrocken of the upper half of the Hauptsalz also suggest higher evaporation levels. These explanations would support the hypothesis that the Kristallbrocken are not primarily grown crystals, but more likely formed in a syn-sedimentary or postsedimentary process (Küster et al. 2007b) from originally finer-grained halite with the contribution of bromide-rich (Gorleben) or bromide-poor (Teutschenthal) fluids.

\subsubsection{Conclusions}

This study yields important findings concerning the bromide distribution in bedded versus domal salt, the influence of salt migration-related processes on the bromide distribution, and the bromide content of different halite types.

In all studied locations, the bromide profile of the Hauptsalz is characterized by relatively low bromide values in the lower part of the Hauptsalz and more or less steeply increasing bromide values in the upper part. The low bromide contents in the lower half of the profiles are most likely a result of recycling processes, i.e. halite formed from brines that reached saturation by the dissolution of previously precipitated halite. In the upper half of the Hauptsalz, the average bromide contents are lower in the bedded salt than in the domal salt, which can be most satisfactorily explained by different paleogeographic positions in the Zechstein Basin. The rather steep inclination in the upper part of the Morsleben profile indicates rapid changes in salinity due to a decreased brine volume as a consequence of the paleogeographic situation in the Zechstein Basin. Alternatively, the strongly inclined profile may also be due to sampling of Hauptsalz sections, whose original thickness may have been altered by halokinetic processes such as thinning, thickening or folding of halite beds.

The comparison of the bromide profiles of the bedded salt of Teutschenthal and the domal salt of Morsleben and Gorleben clearly indicates a relationship between salt migrationrelated processes and bromide distribution. For example, the absence of laminated 
Kristallbrocken in the lower half of the domal salt shows that this halite type recrystallised during salt migration, thereby forming the clear, medium to coarse grained matrix halite. The comparatively smooth bromide profile in the lower half of the Hauptsalz in Morsleben and Gorleben are most likely associated with a redistribution of bromide that eventually results in a homogenization of the varying bromide contents. In contrast, in the upper half of the Hauptsalz, the Kristallbrocken are still present and the dispersion of bromide contents along the running average curve is higher than in the lower part, but still lower than that in the same part of the profile in Teutschenthal. These results can be explained either by an initially higher dispersion of bromide contents in the upper part of the profile (similar to Teutschenthal) or by varying degrees of deformation across the Hauptsalz during salt migration, i.e. the upper half of the Hauptsalz was subjected to less intense deformation than the lower half.

Selective sampling of the Kristallbrocken and matrix halite revealed a disparity in bromide content between the different halite types. The different degrees of disparity observed in different locations are interesting insofar as they can lead to further research that may delineate which depositional conditions are related to which kind of disparity. For example, future research might examine the origin of the Kristallbrocken and potential differences between the Kristallbrocken in Teutschenthal on the one hand and the Kristallbrocken in Gorleben on the other hand. 


\subsection{Additional results}

\subsubsection{Detailed sampling of Kristallbrocken samples}

In addition to the bromide profiles achieved by sampling the entire Hauptsalz section of Teutschenthal, Morsleben, and Gorleben (chapter 3.1), nine drilling core slabs of Teutschenthal were selected for sampling of several Kristallbrocken within each slab. The analytical results of this detailed Kristallbrocken sampling are presented in Table A.4.

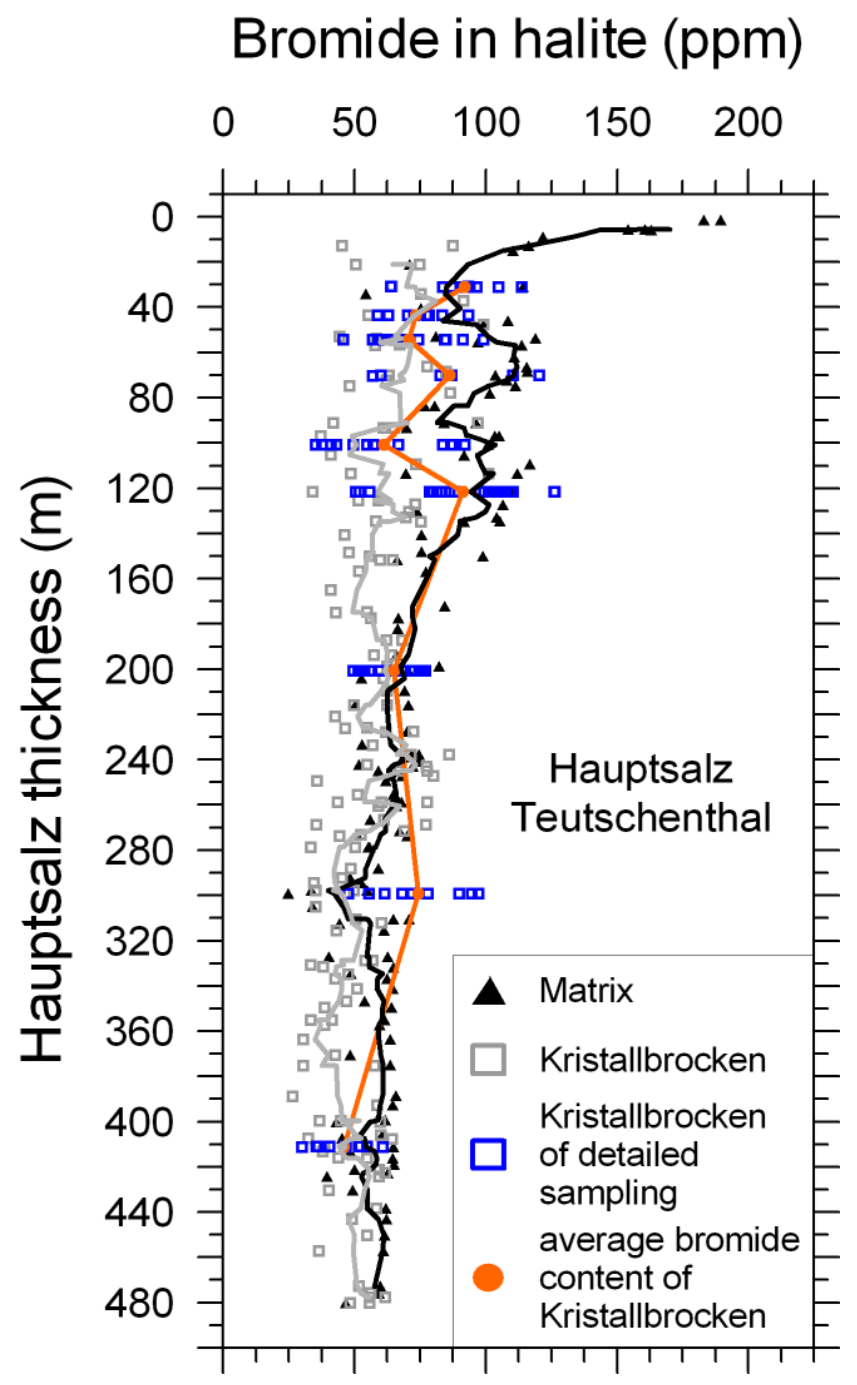

Fig. 3.10: Plot of bromide content versus thickness of the cored Hauptsalz with the data of Kristallbrocken and matrix with a running average of 5 points for both of the two halite types in Teutschenthal. Solid triangle symbols represent the bromide content of matrix halite, and open square symbols represent the bromide content of Kristallbrocken. Blue square symbols signify the results of detailed Kristallbrocken sampling. The average bromide content of Kristallbrocken within each drilling core slab is indicated by orange solid circles.

Appendix B presents diagrams, with bromide contents of Kristallbrocken plotted versus depth in corresponding drilling core slab, and photographs of the core slabs showing the 
sampling positions. In most drilling core slabs, the bromide content of the Kristallbrocken varies considerably. For example, in sample Lt60-16-154, the bromide values range from 51 to $126 \mathrm{ppm}$ (Table A.4). Across the particular drilling core slabs, bromide values generally show an increasing trend from bottom to top. The only exceptions are samples Lt60-11-85 and Lt60-16-154, in which the linear fit of the Kristallbrocken bromide contents shows a slightly decreasing trend. Partially, the bromide content of Kristallbrocken decreases noticeably from one rock salt zone to the next (e.g., samples Lt60-11-85, Lt60-15-136), i.e. with an anhydrite layer between, but such decrease can also be observed within a rock salt zone (e.g., sample Lt60-16-154).

In Fig. 3.10, the results of detailed Kristallbrocken sampling are presented in relation to the bromide distribution of both halite types across the Hauptsalz of Teutschenthal. As in the bromide profile of the entire Hauptsalz, the variance of the bromide contents in Kristallbrocken is quite high, ranging from 30 to $126 \mathrm{ppm}$ (Table A.4). With the exception of the Kristallbrocken of the drilling core slab at about $300 \mathrm{~m}$ thickness, the average Kristallbrocken bromide values of particular drilling core slabs lie mostly below the running average curve of the matrix halite bromide contents. From the lower part of the Hauptsalz upwards, the average bromide content of the Kristallbrocken in drilling core slabs slightly increases.

\subsubsection{Bulk analysis of all locations}

The analytical results of the bulk analyses for all locations are presented in Tables A.5-A.7. The anhydrite content of Teutschenthal varies considerably between the different sampled drilling cores, ranging from about $7 \%$ to $18 \%$. However, as only individual drilling core slabs were sampled, and the anhydrite layer thickness and frequency is different in each drilling core slab, these anhydrite contents are not as representative as those of the other locations, where a complete drilling core was sampled. In Morsleben, the average anhydrite content of $4-5 \%$ is nearly constant throughout the entire Hauptsalz. In Gorleben, the average anhydrite content slightly decreases from about $6 \%$ in the lower part to about $4 \%$ and $2 \%$ in the middle and upper part, respectively.

In Fig. 3.11, the bromide contents of the bulk samples are plotted against average thicknesses of the different Hauptsalz sections (lower, middle, and upper Hauptsalz; Figs. 3.11B, C), or against the average thickness of the particular drilling core slabs (Fig. 3.11A). In all locations, the bromide values follow the same bromide profile trend as the data of the separate sampling of matrix and Kristallbrocken halite. However, the values lie more or less extensively above the running average curve (orange) through the bromide values of the 
samples taken by $1 \mathrm{~mm}$ drill bits (Fig. 3.11). Especially in Teutschenthal, the difference in bromide contents between the data sets is noticeably high.

(A)
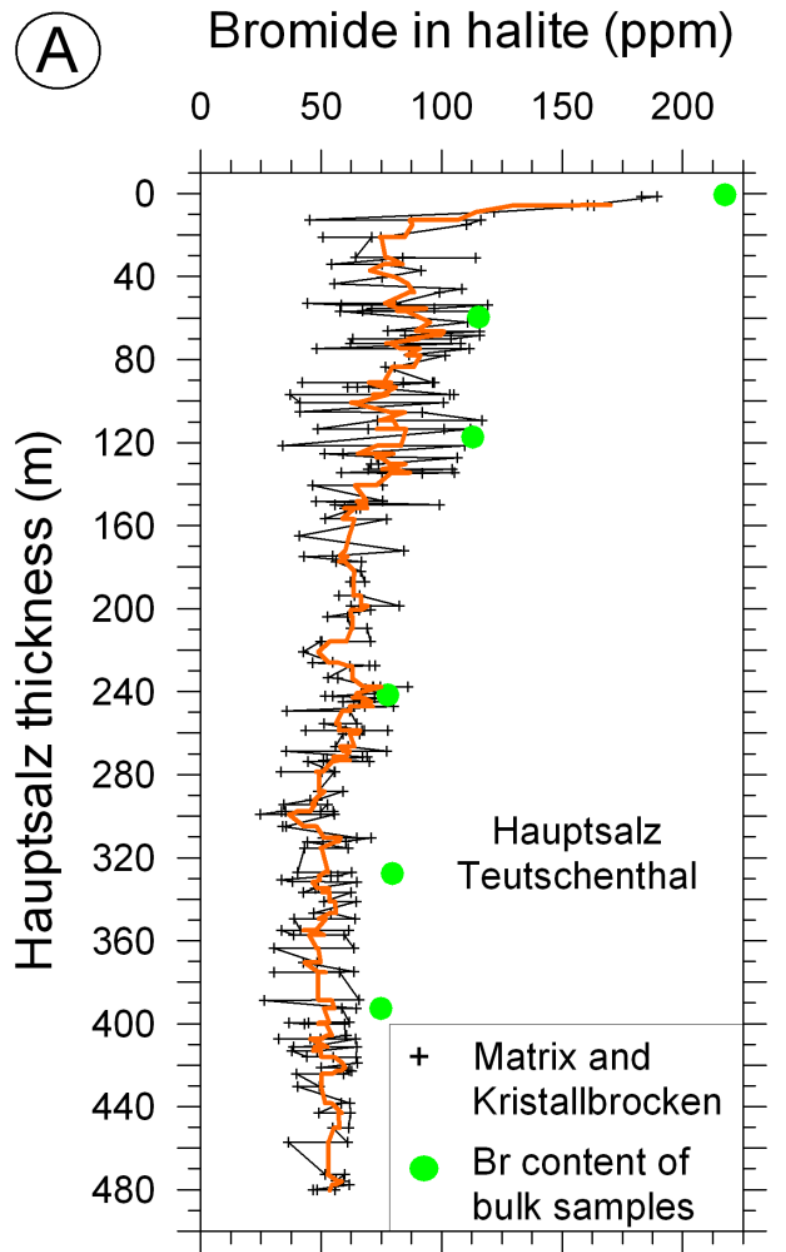

(B) Bromide in halite (ppm)

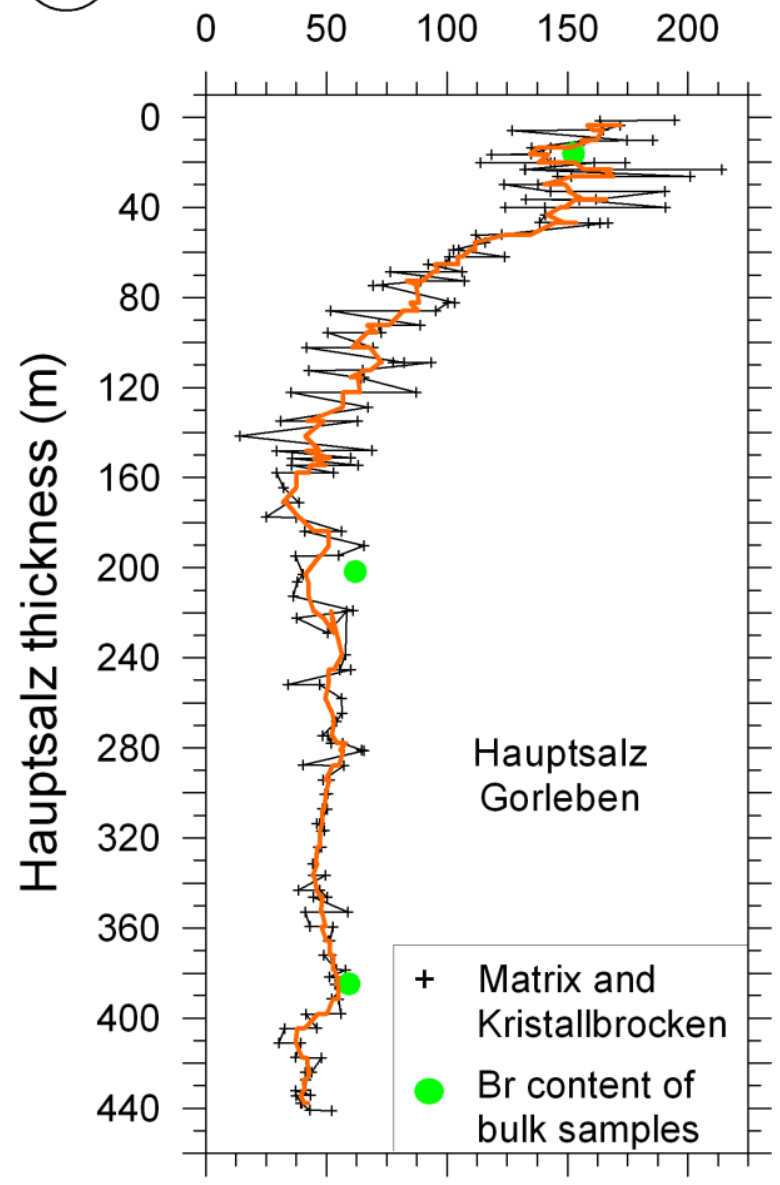

(C) Bromide in halite (ppm)

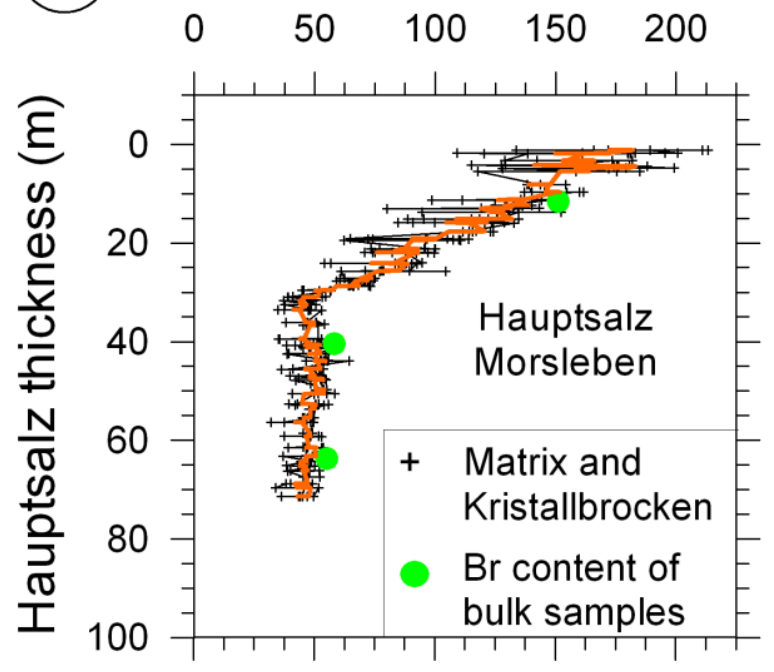

Fig. 3.11: Bromide content of bulk samples in relation to the bromide contents plotted versus depth in well for all samples in (A) Teutschenthal, (B) Morsleben, and (C) Gorleben. 


\subsubsection{Electron microprobe analysis of a Kristallbrocken sample}

In addition to the wet chemical analyses of drilled sample material, it was tried to measure the bromide distribution by means of an electron microprobe (Cameca SX100), as this more detailed method may reveal small-scaled differences in the bromide distribution in Kristallbrocken. For this purpose, one Kristallbrocken was prepared from a drilling core that was taken from the upper part of the Hauptsalz, at a thickness of about $37 \mathrm{~m}$. From the same Kristallbrocken, a sample was taken for wet chemical analysis.

The results of the bromide measurements via electron microprobe are presented in Table A.8 and Fig. 3.12. In general, the bromide values across this Kristallbrocken range between 63 and $123 \mathrm{ppm}$, with an average of $90 \pm 21 \mathrm{ppm}$. This agrees well with the bromide value of $91 \mathrm{ppm}$ of the same Kristallbrocken achieved by wet chemical analysis (sample Lt19, Table A.1). In the lower right part of the Kristallbrocken, the bromide values are rather constant, ranging from 71 to $88 \mathrm{ppm}$. Similar low bromide contents can be observed at measuring points 7-10 and 2-3. Along the line between the measuring points 2 and 6 , as well as 10 and 5, the bromide content continuously increases. As the Kristallbrocken layer is bent almost $85^{\circ}$, these increasing bromide values are in good agreement with the stratigraphy. The only exception is the bromide content at measuring point 1 , which is expected to be lower than 83 ppm. However, as the measurement was near the border of the Kristallbrocken, the measurement may have been impaired by the bromide content of adjacent halite.
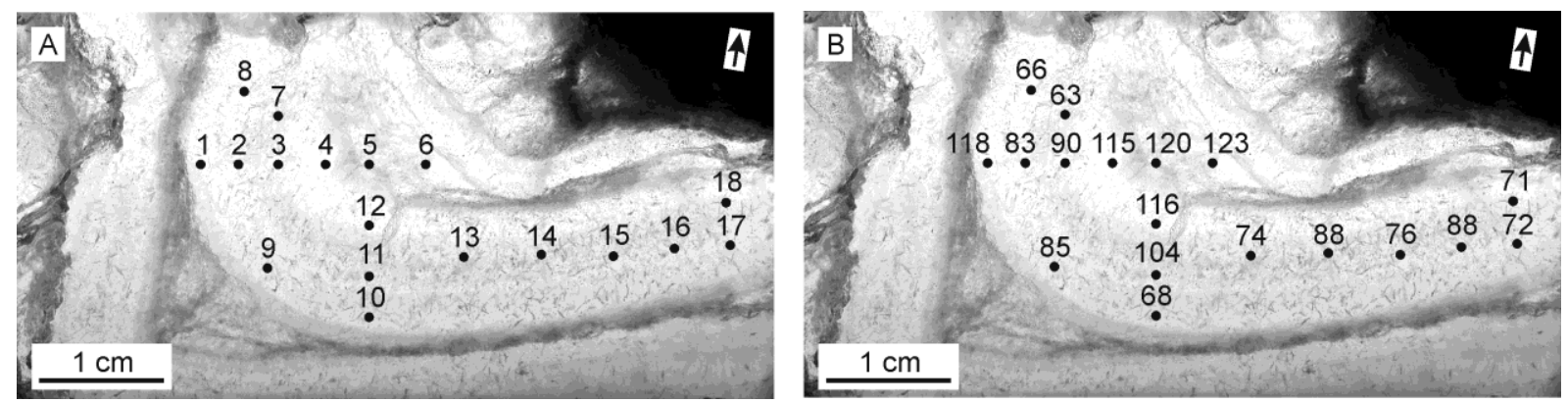

Fig. 3.12: Photograph of a bent Kristallbrocken from the Hauptsalz of Teutschenthal showing the approximate position of the measuring points (A) and the results (B) of the electron microprobe analysis. Arrow in white box indicates the stratigraphic up direction. 


\section{KRISTALLBROCKEN}

\subsection{Structural characteristics of the halite fabric type 'Kristallbrocken' from the Zechstein Basin with regard to its development}

Yvonne Küster, Bernd Leiss, Michael Schramm, International Journal of Earth Sciences 99 (2010), 505-526.

\subsubsection{Abstract}

The Kristallbrocken are a characteristic $\mathrm{cm}$ - to dm-sized, laminated halite fabric type occurring in the Stassfurt Formation in the Zechstein Basin. Up to now, the nature of the Kristallbrocken, i.e. if they are relics of fine-grained, polycrystalline halite beds or clasts of 'single crystal-layers', as well as the deformation mechanisms of this halite type, were not clear from the literature. Drill core material from the salt deposit Teutschenthal at the southern rim of the Zechstein Basin now allowed investigating less intensely deformed samples for the first time.

The deformational behavior of these Kristallbrocken ranges from brittle to ductile, which is evidenced by fractured Kristallbrocken on the one hand and weakly bent or even folded Kristallbrocken on the other hand. Local X-ray texture measurements demonstrated that Kristallbrocken are definitely single crystals and that they can be regarded as relics of formerly larger 'single crystal-layers' of up to several $\mathrm{dm}^{2}$ in size. The folded Kristallbrocken clearly display by their single grain texture characteristics that their crystal lattice is bent, which was most likely enabled by a kind of flexural-shear folding, and did not develop after deformation from a fine-grained aggregate by recrystallisation. Due to their monocrystallinity, 
their originally large size, and the solid inclusions forming the internal lamination, the Kristallbrocken have clearly stronger rheological properties than the surrounding fine- to coarse-grained polycrystalline rock salt, and thus also deform by fracturing.

\subsubsection{Introduction}

The rock salt of the Stassfurt Formation in Northern and Eastern Germany is of particular significance due to its relevance as host rock for hydrocarbon storage caverns (e.g., Hofrichter 1972; Hofrichter 1974; Jagsch \& Theylich 1999; Wilke et al. 2002) and as host rock for the disposal of radioactive waste (Jaritz 1983, 1993; Bornemann 1987). Therefore, it has been subjected to numerous studies concerning stratigraphy, bromide distribution, and deformation characteristics (Schulze 1958, 1960a; Jung 1968; Simon \& Haltenhof 1970; Simon 1972; Bachmann 1985; Popp et al. 1999; Herrmann 2000; Bornemann et al. 2000; Popp et al. 2001; Schramm et al. 2005; Küster et al. 2007a). The present study focuses on a certain halite type of the Stassfurt rock salt, referred to as Kristallbrocken (German: "Kristallbrocken" = crystal fragments; Simon 1972; Fig. 4.1A), which has been mentioned in several previous publications and appears to be characteristic for the salt deposits of the Zechstein Basin (Fig. 4.2). It predominantly occurs in the Stassfurt Formation rock salts of Germany (e.g., RichterBernburg 1955b; Lotze 1957; Simon \& Haltenhof 1970; Simon 1972) and the Netherlands as well as in the Oldest and Older Halite (equivalent to Werra and Stassfurt Formation respectively) of Poland (Czapowski 1986, 1987, Czapowski et al. 1990, 1993) (Fig. 4.2). The formation of this halite type has been discussed for many decades (Schünemann 1913; Lachmann 1914; Lotze 1957; Richter-Bernburg 1955b; Schauberger \& Kühn 1959; Simon 1972), but is still not fully understood.

A characteristic feature of these cm-sized Kristallbrocken is the internal lamination (Fig. 4.1B) that is defined by variations in sulphate inclusion content (e.g., Simon 1972; Czapowski 1986; Küster et al. 2007b). These inclusions can be relatively large, with sizes of about $100 \mu \mathrm{m}$, partially up to $600 \mu \mathrm{m}$ (Küster et al. 2007b). Another distinctive feature is that some of these sulphate aggregates are enclosed by a certain amount of brine (Küster et al. 2007b), a feature that has not yet been reported from other halite types. Due to the lamination, the Kristallbrocken resemble laminated sedimentary rocks as for instance layered mudstones, or sandstones, as well as the bedded or laminated halite described, for example, in Anderson et al. (1972), Schreiber et al. (1976), or Kendall (1992). From this fact, the Kristallbrocken are considered as relics of formerly continuous sedimentary halite beds (Schünemann 1913; Richter-Bernburg 1955b). However, the individual layers of the above mentioned bedded or 
laminated halite beds are composed of numerous grains, whereas the internally laminated Kristallbrocken do not show any macroscopically visible grain boundaries inside.
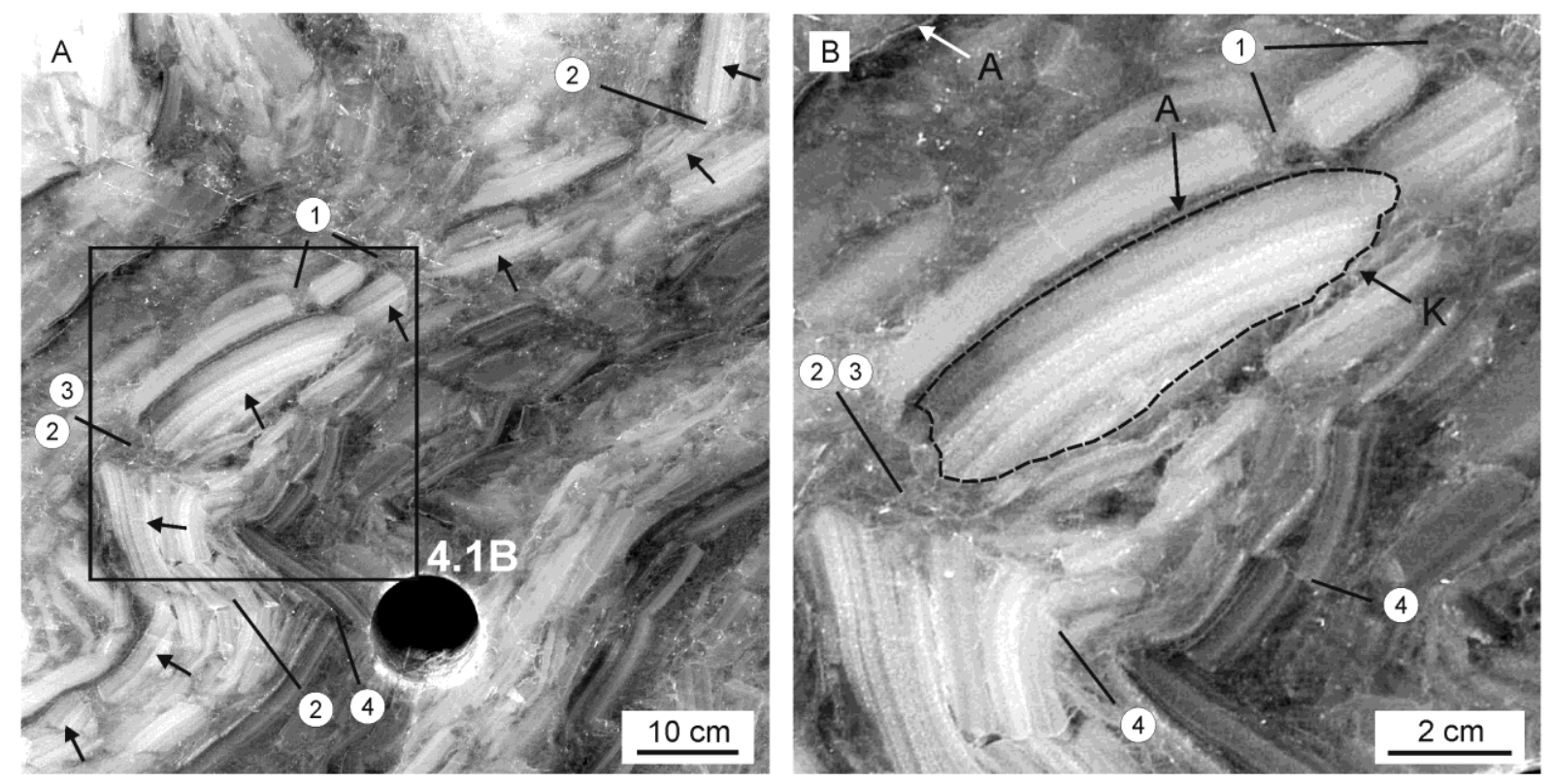

Fig. 4.1: A) Photograph of a polished Stassfurt rock salt slab cut from a salt deposit in Northern Germany (Asse salt mine) showing the individual Kristallbrocken pieces (arrows) of an earlier coherent layer broken and pulled apart during folding. This resulted in well-developed boudinage structures with recrystallisation and/or solution-precipitation in the necking areas (1) of the Kristallbrocken pieces. While the extension area of the folded layer is broken (2) and the opened space is filled with recrystallised and/or precipitated salt (3), in the compression area, a beginning stacking of the Kristallbrocken can be observed (4). B) Scaled-up section of Fig. 1a. The Kristallbrocken in the central part (outlined by dashed line) has a thickness of $\sim 2.5 \mathrm{~cm}$ and a length of $\sim 9 \mathrm{~cm}$, and is overlain by a thin, massive anhydrite layer (A). The lamination of this Kristallbrocken is well developed. According to the lamination, the original continuous layer can be visually reconstructed. Within the Kristallbrocken, there are no macroscopically visible grain boundaries. The grain boundary areas of the Kristallbrocken are partially rounded due to recrystallisation and/or dissolution processes. This example well documents the concurrent brittle and ductile deformation.

Simon (1972) described the Kristallbrocken as $1-5 \mathrm{~cm}$ thick and up to $30 \mathrm{~cm}$ long, in cross section-view brick-like, sometimes oval-shaped, and opaque to transparent salt crystals, with the long axes oriented parallel to the bedding. They are mostly arranged in layers, and these layers are, like in Fig. 4.1, also affected by folding of the rock salt sequences, with the individual Kristallbrocken having been moved against each other or rotated. In more intensely deformed Stassfurt rock salts, e.g. in the salt structures of Morsleben or Gorleben (Bornemann 1991; Behlau \& Mingerzahn 2001), rectangular to oval-shaped Kristallbrocken occur relatively isolated from each other, being embedded in a fluid inclusion-poor halite matrix (e.g., Bornemann et al. 2000; Pape et al. 2002). Simon (1972) regarded the Kristallbrocken as relics of formerly continuous crystal layers, which formed either by dissolution of parts of the crystal layers or by breaking apart of these layers during folding. He suggested that the 
occurrence of the Kristallbrocken layers in areas that are less subjected to deformation argues for dissolution of crystal layers as reason for their formation. However, in domal salt deposits, it is difficult to reconstruct the development of the Kristallbrocken layers during salt migration-related processes as well as their formation and deformation mechanisms, because the original sedimentary fabric has been largely destroyed. Bedded or less intensely deformed salt deposits with well-preserved Kristallbrocken are almost not accessible. But drilling for hydrocarbon storage caverns in the salt deposit Teutschenthal (Fig. 4.2) exposed less intensely deformed Stassfurt rock salt, in which the original sedimentary fabric, namely a rhythmic bedding of rock salt sequences and continuous anhydrite layers, has largely been preserved and the deformation characteristics of the Kristallbrocken layers are especially well observable. For example, these drilling cores show that the deformational behavior of the Kristallbrocken ranges from brittle to ductile, and due to their internal lamination, the development of them can be visually reconstructed, which provides insights into the deformation mechanisms of the Kristallbrocken. The access to these drilling cores in the drill core storage facility of the Federal Institute for Geosciences and Natural Resources (BGR) now allowed us to contribute new data to the characteristics of the Kristallbrocken for a better understanding of the development of the Kristallbrocken fabric.
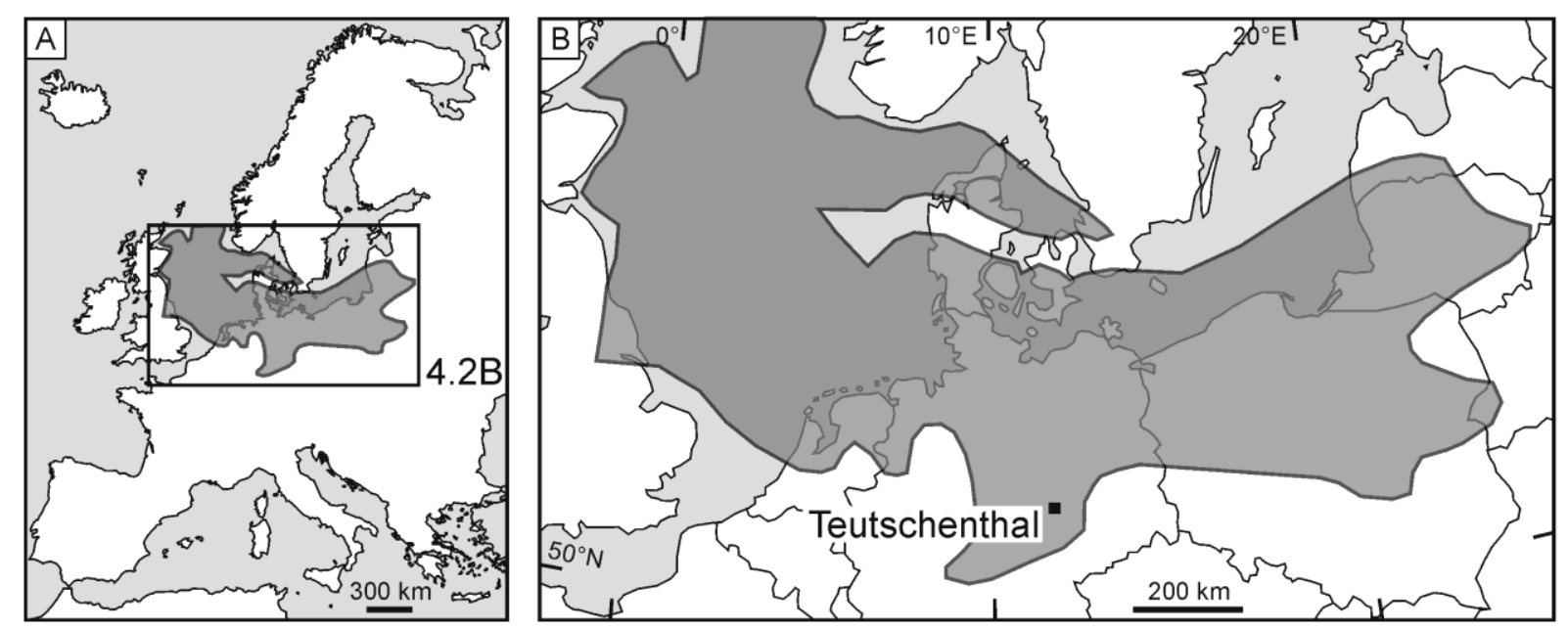

Fig. 4.2: A) Map of Europe with an outline of the Late Permian Zechstein Basin (modified from Taylor 1998). B) Sketch map of this basin showing the studied location Teutschenthal.

The aim of this study was to answer the following questions that arise from the above outlined observations: 1 . Are the Kristallbrocken relics of very fine-grained, polycrystalline halite beds or clasts of 'single crystal-layers', or can they be regarded as postdeformational blasts? 2. When and how did they form and deform? For this purpose, we investigated the deformational characteristics of the Kristallbrocken based on samples from the salt deposit 
Teutschenthal and determined their local crystallographic preferred orientations $(\mathrm{CPO}=$ textures) by X-ray texture goniometry. The better understanding of the texture of this halite fabric type may help us elucidating the deformation mechanisms that explain the observed microstructures.

\subsubsection{Geological setting}

The Zechstein Basin extended from Eastern England and the Southern North Sea in the west to Poland and Lithuania in the east (Fig. 4.2). During the Late Permian (Zechstein), the basin was repeatedly transgressed by sea water coming from the Arctic Sea. The cyclicity of these marine transgressions was presumably caused by glacio-eustatic fluctuations in sea level as well as tectonic processes (e.g., Smith 1979; Ziegler 1981, 1990; Taylor 1998). The high evaporation rates due to the arid climate conditions during the Zechstein, combined with cyclic restriction of sea water influx into the basins, resulted in the deposition of the Zechstein carbonates and evaporites.

In Germany, the Zechstein group comprises 4 main evaporation cycles referred to as the Werra (Z1), Stassfurt (Z2), Leine (Z3), and Aller (Z4) Formations (Richter-Bernburg 1955a) and 3 rudimentary and only regionally occurring cycles referred to as the Ohre (Z5), Friesland (Z6), and Fulda (Z7) Formations (Käding 1978, 2000) (Fig. 4.3). Each cycle is characteristic for a progressive evaporation phase, starting with clastic sediments like mudstones and followed by carbonates, anhydrites, rock salt, and potash salts. Today, Zechstein sediments occur in both flat-lying, apparently undisturbed settings, as well as in diapiric structures formed by salt tectonics (e.g., Trusheim 1960; Jaritz 1973; Kockel 1998).

\begin{tabular}{|c|c|c|c|c|c|c|}
\hline \multicolumn{2}{|c|}{$\begin{array}{l}\text { Chrono- } \\
\text { stratigraphy }\end{array}$} & \multicolumn{3}{|c|}{ Lithostratigraphy } & \multirow{2}{*}{\multicolumn{2}{|c|}{$\begin{array}{c}\text { Lithostratigraphy } \\
\text { Lithology }\end{array}$}} \\
\hline Period & Epoch & Group & Formation & Symbol & & \\
\hline \multirow[t]{2}{*}{ 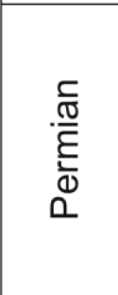 } & \multirow{2}{*}{ 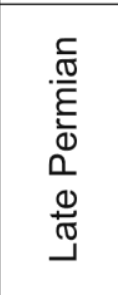 } & \multirow[t]{2}{*}{$\begin{array}{l}\cdot \frac{c}{D} \\
\frac{D}{0} \\
\frac{D}{0} \\
\mathbb{d} \\
N\end{array}$} & $\begin{array}{l}\text { Fulda } \\
\text { Friesland } \\
\text { Ohre } \\
\text { Aller } \\
\text { Leine }\end{array}$ & $\begin{array}{l}\mathrm{Z7} \\
\mathrm{Z6} \\
\mathrm{Z} 5 \\
\mathrm{Z4} \\
\mathrm{Z3}\end{array}$ & \multirow{2}{*}{\begin{tabular}{|c|}
$\begin{array}{c}\text { claystone } \\
\text { anhydrite } \\
\text { potash salts }\end{array}$ \\
rock salt \\
$\begin{array}{c}\text { anhydrite } \\
\text { carbonate } \\
\text { claystone }\end{array}$
\end{tabular}} & \begin{tabular}{|c} 
Hangendsalz \\
Hauptsalz \\
Basissalz
\end{tabular} \\
\hline & & & $\begin{array}{l}\text { Stassfurt } \\
\text { Werra }\end{array}$ & $\frac{Z 2}{71}$ & & \\
\hline
\end{tabular}

Fig. 4.3: Stratigraphic table of the German Zechstein group (Richter-Bernburg 1955a; Käding 1978, 2000). 


\subsubsection{Samples and methods}

The samples investigated in this study belong to the Hauptsalz (German: "Hauptsalz" = main salt) of the Stassfurt Formation (Fig. 4.3) of the salt deposit Teutschenthal (Fig. 4.4), a NWSE trending anticlinal structure located at the southern rim of the former Zechstein Basin and formed by the accumulation of salt migrating from adjacent areas. They were obtained from wells drilled for hydrocarbon storage caverns, in which the rock salt of the Stassfurt Formation reaches a total thickness of approximately $480 \mathrm{~m}$. The original thickness of the Stassfurt Formation rock salt in this area is estimated to range between $300 \mathrm{~m}$ and $400 \mathrm{~m}$, but due to salt migration, the present thickness varies considerably, with a maximum of about $1000 \mathrm{~m}$ (Jagsch \& Theylich 1999). The rock salt horizons are even bedded and largely undisturbed, consisting of layers with matrix halite and layers with the Kristallbrocken, and alternate with massive, continuous anhydrite layers.

For a macroscopical description of the Kristallbrocken, $1 \mathrm{~cm}$ thick drilling core (diameter $10 \mathrm{~cm}$ ) slabs cut parallel to the core axis were used. Samples were manually ground (dry) on a grinding instrument, using 60-, 120-, 500-, and 1000-grit $\mathrm{SiC}$ abrasive papers and polished with diamond spray $(3.0$ and $1.0 \mu \mathrm{m})$ on a low-napped synthetic cloth. Then, the surface of these slabs was wiped with a wet cloth in order to visualize the grains for reflected light photographs. The prepared slabs were studied by transmitted light using a Wild M3 stereomicroscope and photographed on a light table.

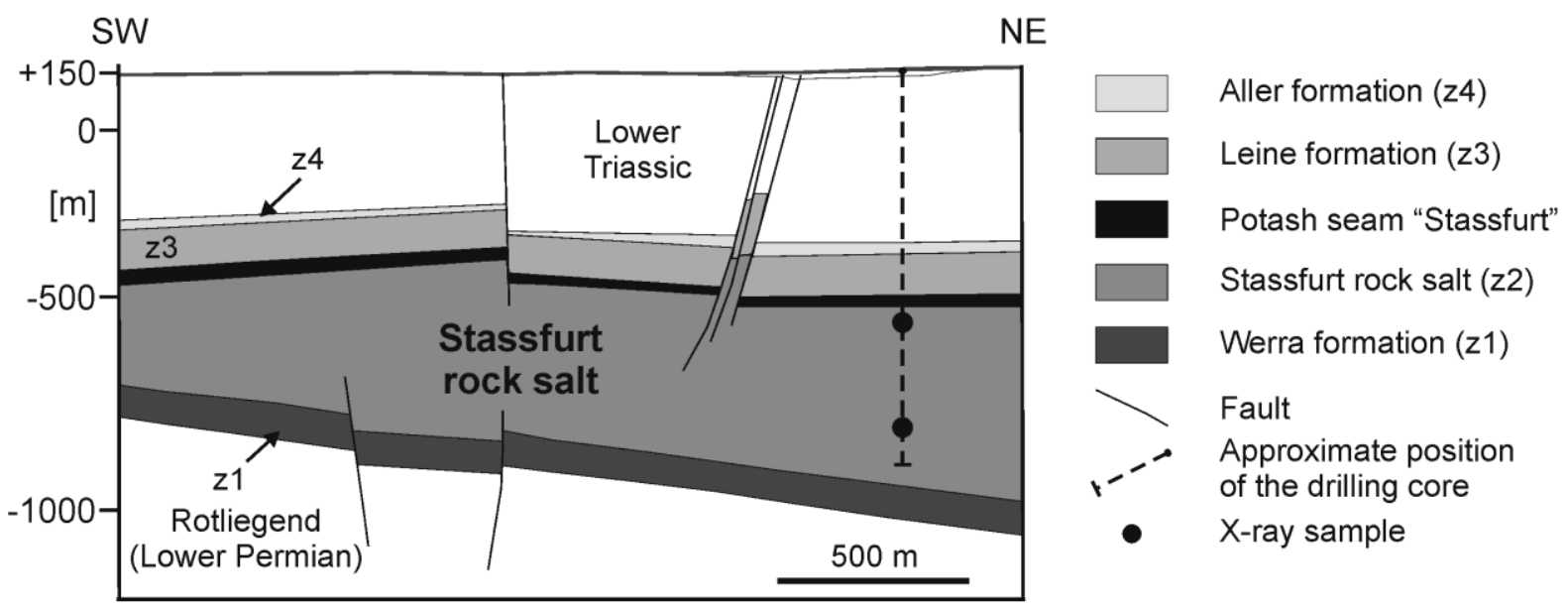

Fig. 4.4: Cross section of the flat-lying salt deposit Teutschenthal (modified from Jagsch \& Theylich 1999) showing the approximate position of the drilling core. The samples for the X-ray texture analysis originate from depths of $\sim 940 \mathrm{~m}$ (Lt62-6-125) and $\sim 665 \mathrm{~m}$ (Lt60-12-89) below the surface.

For microstructural investigations by reflected light microscopy, polished thick sections were etched with distilled water for $5 \mathrm{sec}$, then rinsed for some seconds with methanol, and finally dried in a jet of warm air. This procedure yielded optimal results in respect to the 
visualization of grain boundaries and dislocation substructures within the grain. In view of Electron Backscatter Diffraction (EBSD) analyses, other etching mediums were tested, including slightly undersaturated $\mathrm{NaCl}$ solution, $0.2 \mu \mathrm{m}$ water-free silica suspension, and diluted $\mathrm{HCl}$, with a mixture ratio of $\mathrm{H}_{2} \mathrm{O}: \mathrm{HCl}=5: 1$. However, the preparation of the Kristallbrocken was quite problematic because of the solid inclusions and the fluids that surround them. During polishing, the sulphate crystals fall off and scratch the sample surface, and the brine released during etching leads to minute halite crystals on the surface.

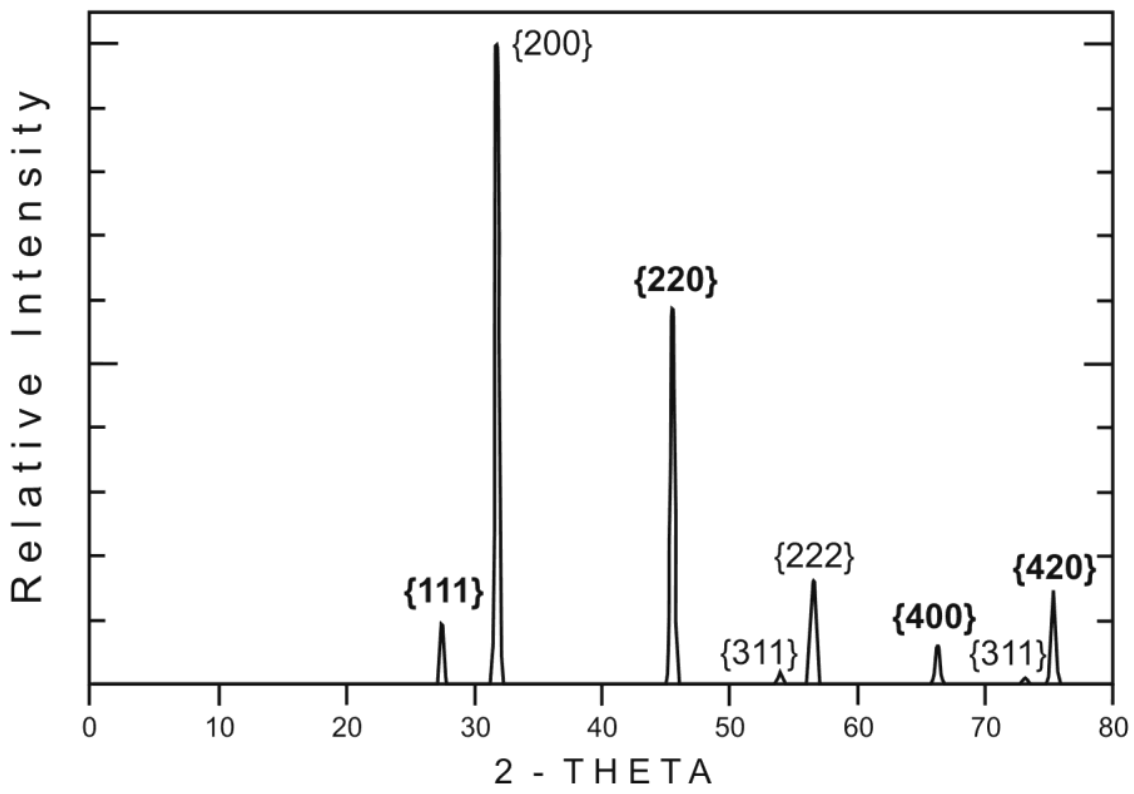

Fig. 4.5: Diffraction pattern of halite computed by means of Xpow (Downs et al. 1993). Pole figures were measured of reflections indicated in bold. For the basal planes, the intensities of the $\{400\}$ instead of the $\{200\}$ reflection was measured, because the high intensity of the $\{200\}$ reflection of the single crystal texture type could have destroyed the X-ray detector.

The two samples for X-ray texture analysis originate from depths of about $940 \mathrm{~m}$ (Lt62-6125) and $665 \mathrm{~m}$ (Lt60-12-89) below the surface (Fig. 4.4). Generally, the Kristallbrocken of the Stassfurt rock salt of Teutschenthal consist of halite and anhydrite, with the latter estimated to range from about 1-5\%. For texture analysis, we prepared $1 \mathrm{~cm}$ thick sections from the drilling core slabs used for the macroscopic description of the Kristallbrocken. The sample sizes are 6x3 cm (Lt62-6-125) and 7x6 cm (Lt60-12-89). The Kristallbrocken in these sections are normally cut approximately perpendicular to their lamination and parallel to the core axis. The sample pieces were manually ground in order to get a planar surface and to remove new halite precipitates that result from slight etching of the sample surface by air moisture. Immediately before the measurements, the sample surface was cleaned with pure water and then quickly dried with a tissue. This was done in order to remove lattice defects of the uppermost surface that have potentially been induced mechanically by grinding. Besides, 
after the measurements, it was checked by reflected light microscopy if new crystals formed on the surface of the sample.

Texture measurements of the Kristallbrocken were carried out with conventional but modern X-ray texture goniometry: a poly-capillary glass fiber lens at the primary beam side provides high X-ray intensities and a large beam size of up to $7 \mathrm{~mm}$ for diffraction on the sample, a cross slit system in front of the poly-capillary lens allows varying beam sizes, and a computer-controlled sample movement allows automated measurements of series of local textures on a regular and irregular grid (Leiss 2005; Leiss \& Ullemeyer 2006). The measurements were performed using a PANalytical X-ray texture measuring system (based on the company diffraction components PW-3040, PW3050/60, PW3060/20). A diffraction pattern of halite is presented in Fig. 4.5. For each sample, several positions for measuring locations were determined. A beam size of $2 \times 2 \mathrm{~mm}$, an anode current of $30 \mathrm{~mA}$, a voltage of $30 \mathrm{kV}$, and a measuring grid for the pole figures of $5^{\circ} \times 5^{\circ}$ was applied. From a sample rotation angle Phi $=360^{\circ}$ and a tilting angle Psi $=85^{\circ}$, an incomplete pole figure measuring grid of 1296 intensities resulted. For the rotation angle Phi, continuous measuring was applied to integrate the intensities between the grid points. The reflected intensities of the hkl-reflections $\{111\},\{220\},\{400\}$, and $\{420\}$ were measured. The resulting data were converted by means of the computer program XTexCor 1.0 (written by Ullemeyer in 2006). For pole figure presentations, we used the program PFPlot 2.2 (written by Umlauf \& Ullemeyer in 2006). Pole figures are presented as equal area projections for the lower hemisphere. In the pole figures, the orientation is presented as multiples of a random distribution (m.r.d.). Lowest contour lines are equal to 1 and 5 m.r.d. and illustrated in grey; from 10 m.r.d., contour lines are illustrated in black, with a contour level distance of 20 m.r.d.

To check the crystallographic compatibility of the pole figures, the so-called texture component method was applied in a qualitative sense by means of the program MulTex 1.0 (e.g., Helming \& Eschner 1990; Helming 1995). By this method, Gaussian-shaped texture components are fitted in the experimental pole figures, with each component representing a crystallographic preferred orientation locally restricted in the orientation space (see, e.g., Leiss et al. 1994, Leiss \& Molli 2003 for descriptive applications of this method).

\subsubsection{Results}

\subsubsection{Microstructural characteristics}

Although the Teutschenthal anticline is a flat-lying salt deposit with largely undisturbed evaporite sequences, the Stassfurt Formation rock salt shows a set of microstructural features 

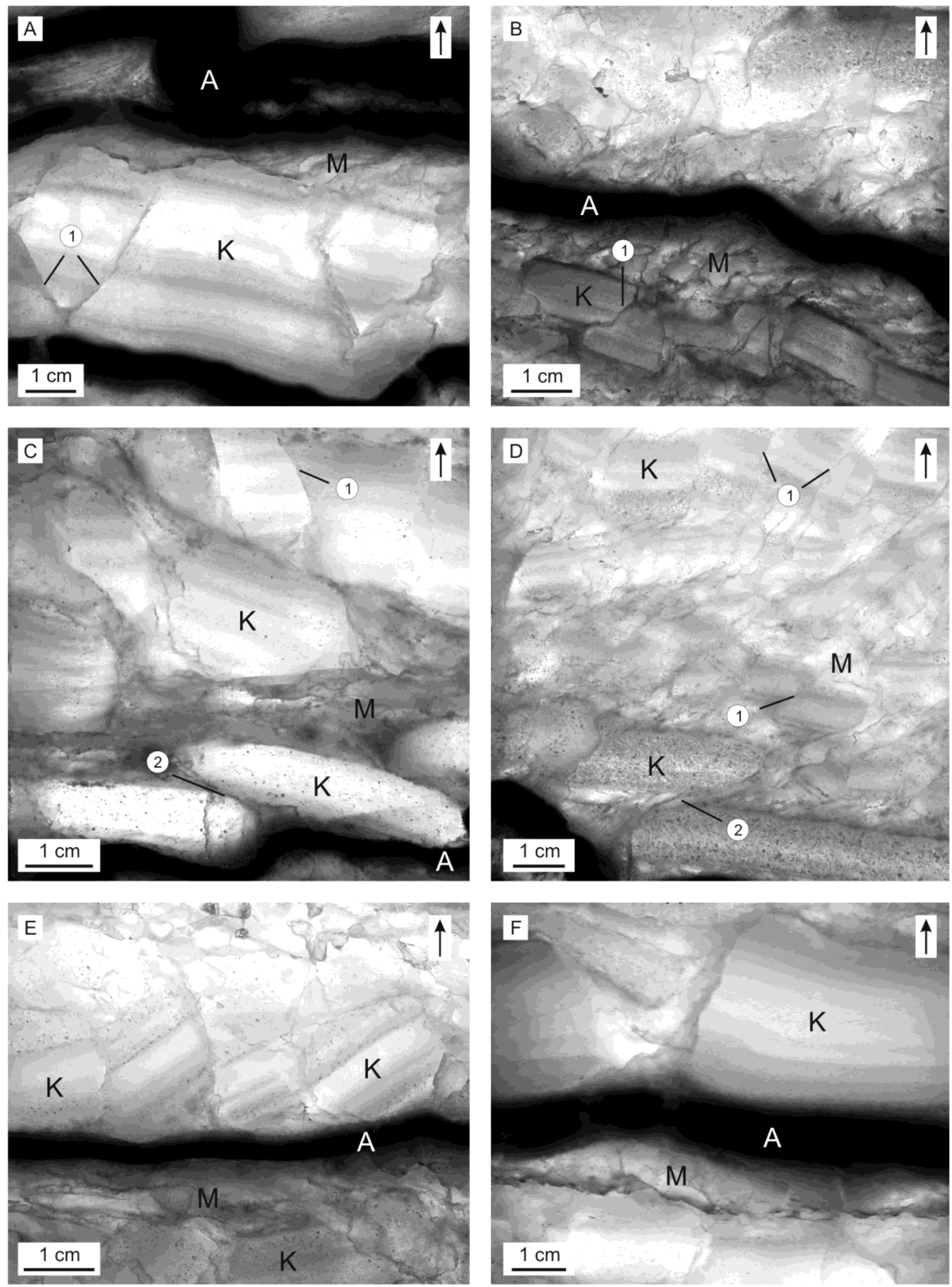

Fig. 4.6: Drill core photographs of Stassfurt rock salt samples of the flat-lying salt deposit Teutschenthal showing the deformational characteristics of the Kristallbrocken. Arrow in white box indicates stratigraphic up direction (= core axis). In general, the rock salt horizons consist of welllaminated halite, the so-called Kristallbrocken $(\mathrm{K})$, and fluid inclusion-poor, middle- to coarse-grained matrix halite (M), and alternate with thin, partly folded anhydrite layers (A). A-B) Kristallbrocken transected by faults (1) that caused relative displacement of the fragments. C-D) The individual fragments of the broken Kristallbrocken were moved passively against each other and stacked (2). E) Broken relics of a Kristallbrocken rotated away from each other. F) Two Kristallbrocken pieces dragged apart. 

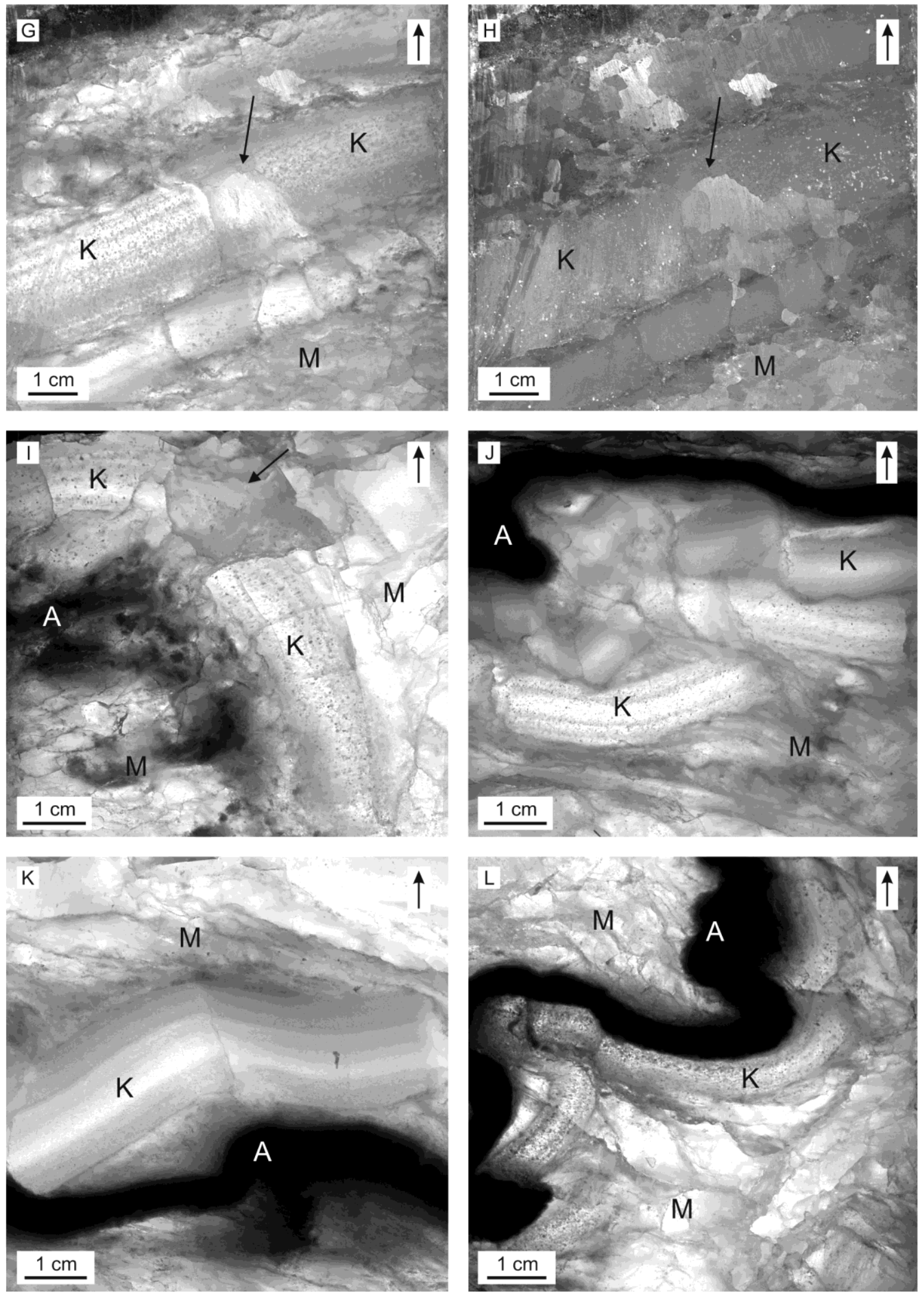

Fig. 4.6 (continued): G-H) Thick section photograph in transmitted (Fig. 4.6G) and reflected light (Fig. 4.6H) showing a Kristallbrocken with new grains (3) in the middle part that do not show the internal lamination anymore. I) Formerly bent Kristallbrocken with an internal lamination. In the curvature zone, new grains formed (3), with the internal lamination having been destroyed. J-L) Thick section photographs showing slightly bent and folded Kristallbrocken. 
that suggest deformation-related processes and therefore documents the beginning of salt migration and accumulation. Such indicators can be observed in context with several Kristallbrocken, with matrix halite, and with anhydrite layers.

The most distinguishing feature of the Kristallbrocken in comparison to the halite matrix is that they show not only ductile, but also brittle deformational behavior. For example, numerous Kristallbrocken could be observed in the Stassfurt Formation rock salt of Teutschenthal that were transected by sets of faults that caused relative displacement of the fragments (Figs. 4.6A-B). These faults do not continue into the halite matrix surrounding the Kristallbrocken. The individual fragments of the broken Kristallbrocken can be moved passively against each other and stacked (Figs. 4.6C-D), they can be rotated away from each other, or, less frequently, dragged apart (Figs. 4.6E-F). Such motions relative to each other can be well reconstructed due to the internal lamination of the Kristallbrocken. The Kristallbrocken are also subjected to ductile deformation, which can be observed in etched Kristallbrocken surfaces that show a network of subgrains under reflected light (Fig. 4.6G). Furthermore, some Kristallbrocken show areas in which the internal lamination has been destroyed and new grains (Figs. 4.6G-I) were formed by recrystallisation, or possibly by microfracturing and subsequent healing by precipitation of halite. A special phenomenon is the occurrence of bent or even folded Kristallbrocken (Figs. 4.6J-L, 4.12), with observed interlimb angles ranging from $170^{\circ}$ up to $85^{\circ}$. The oval shape of many Kristallbrocken may be due to local recrystallisation or dissolution of the boundary areas. Some Kristallbrocken are bent and fractured. The arrangement of the microstructures indicate a beginning buckling of the Kristallbrocken layer, which is followed by fracturing, presumably when the stress cannot be accommodated by bending anymore (Fig. 4.6K-L).

Individual fragments of the Kristallbrocken or layers containing large Kristallbrocken are mostly surrounded by the halite matrix that is composed of clear, partially elongated halite grains, with grain sizes ranging from 0.2 to $1 \mathrm{~cm}$ (Fig. 4.7A). These grains rarely show internal fluid or anhydrite inclusions, but exhibit worm-like fluid or gaseous inclusions in large quantities at their grain boundaries (Figs. 4.7B-C). In addition, individual anhydrite crystals or aggregates are often arranged at the grain boundaries of the matrix halite (Figs. 4.7D-F). The presence of fluid inclusions at the grain boundaries suggests that the matrix halite has been largely recrystallised (Roedder 1984). Reflected light examination of etched sample surfaces revealed that the matrix halite contains both subgrain-free and subgrain-rich grains in different parts of the Hauptsalz (Figs. 4.7D-F). The sub-grain size distribution is rather heterogeneous, with sizes ranging between about $40 \mu \mathrm{m}$ and $500 \mu \mathrm{m}$. Some boundaries 
of sub-grain-free grains show lobate shapes in relation to sub-grain-rich grains (Fig. 4.7D) indicating the direction of the migrating boundary (Urai et al. 1986a; Passchier \& Trouw 1998). During such grain boundary migration recrystallisation (GBM), highly sub-structured grains are consumed by less sub-structured grains. In some areas of the rock salt, strain shadows consisting of very fine-grained matrix halite formed in the hinge domains of folded
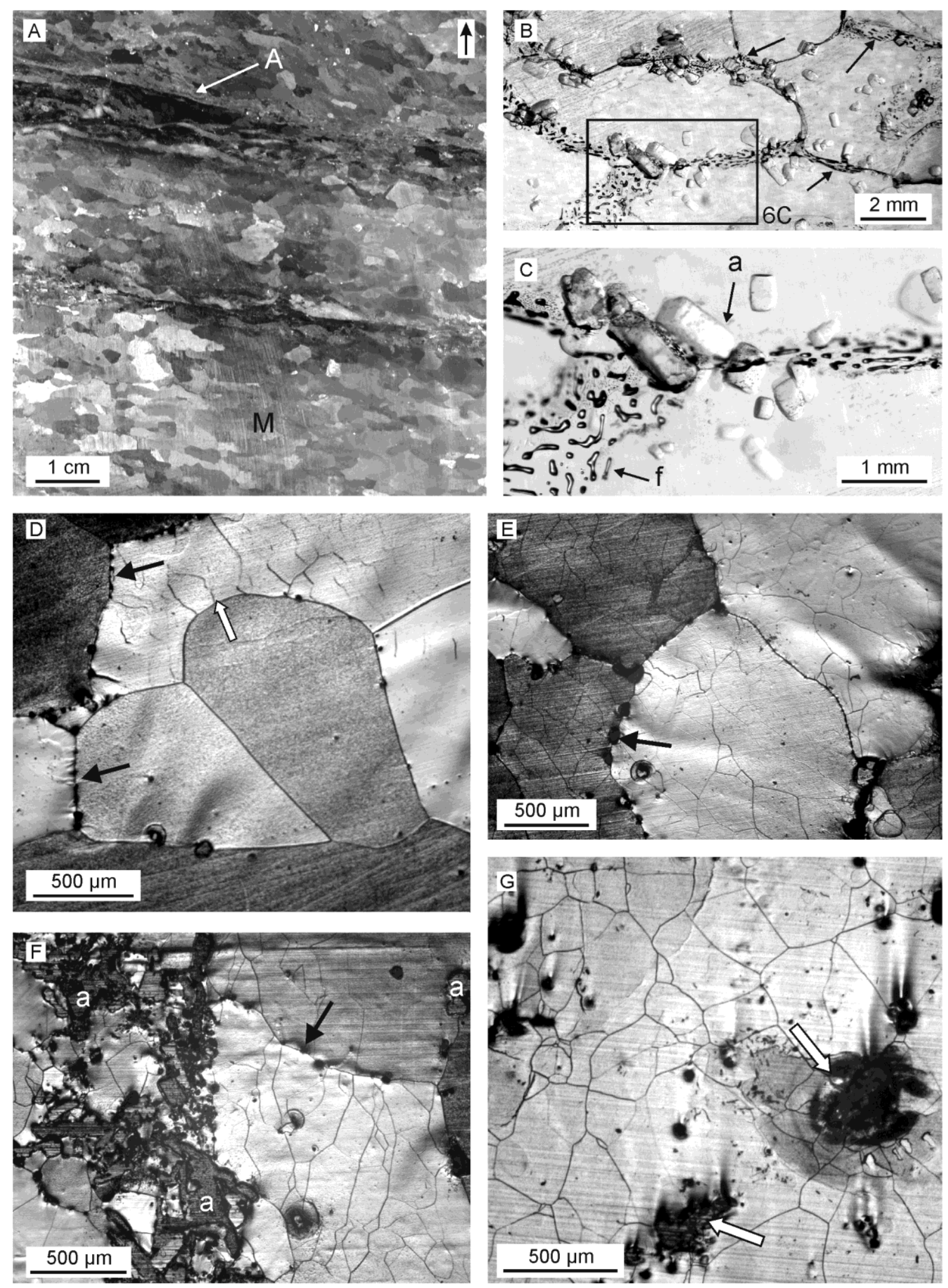

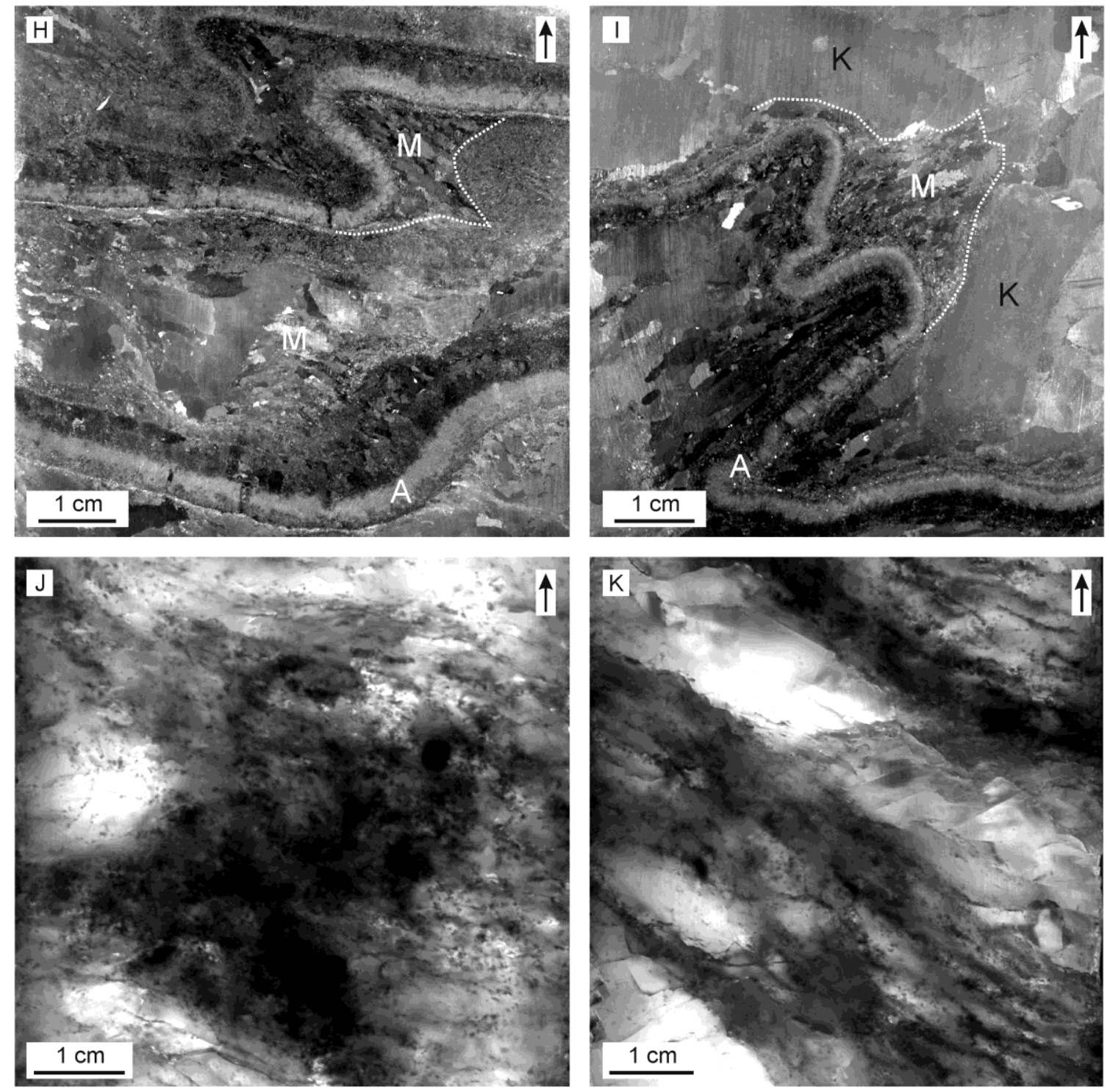

anhydrite layers (Figs. 4.7H-I).

The interbedded anhydrite layers are partially irregularly folded (Figs. 4.6A, 4.6L,

\section{$\leftarrow \uparrow$}

Fig. 4.7: A-I) Photographs of Stassfurt rock salt samples of Teutschenthal. Arrow in white box indicates stratigraphic up direction (= core axis). A) Drill core photograph (reflected light) showing the middle- to coarse-grained matrix halite $(\mathrm{M})$ alternating with very thin, massive anhydrite layers (A). B) Microphotograph (transmitted light) showing the relatively inclusion-poor matrix halite grains, with most fluid or gaseous inclusions as well as anhydrite crystals at their grain boundaries. C) Scaledup section of Fig. 4.7B showing arrays of worm-like fluid inclusions (f) and anhydrite crystals (a) at the grain boundaries. D-F) Reflected light photomicrographs of etched halite matrix sample surfaces (from Küster et al. 2008). G) Reflected light photomicrograph of an etched Kristallbrocken surface showing a network of subgrains. Thin dark lines are subgrain boundaries. Black spots represent former fluid or gaseous inclusions opened during the etching procedure. White arrows point to sulphate inclusions. H-I) Drill core photographs (reflected light) showing strain shadows (dotted line) consisting of fine-grained matrix halite (M) developed in the hinge domain of the folded anhydrite layers (A). J-K) Drill core photographs showing Stassfurt rock salt samples of the salt diapir Morsleben. Arrow in white box indicates stratigraphic up direction (= core axis). Note that anhydrite layers are mostly no continuous beds anymore, but largely occur as layer fragments or are finely dispersed in the rock salt. 
4.6H-I) or boudinaged, which results from deformation processes in consequence of the strong competence contrast between matrix halite and anhydrite layers. Partly, the anhydrite layers were subjected to recrystallisation of the halite yet, which can be seen by the finely dispersed anhydrite in the surrounding matrix halite. In comparison, in the Stassfurt rock salt of diapiric settings, anhydrite layers are mostly no continuous beds anymore, but largely occur as layer fragments or are finely dispersed in the rock salt (Fig. 4.7J-K).

\subsubsection{Texture analyses}

\section{Sample Lt62-6-125}

Figure 4.8A shows the sample Lt62-6-125 consisting of matrix halite and the Kristallbrocken. The investigated Kristallbrocken (Fig. 4.8B) comprises two distinguishable Kristallbrocken pieces: a Kristallbrocken relict on the left side and one in the central part. The latter shows a healed fracture in the middle. The lamination is clearly visible and suggests that this Kristallbrocken was slightly bent before being fractured. The crystallographic orientation was measured at nine locations that are regularly distributed on the different Kristallbrocken areas (Fig. 4.8B). The experimental pole figures for the reflections $\{111\},\{220\},\{400\}$, and $\{420\}$ are presented in Fig. 4.9.
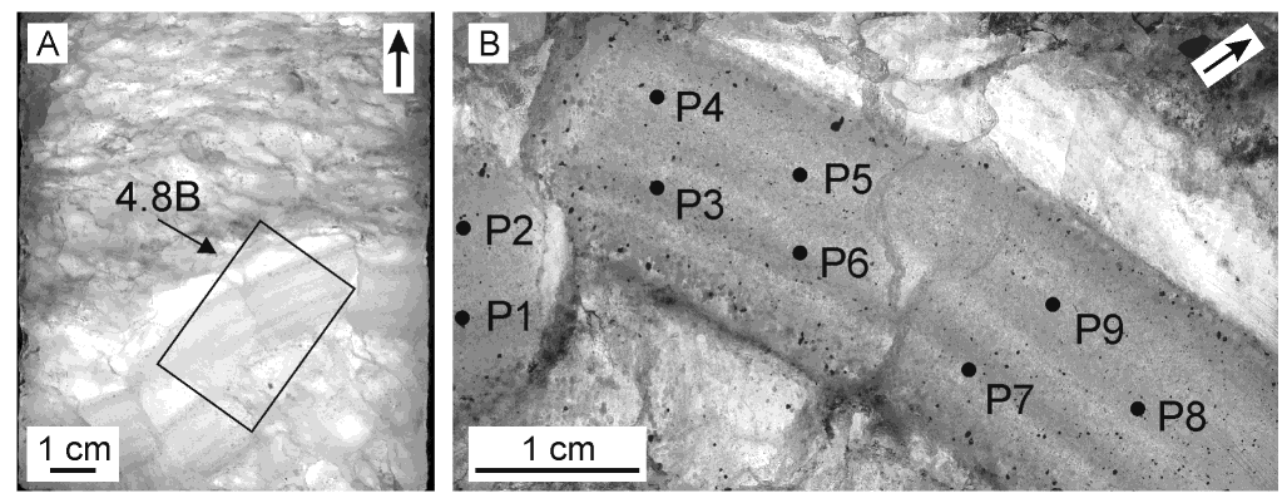

Fig. 4.8: A) Thick section photograph of sample Lt62-6-125 (Teutschenthal) showing the investigated Kristallbrocken. B) Scaled-up section of Fig. 4.8A showing the 9 measuring locations for the X-ray texture measurements. The Kristallbrocken is slightly bent, with a fracture in the middle part. Arrow in white box indicates stratigraphic up direction (= core axis).

In all pole figures at all measuring locations, distinct, strongly developed intensity maxima can be observed. These clear and strong maxima can only result from a single crystal structure and not from a very fine-grained aggregate-structure of the Kristallbrocken. When comparing the results of the different Kristallbrocken areas, namely the pole figures of P1 and P2; P3, P4, P5, and P6; as well as P7, P8, and P9, the positions of the maxima are nearly identical for these areas (Fig. 4.9). This observation also supports the idea of the single crystal 
structure of the whole Kristallbrocken. When adding the pole figures of representative locations of neighboring Kristallbrocken areas, namely P1-P6, or P3-P9, a relationship can be observed suggesting that the separated areas most likely originally formed one big undisturbed single crystal (Fig. 4.10). For example, the combined pole figures of P3-P6 and

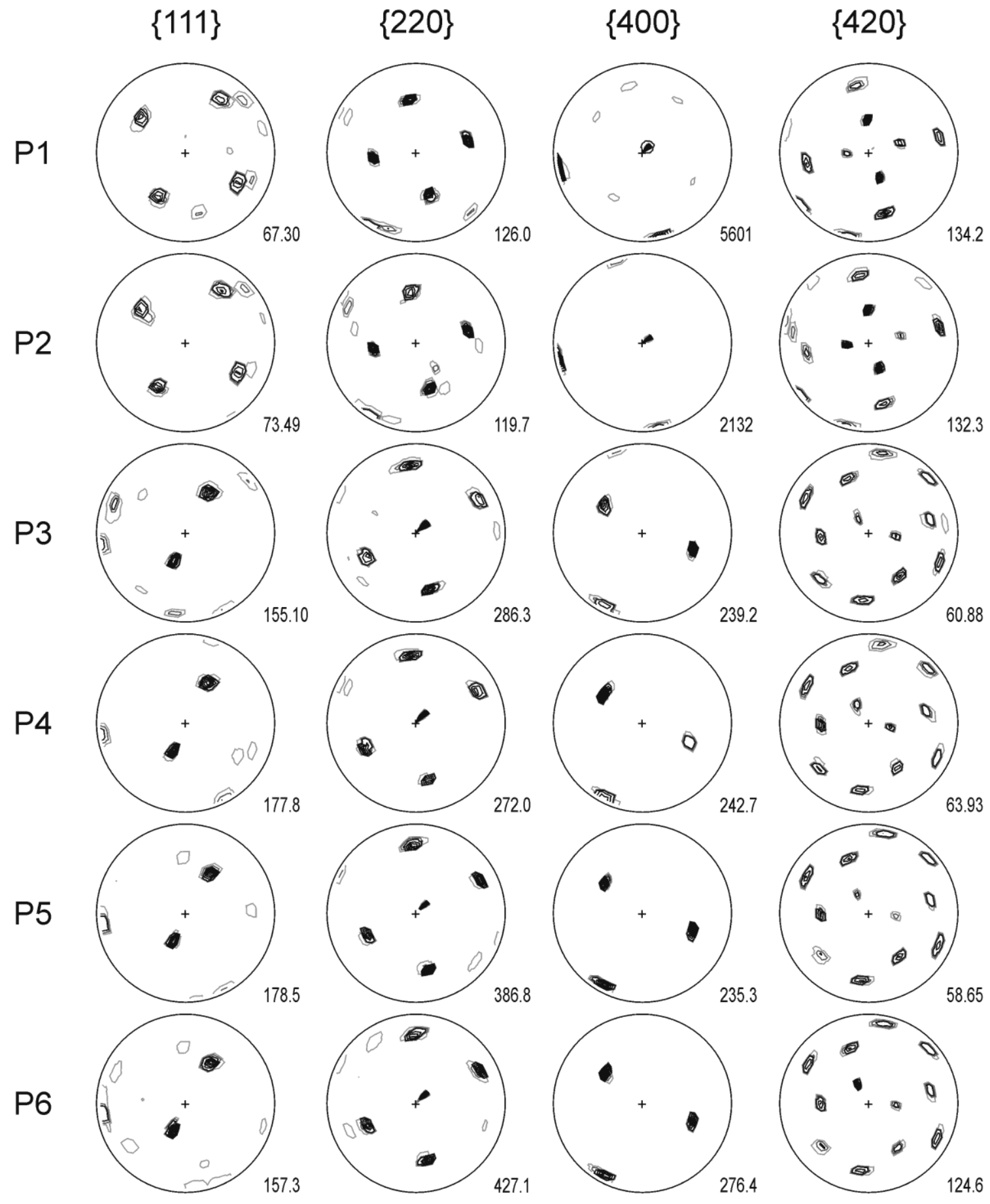

Fig. 4.9: Experimental pole figures of the reflections $\{111\},\{220\},\{400\}$, and $\{420\}$ of the measuring locations on sample Lt62-6-125 (Fig. 4.8). Lowest contour lines (grey) are equal to 1 and 5 multiples of random distribution (m.r.d.). From contour line 10 m.r.d. (black), the contour interval is 20 m.r.d. Note that all pole figures show strongly developed maxima. The positions of the maxima are nearly identical in the pole figures of $\mathrm{P} 1$ and P2; P3, P4, P5, and P6; as well as P7, P8, and P9. 


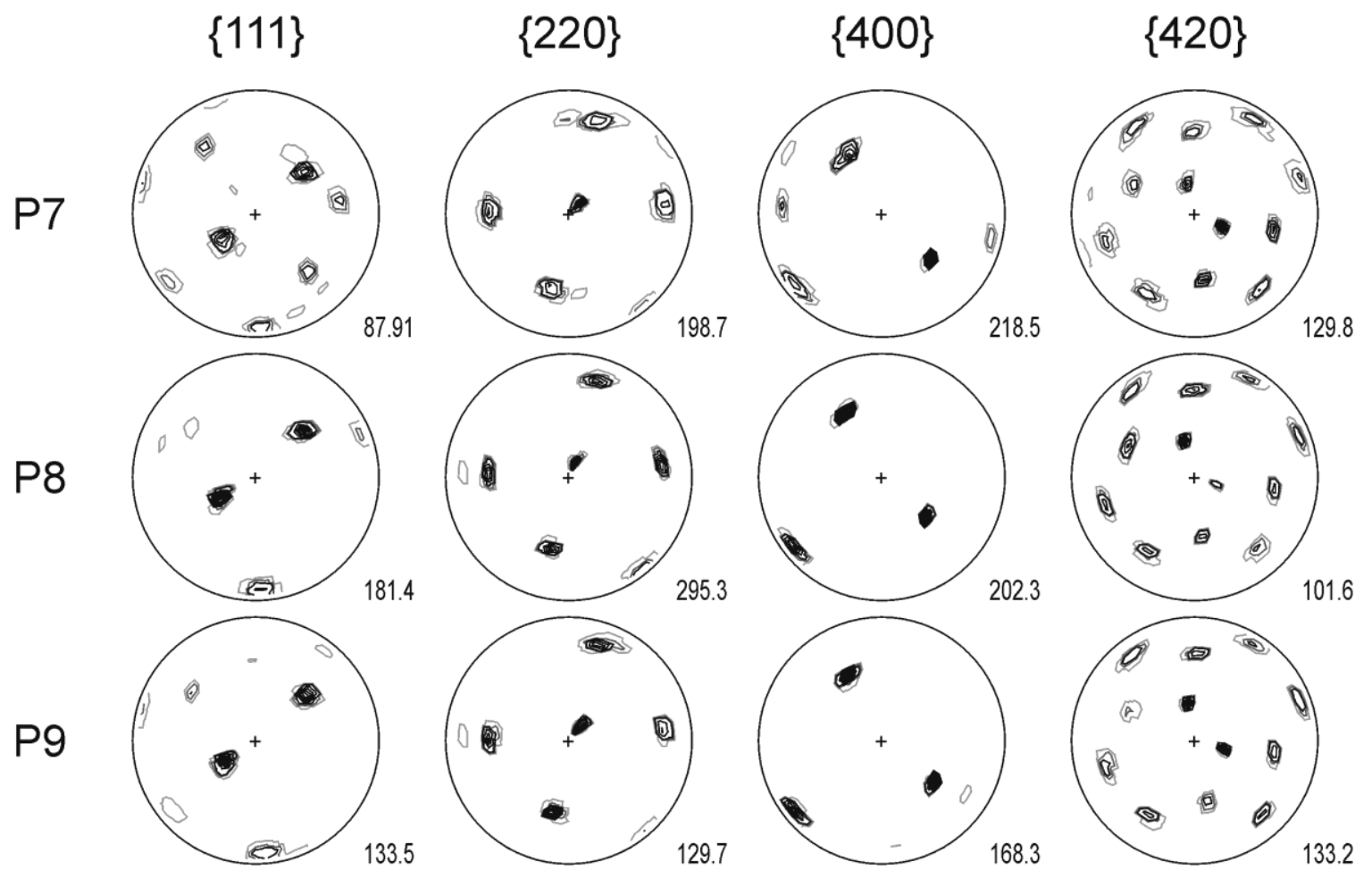

Fig. 4.9 (continued).

P7-P9 illustrate an angular difference of the crystallographic orientations between the two Kristallbrocken pieces of about $20^{\circ}$ around an axis normal to the pole figure projection plane. The relationship between the left and the middle Kristallbrocken area (P1-P2 and P3-P6; Fig. 4.10) is more complex. This is not the result of just a rotation around the bending axis but obviously also shows a tilting around an axis parallel to the pole figure projection plane.

By means of the texture component method, the compatibility of the experimental pole figures could be well demonstrated, especially in view of the maxima positions (Fig. 4.11, Table 1). The intensities of the maxima, however, are partly incompatible within and between the pole figures. This is mainly because of two experimental conditions: (1) the single crystal structure of the Kristallbrocken pieces causes very strong peaks, which cannot be quantitatively measured with a measuring grid of $5^{\circ} \times 5^{\circ}$ because the very sharp maximum intensities may be located between the grid points of the small circles associated to the tilt angle steps of $5^{\circ}$; (2) during pole figure measuring, the reflected X-ray intensities decrease due to defocusing beam geometry conditions at high tilt angles. A correction of the defocusing effect was not carried out since in this case of single crystals, it would be a complex duty, especially in combination with point (1). Besides, such corrections would not help to understand this texture in a better way or give us more information in view of the Kristallbrocken formation. The main question, namely if the Kristallbrocken form a single 
4.1 Structural characteristics of the halite fabric type 'Kristallbrocken' from the Zechstein Basin with regard to its development

crystal texture, can be clearly answered by the crystallographic compatibility of the sharp maxima.

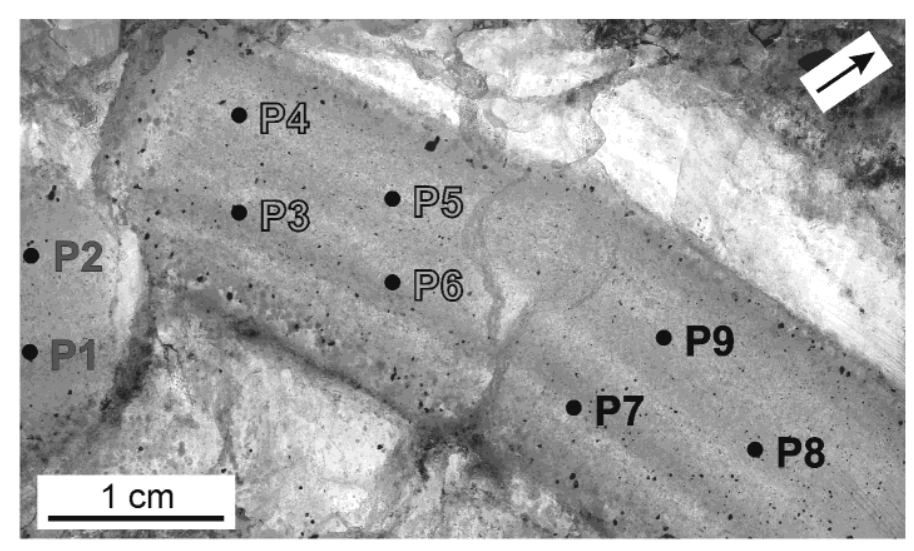

$\{111\}$
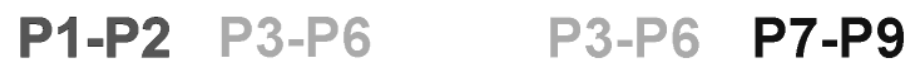

$\{220\}$
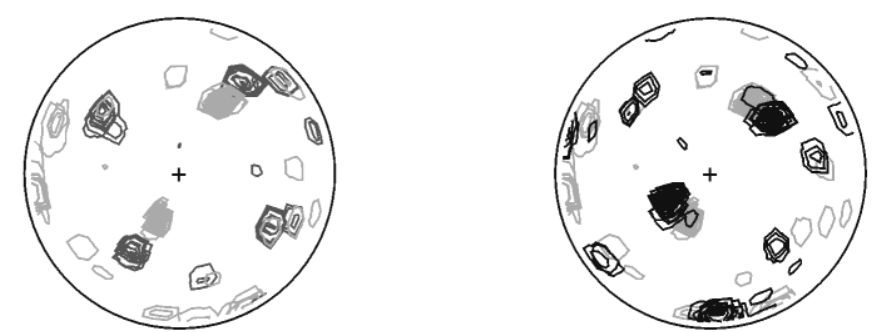

$\{400\}$
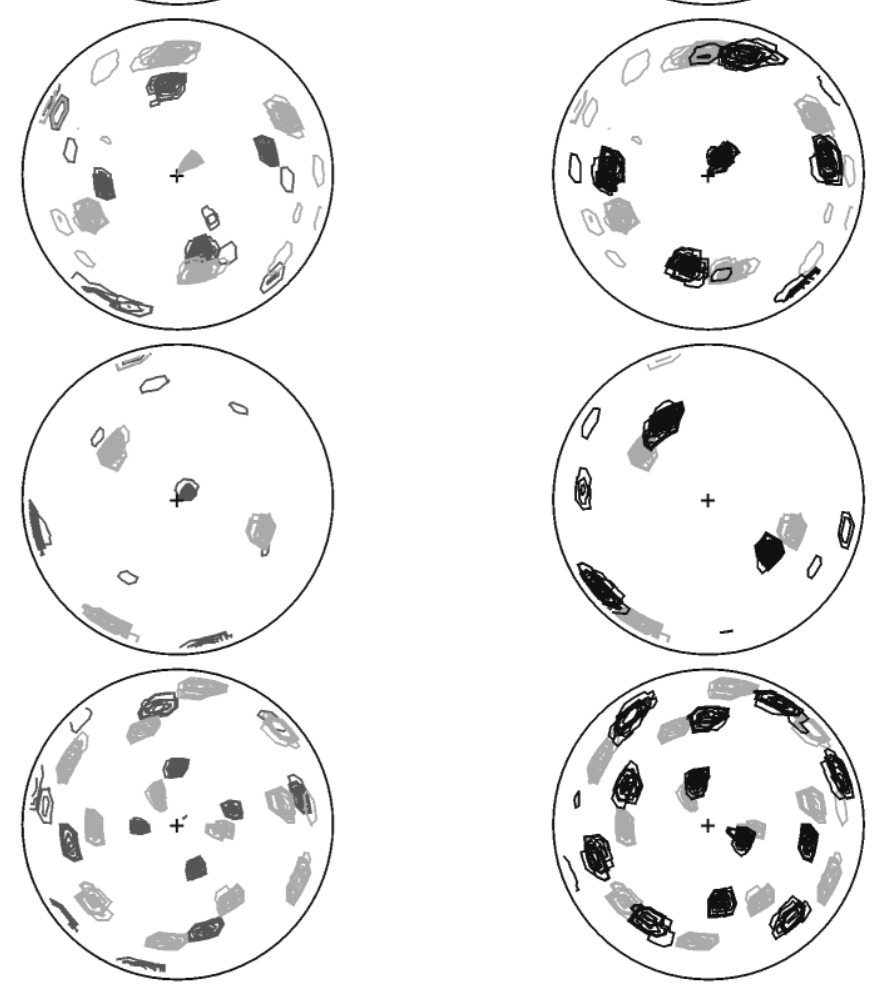

Fig. 4.10: Added pole figures of the reflections $\{111\},\{220\},\{400\}$, and $\{420\}$ of the measuring locations P1-P6 and P3-P9 of sample Lt62-6-125 (Fig. 4.8). For comparison, the contour lines are colored in dark-grey for P1-P2, in light grey for P3-P6, and in black for P7-P9. Arrow in white box indicates stratigraphic up direction. 
Sample Lt60-12-89

Sample Lt60-12-89 contains a folded Kristallbrocken cut nearly perpendicular to the fold axis. The lamination of the Kristallbrocken is rather weak, with few, relatively large sulphate inclusions. The measuring locations P1 to P12 were arranged along the fold profile, whereas P13 and P14 were located on a piece that was separated from the limb of the Kristallbrocken fold (Fig. 4.12). The experimental pole figures are presented in Fig. 4.13.
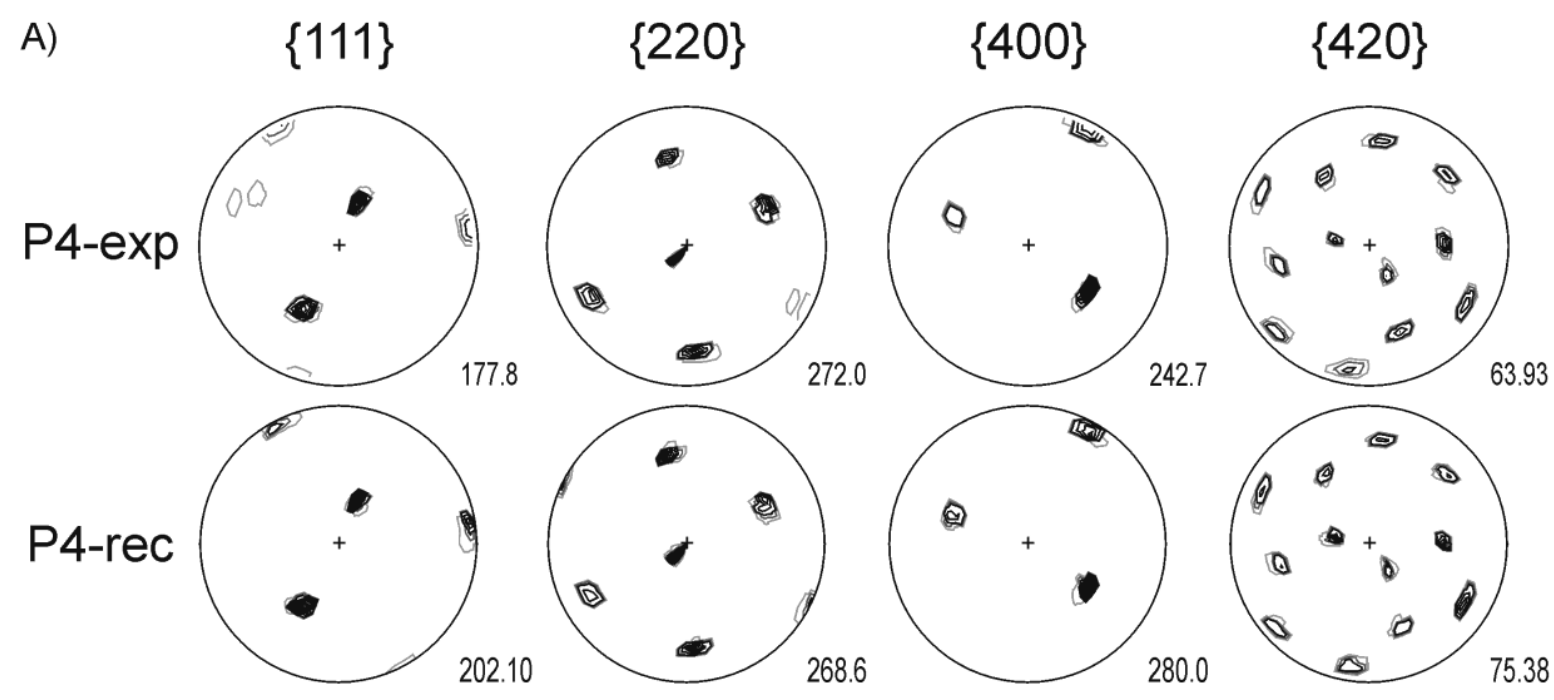

B)

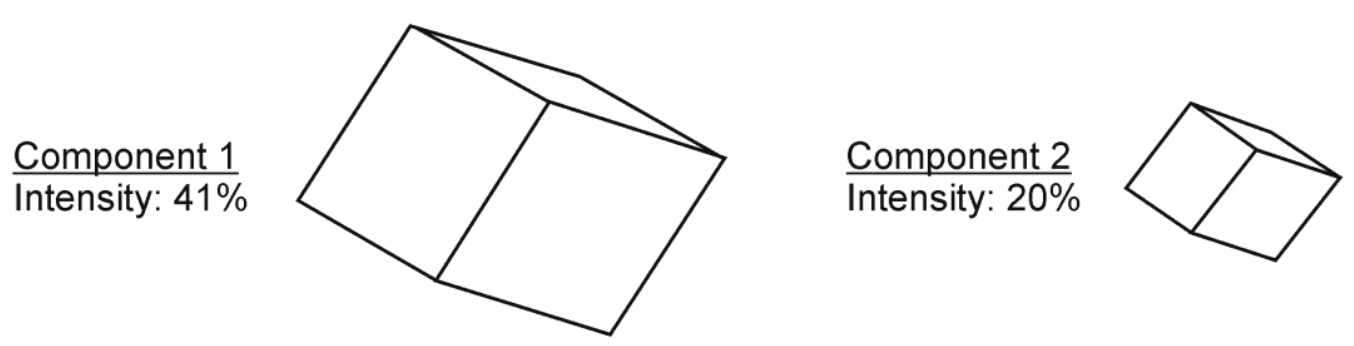

Fig. 4.11: A) Experimental (exp) and recalculated (rec) pole figures from the texture component model for the reflections $\{111\},\{220\},\{400\}$, and $\{420\}$ of P4 of sample Lt62-6-125 (Fig. 4.8). Lowest contour lines (grey) are equal to 1 and 5 m.r.d. From contour line 10 m.r.d. (black), the contour interval is 20 m.r.d. Note that the texture could be very well reproduced. B) Orientation and relative intensity of the two main components that represent the single crystal texture of the Kristallbrocken.

All pole figures reveal distinct intensity maxima, similar to sample Lt62-6-125, and therefore again indicate that the Kristallbrocken are single crystals. However, in this sample, the positions of the maxima in all pole figures and thus the orientation of the halite single crystal changes continuously from point P1 to P12 following the expected change of the folded Kristallbrocken structure. Besides, the pole figures of the hinge area show clear elongations of the maxima. These elongations are especially striking at the periphery of the pole figures indicating a bending of the crystal around a fold/rotation axis located close to the 
centre of the pole figure. A summary of all pole figures of the folded Kristallbrocken (P1 to P12; Fig. 4.16) represents the bulk texture of the folded Kristallbrocken and more clearly visualizes this observation. This also proves a fold/rotation axis with a direction near the centre of the pole figure.

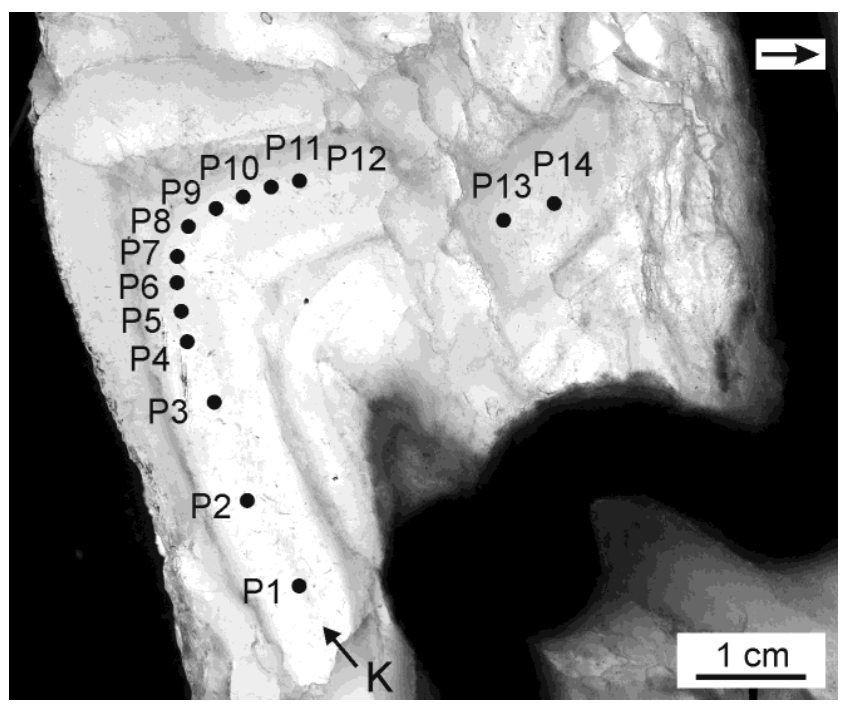

Fig. 4.12: Thick section photograph of sample Lt60-12-89 (Teutschenthal) showing the 14 measuring locations for X-ray texture measurements. The size of the drawn spots is equivalent to the beam width of about $2 \mathrm{~mm}$. The distance between the measuring locations P4 to P12 is around $3 \mathrm{~mm}$ The Kristallbrocken $(\mathrm{K})$ is folded, with an interlimb angle of about $\sim 85^{\circ}$. Arrow in white box indicates stratigraphic up direction (= core axis).

Again, the texture component method was used to check the crystallographic compatibility of the measured pole figures. In the first instance, we checked this for the measurement at P5 (Fig. 4.14). In principle, the single crystal texture type of the Kristallbrocken at one measuring type could be well described by various components (Fig. 4.14). In detail, however, especially in the experimental and recalculated $\{400\}$ pole figure, the elongations of the maxima could not be fully represented. This can again be explained by the defocusing effect. At higher tilt angles, the beam covers a larger measuring area due to a changed geometry of the beam, which is well illustrated in Fig. 4.15A. A larger measuring area means that a more folded area of the Kristallbrocken crystal lattice (Fig. 4.12) is captured and a stronger elongation of the maxima can be expected. In this context, it has to be considered that the characteristics of this effect additionally depend on the $2 \theta$ angle (Fig. 4.15A).

We also checked the crystallographic compatibility of the summarized pole figures of P1 to 12 of Fig. 4.16. These summarized pole figures (Fig. 4.16) are an approach to represent the bulk texture of the bent Kristallbrocken structure with the advantage that some of the problematic effects of the pole figure compatibility are smoothed. Consequently, the bulk 
texture of the folded Kristallbrocken structure could be very well represented by 10 components and therefore proves the plausibility of the measured data (Fig. 4.16, Table 1).

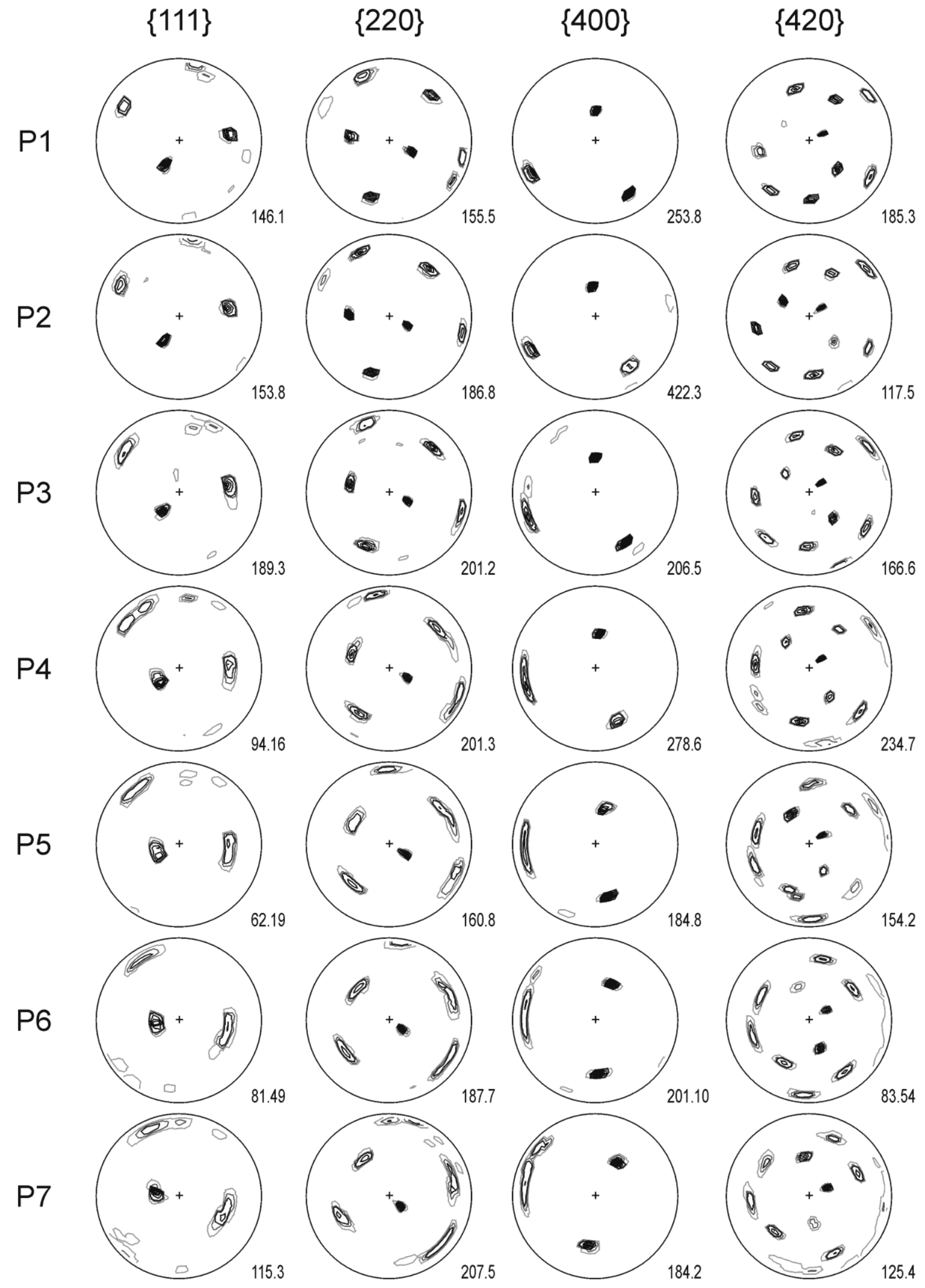


$\{111\}$

P8

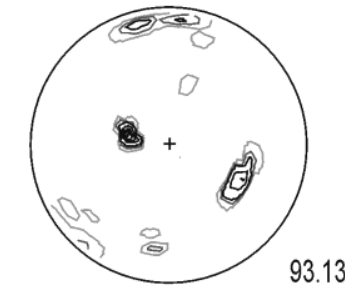

93.13

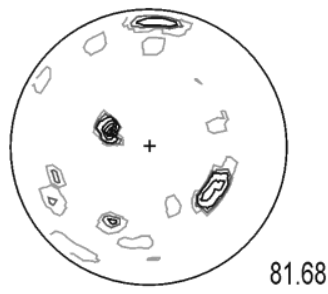

P9

81.68

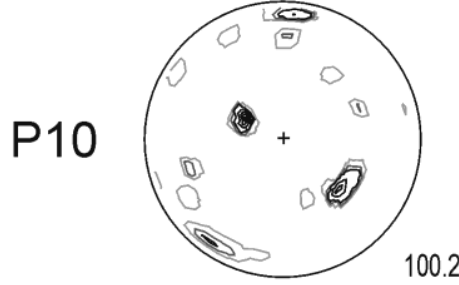

100.2

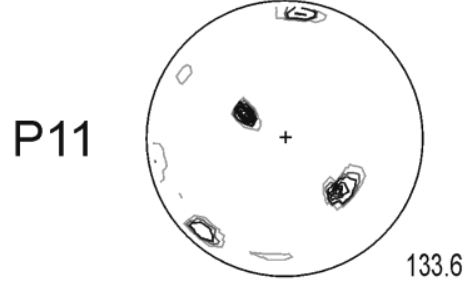

133.6
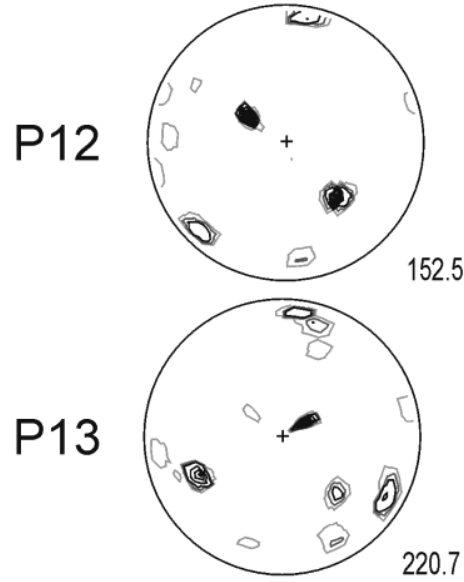

220.7

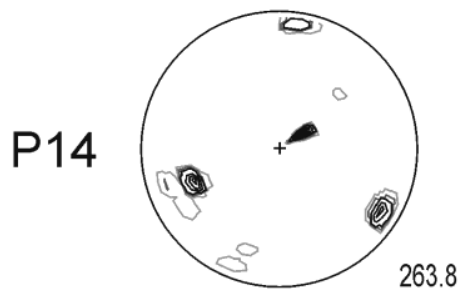

263.8
$\{220\}$

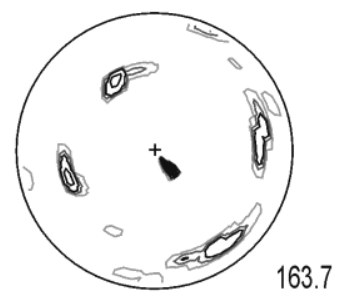

163.7
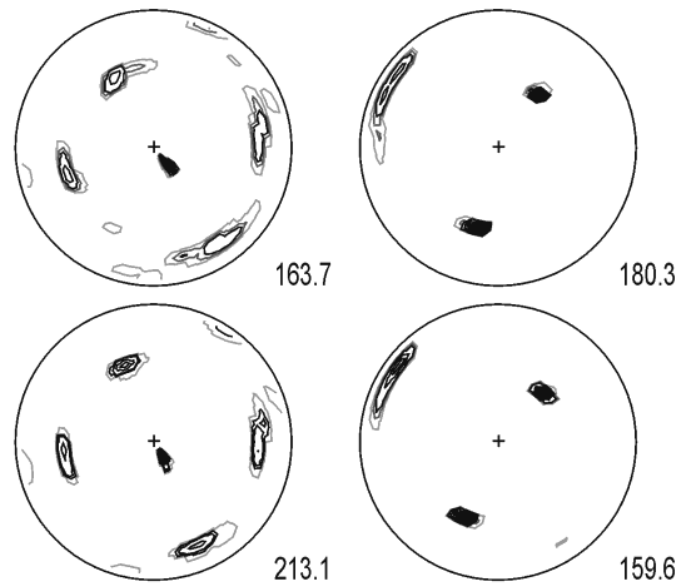

180.3
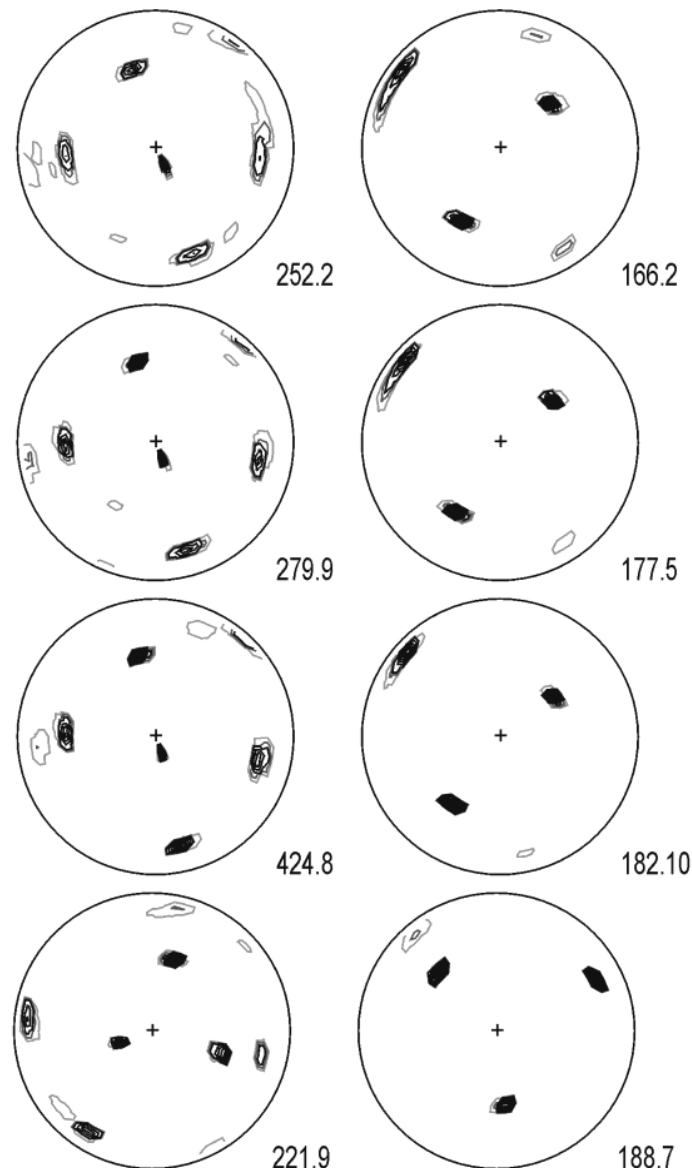

188.7
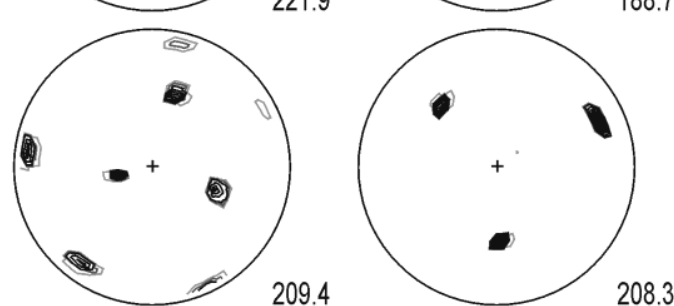

$\{420\}$
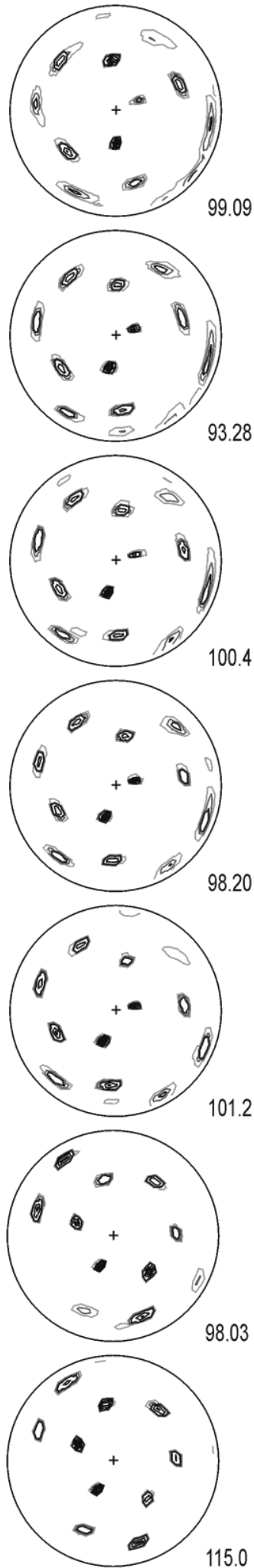

$\leftarrow \uparrow$

Fig. 4.13: Experimental pole figures for the reflections $\{111\},\{220\},\{400\}$, and $\{420\}$ of the measuring locations on the folded Kristallbrocken of sample Lt60-12-89 (Fig. 4.12). Lowest contour lines (grey) are equal to 1 and 5 m.r.d. From contour line 10 m.r.d. (black), contour interval is 20 m.r.d. Note that the position of the maxima in the pole figure and thus the crystallographic orientation changes continuously from point P1 to P12 following the fold structure. The Kristallbrocken piece that is separated from right limb of the fold has a clearly different crystallographic orientation (P13, P14). 


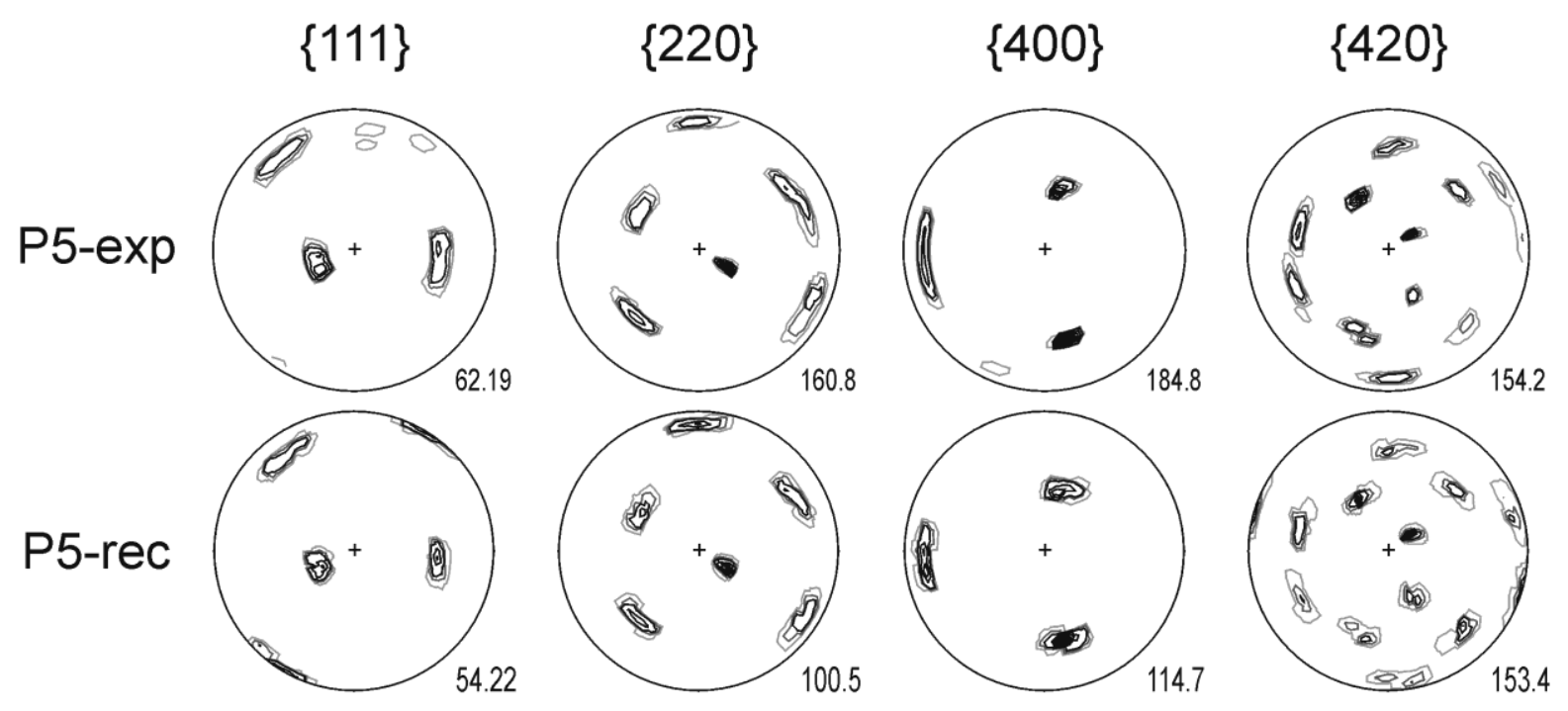

Fig. 4.14: Experimental (exp) and recalculated (rec) pole figures for the reflections $\{111\},\{220\}$, $\{400\}$, and $\{420\}$ of P5 of sample Lt60-12-89 (Fig. 4.12). Lowest contour lines (grey) are equal to 1 and 5 m.r.d. From contour line 10 m.r.d. (black), contour interval is 20 m.r.d. The single crystal texture could be basically reproduced. The reasons for some deviations mainly obvious in the $\{400\}$ pole figure are discussed in detail in the text.

\subsubsection{Discussion}

An especially for rock samples configured X-ray texture goniometer was applied for the texture analysis of the rock salt type Kristallbrocken to analyze their internal structure to learn more about their development and deformation. This first study does not only prove the monocrystalline character of the Kristallbrocken, but also reveals experimental characteristics of this special application, which help to refine further methodical strategies for a more quantitative approach to the structural analysis of the Kristallbrocken. These methodical aspects as well as the consequences of the monocrystalline character of the Kristallbrocken for the understanding of the Kristallbrocken formation and their subsequent deformation will be discussed in the following.

\subsubsection{Texture analysis - methodical aspects}

The results of the local X-ray texture measurements revealed that the neighboring Kristallbrocken areas of sample Lt62-6-125 are monocrystalline and that these three separated pieces formerly formed one single monocrystalline Kristallbrocken. However, the single crystal structure of the Kristallbrocken is not perfect, which is obvious from the partially elongated maxima indicating that the single crystal pieces are weakly bent. This becomes much more obvious from the results of sample Lt60-12-89. While the local X-ray texture measurements of this folded Kristallbrocken again demonstrate the monocrystalline structure of the Kristallbrocken, the summarized local texture measurements, i.e. the bulk texture of 
this Kristallbrocken, clearly illustrate that this monocrystalline structure was bent or folded as a whole. The Kristallbrocken is neither internally recrystallised nor was it folded as a finegrained polycrystal.

For the aim of this study, this general result is sufficient to draw conclusions on the formation and the deformation of the Kristallbrocken. Furthermore, the results demonstrate that the presented X-ray texture goniometer configuration is suitable to analyze such monocrystalline structures in a quick and efficient way. All this holds true for a general approach to the crystallographic analysis of the Kristallbrocken structure. A more detailed analysis of the results, however, shows some minor incompatibilities of the resulting pole figures, which make a more refined (i.e. quantitative) approach difficult. From the results, the following experimental conditions can be discussed to be responsible for the minor incompatibilities of the pole figures (compare with Fig. 4.15):

(1) The diffracted X-ray beam becomes defocused at large tilt angles, which leads to a decrease of the measured intensity towards the pole figure edge.

(2) A beam defocus is also associated with a changing geometry of the beam, i.e. the actually circular beam becomes an ellipse with increasing tilt angles (Fig. 4.15A). Consequently, the area of exposure on the sample surface changes as a function of the tilt angle.

(3) The shape and orientation of the beam and thus the area of exposure on the sample surface also changes as a function of the $2 \theta$ angle of the different pole figure reflection (Fig. 4.15A).

(4) The absolute maxima and positions of the strong peaks of these single crystal structures cannot always be exactly measured due to the applied relative rough measuring grid of $5^{\circ} \times 5^{\circ}$

(5) Additional minor effects can be induced by the sample rotation in the area of the fold hinge. In the position of the fold axial plane parallel to the beam, a less strongly bent area is covered than in the position of the fold axial plane normal to the beam (Fig. 4.15B).

All these effects are related to each other. The correction would be very elaborate and complex. However, as already mentioned, in this study, a more quantitative approach would not help to improve the understanding of the crystallographic structure of the Kristallbrocken and therefore, we did not follow up the corrections. Anyway, in this case of single crystal structure analysis, the application of other techniques, for example the use of an area instead of a single detector, is much more promising for the future (e.g., Bunge \& Klein 1996; Wcislak et al. 2002). 
a)

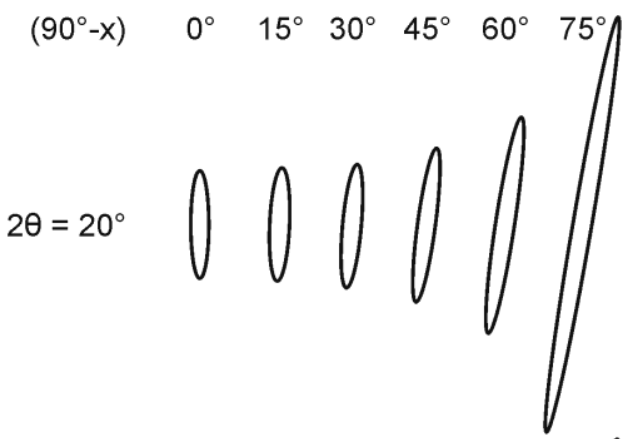

$$
\begin{aligned}
& 2 \theta=40^{\circ} \quad 0 \quad 0 \quad 00 / / / \\
& 2 \theta=60^{\circ} \quad 0 \quad 000000
\end{aligned}
$$

b)

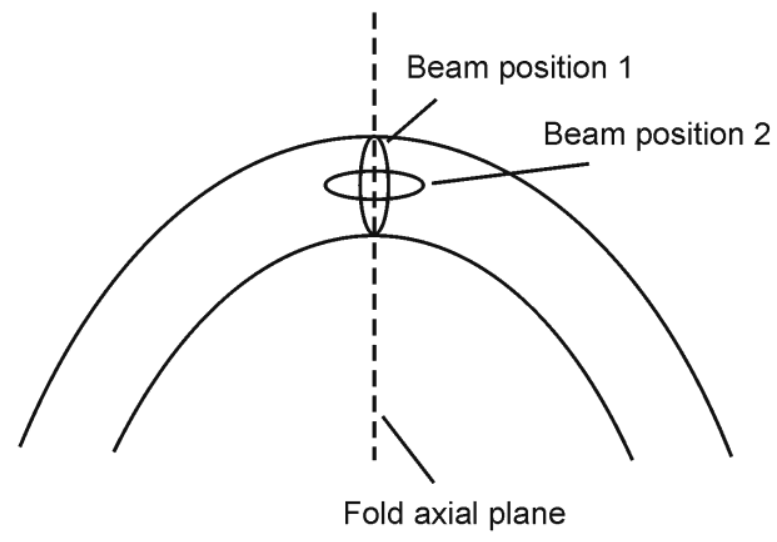

Fig. 4.15: A) Change in shape and orientation of the irradiated spot on the sample surface for different sample orientations as a function of tilt angle and Bragg angle $2 \theta$. The incident beam is cylindrical with $2 \mathrm{~mm}$ diameter. Figure from Kocks et al. (1998). For comparison, the Bragg angles of the four reflections measured in this study are $2<$ THETA $>\{111\}=27.335^{\circ}, 2<$ THETA $>\{220\}=45.450^{\circ}$, $2\left\langle\right.$ THETA $>\{400\}=66.229^{\circ}$, and $2\left\langle\right.$ THETA $>\{420\}=75.304^{\circ}$. B) Changing texture due to changing measuring areas during sample rotation in the area of the fold hinge. In contrast to beam position 1, in beam position 2 , an area with increased misorientation angle is covered.

\subsubsection{Texture analysis - microstructural aspects}

Besides the above mentioned experimental aspects of producing minor incompatibilities of the pole figures, microstructural aspects might also be responsible:

(1) As it is shown in Fig. 4.7G, the microstructures of the Kristallbrocken show a regular mosaic of subgrains. They are responsible for a weak broadening of the maxima in the pole figures and, locally, can also be responsible for a slight deviation of the maxima elongation of the general structure. For a quantitative characterization of these effects, we applied the Electron Backscatter Diffraction (EBSD) technique on a scanning electron microscope (e.g., Prior et al. 1999; Trimby et al. 2000a). However, due to major sample preparation problems, such characterization was not possible. The numerous solid inclusions and fluids surrounding them (e.g., Figs. 4.7C, 4.7G) inhibited the preparation of a well measurable surface despite testing different polishing and etching techniques. Thus, it was not possible to analyze a statistically representative number of diffraction patterns within a regular measuring grid.

(2) As it will be discussed further below, it is difficult to exactly correlate the rotation/fold axis induced from the maxima elongations with a crystallographic direction of the ideal single 
crystal orientation. The reason might be the activation of a secondary slip system resulting from non-cylindrical folding. This effect can also result in apparent incompatibilities of the pole figures, but is too weak to be sufficiently resolved by texture components and/or would not be distinguishable from the other error-inducing effects described above.
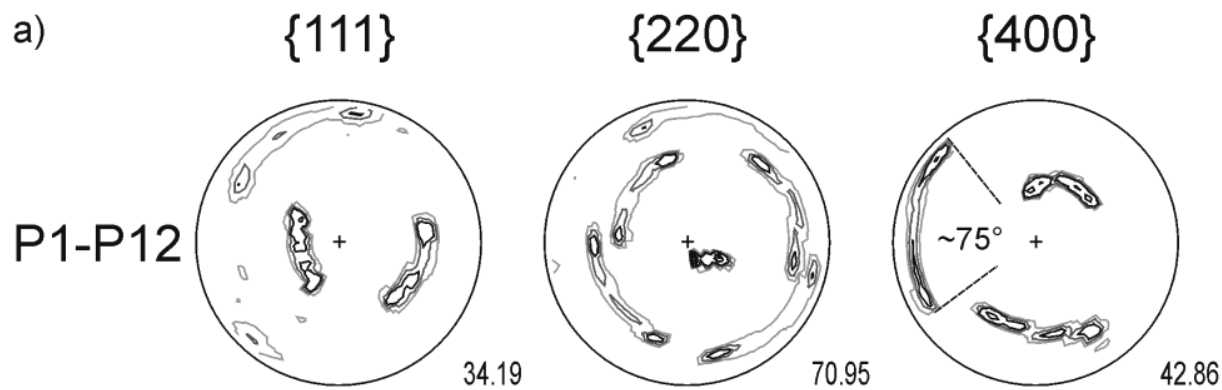

$\{420\}$
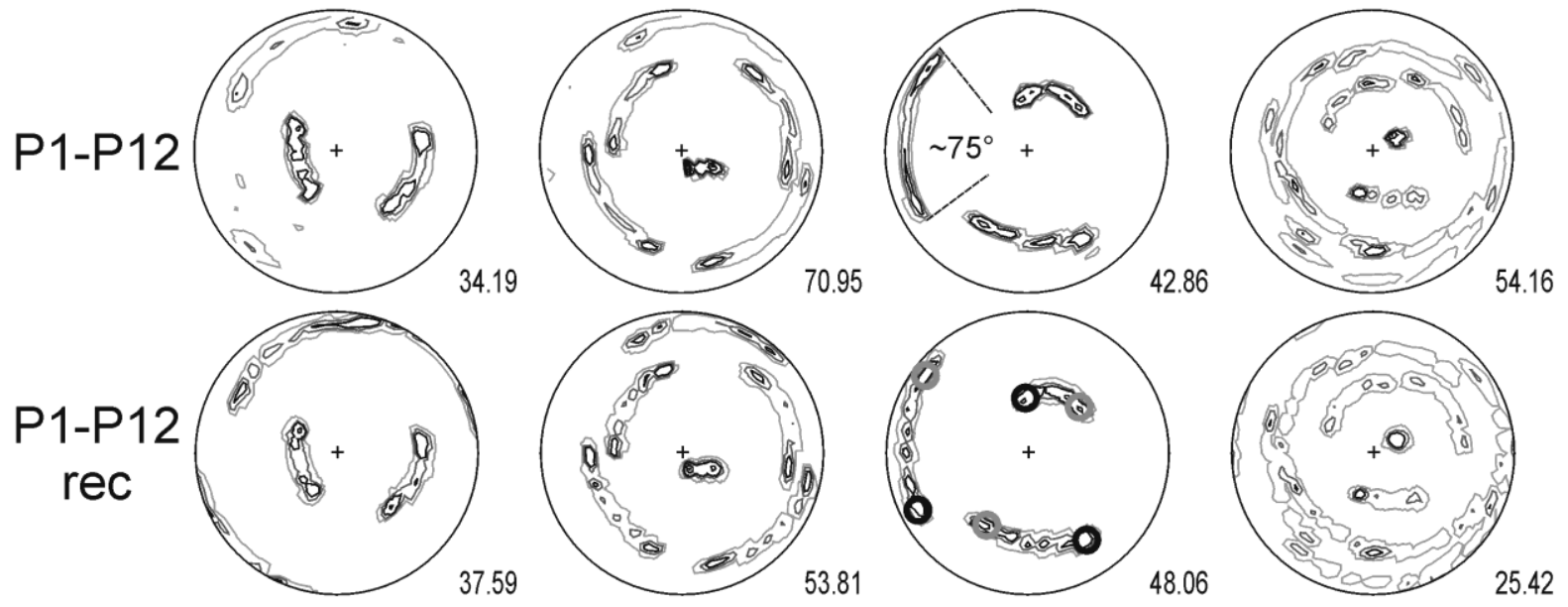

b)

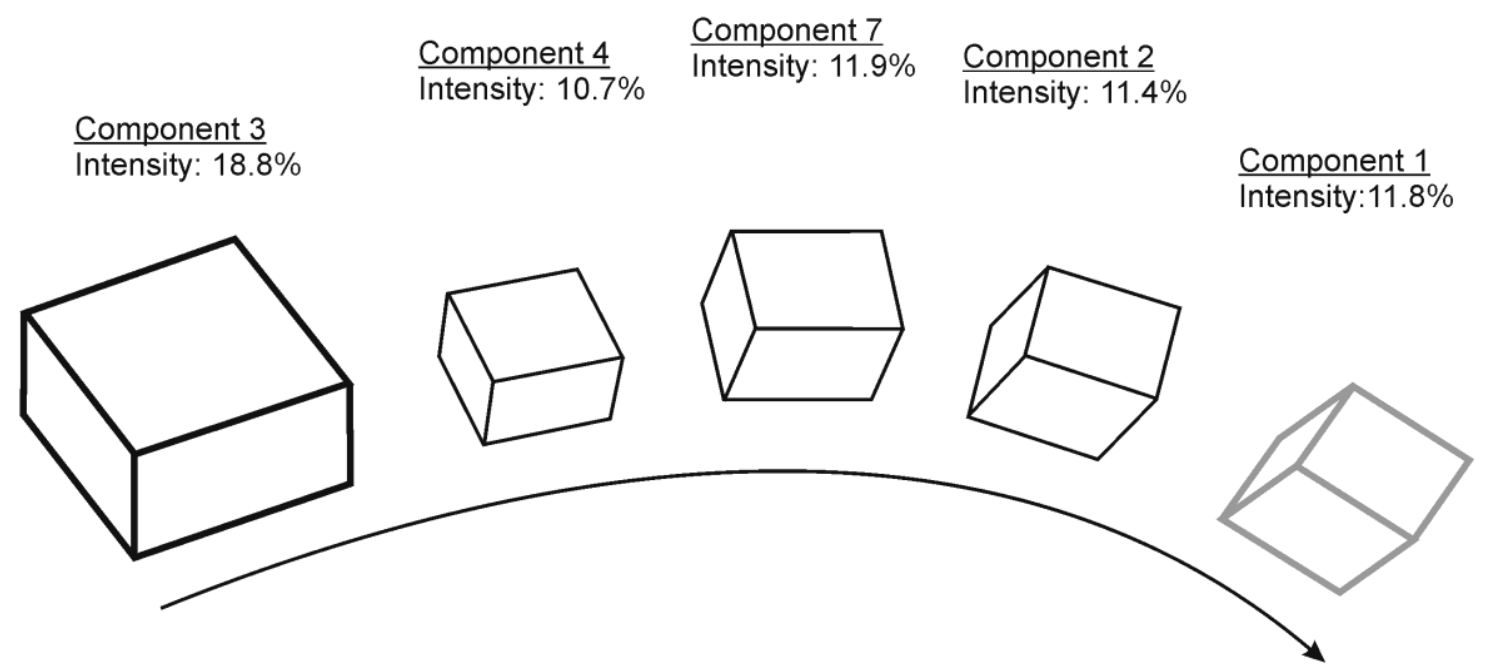

Fig. 4.16: A) Added and recalculated pole figures of the reflections $\{111\},\{220\},\{400\}$, and $\{420\}$ of the measuring points P1-P12 of sample Lt60-12-89 (Fig. 4.12; Teutschenthal). Lowest contour lines (grey) are equal to 1 and 5 m.r.d. From contour line 10 m.r.d. (black), contour interval is 20 m.r.d. Note that the elongation of the maxima along small circles $\left(\sim 75^{\circ}\right)$ approximately reflects the interlimb angle of the Kristallbrocken fold $\left(\sim 85^{\circ}\right.$; Fig. 4.12). B) Orientation and relative intensity of the 5 components with highest intensity $(>10 \%)$ that represent the bulk texture of the folded Kristallbrocken.

\subsubsection{Deformation mechanisms of Kristallbrocken}

The microstructural and textural investigations revealed that the Kristallbrocken show deformational characteristics ranging from brittle to ductile behavior. Furthermore, the local 
X-ray texture measurements document the monocrystalline structure of the Kristallbrocken, as well as the monocrystalline structure of the bent Kristallbrocken. These findings help answering the questions how the Kristallbrocken deform, and what are the reasons for the basically different deformation mechanisms of the Kristallbrocken.

\section{Brittle deformation}

In general, the deformational behavior of the Kristallbrocken appears to resemble that of porphyroclasts in mylonitic rocks. This generally observed strong competence contrast between the Kristallbrocken and the finer-grained halite matrix can be explained by the monocrystallinity as well as the originally large size of the 'single crystal-layers' (see also discussion below). Additionally, the rigidity of the Kristallbrocken is expected to be further enhanced by the relatively large sulphate inclusions forming the internal lamination (Fig. 4.7G). It is a well-known problem in, e.g., foundry industry or metallurgy that cavities (e.g., shrinkage holes, blow holes) or brittle, non-metallic inclusions can cause an embrittlement of steel or other solids (cf., Griffith 1924; Lawn \& Wilshaw 1975). The presence of such inclusions leads to a restricted mobility of dislocations in the material, and, consequently, the Kristallbrocken basically accommodates the stress by brittle rather than by ductile deformation (Figs. 4.6A-F, 4.6K). With progressive deformation, however, a dynamic recrystallisation and/or solution-precipitation process starts at the boundaries of the Kristallbrocken leading to the typical core-mantle-structures (e.g., Fig. 4.1 and further deformed samples in the Hauptsalz from the Asse salt mine) and can probably end in completely recrystallised or dissolved Kristallbrocken.

\section{Ductile deformation}

Although the Kristallbrocken predominantly show brittle behavior, they also show, apart from the already mentioned recrystallisation at the boundaries, a clear ductile behavior by bending or folding (Figs. 4.6J-L, 4.12). These Kristallbrocken reveal substructures but no significant internal dynamic recrystallisation. This observation and the local texture analysis of the folded Kristallbrocken (Fig. 4.12) clearly documents that the crystal lattice as a more or less intact structure is bent. When adding the pole figures of P1-P12, the maxima in the resulting pole figures are elongated along small circles (Fig. 4.16). The maximum elongation at the rim of the pole figure is about $75^{\circ}$ and approximately reflects the interlimb angle of the fold (Fig. 4.12). Two of the added pole figures have a maximum close to the centre; one is the $\{220\}$ and the other the $\{420\}$ pole figure. These maxima only show a weak or no elongation, so the fold/rotation axis is located near the centre of the pole figure, i.e. parallel or near the 
4.1 Structural characteristics of the halite fabric type 'Kristallbrocken' from the Zechstein Basin with regard to its development

corresponding maxima of the $\{220\}$ or $\{420\}$ normal (Fig. 4.16). From these observations, a kind of flexural-shear folding (Fig. 4.17B; compare, e.g., with Twiss \& Moores 1992) can be assumed as the deformation mechanism of the bent or folded Kristallbrocken (Fig. 4.17A). The lattice planes operate as shear planes. Intracrystalline slip on these lattice planes is enabled by dislocations (Fig. 4.17C) and the most probable slip system seems to be $\{110\}<110>$ (Fig. 4.17D). This conclusion is supported by the fact that this slip system shows the lowest critical resolved shear stress in halite at all temperatures (e.g., Carter \& Heard 1970; Skrotzki \& Haasen 1981, Skrotzki et al. 1981). However, the maxima near the centre of the added $\{220\}$ and $\{420\}$ pole figures are slightly distorted, suggesting that the orientation of the rotation axis changes across the fold. Consequently, the fold of sample Lt60-12-89 is probably slightly non-cylindrical or distorted. An additional slip system (compare, e.g., with Leiss \& Barber 1999) cannot be inferred from the pole figure measurements because the elongation of the $\{220\}$ maximum close to the centre of the pole figure is only observed in the summarized pole figures (Fig. 4.16) and not in the pole figures of the single measuring spots (Fig. 4.13).

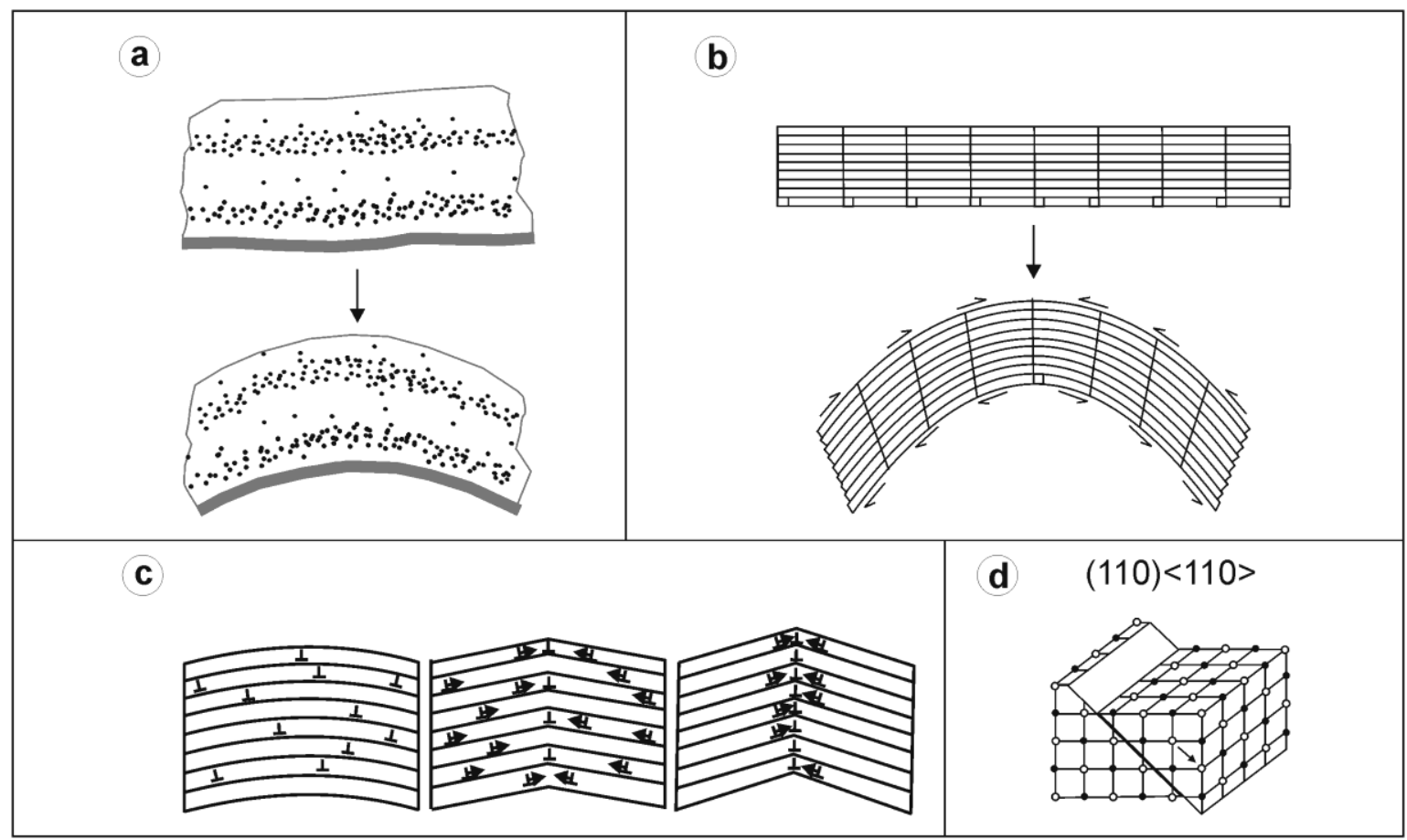

Fig. 4.17: The mechanisms for folding of the Kristallbrocken (A) is supposed to be flexural slip operating on crystallographic planes $(\mathbf{B})$ by dislocation creep (C) (Fig. 4.17B-C from Twiss \& Moores 1992). D) The active slip system as it is deduced from the texture analysis (from Scheffzük 1999).

\section{Rheological specification of the Kristallbrocken}

The observed basic brittle deformational behavior is different from that of granular salt, which is normally only known to be deformed in the ductile regime, i.e. without crack formation 
(e.g., Guillopé \& Poirier 1979; Carter \& Hansen 1983; Carter et al. 1993; Hunsche \& Schulze 1994), even at relatively high stress and low temperature conditions. Depending on the geological and tectonic setting, the strain rates for natural in situ deformation of rock salt range from $10^{-16}$ to $10^{-8} \mathrm{~s}^{-1}$ (e.g., Jackson \& Talbot 1986; Watanabe \& Peach 2002). According to Skrotzki (1984), for the formation of cracks in rock salt, short-term tectonic movements with strain rates higher than $10^{-11} \mathrm{~s}^{-1}$ have to be assumed, or the crack formation develops in weak zones like anhydrite-rich layers. However, due to the monocrystallinity, the large size, and the solid inclusions forming the internal lamination, the Kristallbrocken have clearly stronger rheological properties than fine- to coarse-grained polycrystalline salt, and thus also deform by fracturing.

Additionally, the orientation of the crystal lattice of the Kristallbrocken with respect to the stress field during the deformation plays an important role. As in this case bending or folding is most likely achieved by intracrystalline slip, the orientation of the crystal lattice with respect to the stress field is crucial for activation, because the critical resolved shear stresses (CRSS) are quite different for the different slip systems of rock salt (e.g., Carter \& Heard 1970; Skrotzki \& Haasen 1981; Skrotzki et al. 1981). The X-ray measurements have shown that the lamination of the Kristallbrocken is approximately parallel to the $\{220\}$ plane. The slip system $\{110\}<110>$ with the lowest CRSS for rock salt was already discussed as being responsible for the folding of the Kristallbrocken of this study. At room temperature, other slip systems in halite such as $\{111\}<110>$ and $\{100\}<011>$ have critical resolved shear stresses that are several times higher than required for the activation of the slip system $\{110\}<110>$ (cf. Scheffzük 1999). Consequently, if these shear stresses are not exceeded, or the orientation relative to the stress field is not suitable at all, then stress will be accommodated by brittle fracturing.

For the deformational behavior, the size of the Kristallbrocken also plays a significant role. Although today most Kristallbrocken occur as broken relics, with sizes mainly ranging from 1 to up to $15 \mathrm{~cm}$ and being almost completely surrounded by matrix halite, this study demonstrates that they originally were 'single crystal-layers' of several decimeters in lateral size and an average thickness of at least $2-5 \mathrm{~cm}$ before having been broken apart (e.g., Fig. 4.1).

Another important aspect is the amount of solid inclusions. The folded Kristallbrocken (Fig. 4.12) has relatively few, but large inclusions, whereas the inclusion density of the other Kristallbrocken (Fig. 4.8) is higher, which thus most likely increased the rigidity of the Kristallbrocken and led to brittle fracturing. It is also possible that the bromide content of 
halite has a subordinate influence on the deformational behavior. During the sedimentation of marine salts, bromide is incorporated into the crystal lattice of halite instead of chloride. As the ion radius of bromide $(196 \mathrm{pm})$ is larger than that of chloride $(181 \mathrm{pm})$, the Kristallbrocken with higher bromide contents are potentially harder than those with lower bromide contents and thus more susceptible for brittle deformation. However, the bromide contents of the Kristallbrocken in Teutschenthal are generally relatively low (Küster et al. 2007a), ranging from about 60 to 90 ppm, and there is no significant difference between the bromide contents of the samples examined in this study.

\section{Formation and deformation of the Kristallbrocken layers}

The results of this study do not only clearly indicate that the Kristallbrocken pieces from Teutschenthal formed larger 'single crystal-layers' before deformation (Fig. 4.8; Fig. 4.10), but also imply that the individual Kristallbrocken pieces from other locations with stronger deformation, like for example in the rock salt cube from the Asse salt mine (Fig. 4.1), originally also formed large monocrystalline layers. This allows us to postulate that the Kristallbrocken fabrics from Teutschenthal represent an earlier stage of deformation of the 'single crystal-layers' than the Kristallbrocken fabrics from locations with more intensely deformed rock salt. Finally, the questions arise how and when did such large monocrystalline layers form and when did they deform? Three models can be discussed (Fig. 4.18):

In model A, at first, fine grained halite and sulphate crystals are precipitated and form a polycrystalline halite layer. In a second stage, this layer is subjected to syndiagenetic grain growth, e.g. by grain boundary area reduction (GBAR) or coalescence, that finally leads to the formation of the 'single crystal-layer'. This monocrystalline Kristallbrocken layer is deformed in a third stage due to salt migration-related processes.

In model $\mathrm{B}$, there is also a polycrystalline halite layer at the beginning. In a second stage, this unconsolidated polycrystalline layer is deformed, for example by slump processes, and then subjected to diagenetic grain growth. Although the resulting single crystals look similar to the Kristallbrocken observed in this study, this model seems to be quite unlikely, as for example the grain growth process is not expected to form a single crystal in a 'bent' way and there would be no fracture between the Kristallbrocken pieces that look like having been moved passively against each other.

In model C, the Kristallbrocken layer would be a primarily grown, very large single crystal that deforms in a second stage during salt migration-related process. This model might be a possible alternative to model $\mathrm{A}$, but it is quite difficult to explain the primary growth of 
such large monocrystalline layers, especially because ancient or modern analogues are not known.

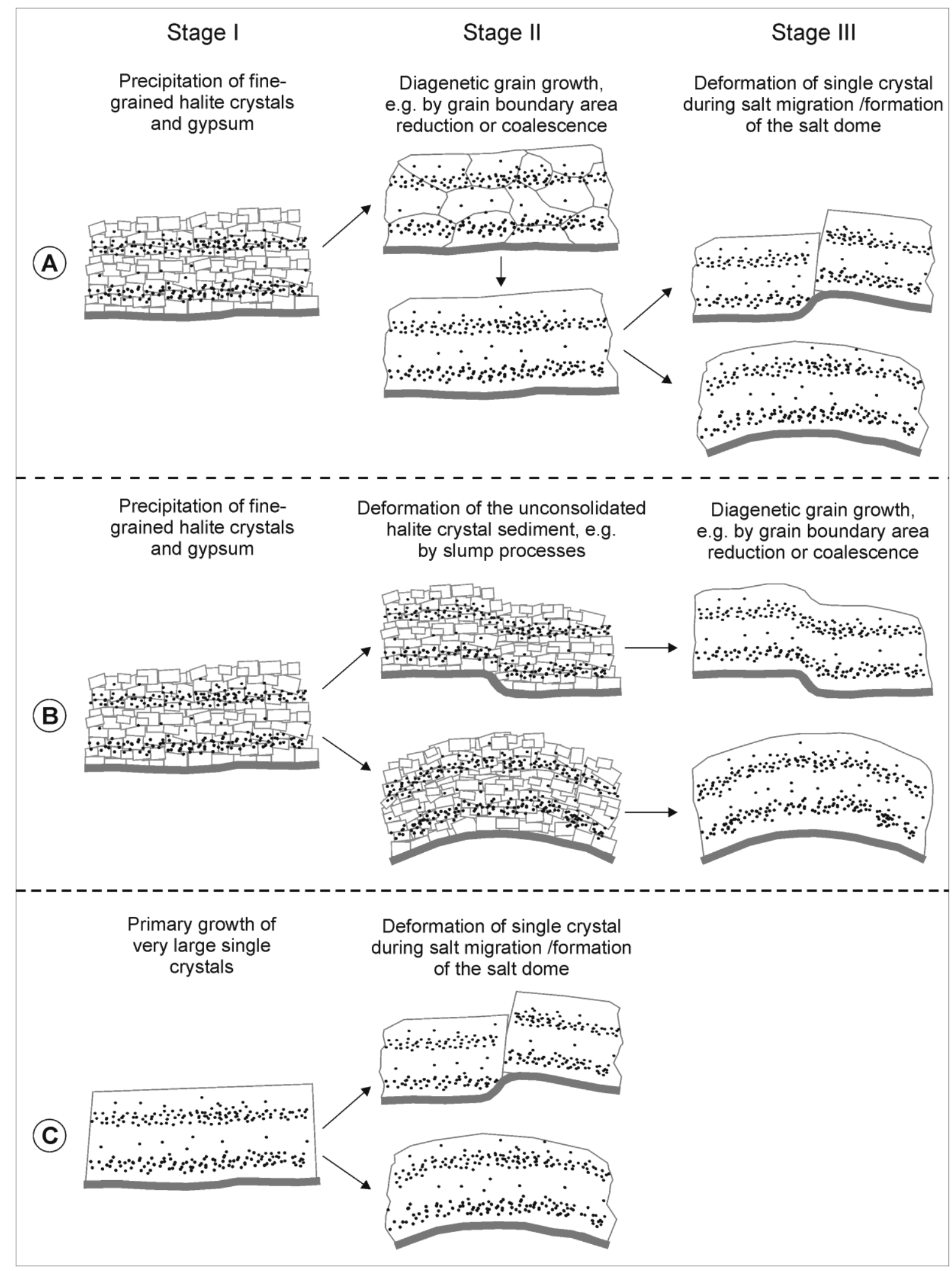

Fig. 4.18: Sketch with 3 models for the formation and development of the Kristallbrocken. Detailed explanations are given in the text. 
For us, model A seems to be the most probable model as it well explains the microstructures observed in the rock salt of Teutschenthal. Furthermore, it is in line with the supposition of Simon (1972), who also took 'breaking apart of formerly continuous crystal layers' into consideration. Most of the Kristallbrocken have been deformed by brittle deformation for the reasons discussed above, but in some special cases, bending of the single crystal was also possible, which has been evidenced by the results of this study. The Kristallbrocken relics are also subjected to dynamic recrystallisation, which usually starts at the boundaries of this halite type resulting in an oval-shaped appearance, but can also take place in the highly stressed bending area of bent or folded Kristallbrocken. In the more intensely deformed Stassfurt rock salt of, e.g., Morsleben or Gorleben, the Kristallbrocken often occur only as relics or have been already completely recrystallised.

\subsubsection{Conclusions}

In this study, the deformation characteristics as well as the local crystallographic preferred orientations of the Kristallbrocken were investigated. The most distinguishing feature of the Kristallbrocken in comparison to the halite matrix is that they show both ductile and brittle deformational behavior. With the local X-ray texture measurements, it could be clearly evidenced that the Kristallbrocken are single crystals and that separated pieces of the Kristallbrocken formerly formed one single monocrystalline halite layer. Furthermore, the results demonstrate that the presented X-ray texture goniometer configuration is suitable to analyze such monocrystalline structures in a quick and efficient way.

The monocrystallinity of the Kristallbrocken and their formerly large size explain the clearly stronger rheological properties of this halite type compared to the surrounding fine- to coarse-grained polycrystalline rock salt. In addition, the rigidity of this halite type is further enhanced by the partially high solid inclusion content. The bulk texture of the folded Kristallbrocken clearly illustrates that the monocrystalline structure was bent or folded as a whole. The deformation mechanism is assumed to be a kind of flexural-shear folding, with the lattice planes of the single crystal operating as shear planes. The most probable slip system seems to be $\{110\}<110\rangle$, which shows the lowest critical resolved shear stress in halite at all temperatures. To enable such a bending process, we suppose that the crystal lattice of the Kristallbrocken must have a certain orientation in respect to the stress field, and the solid inclusion content is relatively low.

From the results of this study, it can be inferred that the Kristallbrocken fabrics from Teutschenthal represent an earlier stage of deformation of the 'single crystal-layers' than the Kristallbrocken fabrics from locations with more intensely deformed Stassfurt rock salt. For 
the formation and development of the Kristallbrocken, model A (Fig. 4.18) seems for us to be the model that explains the observed microstructures in the best way. 


\subsection{Compositional and microstructural characterization of solid inclusions in the laminated halite type 'Kristallbrocken' with regard to its formation in the Central European Zechstein Basin}

Yvonne Küster, Michael Schramm, Bernd Leiss, Zeitschrift der Deutschen Geologischen Gesellschaft 162/3 (2011), 277-294.

\subsubsection{Abstract}

Previous investigations on Kristallbrocken, a laminated halite type that is characteristic for the Stassfurt Formation (Z2) rock salt, showed that they are relics of laminated halite single crystals.

Microscopic investigations showed that the internal lamination of the Kristallbrocken consists of several types of sulfate inclusions (anhydrite, polyhalite). Especially characteristic are anhydrite aggregates with surrounding brine. Strontium analyses indicate that these anhydrites most likely had a gypsum precursor. Based on the volumes relation between anhydrite aggregates and surrounding brine, it can be concluded that these anhydrites can be neither the daughter crystals of a fluid inclusion nor the result of accidental trapping during halite crystal growth. A plausible explanation for the formation of these anhydrite aggregates is that initially gypsum crystals were incorporated in halite, which later converted into anhydrite. The solid volume reduction as well as the release of water in consequence of a complete gypsum-anhydrite conversion explains the present appearance of the characteristic solid inclusions within the Kristallbrocken halite type.

The original size of the monocrystalline beds, their high amount of relatively large solid inclusions as well as the characteristic sedimentary features makes it unlikely that these laminated single crystals were grown directly from a solution. More probable is that an originally fine-grained, laminated halite sediment was converted into monocrystalline Kristallbrocken in a post-sedimentary grain growth process.

\subsubsection{Introduction}

Sedimentary fabrics in rock salt deposits are of major interest for reconstructing depositional processes and environments (e.g., Wardlaw \& Schwerdtner 1966; Müller \& Irion 1969; Arthurton 1973; Schreiber et al. 1976; Gornitz \& Schreiber 1981; Czapowski 1987; Kendall 1992; Benison \& Goldstein 2000; Schreiber \& El Tabakh 2000; Pape et al. 2002). For instance, numerous studies have investigated halite types like chevron and hopper crystals as 
an indicator for primary growth under shallow subaqueous conditions (e.g., Gottesmann 1963; Wardlaw \& Schwerdtner 1966; Shearman 1970; Arthurton 1973; Shearman 1978; Hardie et al. 1983; Pape et al. 2002). On the other hand, polygonal mosaic textures or so-called "foam textures", with the halite grains being fluid and solid inclusion-poor and the grain boundaries meeting at triple junctions with angles approaching $120^{\circ}$, have been described as typical secondary features and indicative for recrystallisation (e.g., Hardie et al. 1983; Roedder 1984; Lowenstein \& Hardie 1985).

The halite type Kristallbrocken is characteristic for the Stassfurt Formation (Z2) rock salt of the German Zechstein Basin (e.g., Richter-Bernburg 1955b; Lotze 1957; Simon \& Haltenhof 1970; Simon 1972) and in the Oldest and Older Halite (Z1 and Z2) of the Polish Zechstein Basin (Czapowski 1986, 1987, Czapowski et al. 1990, 1993), where it is described as "C-halite" type. In a recent study investigating the microstructures of this halite type was demonstrated that the Kristallbrocken are definitely single crystals and that they can be regarded as relics of formerly larger 'single crystal-layers' of up to several $\mathrm{dm}^{2}$ in size (Küster et al. 2010). A characteristic feature of this halite type is the internal lamination (Fig. 4.19B), which looks like sedimentary layers. However, if each Kristallbrocken is a single crystal, then the questions arise how the 'internal lamination' could be formed, for example if it represents a kind of growth zoning, as well as how this halite type itself formed. Do these halite crystals represent giant, primarily grown crystals or were they originally precipitated as numerous small halite crystals that were later transformed into large "single crystal"-layers? The formation of this monocrystalline halite type has been discussed controversial in the literature (Simon 1972; Czapowski 1986) and thus has not been explained conclusively yet. According to Simon (1972), the Kristallbrocken-layers (like in Fig. 4.19) were originally uniform and continuous halite layers that formed by accretive crystallization of normal-grained rock salt, a recrystallisation process that is comparable with the formation of sparite from micrite in carbonate rocks. However, it is not clear if Simon (1972) referred to a secondary process, and if he regarded the fragments of Kristallbrocken as single crystals or as coarse-grained, polycrystalline halite beds. In contrast, although Czapowski (1986) described the "C-halite" type as large, clear halite crystals without distinguishable crystal walls (= grain boundaries), he regarded this halite type as coarse-crystalline halite layers.

The aim of the present study was to contribute to the understanding of the formation of Kristallbrocken as well as the internal lamination. For this purpose, this halite type was investigated in detail by optical microscopy and scanning electron microscopy (SEM), based on samples from different locations of the Zechstein Basin. 

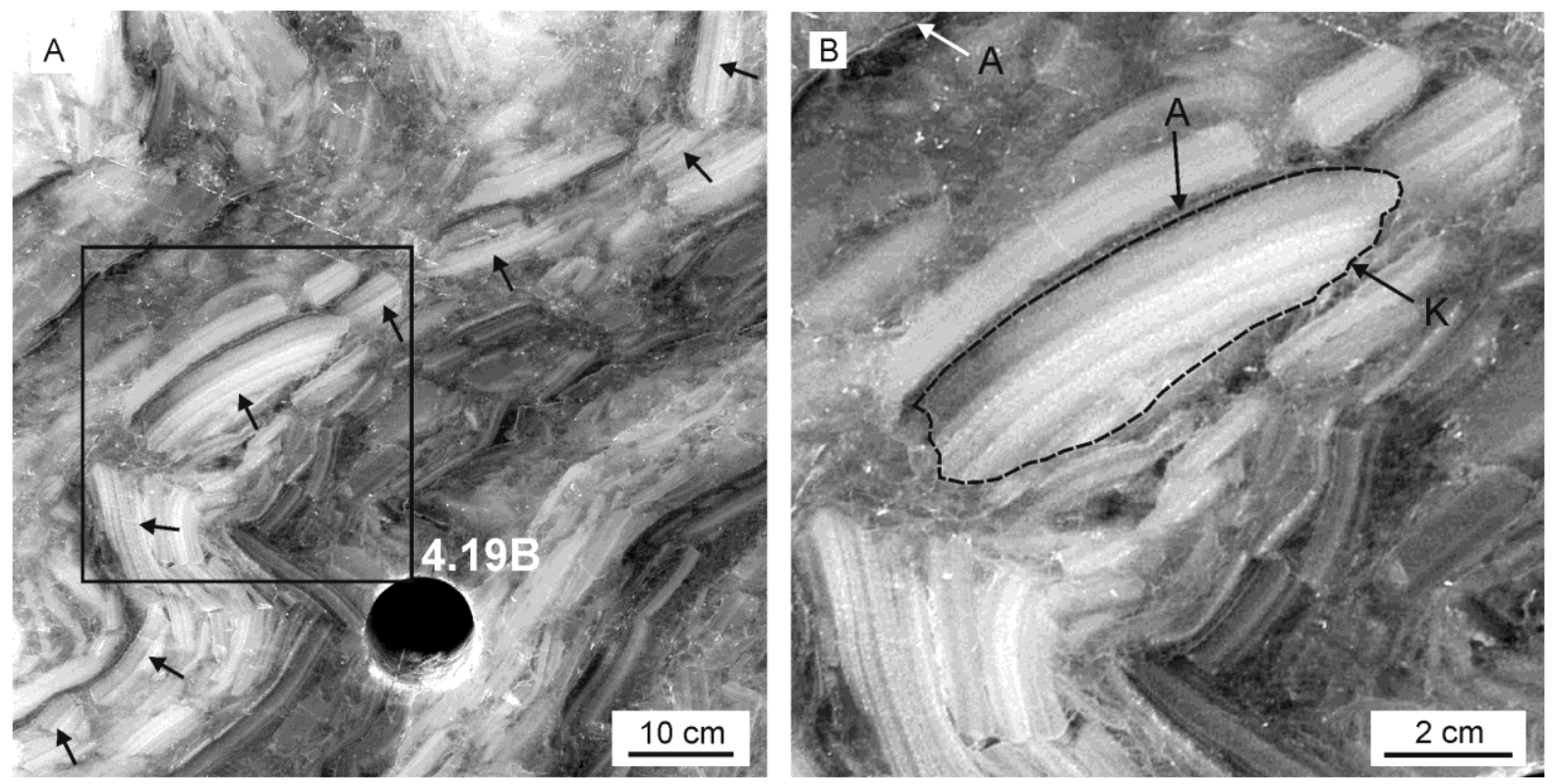

Fig. 4.19: A) Photograph of a Stassfurt rock salt block (Asse salt mine). The individual Kristallbrocken (black arrows) are arranged in slightly folded layers running from the lower left to the upper right corner of the photograph (adapted from Küster et al. 2010). B) Scaled-up section of Fig. 4.19A. The Kristallbrocken in the central part (outlined by dashed line) has a thickness of $\sim 2.5 \mathrm{~cm}$ and a length of $\sim 9 \mathrm{~cm}$, and is overlain by a thin anhydrite layer (A). Note the characteristic lamination within this Kristallbrocken.

\subsubsection{Geological background}

The Zechstein Basin extended from Eastern England and the Southern North Sea in the west to Poland and Lithuania in the east (Fig. 4.20). During the Late Permian (Zechstein), the basin was repeatedly transgressed by seawater coming from the Boreal Ocean. The cyclicity of these marine transgressions was presumably caused by glacio-eustatic fluctuations in sea level as well as tectonic processes (e.g., Smith 1979; Ziegler 1981, 1990; Taylor 1998). The high evaporation rates due to the arid climate conditions during Zechstein, combined with cyclic restriction of seawater influx into the basins, resulted in the deposition of the Zechstein carbonates and evaporites.

In Germany, the Zechstein group comprises 4 main evaporation cycles referred to as the Werra (Z1), Stassfurt (Z2), Leine (Z3), and Aller (Z4) Formations (Richter-Bernburg 1955a) and 3 rudimentary and only regionally occurring cycles referred to as the Ohre (Z5), Friesland (Z6), and Fulda (Z7) Formations (Käding 1978, 2000) (Fig. 4.21). Each cycle contains characteristic features indicative of a progressive evaporation phase. Generally, such an evaporation cycle starts with clastic sediments like mudstones and is followed by carbonates, anhydrites, rock salt, and potash salts. This succession can be observed in the cycles Z1-Z5, whereas the cycles Z6 and Z7 do not contain carbonates and potash salts. Today, Zechstein 
sediments occur in both stratiform, apparently undisturbed settings, as well as in diapiric structures formed by salt tectonics (e.g., Trusheim 1960; Jaritz 1973; Kockel 1998). In Germany, the rock salt of the Stassfurt Formation (Z2) is most widespread, with an estimated original thickness of $500 \mathrm{~m}$ and more (cf. Zharkov 1984). The present thickness, however, is highly variable due to different post-depositional processes like diapirism, leaching, or erosion.
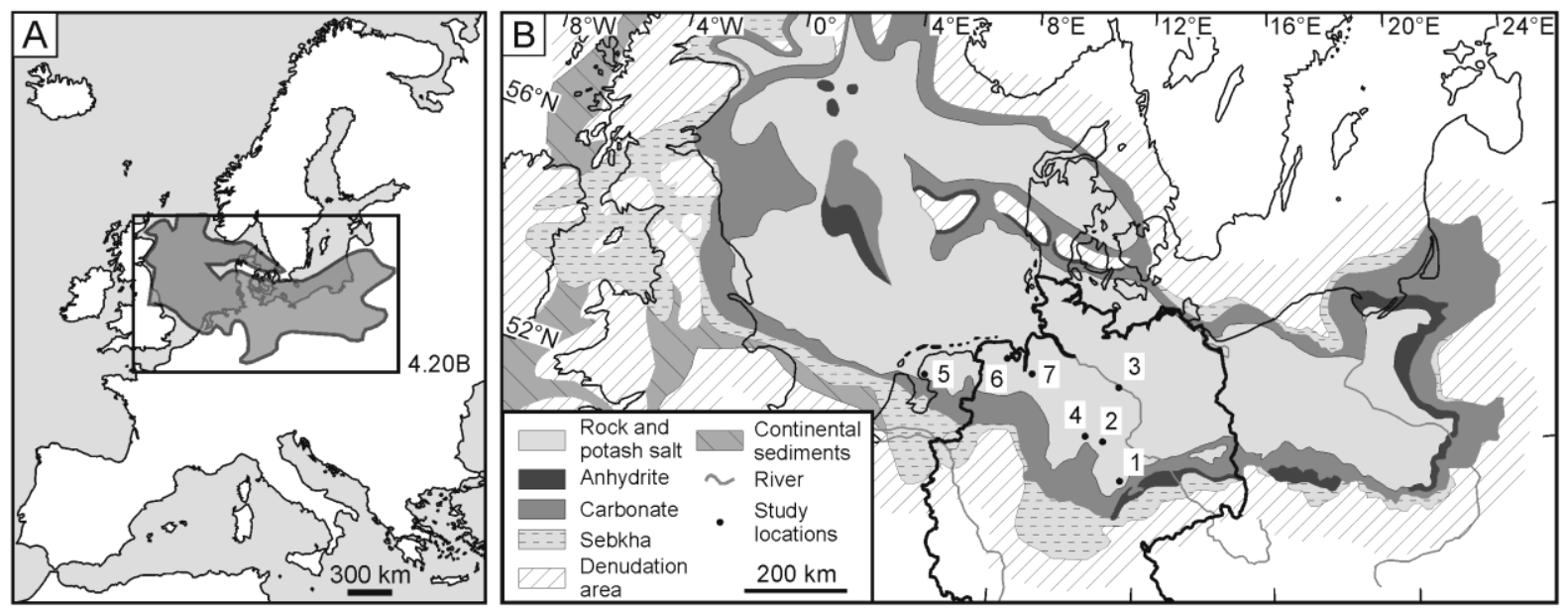

Fig. 4.20: A) Map of Europe with an outline of the Late Permian Zechstein Basin (after Taylor 1998). B) Sketch map of the Zechstein Basin with the paleogeographic situation during the deposition of the Stassfurt Formation (Z2) (after Best 1989) showing the position of the investigated locations (1 Teutschenthal, 2 Morsleben, 3 Gorleben, 4 Asse, 5 Friesland (province of the northern Netherlands), 6 Etzel, 7 Lesum). The border of Germany is outlined.

\subsubsection{Material and methods}

\subsubsection{Study material}

The laminated halite type Kristallbrocken belongs to the rock salt of the Stassfurt Formation (Z2), which is the second main depositional cycle of the German Zechstein group (Fig. 4.21). Samples were obtained from drilling cores of six salt sites situated in Germany (Teutschenthal, Morsleben, Gorleben, Asse, Etzel, Lesum; Fig. 4.20B) and one situated in the northern Netherlands (province Friesland; Fig. 4.20B). In Germany, the Stassfurt Formation rock salt can be further subdivided into three stratigraphic units. These are (from base to top) Basissalz, Hauptsalz, and Hangendsalz (German: "Basissalz" = basal salt; "Hauptsalz" = main salt; "Hangendsalz" = upper salt) (Fig. 4.21). The investigated halite type has primarily been observed in the Hauptsalz and partially in the Basissalz (Teutschenthal, Morsleben). In the drilling cores from Teutschenthal, Morsleben, and Gorleben, several samples of Kristallbrocken were investigated throughout the Hauptsalz unit, whereas of the other location only one sample of this halite type was examined. The studied salt deposits of Teutschenthal and the Netherlands are stratiform salt structures; the samples of Teutschenthal 

halite type 'Kristallbrocken' with regard to its formation in the Central European Zechstein Basin

were taken from various depths between 500 and $1000 \mathrm{~m}$ below sea level, and the sample of the Netherlands comes from a depth of about $2700 \mathrm{~m}$ below sea level. The other salt deposits belong to diapiric salt structures, in which the evaporites have been intensely folded. The studied samples are from depths of $\sim 400 \mathrm{~m}$ (Morsleben), $\sim 1000 \mathrm{~m}$ (Gorleben), $\sim 600 \mathrm{~m}$ (Asse), $\sim 1340 \mathrm{~m}$ (Etzel), and $\sim 1835 \mathrm{~m}$ (Lesum) below sea level.

\begin{tabular}{|c|c|c|c|c|c|c|c|c|}
\hline \multicolumn{4}{|c|}{ Chronostratigraphy (International) } & \multicolumn{3}{|c|}{ Lithostratigraphy (Germany) } & \multirow{2}{*}{\multicolumn{2}{|c|}{$\begin{array}{c}\text { Lithostratigraphy } \\
\text { Lithology }\end{array}$}} \\
\hline Period & & och & Stage & Group & Formation & Symbol & & \\
\hline \multirow{4}{*}{ 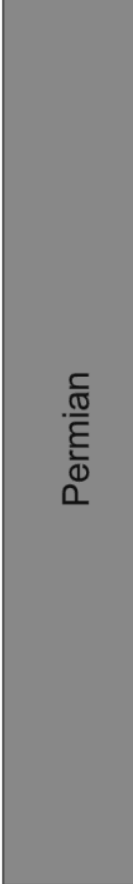 } & $\stackrel{\oplus}{\overparen{\Xi}}$ & $\begin{array}{l}\frac{c}{0} \\
\frac{\overline{0}}{0} \\
\frac{\overline{0}}{0}\end{array}$ & Changhsingian & Zechstein & $\begin{array}{c}\text { Fulda } \\
\text { Friesland } \\
\text { Ohre } \\
\text { Aller } \\
\text { Leine }\end{array}$ & $\begin{array}{l}\mathrm{Z7} \\
\mathrm{Z6} \\
\mathrm{Z} 5 \\
\mathrm{Z} 4 \\
\mathrm{Z3}\end{array}$ & \begin{tabular}{|c|} 
claystone \\
anhydrite \\
potash salts \\
rock salt \\
carbonate \\
\end{tabular} & $\begin{array}{l}\text { Hangendsalz } \\
\text { Hauptsalz } \\
\text { Basissalz }\end{array}$ \\
\hline & & & Wuchiapingian & & Stassfurt & $\begin{array}{l}\mathrm{Z} 2 \\
71\end{array}$ & $\begin{array}{l}\text { anhydrite } \\
\text { clavstone }\end{array}$ & \\
\hline & $\frac{\frac{0}{0}}{\frac{0}{0}}$ & $\begin{array}{l}\frac{c}{\frac{\pi}{0}} \\
\frac{0}{3} \\
\frac{\pi}{0} \\
\frac{\pi}{0} \\
\frac{\pi}{J} \\
0\end{array}$ & $\begin{array}{l}\text { Capitanian } \\
\text { Wordian } \\
\text { Roadian }\end{array}$ & & & & & \\
\hline & $\begin{array}{l}\text { 추 } \\
\text { एٓ }\end{array}$ & 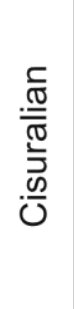 & $\begin{array}{l}\text { Kungurian } \\
\text { Artinskian } \\
\text { Sakmarian } \\
\text { Asselian }\end{array}$ & Rotliegend & & & & \\
\hline
\end{tabular}

Fig. 4.21: Stratigraphic table of the Zechstein group in Germany (according to Richter-Bernburg 1955a and Käding 1978, 2000).

\subsubsection{Methods}

For a macroscopical description of the studied halite type, $1 \mathrm{~cm}$ thick drilling core $(\varnothing 10 \mathrm{~cm})$ slabs cut parallel to the core axis were used. After grinding and polishing, the surface of these slabs was etched with water in order to visualize the grain boundaries. In addition, thick sections $(50 \mu \mathrm{m}, 100 \mu \mathrm{m})$ were prepared from the Kristallbrocken samples, which were studied by transmitted light using a Wild M3 stereomicroscope. For a more detailed examination, the inclusions within the studied halite type were investigated by scanning electron microscopy (SEM) using a FEI Quanta 600 FEG ESEM. For this purpose, fracture surfaces were primarily used, because the internal structure and the composition of the inclusions could be studied very well, whereas in polished samples the surface quality is impaired by polishing marks, and the inclusions opened by the grinding process are partially 
filled with grinding material. To prevent absorption of moisture by the halite, the samples were carefully split immediately before the SEM analysis. Otherwise, the halite crystal surfaces would be slightly etched by moisture, which results in numerous minute halite precipitates and impairs the quality of the SEM images. All samples were imaged in low vacuum mode. Qualitative element analysis was carried out by energy dispersive X-ray analysis (EDX) attached to the SEM.

The thick sections were also used for strontium content analyses of the anhydrite inclusions, measured via the Cameca SX100 electron microprobe using natural standards (celestine and anhydrite). The measurements were performed at an accelerating voltage of $15 \mathrm{kV}$ and a beam current of $20 \mathrm{nA}$. The detection limit for strontium was $163 \mathrm{ppm}$.

\subsubsection{Results}

\subsubsection{Description of the Hauptsalz}

In stratiform salt deposits like Teutschenthal, the Hauptsalz is even bedded and consists of differently developed rock salt horizons as well as regularly interbedded anhydrite layers of several millimeters up to $2 \mathrm{~cm}$ thickness (Figs. 4.22A, 4.22B). Rock salt horizons are 1-15 cm thick, partially up to $20 \mathrm{~cm}$ consisting of matrix halite and Kristallbrocken. The grain size of the matrix halite ranges from 0.2 to $1 \mathrm{~cm}$; the monocrystalline Kristallbrocken halite is several centimeters thick and up to $10 \mathrm{~cm}$ in visible lateral extension (observation limited by the drilling core diameter (Fig. 4.22A). Although the Teutschenthal deposit is characterized by largely undisturbed evaporite sequences, the Hauptsalz shows a set of microstructural features that suggest deformation-related processes (Küster et al. 2010). For example, the Kristallbrocken layers are mostly broken, and the relics have been dragged apart, rotated away from each other, or stacked (e.g., Figs. 4.22B-D). The matrix halite is largely recrystallized (Küster et al. 2009, 2010).

In more intensely deformed diapiric salt structures, such as Morsleben and Gorleben, the Hauptsalz is more homogeneous than in Teutschenthal insofar as the original sedimentary fabric has largely been destroyed by the deformation processes during diapirism. The Kristallbrocken halite fragments are embedded in the recrystallized matrix halite and occur more or less isolated from each other, depending on the intensity of deformation (Figs. 4.22E, 4.22F). The shape of the Kristallbrocken is generally rectangular, but can also be oval-shaped (Bornemann et al. 2000; Pape et al. 2002; Fig. 4.22E), with the latter presumably resulting from recrystallisation and/or dissolution processes. Nevertheless, the characteristic lamination 
4.2 Compositional and microstructural characterization of solid inclusions in the laminated halite type 'Kristallbrocken' with regard to its formation in the Central European Zechstein Basin

within these locally preserved Kristallbrocken fragments indicates that they represent the relics of the broken, formerly larger Kristallbrocken layers observed in Teutschenthal.
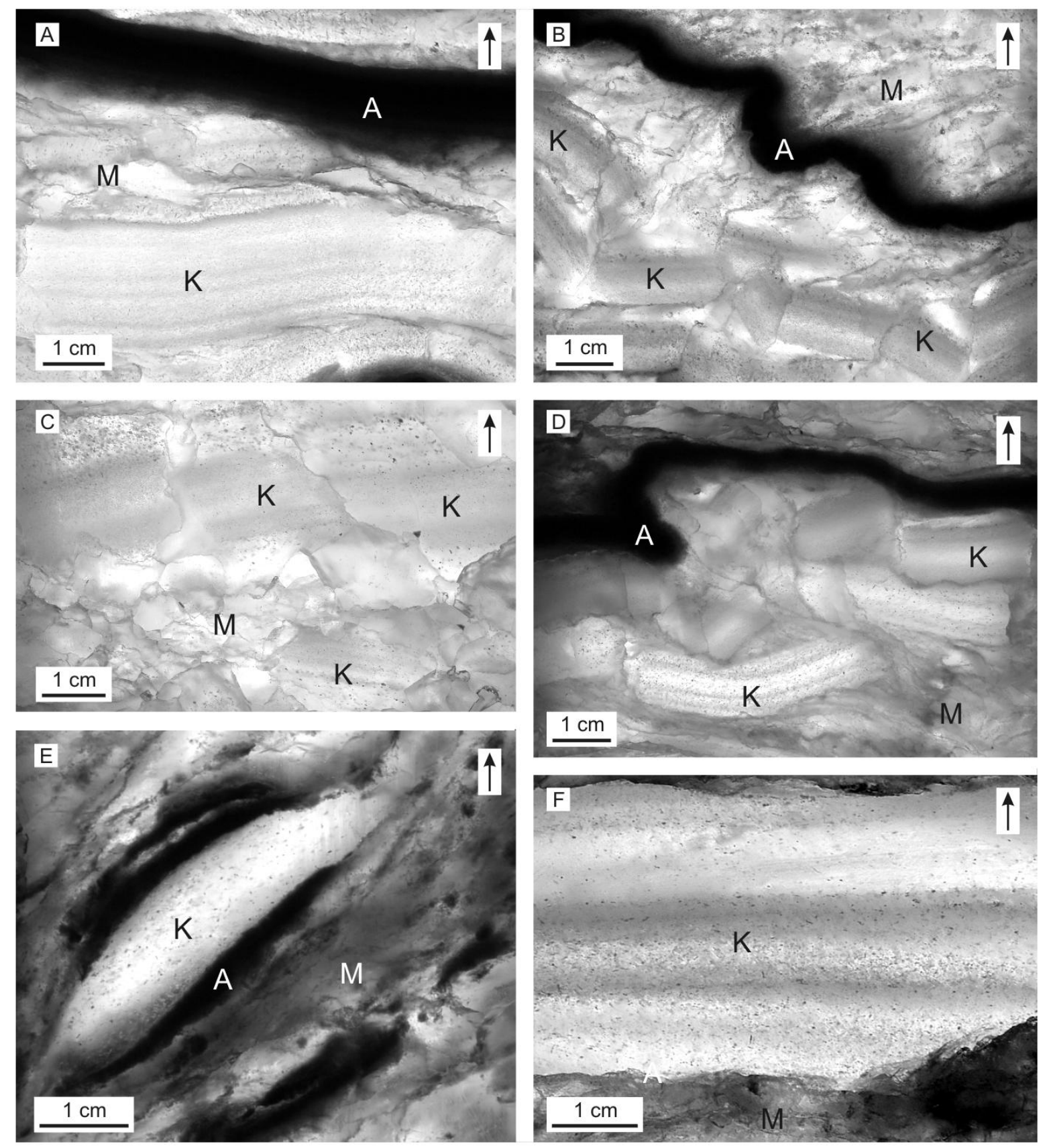

Fig. 4.22: A-D) Drilling core slab photographs of a Hauptsalz sample of the stratiform salt deposit Teutschenthal. Rock salt zones consist of the monocrystalline Kristallbrocken (K) halite type and middle- to coarse-grained matrix halite (M) and alternate with anhydrite layers (A). B-D) Broken Kristallbrocken layers, with the relics having been dragged apart, stacked, or rotated away from each other. In Fig. 4.22C, the size of the solid inclusions within the Kristallbrocken fragments increases from bottom to top. E-F) Drilling core slab photographs of Hauptsalz samples from the more intensely deformed domal salts of Morsleben $(\mathbf{E})$ and Gorleben $(\mathbf{F})$. The original sedimentary fabric, i.e. the rhythmic bedding of rock salt zones and anhydrite layers, is largely destroyed. The Kristallbrocken (K) are embedded in the halite matrix (M), and anhydrite occurs in form of layer fragments (A) or finely dispersed in the matrix halite. Arrow in white box indicates stratigraphic up direction. 
In a previous study, the bromide distribution of the Hauptsalz was investigated in three salt deposits (Küster et al. 2009). In both the bedded (Teutschenthal) and the more intensely deformed domal salts (Morsleben, Gorleben), the characteristic trend of the bromide profile was generally preserved. This could be observed for both the Kristallbrocken and the matrix halite demonstrating that both halite types are from the same environmental setting. Furthermore, results of a preliminary study showed that, within the Kristallbrocken, the bromide content of the laminae increases upward, reflecting progressive evaporation and precipitation (Schlechter 2004). Consequently, this halite type can be regarded as the quasiprimary component of the Hauptsalz, making an investigation of Kristallbrocken samples from different tectonic settings plausible.

\subsubsection{Petrography of the halite type Kristallbrocken}

A characteristic feature of the Kristallbrocken is the internal lamination (Figs. 4.19B, 4.22A$\mathrm{D}, 4.22 \mathrm{~F}$ ) that is defined by variations in the content of fine crystals of included sulfate minerals (e.g., Simon 1972; Czapowski 1986), i.e. zones with just a few solid inclusions that alternate with zones containing many solid inclusions. In some samples, the amount and/or size of solid inclusions increases or decreases gradually from bottom to top (Fig. 4.22C). The lamination can be variably developed, depending on the size and the amount of inclusions. In undeformed parts of the rock salt sequences, these laminae are parallel to the bedding indicating that they reflect the former depositional surface.

Investigations of the thick sections $(100 \mu \mathrm{m})$ via stereomicroscope revealed different types of solid inclusions. On the one hand, individual anhydrite crystals are included in the Kristallbrocken (Figs. 4.23A, 4.23C; denoted by the black arrow). On the other hand, there are circular- to irregular-shaped inclusions (Figs. 4.23B, 4.23C; denoted by the white arrow) that are filled with numerous sulfate crystals, notably visible by their birefringence (Figs. 4.23C, 4.23D). All examples of Kristallbrocken are characterized by this kind of inclusion that occurs in different amounts and sizes. However, the inclusions cannot be resolved sufficiently, neither in thick sections where they look almost opaque (Figs. 4.23B, 4.23C) nor in thin sections $(30 \mu \mathrm{m})$ where they are partly destroyed during preparation due to their large size (Figs. 4.23E, 4.23F). For that reason, the inclusions were additionally investigated by SEM.

Fluid and/or gaseous inclusions within the studied halite type are only present in very rare cases and small sizes. The quantity of such inclusions was too low for systematic investigations. 

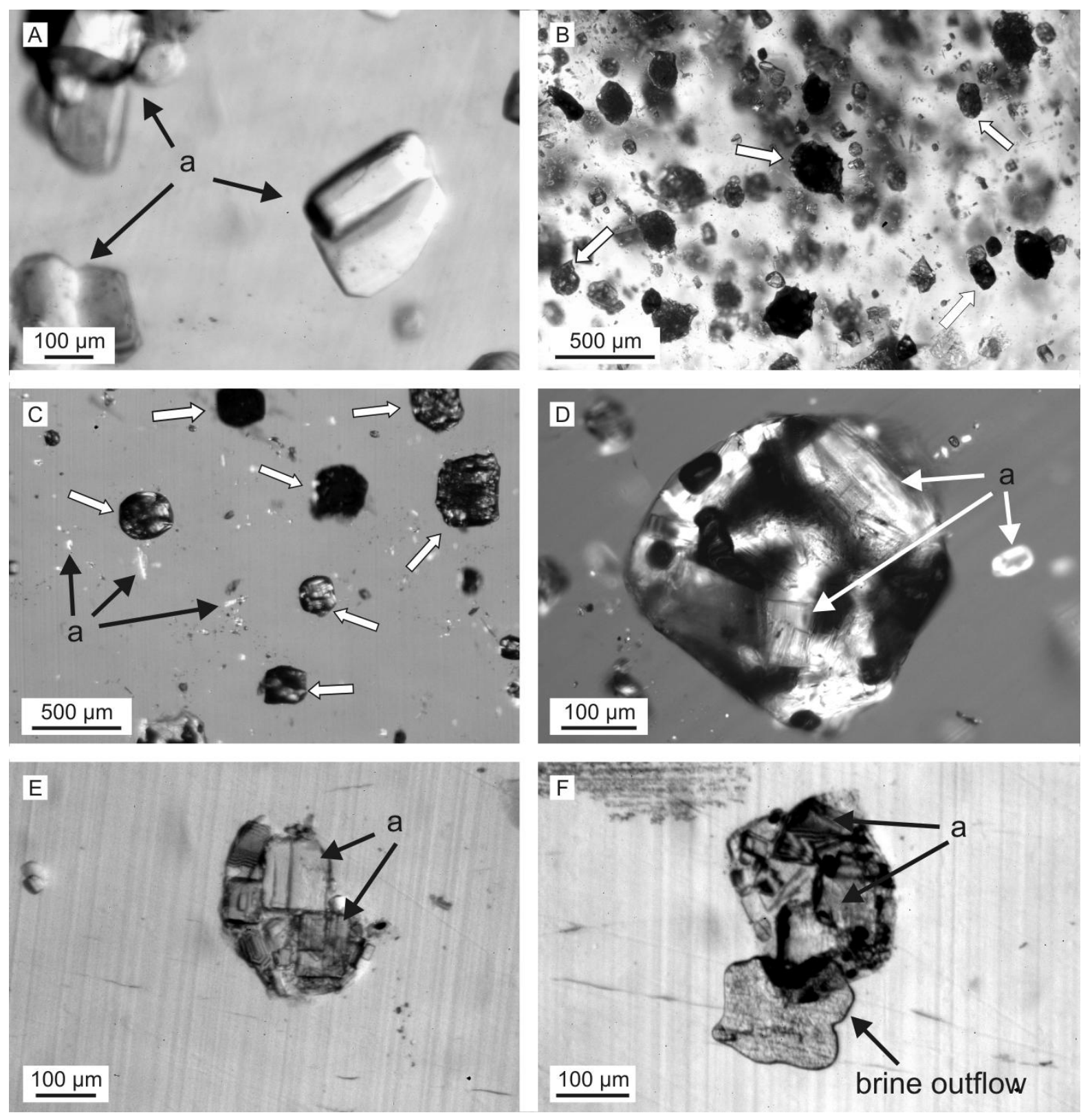

Fig. 4.23: Thick and thin section photomicrographs of the Kristallbrocken from Teutschenthal showing the different inclusion types of the internal lamination. A) Photomicrograph (partly crossed polarizers), showing hypidiomorphic anhydrite crystals (a). B) Thick section photograph with the characteristic circular-shaped inclusions (white arrows). C) Photomicrograph (partly crossed polarizers) showing small anhydrite crystals (a) as well as some relatively large, circular-shaped inclusions (white arrows) filled with anhydrite crystals. Anhydrite can be recognized due to the birefringence that looks white in grayscale color mode. D) Photomicrograph (partly crossed polarizers) with a closer look at such inclusion filled with anhydrite crystals (white) and brine (black). E-F) Thin section photomicrographs showing the characteristic inclusions filled with variously sized, hypidiomorphic to idiomorphic anhydrite crystals (a). The inclusions were opened during the thin section preparation, with the included brine having been completely $(\mathbf{E})$ or partly $(\mathbf{F})$ removed. Note the brine outflow at the lower left edge of the inclusion in Fig. 4.23F. 

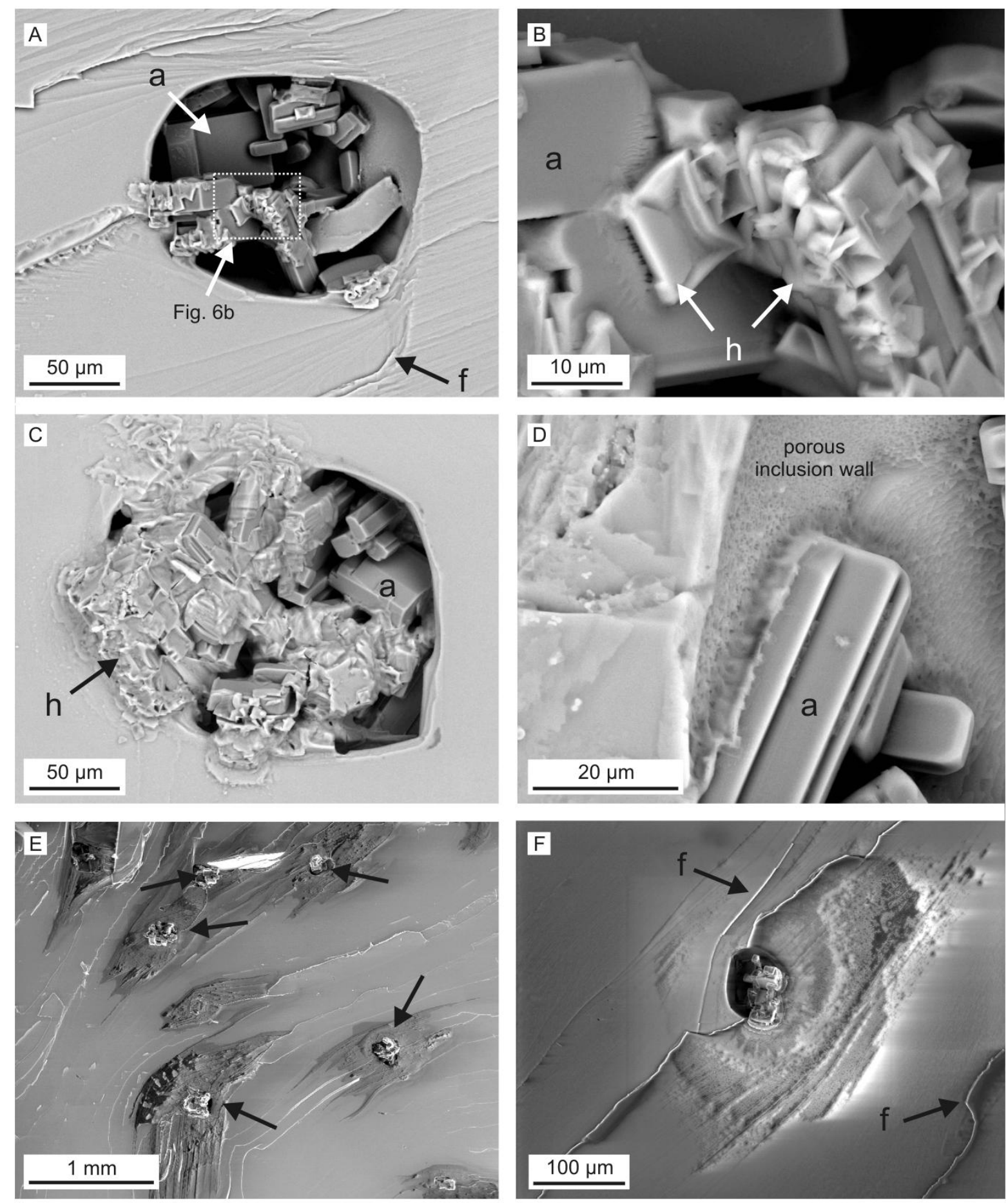

\subsubsection{SEM analyses of the solid inclusions}

Teutschenthal, Morsleben, and Gorleben

In Teutschenthal and Morsleben, the solid inclusions forming the internal lamination are mainly anhydrite aggregates (Figs. 4.24A-D, 4.24G). The inclusions are circular or irregular in shape, with diameters generally ranging between $\sim 100$ and $\sim 300 \mu \mathrm{m}$, and in Teutschenthal partially reaching up to 500 or $600 \mu \mathrm{m}$. The hypidiomorphic to idiomorphic anhydrite crystals have a tabular habit, with a crystal size ranging from 20 to $100 \mu \mathrm{m}$. The inclusion walls look 

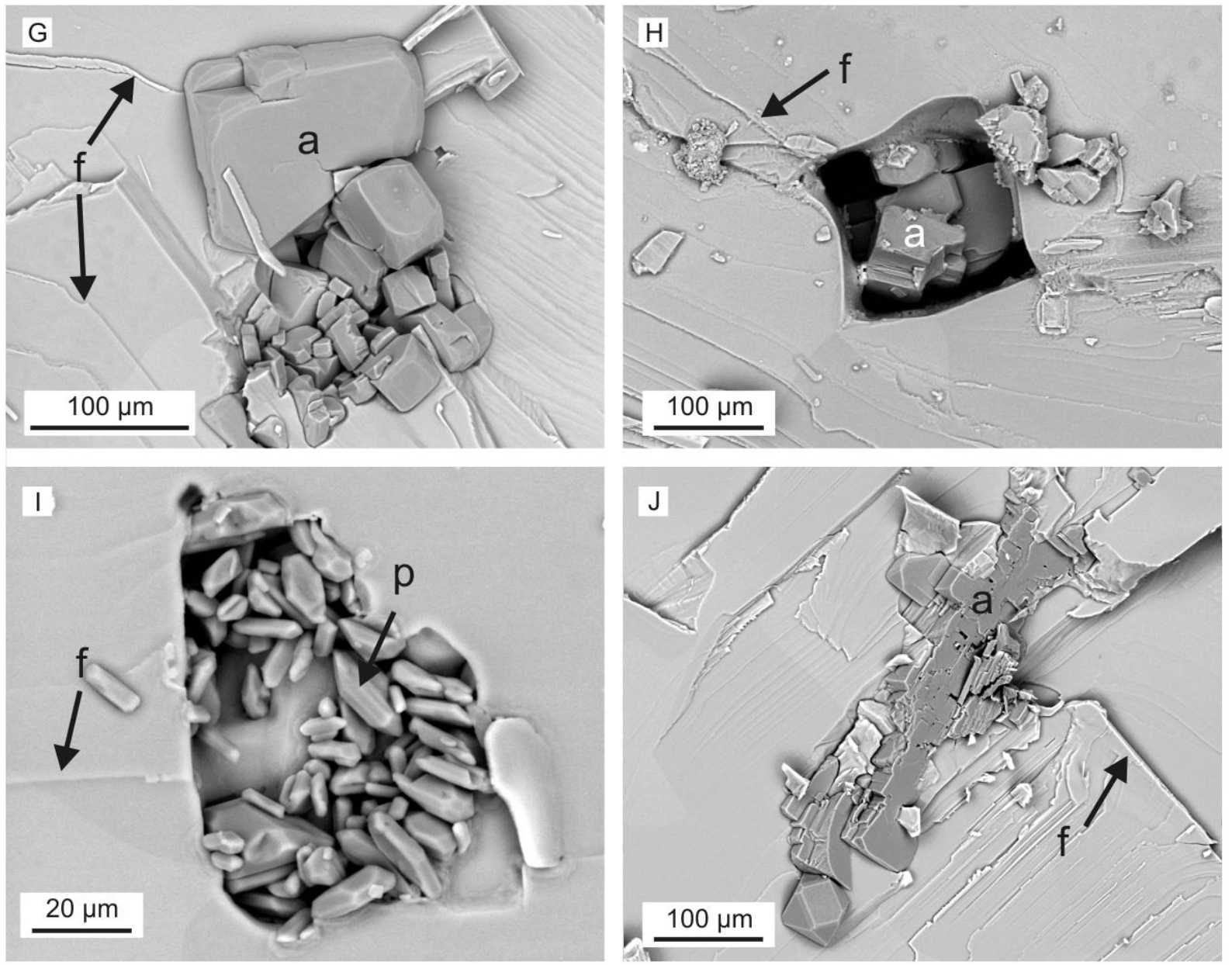

porous (Fig. 4.24D). The former presence of brine within these inclusions can also be visualized using the secondary electron (SE-) detector that shows a pattern around opened inclusions (Figs. 4.24E, 4.24F), which represents the fluid that flowed out after opening the crystal. In addition, on the surface of the anhydrite crystals or nearby the cavity, new small (a

$\leftarrow \uparrow$

Fig. 4.24: Backscattered electron (BSE; Figs. 4.24A-D, 4.24G-J) and secondary electron (SE; Figs. 4.24E-F) images of the different inclusion types in Kristallbrocken obtained from Stassfurt rock salt samples of Teutschenthal and Gorleben. The lines on the halite surface are fractures (f) induced by sample preparation. A-D) BSE images of samples from Teutschenthal with aggregates of anhydrite crystals (a) enclosed in cavities. Fig. 4.24B is a scaled-up section of Fig. 4.24A showing newly grown halite crystals (h) on the surface of the anhydrite crystals or nearby the opened inclusion. In Fig. 4.24D, a closer look at the cavity shows the porous appearance of the inclusion wall. E-F) SE images of a sample from Teutschenthal showing a pattern (black arrows) around the anhydrite-filled cavities that differs from the halite surface farther away from the inclusions. This is obviously induced by the fluid that flowed out after the Kristallbrocken was opened before the SEM analysis. G-I) BSE images of samples from Gorleben. G) Aggregate of anhydrite crystals directly included in the Kristallbrocken; note that a cavity around the anhydrite aggregate, newly grown halite crystals or a porous appearance of the inclusion wall is not existent. H) Anhydrite crystals enclosed in a cavity. I) Polyhalite crystals (p) enclosed in a cavity. J) BSE image of a sample from Teutschenthal with individual anhydrite crystals enclosed without surrounding brine. Note the skeletal habit of the anhydrite crystal, which potentially suggests a gypsum precursor. 
few micrometers) halite crystals can be observed (Figs. 4.24A-C). The entire assemblage of anhydrite takes up a volume of approximately 50-60\% in the opened inclusion. However, this is only an approximation as some crystals might have fallen out of the inclusion during preparation or remained in the complement of the opened inclusion.

In Gorleben, the internal lamination of the Kristallbrocken is characterized by different types of inclusions. Throughout the whole Hauptsalz section, aggregates of anhydrite crystals (Fig. 4.24G) can be observed. The hypidiomorphic anhydrite crystals also have a tabular shape and their size ranges from 20 to $100 \mu \mathrm{m}$. In contrast to the anhydrite aggregates in Teutschenthal and Morsleben, there is no brine around the anhydrite crystals, there are no halite precipitates close to the inclusion, and the inclusion walls are not porous. In the upper parts of the Hauptsalz, the internal lamination occasionally contains anhydrite aggregates with surrounding brine (Fig. 4.24H; like in Teutschenthal and Morsleben), but mostly it is composed of polyhalite aggregates (Fig. 4.24I). The idiomorphic polyhalite crystals are of tabular or stubby-prismatic habit with a crystal size of approximately 20-50 $\mu \mathrm{m}$.

In addition to the anhydrite and polyhalite aggregates that mainly constitute the internal lamination (samples of Teutschenthal, Morsleben, and Gorleben), there are some individual idiomorphic to hypidiomorphic anhydrite inclusions without surrounding brine (Fig. 4.24J). These crystals can be found in all studied Kristallbrocken examples, but they are not as frequent as the sulfate aggregates with surrounding brine. Their size ranges from 50 to $200 \mu \mathrm{m}$. Some of them have a prismatic to skeletal habit potentially indicating the replacement of earlier gypsum (Fig. 4.24J).

\section{Other locations in the Zechstein Basin}

The Kristallbrocken sample from the Asse salt mine, obtained from the upper parts of the Hauptsalz, looks similar to those from Teutschenthal and Morsleben, and the characteristic internal lamination mainly consists of idiomorphic to hypidiomorphic anhydrite aggregates (Fig. 4.25A) with surrounding brine. The walls of the opened inclusions are porous and halite precipitates are distributed around the inclusion. Polyhalite crystals could not be observed in this Kristallbrocken sample.

Inclusions in the Kristallbrocken samples obtained from the Netherlands, Etzel, and Lesum are comparable to those from Gorleben. In general, the appearance of this halite type in these locations is milky due to the high amount of rather small inclusions. The internal lamination is mainly composed of inclusions filled with both anhydrite and polyhalite crystals (Figs. 4.25B-C, 4.25E) as well as surrounding brine. In addition, there are also some inclusions exclusively filled with polyhalite (Figs. 4.25D, 4.25E) and surrounding brine, as 
also observed in the upper parts of the Hauptsalz in Gorleben. In the inclusions that contain both mineral types, there is a clear difference in size between anhydrite and polyhalite
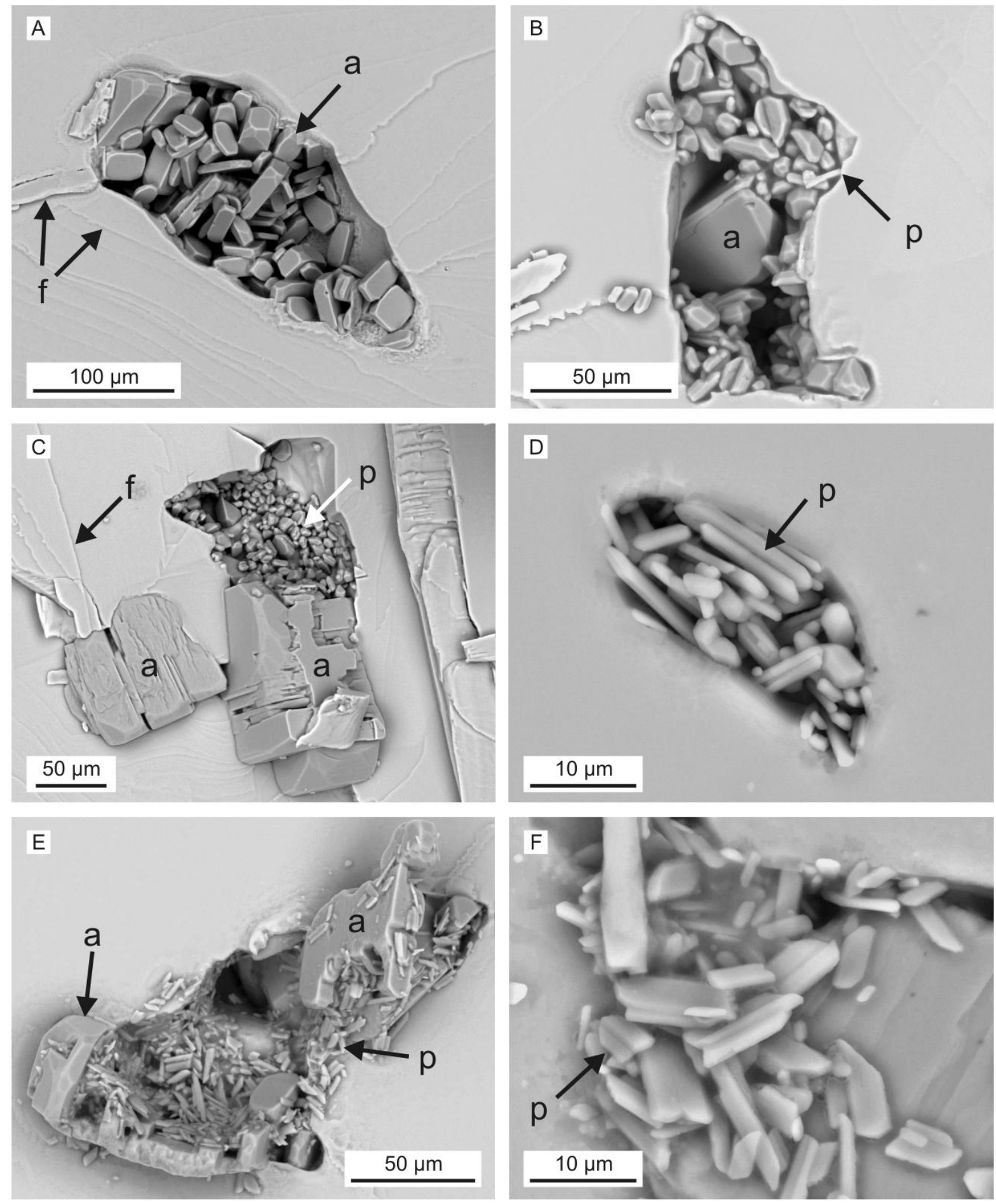

Fig. 4.25: BSE images of different inclusions (anhydrite (a), polyhalite (p) in the Kristallbrocken obtained from Stassfurt rock salt samples of the other sampled locations of the Zechstein basin. The lines on the halite surface are fractures (f) induced by sample preparation. A) Sample from the Asse salt mine showing an aggregate of anhydrite crystals enclosed in a cavity. B-F) Samples from Etzel (B), Lesum (C), and the Netherlands (D-F) showing cavities that are either filled with both anhydrite and polyhalite $(\mathbf{B}, \mathbf{C}, \mathbf{E})$ or exclusively filled with polyhalite $(\mathbf{D}, \mathbf{F})$. E) Large anhydrite crystal that has been partly replaced by polyhalite. F) A closer look at an inclusion shows polyhalite crystals that resemble swallow-tail twins. 
crystals. Some anhydrite crystals look like having been partly replaced by polyhalite (Figs. 4.25C, $4.25 \mathrm{E}$ ). The polyhalite crystals have a prismatic (Figs. 4.25D-F) to stubby-prismatic habit (Figs. 4.25B, 4.25C), and some of the individual crystals resemble swallow-tail twins (Fig. 4.25F).

\subsubsection{Strontium content of the anhydrite inclusions}

The minimum, maximum, and mean values of the strontium content analyses are presented in Tab. 1. Microprobe analyses (Table A.9) have revealed similar strontium contents for the different anhydrite inclusions, ranging from 903 to $2517 \mathrm{ppm}$ in anhydrite crystals formerly surrounded with brine and from 824 to $3329 \mathrm{ppm}$ in anhydrite crystals or aggregates included without surrounding brine. Furthermore, there is no significant difference in the strontium content between the studied locations.

Tab. 1: Number of samples $(\mathrm{N})$, minimum, maximum, and mean values of the strontium content (ppm) are given for the different anhydrite inclusions of the Kristallbrocken samples from Teutschenthal, Morsleben, and Gorleben.

\begin{tabular}{clcc}
\hline & N & $\begin{array}{c}\text { Sr content of individual anhydrite } \\
\text { crystals and anhydrite aggregates } \\
\text { without surrounding brine }\end{array}$ & $\begin{array}{c}\text { Sr content of anhydrite crystals and } \\
\text { aggregates with surrounding brine }\end{array}$ \\
\hline \multirow{5}{*}{ Teutschenthal } & Min & 61 & 14 \\
& Max & 824 & 903 \\
& Mean & 2847 & 2517 \\
& N & 1532 & 1534 \\
& Min & 19 & 12 \\
& Max & 1117 & 1054 \\
& Mean & 2534 & 2374 \\
& N & 1760 & 1694 \\
& Min & 10 & 10 \\
& Max & 1444 & 1051 \\
& Mean & 3329 & 2507 \\
\hline
\end{tabular}

\subsubsection{Discussion}

The studied halite type has been mentioned in several publications (Schünemann 1913; Richter-Bernburg 1955b; Lotze 1957; Simon \& Haltenhof 1970; Simon 1972, Czapowski 1986, 1987; Czapowski et al. 1990, 1993). Although the general sedimentary conditions for the formation of the lamination have been discussed by Czapowski (1986), little is known about how the lamination can be explained within single crystals. The results of the X-ray texture measurements (Küster et al. 2010) evidence that the studied halite type is 
monocrystalline, and that broken pieces formerly most likely belonged together. The latter is also confirmed by the clear correlation between the individual Kristallbrocken pieces by means of the internal lamination. This in turn suggests that the Kristallbrocken fragments arranged in layers running from the lower left to the upper right corner of the exampled salt cube (Fig. 4.19) originally presented a quite large 'single crystal'-layer, with a lateral size of at least $55 \mathrm{~cm}$ and a thickness of $2-5 \mathrm{~cm}$ only for that cube sector. But even the individual Kristallbrocken fragments show relatively large sizes with up to $20 \mathrm{~cm}$ in lateral extent. The question is whether these large single crystals were grown directly from a solution or formed by a secondary, post-sedimentary process as for instance coalescence or diagenetic grain growth of formerly fine-grained halite crystals.

\subsubsection{Kristallbrocken}

Due to the internal, fine lamination of the Kristallbrocken and the strong similarity to the laminated halite beds described, for example, in Anderson et al. (1972), Schreiber et al. (1976), or Kendall (1992), this halite type may be regarded as having formed in deeper water. Such a scenario seems also plausible because of the absence of characteristic primary features such as primary fluid inclusions which trace the growth zones like in chevron crystals (Hardie et al. 1983; Lowenstein \& Hardie 1985) that are preferentially indicators for primary growth under shallow subaqueous conditions (e.g., Gottesmann 1963; Wardlaw \& Schwerdtner 1966; Arthurton 1973; Shearman 1970, 1978; Pape et al. 2002). However, as there are no suitable modern analogs for deep water evaporites, identification of this facies types is based on ancient examples, which is difficult, because most of them are already recrystallized (e.g., Kendall 1992; Warren 2006). Presumed ancient deeper water salts are suggested to be characterized by thin halite beds or laminae consisting of tiny cubic crystals together with halite rafts, with the halite crystals being clear and inclusions-free (e.g., Kendall 1992; Schreiber \& El Tabakh 2000). The halite at the bottom of the Dead Sea, which might be a possible analog for deep water halite (Warren 2006), consists mainly of clear halite aggregates made up of white to clear halite crystals with up to $1 \mathrm{~cm}$ in diameter, interbedded with layers composed of fine-grained (<1 mm) halite (Gavrieli 1997; Herut et al. 1998). The Kristallbrocken halite samples are large single crystals, i.e. neither ancient nor modern deep water evaporites seem to contain halite crystals with sizes comparable to those of the Kristallbrocken.

Large naturally grown halite single crystals have mainly been found in caves in salt mines (e.g., Pippig 1992; Minette 1999) where large available space enables the halite cubes 
to grow up to $50 \mathrm{~cm}$ or even $100 \mathrm{~cm}$ edge length. Halite crystals with several $\mathrm{dm}$ in size have also been observed in modern saline pan deposits, where they fill ancient dissolution pipes and cavities (Chong Diaz et al. 1999). The halite crystals in these deposits (caves, dissolution pipes, cavities) are mostly transparent and pure, or they contain fluid inclusions. In contrast, the studied halite type is full of relatively large (up to $600 \mu \mathrm{m}$ ) solid inclusion and is thus not comparable with these large, primarily grown single crystals. In this context, it has also to be considered that the absence of solid inclusions in large naturally grown halite single crystals suggests that enlarged halite crystals would form maybe more likely if anhydrite or other impurities are absent (e.g., Sonnenfeld 1992). I.e. the presence of sulfate crystals or aggregates on halite crystal faces presumably impairs extensive halite crystal growth.

Another aspect that contradicts primary growth is the length to height ratio of individual Kristallbrocken fragments, which is in the order of 5:1 (e.g., Fig. 4.19). This is rather unusual for naturally grown halite crystals, especially because there should be more space for vertical than for lateral growth on the sea bottom. Of course, it might be assumed that the Kristallbrocken were originally large cubes that were later partly flattened by dissolution. But then any features of such dissolution should have been observed, which not the case is until now.

Although there are no typical primary features like, for example, the characteristic fluid inclusion banding in chevron halite, it could be assumed that the solid inclusions within the Kristallbrocken halite are a kind of primary inclusions. However, if the Kristallbrocken are primarily grown crystals, then solid inclusions should be arranged on certain halite crystal growth planes like, for instance, the fluid inclusion bands in chevron halite crystals, concentrated in layers parallel to the cube faces $\{100\}$ (e.g., Shearman 1978; Roedder 1984; Kendall 1992), or the manganese and iron oxihydroxides on $\{1 \mathrm{k} 0\}$ and $\{-111\}$ growth fronts in gypsum megacrystals (García-Ruiz et al. 2007). But the solid inclusions are randomly distributed forming mm-thick laminae that run parallel to the boundaries of the Kristallbrocken layers as well as, originally, to the underlying or overlying anhydrite layers, or the inclusion size grades up or down from bottom to top. Both features are characteristic for sediments, i.e. the solid inclusions mark the former depositional surface rather than certain crystal growth fronts.

Given the various arguments, namely the presumed originally large size of the Kristallbrocken, the absence of similar halite types in ancient or modern analogs of deep water or other evaporites, the high amount of relatively large solid inclusions, or the characteristic sedimentary features, it seems to be highly unlikely that these laminated single 
crystals were grown directly from a solution. For that reason, we strongly assume that the monocrystalline Kristallbrocken layers formed in a post-sedimentary process from formerly finer-grained halite crystals.

\subsubsection{Internal lamination}

The results of this study show that the internal lamination of the Kristallbrocken can consist of several types of solid inclusions: anhydrite aggregates with surrounding brine, anhydrite aggregates or individual crystals without surrounding brine, polyhalite aggregates as well as polyhalite-anhydrite aggregates, both with surrounding brine (Tab. 2). Especially the presence of the sulfate aggregates with surrounding brine is quite unusual in a single crystal for two reasons. First, the aggregates cannot represent the daughter crystals of fluid inclusions, because the calcium or potassium concentration of the inclusion would be too low to form that large amount of anhydrite or polyhalite, respectively, which can be observed within the inclusions. Second, due to their large size and amount, they can hardly be the result of accidental trapping during single crystal growth. The question arises how and especially when did the sulfate aggregates form and how can the surrounding brine and the irregularity of the whole inclusion be explained.

Tab. 2: Different types of solid inclusions that have been observed in Kristallbrocken samples taken from different salt sites of the Zechstein Basin (Fig. 4.20B). In Teutschenthal, Morsleben, and Gorleben, several samples were investigated throughout the entire Hauptsalz section, whereas of the other locations only one sample was studied exemplarily.

\begin{tabular}{|c|c|c|c|c|c|}
\hline Salt site & $\begin{array}{l}\text { Individual } \\
\text { anhydrite } \\
\text { crystals without } \\
\text { surrounding } \\
\text { brine }\end{array}$ & $\begin{array}{l}\text { Anhydrite } \\
\text { aggregates } \\
\text { without } \\
\text { surrounding } \\
\text { brine }\end{array}$ & $\begin{array}{l}\text { Anhydrite } \\
\text { aggregates with } \\
\text { surrounding } \\
\text { brine }\end{array}$ & $\begin{array}{l}\text { Polyhalite } \\
\text { aggregates with } \\
\text { surrounding } \\
\text { brine }\end{array}$ & $\begin{array}{l}\text { Polyhalite- } \\
\text { anhydrite } \\
\text { aggregates with } \\
\text { surrounding } \\
\text { brine }\end{array}$ \\
\hline Teutschenthal & \multirow{4}{*}{$\begin{array}{c}\uparrow \\
\text { Entire Hauptsalz } \\
\downarrow\end{array}$} & - & $\uparrow$ & - & - \\
\hline & & & Entire Hauptsalz & & \\
\hline Morsleben & & - & $\downarrow$ & - & - \\
\hline Gorleben & & Entire Hauptsalz & $\begin{array}{l}\text { Upper parts of } \\
\text { the Hauptsalz }\end{array}$ & $\begin{array}{l}\text { Upper parts of } \\
\text { the Hauptsalz }\end{array}$ & - \\
\hline Asse & $\mathrm{x}$ & - & $\mathrm{x}$ & - & - \\
\hline $\begin{array}{l}\text { Netherlands, } \\
\text { Etzel, Lesum }\end{array}$ & $\mathrm{x}$ & - & - & $\mathrm{x}$ & $\mathrm{x}$ \\
\hline
\end{tabular}

\section{Anhydrite inclusions}

Based on the strontium analyses of the anhydrite inclusions, gypsum is most likely the primary precipitate of these anhydrite crystals. Evaporation experiments (Usdowski 1973) as 
well as data from gypsum precipitates (e.g., Geisler 1982, Rosell et al. 1998) show that the strontium content of seawater increases with progressive evaporation. Strontium is incorporated into the crystal lattice of calcium sulfates instead of calcium (Noll 1934). According to Usdowski (1973) the partition coefficient for strontium in anhydrite is significantly higher $(b=1210)$ than that for strontium in gypsum $(b=50)$; therefore the anhydrites directly precipitated from seawater are expected to have significantly higher strontium contents. Strontium contents in anhydrites from German Zechstein evaporites range mainly between 800 and 2700 ppm (e.g., Jung \& Knitzsche 1960; Herrmann 1961; Kramm \& Wedepohl 1991), which matches the expected strontium contents in gypsum at sodium chloride saturation of seawater. In this study, the strontium contents ranging between 824 and 3329 ppm (Tab. 2) are in good agreement with previous studies, and thus indicate that the anhydrite inclusions originate from the conversion of primary gypsum.

The most probable explanation for the formation of the irregular inclusions filled with anhydrite and brine is the initial incorporation of gypsum aggregates during the precipitation of the halite crystals (cf. chapter 5.3). Later, during diagenesis and when the halite crystal mush transformed into the monocrystalline Kristallbrocken, these gypsum crystals converted into anhydrite plus water, with anhydrite and water having volumes of $\sim 62 \%$ and $\sim 38 \%$ respectively. As the released water was undersaturated with respect to sodium chloride, parts of the halite surrounding the anhydrite crystals (= inclusion wall) were dissolved until the water was in equilibrium with halite. In order to saturate the water with respect to sodium chloride, about $6 \%$ of the surrounding halite has to be dissolved, yielding a brine volume of $\sim 44 \%$. The presence of undersaturated water inside the inclusion leading to dissolution processes is also evidenced by the porous appearance of the inclusion walls. When splitting the Kristallbrocken before SEM analysis, the previously enclosed brine flows out of the opened inclusions and immediately evaporates, thereby forming new halite crystals on the anhydrites or around the inclusion (Figs. 4.24A-C). Therefore, the cavity that can be observed during SEM analysis results primarily from the solid volume reduction of about $38 \%$ in the course of a complete gypsum-anhydrite conversion and secondarily from the partial dissolution of halite of about $6 \%$ through the undersaturated water released during the gypsum-anhydrite conversion. This estimation is in agreement with the volume of anhydrite crystals of approximately 50-60\%, when it is considered that the solid volume of the complement of the inclusion is unknown and that some anhydrite crystals may have fallen out of the inclusion during the preparation. 
Individual anhydrite crystals and aggregates without surrounding brine are also typical for the Kristallbrocken. The individual anhydrite crystals occur in low quantities all over the Hauptsalz of Teutschenthal, Morsleben and Gorleben and are supposed to have been included as anhydrite, i.e. the conversion from gypsum took place earlier. For instance, warmer surface seawater (more than $20^{\circ} \mathrm{C}$ at halite saturation; Holser 1979) saturated with respect to calcium sulfate enabled early transformation from gypsum to anhydrite. The brine-free anhydrite aggregates were only observed in the Hauptsalz of Gorleben (Tab. 2). They may have also been included as anhydrite, as supposed for the individual anhydrite crystals. Another possibility is that they result from a similar formation process as the anhydrite aggregates with surrounding brine, only that brine was later removed by deformation processes during diapirism. However, at least in the upper parts of the Hauptsalz of Gorleben, brine-free anhydrite aggregates occur together with brine-surrounded anhydrite aggregates, which raises the question why the brine of these inclusions was not removed.

\section{Polyhalite inclusions}

Polyhalite crystals as solid inclusions in Kristallbrocken were observed in the samples from Gorleben, Etzel, Lesum, and the Netherlands (Tab. 1). Their occurrence in these locations is restricted to the upper parts of the Hauptsalz, representing the higher evaporation level of Permian seawater. Polyhalite $\left(\mathrm{K}_{2} \mathrm{MgCa}_{2}\left[\mathrm{SO}_{4}\right]_{4} \cdot 2 \mathrm{H}_{2} \mathrm{O}\right)$ is a common mineral in many ancient (e.g., Schulze 1960b; Simon \& Haltenhof 1970; Peryt et al. 1998; Chong Diaz et al. 1999; Roy et al. 2006) as well as recent evaporite deposits (e.g., Holser 1966b; Irion \& Müller 1968, Perthuisot 1971; Camur \& Mutlu 1996).

Like for the anhydrite crystals, the question arises when these polyhalite crystals formed. There are some petrographic evidences like a partial replacement of anhydrite by polyhalite (Figs. 4.25C, 4.25E) and the presence of swallow-tail twins (Fig. 4.25F) demonstrating that the polyhalite within the inclusions most likely did not precipitate directly from the seawater brine but most likely converted from gypsum or anhydrite (cf. Braitsch 1962). The polyhalite crystals cannot be the daughter crystals of fluid inclusions. Furthermore, it is also less probable that the conversion of gypsum or anhydrite into polyhalite took place inside the inclusion, because the volume of the included brine is too small and therefore does not contain enough potassium as well as magnesium to form the amount of polyhalite that can presently be observed in the inclusions. Therefore, it seems to be more plausible that the polyhalite crystals already existed before they were included in the Kristallbrocken halite type. 


\subsubsection{Propositions for a post-sedimentary formation process}

Initially, numerous small halite crystals were presumably precipitated (Fig. 4.26, stage I), most likely in the deeper parts of the evaporite basin and with a fabric that might be comparable to halite crystal assemblages formed by nucleation on the sea bottom as observed by Arthurton (1973) during evaporation experiments. It can be assumed, that according to Holser (1979) at an evaporation ratio of at least about 11.5 and a temperature range between 0 and $20^{\circ} \mathrm{C}$, gypsum crystals and aggregates were precipitated contemporaneously with halite crystals. Alternatively, gypsum crystals descended from more diluted brines as proposed by Czapowski (1986) (Fig. 4.26, stage I). The fine lamination within the Kristallbrocken is formed by varying amounts of gypsum crystals and documents short-term variations in the seawater salinity. Maybe some gypsum crystals were exposed to slightly more evaporated seawater brine and thus could be converted into anhydrite relatively quickly, whereas the majority of gypsum was presumably enclosed in pore spaces of the halite crystal mush, in which higher evaporated seawater brine could not circulate, and thus gypsum could not yet be converted. In sites with higher evaporation level, polyhalite originates from gypsum or anhydrite (Fig. 4.26, stage I; samples from Gorleben, Lesum, Etzel, and the Netherlands). In a later stage, a kind of grain growth or accumulation process is supposed to have taken place that accounts for the large crystal size of the monocrystalline Kristallbrocken (Fig. 4.26, stage II). During this process, the already existing anhydrite crystals or polyhalite aggregates as well as the not yet transformed gypsum aggregates were incorporated in the halite (Fig. 4.26, stage II). The formation of the studied halite type in its present monocrystalline fabric is assumed to have taken place during early diagenesis and presumably started when the overlying halite sequence had a certain thickness. After the Kristallbrocken halites achieved their present form of large single crystals, the included gypsum aggregates converted into anhydrite. The released water is the brine that presently surrounds the anhydrite aggregates (Fig. 4.26, stage III; chapter 5.2.1).

For the grain growth or accumulation process, several mechanisms are conceivable. Static grain growth processes can be divided into normal and abnormal (=exaggerated) grain growth (e.g., Evans et al. 2001). Such processes are driven by the reduction of surface free energy due to a grain boundary area decrease with increasing average grain sizes. During abnormal grain growth, small grains are preferentially eliminated by the exaggerated growth of few larger grains (e.g., Twiss \& Moores 1992). As only a few grains grow, this process results in an inhomogeneous grain size distribution, which cannot explain the present fabric of 


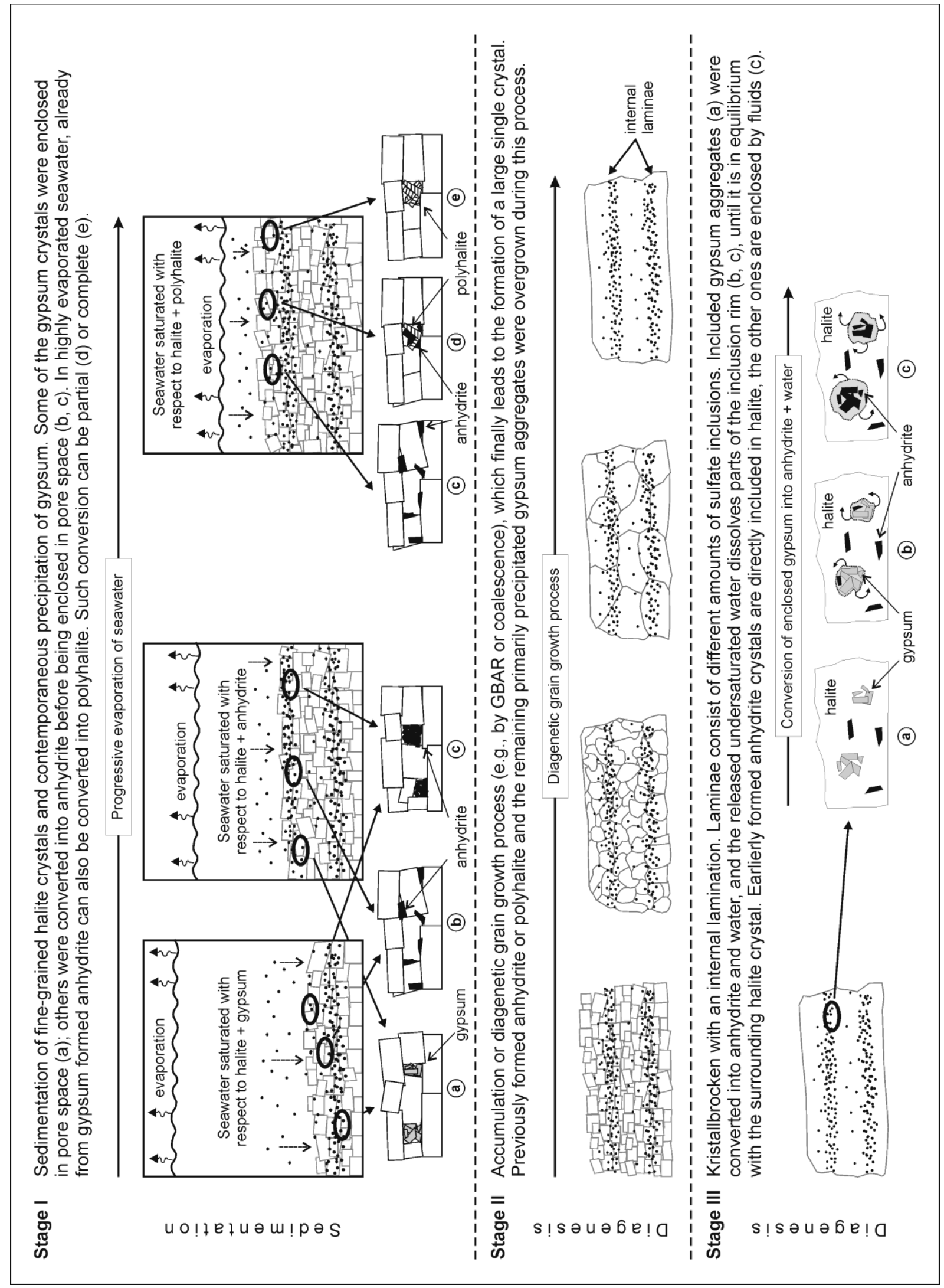

Fig. 4.26: Schematic sketch illustrating the suggested process for the formation of the Kristallbrocken halite type. Detailed explanations are given in the text. 
the Kristallbrocken. During normal grain growth, large grains grow at the expense of smaller ones and the average grain size increases (e.g., Atkinson 1988; Evans et al. 2001). Grain boundary area reduction (GBAR) is a recrystallisation process that results in straightening of grain boundaries and grain growth at the expense of small crystals (e.g., Passchier \& Trouw 1996). However, this process is supposed to lead to a polygonal fabric, also referred to as foam structure, which has also been described as a typical feature in recrystallized halite rocks (e.g., Hardie et al. 1983; Roedder 1984; Lowenstein \& Hardie 1985). If such grain growth process is indeed the formation mechanism of the monocrystalline Kristallbrocken, then it would be expected that some Kristallbrocken can be found in a kind of interim stage, i.e. where the polygonal fabric was still preserved.

For both grain growth processes, it is expected that the boundary migration process should be prevented or at least retarded by the presence of such large (up to $600 \mu \mathrm{m}$ ) solid inclusions (Zener pinning (e.g., Nes et al. 1985); Mas \& Crowley 1996; Evans et al. 2001). However, recent experimental pinning studies have shown that with increasing time the driving force for grain boundary migration can even overcome the counteracting dragging force of the second phases (Brodhag et al. 2007). On the other hand, smaller, more mobile sulfate crystals or fluids are assumed to be purged to grain boundaries during recrystallisation (e.g., Hardie et al. 1983), but this is also not the case. Possibly, such impurity dragging was prevented because the recrystallisation process started from various sides concurrently, caused by underlying and overlying calcium sulfate layers.

Another conceivable process may be the coalescence of formerly fine-grained halite. During this process, grain growth is induced by rotation of grains, which results in a coherent grain-grain interface, i.e. the grains receive the same crystallographic orientation. Eventually, neighboring grains join together through the elimination of common grain boundaries and thus form a single larger grain. Grain-rotation induced grain coalescence has often been described as growth mechanism in nanocrystalline materials (e.g., Moldovan et al. 2002; Leite et al. 2003; Shamsutdinov et al. 2006), but has also been proposed as a possible formation mechanism for garnet porphyroblasts, where individual garnet grains rotated towards coincident orientations when they came into contact with each other (Daniel \& Spear 1998; Spiess et al. 2001). The garnet porphyroblast consists of subdomains, and electron backscatter diffraction showed that these subdomain-bearing garnet grains have a strong crystallographic preferred orientation, clustering close to a single orientation. The rotation process is driven by boundary energy (Sutton \& Baluffi 1987), and the rotation mechanism is thought to be subdomain grain boundary diffusion. Coalescence also relates to the process where adjacent 
grains with identical crystallographic orientations coalesce to form one larger grain. This was, for example, described as a microstructural process during the dynamic recrystallisation of wet bishofite (Urai 1987). A similar process has been proposed for the formation of some stalagmites that, according to Kendall \& Broughton (1978), are in fact composite-crystals formed by individual crystallites. These crystallites form separate terminations on the growth surface, but have a minor space between them that is removed by lateral crystallite coalescence (overgrowth) just behind the growth front. All these processes are conceivable, but it has to be considered that the mm-sized garnet porphyroblast or coalesced bishofite grains are much smaller than the Kristallbrocken halite. I.e., if indeed the Kristallbrocken formed by coalescence of formerly fine-grained halite, this process would have to take place in a significantly larger scale. In addition, the question arises how the sulfate inclusions would influence the coalescence process.

Although there are some considerations concerning the formation of the "single crystal" fabric of Kristallbrocken, it cannot be resolved conclusively. The problem is that there seem to be no suitable analogs, neither for giant, primarily grown halite crystals containing high amounts of relatively large solid inclusions nor for grain growth or coalescence processes in rock salt or other rocks yielding a comparable monocrystalline fabric in a similar scale. The underlying process could be a special case of grain growth or coalescence which is not entirely understood yet.

\subsubsection{Conclusions}

Investigations by optical microscopy and scanning electron microscopy have shown that the laminae within the Kristallbrocken contain several types of solid inclusions: (1) anhydrite aggregates enclosed by solution, (2) anhydrite crystals or aggregates directly included in the halite crystal, and (3) polyhalite crystals, partly together with anhydrite, enclosed in cavities.

Especially characteristic are anhydrite aggregates with surrounding brine. Microprobe analyses of the strontium content indicate that the anhydrites most likely had a gypsum precursor. The amount and size of anhydrite aggregates and the fact that they are surrounded by brine suggests that these solid inclusions can be neither the daughter crystals of a fluid inclusion nor the result of accidental trapping during halite single crystal growth. A plausible explanation for the formation of these anhydrite aggregates is that initially gypsum crystals were incorporated in halite, which later converted into anhydrite. The solid volume reduction as well as the release of water in consequence of a complete gypsum-anhydrite conversion 
explains the present appearance of these characteristic solid inclusions within the laminated Kristallbrocken halite type.

The original size of the monocrystalline beds, their high amount of relatively large solid inclusions as well as the characteristic sedimentary features of this laminated halite type makes it highly unlikely that these laminated single crystals were grown directly from a solution. Therefore, a post-sedimentary process is assumed for the formation of the Kristallbrocken that is based on coalescence or grain growth by grain boundary migration of formerly fine-grained halite crystals. Clear indications for the grain growth mechanism could not be found. This is especially difficult, since also the Kristallbrocken from Teutschenthal are slightly deformed and therefore the intracrystalline microstructures are overprinted. 


\subsection{Additional results}

\subsubsection{Sample Lt62-6-125 - comparison of M1, M2, and M3}

In this section, additional results are presented related to sample Lt62-6-125 (Fig. 4.27). The Kristallbrocken of sample Lt62-6-125 has been described in detail in section 4.1.5.2. It was measured 3 times, with the sample surface having been prepared differently prior to each measurement. Each time, the sample was manually ground on a grinding instrument to get a planar surface, using 60-, 120-, 500-, and 1000-grit SiC abrasive papers. The wheel rotated counter clockwise while the sample rotated clockwise. For the first measurement (M1), grinding and polishing direction was parallel to the longitudinal axis (Fig. 4.27A). For the second measurement (M2), it was normal to the longitudinal axis (Fig. 4.27B). For the third measurement (M3), the polished sample surface was treated with a wet tissue for three times and then dried with a tissue.
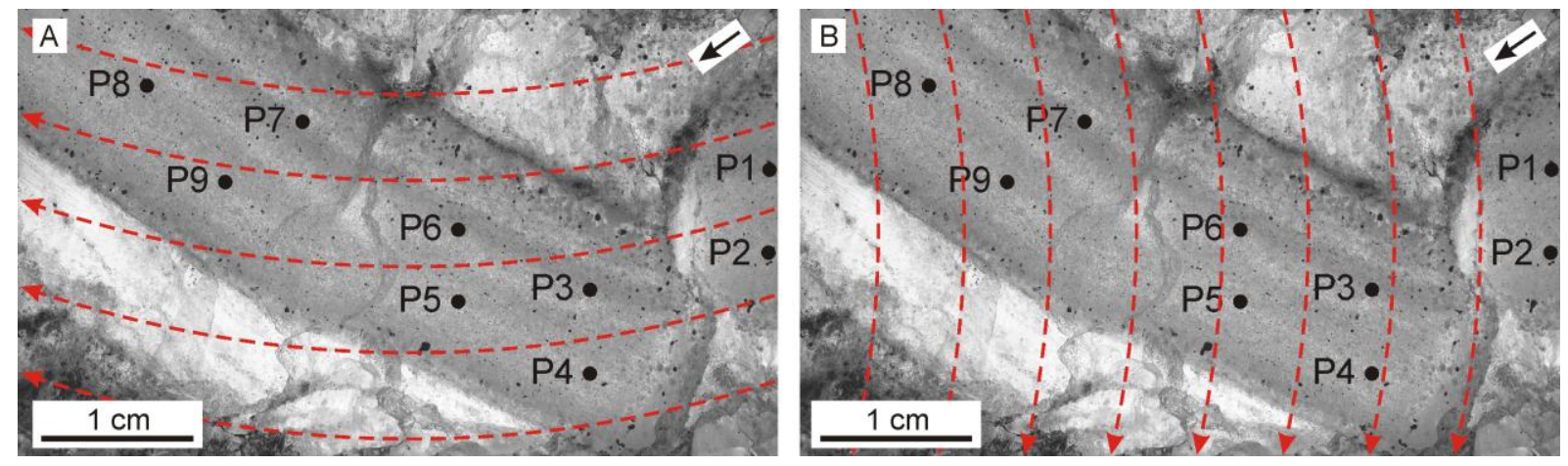

Fig. 4.27: Thick section photograph of sample Lt62-6-125 showing the 9 measuring points for the Xray texture measurements. For the first measurement (M1), grinding and polishing direction (red dashed arrow) was parallel to the longitudinal axis of the sample piece (A). For the second measurement (M2), it was normal to the longitudinal axis of the sample piece (B). Black arrow in white box indicates stratigraphic up direction.

The results of M3 are described and discussed in detail in section 4.1. The sample preparation procedure used for M3 was also applied to the other samples as Lt60-12-89, Lt60-18-174, and Lt62-3-151, which are described in section 4.1 and in this chapter.

The experimental pole figures for the reflections $\{111\},\{220\},\{400\}$, and $\{420\}$ of all measuring points are presented in Appendices C1, C2, and C3. In all pole figures of all three measurements, distinct, strongly developed intensity maxima can be observed. When comparing the results of intact Kristallbrocken pieces, namely the pole figures of P1 and P2, P3, P4, P5, and P6, as well as P7, P8, and P9, the positions of the maxima are nearly identical (Appendices C1-C3). In Fig. 4.28, the X-ray results of the measuring points P5 and P8 of the three measurements (M1, M2, and M3) are shown in comparison to each other. 
One noticeable feature in the pole figures of M1 and M2 is that the maxima are mostly not perfectly circular in all measurements, but the lowest contour lines are slightly or even

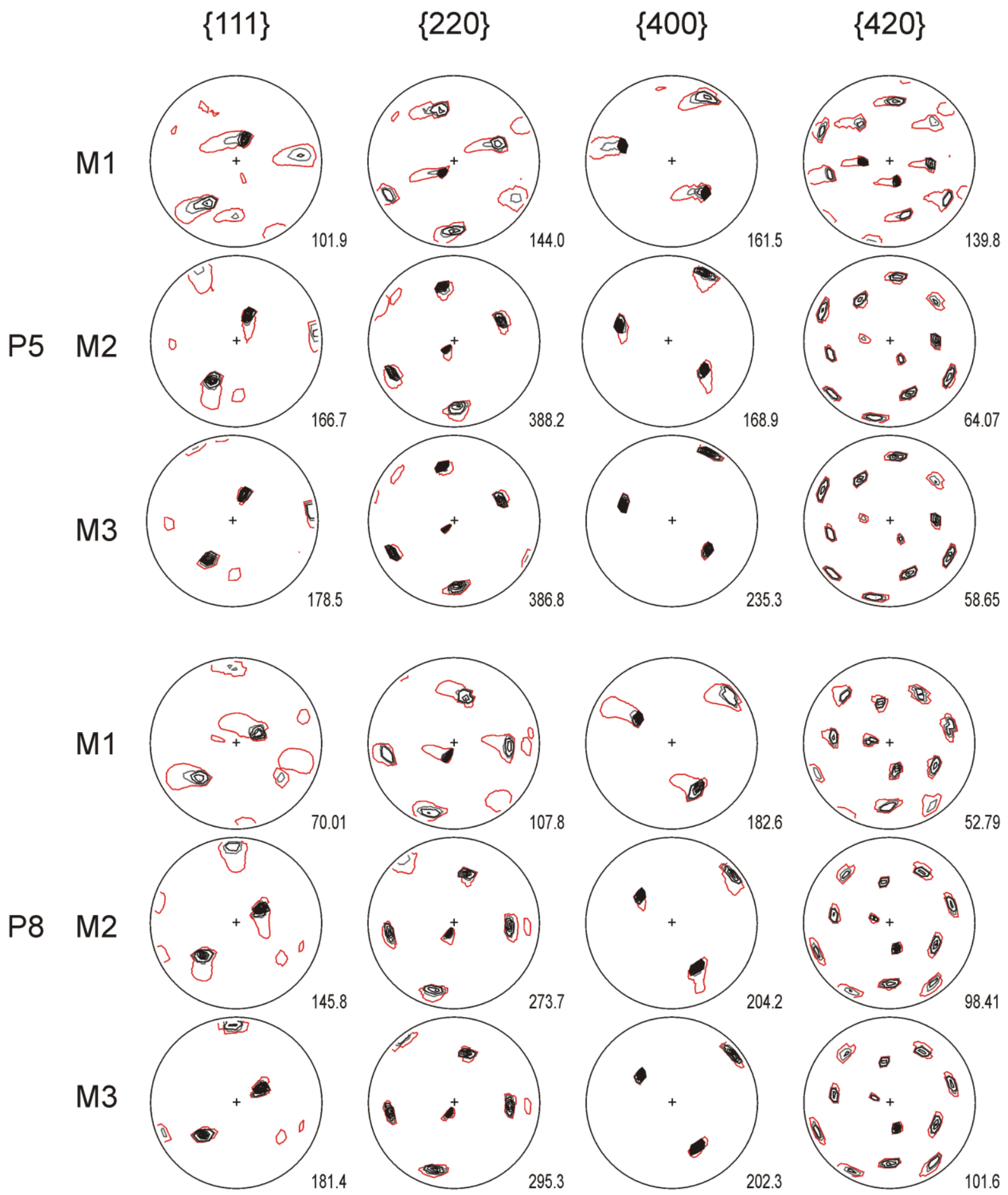

Fig. 4.28: Experimental pole figures for the reflections $\{111\},\{220\},\{400\}$, and $\{420\}$ of the measuring points P5 and P8 on sample Lt62-6-125. The results of the three measurements M1, M2, and M3 are shown in comparison to each other. Lowest contour lines, colored in red and grey, are equal to 1 and 5 m.r.d., respectively. From contour line 10 m.r.d. (black), the contour interval is 20 m.r.d. Note that the contour lines of the lowest intensity (red) of M1 and M2 are elongated asymmetrically in distinct directions, whereas in the pole figures of M3, this effect cannot be observed. 
considerably elongated asymmetrically in one direction. In the pole figures of M1, the elongation of the lowest contour lines (red) is oriented to the left, whereas in the pole figures of M2, it is oriented downwards. This phenomenon can be especially well observed in the pole figures of M1. At the second measurement (M2), it is clearly visible only in the pole figure of the reflections $\{111\}$ and $\{400\}$. In the pole figures of M3, the lowest contour lines do not show any specific elongations.

\subsubsection{Sample Lt60-18-174}

The Kristallbrocken of sample Lt60-18-174 is separated in the middle by a fracture, and the lamination in both pieces is slightly bent (Fig. 4.29). On the right, there is a small Kristallbrocken piece that presumably formerly belonged to the larger Kristallbrocken on the left. The experimental pole figures of all measuring points are shown in Appendix C4.

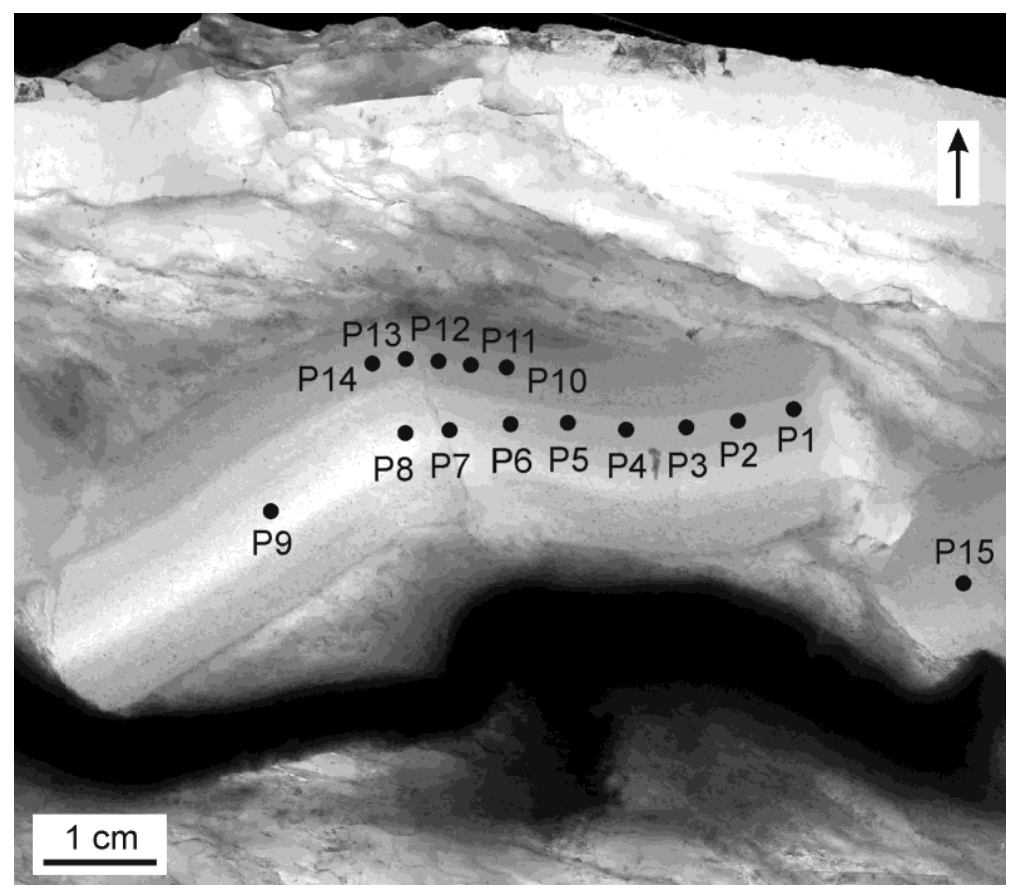

Fig. 4.29: Thick section photograph of sample Lt60-18-174 showing the 15 measuring points on the Kristallbrocken for the X-ray texture measurements. Black arrow in white box indicates stratigraphic up direction.

In general, the pole figures show distinct, strongly developed intensity maxima at all measuring points. The crystallographic orientation of the crystal lattice is quite similar across the large Kristallbrocken, with constant changes from the right piece to the left (Fig. 4.30). On the right piece, the positions of the maxima in the pole figures are nearly identical from P1 to P5 (Appendix C4, Fig. 4.30). The same applies for the left piece, with the measuring points P8, P9, and P14. In the pole figures of the measuring points P6 and P7, as well as P10-P13, two orientations can be observed, reflecting the proximity to the fracture between the 
Kristallbrocken pieces. When combining the added pole figures of representative locations of neighboring Kristallbrocken areas, namely P8, P9, and P14, P10-P13, and P1-P5, the constant change in crystallographic orientation along the Kristallbrocken is clearly visible (Fig. 4.30). This texture is the result of a rotation and correlates well with the bending of the lamination. The pole figure of P15 looks clearly different from those of the large Kristallbrocken indicating that this piece was rotated and tilted when having been separated and moved away (Appendix C4).

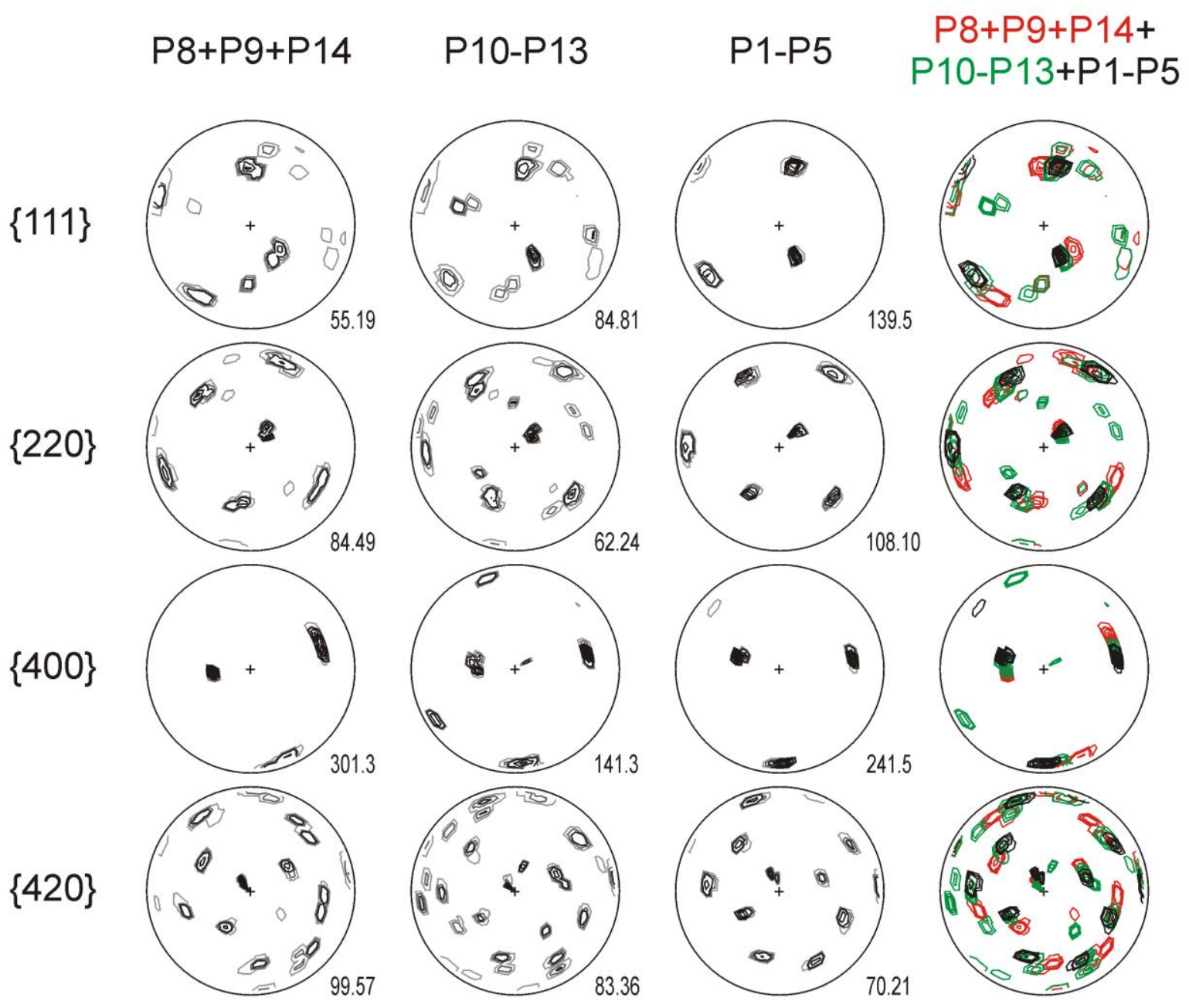

Fig. 4.30: Added pole figures for the reflections $\{111\},\{220\},\{400\}$, and $\{420\}$ of the measuring points P8, P9, and P14, P10-P13, and P1-P5 of sample Lt60-18-174 (Fig. 4.29). Lowest contour lines (grey) are equal to 1 and 5 m.r.d. From contour line 10 m.r.d. (black), the contour interval is 20 m.r.d. The pole figure set on the right represents a combination of the three pole figure sets on the left. For comparison, the contour lines are colored in red for $\mathrm{P} 8, \mathrm{P} 9$, and $\mathrm{P} 14$, in green for P10-P13, and in black for P1-P5. 


\subsubsection{Sample Lt62-3-151}

The Kristallbrocken of sample Lt62-3-151 is adjacent to an intensely folded anhydrite layer and relatively thin. It is broken up into several pieces, with some of the pieces having been slightly folded (Fig. 4.31). The solid inclusions within this Kristallbrocken are clearly visible, but the internal lamination is less well developed than in the other investigated Kristallbrocken samples. The 18 measuring points are arranged on the particular pieces of the Kristallbrocken. The experimental pole figures for the reflections $\{111\},\{220\},\{400\}$, and $\{420\}$ of all measuring points are presented in Appendix C5.

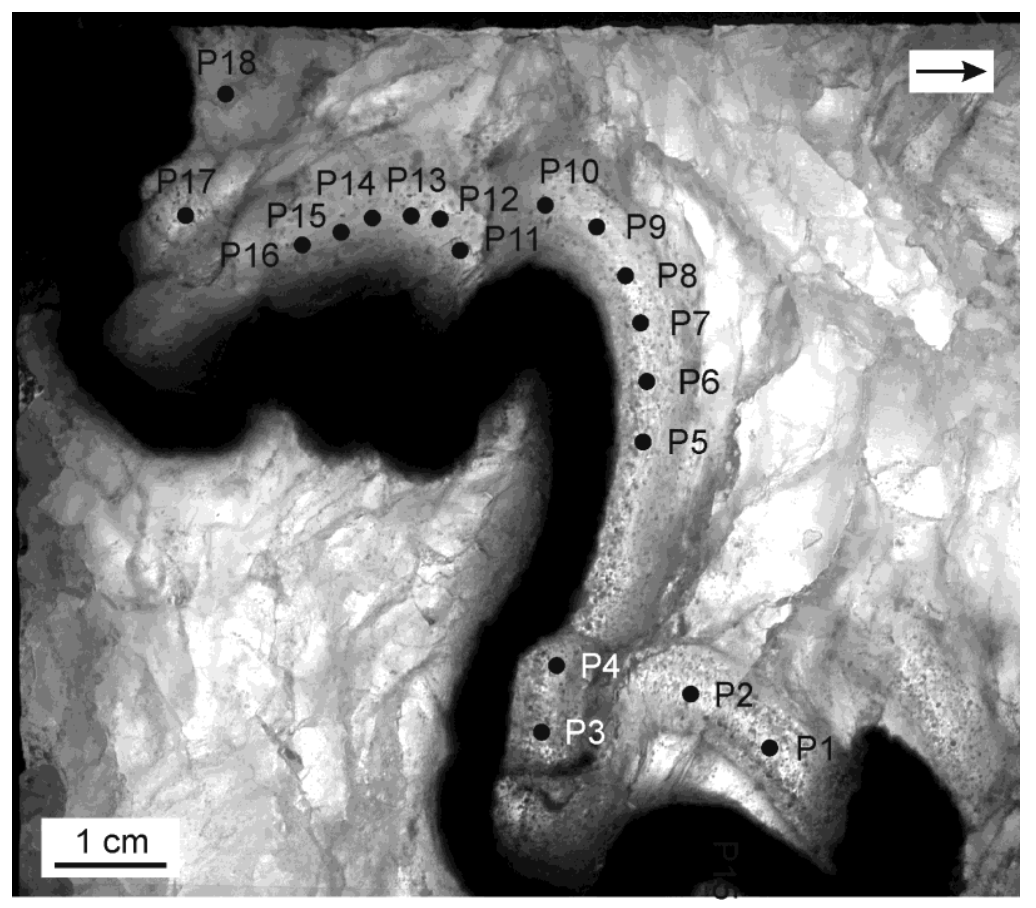

Fig. 4.31: Thick section photograph of sample Lt62-3-151 showing the 18 measuring points for the Xray texture measurements on the Kristallbrocken adjacent to the anhydrite layer. Black arrow in white box indicates stratigraphic up direction.

Similar to the other investigated Kristallbrocken, distinct, strongly developed intensity maxima can be observed in all pole figures. The crystallographic orientation of the crystal lattice is similar within each Kristallbrocken piece, because the positions of the maxima are nearly identical in the pole figures of, e.g., P1 and P2, P5-P10, and P11-P16 (Appendix C5). When adding the pole figures of the measuring points in the various Kristallbrocken pieces, such as P1 and P2, P5-P10, and P11-P16, a constant change in the maxima positions and thus in the crystallographic orientation can be observed (Fig. 4.32) that results from a rotation around a bending axis. A combination of these added pole figures represents the bulk texture of the Kristallbrocken sample and clearly illustrates that this monocrystalline structure was bent or folded, presumably along with the folding of the anhydrite layers. 


\section{$\begin{array}{llc}\text { P11-P16 P5-P10 P1-P2 } & \begin{array}{c}\mathrm{P} 11-\mathrm{P} 16+ \\ \mathrm{P} 5-\mathrm{P} 10+\mathrm{P} 1-\mathrm{P} 2\end{array}\end{array}$}
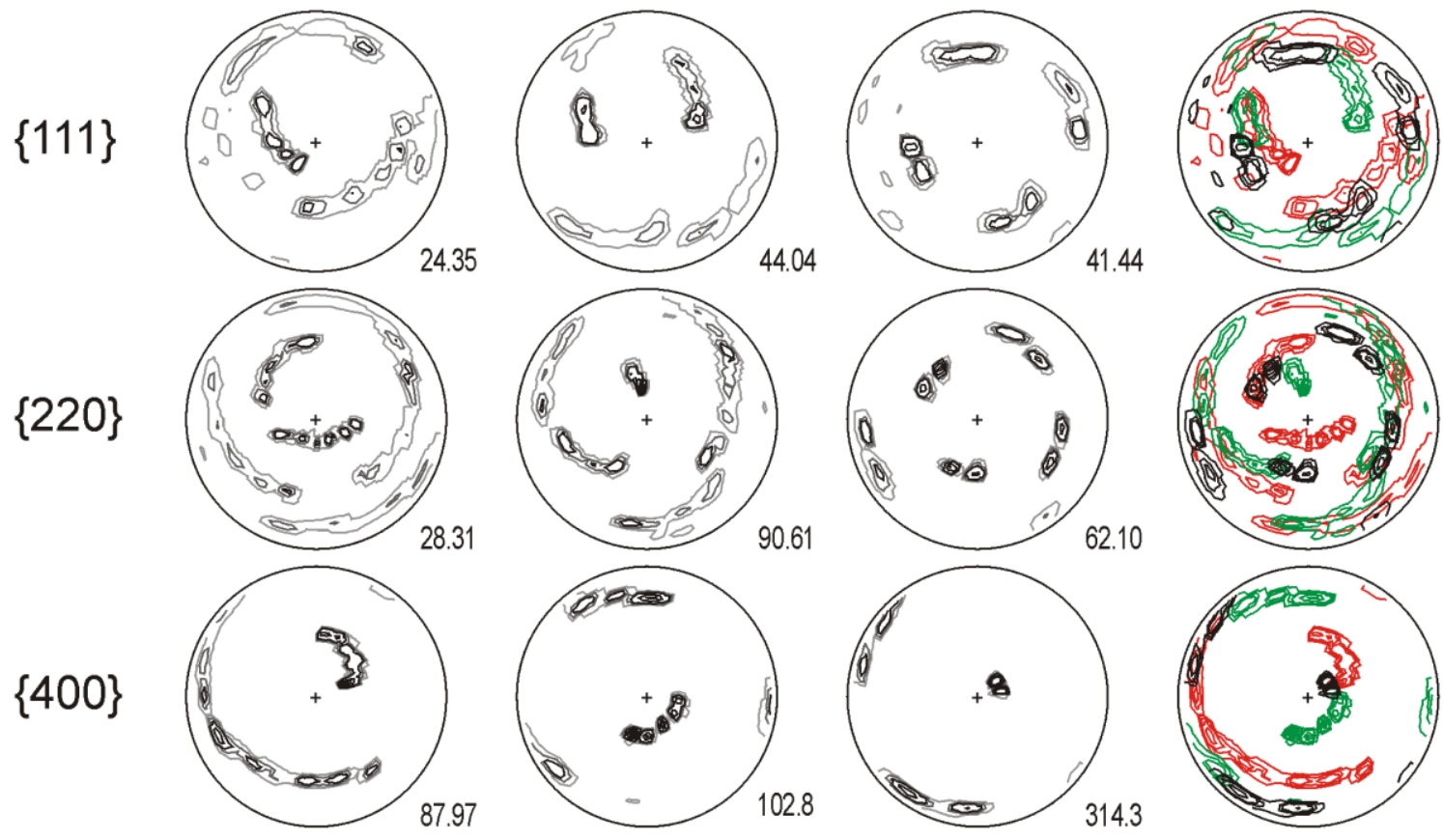

$\{420\}$
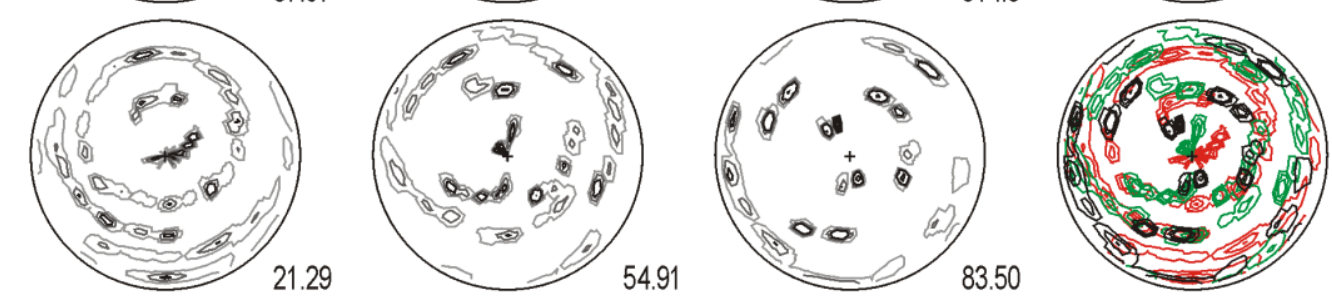

Fig. 4.32: Added pole figures for the reflections $\{111\},\{220\},\{400\}$, and $\{420\}$ of the measuring points P11-P16, P5-P10, and P1-P2 of sample Lt62-3-151 (Fig. 4.31). Lowest contour lines (grey) are equal to 1 and 5 m.r.d. From contour line 10 m.r.d. (black), the contour interval is 20 m.r.d. The pole figure set on the right represents a combination of the three pole figure sets on the left. For comparison, the contour lines are colored in red for P11-P16, in green for P5-P10, and in black for P1$\mathrm{P} 2$. 


\section{DEFORMATION MECHANISMS}

\subsection{Neutron texture analyses of naturally deformed halite rocks - Implications for deformation mechanisms}

Bernd Leiss, Yvonne Küster, Klaus Ullemeyer, Torben Seidel, Michael Schramm, in preparation

\subsubsection{Introduction}

Investigations concerning the development of crystallographic preferred orientations (textures) in halite yield knowledge about deformation mechanisms of rock salt which is important to explain natural deformation processes as well as to understand and predict the long-term rheological behaviour of rock salt formations. From a substantial number of studies that investigated the development of textures in experimentally deformed rock salt (e.g., Kern \& Braun 1973; Skrotzki \& Haasen 1981; Skrotzki \& Welch 1983; Trimby et al. 2000a, b), a variety of well-defined texture types is known. Studies about textures in naturally deformed rock salts are relatively rare (e.g., Clabaugh 1962; Schwerdtner 1966; Goemann \& Schumann 1976, 1977; Kämpf et al. 1986; Ertel et al. 1987) and there are hardly any recent studies (e.g. Schléder \& Urai 2007, Desbois et al. 2010). This is because the measurement of textures in naturally deformed rock salts is especially challenging. Texture analyses with the polarization microscope are not possible due to the optical isotropy of halite, and the applicability of electron- and X-ray diffraction methods is limited, since grain sizes are in the range of $\mathrm{mm}$ to $\mathrm{cm}$, even in shear zones. For statistically representative texture analyses, neutron diffraction is particularly suitable, because the low absorption of neutrons in matter allows measurements 
of large sample volumes - which provides for a good statistical basis even in coarser-grained samples.

Only a few previous texture studies of naturally deformed rock salt show systematic structure/field-related correlations with, e.g., shear zones and fold structures. The aim of this study is therefore a detailed textural characterization of naturally deformed rock salt by correlating textures, measured via neutron texture goniometry, with micro-, macro- as well as large scale salt structures.

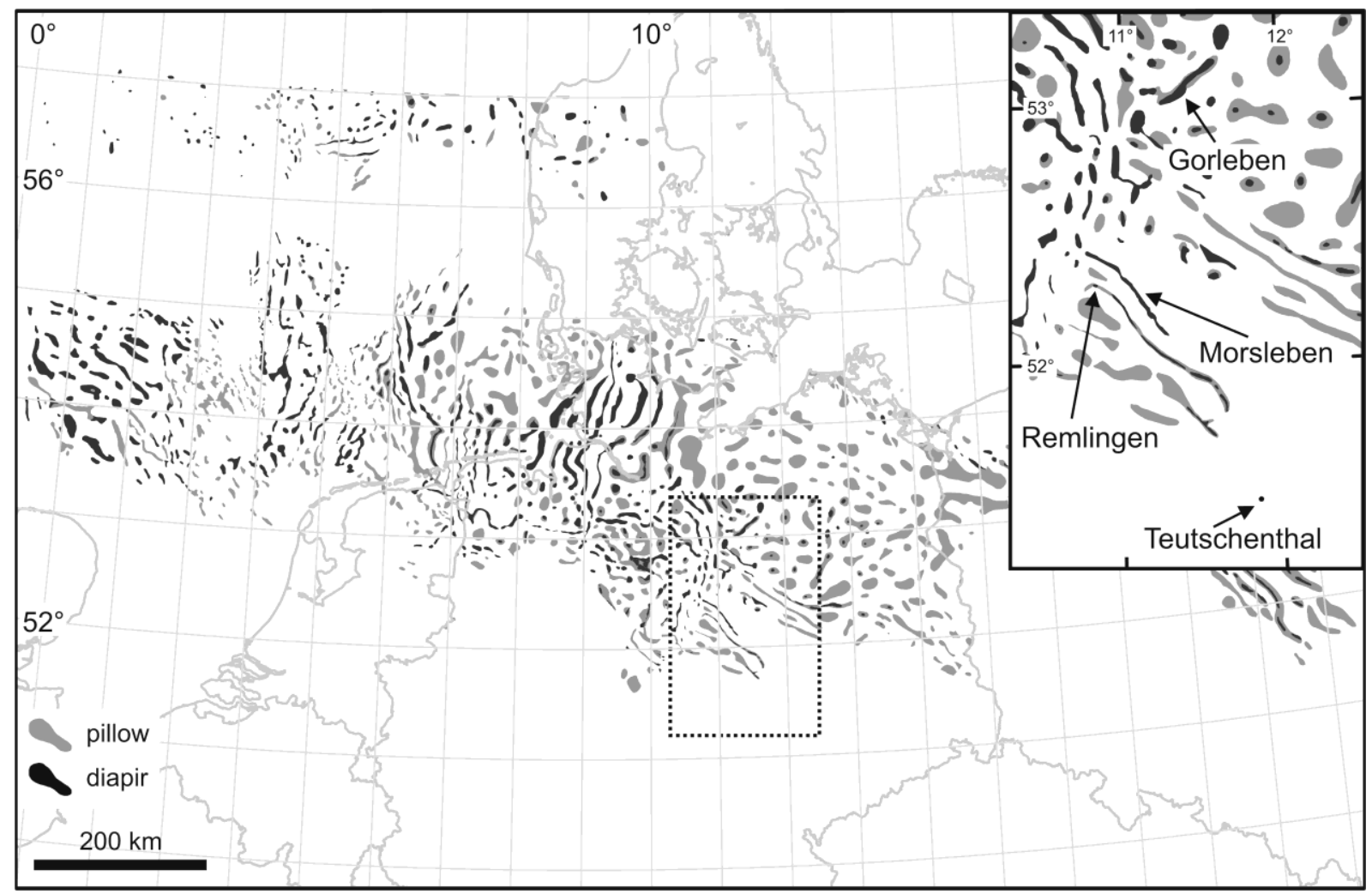

Fig. 5.1: Map showing the salt structures in the former Southern Permian Basin (after Lokhorst 1998). Inserted rectangle shows the location of the salt structures investigated in this study.

\subsubsection{Samples and methods}

Sample material for the first four neutron texture measurements (Seidel et al. 2006) was obtained from drilling cores of various salt structures in northern Germany, namely Gorleben, Morsleben, and Teutschenthal, all situated in the former Southern Permian Basin (Fig. 5.1). The deformation history and intensity of these salt structures is different, varying from a salt pillow structure in Teutschenthal to a diapiric structure in Gorleben. The samples were preferably taken from core segments that show significant grain shape preferred orientations and relatively small grain sizes (long axis several $\mathrm{mm}$ ). These segments were interpreted to represent mylonitic shear zones and were well comparable to observations directly made in 
\begin{tabular}{l}
$\begin{array}{l}5.1 \text { Neutron texture analyses of naturally deformed halite rocks - Implications for } \\
\text { deformation mechanisms }\end{array}$ \\
127 \\
\hline
\end{tabular}

the drifts of the Morsleben salt mine at a larger scale (Fig. 5.2). The samples belong to the Stassfurt Formation (Z2) of the Zechstein Group.

In this study, measurements were carried out at the Time-Of-Flight neutron texture diffractometer SKAT at the research reactor IBR-2 in Dubna, Russia, that allows sample diameters up to $50 \mathrm{~mm}$ (e.g., Ullemeyer et al. 1998). For the measurements, cube-shaped, cylindrical and spherical samples with dimensions up to five centimetres were prepared.

\subsubsection{Results and discussion}

Samples from Morsleben and Gorleben show clear grain shape anisotropies (Fig. 5.3; Seidel, 2006). Grain sizes range between 1 and $10 \mathrm{~mm}$. In general, the grains' aspect ratio is between 2 and 2.5. Samples from Teutschenthal show only weak grain shape anisotropy (Fig. 5.3C).
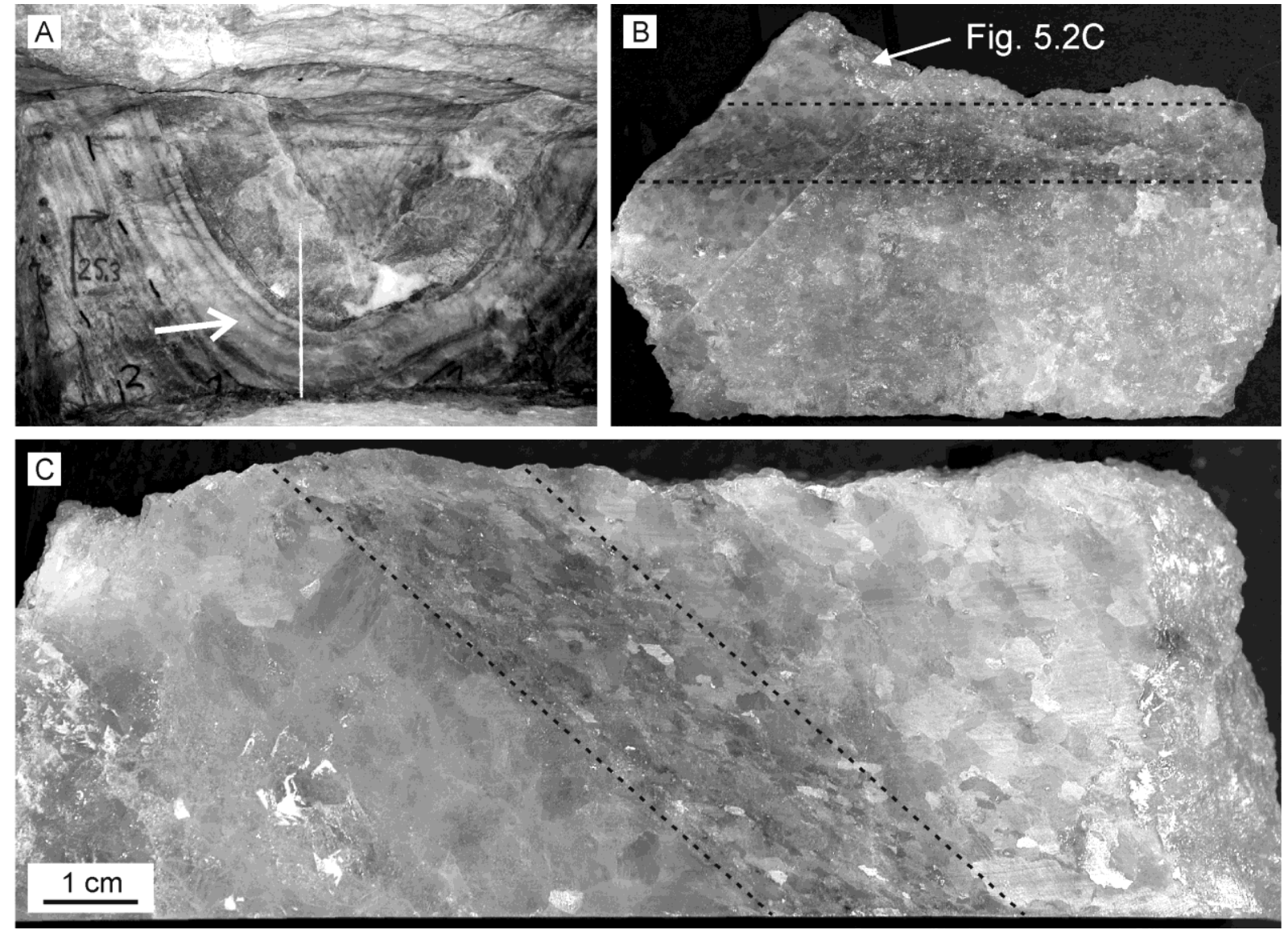

Fig. 5.2: A) Synclinal fold of rock salt in the Morsleben salt mine. The layers in dark grey are shear zones. The white arrow indicates the approximate position where the sample shown in Fig. 5.2B was taken from. B) Sample of the fold shown in Fig. 5.2A. The dashed lines mark the shear zone. C) Detailed view (clockwise rotated about $45^{\circ}$ ) of a segment cut from the upper left of the sample in Fig. 5.2B. The sample surface was ground and polished. Note the large difference in grain size between the shear zone and the adjacent rock salt as well as the strong shape preferred orientation of the grains in the shear zone.

The pole figures of the first four measured samples show no crystallographic preferred orientation (Seidel et al. 2006). Further neutron texture measurements have been carried out 
on 14 samples from Morsleben, Gorleben, Teutschenthal, and Remlingen (Asse), and, in addition to the Stassfurt Formation rock salt, sample material of the Leine (Z3) and the Aller (Z4) Formation as well as the Muschelkalk (Middle Triassic) group was studied. The results of these measurements support the findings of Seidel et al. (2006). All data sets are currently analyzed and prepared for publication.
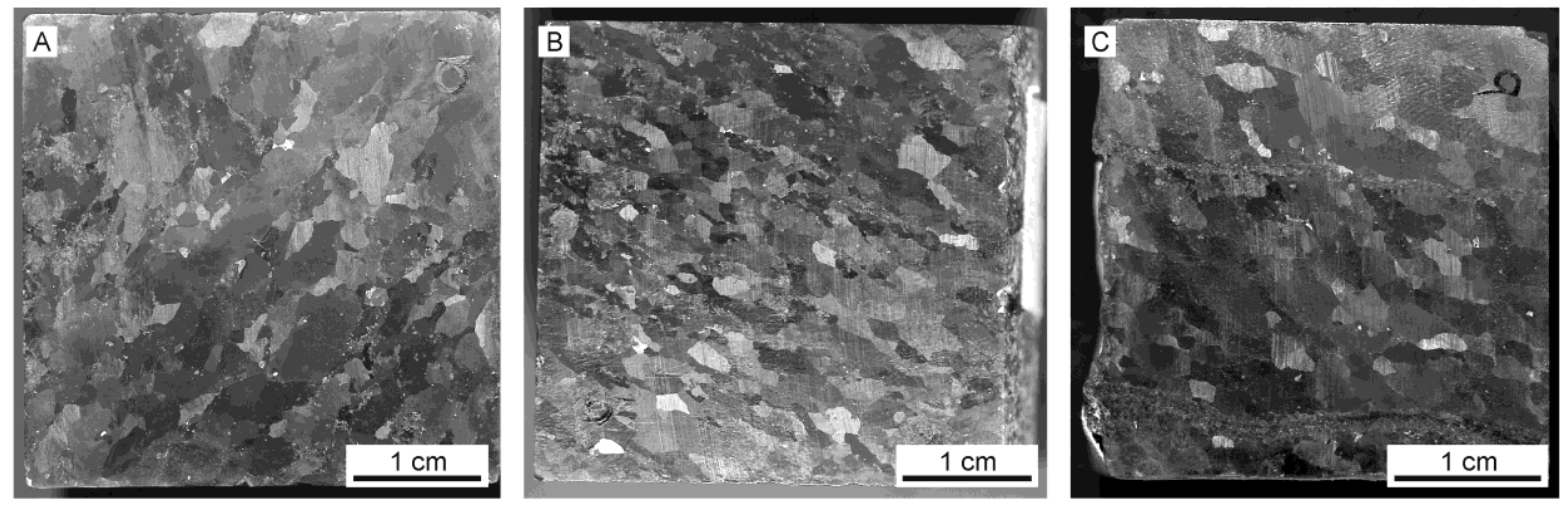

Fig. 5.3: Reflected light photographs of rock salt samples from Gorleben (A), Morsleben (B) and Teutschenthal (C) measured via neutron texture goniometry (modified from Seidel et al. 2006).

The lack of a crystallographic preferred orientation in these samples demonstrates that deformation of the rock salt was not or only subordinately controlled by intracrystalline slip. Therefore, other deformation mechanisms have to be considered to explain the random texture. Natural rock salt samples always contain certain amounts of brine in the form of fluid inclusions or as film at the grain boundaries (Roedder 1984). Due to the high solubility of halite, the presence of only small amounts of brine (>10 ppm) can change the deformation mechanism from dislocation to solution-precipitation creep (e.g., Urai et al. 1986b, Spiers et al. 1990; Peach et al. 2001; Pennock et al. 2006; Urai \& Spiers 2007). I.e. fluid assisted mechanisms such as fluid assisted grain boundary migration or solution-precipitation creep may prevent the development of a crystallographic preferred orientation. This argumentation agrees with the findings of studies made on experimentally deformed rock salt (e.g., Trimby et al. 2000a, b) that demonstrate a lack of texture in pole figures of wet samples (water content $\sim 60 \mathrm{ppm})$.

The results of this study clearly demonstrate that, in nature, the deformation processes of halite need much more attention for the setup of rheological models related to the application of using salt structures as hydrocarbon storage caverns or as host rocks for the disposal of radioactive waste. 


\subsection{Water content}

The analytical results of the water content determination are presented in Tables A.10-A.12 and Fig. 5.4. Prior to the analysis, the selected drilling core sections were divided into three (Gorleben) or five (Teutschenthal, Morsleben) parts in order to check the homogeneity of water content distribution. In Fig. 5.4, the water content of each part is plotted against a standardized depth in the Hauptsalz from which the drilling core sections were obtained.

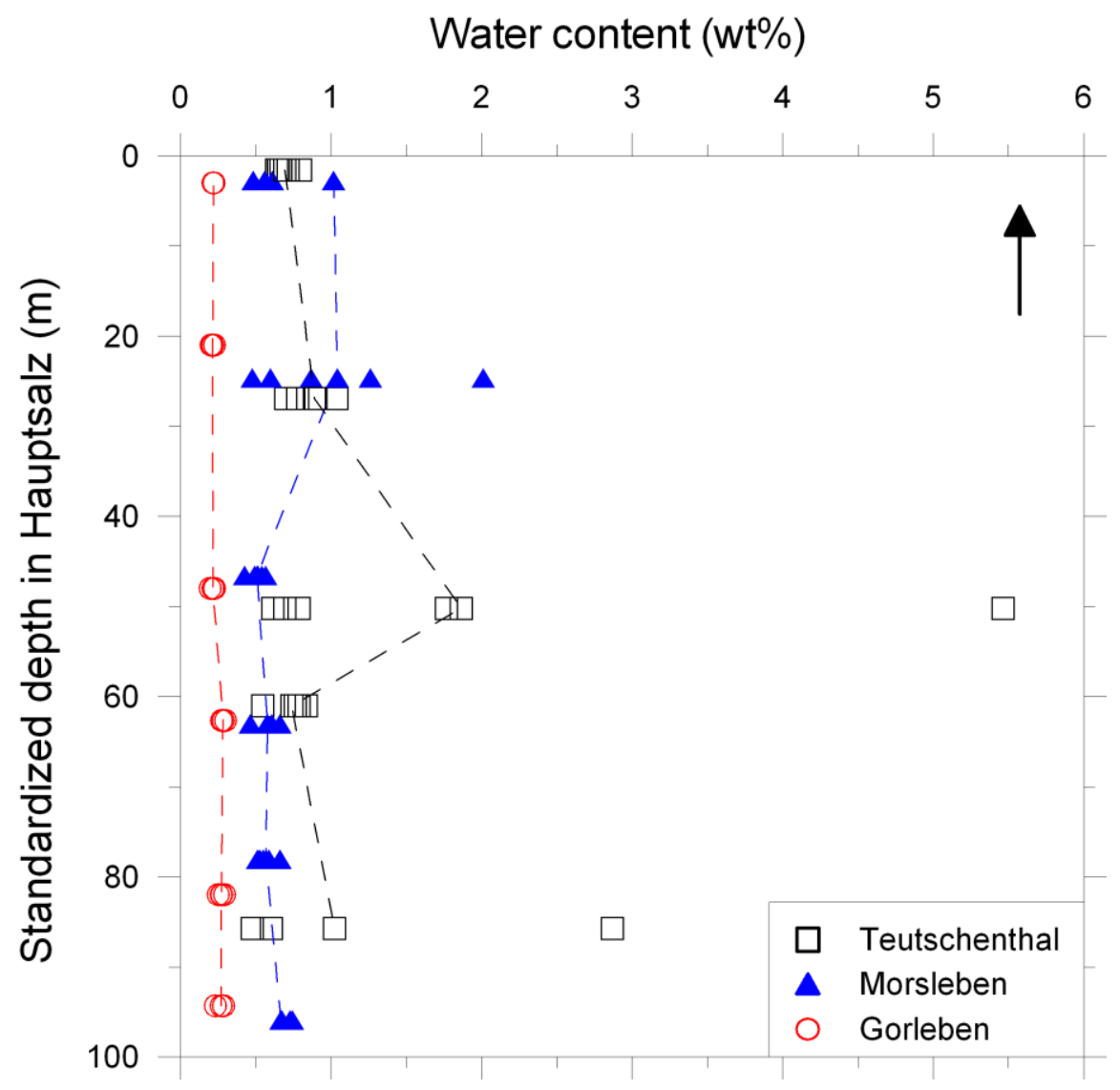

Fig. 5.4: Water content distribution throughout the Hauptsalz of Teutschenthal, Morsleben, and Gorleben. Each drilling core section was divided into 3 (Gorleben) or 5 (Morsleben, Teutschenthal) parts, and the results of the separately analyzed sections are plotted against a standardized depth in the Hauptsalz. The dashed line joins the average values of the drilling core slabs of each location. The black arrow in the upper right indicates the stratigraphic up direction of the Hauptsalz.

In Gorleben, the water content is relatively constant throughout the drilling core, with averaged $0.27 \mathrm{wt} \%$ in the lower parts of the Hauptsalz decreasing to averaged $0.25 \mathrm{wt} \%$ and $0.22 \mathrm{wt} \%$ in the middle and upper parts, respectively. There is only a very small difference in water content between the separately analyzed parts of each drilling core section (Fig. 5.4; Table A.12). In the Hauptsalz of Morsleben, the water contents are generally slightly higher than those in the same section of Gorleben. The water content is relatively constant in the 
lower and middle parts of the Hauptsalz, with values between $0.43 \mathrm{wt} \%$ and $0.74 \mathrm{wt} \%$ and an average of $0.62 \mathrm{wt} \%$ and $0.54 \mathrm{wt} \%$, respectively (Table A.11). In the upper parts of the rock salt, the average water content is $1.03 \mathrm{wt} \%$, and the water content distribution across the drilling core sections is not as homogeneous as in Gorleben (Fig. 5.4; Table A.11). In the rock salt of Teutschenthal, the average water content of the sampled drilling core sections ranges from $0.69 \mathrm{wt} \%$ to $1.89 \mathrm{wt} \%$ (Table A.10). In the drilling core sections at about $50 \mathrm{~m}$ and $85 \mathrm{~m}$, the water content distribution is relatively inhomogeneous, with individual parts of the drilling core sections yielding values of $2.87 \mathrm{wt} \%$ and $5.46 \mathrm{wt} \%$, respectively (Fig. 5.4; Table A.10). In comparison to Gorleben, water contents in Teutschenthal are higher throughout the whole Hauptsalz, and compared to Morsleben, they are higher in the lower parts of the Hauptsalz and partly slightly lower in its upper parts (Fig. 5.4). 


\section{OVERALL RESULTS, CONCLUSIONS, AND OUTLOOK}

\subsection{Overall results}

The main aims of the studies presented in this thesis (Chapters 3 to 5) are threefold: First, to show a possible relationship between deformation intensity and bromide characteristics of the rock salt, based on bromide data sets from Stassfurt Formation rock salt deposits of 3 different tectonic settings as well as microstructural investigations of this rock salt. Second, to contribute to the understanding of the nature, the formation, and the deformation mechanisms of a special, laminated halite type (Kristallbrocken) that occurs in the Stassfurt Formation rock salt, based on X-ray texture analyses on this halite type as well as detailed optical and scanning electron microscopy of its lamination. Third, to detect textures in naturally deformed rock salt via neutron texture goniometry, based on drill core samples from different salt deposits in Germany, and to correlate them with micro-, macro- as well as large scale salt structures.

\subsubsection{Summary and discussion of chapter 3}

Chapter 3 describes the results of various bromide studies concerning a defined stratigraphic section (Hauptsalz) of the Stassfurt Formation rock salt. A bromide data set is presented for three salt deposits, with bedded salt (Teutschenthal) compared to domal salts (Morsleben, Gorleben). This data set also includes a distinction between the two different halite types of the Hauptsalz (matrix, Kristallbrocken) and is complemented by the results of microstructural investigations. Additionally, chapter 3 contains the results of the detailed sampling of the 
Kristallbrocken, the bulk analysis of the drilling cores of the three salt deposits as well as the bromide content determination via electron microprobe. All these investigations have been helpful in answering the following questions:

1. What are the characteristics of the bromide profiles in the three studied locations? How do the three bromide profile trends differ from each other?

2. What are the microstructural characteristics of halite in the studied locations?

3. Does the different deformation history have an influence on the bromide distribution of the different locations?

4. Are the petrographic differences between the two halite types reflected in the bromide content, and if so, does this considerably influence the trend of the bromide profile?

In all studied locations, the bromide profile of the Hauptsalz is characterized by relatively low bromide values in the lower part of the Hauptsalz and more or less steeply increasing bromide values in the upper part. From this follows that the characteristic trend of the bromide profile was generally preserved in both the bedded and the more intensely deformed domal salts. A more detailed comparison shows that, in the bedded salt of Teutschenthal, the dispersion of bromide contents along the running average curve in both the Kristallbrocken and matrix halite is quite high, especially in the upper part of the Hauptsalz. This is in good agreement with the results of detailed sampling of the Kristallbrocken, where the bromide contents vary considerably within particular drilling core slabs. In contrast, the bromide profiles of the domal salts are quite smooth. Furthermore, in the upper half of the Hauptsalz, the average bromide contents are lower in the bedded salt than in the domal salts.

Reflected light examination of etched sample surfaces revealed a quite similar microfabric of matrix halite for the three locations. In all samples from each location, evidence for intracrystalline deformation and recrystallisation can be observed, i.e. the microstructural investigations revealed no significant differences within the Hauptsalz section and between the three studied locations, although they belong to different tectonic settings.

Microstructural investigations have shown that the clearly different regional deformation intensities at the various locations are not reflected in the microfabrics. However, the macrofabric of the Hauptsalz in Morsleben and Gorleben differs considerably from the one in Teutschenthal, as deformation-related processes have destroyed the original sedimentary fabric during salt migration. As a consequence, the Hauptsalz contains less Kristallbrocken and higher amounts of matrix halite, the grain size distribution is more homogeneous, and anhydrite mainly occurs as a fine dispersion in the rock salt or as layer 
fragments and nodules. The comparison of the bromide profiles of the bedded salt of Teutschenthal and the domal salt of Morsleben and Gorleben clearly indicates a relationship between salt migration-related processes and bromide distribution. For example, the absence of laminated Kristallbrocken in the lower half of the domal salt and the results of microstructural investigations demonstrate that this halite type must have been recrystallised during salt migration, thereby forming the clear, medium to coarse grained matrix halite. The comparatively smooth bromide profile in the lower half of the Hauptsalz in Morsleben and Gorleben is most likely associated with a redistribution of bromide that eventually results in a homogenization of the varying bromide contents. In contrast, in the upper half of the Hauptsalz, the Kristallbrocken are still present and the dispersion of bromide contents along the running average curve is higher than in the lower part, but still lower than that in the same part of the profile in Teutschenthal. These results can be explained either by an initially higher dispersion of bromide contents in the upper part of the profile (similar to Teutschenthal) or by varying degrees of deformation across the Hauptsalz during salt migration, i.e. the upper half of the Hauptsalz was subjected to less intense deformation than the lower half.

Selective sampling of the Kristallbrocken and matrix halite revealed a disparity in bromide content between the different halite types, e.g. bromide contents in the Kristallbrocken are comparatively lower than those in the matrix halite like in Teutschenthal, or vice versa like in Gorleben. In the bedded salt of Teutschenthal, the average bromide contents of both studied halite types differ significantly from each other, whereas in the studied domal salts, the average bromide contents lie more closely together. However, the trend of the average bromide curve is similar in both halite types, namely characterized by continuously increasing bromide values from bottom to top. Detailed sampling of Kristallbrocken halite in drilling core slabs also shows that, from the lower part of the Hauptsalz section upwards, the average bromide content of the Kristallbrocken increases. From this follows that the differences in bromide content between the two halite types do not considerably influence the general trend of the bromide profile.

The bromide content determination of the bulk samples yielded values that lie clearly above the running average curve through the bromide values of the samples taken by $1 \mathrm{~mm}$ drill bits. This result can be observed in all 3 studied locations and may have different explanations. One hypothesis could be the accidental sampling of the bromide-richer brine in fluid inclusions, as sampling was carried out with a larger drill bit size. As the bromide content of included brine is generally considerably higher than that of the solid (halite $D_{\mathrm{Br}}<1$ ), a contribution of fluid inclusions would result in higher bromide contents. In Teutschenthal, the 
values seem to be still higher than those of Morsleben and Gorleben, which may also be due to the fact that the bulk samples were only taken across certain drill core sections $(70 \mathrm{~cm}$ long), i.e. these samples may therefore not be representative enough. Another difference between bulk and detailed sampling is the amount of material available for the analyses and thus also the used analytical method. From the bulk samples, more material was available and thus the whole sample could be analyzed by ICP-OES, whereas the other samples contained less material making a separate analysis of anions and cations necessary.

The average bromide content of the Kristallbrocken analyzed via electron microprobe agrees with the value obtained by wet chemical analysis. This demonstrates that the electron microprobe is a suitable means for the determination of the bromide content, especially when a more detailed resolution is necessary. In the example of this study, the similar bromide contents within the bent layer indicate that the whole Kristallbrocken crystal was originally parallel to the depositional surface. The preservation of the bromide contents suggests that the deformation of this halite type did not have any influence on the bromide distribution demonstrating that folding probably took place without the presence of brine.

\subsubsection{Summary and discussion of Chapter 4}

The rock salt of the Stassfurt Formation (Z2) contains a characteristic halite type that was discussed in former literature only marginally. The characteristic of this halite type is the internal lamination that makes it look like a sedimentary halite bed, while it does not show any macroscopically visible grain boundaries inside. Chapter 4 presents the results of X-ray texture measurements as well as of SEM investigations of the solid inclusions in this halite type. These results provide insight into the following set of questions:

1. What is the nature of the Kristallbrocken? Are they relics of very fine-grained, polycrystalline halite beds or clasts of 'single crystal-layers', or can they be regarded as postdeformational blasts?

2. Which kinds of inclusions build up the internal lamination of this halite type and how did they form?

3. What are the deformation mechanisms of the Kristallbrocken?

4. When and how did this halite type form and deform?

With the local X-ray texture measurements on the various Kristallbrocken samples described in Chapter 4.1 and 4.3, it could be clearly evidenced that the Kristallbrocken are single 
crystals and that separated pieces of this halite type formerly formed one single monocrystalline halite layer.

Investigations by optical microscopy and scanning electron microscopy have shown that the laminae within the Kristallbrocken can contain several types of solid inclusions: (1) anhydrite aggregates enclosed by solution, (2) anhydrite crystals or aggregates directly included in the halite crystal, and (3) polyhalite crystals, partly together with anhydrite, enclosed in cavities. The large number of anhydrite crystals within these inclusions as well as the presence of brine around the aggregates suggests that the solid inclusions are not the daughter crystals of a fluid inclusion or the result of accidental trapping during halite crystal growth. The most plausible explanation, for the formation of the anhydrite aggregates with surrounding solution, is that the original deposit was of gypsum aggregates, incorporated during the formation of the monocrystalline beds. This was followed by a solid volume reduction in consequence of a complete gypsum-anhydrite conversion that yielded fluid together with anhydrite crystals together with the partial internal dissolution of halite due to the released undersaturated water. The presence of anhydrite crystals or aggregates without surrounding solution in the same samples indicates that some of these sulfates already existed before the monocrystalline bed formed. The same applies for the polyhalite crystals as it is not plausible that the polyhalite crystals formed from gypsum or anhydrite inside the inclusions.

The investigations in this thesis demonstrated that Kristallbrocken show both ductile and brittle deformational behavior. The clearly stronger rheological properties of this halite type compared to the surrounding fine- to coarse-grained polycrystalline rock salt can be explained by the monocrystallinity of the Kristallbrocken and their formerly large size. In addition, the rigidity of this halite type is further enhanced by the partially high solid inclusion content. The bulk texture of the folded Kristallbrocken clearly illustrates that the monocrystalline structure was bent or folded as a whole. The deformation mechanism is assumed to be a kind of flexural-shear folding, with the lattice planes of the single crystal operating as shear planes. The most probable slip system seems to be $\{110\}<110\rangle$, which shows the lowest critical resolved shear stress in halite at all temperatures. To enable such a bending process, the crystal lattice of the Kristallbrocken must have a certain orientation in respect to the stress field, and the solid inclusion content is supposed to be relatively low.

From the results of this study, it can be inferred that the Kristallbrocken fabrics from Teutschenthal represent an earlier stage of deformation of the 'single crystal-layers' than the Kristallbrocken fabrics from locations with more intensely deformed Stassfurt rock salt. For the formation of the Kristallbrocken halite type, a post-sedimentary process is assumed. At 
first, fine grained halite and sulphate crystals are precipitated and form a polycrystalline halite layer. In a second stage, this layer is subjected to syndiagenetic grain growth, e.g. by grain boundary area reduction (GBAR) or coalescence, that finally leads to the formation of the 'single crystal-layer'. This monocrystalline Kristallbrocken layer is deformed in a third stage due to salt migration-related processes. Clear indications for the grain growth mechanism could not be found. This is especially difficult, since also the Kristallbrocken from Teutschenthal are slightly deformed and therefore the intracrystalline microstructures are overprinted.

The results of the X-ray texture measurements on the same, but differently prepared Kristallbrocken sample (section 4.3.1) clearly demonstrate that the preparation has an influence on the measurements. The lowest contour lines in the pole figures are slightly or considerably elongated in distinct directions (Fig. 4.29), and these directions correlate with the grinding and polishing direction (Fig. 4.28). This suggests that the sample must have been affected through the preparation procedure. Presumably, the uppermost parts of the crystal lattice have been bent by polishing (Fig. 6.1), resulting in elongated contour lines in the pole figures. As only a relatively small volume of the sample was impacted, the bending can only be realized in the lowest contour lines.

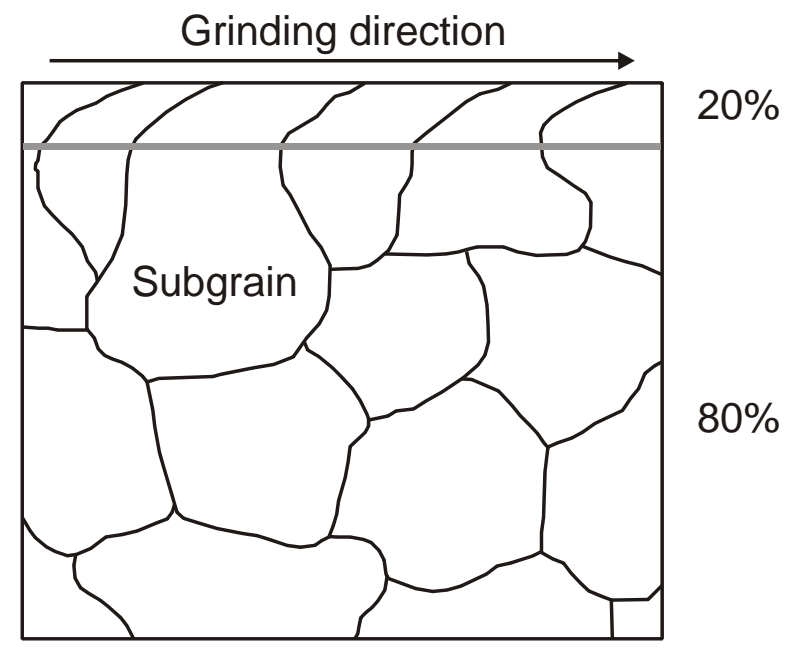

Fig. 6.1: Potential influence of grinding on the sample surface. The uppermost part of the crystal lattice is affected by grinding and polishing and leads to bending of the crystal lattice.

\subsubsection{Summary and discussion of Chapter 5}

Chapter 5 describes the results of neutron texture measurements (chapter 5.1) as well as water content analyses (chapter 5.2) of rock salt samples from the salt deposits Teutschenthal, Morsleben, and Gorleben. 


\subsubsection{Texture measurements}

In this study, four rock salt samples from the salt deposits Teutschenthal, Morsleben, and Gorleben were examined. Grain shape preferred orientations and a relatively small grain size (long axes max. several $\mathrm{mm}$ ) implied that these samples represent mylonitic shear zones. Such fabric can also be a typical indication for plastic deformation. However, neutron texture measurements did not show any crystallographic preferred orientations (textures) in these samples. These findings indicate that intracrystalline deformation mechanisms such as dislocation creep or dislocation glide can not be the dominating deformation mechanism during the deformation of the investigated rock salt. This, however, is in contrast to literature about experimentally deformed and annealed rock salts from which a variety of well-defined texture types is known. The lack of a texture in naturally deformed rock salts can possibly be explained by the presence of water, as already small amounts of brine (>10 ppm) can change the deformation mechanism from dislocation to solution-precipitation creep (e.g., Urai et al. 1986b, Spiers et al. 1990; Peach et al. 2001; Pennock et al. 2006; Urai \& Spiers 2007). Fluid assisted deformation mechanisms such as solution-precipitation creep or fluid assisted grain boundary migration may therefore prevent the development of a crystallographic preferred orientation. This argumentation is in agreement with the findings of studies made on experimentally deformed rock salt (e.g., Trimby et al. 2000a, b) that demonstrate a random texture in the pole figures of wet samples (water content $\sim 60 \mathrm{ppm}$ ). Furthermore, argumentation is supported by the relatively high water contents of the rock salts from Teutschenthal, Morsleben, and Gorleben (chapter 5.2).

\subsubsection{Water content analyses}

The knowledge about the water content of a rock salt plays an important role in the characterization of a salt deposit in view of its use as a repository for nuclear waste (e.g., Jockwer 1981; Roedder \& Bassett 1981; Gies et al. 1990; De Las Cuevas \& Pueyo 1995). Particularly the amounts of water present in rock salt as well as the chemical composition of the brine have to be taken into account in the design and the safety assessment of the repository. This is because water can migrate through the repository as a result of thermal gradients induced by the presence of heat generating wastes, corrode the waste containers, and potentially leach the radionuclides present in the waste (e.g., Olander 1982; De Las Cuevas \& Pueyo 1995). The water content is also of considerable importance for the discussion on deformation mechanisms during salt migration, as intergranular water can significantly influence the rheological properties of the rock salt (e.g., Schenk \& Urai 2004; Spiers et al. 1986; Urai 1986b). Furthermore, as demonstrated in section 2.2.6, the amount and distribution 
of water in rock salt affects the quality of sample preparation and thus the quality of microstructural investigations by, for example, reflected light microscopy or EBSD.

The water content analyses of the present study yielded average values ranging between 0.69 and $1.86 \mathrm{wt} \%$ in the Hauptsalz of Teutschenthal, between 0.51 and $1.04 \mathrm{wt} \%$ in the Hauptsalz of Morsleben, and between 0.21 and $0.28 \mathrm{wt} \%$ in the Hauptsalz of Gorleben (Tables A10-A12). In general, the water contents of the various locations reflect the tectonic setting of the corresponding salt deposits insofar as the average water content is highest in the bedded rock salt of Teutschenthal and comparatively lower in the domal rock salts of Morsleben and Gorleben. The lower amounts in domal salts can be most satisfactorily explained with the emplacement of the salt dome, during which the bulk of the original water is lost. In principle, the results are also in the range of water contents usually expected for domal salts (0.00X to 0.X wt \%) and bedded salts (X wt \%) (Roedder \& Bassett 1981). However, there is a clear discrepancy to former water content determinations of similar Gorleben rock salt samples, which yielded water contents of averaged 0.014 wt \% (Sander \& Herbert 2000), i.e. values one order of magnitude lower than the present results.

A very probable reason for this discrepancy might be the different preparation technique prior to the analysis. In earlier studies, samples have been reduced to small pieces in a jaw crusher and then a representative sample was obtained from the homogenized sample material. However, during this process, a certain amount of brine might have been removed from the samples due to friction heat, and this might explain the consistently lower water contents of these samples. In the present study, such water loss could be largely excluded, since the samples were crushed to small pieces inside a hermetically sealed PE foil. Another difference between the analyses is the analytical method itself. Although the water content of all samples was determined according to Karl-Fischer titration (e.g., Jockwer 1981), the water extraction procedures were carried out in different ways. In former analyses, water was released via heating the sample material to $500^{\circ} \mathrm{C}$, whereas in this study water is extracted by using water-free, dried 1,4-dioxane, an organic compound that is miscible with water. Potentially, the heating rate was not high enough to induce fracturing of the salt and the release of all the intracrystalline water (cf. Roedder \& Basset 1981), i.e. the results of earlier analyses might have been generally too low. Unfortunately, both analytical techniques have not been compared with each other yet, therefore it is not clear which of them provides results closest to reality. 


\subsection{Conclusions}

The comparison of the bromide characteristics of rock salt from salt deposits of different tectonic settings aimed to show a possible relationship between deformation intensity and bromide characteristics of the rock salt. This approach was complemented by microstructural investigations that were carried out to show to what extent the different deformation history of the salt deposits is reflected in the microstructural characteristics of the rock salt. From the results it can be concluded that, on the one hand, there are clear indications for the influence of salt migration-related processes on the bromide distribution characteristics insofar that there is a lower dispersion of the bromide contents in the domal salts. It implies that these processes are associated with a redistribution of bromide, which eventually results in a homogenization of the originally varying bromide contents. On the other hand, the characteristic trend in the bromide profiles was preserved in both the bedded and the more intensely deformed domal salts indicating that large-scale brecciation, folding processes, or circulating bromide-rich fluids played only a minor role during the formation of the salt domes. The differences in bromide content between the two halite types do also not considerably influence the general trend of the bromide profile.

Local X-ray texture measurements could clearly evidence that the laminated Kristallbrocken halite type from the Stassfurt Formation rock salt is monocrystalline and that separated pieces of the Kristallbrocken formerly formed one single monocrystalline halite layer. The studied halite type shows brittle as well as ductile deformation behavior. Optical microscopy and SEM analyses revealed that the solid inclusions forming the internal lamination are anhydrite/polyhalite crystals and aggregates. The brittle behavior of Kristallbrocken can be well explained by their monocrystallinity, their formerly large size, and the partially high solid inclusion content. For the formation of the studied halite type, a post-sedimentary process is assumed that is based on coalescence or grain growth by grain boundary migration of a formerly fine-grained, laminated halite sediment. Clear indications for the grain growth mechanism could not be found. This is especially difficult, since also the Kristallbrocken from the bedded salt of Teutschenthal are slightly deformed and therefore the intracrystalline microstructures are overprinted.

The results of neutron texture investigations on naturally deformed rock salt demonstrate a random texture, i.e. a lack of crystallographic preferred orientations, although the samples show clear grain shape preferred orientations. The proof of such a 'non-texture' strongly indicates that deformation of natural rock salt in the shear zones is not or only subordinately controlled by intracrystalline slip. It is largely controlled by fluid assisted 
deformation mechanisms like solution-precipitation creep or fluid assisted grain boundary migration as it is increasingly postulated in the literature for long-term deformations (e.g. Urai \& Spiers 2007). The relatively high water contents of the rock salt samples from the same salt deposits support this argumentation, as already small amounts of water can lead to solution/precipitation or diffusion processes (Urai et al. 1986b; Spiers et al. 1990). The results of this study clearly demonstrate that the deformation mechanisms of natural rock salt still need attention for the setup of rheological models related to the application of using salt structures as hydrocarbon storage caverns or as host rocks for the disposal of radioactive waste.

\subsection{Outlook}

This study has been very illuminative concerning the nature and the deformational behavior of the halite type Kristallbrocken. However, the formation of this halite type is still not resolved conclusively. The problem is that there seem to be no suitable analogs, neither for giant, primarily grown halite crystals containing high amounts of relatively large solid inclusions nor for grain growth or coalescence processes in rock salt or other rocks yielding a comparable monocrystalline fabric in a similar scale. Although it seems very unlikely that the Kristallbrocken halite type is the result of primary growth, a scientific proof would be helpful to clarify this point conclusively. Future research should thus attempt a quantitative chemical analysis of the brine surrounding the solid inclusions in this halite type, with a special attention on bromide contents. This could potentially be achieved by the ESEM-EDS technique (Timofeeff et al. 2000), which is an X-ray microanalysis of frozen fluid inclusions. Problems could be the absence of a flat horizontal working surface due to an irregular distribution of the brine around the solid inclusions as well as the very low brine volume.

The results of this study demonstrated that bromide content analyses can also be carried out via electron microprobe. This opens possibilities to examine small-scale differences in the bromide distribution of the Kristallbrocken, which may provide more information about the formation of this halite type. For example, it would be interesting to know if the variation in sea water salinity is also reflected in Kristallbrocken samples, especially in those with polyhalites as solid inclusions.

Another interesting point that may improve the understanding of the formation of the Kristallbrocken is their crystallographic orientation in relation to the bedding or the foliation of the whole rock salt sequence. The results presented in chapter 4.1 and 4.3 should therefore be supplemented by texture analyses of a set of individual Kristallbrocken pieces from various drilling cores. 
The water contents in this study showed a clear discrepancy to the results of former analyses, with values one order of magnitude higher than in former analyses. This is a critical finding because the long-term safety evaluation of salt deposits as final repositories for radioactive wastes is also based on such data. For that reason, it is very important to explain the discrepancy between the results. Both studies used the same method (Karl-Fischer Titration), albeit the release of water was accomplished in different ways. Therefore, the two different analytical techniques should be compared with each other at samples with known water contents to see which of them provides results closest to reality.

Future research should include the texture analysis of naturally deformed rock salts. The results of this study should be further supported by additional samples, possibly also by samples from locations that have been investigated in earlier studies (cf., Scheffzük 1999). In addition, it would be important to get samples directly from salt deposits to exclude potential influences by storage in drilling core storage facilities.

Another point that needs some attention is the bromide content analysis of bulk rock salt samples as this study yielded values that lie more or less extensively above the running average curve through the bromide values of separate sampling. To exclude analytical causes, the bulk sample material should be analyzed in the same way as the material of separate sampling, i.e. with a separate analysis of anions and cations by IC and ICP-OES, respectively. 



\section{BIBLIOGRAPHY}

Albrecht, H. and Hunsche, U. (1980). Gebirgsmechanische Aspekte bei der Endlagerung radioaktiver Abfälle in Salzdiapiren unter besonderer Berücksichtigung des Fließverhaltens von Steinsalz. Fortschr. Miner., 58, 212-247.

Anderson, R.Y., Dean, W.E., Kirkland, D.W., and Snider, H.I. (1972). Permian Castile varved evaporite sequence, West Texas and New Mexico. Geol. Soc. Am. Bull., 83, 59-85.

Arthurton, R.S. (1973). Experimentally produced halite compared with Triassic layered halite-rock from Cheshire, England. Sedimentol., 20, 145-160.

Atkinson, H.V. (1988). Theories of normal grain growth in pure single phase systems. Acta Metallurgica, 36, 469-491.

Baar, A. (1954). Investigation of the bromine content in Zechstein salt. Bergbautechnik, 4, $284-288$.

Baar, C.A. (1963). Der Bromgehalt im Steinsalz als stratigraphischer und genetischer Indikator im norddeutschen Zechstein. Z. Deut. Geol. Ges., 115, 572-608.

Bachmann, K. (1985). Mineralogische und geochemische Untersuchungen an Bohrkernen des Staßfurt-Steinsalzes im Salzstock Asse. Kali und Steinsalz, 9, 132-138.

Bachu, S. and Rothenburg, L. (2003). Carbon dioxide sequestration in salt caverns: capacity and long term fate. In: Proceedings of the Second Annual Conference on Carbon Dioxide Sequestration (CD-ROM), Alexandria, VA, May 5-8. Available online at: 
http://www.netl.doe.gov/publications/proceedings/03/carbon-seq/PDFs/011.pdf [Accessed 07 March 2010].

Balzer, D. (1992). Petrologische Untersuchungen von Anhydrit- und Gipsgesteinen an ausgewählten Bohrprofilen aus dem Hutgestein des Allertaldiapirs. Unpublished PhD thesis, University of Greifswald, Greifswald.

Bäuerle, G. (2000). Geochemisch-mineralogische Untersuchungen zur Genese, Lösungs- und Gasführung der Gorleben-Bank (Zechstein 3) im Salzstock Gorleben. Unpublished PhD thesis, Clausthal University of Technology, Clausthal-Zellerfeld.

Behlau, J. and Mingerzahn, G. (2001). Geological and tectonic investigations in the former Morsleben salt mine (Germany) as a basis for the safety assessment of a radioactive waste repository. Eng. Geol., 61, 83-97.

Benison, K.C. and Goldstein, R.H. (1999). Permian paleoclimate data from fluid inclusions in halite. Chem. Geol., 154, 113-132.

Benison, K.C. and Goldstein, R.H. (2000). Sedimentology of ancient saline pans: an example from the Permian Opeche Shale, Williston Basin, North Dakota, U.S.A. J. Sediment. Res., 70, 159-169.

Best, G. (1989). Die Grenze Zechstein/Buntsandstein in Nordwest-Deutschland nach Bohrlochmessungen. Z. Deut. Geol. Ges., 140, 73-85.

Best, G. and Zirngast, M. (1999). Reconstruction of the Structural Development of the Exhumed Upper Allertal Salt Structure. J. of Conference Abstracts, EUG 10, vol. 4, p. 518.

BfS (Bundesamt für Strahlenschutz) (2001). Endlager Morsleben - Das Endlager für radioaktive Abfälle vor der Stilllegung, p. 10, BfS, Salzgitter.

Bobst, A.L., Lowenstein, T.K., Jordan, T.E., Godfrey, L.V., Ku, T.-L., and Luo, S. (2001). A 106 ka paleoclimate record from drill core of the Salar de Atacama, northern Chile: Palaeogeogr., Palaeocl., Palaeoecol., 173, 21-42.

Boeke, H.E. (1908). Über das Krystallisationsschema der Chloride, Bromide, Jodide von Natrium, Kalium und Magnesium, sowie über das Vorkommen des Broms und Fehlen von Jod in den Kalisalzlagerstätten. Z. Kristallogr., 45, 346-391. 
Bornemann O (1987). Die geologische Erkundung des Salzstocks Gorleben. Kerntechnik, 50, $138-142$.

Bornemann, O. (1991). Zur Geologie des Salzstocks Gorleben nach den Bohrergebnissen. BfS-Schriften, 4, 1-67.

Bornemann, O., Fischbeck, R., and Bäuerle, G. (2000). Investigation of deformation textures of salt rock from various Zechstein units and their relationship to the formation of the salt diapirs in NW Germany. In: 8th World Salt Symposium (Ed. R.M. Geertman), vol. 1, pp. 89-94, Elsevier, Amsterdam.

Bornemann, O., Behlau, J., Fischbeck, R., Hammer, J., Jaritz, W., Keller, S., Mingerzahn, G., and Schramm, M. (2008). Standortbeschreibung Gorleben Teil III: Ergebnisse der überund untertägigen Erkundung des Salinars. Geol. Jb., Reihe C, 73, 212 pp.

Braitsch, O. (1962). Entstehung und Stoffbestand der Salzlagerstätten. Springer-Verlag, Berlin, $232 \mathrm{pp}$.

Braitsch, O. and Herrmann, A.G. (1963). Zur Geochemie des Broms in salinaren Sedimenten, Teil I: Experimentelle Bestimmung der Br-Verteilung in verschiedenen natürlichen Salzsystemen. Geochim. Cosmochim. Acta, 27, 361-391.

Brodhag, S., Herwegh, M., Berger, A., and Pfiffner, A. (2007). The role of static processes on microstructures and textures. Geophysical Res. Abstracts, 9, Vienna.

Brokmeier, H.-G. (1994). Application of neutron diffraction to measure preferred orientations of geological materials. In: Textures of geological materials (Eds. H.J. Bunge, S. Siegesmund, W. Skrotzki \& K. Weber.), 327-344, DGM Oberursel.

Bruland, K.W. (1983). Trace elements in sea-water. In: Chemical Oceanography (Eds. J.P. Riley and R. Chester), 8, 157-220, Academic Press, New York.

Bunge, H.J. and Klein, H. (1996). Determination of quantitative, high-resolution pole figures with the area detector. Z. Metallkunde, 87, 465-475.

Camur, M.Z. and Mutlu, H. (1996). Major-ion geochemistry and mineralogy of the Salt Lake (Tuz Gölü) basin, Turkey. Chem. Geol., 127, 313-329. 
Carter, N.L. and Heard, H.C. (1970). Temperature and rate dependent deformation of halite. Am. J. Sci., 269, 193-249.

Carter, N.L. and Hansen, F.D. (1983). Creep of rock salt. Tectonophysics, 92, 275-333.

Carter, N.L., Horsemann, S.T., Russel, J.E., and Handin, J. (1993). Rheology of rocksalt. J. Struct. Geol., 15, 1257-1271.

Chester, R. (2000). Marine geochemistry. Blackwell Science, Oxford, 506 pp.

Chong Diaz, G., Mendoza, M., Garcia-Veigas, J., Pueyo, J.J., and Turner, P. (1999). Evolution and geochemical signatures in a Neogene forearc evaporitic basin: the Salar Grande (Central Andes of Chile). Palaeogeogr., Palaeocl., Palaeoecol., 151, 39-54.

Clabaugh, P.S. (1962). Petrofabric study of deformed salt. Science, 136, 389-391.

Czapowski, G. (1986). Internal lamination in halite rocks. Przeglad Geologiczny, 4 (396), 202-204.

Czapowski, G. (1987). Sedimentary facies in the oldest rock salt (Na1) of the Leba elevation (Northern Poland). In: The Zechstein Facies in Europe: Lecture Notes in Earth Sciences (Ed. T.M. Peryt), 10, 207-224, Springer, Berlin.

Czapowski, G., Antonowicz, L., and Peryt, T.M. (1990). Facies and Palaeogeography of the Zechstein (Upper Permian) Older Halite (Na2) in Poland. Bulletin of the Polish Acadamy of Sciences, Earth Sciences, 38 (1-4), 45-55.

Czapowski, G., Peryt, T., and Antonowicz, L. (1993). Facies and Palaeogeography of the Zechstein (Upper Permian) Oldest Halite (Na1) in Poland. Bulletin of the Polish Acadamy of Sciences, Earth Sciences, 41 (4), 217-227.

Daniel, C.G. and Spear, F.S. (1998). 3-Dimensional patterns of garnet nucleation and growth. Geology, 26, 503-506.

D’Ans, J. and Kühn, R. (1940). Über den Bromgehalt von Salzgesteinen der Kalisalzlagerstätten I-V. Kali, verwandte Salze und Erdöl, 34, 43-46, 59-64, 77-83.

D'Ans, J. and Kühn, R. (1944). Über den Bromgehalt von Salzgesteinen der Kalisalzlagerstätten VI. Kali, verwandte Salze und Erdöl, 38, 167-169. 
De Las Cuevas, C. and Pueyo, J.J. (1995). The influence of mineralogy and texture in the water content of rock salt formations. Its implication in radioactive waste disposal. Appl. Geochem., 10, 317-327.

Desbois, G., Zavada, P., Schléder, Z., and Urai, J.L (2010). Deformation and recrystallization mechanisms in naturally deformed salt fountain: microstructural evidence for a switch in deformation mechanisms with increased availability of meteoric water and decreased grain size (Qum Kuh, central Iran). J. Struct. Geol., 32, 580-594.

Donald, A.M. (2003). The use of environmental scanning electron microscopy for imaging wet and insulating materials. Nature Materials, 2, 511-516.

Downs, R.T., Bartelmehs, K.L., Gibbs, G.V., and Boisen, M.B. Jr. (1993). Interactive software for calculating and displaying X-ray or neutron powder diffractometer patterns of crystalline materials. Am. Mineral., 78, 1104-1107.

Drury, M.R. and Urai, J.L. (1990). Deformation-related recrystallization processes. Tectonophysics, 172, 235-253.

Dusseault, M.B., Bachu, S., and Rothenburg, L. (2004). Sequestration of $\mathrm{CO}_{2}$ in salt caverns. J. Can. Petrol. Technol., 43, 49-55.

Ertel, A., Betzl, M., Paufler, P., and Voitus, W. (1987). Application of neutron diffraction methods to texture on natural rock salt. Cryst. Res. Technol., 22, 209-215.

Eschner, T. (1993). Texture analysis by means of model functions. Texture Microstruct., 21, 139-146.

Es-Said, S.I. (1974). Brom-Untersuchungen zur Genese des Schwadensalzes (Zechstein 3) im Bereich Hannover. Geol. Jb., D 6, 3-59.

Evans, B., Renner, J., and Hirth, G. (2001). A few remarks on the kinetics of static grain growth in rocks. Int. J. Earth Sci., 90, 88-103.

Fisher, R.S. and Hovorka, S.D. (1987). Relations between bromide content and depositional processes in bedded halite, Permian San Andres Formation, Palo Duro Basin, Texas. Carbonate Evaporite, 2, 67-82. 
Garcia Celma, A., Donker, H. (Eds.) (1996). The Effect of Gamma Radiation in Salt. EURReport 16743EN.

García-Ruiz, J.M., Villasuso, R., Ayora, C., Canals, A., and Otálora, F. (2007). Formation of natural gypsum megacrystals in Naica, Mexico. Geology, 35 (4), 327-330.

Gavrieli, I. (1997). Halite deposition in the Dead Sea: 1960-1993. In: The Dead Sea (Eds. T. Neimi, Z. Ben-Avraham, J.R. Gat), 161-171, Oxford University Press.

Geisler, D. (1982). De la mer au sel: les faciès superficiels des Marais Salants de Salin-deGiraud (Sud de la France). Géologie Mediterranéenne, 9, 521-550.

Gies, H., Herbert, H.-J., and Jockwer, N. (1990). Zur Bedeutung der Wassergehalte für die Lithostratigraphie in Steinsalzhorizonten des Zechsteins. Kali und Steinsalz, 10, 265-271.

Goemann, U. and Schuhmann, H. (1976). Über die bevorzugte kristallographische Orientierung der Einzelkristalle in natürlichen Faserhalitaggregaten. Tschermaks Mineral. Petrogr. Mitt., 23, 137-150.

Goemann, U. and Schuhmann, H. (1977).Röntgenographische Gefüge - Untersuchung an einer orientiert entnommenen Probe von grobkörnigem Steinsalz. Tschermaks Mineral. Petrogr. Mitt., 24, 179-190.

Gornitz, V.M. and Schreiber, B.C. (1981). Displacive halite hoppers from the Dead Sea: some implications for ancient evaporite deposits. J. Sediment. Petrol., 51, 787-794.

Gottesmann, W. (1963). Eine häufig auftretende Struktur des Halits im Kaliflöz Staßfurt. Geologie, 12, 576-581.

Griffith, A.A. (1924). The theory of rupture. In: Proc 1st Int. Congr. Applied Mechanics, Delft, Netherlands (Eds. C.B. Bienzo and J.M. Burgers), 55-63.

Guillopé, M. and Poirier, J.P. (1979). Dynamic recrystallization during creep of singlecrystalline halite: An experimental study. J. Geophys. Res., 84, 5557-5567.

Haltenhof, M. and Hofrichter, E. (1972). Feinstratigraphie, Fazies und Bromgehalte isochroner Schichten des Liniensalzes (Zechstein 3) im zentralen Teil des Zechsteinbeckens (Raum Hannover). Geol. Jb., 90, 1-66. 
Hardie, L.A. (1991). On the significance of evaporites. Annual Review of Earth and Planetary Sciences, 19, 131-168.

Hardie, L.A., Lowenstein, T.K., and Spencer, R.J. (1983). The problem of distinguishing between primary and secondary features in evaporites. In: Sixth International Symposium on Salt (Eds. C. Schreiber and H.L. Harner), 1, 11-39, The Salt Institute, Alexandria, VA.

Helming, K. (1995). Texturapproximation durch Modellkomponenten. Habilitationsschrift, TU Clausthal, pp. 119.

Helming, K. (2000). Textur und Anisotropie kristalliner Materialien (online). Available at: http://www.texture.de/ [Accessed 28 February 2010].

Helming, K. and Eschner, T. (1990). A new approach to texture analysis of multiphase materials using a texture component model. Cryst. Res. Technol., 25, K203-K208.

Herrmann, A.G. (1961). Zur Geochemie des Sr in den salinaren Zechsteinablagerungen der Stassfurt-Serie des Südharzbezirks. Chemie der Erde, 21, 137.

Herrmann, A.G. (1980). Geochemische und mineralogische Grundlagen für die Endlagerung radioaktiver Substanzen in Salzdiapiren Norddeutschlands. Fortschr. Miner., 58, 169-211.

Herrmann, A.G. (2000). Br-Profil für das Staßfurt-Steinsalz des Salzstocks Gorleben. Kali und Steinsalz, 13, 57-67.

Herrmann, A.G., Knake, D., Schneider, J., and Peters, H. (1973). Geochemistry of modern seawater and brines from salt pans: main components and bromine distribution. Contr. Mineral. Petrol., 40, 1-24.

Herut, B., Gavrieli, I., and Halicz, L. (1998). Coprecipitation of trace and minor elements in modern authigenic halites from the hypersaline Dead Sea brine. Geochim. Cosmochim. Acta, 62 (9), 1587-1598.

Hofrichter, E. (1972). Behälterlose Speicherung von Energieträgern in ausgesolten Kavernen - geologisch-lagerstättenkundliche Probleme. Erdöl-Erdgas-Z., 88, 284-294.

Hofrichter, E. (1974). Geologische Bearbeitung von Kavernenspeicher-Projekten in Salzstöcken Nordwestdeutschlands. Erdöl und Kohle, 27, 190-194. 
Holland, H.D. (1978) The Chemistry of the Atmosphere and Oceans. Princeton Univ. Press.

Holser, W.T. (1966a). Bromide geochemistry of salt rocks. In: Second Symposium on Salt (Ed. J.L. Rau), 1, 248-275, Cleveland, OH.

Holser, W.T. (1966b). Diagenetic polyhalite in recent salt from Baja California. Am. Mineral., 51, 99-109.

Holser, W.T. (1979): Mineralogy of evaporites. - In: Marine Minerals (Ed. R.G. Burns), 211294, Washington (Min. Soc. Am.), Short course notes.

Horita, J., Friedman, T.J., Lazar, B., and Holland, H.D. (1991). The composition of Permian seawater. Geochim. Cosmochim. Acta, 55, 417-432.

Horita, J., Zimmermann, H., and Holland, H.D. (2002). Chemical evolution of seawater during the Phanerozoic: Implications from the record of marine evaporites. Geochim. Cosmochim. Acta, 66, 3733-3756.

Hovorka, S.D., Knauth, L.P., Fisher, R.S., and Gao, G. (1993). Marine to nonmarine facies transition in Permian evaporites of the Palo Duro Basin, Texas: Geochemical response. Geol. Soc. Am. Bull., 105, 1119-1134.

Hunsche, U. and Schulze, O. (1994). Das Kriechverhalten von Steinsalz. Kali und Steinsalz, $11,238-255$.

Hunsche, U. and Hampel, A. (1999). Rock salt - the mechanical properties of the host rock material for a radioactive waste repository. Eng. Geol., 52, 271-291.

Irion, G. and Müller, G. (1968). Huntite, magnesite and polyhalite of recent age from Tuz Gölü, Turkey. Nature, 220, 1309-1310.

Jackson, M.P.A. and Talbot, C.J. (1986). External shapes, strain rates and dynamics of salt structures. Geol. Soc. Am. Bull., 97, 305-323.

Jagsch, R. and Theylich, H. (1999). Speichergeologische und geotechnische Bedingungen an den Kavernenstandorten Teutschenthal und Bernburg. In: Kali-, Steinsalz und Kupferschiefer in Mitteldeutschland (Ed. O. Hartmann), 115-129, Gesellschaft für Geowissenschaften (GGW), Berlin. 
Jaritz, W. (1973). Zur Entstehung der Salzstrukturen Nordwestdeutschlands. Geol. Jb., A 10, $1-77$.

Jaritz, W. (1983). Das Konzept der Erkundung des Salzstocks Gorleben von Übertage und die Festlegung von Schachtansatzpunkten. N. Jahrb. Geol. Paläontol., Abh. 166, 19-33.

Jaritz, W. (1993). Die geowissenschaftliche Untersuchung des Salzstocks Gorleben auf seine Eignung für ein Endlager für radioaktive Abfälle - Stand 1993. Geol. Jb., A 142, 295-304.

Jockwer, N. (1980). Laboratory investigation of water content within rock salt and its behaviour in a temperature field of diposed high-level waste. In: Scientific basis for waste management (Ed. J.G. Moore), 3, 35-42.

Jockwer, N. (1981). Untersuchungen zur Art und Menge des im Steinsalz des Zechsteins enthaltenen Wassers sowie dessen Freisetzung und Migration im Temperaturfeld endgelagerter radioaktiver Abfälle. - Diss. TU Clausthal. GSF-Bericht T 119.

Jubitz, K.-B., Beutler, G., Schwab, G., and Stackebrandt, W. (1991). Zur Strukturentwicklung des Spaltendiapirs der Allertalzone (Subherzyne Senke). Z. geol. Wiss., 19, 409-421.

Jung, W. (1968). Die Ausbildung des Staßfurtsteinsalzes (Na2) im südöstlichen Harzvorland. Bergakademie, 20, 509-515.

Jung, W. and Knitzsche, G., (1960). Kombiniert-feinstratigraphisch-geochemische Untersuchungen der Anhydrite des Zechstein 1 im SE Harzvorland. Geologie, 9, 58.

Käding, K.-C. (1978). Stratigraphische Gliederung des Zechsteins im Werra-Fulda Becken. Geol. Jb. Hessen, 106, 123-130.

Käding, K.-C. (2000). Die Aller-, Ohre-, Friesland- und Fulda-Folge (vormals Bröckelschiefer-Folge) - Stratigraphie und Verbreitung im Zechstein-Becken. Kali und Steinsalz, 13, 86-96.

Käding, K.-C. (2003). Bromprofile aus dem Zechstein 4 und 5 - ein Beitrag zur Stratigraphie der Aller- und Ohre-Folge. Kali und Steinsalz, 1, 6-17.

Kämpf, H., Ertel, A., Bankwitz, P., Betzl, M., and Zänker, G. (1987). Texturanalyse an Evaporiten der Lagerstätte Zielitz - Nachweis einer Fasertextur in Halititen. Z. angew. Geol., 33, 104-107. 
Kendall, A.C. (1992). Evaporites. In: Response to sea level changes (Eds. R.G. Walker and N.P. James), Geol. Assoc. Can., 375-409.

Kendall, A.C. and Broughton, P.L. (1978). Origin of fabrics in speleothems composed of columnar calcite crystals. J. Sediment. Petrol., 48 (2), 519-538.

Kern, H. and Braun, G. (1973). Deformation und Gefügeregelung von Steinsalz im Temperaturbereich 20-200 ${ }^{\circ}$ C. Contr. Mineral. Petrol., 40, 169-181.

Kern, H. and Richter, A. (1985). Microstructures and textures in evaporites. In: Preferred orientation in deformed metals and rocks: an introduction to modern texture analysis (Ed. H.-R. Wenk), Academic Press, Orlando, Florida, 317-333.

Kirkland, D.W., Denison, R.E., and Dean, W.E. (2000). Parent brine of the Castile evaporites (Upper Permian), Texas and New Mexico. J. Sediment. Res., 70, 749-761.

Kockel, F. (1998). Salt problems in Northwest Germany and the German North Sea sector. J. Seism. Explor., 7, 219-235.

Kocks, U.F., Tomé, C., and Wenk, H.-R. (1998). Texture and Anisotropy. Preferred Orientations in Polycrystals and their Effect on Materials Properties. Cambridge University Press, Cambridge.

Kramm, U. and Wedepohl, K.H. (1991). The isotopic composition of strontium and sulfur in seawater of Late Permian (Zechstein) age: Chem. Geol. 90, 253-262.

Kühn, R. (1955). Tiefenberechnung des Zechsteinmeeres nach dem Bromgehalt der Salze. Z. Deut. Geol. Ges., 105, 646-663.

Kühn, R. (1968). Geochemistry of the German Potash deposits. Geol. Soc. Am. Spec. Pub., $88,427-504$.

Kunze, K., Heidelbach, F., Wenk, H.-R. and Adams, B.L. (1994). Orientation Imaging Microscopy of Calcite Rocks. In: Textures of Geological Materials (Eds. H.-J. Bunge, S. Siegesmund, W. Skrotzki, K. Weber), 127-146, DGM Press, Oberursel.

Küster, Y., Schramm, M., Bornemann, O., and Leiss, B. (2007a). Bromide characteristics in bedded and domal rock salts of the Stassfurt formation (Zechstein 2): implications for the influence of salt migration-related processes. Geophys. Res. Abstr., 9, 03369. 
Küster, Y., Schramm, M., and Leiss, B. (2007b). Different types of solid inclusions as indicators for the formation of laminated halite beds of Late Permian rock salt sequences. Geophys. Res. Abstracts, 9, 03410.

Küster, Y., Schramm, M., Bornemann, O., and Leiss, B. (2008). Bromide distribution characteristics of different Zechstein 2 rock salt sequences of the Southern Permian Basin: a comparison between bedded and domal salts. Sedimentol. doi:10.1111/j-13653091.2008.01038.x.

Küster, Y., Leiss, B., and Schramm, M. (2010). Structural characteristics of the halite fabric type 'Kristallbrocken' from the Zechstein Basin with regard to its development. Int. J. Earth Sci., 99, 505-526.

Küster, Y., Schramm, M., Bornemann, O., and Leiss, B. (2009). Bromide distribution characteristics of different Zechstein 2 rock salt sequences of the Southern Permian Basin: a comparison between bedded and domal salts. Sedimentol., 56, 1368-1391.

Lachmann, R. (1914). Diskussionsbemerkungen zum Vortrag von E. Seidl „Die Steinsalzablagerungen des oberen Zechsteins bei Schönebeck nach den Grubenaufschlüssen des Graf-Moltke-Schachtes“. Z. Dtsch. Geol. Ges., 65, 62-64.

Lawn, B.R. and Wilshaw, T.R. (1975). Fracture of Brittle Solids. Cambridge University Press, Cambridge.

Leiss, B. (1996). Strukturbezogene Textur- und Korngefügeuntersuchungen duktil deformierter Dolomitgesteine am Südwestrand des Damara Orogens (Namibia) Mechanismen der Texturbildung und ihre kinematische Bedeutung. Geotekt. Forsch., 84, $130 \mathrm{p}$.

Leiss, B. (2005). New techniques, measuring strategies and applications of conventional Xray texture analysis. Conference Abstracts 'Deformation Mechanism, Rheology and Tectonics', Zurich, Switzerland.

Leiss, B., Siegesmund, S., Weber, K., and Olesen, N.Ø. (1994). Localized texture components of a naturally deformed dolomite - a contribution to the analysis of texture-forming processes. In: Textures of Geological Materials (Eds. H.-J. Bunge, S. Siegesmund, W. Skrotzki, K. Weber), DGM Press, 261-275. 
Leiss, B. and Barber, D.J. (1999). Mechanisms of dynamic recrystallization in naturally deformed dolomite inferred from EBSP analyses. Tectonophysics, 303, 51-69.

Leiss, B. and Molli, G. (2003). "High-Temperature" texture in naturally deformed Calcite marble from the Alpi Apuane, Italy. J. Struct. Geol., 25, 649-658.

Leiss, B. and Ullemeyer, K. (2006). Neue Perspektiven der Texturanalytik von Gesteinen mit konventioneller Röntgenbeugung. In: 11. Symposium ,Tektonik, Struktur- und Kristallingeologie' (Eds. S.L. Philipp, B. Leiss, A. Vollbrecht, D. Tanner, and A. Gudmundsson), Universitätsverlag Göttingen, 128-130.

Leite, E.R., Giraldi, T.R., Pontes, F.M., Longo, E., Beltrán, A., and Andrés, J. (2003). Crystal growth in colloidal tin oxide nanocrystals induced by coalescence at room temperature. Appl. Phys. Lett., 83 (8), 1566-1568.

Löffler, J. and Schulze, G. (1962). Die Kali- und Steinsalzlagerstätten des Zechsteins der Deutschen Demokratischen Rebublik, Teil III Sachsen-Anhalt. Freib. Forsch., C97, 1347.

Lokhorst, A. (1998). NW European Gas Atlas - Composition and Isotope Ratios of Natural Gases. BGR, Hannover.

Lotze, F. (1957). Steinsalz und Kalisalze - 1. Allgemein-geologischer Teil. Bornträger, Berlin.

Lowenstein, T.K. and Hardie, L.A. (1985). Criteria for the recognition of salt-pan evaporites. Sedimentol., 32, 627-644.

Lowenstein, T.K., Li, J., and Brown, C.B. (1998). Paleotemperatures from fluid inclusions in halite: method verification and a 100,000 year paleotemperature record, Death Valley, CA. Chem. Geol., 150, 223-245.

Lowenstein, T.K., Timofeeff, M.N., Brennan, S.T., Hardie, L.A., and Demicco, R.V. (2001). Oscillations in Phanerozoic seawater chemistry: Evidence from fluid inclusions. Science, 294, 1086-1088.

Lowenstein, T.K., Timofeeff, M.N., Kovalevych, V.M., and Horita, J. (2005). The major-ion composition of Permian seawater. Geochim. Cosmochim. Acta, 69, 1701-1719. 
Mas, D.L. and Crowley, P.D. (1996). The effect of second phase particles on stable grain size in regionally metamorphosed polyphase calcite marbles. J. Metamorph. Geol., 14, 155162.

Minette, J.W. (1999). Great Pockets: The Carlsbad Halite Caves. Mineralogical Record, 30, $369-372$.

Moldovan, D., Yamakov, V., Wolf, D., and Phillpot, S.R. (2002). Scaling Behavior of GrainRotation-Induced Grain Growth. Physical Review Letters, 89, 206101.

Müller, G. and Irion, G. (1969). "Salt-biscuits" - a special growth structure of $\mathrm{NaCl}$ in salt sediments of the Tuz Gölü ("Salt Lake”), Turkey. J. Sediment. Petrol., 39, 1604-1607.

Nes, E., Ryum, N., and Hunderi, O. (1985). On the Zener drag. Acta Metallica, 33, 11-22.

Noll, W. (1934). Geochemie des Strontiums. Chem. Erde, 8, 507-600.

Nölte, J. (2002). ICP Emissionsspektrometrie für Praktiker. Wiley-VCH Verlag, Weinheim, $386 \mathrm{pp}$.

Olander, D.R. (1982). A model of brine migration and water transport in rock salt supporting a temperature gradient. Nucl. Technol., 58, 256-270.

Pape, T., Michalzik, D., and Bornemann, O. (2002). Chevronkristalle im Kristallbrockensalz (Zechstein 2) des Salzstocks Gorleben - Primärgefüge salinarer Flachwassersedimentation im Zechsteinbecken. Z. Deut. Geol. Ges., 153, 115-129.

Passchier, C.W. and Trouw, R.A.J. (1996). Microtectonics. Springer-Verlag, Berlin, 289 pp.

Passchier, C.W. and Trouw, R.A.J. (1998). Microtectonics. Springer-Verlag, Berlin, 289 pp.

Passchier, C.W. and Trouw, R.A.J. (2005). Microtectonics. Springer-Verlag, Berlin, 314 pp.

Peach, C., Spiers, C. J., and Trimby, P. W. (2001). Effect of confining pressure on dilatation, recrystallization, and flow of rock salt at $150^{\circ} \mathrm{C}$. J. Geophys. Res., 106, 13315-13328.

Pennock, G.M., Drury, M.R., Spiers, C.J. (2005). The development of subgrain misorientations with strain in dry synthetic $\mathrm{NaCl}$ measured using EBSD. J. Struct. Geol., 27, 2159-2170. 
Pennock, G.M., Drury, M.R., Peach, C.J., and Spiers, C.J. (2006). The influence of water on deformation microstructures and textures in synthetic $\mathrm{NaCl}$ measured using EBSD. $J$. Struct. Geol., 28, 588-601.

Perthuisot, J.-P. (1971). Recent polyhalite from Sebkha el Melah (Tunisia). Nature Physical Science, 232, 186-187.

Peryt, T.M., Pierre, C., and Gryniv, S.P. (1998). Origin of polyhalite deposits in the Zechstein (Upper Permian) Zdrada platform (northern Poland). Sedimentol., 45, 565-578.

Pippig, M. (1992). Über das Vorkommen einer Kristallsalzschlotte im Kalibergwerk Merkers. Kali und Steinsalz, 11, 2-7.

Plötz, C. (2003). Sequestrierung von $\mathrm{CO}_{2}$ : Technologien, Potenziale, Kosten und Umweltauswirkungen; Externe Expertise für das WBGU-Hauptgutachten 2003 „Welt im Wandel: Energiewende zur Nachhaltigkeit“; Berlin, Springer Verlag. (Also available at: http://www.wbgu.de/wbgu_jg2003_ex07.pdf [Accessed 07 March 2010]).

Popp, T., Kern, H., and Schulze, O. (1999). Lithologische Variabilität der petrophysikalischen und mineralogisch-gefügekundlichen Eigenschaften des älteren Steinsalzes (z2) aus dem Salzstock Gorleben. Meyniana, 51, 55-75.

Popp, T., Kern, H., and Schulze, O. (2001). Evolution of dilantancy and permeability in rock salt during hydrostatic compaction and triaxial deformation. J. Geophys. Res., 106, 40614078.

Prior, D.J., Boyle, A.P., Brenker, F., Cheadle, M.C., Day, A., Lopez, G., Peruzzo, L., Potts, G.J., Reddy, S., Spiess, R., Timms, N.E., Trimby, P., Wheeler, J., and Zetterström, L. (1999). The application of electron backscatter diffraction and orientation contrast imaging in the SEM to textural problems in rocks. Am. Mineral., 84, 1741-1759.

Raup, O.B. and Hite, R.J. (1978). Bromine distribution in marine halite rocks. SEPM Short Course, 4, 105- 123.

Raup, O.B. and Hite, R.J. (1996). Bromine Geochemistry of chloride rocks of the Middle Pennsylvanian Paradox Formation of the Hermosa Group, Paradox basin, Utah and Colorado. U.S. Geol. Surv. Bull. 2000-M, 117 pp. 
Raymer, D.G. and Kendall, J.M. (1998). Seismic anisotropy in salt structures due to preferred crystal orientation. Revue de l'institut français du pétrole, 53, 585-594.

Raymer, D.G., Tommasi, A. and Kendall, J.M. (2000). Predicting the seismic implications of salt anisotropy using numerical simulations of halite deformation. Geophysics, 65, 12721280.

Reed, S.J.B. (1996). Electron Microprobe and Scanning Electron Microscopy in Geology. Cambridge University Press, Cambridge, 201 pp.

Richter-Bernburg, G. (1955a). Stratigraphische Gliederung des deutschen Zechsteins. Z. Deut. Geol. Ges. 105, 843-854.

Richter-Bernburg, G. (1955b). Über salinare Sedimentation. Z. Dtsch. Geol. Ges., 105, 593645.

Richter-Bernburg, G. (1970). Geologische Voraussetzungen für die Anlage von RohölSpeichern in Salzkavernen. Öl, 7, 209-213.

Roedder, E. (1984). The fluids in salt. Am. Mineral., 69, 413-439.

Roedder, E. and Basset, R.L. (1981) Problems in determination of the water content of rocksalt samples and its significance in nuclear-waste storage siting. Geology, 9, 525-530.

Rosell, L., Ortí, F., Kasprzyk, A., Playà, E., and Peryt, T.M. (1998). Strontium geochemistry of Miocene primary gypsum: Messianian of southeastern Spain and Sicily and Badenian of Poland. J. Sediment. Res., 68, 63-79.

Roy, P.D., Smykatz-Kloss, W., and Sinha, R. (2006). Late Holocene geochemical history inferred from Sambhar and Didwana playa sediments, Thar Desert, India: Comparison and synthesis. Quaternary Int., 144, 84-98.

Sander, W. and Herbert, H.-J. (2000). Wassergehaltsbestimmungen am Steinsalz (Erkundungssohle), Zwischenbericht für den Zeitraum 01.01.1998-31.12.1999. - GRSBericht; Braunschweig.

Satterfield, C.L., Lowenstein, T.K., Vreeland, R.H., and Rosenzweig, W.D. (2005). Paleobrine temperatures, chemistries, and paleoenvironments of Silurian Salina 
Formation F-1 Salt, Michigan Basin, U.S.A., from petrography and fluid inclusions in halite. J. Sediment. Res., 75, 534-546.

Schauberger, O. and Kühn, R. (1959). Über die Entstehung des alpinen Augensalzes. $N$. Jahrb. Geol. Paläontol., Monatshefte 6, 247-259.

Scheffzük, C.M. (1999). Neutronographische Texturanalysen und Mikrostrukturuntersuchungen natürlicher und triaxial verformter Halite. Dissertation RWTH Aachen, Scientific Technical Report STR99/15, GeoForschungsZentrum Potsdam.

Schenk, O. and Urai, J.L. (2004). Microstructural evolution and grain boundary structure during static recrystallization in synthetic polycrystals of sodium chloride containing saturated brine. Contrib. Mineral. Petrol., 146, 671-682.

Schlechter, E. (2004). Bromid-Untersuchungen am Kristallbrockensalz der Staßfurt-Folge (Zechstein 2) des Forschungsbergwerks Asse. Unpublished B.S. thesis, University of Hannover, Hannover.

Schléder, Z. (2006). Deformation mechanisms of naturally deformed rocksalt. PhD thesis, Rheinisch-Westfälische Technische Hochschule Aachen.

Schléder, Z. and Urai, J.L. (2005). Microstructural evolution of deformation-modified primary Halite from Hengelo, the Netherlands. Int. J. Earth Sci., 94, 941-956.

Schléder, Z. and Urai, J.L. (2007). Deformation and recrystallization mechanisms in mylonitic shear zones in naturally deformed extrusive Eocene-Oligocene rocksalt from Eyvanekey plateau and Garmsar hills (central Iran). J. Struct. Geol., 29, 241-255.

Schneider, H.-J. (1988). Geotechnical requirements of subsurface repositories in mines, rock and salt caverns for interim or final disposal of hazardous wastes. Bulletin of Engineering Geology and the Environment, 37, 71-76.

Schobert, E. (1912). Über die Kristallisation von Chlornatrium, Bromnatrium und Jodnatrium aus Schmelzen und wässrigen Lösungen. Dissertation, University of Leipzig, Leipzig. 
Schramm, M., Bornemann, O., Siemann, M., Wilke, F., and Geluk, M. (2005). Correlation between bromine concentrations in halites and their stratigraphical position in Zechstein 2 salt deposits of North-West Europe. Geophys. Res. Abstr., 7, 04552.

Schramm, M., Bornemann, O., Wilke, F., Siemann, M., and Dijk, H.L. (2002). Bromine analysis - A powerful tool to solve stratigraphic problems in exploration boreholes for salt caverns. In: Technical Meeting papers, Fall 2002 Meeting, Solution Mining Research Institute, Bad Ischl, Austria, pp. 351-362.

Schreiber, B.C., Friedman, G.M., Decima, A., and Schreiber, E. (1976). Depositional environments of Upper Miocene (Messinian) evaporite deposits of the Silician Basin. Sedimentol., 23, 729-760.

Schreiber, B.C. and El Tabakh, M. (2000). Deposition and early alteration of evaporites: Sedimentol., 47, Supplement 1, 215-238.

Schulze, G. (1958). Beitrag zur Stratigraphie und Genese der Steinsalzserien I-IV des mitteldeutschen Zechsteins unter besonderer Berücksichtigung der Bromverteilung. Freib. Forsch., A 123, 175-192.

Schulze, G. (1960a). Stratigraphie und genetische Deutung der Bromverteilung in den mitteldeutschen Steinsalzlagern des Zechsteins. Freib. Forsch., C 83, 114 pp.

Schulze, G. (1960b). Beitrag zur Genese des Polyhalites im deutschen Zechsteinsalinar: Z. Angew. Geol., 6, 310-317.

Schulze, G. (1962). Die Steinsalzlagerstätte des Allertalgrabens. In: Die Kali- und Steinsalzlagerstätten des Zechsteins der Deutschen Demokratischen Republik (Ed. J. Löffler), Freib. Forsch., C 97, 202-250.

Schulze, O. and Popp, T. (2002). Untersuchungen zum Dilatanzkriterium und zum Laugendruckkriterium für die Beurteilung der Integrität eines Endlagerbergwerks in einer Steinsalzformation. Z. Angew. Geol., 2, 16-22.

Schünemann, F. (1913). Vorläufige Mitteilung über einzelne Ergebnisse meiner Untersuchungen auf den Kaliwerken des Staßfurter Sattels. Z. praktische Geol., 21, 205216. 
Schwerdtner, W.M. (1966). Preferred orientation of halite in a „salt seismogram“. In: Second Symposium on Salt (Ed. J.L. Rau), Northern Ohio Geol. Soc., Cleveland, 70-84.

Sell, R. (1988). Die Bestimmung des Haftwassers. In: Sonderheft Titration und Elektrochemie, Merck Spectrum, p. 18-23.

Seidel, T., Leiss, B., Küster, Y., Ullemeyer, K., and Schramm, M. (2006): Texturanalysen von Halitmyloniten aus den Salzstrukturen Gorleben, Morsleben und Teutschenthal. In: 11. Symposium ,Tektonik, Struktur- und Kristallingeologie' (Eds. S.L. Philipp, B. Leiss, A. Vollbrecht, D. Tanner, and A. Gudmundsson), Universitätsverlag Göttingen, 211-214.

Senseny, P.E., Hansen, F.D., Russell, J.E., Carter, N.L., and Handin, J. (1992). Mechanical behaviour of rock salt: phenomenology and micromechanisms. International Journal of Rock Mechanics Mining Sciences. Geomechanical Abstracts, 29, 363-378.

Shamsutdinov, N.R., Böttger, A.J., and Thijsse, B.J. (2006). Grain coalescence and its effect on stress and elasticity in nanocrystalline metal films. Acta Materialia, 55 (3), 777-784.

Shearman, D.J. (1970). Recent halite rock, Baja California, Mexico. Institution of Mining and Metallurgy Transactions, 79, B155-B162.

Shearman, D.J. (1978). Evaporites of coastal sabkhas. In: Marine evaporites (Eds. W.E. Dean and C. Schreiber), SEPM Short Course, 4, 6-42.

Shi, J.Q. and Durucan, S. (2005). $\mathrm{CO}_{2}$ storage in caverns and mines. Oil \& Gas Science and Technology - Rev. IFP, 60, 569-571.

Siemann, M. and Schramm, M. (2002). Henry's and non-Henry's law behavior of Br in simple marine systems. Geochim. Cosmochim. Acta, 66, 1387-1399.

Siemann, M.G. and Ellendorf, B. (2001). The composition of gases in fluid inclusions of late Permian (Zechstein) marine evaporites in Northern Germany. Chem. Geol., 173, 31-44.

Simon, P. (1972). Stratigraphie und Bromgehalt des Staßfurt-Steinsalzes (Zechstein 2) im hannoverschen Kalisalzbergbaugebiet. Geol. Jb., 90, 67-126.

Simon, P. and Haltenhof, M. (1970). Feinstratigraphie, Fazies und Bromgehalt des StaßfurtSteinsalzes (Zechstein 2) im Kali- und Steinsalzbergwerk „Asse“ (Schacht 2) bei Baunschweig. Geol. Jb., 88, 159-202. 
Skrotzki, W. (1984). An estimate of the brittle to ductile transition in salt. Proc. 1. Conf. on the Mechanical Behaviour of Salt, Penn State Univ. In: Hardy Jr. RH, Langer M (eds) Mechanical Behaviour of Salt I. Trans Tech Publications, Clausthal-Zellerfeld, Series on Rock and Soil Mechanics, 9, 381-388.

Skrotzki, W. (1994). Mechanisms of texture development in rocks. In: Textures of Geological Materials (Eds. H.J. Bunge, S. Siegesmund, W. Skrotzki, and K. Weber), DGM Press, 167-186.

Skrotzki, W. and Haasen, P. (1981). Hardening mechanisms of ionic crystals on (110) and (100) slip planes. J. Phys., 42, C3, 119-148.

Skrotzki, W. and Welch, P. (1983). Development of texture and microstructure in extruded ionic polycrystalline aggregates. Tectonophysics, 99, 47-62.

Skrotzki, W., Frommeyer, G., and Haasen, P. (1981). Plasticity of polycrystalline ionic solids. Physica Status Solidi, (a) 66, 219-228.

Skrotzki, W., Helming, K., Brokmeier, H.-G., Dornbusch, H.-J., and Welch, P. (1995). Textures in pure shear deformed rock salt. Textures and Microstructures, 24, 133-141.

Smith, D.B. (1979) Rapid marine transgressions and regressions of the Upper Permian Zechstein Sea. J. Geol. Soc. London, 136, 155-156.

Smith, D.B., Raup, O.B., and Holmes, R. (1995). Bromine content of English Zechstein Cycle 3 chloride salts on Teesside and in the Staithes area of Co. Cleveland, N.E. England. Proc. Yorks. Geol. Soc., 50, 239-244.

Sonnenfeld, P. (1992). Genesis of marine evaporites - a summation. Geologica Carpathica, $43,259-274$.

Spiers, C.J. and Carter, N.L. (1998). Microphysics of rocksalt flow in nature. In: Proc. Fourth Conf. on the Mechanical Behavior of Salt (Eds. M. Aubertin and H.R. Hardy), 22, pp. 115-128, Trans. Tech. Publications, Series on rock and soil mechanics, ClausthalZellerfeld.

Spiers, C.J., Urai, J.L., Lister, G.S., Boland, J.N., and Zwart, H.J. (1986). The influence of fluid-rock interaction on the rheology of salt rock. Nuclear Science and Technology, EUR 
10399 EN, Office for Official Publications of the European Communities, Luxembourg, $131 \mathrm{pp}$.

Spiers, C.J., Schutjens, P.M.T.M., Brzesowsky, R.H., Peach, C.J., Liezenberg, J.L., and Zwart, H.J. (1990). Experimental determination of constitutive parameters governing creep of rocksalt by pressure solution. In: Deformation Mechanisms, Rheology and Tectonics (Eds. R.J. Knipe and E.H. Rutter), Geol. Soc. London Spec. Publ., 54, 215-227.

Spiess, P., Peruzzo, L., Prior, D.J., and Wheeler, J. (2001). Development of garnet porphyroblasts by multiple nucleation, coalescence and boundary misorientation-driven rotations. J. Metamorph. Geol., 19, 269-290.

Strohmenger, C., Voigt, E., and Zimdars, J. (1996). Sequence stratigraphy and cyclic development of Basal Zechstein carbonate-evaporite deposits (Upper Permian, northwest Germany). Sedimentol., 102, 33-54.

Sutton, A.P. and Baluffi, R.W. (1987). On geometric criteria for low interfacial energy. Acta Metallurgica, 35, 2177-2201.

Taylor, J.C.M. (1998). Upper Permian - Zechstein. In: Petroleum geology of the North Sea Basic concepts and recent advances (Ed. K.W. Glennie), pp. 174-211, Blackwell Science, London.

Thoms, R.L. and Gehle, R.M. (2000). A brief history of salt cavern use (keynote paper). In: Proc. 8th World Salt Symp. (Ed. R.M. Geertman), Elsevier, I, 207-214.

Timofeeff, M.N., Lowenstein, T.K., and Blackburn, W.H. (2000). ESEM-EDS: an improved technique for major element chemical analysis of fluid inclusions. Chem. Geol., 164, 171182.

Timofeeff, M.N., Lowenstein, T.K., Brennan, S.T., Demicco, R.V., Zimmermann, H., Horita, J., and von Borstel, L.E. (2001). Evaluating seawater chemistry from fluid inclusions in halite: Examples from modern marine and nonmarine environments. Geochim. Cosmochim. Acta, 65, 2293-2300.

Trimby, P.W., Drury, M.R., and Spiers, C.J. (2000a). Misorientations across etched boundaries in deformed rocksalt: a study using electron backscatter diffraction. J. Struct. Geol., 22, 81-89. 
Trimby, P.W., Drury, M.R. and Spiers, C.J. (2000b). Recognising the crystallographic signature of recrystallisation processes in deformed rocks: a study of experimentally deformed rocksalt. J. Struct. Geol., 22, 1609-1620.

Trusheim, F. (1960). Mechanism of salt migration in North Germany. AAPG Bull., 44, 15191540.

Twiss, R.J. and Moores, E.M. (1992). Structural Geology. W.H. Freeman and Company, New York, $532 \mathrm{pp}$.

Ullemeyer, K. and Weber, K. (1994). Correction of phyllosilicate (002) X-ray pole figure measurements. In: Textures of Geological Materials, (Eds. H.J. Bunge, S. Siegesmund, W. Skrotzki, K. Weber), DGM Press, 83-92.

Ullemeyer, K., Spalthoff, P., Heinitz, J., Isakov, N.N., Nikitin, A.N., and Weber, K. (1998). The SKAT texture diffractometer at the pulsed reactor IBR-2 at Dubna: experimental layout and first measurements. Nucl. Instr. Meth. Phys. Res., A412, 80-88.

Urai, J.L. (1987). Development of microstructure during deformation of carnallite and bischofite in transmitted light. Tectonophysics, 135, 251-263.

Urai, J.L. and Spiers, C.J. (2007): The effect of grain boundary water on deformation mechanisms and rheology of rocksalt during long-term deformation. In: The Mechanical Behavior of Salt - Understanding of THMC Processes in Salt (Eds. M. Wallner, K. Lux, W. Minkley and H. Hardy Jr.), Proc. 6th conf. on the mechanical behavior of salt, 'SaltMech6'.

Urai, J.L., Means, W.D., and Lister, G.S. (1986a). Dynamic recrystallization of minerals. In: Mineral and Rock Deformation: Laboratory Studies - The Paterson Volume (Ed. B.E. Hobbs and H.C. Heard). Geophys. Monograph, 36, 161-199.

Urai, J.L., Spiers, C.J., Zwart, H.J., and Lister, G.S. (1986b). Weakening of rock salt by water during long term creep. Nature, 324, 554-557.

Urai, J.L., Spiers, C.J., Peach, C.J., Franssen, R.C.M.W. and Liezenberg, J.L. (1987). Deformation mechanisms operating in naturally deformed halite rocks as deduced from microstructural investigations. Geologie en Mijnbouw, 66, 165-176. 
Usdowski, E. (1973). Das geochemische Verhalten des Strontium bei der Genese und Diagenese von Ca-Karbonaten und Ca-Sulfat-Mineralen. Contrib. Mineral. Petrol., 38, $177-195$.

Valyashko, M.G. (1956). Geochemistry of bromine in the processes of salt deposition and the use of the bromine content as a genetic and prospecting criterion. Geochemistry, 6, 570589.

Wallner, M., Brennecke, P., and Closs, K.-D. (2002). Endlagerung radioaktiver Abfälle in Deutschland - Hintergrund, Status, zukünftige Forschung. Z. Angew. Geol., 2, 2-15.

Wardlaw, N.C. and Schwerdtner, W.M. (1966). Halite-anhydrite seasonal layers in the Middle Devonian Prairie Evaporite Formation, Sasketchewan, Canada. Geol. Soc. Am. Bull., 77, 331-342.

Warren, J.K. (2006). Evaporites: Sediments, Resources and Hydrocarbons. Springer-Verlag, Berlin-Heidelberg, 1035 pp.

Watanabe, T. and Peach, C.J. (2002). Electrical impedance measurement of plastically deforming halite rocks at $125^{\circ} \mathrm{C}$ and $50 \mathrm{MPa}$. J. Geophys. Res., 107, B1, 1-12.

Wcislak, L., Klein, H., Bunge, H.J., Garbe, U., Tschentscher, T., and Schneider, J.R. (2002). Texture analysis with high-energy synchrotron radiation. J. Appl. Crystallogr., 35, 82-95.

Weiß, J. (2001). Ionenchromatographie. Wiley-VCH Verlag, Weinheim, 952 pp.

Wieland, G. (1985). Wasserbestimmung durch Karl-Fischer-Titration. Theorie und Praxis. GIT Verlag GmbH, Darmstadt, 102 pp.

Wenk, H.-R. and Van Houtte, P. (2004). Texture and anisotropy. Rep. Progr. Phys., 67, 13671428.

Wilke, F., Bornemann, O., Behlau, J., and Mingerzahn, G. (2002). Anwendung geologischer Untersuchungsmethoden des Salzstockes Gorleben auf Kavernenprojekte im mitteleuropäischen Zechsteinbecken. Erdöl Erdgas Kohle, 11, 518-522.

Zharkov, M.A. (1984). Paleozoic salt bearing formations of the world. Springer-Verlag, Berlin, 427 pp. 
Ziegler, P.A. (1981). Evolution of sedimentary basins in North-West Europe. In: Petroleum Geology of the Continental Shelf of Northwest Europe (Eds. L.V. Illing and G.D. Hobson), pp. 3-39, Heyden, London.

Ziegler, P.A. (1990). Geological Atlas of Western and Central Europe. 2nd Ed. Shell Internationale Petroleum Maatschappij B.V., Geol. Soc. London, Elsevier, Amsterdam, 239 pp.

Zirngast, M. (1991). Die Entwicklungsgeschichte des Salzstocks Gorleben - Ergebnis einer strukturgeologischen Bearbeitung. Geol. Jb., 132, 3-31. 



\title{
8 APPENDICES
}

\author{
Appendix A Analytical Results
}

Appendix B Results of Kristallbrocken sampling

Appendix C Results of X-ray texture goniometry 


\section{APPENDiX A ANALYTICAL RESUlts}

The rock salt material sampled for bromide content determination was analyzed for major cations, including potassium, sodium, magnesium, and calcium, and major and trace anions, including chloride, sulphate, and bromide. The determination of the cations was conducted by inductively coupled plasma optical emission spectrometry (ICP-OES), using a Spectro CIROS (Spectro Analytical Instruments GmbH \& Co. KG, Kleve, Germany). Anion analysis was performed on a Dionex DX500 ion chromatograph (IC; Dionex GmbH, Idstein, Germany). Based on the chemical analyses, the quantitative mineral composition of the sample was calculated. As samples contained no potash-bearing salt minerals, the analyzed bromide content could be directly related to the calculated halite content of the sample.

\section{ICP-OES}

The principle used in ICP-OES is optical emission spectroscopy, a widely used method for measuring elements in liquid solutions. A liquid sample is introduced into the inductively coupled argon plasma by a pneumatic nebuliser. Within the plasma, the elements of the liquid are atomized and ionized at temperatures between 5000 and $10000 \mathrm{~K}$. The high temperature leads to an excitation of the ground state atoms to higher energy levels. When the atoms or ions return to lower levels of energy, light is emitted, dispersed by means of a polychromator, and detected with photomultiplier tubes. As each element only emits light of definite wavelengths, spectral lines are produced that are dependent on the element (Nölte 2002). These lines can then be used for qualitative and quantitative analysis of the components of the sample after a calibration.

\section{IC}

Ion chromatography (IC) is an analytical technique used for separating and quantifying organic and inorganic ions in solution. During IC, a sample that consists of a mixture of components is injected into the mobile phase (eluent) and carried through an ion-exchange column. In this column, the separation of the different components in the solution is based on different affinities of these components to the column packing material (stationary phase), i.e. some components will stay shorter, whereas others will stay longer in the mobile phase (Weiß 2001). The different residence times of each component in the mobile phase allows for the separation. The higher the affinity of the component to the stationary phase, the later it is eluted from the column. Once the component exits the column, it is measured by a conductivity detector. The result is referred to as chromatogram, which is a plot that contains 
different peaks representing the different components of the sample. When compared against known standards, each component can be quantified.

Table A.1: Bromide data Teutschenthal (drilling core Lt60)

\begin{tabular}{|c|c|c|c|c|c|c|c|c|}
\hline $\begin{array}{l}\text { Sample } \\
\text { name }\end{array}$ & $\begin{array}{l}\text { Hauptsalz } \\
\text { thickness } \\
\text { (m) }\end{array}$ & $\begin{array}{c}\text { Halite } \\
\text { wt } \%\end{array}$ & $\begin{array}{c}\text { Anhydrite } \\
\text { wt } \%\end{array}$ & $\begin{array}{c}\text { Polyhalite } \\
\text { wt } \%\end{array}$ & $\begin{array}{c}\text { Kieserite } \\
\text { wt } \%\end{array}$ & $\begin{array}{l}\text { Sylvine } \\
\text { wt } \%\end{array}$ & $\begin{array}{c}\text { Br / } \\
\text { Halite } \\
\text { ppm }\end{array}$ & $\begin{array}{c}\text { Sample } \\
\text { type }\end{array}$ \\
\hline Lt60-1 & 1.28 & 100.1 & 0.0 & 0.5 & 0.0 & 0.0 & 183 & $\mathrm{M}$ \\
\hline Lt60-2 & 1.36 & 99.2 & 1.1 & 0.1 & 0.0 & 0.0 & 189 & M \\
\hline Lt60-3 & 5.56 & 97.6 & 1.0 & 0.0 & 0.0 & 0.0 & 161 & M \\
\hline Lt60-4 & 5.62 & 98.9 & 1.3 & 0.0 & 0.0 & 0.0 & 154 & M \\
\hline Lt60-5 & 5.67 & 94.1 & 5.6 & 0.0 & 0.0 & 0.0 & 163 & M \\
\hline Lt60-6 & 8.84 & 98.4 & 1.2 & 0.0 & 0.0 & 0.0 & 122 & M \\
\hline Lt60-8 & 12.71 & 99.4 & 1.1 & 0.0 & 0.0 & 0.0 & 45 & $\mathrm{~K}$ \\
\hline Lt60-7 & 12.73 & 99.4 & 0.5 & 0.0 & 0.0 & 0.0 & 87 & $\mathrm{~K}$ \\
\hline Lt60-9 & 12.77 & 99.7 & 0.7 & 0.0 & 0.0 & 0.0 & 116 & M \\
\hline Lt60-10 & 15.14 & 99.7 & 0.9 & 0.0 & 0.0 & 0.0 & 110 & M \\
\hline Lt60-11 & 21.13 & 98.6 & 1.3 & 0.0 & 0.0 & 0.0 & 75 & K \\
\hline Lt60-12 & 21.17 & 98.6 & 0.9 & 0.0 & 0.0 & 0.0 & 51 & $\mathrm{~K}$ \\
\hline Lt60-13 & 21.25 & 99.9 & 1.0 & 0.0 & 0.0 & 0.0 & 71 & $\mathrm{M}$ \\
\hline Lt60-16 & 30.86 & 99.4 & 0.6 & 0.0 & 0.0 & 0.0 & 64 & $\mathrm{~K}$ \\
\hline Lt60-14 & 30.95 & 92.8 & 8.0 & 0.0 & 0.0 & 0.0 & 114 & M \\
\hline Lt60-15 & 31.02 & 100.1 & 0.3 & 0.1 & 0.0 & 0.0 & 84 & $\mathrm{~K}$ \\
\hline Lt60-17 & 34.12 & 99.4 & 0.9 & 0.0 & 0.0 & 0.0 & 54 & M \\
\hline Lt60-18 & 34.19 & 99.4 & 0.4 & 0.0 & 0.0 & 0.0 & 75 & $\mathrm{~K}$ \\
\hline Lt60-19 & 37.26 & 98.4 & 1.4 & 0.0 & 0.0 & 0.0 & 91 & $\mathrm{~K}$ \\
\hline Lt60-20 & 40.52 & 98.4 & 1.1 & 0.0 & 0.0 & 0.0 & 75 & $\mathrm{M}$ \\
\hline Lt60-21 & 43.47 & 99.4 & 1.0 & 0.0 & 0.0 & 0.0 & 55 & $\mathrm{~K}$ \\
\hline Lt60-22 & 45.83 & 97.6 & 2.2 & 0.0 & 0.0 & 0.0 & 108 & M \\
\hline Lt60-23 & 47.54 & 97.9 & 1.3 & 0.0 & 0.0 & 0.0 & 99 & $\mathrm{~K}$ \\
\hline Lt60-24 & 47.58 & 96.8 & 2.7 & 0.0 & 0.0 & 0.0 & 99 & M \\
\hline Lt60-26 & 52.93 & 97.6 & 2.3 & 0.0 & 0.0 & 0.0 & 81 & M \\
\hline Lt60-25 & 52.97 & 99.1 & 0.9 & 0.0 & 0.0 & 0.0 & 44 & $\mathrm{~K}$ \\
\hline Lt60-28 & 53.65 & 99.6 & 0.3 & 0.1 & 0.0 & 0.0 & 58 & $\mathrm{~K}$ \\
\hline Lt60-27 & 53.73 & 96.3 & 3.4 & 0.0 & 0.0 & 0.0 & 119 & M \\
\hline Lt60-29 & 55.25 & 99.9 & 0.2 & 0.0 & 0.0 & 0.0 & 97 & $\mathrm{M}$ \\
\hline Lt60-30 & 55.31 & 98.7 & 0.5 & 0.0 & 0.0 & 0.0 & 71 & $\mathrm{~K}$ \\
\hline Lt60-33 & 56.63 & 99.7 & 0.3 & 0.0 & 0.0 & 0.0 & 67 & $\mathrm{~K}$ \\
\hline Lt60-31 & 56.75 & 95.5 & 4.0 & 0.0 & 0.0 & 0.0 & 114 & $\mathrm{M}$ \\
\hline Lt60-32 & 56.82 & 98.4 & 0.8 & 0.0 & 0.0 & 0.0 & 58 & $\mathrm{~K}$ \\
\hline Lt60-34 & 61.93 & 93.5 & 6.0 & 0.0 & 0.0 & 0.0 & 111 & $\mathrm{M}$ \\
\hline Lt60-35 & 66.27 & 98.9 & 0.8 & 0.0 & 0.0 & 0.0 & 78 & $\mathrm{~K}$ \\
\hline Lt60-36 & 66.35 & 99.1 & 0.5 & 0.0 & 0.0 & 0.0 & 116 & $\mathrm{M}$ \\
\hline Lt60-38 & 68.40 & 98.9 & 0.8 & 0.0 & 0.0 & 0.0 & 85 & $\mathrm{~K}$ \\
\hline Lt60-37 & 68.42 & 85.2 & 14.7 & 0.0 & 0.0 & 0.0 & 116 & M \\
\hline Lt60-39 & 70.10 & 98.1 & 1.7 & 0.0 & 0.0 & 0.0 & 104 & M \\
\hline Lt60-40 & 70.13 & 98.6 & 1.3 & 0.0 & 0.0 & 0.0 & 63 & $\mathrm{~K}$ \\
\hline Lt60-41 & 72.19 & 99.7 & 0.7 & 0.0 & 0.0 & 0.0 & 62 & $\mathrm{~K}$ \\
\hline Lt60-42 & 72.22 & 92.5 & 7.5 & 0.0 & 0.0 & 0.0 & 108 & M \\
\hline Lt60-44 & 74.62 & 100.4 & 0.2 & 0.0 & 0.0 & 0.0 & 48 & $\mathrm{~K}$ \\
\hline
\end{tabular}


Table A.1 (continued): Bromide data Teutschenthal (drilling core Lt60)

\begin{tabular}{|c|c|c|c|c|c|c|c|c|}
\hline $\begin{array}{l}\text { Sample } \\
\text { name }\end{array}$ & $\begin{array}{l}\text { Hauptsalz } \\
\text { thickness } \\
(\mathrm{m})\end{array}$ & $\begin{array}{l}\text { Halite } \\
\text { wt } \%\end{array}$ & $\begin{array}{c}\text { Anhydrite } \\
\text { wt } \%\end{array}$ & $\begin{array}{c}\text { Polyhalite } \\
\text { wt } \%\end{array}$ & $\begin{array}{c}\text { Kieserite } \\
\text { wt } \%\end{array}$ & $\begin{array}{l}\text { Sylvine } \\
\text { wt } \%\end{array}$ & $\begin{array}{c}\text { Br / } \\
\text { Halite } \\
\text { ppm } \\
\end{array}$ & $\begin{array}{c}\text { Sample } \\
\text { type }\end{array}$ \\
\hline Lt60-43 & 74.75 & 98.4 & 2.0 & 0.0 & 0.0 & 0.0 & 111 & $\bar{M}$ \\
\hline Lt60-46 & 77.89 & 99.4 & 1.1 & 0.0 & 0.0 & 0.0 & 86 & $\mathrm{~K}$ \\
\hline Lt60-45 & 77.99 & 95.1 & 4.2 & 0.0 & 0.0 & 0.0 & 102 & M \\
\hline Lt60-47 & 83.63 & 97.9 & 2.3 & 0.0 & 0.0 & 0.0 & 81 & M \\
\hline Lt60-48 & 83.67 & 99.1 & 1.4 & 0.0 & 0.0 & 0.0 & 77 & M \\
\hline Lt60-49 & 91.01 & 99.7 & 1.0 & 0.0 & 0.0 & 0.0 & 96 & M \\
\hline Lt60-50 & 91.01 & 98.1 & 0.7 & 0.0 & 0.0 & 0.0 & 42 & $\mathrm{~K}$ \\
\hline Lt60-52 & 91.03 & 97.6 & 2.7 & 0.0 & 0.0 & 0.0 & 84 & M \\
\hline Lt60-51 & 91.04 & 98.9 & 1.2 & 0.0 & 0.0 & 0.0 & 97 & $\mathrm{~K}$ \\
\hline Lt60-53 & 93.28 & 99.7 & 0.4 & 0.0 & 0.0 & 0.0 & 65 & $\mathrm{~K}$ \\
\hline Lt60-54 & 93.28 & 100.2 & 0.3 & 0.0 & 0.0 & 0.0 & 61 & $\mathrm{~K}$ \\
\hline Lt60-55 & 93.36 & 100.2 & 0.2 & 0.0 & 0.0 & 0.0 & 70 & M \\
\hline Lt60-57 & 96.75 & 93.5 & 5.8 & 0.0 & 0.0 & 0.0 & 103 & M \\
\hline Lt60-58 & 96.82 & 91.3 & 8.0 & 0.0 & 0.0 & 0.0 & 105 & M \\
\hline Lt60-56 & 96.86 & 99.6 & 0.5 & 0.0 & 0.0 & 0.0 & 37 & $\mathrm{~K}$ \\
\hline Lt60-59 & 100.74 & 99.6 & 0.4 & 0.1 & 0.0 & 0.0 & 41 & $\mathrm{~K}$ \\
\hline Lt60-60 & 100.78 & 97.3 & 1.8 & 0.0 & 0.0 & 0.0 & 101 & M \\
\hline Lt60-61 & 105.28 & 99.9 & 0.2 & 0.0 & 0.0 & 0.0 & 41 & $\mathrm{~K}$ \\
\hline Lt60-62 & 105.37 & 98.9 & 1.0 & 0.0 & 0.0 & 0.0 & 92 & M \\
\hline Lt60-64 & 109.22 & 89.7 & 9.5 & 0.0 & 0.0 & 0.0 & 117 & M \\
\hline Lt60-63 & 109.25 & 99.6 & 0.2 & 0.0 & 0.0 & 0.0 & 73 & $\mathrm{~K}$ \\
\hline Lt60-67 & 113.40 & 98.9 & 0.4 & 0.0 & 0.0 & 0.0 & 48 & $\mathrm{~K}$ \\
\hline Lt60-68 & 113.50 & 99.1 & 0.1 & 0.0 & 0.0 & 0.0 & 70 & M \\
\hline Lt60-65 & 113.58 & 97.9 & 1.7 & 0.1 & 0.0 & 0.0 & 101 & $\mathrm{~K}$ \\
\hline Lt60-66 & 113.60 & 95.3 & 4.5 & 0.0 & 0.0 & 0.0 & 112 & M \\
\hline Lt60-69 & 121.48 & 99.9 & 0.2 & 0.0 & 0.0 & 0.0 & 34 & $\mathrm{~K}$ \\
\hline Lt60-70 & 121.57 & 98.6 & 1.0 & 0.0 & 0.0 & 0.0 & 110 & M \\
\hline Lt60-71 & 125.36 & 99.9 & 0.2 & 0.0 & 0.0 & 0.0 & 59 & $\mathrm{~K}$ \\
\hline Lt60-72 & 125.37 & 99.4 & 0.3 & 0.0 & 0.0 & 0.0 & 51 & $\mathrm{~K}$ \\
\hline Lt60-73 & 127.12 & 98.6 & 0.4 & 0.0 & 0.0 & 0.0 & 73 & $\mathrm{~K}$ \\
\hline Lt60-74 & 127.17 & 98.4 & 1.0 & 0.0 & 0.0 & 0.0 & 107 & M \\
\hline Lt60-75 & 130.26 & 98.6 & 0.7 & 0.0 & 0.0 & 0.0 & 74 & M \\
\hline Lt60-76 & 130.30 & 99.1 & 1.6 & 0.0 & 0.0 & 0.0 & 71 & $\mathrm{~K}$ \\
\hline Lt60-77 & 132.71 & 96.4 & 3.3 & 0.1 & 0.0 & 0.0 & 69 & $\mathrm{~K}$ \\
\hline Lt60-78 & 132.77 & 96.9 & 2.1 & 0.0 & 0.0 & 0.0 & 104 & M \\
\hline Lt60-81 & 134.55 & 99.4 & 0.5 & 0.0 & 0.0 & 0.0 & 58 & $\mathrm{~K}$ \\
\hline Lt60-82 & 134.57 & 96.9 & 2.2 & 0.0 & 0.0 & 0.0 & 105 & M \\
\hline Lt60-79 & 134.67 & 96.9 & 2.5 & 0.0 & 0.0 & 0.0 & 92 & M \\
\hline Lt60-80 & 134.73 & 98.2 & 0.9 & 0.0 & 0.0 & 0.0 & 75 & $\mathrm{~K}$ \\
\hline Lt60-83 & 140.46 & 96.8 & 3.5 & 0.0 & 0.0 & 0.0 & 75 & M \\
\hline Lt60-84 & 140.55 & 99.4 & 0.4 & 0.0 & 0.0 & 0.0 & 46 & $\mathrm{~K}$ \\
\hline Lt60-85 & 148.14 & 92.5 & 7.3 & 0.0 & 0.0 & 0.0 & 75 & M \\
\hline Lt60-86 & 148.15 & 100.2 & 0.2 & 0.0 & 0.0 & 0.0 & 48 & $\mathrm{~K}$ \\
\hline Lt60-87 & 149.91 & 96.9 & 3.9 & 0.0 & 0.0 & 0.0 & 99 & M \\
\hline Lt60-88 & 149.98 & 99.1 & 0.6 & 0.0 & 0.0 & 0.0 & 56 & $\mathrm{~K}$ \\
\hline Lt60-89 & 151.65 & 95.6 & 4.0 & 0.0 & 0.0 & 0.0 & 66 & M \\
\hline Lt60-90 & 151.70 & 97.6 & 1.2 & 0.0 & 0.0 & 0.0 & 60 & $\mathrm{~K}$ \\
\hline Lt60-91 & 151.79 & 98.1 & 0.8 & 0.0 & 0.0 & 0.0 & 65 & $\mathrm{~K}$ \\
\hline
\end{tabular}


Table A.1 (continued): Bromide data Teutschenthal (drilling cores Lt60/Lt62)

\begin{tabular}{|c|c|c|c|c|c|c|c|c|}
\hline $\begin{array}{l}\text { Sample } \\
\text { name }\end{array}$ & $\begin{array}{l}\text { Hauptsalz } \\
\text { thickness } \\
(\mathrm{m})\end{array}$ & $\begin{array}{l}\text { Halite } \\
\text { wt } \%\end{array}$ & $\begin{array}{c}\text { Anhydrite } \\
\text { wt\% }\end{array}$ & $\begin{array}{c}\text { Polyhalite } \\
\text { wt } \%\end{array}$ & $\begin{array}{c}\text { Kieserite } \\
\text { wt } \%\end{array}$ & $\begin{array}{c}\text { Sylvine } \\
\text { wt } \%\end{array}$ & $\begin{array}{c}\mathrm{Br} / \\
\text { Halite } \\
\mathrm{ppm}\end{array}$ & $\begin{array}{l}\text { Sample } \\
\text { type }\end{array}$ \\
\hline Lt60-92 & 156.77 & 99.3 & 0.7 & 0.0 & 0.0 & 0.0 & 52 & K \\
\hline Lt60-93 & 156.84 & 98.9 & 0.3 & 0.0 & 0.0 & 0.0 & 77 & M \\
\hline Lt60-94 & 165.00 & 98.5 & 0.7 & 0.0 & 0.0 & 0.0 & 41 & $\mathrm{~K}$ \\
\hline Lt60-95 & 172.03 & 96.5 & 2.6 & 0.0 & 0.0 & 0.0 & 84 & M \\
\hline Lt60-96 & 174.61 & 99.1 & 0.5 & 0.0 & 0.0 & 0.0 & 55 & $\mathrm{~K}$ \\
\hline Lt60-97 & 174.70 & 98.6 & 0.3 & 0.0 & 0.0 & 0.0 & 43 & $\mathrm{~K}$ \\
\hline Lt60-98 & 177.35 & 96.6 & 3.0 & 0.0 & 0.0 & 0.0 & 67 & M \\
\hline Lt60-99 & 177.40 & 98.5 & 0.6 & 0.0 & 0.0 & 0.0 & 56 & $\mathrm{~K}$ \\
\hline Lt60-100 & 182.20 & 99.9 & 0.4 & 0.0 & 0.0 & 0.0 & 66 & M \\
\hline Lt60-101 & 187.00 & 98.6 & 1.1 & 0.1 & 0.0 & 0.0 & 68 & K \\
\hline Lt60-102 & 187.03 & 99.9 & 0.5 & 0.0 & 0.0 & 0.0 & 62 & $\mathrm{~K}$ \\
\hline Lt60-105 & 193.68 & 98.6 & 1.1 & 0.0 & 0.0 & 0.0 & 64 & $\mathrm{~K}$ \\
\hline Lt60-103 & 193.77 & 99.1 & 0.6 & 0.0 & 0.0 & 0.0 & 57 & $\mathrm{~K}$ \\
\hline Lt60-104 & 193.82 & 96.9 & 3.1 & 0.0 & 0.0 & 0.0 & 66 & M \\
\hline Lt60-106 & 198.73 & 99.4 & 0.9 & 0.0 & 0.0 & 0.0 & 82 & M \\
\hline Lt60-107 & 198.81 & 99.4 & 0.8 & 0.0 & 0.0 & 0.0 & 62 & $\mathrm{~K}$ \\
\hline Lt60-108 & 200.52 & 98.7 & 0.5 & 0.0 & 0.0 & 0.0 & 66 & $\mathrm{~K}$ \\
\hline Lt60-109 & 200.63 & 98.3 & 1.3 & 0.0 & 0.0 & 0.0 & 71 & $\mathrm{M}$ \\
\hline Lt60-110 & 203.82 & 99.4 & 0.6 & 0.0 & 0.0 & 0.0 & 53 & $\mathrm{M}$ \\
\hline Lt60-111 & 203.91 & 99.9 & 0.3 & 0.0 & 0.0 & 0.0 & 61 & $\mathrm{~K}$ \\
\hline Lt60-113 & 209.58 & 99.4 & 0.6 & 0.1 & 0.0 & 0.0 & 62 & $\mathrm{~K}$ \\
\hline Lt60-114 & 209.59 & 97.6 & 2.2 & 0.0 & 0.0 & 0.0 & 69 & $\mathrm{M}$ \\
\hline Lt60-112 & 215.82 & 96.3 & 3.2 & 0.0 & 0.0 & 0.0 & 70 & M \\
\hline Lt60-115 & 215.86 & 99.4 & 0.4 & 0.0 & 0.0 & 0.0 & 50 & M \\
\hline Lt60-116 & 215.93 & 98.1 & 1.4 & 0.0 & 0.0 & 0.0 & 50 & $\mathrm{~K}$ \\
\hline Lt60-117 & 220.79 & 98.9 & 0.8 & 0.0 & 0.0 & 0.0 & 43 & $\mathrm{~K}$ \\
\hline Lt60-118 & 225.87 & 98.6 & 1.1 & 0.0 & 0.0 & 0.0 & 55 & $\mathrm{~K}$ \\
\hline Lt60-119 & 225.97 & 98.9 & 0.7 & 0.0 & 0.0 & 0.0 & 47 & $\mathrm{~K}$ \\
\hline Lt62-3 & 227.53 & 97.6 & 1.2 & 0.0 & 0.0 & 0.0 & 70 & M \\
\hline Lt62-2 & 227.57 & 95.1 & 3.3 & 0.0 & 0.1 & 0.0 & 72 & $\mathrm{~K}$ \\
\hline Lt62-1 & 227.60 & 98.4 & 0.6 & 0.0 & 0.0 & 0.0 & 62 & $\mathrm{~K}$ \\
\hline Lt60-120 & 233.39 & 98.9 & 1.2 & 0.0 & 0.0 & 0.0 & 53 & M \\
\hline Lt60-121 & 233.45 & 98.2 & 1.3 & 0.1 & 0.0 & 0.0 & 57 & $\mathrm{~K}$ \\
\hline Lt62-7 & 237.65 & 98.1 & 1.3 & 0.0 & 0.0 & 0.0 & 71 & $\mathrm{~K}$ \\
\hline Lt62-6 & 237.68 & 98.9 & 0.2 & 0.0 & 0.0 & 0.0 & 72 & M \\
\hline Lt62-4 & 237.77 & 95.1 & 3.6 & 0.0 & 0.1 & 0.0 & 86 & $\mathrm{~K}$ \\
\hline Lt62-5 & 237.80 & 95.1 & 3.3 & 0.0 & 0.0 & 0.0 & 75 & M \\
\hline Lt60-122 & 238.72 & 96.3 & 2.2 & 0.0 & 0.0 & 0.0 & 69 & $\mathrm{M}$ \\
\hline Lt62-8 & 240.77 & 98.4 & 1.0 & 0.0 & 0.0 & 0.0 & 75 & M \\
\hline Lt60-123 & 242.25 & 99.3 & 0.6 & 0.0 & 0.0 & 0.0 & 55 & K \\
\hline Lt60-124 & 242.27 & 99.1 & 1.0 & 0.0 & 0.0 & 0.0 & 52 & M \\
\hline Lt62-10 & 243.02 & 94.1 & 5.6 & 0.0 & 0.0 & 0.0 & 72 & M \\
\hline Lt62-9 & 243.06 & 96.3 & 2.8 & 0.0 & 0.1 & 0.0 & 78 & $\mathrm{~K}$ \\
\hline Lt62-13 & 244.88 & 98.6 & 0.4 & 0.0 & 0.0 & 0.0 & 59 & M \\
\hline Lt62-12 & 244.97 & 96.3 & 3.3 & 0.0 & 0.0 & 0.0 & 78 & $\mathrm{~K}$ \\
\hline Lt62-11 & 244.98 & 98.1 & 1.2 & 0.0 & 0.0 & 0.0 & 67 & $\mathrm{~K}$ \\
\hline Lt62-14 & 247.13 & 97.9 & 2.0 & 0.0 & 0.0 & 0.0 & 64 & M \\
\hline Lt62-15 & 247.17 & 95.8 & 3.4 & 0.0 & 0.0 & 0.0 & 68 & M \\
\hline
\end{tabular}


Table A.1 (continued): Bromide data Teutschenthal (drilling core Lt62)

\begin{tabular}{|c|c|c|c|c|c|c|c|c|}
\hline $\begin{array}{l}\text { Sample } \\
\text { name }\end{array}$ & $\begin{array}{l}\text { Hauptsalz } \\
\text { thickness } \\
(\mathrm{m})\end{array}$ & $\begin{array}{c}\text { Halite } \\
\text { wt } \%\end{array}$ & $\begin{array}{c}\text { Anhydrite } \\
\text { wt\% }\end{array}$ & $\begin{array}{c}\text { Polyhalite } \\
\text { wt\% }\end{array}$ & $\begin{array}{c}\text { Kieserite } \\
\text { wt } \%\end{array}$ & $\begin{array}{l}\text { Sylvine } \\
\text { wt\% }\end{array}$ & $\begin{array}{c}\mathrm{Br} / \\
\text { Halite } \\
\mathrm{ppm}\end{array}$ & $\begin{array}{c}\text { Sample } \\
\text { type }\end{array}$ \\
\hline Lt62-16 & 247.24 & 994.6 & 3.6 & 0.0 & 0.1 & 0.0 & 80 & $\mathrm{~K}$ \\
\hline Lt62-17 & 249.30 & 98.6 & 0.7 & 0.0 & 0.0 & 0.0 & 36 & $\mathrm{~K}$ \\
\hline Lt62-18 & 249.41 & 95.8 & 4.4 & 0.0 & 0.0 & 0.0 & 62 & M \\
\hline Lt62-19 & 255.42 & 97.9 & 0.9 & 0.0 & 0.0 & 0.0 & 65 & M \\
\hline Lt62-20 & 255.49 & 97.6 & 1.8 & 0.0 & 0.1 & 0.0 & 51 & $\mathrm{~K}$ \\
\hline Lt62-24 & 258.66 & 97.6 & 1.8 & 0.0 & 0.0 & 0.0 & 67 & M \\
\hline Lt62-25 & 258.69 & 98.4 & 1.2 & 0.0 & 0.0 & 0.0 & 44 & $\mathrm{~K}$ \\
\hline Lt62-21 & 258.78 & 98.4 & 0.6 & 0.0 & 0.0 & 0.0 & 60 & $\mathrm{~K}$ \\
\hline Lt62-22 & 258.80 & 96.3 & 2.6 & 0.0 & 0.1 & 0.0 & 78 & $\mathrm{~K}$ \\
\hline Lt62-23 & 258.86 & 97.9 & 0.9 & 0.0 & 0.0 & 0.0 & 68 & M \\
\hline Lt62-26 & 260.25 & 93.0 & 6.0 & 0.0 & 0.0 & 0.0 & 66 & M \\
\hline Lt62-27 & 260.33 & 98.6 & 0.4 & 0.0 & 0.0 & 0.0 & 59 & $\mathrm{~K}$ \\
\hline Lt62-28 & 266.44 & 98.9 & 0.3 & 0.0 & 0.0 & 0.0 & 56 & M \\
\hline Lt62-29 & 266.51 & 98.5 & 0.4 & 0.0 & 0.0 & 0.0 & 61 & $\mathrm{~K}$ \\
\hline Lt62-30 & 268.60 & 95.9 & 3.8 & 0.1 & 0.1 & 0.0 & 77 & $\mathrm{~K}$ \\
\hline Lt62-31 & 268.70 & 98.7 & 1.2 & 0.1 & 0.0 & 0.0 & 35 & $\mathrm{~K}$ \\
\hline Lt62-32 & 271.43 & 98.8 & 0.6 & 0.0 & 0.0 & 0.0 & 67 & M \\
\hline Lt62-33 & 271.52 & 95.6 & 3.7 & 0.1 & 0.1 & 0.0 & 69 & $\mathrm{~K}$ \\
\hline Lt62-86 & 273.04 & 98.1 & 1.8 & 0.0 & 0.0 & 0.0 & 51 & M \\
\hline Lt62-34 & 273.05 & 97.6 & 1.3 & 0.1 & 0.0 & 0.0 & 52 & $\mathrm{~K}$ \\
\hline Lt62-35 & 273.51 & 96.2 & 2.7 & 0.0 & 0.0 & 0.0 & 70 & $\mathrm{M}$ \\
\hline Lt62-36 & 273.59 & 99.7 & 0.3 & 0.0 & 0.0 & 0.0 & 44 & $\mathrm{~K}$ \\
\hline Lt62-39 & 278.57 & 97.4 & 2.5 & 0.0 & 0.0 & 0.0 & 56 & M \\
\hline Lt62-40 & 278.60 & 98.1 & 1.1 & 0.0 & 0.0 & 0.0 & 50 & $\mathrm{~K}$ \\
\hline Lt62-37 & 278.64 & 99.6 & 0.6 & 0.0 & 0.0 & 0.0 & 33 & $\mathrm{~K}$ \\
\hline Lt62-38 & 278.72 & 98.1 & 1.8 & 0.0 & 0.0 & 0.0 & 55 & M \\
\hline Lt62-41 & 287.89 & 99.1 & 0.4 & 0.0 & 0.0 & 0.0 & 49 & $\mathrm{~K}$ \\
\hline Lt62-42 & 287.95 & 93.8 & 6.0 & 0.0 & 0.0 & 0.0 & 59 & M \\
\hline Lt62-43 & 292.16 & 95.6 & 3.7 & 0.0 & 0.0 & 0.0 & 48 & M \\
\hline Lt62-44 & 292.24 & 99.2 & 1.3 & 0.1 & 0.0 & 0.0 & 45 & $\mathrm{~K}$ \\
\hline Lt62-45 & 294.45 & 99.1 & 1.0 & 0.0 & 0.0 & 0.0 & 34 & $\mathrm{~K}$ \\
\hline Lt62-46 & 294.49 & 99.1 & 0.7 & 0.0 & 0.0 & 0.0 & 53 & M \\
\hline Lt62-49 & 297.61 & 99.1 & 0.9 & 0.0 & 0.0 & 0.0 & 50 & $\mathrm{~K}$ \\
\hline Lt62-50 & 297.66 & 97.1 & 2.5 & 0.0 & 0.0 & 0.0 & 55 & M \\
\hline Lt62-47 & 297.72 & 99.9 & 0.8 & 0.0 & 0.0 & 0.0 & 35 & $\mathrm{~K}$ \\
\hline Lt62-48 & 297.81 & 98.6 & 0.5 & 0.0 & 0.0 & 0.0 & 34 & M \\
\hline Lt62-51 & 298.97 & 96.6 & 4.0 & 0.0 & 0.0 & 0.0 & 25 & M \\
\hline Lt62-52 & 299.05 & 97.1 & 1.7 & 0.0 & 0.0 & 0.0 & 56 & $\mathrm{~K}$ \\
\hline Lt62-53 & 304.80 & 98.9 & 0.5 & 0.0 & 0.0 & 0.0 & 35 & $\mathrm{~K}$ \\
\hline Lt62-54 & 304.87 & 99.9 & 0.5 & 0.0 & 0.0 & 0.0 & 34 & M \\
\hline Lt62-55 & 310.45 & 97.1 & 1.9 & 0.0 & 0.0 & 0.0 & 65 & M \\
\hline Lt62-56 & 310.45 & 96.9 & 1.8 & 0.1 & 0.0 & 0.0 & 51 & $\mathrm{~K}$ \\
\hline Lt62-57 & 310.52 & 96.6 & 1.4 & 0.0 & 0.0 & 0.0 & 71 & M \\
\hline Lt62-58 & 312.15 & 98.5 & 0.7 & 0.0 & 0.0 & 0.0 & 60 & $\mathrm{~K}$ \\
\hline Lt62-59 & 312.24 & 97.6 & 1.6 & 0.0 & 0.0 & 0.0 & 44 & M \\
\hline Lt62-60 & 315.44 & 96.3 & 2.6 & 0.0 & 0.0 & 0.0 & 61 & $\mathrm{M}$ \\
\hline Lt62-61 & 315.51 & 97.6 & 1.2 & 0.1 & 0.0 & 0.0 & 43 & $\mathrm{~K}$ \\
\hline Lt62-62 & 326.99 & 97.1 & 2.3 & 0.0 & 0.0 & 0.0 & 40 & M \\
\hline
\end{tabular}


Table A.1 (continued): Bromide data Teutschenthal (drilling core Lt62)

\begin{tabular}{|c|c|c|c|c|c|c|c|c|}
\hline $\begin{array}{l}\text { Sample } \\
\text { name }\end{array}$ & $\begin{array}{c}\text { Hauptsalz } \\
\text { thickness } \\
(\mathrm{m})\end{array}$ & $\begin{array}{l}\text { Halite } \\
\text { wt } \%\end{array}$ & $\begin{array}{c}\text { Anhydrite } \\
\text { wt } \%\end{array}$ & $\begin{array}{c}\text { Polyhalite } \\
\text { wt } \%\end{array}$ & $\begin{array}{c}\text { Kieserite } \\
\text { wt } \%\end{array}$ & $\begin{array}{c}\text { Sylvine } \\
\text { wt } \%\end{array}$ & $\begin{array}{c}\mathrm{Br} / \\
\text { Halite } \\
\mathrm{ppm}\end{array}$ & $\begin{array}{c}\text { Sample } \\
\text { type }\end{array}$ \\
\hline Lt62-63 & 327.07 & 92.5 & ב6.6 & $\begin{array}{c}0.0 \\
\end{array}$ & 0.0 & 0.0 & 63 & $\overline{\mathrm{M}}$ \\
\hline Lt62-64 & 328.69 & 96.3 & 2.5 & 0.0 & 0.0 & 0.0 & 57 & $\mathrm{~K}$ \\
\hline Lt62-65 & 328.78 & 98.1 & 0.8 & 0.0 & 0.0 & 0.0 & 54 & $\mathrm{~K}$ \\
\hline Lt62-66 & 330.54 & 98.7 & 0.8 & 0.0 & 0.0 & 0.0 & 33 & $\mathrm{~K}$ \\
\hline Lt62-67 & 331.56 & 97.3 & 1.2 & 0.0 & 0.0 & 0.0 & 38 & $\mathrm{~K}$ \\
\hline Lt62-68 & 331.62 & 97.1 & 2.1 & 0.0 & 0.0 & 0.0 & 65 & $\mathrm{M}$ \\
\hline Lt62-69 & 334.63 & 96.3 & 2.5 & 0.0 & 0.0 & 0.0 & 49 & M \\
\hline Lt62-70 & 334.69 & 98.7 & 0.4 & 0.0 & 0.0 & 0.0 & 48 & $\mathrm{~K}$ \\
\hline Lt62-71 & 336.85 & 98.6 & 0.8 & 0.0 & 0.0 & 0.0 & 43 & $\mathrm{~K}$ \\
\hline Lt62-72 & 336.87 & 97.6 & 0.9 & 0.0 & 0.0 & 0.0 & 62 & $\mathrm{M}$ \\
\hline Lt62-73 & 341.13 & 97.9 & 0.9 & 0.0 & 0.0 & 0.0 & 51 & $\mathrm{~K}$ \\
\hline Lt62-74 & 341.17 & 98.9 & 0.3 & 0.0 & 0.0 & 0.0 & 65 & $\mathrm{M}$ \\
\hline Lt62-75 & 346.67 & 98.2 & 1.2 & 0.0 & 0.0 & 0.0 & 47 & $\mathrm{~K}$ \\
\hline Lt62-76 & 346.71 & 96.4 & 3.5 & 0.0 & 0.0 & 0.0 & 54 & $\mathrm{M}$ \\
\hline Lt62-77 & 349.45 & 98.4 & 0.4 & 0.0 & 0.0 & 0.0 & 64 & $\mathrm{M}$ \\
\hline Lt62-78 & 349.52 & 98.2 & 0.6 & 0.0 & 0.0 & 0.0 & 39 & $\mathrm{~K}$ \\
\hline Lt62-79 & 354.96 & 98.9 & 0.6 & 0.0 & 0.0 & 0.0 & 41 & $\mathrm{~K}$ \\
\hline Lt62-80 & 354.99 & 97.8 & 1.4 & 0.0 & 0.0 & 0.0 & 61 & $\mathrm{M}$ \\
\hline Lt62-81 & 355.01 & 98.6 & 0.3 & 0.0 & 0.0 & 0.0 & 33 & $\mathrm{~K}$ \\
\hline Lt62-82 & 357.16 & 98.6 & 0.3 & 0.0 & 0.0 & 0.0 & 39 & $\mathrm{~K}$ \\
\hline Lt62-83 & 357.23 & 99.1 & 0.6 & 0.0 & 0.0 & 0.0 & 59 & $\mathrm{M}$ \\
\hline Lt62-84 & 363.52 & 97.6 & 1.4 & 0.0 & 0.0 & 0.0 & 64 & $\mathrm{M}$ \\
\hline Lt62-85 & 363.57 & 98.4 & 0.8 & 0.0 & 0.0 & 0.0 & 30 & $\mathrm{~K}$ \\
\hline Lt62-87 & 370.37 & 97.3 & 1.4 & 0.1 & 0.0 & 0.0 & 48 & M \\
\hline Lt62-88 & 370.42 & 98.7 & 0.9 & 0.1 & 0.0 & 0.0 & 43 & $\mathrm{~K}$ \\
\hline Lt62-89 & 375.02 & 95.8 & 3.4 & 0.0 & 0.0 & 0.0 & 64 & M \\
\hline Lt62-90 & 375.07 & 98.4 & 1.0 & 0.0 & 0.0 & 0.0 & 30 & $\mathrm{~K}$ \\
\hline Lt62-91 & 375.11 & 98.9 & 0.4 & 0.0 & 0.0 & 0.0 & 58 & $\mathrm{~K}$ \\
\hline Lt62-92 & 388.54 & 97.4 & 1.6 & 0.0 & 0.0 & 0.0 & 66 & $\mathrm{M}$ \\
\hline Lt62-93 & 388.61 & 98.1 & 0.5 & 0.0 & 0.0 & 0.0 & 26 & $\mathrm{~K}$ \\
\hline Lt62-94 & 392.62 & 95.1 & 3.2 & 0.0 & 0.0 & 0.0 & 65 & M \\
\hline Lt62-95 & 392.72 & 97.3 & 1.9 & 0.1 & 0.1 & 0.0 & 59 & $\mathrm{~K}$ \\
\hline Lt62-96 & 399.38 & 99.3 & 0.4 & 0.0 & 0.0 & 0.0 & 62 & $\mathrm{M}$ \\
\hline Lt62-97 & 399.39 & 99.0 & 0.7 & 0.0 & 0.0 & 0.0 & 45 & $\mathrm{~K}$ \\
\hline Lt62-98 & 399.45 & 98.2 & 1.0 & 0.1 & 0.0 & 0.0 & 37 & $\mathrm{~K}$ \\
\hline Lt62-99 & 400.06 & 97.6 & 1.3 & 0.0 & 0.0 & 0.0 & 43 & $\mathrm{M}$ \\
\hline Lt62-100 & 400.08 & 98.7 & 0.7 & 0.0 & 0.0 & 0.0 & 60 & $\mathrm{~K}$ \\
\hline Lt62-101 & 405.69 & 99.0 & 0.3 & 0.0 & 0.0 & 0.0 & 60 & $\mathrm{~K}$ \\
\hline Lt62-102 & 405.73 & 99.2 & 0.1 & 0.0 & 0.0 & 0.0 & 60 & M \\
\hline Lt62-103 & 407.24 & 98.4 & 0.8 & 0.0 & 0.0 & 0.0 & 50 & M \\
\hline Lt62-104 & 407.28 & 98.9 & 0.7 & 0.1 & 0.0 & 0.0 & 32 & $\mathrm{~K}$ \\
\hline Lt62-105 & 407.33 & 97.6 & 1.8 & 0.0 & 0.0 & 0.0 & 45 & $\mathrm{M}$ \\
\hline Lt62-106 & 407.35 & 98.5 & 1.1 & 0.0 & 0.0 & 0.0 & 64 & $\mathrm{~K}$ \\
\hline Lt62-107 & 410.99 & 98.3 & 0.6 & 0.0 & 0.0 & 0.0 & 47 & $\mathrm{~K}$ \\
\hline Lt62-108 & 411.02 & 98.9 & 0.4 & 0.0 & 0.0 & 0.0 & 39 & $\mathrm{~K}$ \\
\hline Lt62-109 & 411.05 & 91.7 & 7.6 & 0.0 & 0.0 & 0.0 & 65 & $\mathrm{M}$ \\
\hline Lt62-110 & 413.11 & 97.6 & 1.3 & 0.0 & 0.0 & 0.0 & 48 & M \\
\hline Lt62-111 & 413.18 & 98.4 & 1.1 & 0.0 & 0.0 & 0.0 & 38 & $\mathrm{~K}$ \\
\hline
\end{tabular}


Table A.1 (continued): Bromide data Teutschenthal (drilling core Lt62)

\begin{tabular}{lcccccccc}
\hline \hline Sample & $\begin{array}{c}\text { Hauptsalz } \\
\text { thickness } \\
\text { name }\end{array}$ & $\begin{array}{c}\text { Halite } \\
\text { wt\% }\end{array}$ & $\begin{array}{c}\text { Anhydrite } \\
\text { wt\% }\end{array}$ & $\begin{array}{c}\text { Polyhalite } \\
\text { wt } \%\end{array}$ & $\begin{array}{c}\text { Kieserite } \\
\text { wt\% }\end{array}$ & $\begin{array}{c}\text { Sylvine } \\
\text { wt\% }\end{array}$ & $\begin{array}{c}\text { Br } / \\
\text { Halite } \\
\text { ppm }\end{array}$ & $\begin{array}{c}\text { Sample } \\
\text { type }\end{array}$ \\
\hline \hline Lt62-112 & 415.96 & 98.4 & 0.6 & 0.0 & 0.0 & 0.0 & 44 & $\mathrm{~K}$ \\
Lt62-113 & 416.00 & 99.0 & 1.1 & 0.0 & 0.1 & 0.0 & 55 & $\mathrm{~K}$ \\
Lt62-114 & 416.27 & 98.1 & 1.3 & 0.0 & 0.0 & 0.0 & 65 & $\mathrm{M}$ \\
Lt62-115 & 418.99 & 96.9 & 2.1 & 0.0 & 0.0 & 0.0 & 65 & $\mathrm{M}$ \\
Lt62-116 & 421.02 & 94.7 & 4.1 & 0.0 & 0.0 & 0.0 & 50 & $\mathrm{M}$ \\
Lt62-117 & 421.07 & 99.9 & 0.1 & 0.0 & 0.0 & 0.0 & 59 & $\mathrm{~K}$ \\
Lt62-118 & 422.55 & 96.2 & 3.1 & 0.0 & 0.0 & 0.0 & 62 & $\mathrm{~K}$ \\
Lt62-119 & 422.63 & 98.0 & 2.0 & 0.0 & 0.0 & 0.0 & 63 & $\mathrm{M}$ \\
Lt62-120 & 424.24 & 99.6 & 0.3 & 0.0 & 0.0 & 0.0 & 59 & $\mathrm{~K}$ \\
Lt62-121 & 424.25 & 98.4 & 0.7 & 0.0 & 0.0 & 0.0 & 40 & $\mathrm{M}$ \\
Lt62-122 & 430.27 & 97.9 & 1.5 & 0.0 & 0.0 & 0.0 & 49 & $\mathrm{M}$ \\
Lt62-123 & 430.34 & 99.1 & 0.4 & 0.0 & 0.0 & 0.0 & 40 & $\mathrm{~K}$ \\
Lt62-124 & 438.30 & 98.7 & 0.7 & 0.0 & 0.0 & 0.0 & 62 & $\mathrm{M}$ \\
Lt62-125 & 438.33 & 97.6 & 1.5 & 0.0 & 0.1 & 0.0 & 58 & $\mathrm{~K}$ \\
Lt62-126 & 442.87 & 98.6 & 0.4 & 0.0 & 0.0 & 0.0 & 49 & $\mathrm{~K}$ \\
Lt62-127 & 442.91 & 98.6 & 1.6 & 0.0 & 0.0 & 0.0 & 62 & $\mathrm{M}$ \\
Lt62-128 & 450.07 & 98.1 & 1.6 & 0.0 & 0.0 & 0.0 & 61 & $\mathrm{M}$ \\
Lt62-129 & 450.14 & 99.1 & 0.5 & 0.0 & 0.0 & 0.0 & 55 & $\mathrm{~K}$ \\
Lt62-130 & 457.19 & 97.1 & 2.2 & 0.0 & 0.0 & 0.0 & 61 & $\mathrm{M}$ \\
Lt62-131 & 457.23 & 98.6 & 0.3 & 0.0 & 0.0 & 0.0 & 36 & $\mathrm{~K}$ \\
Lt62-132 & 472.60 & 98.7 & 1.4 & 0.1 & 0.0 & 0.0 & 52 & $\mathrm{~K}$ \\
Lt62-133 & 472.64 & 99.1 & 0.4 & 0.0 & 0.0 & 0.0 & 60 & $\mathrm{M}$ \\
Lt62-139 & 475.70 & 99.4 & 0.2 & 0.0 & 0.0 & 0.0 & 56 & $\mathrm{~K}$ \\
Lt62-140 & 475.74 & 99.4 & 1.0 & 0.1 & 0.0 & 0.0 & 59 & $\mathrm{M}$ \\
Lt62-137 & 477.42 & 98.4 & 0.4 & 0.0 & 0.0 & 0.0 & 56 & $\mathrm{~K}$ \\
Lt62-138 & 477.45 & 98.6 & 0.4 & 0.0 & 0.0 & 0.0 & 62 & $\mathrm{~K}$ \\
Lt62-134 & 479.95 & 99.3 & 0.6 & 0.0 & 0.0 & 0.0 & 47 & $\mathrm{M}$ \\
Lt62-135 & 480.00 & 99.1 & 0.4 & 0.0 & 0.0 & 0.0 & 48 & $\mathrm{~K}$ \\
Lt62-136 & 480.12 & 98.9 & 0.6 & 0.0 & 0.0 & 0.0 & 56 & $\mathrm{~K}$ \\
\hline & & & & & & & &
\end{tabular}


Table A.2: Bromide data Morsleben (drilling core RB606)

\begin{tabular}{|c|c|c|c|c|c|c|c|c|}
\hline $\begin{array}{l}\text { Sample } \\
\text { name }\end{array}$ & $\begin{array}{l}\text { Hauptsalz } \\
\text { thickness } \\
(\mathrm{m})\end{array}$ & $\begin{array}{c}\text { Halite } \\
\text { wt } \%\end{array}$ & $\begin{array}{c}\text { Anhydrite } \\
\text { wt } \%\end{array}$ & $\begin{array}{c}\text { Polyhalite } \\
\text { wt } \%\end{array}$ & $\begin{array}{c}\text { Kieserite } \\
\text { wt } \%\end{array}$ & $\begin{array}{c}\text { Sylvine } \\
\text { wt } \%\end{array}$ & $\begin{array}{c}\text { Br / } \\
\text { Halite } \\
\text { ppm } \\
\end{array}$ & $\begin{array}{l}\text { Sample } \\
\text { type }\end{array}$ \\
\hline Mo 215 & 1.15 & 97.9 & 0.7 & 0.0 & 0.4 & 0.5 & 211 & $\mathrm{~K}$ \\
\hline MoF99 & 1.17 & 97.6 & 0.0 & 1.8 & 0.0 & 0.0 & 213 & $\mathrm{M}$ \\
\hline MoE5 & 1.20 & 98.7 & 0.0 & 0.5 & 0.0 & 0.0 & 134 & $\mathrm{~K}$ \\
\hline MoF98 & 1.20 & 99.1 & 0.2 & 0.0 & 0.1 & 0.2 & 172 & $\mathrm{~K}$ \\
\hline Mo 5 & 1.21 & 98.2 & 0.0 & 1.1 & 0.0 & 0.0 & 166 & $\mathrm{~K}$ \\
\hline Mo 214 & 1.21 & 98.9 & 0.1 & 0.0 & 0.1 & 0.1 & 189 & $\mathrm{~K}$ \\
\hline Mo 181 & 1.73 & 98.9 & 0.5 & 0.0 & 0.2 & 0.2 & 201 & $\mathrm{~K}$ \\
\hline MoE11 & 1.74 & 97.8 & 0.2 & 0.9 & 0.0 & 0.0 & 183 & $\mathrm{~K}$ \\
\hline Mo 6 & 1.75 & 98.1 & 0.0 & 0.3 & 0.0 & 0.0 & 109 & $\mathrm{~K}$ \\
\hline MoF95 & 1.77 & 95.6 & 1.9 & 0.2 & 0.2 & 0.7 & 180 & $\mathrm{M}$ \\
\hline Mo 7 & 1.78 & 96.9 & 0.0 & 0.4 & 0.0 & 0.0 & 161 & $\mathrm{~K}$ \\
\hline Mo 180 & 1.78 & 99.2 & 0.2 & 0.4 & 0.0 & 0.0 & 195 & $\mathrm{~K}$ \\
\hline MoF97 & 1.80 & 96.9 & 2.2 & 0.6 & 0.1 & 0.1 & 183 & M \\
\hline Mo 8 & 1.82 & 98.9 & 0.1 & 0.3 & 0.0 & 0.0 & 120 & $\mathrm{~K}$ \\
\hline MoE6 & 1.84 & 97.8 & 0.2 & 1.7 & 0.0 & 0.0 & 180 & M \\
\hline MoF96 & 1.85 & 98.4 & 0.9 & 0.0 & 0.4 & 0.5 & 181 & M \\
\hline Mo 179 & 1.86 & 99.1 & 0.0 & 0.3 & 0.0 & 0.0 & 138 & $\mathrm{~K}$ \\
\hline Mo 211 & 3.26 & 97.8 & 0.5 & 0.7 & 0.0 & 0.0 & 129 & M \\
\hline MoF94 & 3.30 & 94.6 & 3.1 & 1.5 & 0.0 & 0.0 & 182 & M \\
\hline Mo 212 & 3.33 & 99.4 & 0.7 & 0.0 & 0.0 & 0.0 & 142 & M \\
\hline MoE7 & 3.33 & 96.9 & 1.3 & 0.2 & 0.0 & 0.0 & 173 & M \\
\hline Mo 175 & 4.23 & 98.4 & 1.4 & 0.0 & 0.0 & 0.1 & 153 & M \\
\hline MoF93 & 4.25 & 98.9 & 0.9 & 0.0 & 0.1 & 0.1 & 181 & M \\
\hline Mo 9 & 4.27 & 98.4 & 0.8 & 0.3 & 0.0 & 0.0 & 129 & M \\
\hline MoE8 & 4.27 & 99.1 & 0.1 & 0.0 & 0.0 & 0.1 & 115 & M \\
\hline Mo 178 & 4.28 & 98.1 & 0.9 & 0.7 & 0.0 & 0.0 & 127 & M \\
\hline Mo 176 & 4.33 & 96.4 & 0.9 & 2.2 & 0.0 & 0.0 & 175 & M \\
\hline MoF92 & 4.33 & 97.1 & 1.7 & 0.8 & 0.3 & 0.4 & 176 & M \\
\hline Mo 10 & 4.38 & 98.7 & 0.7 & 0.2 & 0.0 & 0.0 & 174 & M \\
\hline Mo 177 & 4.39 & 98.4 & 1.0 & 0.5 & 0.0 & 0.0 & 188 & M \\
\hline MoE9 & 4.39 & 97.4 & 2.4 & 0.1 & 0.0 & 0.0 & 176 & M \\
\hline Mo 210 & 4.80 & 99.4 & 0.2 & 0.2 & 0.0 & 0.0 & 199 & M \\
\hline MoF91 & 4.82 & 94.3 & 1.2 & 3.6 & 0.0 & 0.0 & 179 & M \\
\hline MoE10 & 4.83 & 99.6 & 0.3 & 0.3 & 0.0 & 0.0 & 157 & M \\
\hline Mo 209 & 4.84 & 98.2 & 1.3 & 0.2 & 0.0 & 0.0 & 172 & M \\
\hline Mo 213 & 4.87 & 97.6 & 1.1 & 0.0 & 0.1 & 0.2 & 128 & M \\
\hline Mo 207 & 5.46 & 99.4 & 0.3 & 0.0 & 0.0 & 0.0 & 175 & M \\
\hline MoE12 & 5.48 & 99.1 & 0.5 & 0.0 & 0.0 & 0.0 & 158 & M \\
\hline Mo 208 & 5.49 & 97.4 & 1.6 & 0.3 & 0.0 & 0.0 & 185 & M \\
\hline MoF90 & 5.49 & 95.3 & 2.7 & 2.3 & 0.1 & 0.1 & 118 & M \\
\hline MoF89 & 8.22 & 96.6 & 2.3 & 0.0 & 0.0 & 0.0 & 144 & M \\
\hline Mo 206 & 8.23 & 97.6 & 2.2 & 0.0 & 0.0 & 0.0 & 154 & M \\
\hline MoE13 & 8.23 & 97.8 & 1.0 & 0.0 & 0.0 & 0.0 & 138 & M \\
\hline Mo 203 & 9.64 & 97.1 & 1.6 & 0.0 & 0.0 & 0.0 & 140 & M \\
\hline MoF88 & 9.65 & 85.9 & 13.2 & 0.0 & 0.0 & 0.0 & 160 & M \\
\hline MoE14 & 9.66 & 97.9 & 1.9 & 0.0 & 0.0 & 0.0 & 137 & M \\
\hline Mo 204 & 9.69 & 97.1 & 1.6 & 0.0 & 0.0 & 0.0 & 161 & M \\
\hline MoF87 & 9.69 & 97.8 & 1.7 & 0.0 & 0.0 & 0.0 & 145 & $\mathrm{~K}$ \\
\hline
\end{tabular}


Table A.2 (continued): Bromide data Morsleben (drilling core RB606)

\begin{tabular}{|c|c|c|c|c|c|c|c|c|}
\hline $\begin{array}{l}\text { Sample } \\
\text { name }\end{array}$ & $\begin{array}{l}\text { Hauptsalz } \\
\text { thickness } \\
(\mathrm{m})\end{array}$ & $\begin{array}{l}\text { Halite } \\
\text { wt } \%\end{array}$ & $\begin{array}{c}\text { Anhydrite } \\
\text { wt } \%\end{array}$ & $\begin{array}{c}\text { Polyhalite } \\
\text { wt } \%\end{array}$ & $\begin{array}{c}\text { Kieserite } \\
\text { wt } \%\end{array}$ & $\begin{array}{c}\text { Sylvine } \\
\text { wt } \%\end{array}$ & $\begin{array}{c}\mathrm{Br} / \\
\text { Halite } \\
\mathrm{ppm}\end{array}$ & $\begin{array}{c}\text { Sample } \\
\text { type }\end{array}$ \\
\hline Mo 205 & 9.73 & 98.9 & 0.1 & 0.0 & 0.0 & 0.0 & 155 & $\bar{M}$ \\
\hline Mo 171 & 11.25 & 99.1 & 0.7 & 0.0 & 0.0 & 0.0 & 149 & M \\
\hline MoE15 & 11.25 & 97.9 & 2.1 & 0.0 & 0.0 & 0.0 & 136 & M \\
\hline MoF86 & 11.26 & 98.1 & 1.3 & 0.0 & 0.0 & 0.0 & 99 & $\mathrm{M}$ \\
\hline Мo 172 & 11.27 & 98.9 & 0.5 & 0.0 & 0.0 & 0.0 & 111 & $\mathrm{M}$ \\
\hline Mo 173 & 11.29 & 97.8 & 2.0 & 0.0 & 0.0 & 0.0 & 144 & M \\
\hline Mo 174 & 11.33 & 98.7 & 0.6 & 0.0 & 0.0 & 0.0 & 147 & $\mathrm{M}$ \\
\hline Mo 11 & 12.32 & 98.1 & 1.8 & 0.0 & 0.0 & 0.0 & 129 & M \\
\hline Mo 169 & 12.34 & 99.1 & 0.4 & 0.0 & 0.0 & 0.0 & 133 & $\mathrm{~K}$ \\
\hline Mo 170 & 12.36 & 98.4 & 1.6 & 0.0 & 0.0 & 0.0 & 140 & M \\
\hline MoE16 & 12.39 & 98.4 & 2.1 & 0.0 & 0.0 & 0.0 & 125 & $\mathrm{M}$ \\
\hline Mo 167 & 12.43 & 98.4 & 1.5 & 0.0 & 0.0 & 0.0 & 129 & $\mathrm{~K}$ \\
\hline Mo 12 & 12.44 & 98.4 & 1.4 & 0.0 & 0.0 & 0.0 & 129 & M \\
\hline Мo 168 & 12.44 & 98.9 & 0.7 & 0.0 & 0.0 & 0.0 & 132 & $\mathrm{~K}$ \\
\hline MoE17 & 12.46 & 94.0 & 5.1 & 0.0 & 0.0 & 0.0 & 130 & M \\
\hline MoF85 & 12.47 & 93.8 & 4.8 & 0.0 & 0.0 & 0.0 & 136 & M \\
\hline Mo 13 & 12.93 & 98.9 & 0.3 & 0.0 & 0.0 & 0.0 & 119 & $\mathrm{~K}$ \\
\hline Мo 160 & 12.98 & 96.4 & 2.5 & 0.0 & 0.0 & 0.0 & 143 & $\mathrm{M}$ \\
\hline MoE18 & 12.98 & 97.8 & 2.0 & 0.0 & 0.0 & 0.0 & 125 & M \\
\hline Mo 161 & 12.99 & 98.7 & 0.3 & 0.0 & 0.0 & 0.0 & 80 & M \\
\hline MoF84 & 12.99 & 95.1 & 4.6 & 0.0 & 0.0 & 0.0 & 134 & M \\
\hline Mo 14 & 13.07 & 98.4 & 0.6 & 0.0 & 0.0 & 0.0 & 124 & $\mathrm{~K}$ \\
\hline MoE19 & 13.68 & 96.4 & 2.8 & 0.0 & 0.0 & 0.0 & 131 & M \\
\hline Mo 16 & 13.69 & 98.2 & 1.2 & 0.0 & 0.0 & 0.0 & 130 & M \\
\hline MoF83 & 13.74 & 97.1 & 2.2 & 0.0 & 0.0 & 0.0 & 95 & $\mathrm{M}$ \\
\hline Mo 15 & 13.76 & 98.6 & 0.6 & 0.0 & 0.0 & 0.0 & 152 & $\mathrm{~K}$ \\
\hline MoE20 & 13.77 & 95.8 & 3.9 & 0.0 & 0.0 & 0.0 & 135 & $\mathrm{~K}$ \\
\hline Mo 18 & 15.12 & 97.9 & 2.2 & 0.0 & 0.0 & 0.0 & 125 & M \\
\hline Mo 17 & 15.13 & 99.2 & 0.2 & 0.0 & 0.0 & 0.0 & 122 & M \\
\hline MoF81 & 15.15 & 96.9 & 1.9 & 0.0 & 0.0 & 0.0 & 126 & M \\
\hline Mo 19 & 15.16 & 97.9 & 0.7 & 0.0 & 0.0 & 0.0 & 118 & $\mathrm{~K}$ \\
\hline MoE21 & 15.17 & 98.1 & 2.4 & 0.0 & 0.0 & 0.0 & 115 & $\mathrm{~K}$ \\
\hline MoF82 & 15.19 & 97.9 & 1.3 & 0.0 & 0.0 & 0.0 & 89 & $\mathrm{~K}$ \\
\hline Mo 162 & 15.21 & 97.4 & 2.2 & 0.0 & 0.0 & 0.0 & 95 & M \\
\hline Mo 163 & 15.21 & 95.8 & 2.5 & 0.0 & 0.0 & 0.0 & 135 & M \\
\hline MoE22 & 15.80 & 99.6 & 0.5 & 0.0 & 0.0 & 0.0 & 121 & M \\
\hline Mo 164 & 15.82 & 97.9 & 1.0 & 0.0 & 0.0 & 0.0 & 129 & M \\
\hline Mo 20 & 15.83 & 99.1 & 0.6 & 0.0 & 0.0 & 0.0 & 124 & $\mathrm{M}$ \\
\hline Mo 165 & 15.86 & 97.3 & 1.3 & 0.0 & 0.0 & 0.0 & 100 & M \\
\hline MoF79 & 15.86 & 97.4 & 3.4 & 0.0 & 0.0 & 0.0 & 124 & M \\
\hline Mo 21 & 15.89 & 98.1 & 0.4 & 0.0 & 0.0 & 0.0 & 91 & $\mathrm{~K}$ \\
\hline Mo 22 & 15.89 & 98.2 & 0.2 & 0.0 & 0.0 & 0.0 & 84 & $\mathrm{~K}$ \\
\hline MoF80 & 15.93 & 93.0 & 7.3 & 0.0 & 0.0 & 0.0 & 123 & M \\
\hline Mo 166 & 15.94 & 97.3 & 1.6 & 0.0 & 0.0 & 0.0 & 133 & M \\
\hline MoE23 & 17.61 & 99.7 & 0.7 & 0.0 & 0.0 & 0.0 & 114 & $\mathrm{M}$ \\
\hline MoF77 & 17.63 & 97.4 & 2.3 & 0.0 & 0.0 & 0.0 & 117 & M \\
\hline Mo 23 & 17.64 & 96.9 & 2.4 & 0.0 & 0.0 & 0.0 & 116 & $\mathrm{M}$ \\
\hline Mo 158 & 17.66 & 95.8 & 4.1 & 0.0 & 0.0 & 0.0 & 123 & $\mathrm{M}$ \\
\hline
\end{tabular}


Table A.2 (continued): Bromide data Morsleben (drilling core RB606)

\begin{tabular}{|c|c|c|c|c|c|c|c|c|}
\hline $\begin{array}{l}\text { Sample } \\
\text { name }\end{array}$ & $\begin{array}{l}\text { Hauptsalz } \\
\text { thickness } \\
\text { (m) }\end{array}$ & $\begin{array}{l}\text { Halite } \\
\text { wt } \%\end{array}$ & $\begin{array}{c}\text { Anhydrite } \\
\text { wt } \%\end{array}$ & $\begin{array}{c}\text { Polyhalite } \\
\text { wt } \%\end{array}$ & $\begin{array}{c}\text { Kieserite } \\
\text { wt } \%\end{array}$ & $\begin{array}{l}\text { Sylvine } \\
\text { wt } \%\end{array}$ & $\begin{array}{c}\mathrm{Br} / \\
\text { Halite } \\
\mathrm{ppm}\end{array}$ & $\begin{array}{c}\text { Sample } \\
\text { type }\end{array}$ \\
\hline Mo 157 & 17.67 & 98.9 & 0.9 & 0.0 & 0.0 & 0.0 & 124 & $\bar{M}$ \\
\hline MoF78 & 17.67 & 97.6 & 2.0 & 0.0 & 0.0 & 0.0 & 111 & M \\
\hline Mo 24 & 19.14 & 98.9 & 0.2 & 0.0 & 0.0 & 0.0 & 65 & $\mathrm{~K}$ \\
\hline MoE24 & 19.15 & 98.1 & 2.5 & 0.0 & 0.0 & 0.0 & 105 & $\mathrm{M}$ \\
\hline MoF74 & 19.16 & 91.8 & 7.5 & 0.0 & 0.0 & 0.0 & 97 & $\mathrm{M}$ \\
\hline Mo 159 & 19.19 & 98.4 & 1.1 & 0.0 & 0.0 & 0.0 & 114 & M \\
\hline Mo 156 & 19.23 & 99.9 & 0.5 & 0.0 & 0.0 & 0.0 & 72 & $\mathrm{~K}$ \\
\hline MoF76 & 19.26 & 94.3 & 5.8 & 0.0 & 0.0 & 0.0 & 74 & M \\
\hline Mo 26 & 19.31 & 97.8 & 0.7 & 0.0 & 0.0 & 0.0 & 107 & M \\
\hline MoE25 & 19.35 & 98.6 & 0.8 & 0.0 & 0.0 & 0.0 & 96 & $\mathrm{~K}$ \\
\hline MoF75 & 19.35 & 98.1 & 0.9 & 0.0 & 0.0 & 0.0 & 110 & $\mathrm{M}$ \\
\hline Mo 155 & 19.41 & 98.1 & 1.9 & 0.0 & 0.0 & 0.0 & 111 & M \\
\hline Mo 25 & 19.45 & 98.1 & 0.2 & 0.0 & 0.0 & 0.0 & 62 & $\mathrm{~K}$ \\
\hline Mo 28 & 21.11 & 98.2 & 1.1 & 0.0 & 0.0 & 0.0 & 96 & $\mathrm{M}$ \\
\hline Mo 27 & 21.16 & 99.4 & 0.5 & 0.0 & 0.0 & 0.0 & 73 & $\mathrm{~K}$ \\
\hline MoF73 & 21.17 & 97.9 & 1.6 & 0.0 & 0.0 & 0.0 & 96 & M \\
\hline Mo 154 & 21.19 & 98.6 & 1.3 & 0.0 & 0.0 & 0.0 & 100 & M \\
\hline Мо 153 & 21.21 & 97.4 & 2.1 & 0.0 & 0.0 & 0.0 & 100 & $\mathrm{M}$ \\
\hline Mo 29 & 21.23 & 96.5 & 2.8 & 0.0 & 0.0 & 0.0 & 77 & M \\
\hline Mo 151 & 21.86 & 97.6 & 2.1 & 0.0 & 0.0 & 0.0 & 74 & M \\
\hline MoE27 & 21.87 & 99.7 & 0.5 & 0.0 & 0.0 & 0.0 & 75 & M \\
\hline Mo 30 & 21.89 & 95.9 & 4.2 & 0.0 & 0.0 & 0.0 & 82 & M \\
\hline Mo 31 & 21.91 & 96.3 & 3.0 & 0.0 & 0.0 & 0.0 & 71 & M \\
\hline Mo 150 & 21.91 & 97.4 & 2.7 & 0.0 & 0.0 & 0.0 & 97 & M \\
\hline Мо 149 & 21.95 & 98.4 & 1.1 & 0.0 & 0.0 & 0.0 & 82 & $\mathrm{~K}$ \\
\hline MoF71 & 21.95 & 96.4 & 3.5 & 0.0 & 0.0 & 0.0 & 90 & M \\
\hline Mo 147 & 22.00 & 97.9 & 1.5 & 0.0 & 0.0 & 0.0 & 100 & M \\
\hline MoF72 & 22.03 & 96.3 & 3.0 & 0.0 & 0.0 & 0.0 & 92 & M \\
\hline Mo 32 & 22.04 & 99.2 & 0.7 & 0.0 & 0.0 & 0.0 & 88 & M \\
\hline Mo 145 & 24.05 & 97.6 & 1.6 & 0.0 & 0.0 & 0.0 & 95 & M \\
\hline Mo 35 & 24.10 & 97.8 & 2.2 & 0.0 & 0.0 & 0.0 & 85 & M \\
\hline MoE28 & 24.10 & 97.1 & 2.2 & 0.0 & 0.0 & 0.0 & 57 & M \\
\hline MoF70 & 24.10 & 97.4 & 2.1 & 0.0 & 0.0 & 0.0 & 88 & M \\
\hline Mo 34 & 24.12 & 99.7 & 0.1 & 0.0 & 0.0 & 0.0 & 54 & $\mathrm{~K}$ \\
\hline Mo 33 & 24.13 & 99.4 & 0.6 & 0.1 & 0.0 & 0.0 & 83 & M \\
\hline Mo 152 & 24.16 & 99.1 & 0.6 & 0.0 & 0.0 & 0.0 & 90 & M \\
\hline MoF69 & 24.16 & 91.5 & 7.8 & 0.0 & 0.0 & 0.0 & 87 & M \\
\hline Мo 146 & 24.18 & 98.9 & 1.1 & 0.0 & 0.0 & 0.0 & 92 & $\mathrm{M}$ \\
\hline Mo 148 & 25.62 & 97.8 & 1.1 & 0.0 & 0.0 & 0.0 & 89 & M \\
\hline Mo 36 & 25.64 & 99.4 & 0.7 & 0.0 & 0.0 & 0.0 & 78 & M \\
\hline MoE29 & 25.66 & 97.1 & 2.6 & 0.0 & 0.0 & 0.0 & 78 & M \\
\hline MoF67 & 25.66 & 99.9 & 0.7 & 0.0 & 0.0 & 0.0 & 71 & M \\
\hline Mo 37 & 25.67 & 97.9 & 1.3 & 0.0 & 0.0 & 0.0 & 79 & M \\
\hline Mo 144 & 25.71 & 97.3 & 1.9 & 0.0 & 0.0 & 0.0 & 104 & M \\
\hline MoF68 & 25.73 & 94.8 & 5.2 & 0.0 & 0.0 & 0.0 & 77 & $\mathrm{M}$ \\
\hline Mo 38 & 25.74 & 99.7 & 0.8 & 0.0 & 0.0 & 0.0 & 61 & M \\
\hline Mo 140 & 27.10 & 95.0 & 4.0 & 0.0 & 0.0 & 0.0 & 62 & M \\
\hline MoF65 & 27.12 & 98.6 & 1.5 & 0.0 & 0.0 & 0.0 & 75 & M \\
\hline
\end{tabular}


Table A.2 (continued): Bromide data Morsleben (drilling core RB606)

\begin{tabular}{|c|c|c|c|c|c|c|c|c|}
\hline $\begin{array}{l}\text { Sample } \\
\text { name }\end{array}$ & $\begin{array}{c}\text { Hauptsalz } \\
\text { thickness } \\
(\mathrm{m}) \\
\end{array}$ & $\begin{array}{c}\text { Halite } \\
\text { wt } \%\end{array}$ & $\begin{array}{c}\text { Anhydrite } \\
\text { wt } \%\end{array}$ & $\begin{array}{c}\text { Polyhalite } \\
\text { wt } \%\end{array}$ & $\begin{array}{c}\text { Kieserite } \\
\text { wt } \%\end{array}$ & $\begin{array}{c}\text { Sylvine } \\
\text { wt } \%\end{array}$ & $\begin{array}{c}\mathrm{Br} / \\
\text { Halite } \\
\mathrm{ppm} \\
\end{array}$ & $\begin{array}{c}\text { Sample } \\
\text { type }\end{array}$ \\
\hline Mo 39 & 27.13 & 99.4 & 1.1 & 0.0 & 0.0 & 0.0 & 72 & $\mathrm{M}$ \\
\hline MoF66 & 27.16 & 94.6 & 4.9 & 0.0 & 0.0 & 0.0 & 75 & M \\
\hline Mo 24 & 19.14 & 98.9 & 0.2 & 0.0 & 0.0 & 0.0 & 65 & M \\
\hline MoE30 & 27.18 & 98.4 & 1.2 & 0.0 & 0.0 & 0.0 & 73 & M \\
\hline Mo 40 & 27.21 & 96.8 & 2.0 & 0.0 & 0.0 & 0.0 & 73 & M \\
\hline Mo 141 & 27.21 & 98.0 & 1.6 & 0.0 & 0.0 & 0.0 & 61 & M \\
\hline Mo 42 & 27.53 & 97.8 & 1.4 & 0.0 & 0.0 & 0.0 & 72 & $\mathrm{M}$ \\
\hline Mo 139 & 27.60 & 94.7 & 4.3 & 0.0 & 0.0 & 0.0 & 74 & M \\
\hline MoE31 & 27.60 & 98.9 & 1.0 & 0.0 & 0.0 & 0.0 & 71 & M \\
\hline Mo 41 & 27.61 & 97.3 & 1.4 & 0.0 & 0.0 & 0.0 & 71 & M \\
\hline MoF64 & 27.61 & 98.6 & 1.0 & 0.0 & 0.0 & 0.0 & 72 & $\mathrm{M}$ \\
\hline Mo 138 & 27.66 & 98.9 & 0.7 & 0.0 & 0.0 & 0.0 & 59 & M \\
\hline MoF63 & 27.68 & 96.6 & 3.7 & 0.0 & 0.0 & 0.0 & 70 & M \\
\hline MoF61 & 28.57 & 95.4 & 3.8 & 0.0 & 0.0 & 0.0 & 68 & M \\
\hline Mo 43 & 28.58 & 99.4 & 1.0 & 0.0 & 0.0 & 0.0 & 65 & M \\
\hline MoE32 & 28.59 & 98.9 & 1.0 & 0.0 & 0.0 & 0.0 & 65 & M \\
\hline Mo 142 & 28.60 & 96.0 & 3.2 & 0.0 & 0.0 & 0.0 & 72 & M \\
\hline MoE33 & 28.65 & 95.1 & 4.2 & 0.0 & 0.0 & 0.0 & 64 & M \\
\hline Mo 44 & 28.66 & 95.5 & 3.0 & 0.0 & 0.0 & 0.0 & 66 & M \\
\hline Mo 143 & 28.73 & 98.8 & 0.7 & 0.0 & 0.0 & 0.0 & 73 & M \\
\hline MoF62 & 28.73 & 98.4 & 1.1 & 0.0 & 0.0 & 0.0 & 66 & M \\
\hline Mo 196 & 29.62 & 97.1 & 2.8 & 0.0 & 0.0 & 0.0 & 46 & M \\
\hline MoF60 & 29.64 & 96.1 & 3.6 & 0.0 & 0.0 & 0.0 & 45 & M \\
\hline MoE34 & 29.67 & 97.6 & 2.0 & 0.0 & 0.0 & 0.0 & 56 & M \\
\hline Mo 197 & 29.70 & 98.2 & 1.4 & 0.0 & 0.0 & 0.0 & 52 & M \\
\hline Mo 198 & 29.73 & 95.6 & 3.6 & 0.0 & 0.0 & 0.0 & 57 & M \\
\hline Mo 47 & 30.88 & 97.6 & 1.6 & 0.0 & 0.0 & 0.0 & 41 & M \\
\hline MoF59 & 30.91 & 98.9 & 1.6 & 0.0 & 0.0 & 0.0 & 55 & M \\
\hline MoF58 & 30.93 & 94.3 & 5.3 & 0.0 & 0.0 & 0.0 & 53 & M \\
\hline MoE35 & 30.97 & 99.4 & 0.5 & 0.0 & 0.0 & 0.0 & 49 & $\mathrm{M}$ \\
\hline Mo 45 & 31.00 & 98.6 & 1.0 & 0.0 & 0.0 & 0.0 & 39 & M \\
\hline Mo 46 & 31.00 & 99.9 & 0.3 & 0.0 & 0.0 & 0.0 & 39 & M \\
\hline MoF56 & 31.59 & 95.3 & 4.9 & 0.0 & 0.0 & 0.0 & 50 & M \\
\hline MoE36 & 31.64 & 96.9 & 1.3 & 0.0 & 0.0 & 0.0 & 50 & M \\
\hline Mo 49 & 31.65 & 97.9 & 1.0 & 0.0 & 0.0 & 0.0 & 49 & M \\
\hline MoF57 & 31.69 & 99.7 & 0.6 & 0.0 & 0.0 & 0.0 & 37 & M \\
\hline Mo 48 & 31.71 & 94.1 & 0.7 & 0.0 & 0.0 & 0.0 & 37 & M \\
\hline Mo 52 & 32.40 & 99.7 & 0.7 & 0.0 & 0.0 & 0.0 & 47 & M \\
\hline Mo 136 & 32.41 & 99.3 & 0.8 & 0.0 & 0.0 & 0.0 & 49 & M \\
\hline MoF55 & 32.47 & 91.0 & 7.9 & 0.1 & 0.1 & 0.0 & 51 & M \\
\hline Mo 51 & 32.50 & 96.1 & 4.0 & 0.1 & 0.1 & 0.0 & 48 & M \\
\hline Mo 50 & 32.53 & 98.8 & 1.3 & 0.0 & 0.0 & 0.0 & 38 & $\mathrm{M}$ \\
\hline Mo 54 & 33.56 & 99.7 & 0.5 & 0.0 & 0.0 & 0.0 & 48 & M \\
\hline Mo 53 & 33.59 & 98.6 & 1.9 & 0.0 & 0.0 & 0.0 & 48 & M \\
\hline MoF51 & 33.59 & 96.4 & 3.2 & 0.0 & 0.0 & 0.0 & 37 & M \\
\hline MoE38 & 33.61 & 97.9 & 1.3 & 0.0 & 0.0 & 0.0 & 35 & M \\
\hline Mo 55 & 33.63 & 99.1 & 0.9 & 0.0 & 0.0 & 0.0 & 47 & M \\
\hline Mo 137 & 33.65 & 91.5 & 8.7 & 0.0 & 0.0 & 0.0 & 53 & M \\
\hline
\end{tabular}


Table A.2 (continued): Bromide data Morsleben (drilling core RB606)

\begin{tabular}{|c|c|c|c|c|c|c|c|c|}
\hline $\begin{array}{l}\text { Sample } \\
\text { name }\end{array}$ & $\begin{array}{l}\text { Hauptsalz } \\
\text { thickness } \\
(\mathrm{m})\end{array}$ & $\begin{array}{c}\text { Halite } \\
\text { wt } \%\end{array}$ & $\begin{array}{c}\text { Anhydrite } \\
\text { wt } \%\end{array}$ & $\begin{array}{c}\text { Polyhalite } \\
\text { wt } \%\end{array}$ & $\begin{array}{c}\text { Kieserite } \\
\text { wt } \%\end{array}$ & $\begin{array}{l}\text { Sylvine } \\
\text { wt\% }\end{array}$ & $\begin{array}{c}\text { Br / } \\
\text { Halite } \\
\text { ppm } \\
\end{array}$ & $\begin{array}{l}\text { Sample } \\
\text { type }\end{array}$ \\
\hline Mo 56 & 36.05 & 96.6 & 3.3 & 0.0 & 0.0 & 0.0 & 46 & $\mathrm{M}$ \\
\hline MoF52 & 36.06 & 94.6 & 5.4 & 0.0 & 0.0 & 0.0 & 38 & M \\
\hline MoE39 & 36.08 & 97.4 & 2.4 & 0.0 & 0.0 & 0.0 & 47 & M \\
\hline MoE30 & 27.18 & 98.4 & 1.2 & 0.0 & 0.0 & 0.0 & 73 & M \\
\hline MoF50 & 36.09 & 95.1 & 4.8 & 0.0 & 0.0 & 0.0 & 50 & M \\
\hline Mo 57 & 36.10 & 96.6 & 3.6 & 0.0 & 0.0 & 0.0 & 47 & M \\
\hline Mo 135 & 36.11 & 95.1 & 4.8 & 0.0 & 0.0 & 0.0 & 51 & M \\
\hline MoF53 & 36.49 & 95.8 & 4.2 & 0.0 & 0.0 & 0.0 & 54 & M \\
\hline Mo 58 & 36.65 & 99.2 & 0.6 & 0.0 & 0.0 & 0.0 & 46 & M \\
\hline MoE40 & 36.66 & 99.1 & 0.5 & 0.0 & 0.0 & 0.0 & 45 & M \\
\hline MoF49 & 36.66 & 99.4 & 0.6 & 0.0 & 0.0 & 0.0 & 51 & M \\
\hline MoF47 & 39.40 & 93.5 & 7.2 & 0.0 & 0.1 & 0.0 & 51 & M \\
\hline Mo 193 & 39.42 & 98.4 & 1.0 & 0.0 & 0.0 & 0.0 & 46 & M \\
\hline Mo 194 & 39.44 & 98.9 & 1.1 & 0.0 & 0.0 & 0.0 & 36 & M \\
\hline MoE41 & 39.45 & 94.1 & 5.4 & 0.1 & 0.0 & 0.0 & 35 & M \\
\hline Mo 199 & 39.46 & 97.1 & 1.9 & 0.0 & 0.0 & 0.0 & 53 & M \\
\hline Mo 130 & 40.59 & 97.4 & 1.4 & 0.0 & 0.0 & 0.0 & 50 & M \\
\hline MoF54 & 40.62 & 92.3 & 7.6 & 0.0 & 0.0 & 0.0 & 52 & M \\
\hline Mo 131 & 40.64 & 96.6 & 2.9 & 0.0 & 0.0 & 0.0 & 55 & M \\
\hline Mo 132 & 40.67 & 98.6 & 1.5 & 0.0 & 0.0 & 0.0 & 51 & M \\
\hline Mo 59 & 40.68 & 98.4 & 1.2 & 0.0 & 0.0 & 0.0 & 48 & M \\
\hline Mo 60 & 40.72 & 99.2 & 1.4 & 0.0 & 0.0 & 0.0 & 44 & M \\
\hline Mo 133 & 40.72 & 99.4 & 1.0 & 0.0 & 0.0 & 0.0 & 38 & M \\
\hline Mo 61 & 40.75 & 93.6 & 5.3 & 0.1 & 0.0 & 0.0 & 48 & M \\
\hline MoF48 & 40.75 & 93.8 & 6.0 & 0.0 & 0.0 & 0.0 & 52 & M \\
\hline Mo 134 & 40.79 & 96.6 & 2.8 & 0.0 & 0.0 & 0.0 & 51 & M \\
\hline MoE42 & 40.81 & 97.6 & 2.3 & 0.0 & 0.0 & 0.0 & 42 & M \\
\hline MoF46 & 41.20 & 98.4 & 2.1 & 0.0 & 0.0 & 0.0 & 52 & M \\
\hline Mo 63 & 41.23 & 96.9 & 3.6 & 0.0 & 0.0 & 0.0 & 48 & M \\
\hline Mo 62 & 41.26 & 98.7 & 0.9 & 0.1 & 0.0 & 0.0 & 48 & M \\
\hline MoE43 & 41.27 & 99.1 & 0.3 & 0.0 & 0.0 & 0.0 & 45 & M \\
\hline MoF45 & 41.30 & 96.9 & 2.7 & 0.0 & 0.0 & 0.0 & 58 & M \\
\hline Mo 64 & 42.39 & 97.6 & 1.2 & 0.0 & 0.0 & 0.0 & 51 & M \\
\hline Mo 65 & 42.40 & 99.2 & 0.6 & 0.0 & 0.0 & 0.0 & 52 & M \\
\hline MoF44 & 42.43 & 97.1 & 2.7 & 0.0 & 0.0 & 0.0 & 56 & M \\
\hline Mo 67 & 42.46 & 94.8 & 5.8 & 0.0 & 0.0 & 0.0 & 39 & M \\
\hline MoF43 & 42.49 & 89.7 & 9.9 & 0.0 & 0.1 & 0.0 & 54 & M \\
\hline MoE44 & 42.51 & 99.1 & 1.6 & 0.0 & 0.0 & 0.0 & 50 & M \\
\hline Mo 66 & 42.52 & 95.9 & 4.2 & 0.0 & 0.0 & 0.0 & 39 & M \\
\hline Mo 200 & 43.81 & 99.1 & 1.0 & 0.0 & 0.0 & 0.0 & 56 & M \\
\hline MoF41 & 43.87 & 91.3 & 8.8 & 0.0 & 0.0 & 0.0 & 54 & M \\
\hline Мo 201 & 43.93 & 94.6 & 5.3 & 0.0 & 0.0 & 0.0 & 55 & M \\
\hline MoE45 & 43.93 & 96.9 & 2.5 & 0.0 & 0.0 & 0.0 & 46 & M \\
\hline MoF42 & 43.93 & 94.3 & 5.8 & 0.0 & 0.0 & 0.0 & 53 & M \\
\hline Mo 202 & 43.94 & 97.1 & 1.5 & 0.0 & 0.0 & 0.0 & 64 & M \\
\hline Mo 128 & 45.50 & 98.3 & 1.5 & 0.0 & 0.0 & 0.0 & 41 & M \\
\hline Мo 68 & 45.52 & 97.1 & 3.2 & 0.0 & 0.0 & 0.0 & 50 & M \\
\hline MoF39 & 45.58 & 93.0 & 7.0 & 0.0 & 0.0 & 0.0 & 54 & M \\
\hline
\end{tabular}


Table A.2 (continued): Bromide data Morsleben (drilling core RB606)

\begin{tabular}{|c|c|c|c|c|c|c|c|c|}
\hline $\begin{array}{l}\text { Sample } \\
\text { name }\end{array}$ & $\begin{array}{c}\text { Hauptsalz } \\
\text { thickness } \\
(\mathrm{m}) \\
\end{array}$ & $\begin{array}{c}\text { Halite } \\
\text { wt } \%\end{array}$ & $\begin{array}{c}\text { Anhydrite } \\
\text { wt } \%\end{array}$ & $\begin{array}{c}\text { Polyhalite } \\
\text { wt } \%\end{array}$ & $\begin{array}{c}\text { Kieserite } \\
\text { wt } \%\end{array}$ & $\begin{array}{c}\text { Sylvine } \\
\text { wt } \%\end{array}$ & $\begin{array}{c}\mathrm{Br} / \\
\text { Halite } \\
\mathrm{ppm} \\
\end{array}$ & $\begin{array}{c}\text { Sample } \\
\text { type }\end{array}$ \\
\hline MoE46 & 45.62 & 94.1 & 5.7 & 0.0 & 0.0 & 0.0 & 36 & $\mathrm{M}$ \\
\hline MoF40 & 45.65 & 93.5 & 6.4 & 0.0 & 0.1 & 0.0 & 49 & M \\
\hline MoE47 & 46.80 & 98.2 & 1.9 & 0.0 & 0.0 & 0.0 & 52 & M \\
\hline MoF37 & 46.83 & 96.8 & 3.8 & 0.0 & 0.0 & 0.0 & 53 & M \\
\hline Mo 70 & 46.85 & 96.3 & 3.3 & 0.0 & 0.0 & 0.0 & 53 & M \\
\hline Mo 69 & 46.91 & 97.9 & 2.3 & 0.0 & 0.0 & 0.0 & 40 & M \\
\hline MoF38 & 46.95 & 97.4 & 3.0 & 0.0 & 0.0 & 0.0 & 52 & $\mathrm{M}$ \\
\hline Mo 129 & 47.43 & 97.1 & 2.7 & 0.0 & 0.0 & 0.0 & 43 & M \\
\hline MoE48 & 47.45 & 99.7 & 0.3 & 0.0 & 0.0 & 0.0 & 52 & M \\
\hline MoF34 & 47.48 & 97.9 & 2.0 & 0.0 & 0.0 & 0.0 & 53 & M \\
\hline MoF36 & 47.53 & 96.1 & 3.6 & 0.0 & 0.1 & 0.0 & 54 & $\mathrm{M}$ \\
\hline Mo 72 & 47.77 & 99.1 & 1.7 & 0.0 & 0.0 & 0.0 & 53 & M \\
\hline MoF35 & 47.77 & 94.8 & 5.2 & 0.0 & 0.0 & 0.0 & 55 & M \\
\hline MoE49 & 47.85 & 97.0 & 2.4 & 0.0 & 0.0 & 0.0 & 53 & M \\
\hline Mo 71 & 47.87 & 97.3 & 2.6 & 0.0 & 0.0 & 0.0 & 42 & M \\
\hline MoE56 & 48.52 & 97.1 & 3.0 & 0.0 & 0.0 & 0.0 & 48 & M \\
\hline Mo 73 & 49.68 & 98.5 & 1.4 & 0.0 & 0.0 & 0.0 & 53 & M \\
\hline MoE50 & 49.72 & 98.6 & 2.1 & 0.0 & 0.0 & 0.0 & 55 & M \\
\hline MoF33 & 49.77 & 95.0 & 4.6 & 0.0 & 0.0 & 0.0 & 54 & M \\
\hline Mo 74 & 49.78 & 97.5 & 2.4 & 0.0 & 0.0 & 0.0 & 51 & M \\
\hline Mo 127 & 50.52 & 94.8 & 4.7 & 0.0 & 0.0 & 0.0 & 58 & M \\
\hline MoE51 & 50.54 & 93.3 & 6.4 & 0.0 & 0.0 & 0.0 & 51 & M \\
\hline MoF32 & 50.57 & 96.1 & 3.3 & 0.0 & 0.0 & 0.0 & 55 & M \\
\hline Mo 75 & 50.61 & 95.8 & 4.3 & 0.0 & 0.0 & 0.0 & 41 & M \\
\hline Mo 76 & 50.64 & 97.0 & 3.2 & 0.0 & 0.0 & 0.0 & 50 & M \\
\hline Mo 123 & 52.65 & 98.5 & 1.3 & 0.0 & 0.0 & 0.0 & 43 & M \\
\hline Mo 77 & 52.68 & 99.2 & 1.2 & 0.0 & 0.0 & 0.0 & 39 & M \\
\hline MoF31 & 52.69 & 96.9 & 3.0 & 0.0 & 0.0 & 0.0 & 52 & M \\
\hline MoF30 & 52.73 & 97.6 & 2.4 & 0.0 & 0.0 & 0.0 & 50 & M \\
\hline Mo 124 & 52.75 & 97.3 & 1.9 & 0.0 & 0.0 & 0.0 & 56 & $\mathrm{M}$ \\
\hline MoE52 & 52.79 & 98.6 & 1.3 & 0.0 & 0.0 & 0.0 & 51 & M \\
\hline Mo 125 & 52.83 & 98.1 & 1.4 & 0.0 & 0.0 & 0.0 & 42 & M \\
\hline Mo 126 & 52.86 & 97.3 & 3.1 & 0.0 & 0.0 & 0.0 & 54 & M \\
\hline MoF28 & 53.58 & 98.2 & 2.1 & 0.0 & 0.0 & 0.0 & 50 & M \\
\hline Mo 79 & 53.60 & 98.9 & 1.8 & 0.0 & 0.0 & 0.0 & 50 & M \\
\hline MoE53 & 53.61 & 98.6 & 1.0 & 0.0 & 0.0 & 0.0 & 50 & M \\
\hline Mo 78 & 53.64 & 99.4 & 1.3 & 0.0 & 0.0 & 0.0 & 48 & M \\
\hline Mo 80 & 53.69 & 95.8 & 4.6 & 0.0 & 0.0 & 0.0 & 49 & M \\
\hline Mo 83 & 55.39 & 96.4 & 3.1 & 0.1 & 0.0 & 0.0 & 46 & M \\
\hline MoF26 & 55.40 & 96.1 & 3.6 & 0.0 & 0.0 & 0.0 & 50 & M \\
\hline Mo 82 & 55.45 & 96.3 & 3.3 & 0.0 & 0.0 & 0.0 & 49 & M \\
\hline Mo 81 & 55.47 & 97.6 & 1.9 & 0.0 & 0.0 & 0.0 & 45 & $\mathrm{M}$ \\
\hline MoF27 & 55.47 & 93.8 & 6.2 & 0.1 & 0.0 & 0.0 & 49 & M \\
\hline MoE54 & 55.48 & 99.9 & 0.6 & 0.0 & 0.0 & 0.0 & 48 & M \\
\hline Mo 122 & 56.33 & 97.0 & 2.1 & 0.0 & 0.0 & 0.0 & 37 & M \\
\hline MoF23 & 56.34 & 97.1 & 3.1 & 0.0 & 0.0 & 0.0 & 48 & M \\
\hline Mo 84 & 56.38 & 96.3 & 3.5 & 0.0 & 0.0 & 0.0 & 46 & M \\
\hline MoE55 & 56.40 & 96.9 & 3.1 & 0.0 & 0.0 & 0.0 & 32 & M \\
\hline
\end{tabular}


Table A.2 (continued): Bromide data Morsleben (drilling core RB606)

\begin{tabular}{|c|c|c|c|c|c|c|c|c|}
\hline $\begin{array}{l}\text { Sample } \\
\text { name }\end{array}$ & $\begin{array}{l}\text { Hauptsalz } \\
\text { thickness } \\
(\mathrm{m})\end{array}$ & $\begin{array}{c}\text { Halite } \\
\text { wt } \%\end{array}$ & $\begin{array}{c}\text { Anhydrite } \\
\text { wt } \%\end{array}$ & $\begin{array}{c}\text { Polyhalite } \\
\text { wt } \%\end{array}$ & $\begin{array}{c}\text { Kieserite } \\
\text { wt } \%\end{array}$ & $\begin{array}{l}\text { Sylvine } \\
\text { wt } \%\end{array}$ & $\begin{array}{c}\text { Br / } \\
\text { Halite } \\
\text { ppm } \\
\end{array}$ & $\begin{array}{l}\text { Sample } \\
\text { type }\end{array}$ \\
\hline Mo 85 & 56.41 & 94.6 & 5.7 & 0.0 & 0.0 & 0.0 & 47 & $\mathrm{M}$ \\
\hline MoF24 & 56.43 & 94.8 & 4.9 & 0.0 & 0.0 & 0.0 & 50 & M \\
\hline MoF25 & 58.53 & 89.5 & 10.8 & 0.0 & 0.1 & 0.0 & 48 & M \\
\hline Mo 86 & 58.54 & 98.8 & 1.1 & 0.0 & 0.0 & 0.0 & 48 & M \\
\hline MoF29 & 58.55 & 98.1 & 1.5 & 0.0 & 0.0 & 0.0 & 49 & M \\
\hline Mo 87 & 58.58 & 97.4 & 2.2 & 0.0 & 0.0 & 0.0 & 45 & M \\
\hline Mo 89 & 59.09 & 97.6 & 2.3 & 0.0 & 0.0 & 0.0 & 48 & M \\
\hline MoF18 & 59.11 & 93.0 & 7.1 & 0.0 & 0.0 & 0.0 & 48 & M \\
\hline Mo 121 & 59.12 & 95.5 & 3.9 & 0.0 & 0.0 & 0.0 & 52 & M \\
\hline Mo 88 & 59.19 & 99.4 & 0.3 & 0.0 & 0.0 & 0.0 & 37 & M \\
\hline MoE57 & 59.19 & 100.2 & 0.4 & 0.0 & 0.0 & 0.0 & 48 & M \\
\hline Mo 120 & 59.23 & 98.4 & 1.4 & 0.0 & 0.0 & 0.0 & 53 & M \\
\hline MoF19 & 59.25 & 97.6 & 2.7 & 0.0 & 0.0 & 0.0 & 48 & M \\
\hline MoF20 & 61.41 & 99.1 & 1.4 & 0.0 & 0.0 & 0.0 & 45 & M \\
\hline Mo 118 & 61.44 & 98.0 & 2.0 & 0.0 & 0.0 & 0.0 & 39 & M \\
\hline Mo 119 & 61.50 & 99.0 & 0.9 & 0.0 & 0.0 & 0.0 & 53 & M \\
\hline MoE58 & 61.50 & 99.4 & 0.7 & 0.0 & 0.0 & 0.0 & 47 & M \\
\hline Mo 116 & 61.54 & 95.7 & 3.5 & 0.0 & 0.0 & 0.0 & 54 & M \\
\hline MoF21 & 61.54 & 94.6 & 6.0 & 0.0 & 0.1 & 0.0 & 47 & M \\
\hline Mo 117 & 61.58 & 93.8 & 5.8 & 0.0 & 0.0 & 0.0 & 54 & M \\
\hline Mo 114 & 63.15 & 99.4 & 0.8 & 0.0 & 0.0 & 0.0 & 52 & M \\
\hline MoE59 & 63.17 & 99.1 & 1.0 & 0.0 & 0.0 & 0.0 & 46 & M \\
\hline Mo 115 & 63.19 & 95.0 & 4.8 & 0.0 & 0.0 & 0.0 & 53 & M \\
\hline MoF16 & 63.20 & 93.6 & 6.2 & 0.1 & 0.0 & 0.0 & 49 & M \\
\hline Mo 113 & 63.21 & 95.4 & 4.4 & 0.1 & 0.0 & 0.0 & 52 & M \\
\hline MoF15 & 63.23 & 94.6 & 5.5 & 0.0 & 0.0 & 0.0 & 37 & M \\
\hline MoF22 & 64.23 & 98.2 & 1.7 & 0.0 & 0.0 & 0.0 & 48 & M \\
\hline Mo 91 & 64.25 & 97.6 & 2.5 & 0.0 & 0.0 & 0.0 & 46 & M \\
\hline MoF17 & 64.28 & 98.9 & 0.9 & 0.0 & 0.0 & 0.0 & 49 & M \\
\hline Mo 90 & 64.30 & 99.4 & 0.6 & 0.0 & 0.0 & 0.0 & 44 & M \\
\hline MoE60 & 64.30 & 98.2 & 0.5 & 0.0 & 0.0 & 0.0 & 47 & M \\
\hline Mo 92 & 65.17 & 97.1 & 2.5 & 0.0 & 0.0 & 0.0 & 38 & M \\
\hline MoE61 & 65.25 & 96.9 & 3.4 & 0.0 & 0.0 & 0.0 & 43 & M \\
\hline MoF12 & 65.25 & 92.0 & 7.3 & 0.0 & 0.0 & 0.0 & 48 & M \\
\hline Mo 93 & 65.27 & 95.7 & 3.8 & 0.0 & 0.0 & 0.0 & 43 & M \\
\hline Mo 107 & 65.27 & 95.9 & 3.8 & 0.0 & 0.0 & 0.0 & 50 & M \\
\hline Mo 187 & 66.16 & 98.3 & 0.4 & 0.0 & 0.0 & 0.0 & 40 & M \\
\hline Мo 192 & 66.21 & 99.0 & 0.3 & 0.0 & 0.0 & 0.0 & 52 & M \\
\hline MoE62 & 66.21 & 99.4 & 0.9 & 0.0 & 0.0 & 0.0 & 46 & M \\
\hline MoF10 & 66.24 & 98.2 & 1.4 & 0.1 & 0.0 & 0.0 & 48 & M \\
\hline Мo 191 & 66.26 & 98.5 & 1.2 & 0.0 & 0.0 & 0.0 & 39 & M \\
\hline MoE63 & 67.43 & 99.1 & 1.1 & 0.0 & 0.0 & 0.0 & 45 & M \\
\hline Мo 195 & 67.44 & 98.4 & 1.3 & 0.0 & 0.0 & 0.0 & 52 & M \\
\hline MoF11 & 67.46 & 99.2 & 0.7 & 0.0 & 0.0 & 0.0 & 47 & M \\
\hline MoE64 & 68.76 & 94.8 & 4.6 & 0.0 & 0.0 & 0.0 & 47 & M \\
\hline Mo 185 & 68.78 & 95.7 & 3.7 & 0.0 & 0.0 & 0.0 & 40 & M \\
\hline MoF14 & 68.78 & 83.7 & 15.5 & 0.0 & 0.0 & 0.0 & 49 & M \\
\hline Mo 184 & 68.82 & 97.6 & 1.9 & 0.0 & 0.0 & 0.0 & 38 & M \\
\hline
\end{tabular}


Table A.2 (continued): Bromide data Morsleben (drilling core RB606)

\begin{tabular}{lcccccccc}
\hline \hline $\begin{array}{l}\text { Sample } \\
\text { name }\end{array}$ & $\begin{array}{c}\text { Hauptsalz } \\
\text { thickness } \\
(\mathrm{m})\end{array}$ & $\begin{array}{c}\text { Halite } \\
\text { wt\% }\end{array}$ & $\begin{array}{c}\text { Anhydrite } \\
\text { wt\% }\end{array}$ & $\begin{array}{c}\text { Polyhalite } \\
\text { wt\% }\end{array}$ & $\begin{array}{c}\text { Kieserite } \\
\text { wt\% }\end{array}$ & $\begin{array}{c}\text { Sylvine } \\
\text { wt\% }\end{array}$ & $\begin{array}{c}\text { Br } / \\
\text { Halite } \\
\text { ppm }\end{array}$ & $\begin{array}{c}\text { Sample } \\
\text { type }\end{array}$ \\
\hline \hline Mo 94 & 69.67 & 98.0 & 1.4 & 0.0 & 0.0 & 0.0 & 34 & $\mathrm{M}$ \\
MoF13 & 69.68 & 92.5 & 7.1 & 0.0 & 0.0 & 0.0 & 49 & $\mathrm{M}$ \\
MoE65 & 69.69 & 96.6 & 3.1 & 0.0 & 0.0 & 0.0 & 45 & $\mathrm{M}$ \\
Mo 112 & 69.70 & 96.8 & 2.6 & 0.0 & 0.0 & 0.0 & 52 & $\mathrm{M}$ \\
Mo 111 & 71.41 & 99.1 & 0.4 & 0.0 & 0.0 & 0.0 & 49 & $\mathrm{M}$ \\
Mo 110 & 71.42 & 98.1 & 1.3 & 0.0 & 0.0 & 0.0 & 47 & $\mathrm{M}$ \\
Mo 95 & 71.43 & 98.1 & 0.4 & 0.0 & 0.0 & 0.0 & 45 & $\mathrm{M}$ \\
Mo 109 & 71.44 & 93.8 & 6.9 & 0.0 & 0.0 & 0.0 & 36 & $\mathrm{M}$ \\
MoE66 & 71.44 & 99.1 & 0.5 & 0.0 & 0.0 & 0.0 & 43 & $\mathrm{M}$ \\
Mo 96 & 71.45 & 93.0 & 5.7 & 0.0 & 0.0 & 0.0 & 44 & $\mathrm{M}$ \\
\hline
\end{tabular}


Table A.3: Bromide data Gorleben (drilling core RB119)

\begin{tabular}{|c|c|c|c|c|c|c|c|c|}
\hline $\begin{array}{l}\text { Sample } \\
\text { name }\end{array}$ & $\begin{array}{c}\text { Hauptsalz } \\
\text { thickness } \\
(\mathrm{m}) \\
\end{array}$ & $\begin{array}{l}\text { Halite } \\
\text { wt } \%\end{array}$ & $\begin{array}{c}\text { Anhydrite } \\
\text { wt } \%\end{array}$ & $\begin{array}{c}\text { Polyhalite } \\
\text { wt } \%\end{array}$ & $\begin{array}{c}\text { Kieserite } \\
\text { wt } \%\end{array}$ & $\begin{array}{c}\text { Sylvine } \\
\text { wt } \%\end{array}$ & $\begin{array}{c}\mathrm{Br} / \\
\text { Halite } \\
\mathrm{ppm} \\
\end{array}$ & $\begin{array}{c}\text { Sample } \\
\text { type }\end{array}$ \\
\hline RB119-1 & 441.06 & 82.4 & 16.3 & 0.0 & 0.1 & 0.0 & 52 & $\mathrm{M}$ \\
\hline RB119-2 & 440.92 & 99.4 & 0.2 & 0.1 & 0.0 & 0.0 & 43 & M \\
\hline RB119-3 & 437.79 & 98.9 & 1.0 & 0.0 & 0.0 & 0.0 & 39 & M \\
\hline RB119-4 & 437.64 & 98.2 & 1.6 & 0.1 & 0.0 & 0.0 & 40 & M \\
\hline RB119-5 & 434.42 & 95.8 & 4.0 & 0.0 & 0.0 & 0.0 & 37 & M \\
\hline RB119-6 & 434.28 & 98.9 & 0.9 & 0.1 & 0.0 & 0.0 & 43 & M \\
\hline RB119-7 & 432.05 & 91.3 & 7.2 & 0.1 & 0.0 & 0.0 & 37 & M \\
\hline RB119-8 & 432.01 & 98.7 & 0.5 & 0.0 & 0.0 & 0.0 & 42 & M \\
\hline RB119-9 & 427.35 & 96.9 & 2.3 & 0.0 & 0.1 & 0.0 & 41 & M \\
\hline RB119-10 & 427.27 & 96.4 & 2.7 & 0.1 & 0.0 & 0.0 & 41 & M \\
\hline RB119-11 & 423.99 & 99.4 & 0.2 & 0.0 & 0.0 & 0.0 & 41 & M \\
\hline RB119-12 & 423.90 & 98.1 & 1.7 & 0.1 & 0.0 & 0.0 & 44 & M \\
\hline RB119-13 & 417.60 & 99.9 & 0.1 & 0.0 & 0.0 & 0.0 & 48 & M \\
\hline RB119-14 & 417.53 & 96.8 & 3.0 & 0.1 & 0.0 & 0.0 & 37 & M \\
\hline RB119-15 & 410.99 & 91.8 & 8.1 & 0.0 & 0.1 & 0.0 & 39 & M \\
\hline RB119-16 & 410.91 & 99.1 & 0.5 & 0.1 & 0.0 & 0.0 & 30 & M \\
\hline RB119-17 & 404.56 & 95.0 & 5.3 & 0.1 & 0.1 & 0.0 & 33 & M \\
\hline RB119-18 & 404.45 & 97.6 & 1.8 & 0.1 & 0.0 & 0.0 & 46 & M \\
\hline RB119-19 & 398.17 & 98.7 & 1.1 & 0.1 & 0.0 & 0.0 & 42 & M \\
\hline RB119-20 & 398.06 & 98.1 & 1.4 & 0.1 & 0.0 & 0.0 & 56 & M \\
\hline RB119-21 & 391.66 & 98.1 & 1.6 & 0.1 & 0.0 & 0.0 & 55 & M \\
\hline RB119-22 & 391.52 & 97.6 & 2.2 & 0.0 & 0.0 & 0.0 & 52 & M \\
\hline RB119-23 & 385.15 & 92.3 & 7.1 & 0.0 & 0.1 & 0.0 & 58 & M \\
\hline RB119-24 & 384.99 & 96.9 & 2.5 & 0.1 & 0.0 & 0.0 & 54 & M \\
\hline RB119-25 & 381.97 & 99.2 & 0.5 & 0.0 & 0.0 & 0.0 & 54 & M \\
\hline RB119-26 & 381.84 & 99.1 & 0.5 & 0.0 & 0.0 & 0.0 & 51 & M \\
\hline RB119-27 & 378.55 & 91.5 & 7.3 & 0.1 & 0.1 & 0.0 & 58 & M \\
\hline RB119-28 & 378.48 & 98.1 & 1.2 & 0.1 & 0.0 & 0.0 & 54 & M \\
\hline RB119-29 & 372.06 & 92.0 & 7.0 & 0.1 & 0.0 & 0.0 & 49 & M \\
\hline RB119-30 & 371.98 & 98.1 & 1.3 & 0.0 & 0.0 & 0.0 & 52 & M \\
\hline RB119-31 & 365.68 & 96.6 & 1.9 & 0.1 & 0.0 & 0.0 & 51 & M \\
\hline RB119-32 & 365.61 & 97.5 & 2.1 & 0.0 & 0.0 & 0.0 & 52 & M \\
\hline RB119-33 & 359.43 & 98.6 & 0.5 & 0.0 & 0.0 & 0.0 & 53 & M \\
\hline RB119-34 & 359.30 & 99.1 & 0.1 & 0.0 & 0.0 & 0.0 & 43 & $\mathrm{M}$ \\
\hline RB119-35 & 352.79 & 94.6 & 4.3 & 0.1 & 0.0 & 0.0 & 41 & M \\
\hline RB119-36 & 352.73 & 88.2 & 10.3 & 0.0 & 0.1 & 0.0 & 59 & M \\
\hline RB119-37 & 346.32 & 98.4 & 0.2 & 0.0 & 0.0 & 0.0 & 45 & M \\
\hline RB119-38 & 346.26 & 95.3 & 3.7 & 0.1 & 0.0 & 0.0 & 50 & M \\
\hline RB119-39 & 343.22 & 95.4 & 4.0 & 0.1 & 0.0 & 0.0 & 47 & M \\
\hline RB119-40 & 343.10 & 99.4 & 0.1 & 0.0 & 0.0 & 0.0 & 38 & M \\
\hline RB119-41 & 336.47 & 92.8 & 6.2 & 0.1 & 0.1 & 0.0 & 50 & $\mathrm{M}$ \\
\hline RB119-42 & 336.41 & 98.4 & 1.0 & 0.1 & 0.0 & 0.0 & 45 & M \\
\hline RB119-43 & 331.38 & 98.6 & 1.3 & 0.1 & 0.0 & 0.0 & 45 & M \\
\hline RB119-44 & 331.31 & 96.9 & 2.4 & 0.1 & 0.0 & 0.0 & 44 & M \\
\hline RB119-45 & 324.02 & 94.6 & 5.4 & 0.0 & 0.1 & 0.0 & 48 & M \\
\hline RB119-46 & 323.97 & 98.4 & 1.3 & 0.0 & 0.0 & 0.0 & 47 & M \\
\hline RB119-47 & 316.93 & 98.2 & 1.5 & 0.0 & 0.0 & 0.0 & 48 & M \\
\hline RB119-48 & 316.80 & 89.5 & 10.2 & 0.0 & 0.1 & 0.0 & 49 & M \\
\hline
\end{tabular}


Table A.3 (continued): Bromide data Gorleben (drilling core RB119)

\begin{tabular}{|c|c|c|c|c|c|c|c|c|}
\hline $\begin{array}{l}\text { Sample } \\
\text { name }\end{array}$ & $\begin{array}{l}\text { Hauptsalz } \\
\text { thickness } \\
(\mathrm{m})\end{array}$ & $\begin{array}{l}\text { Halite } \\
\text { wt } \%\end{array}$ & $\begin{array}{c}\text { Anhydrite } \\
\text { wt } \%\end{array}$ & $\begin{array}{c}\text { Polyhalite } \\
\text { wt } \%\end{array}$ & $\begin{array}{c}\text { Kieserite } \\
\text { wt } \%\end{array}$ & $\begin{array}{l}\text { Sylvine } \\
\text { wt } \%\end{array}$ & $\begin{array}{c}\mathrm{Br} / \\
\text { Halite } \\
\mathrm{ppm}\end{array}$ & $\begin{array}{c}\text { Sample } \\
\text { type }\end{array}$ \\
\hline RB119-49 & 313.74 & 95.3 & 3.9 & 0.0 & 0.0 & 0.0 & 46 & $\bar{M}$ \\
\hline RB119-50 & 313.65 & 97.8 & 2.3 & 0.0 & 0.0 & 0.0 & 47 & M \\
\hline RB119-51 & 307.13 & 97.4 & 1.9 & 0.1 & 0.0 & 0.0 & 50 & M \\
\hline RB119-52 & 307.07 & 98.9 & 0.7 & 0.1 & 0.0 & 0.0 & 49 & $\mathrm{M}$ \\
\hline RB119-53 & 300.54 & 97.4 & 1.8 & 0.0 & 0.0 & 0.0 & 49 & $\mathrm{M}$ \\
\hline RB119-54 & 300.46 & 91.2 & 8.3 & 0.1 & 0.0 & 0.0 & 50 & M \\
\hline RB119-55 & 294.36 & 97.6 & 2.9 & 0.1 & 0.0 & 0.0 & 51 & M \\
\hline RB119-56 & 294.29 & 98.6 & 1.8 & 0.1 & 0.0 & 0.0 & 49 & M \\
\hline RB119-57 & 287.80 & 96.1 & 4.1 & 0.0 & 0.0 & 0.0 & 57 & M \\
\hline RB119-58 & 287.73 & 96.6 & 2.8 & 0.1 & 0.0 & 0.0 & 40 & M \\
\hline RB119-59 & 281.18 & 94.6 & 5.3 & 0.1 & 0.0 & 0.0 & 66 & M \\
\hline RB119-60 & 281.07 & 97.4 & 2.5 & 0.0 & 0.1 & 0.0 & 65 & M \\
\hline RB119-61 & 277.92 & 88.0 & 11.6 & 0.1 & 0.1 & 0.0 & 57 & M \\
\hline RB119-62 & 277.88 & 97.9 & 1.0 & 0.0 & 0.0 & 0.0 & 52 & M \\
\hline RB119-63 & 274.67 & 96.9 & 2.1 & 0.1 & 0.0 & 0.0 & 51 & M \\
\hline RB119-64 & 274.59 & 96.9 & 2.4 & 0.0 & 0.0 & 0.0 & 48 & M \\
\hline RB119-65 & 268.09 & 98.1 & 1.6 & 0.1 & 0.0 & 0.0 & 54 & M \\
\hline RB119-66 & 264.75 & 93.5 & 5.6 & 0.0 & 0.0 & 0.0 & 57 & $\mathrm{M}$ \\
\hline RB119-67 & 258.16 & 99.4 & 0.3 & 0.0 & 0.0 & 0.0 & 56 & M \\
\hline RB119-68 & 251.92 & 99.7 & 0.0 & 0.1 & 0.0 & 0.0 & 47 & M \\
\hline RB119-69 & 251.85 & 99.1 & 0.0 & 0.0 & 0.0 & 0.0 & 34 & M \\
\hline RB119-70 & 245.39 & 99.7 & 0.9 & 0.0 & 0.0 & 0.0 & 60 & M \\
\hline RB119-71 & 245.30 & 100.4 & 0.3 & 0.0 & 0.0 & 0.0 & 56 & $\mathrm{M}$ \\
\hline RB119-72 & 238.71 & 99.9 & 0.1 & 0.0 & 0.0 & 0.0 & 58 & M \\
\hline RB119-73 & 219.18 & 99.1 & 0.3 & 0.0 & 0.0 & 0.0 & 58 & M \\
\hline RB119-74 & 228.93 & 98.9 & 0.7 & 0.0 & 0.0 & 0.0 & 50 & M \\
\hline RB119-75 & 222.47 & 98.1 & 1.2 & 0.0 & 0.0 & 0.0 & 38 & M \\
\hline RB119-76 & 219.08 & 99.9 & 0.3 & 0.0 & 0.0 & 0.0 & 61 & M \\
\hline RB119-77 & 212.68 & 99.6 & 0.5 & 0.1 & 0.0 & 0.0 & 36 & M \\
\hline RB119-78 & 206.32 & 97.4 & 2.4 & 0.0 & 0.0 & 0.0 & 38 & M \\
\hline RB119-79 & 202.91 & 99.4 & 0.1 & 0.1 & 0.0 & 0.0 & 40 & M \\
\hline RB119-80 & 194.68 & 97.5 & 2.4 & 0.0 & 0.0 & 0.0 & 37 & M \\
\hline RB119-81 & 194.56 & 99.4 & 0.2 & 0.0 & 0.0 & 0.0 & 55 & $\mathrm{~K}$ \\
\hline RB119-82 & 190.35 & 98.9 & 0.0 & 0.0 & 0.0 & 0.0 & 66 & M \\
\hline RB119-83 & 183.91 & 97.4 & 2.1 & 0.0 & 0.0 & 0.0 & 41 & M \\
\hline RB119-84 & 183.84 & 99.6 & 0.2 & 0.0 & 0.0 & 0.0 & 56 & $\mathrm{~K}$ \\
\hline RB119-85 & 177.57 & 99.1 & 0.3 & 0.1 & 0.0 & 0.0 & 37 & M \\
\hline RB119-86 & 177.46 & 99.7 & 0.4 & 0.0 & 0.0 & 0.0 & 25 & M \\
\hline RB119-87 & 171.06 & 99.1 & 0.5 & 0.0 & 0.0 & 0.0 & 34 & $\mathrm{~K}$ \\
\hline RB119-88 & 170.98 & 98.4 & 1.0 & 0.0 & 0.0 & 0.0 & 39 & M \\
\hline RB119-89 & 164.52 & 99.1 & 0.8 & 0.0 & 0.0 & 0.0 & 32 & M \\
\hline RB119-90 & 157.85 & 98.4 & 0.8 & 0.0 & 0.0 & 0.0 & 29 & M \\
\hline RB119-91 & 157.72 & 97.9 & 1.4 & 0.0 & 0.0 & 0.0 & 53 & $\mathrm{~K}$ \\
\hline RB119-92 & 154.49 & 98.4 & 0.5 & 0.0 & 0.0 & 0.0 & 36 & $\mathrm{M}$ \\
\hline RB119-93 & 154.43 & 99.4 & 0.2 & 0.0 & 0.0 & 0.0 & 63 & $\mathrm{~K}$ \\
\hline RB119-94 & 151.35 & 98.1 & 0.9 & 0.0 & 0.0 & 0.0 & 36 & M \\
\hline RB119-95 & 151.28 & 98.1 & 1.4 & 0.1 & 0.0 & 0.0 & 60 & $\mathrm{~K}$ \\
\hline RB119-96 & 147.98 & 98.6 & 1.2 & 0.0 & 0.0 & 0.0 & 29 & $\mathrm{M}$ \\
\hline
\end{tabular}


Table A.3 (continued): Bromide data Gorleben (drilling core RB119)

\begin{tabular}{|c|c|c|c|c|c|c|c|c|}
\hline $\begin{array}{l}\text { Sample } \\
\text { name }\end{array}$ & $\begin{array}{l}\text { Hauptsalz } \\
\text { thickness } \\
(\mathrm{m})\end{array}$ & $\begin{array}{l}\text { Halite } \\
\text { wt } \%\end{array}$ & $\begin{array}{c}\text { Anhydrite } \\
\text { wt\% }\end{array}$ & $\begin{array}{c}\text { Polyhalite } \\
\text { wt } \%\end{array}$ & $\begin{array}{c}\text { Kieserite } \\
\text { wt } \%\end{array}$ & $\begin{array}{c}\text { Sylvine } \\
\text { wt } \%\end{array}$ & $\begin{array}{c}\mathrm{Br} / \\
\text { Halite } \\
\mathrm{ppm}\end{array}$ & $\begin{array}{l}\text { Sample } \\
\text { type }\end{array}$ \\
\hline RB119-97 & 147.94 & 98.7 & 0.9 & 0.1 & 0.0 & 0.0 & 69 & $\mathrm{~K}$ \\
\hline RB119-98 & 141.48 & 99.7 & 0.8 & 0.0 & 0.0 & 0.0 & 14 & M \\
\hline RB119-99 & 134.87 & 100.1 & 0.4 & 0.1 & 0.0 & 0.0 & 63 & M \\
\hline RB119-100 & 134.75 & 99.7 & 0.1 & 0.1 & 0.0 & 0.0 & 31 & M \\
\hline RB119-101 & 128.69 & 99.6 & 0.1 & 0.1 & 0.0 & 0.0 & 67 & M \\
\hline RB119-102 & 122.26 & 99.1 & 0.1 & 0.0 & 0.0 & 0.0 & 35 & M \\
\hline RB119-103 & 122.18 & 98.6 & 1.1 & 0.1 & 0.0 & 0.0 & 87 & $\mathrm{~K}$ \\
\hline RB119-104 & 115.68 & 99.4 & 0.9 & 0.0 & 0.0 & 0.0 & 64 & M \\
\hline RB119-105 & 115.65 & 99.1 & 0.6 & 0.0 & 0.0 & 0.0 & 65 & $\mathrm{~K}$ \\
\hline RB119-106 & 115.59 & 98.4 & 0.6 & 0.1 & 0.0 & 0.0 & 63 & $\mathrm{~K}$ \\
\hline RB119-107 & 112.35 & 98.7 & 1.0 & 0.1 & 0.0 & 0.0 & 43 & $\mathrm{M}$ \\
\hline RB119-108 & 112.27 & 99.9 & 0.1 & 0.0 & 0.0 & 0.0 & 65 & $\mathrm{~K}$ \\
\hline RB119-109 & 109.02 & 98.4 & 0.3 & 0.0 & 0.0 & 0.0 & 93 & $\mathrm{~K}$ \\
\hline RB119-110 & 108.94 & 98.9 & 0.2 & 0.0 & 0.0 & 0.0 & 78 & $\mathrm{~K}$ \\
\hline RB119-111 & 108.88 & 98.4 & 0.7 & 0.0 & 0.0 & 0.0 & 82 & M \\
\hline RB119-112 & 102.37 & 98.4 & 0.4 & 0.0 & 0.0 & 0.0 & 42 & M \\
\hline RB119-113 & 102.33 & 99.1 & 0.5 & 0.0 & 0.0 & 0.0 & 69 & $\mathrm{~K}$ \\
\hline RB119-114 & 102.23 & 99.1 & 0.6 & 0.0 & 0.0 & 0.0 & 69 & $\mathrm{~K}$ \\
\hline RB119-115 & 95.60 & 98.9 & 0.8 & 0.0 & 0.0 & 0.0 & 50 & $\mathrm{~K}$ \\
\hline RB119-116 & 95.56 & 99.2 & 0.3 & 0.1 & 0.0 & 0.0 & 73 & M \\
\hline RB119-117 & 92.31 & 98.9 & 0.3 & 0.1 & 0.0 & 0.0 & 72 & M \\
\hline RB119-118 & 92.26 & 98.9 & 0.5 & 0.1 & 0.0 & 0.0 & 89 & $\mathrm{~K}$ \\
\hline RB119-119 & 85.97 & 98.6 & 0.2 & 0.1 & 0.0 & 0.0 & 52 & M \\
\hline RB119-120 & 85.88 & 98.6 & 0.4 & 0.1 & 0.0 & 0.0 & 95 & $\mathrm{~K}$ \\
\hline RB119-121 & 82.37 & 98.6 & 0.3 & 0.1 & 0.0 & 0.0 & 100 & $\mathrm{~K}$ \\
\hline RB119-122 & 82.27 & 97.6 & 1.9 & 0.0 & 0.0 & 0.0 & 103 & M \\
\hline RB119-123 & 74.70 & 98.1 & 1.0 & 0.1 & 0.0 & 0.0 & 73 & $\mathrm{~K}$ \\
\hline RB119-124 & 74.64 & 97.9 & 0.9 & 0.0 & 0.0 & 0.0 & 69 & $\mathrm{M}$ \\
\hline RB119-125 & 72.64 & 99.7 & 0.4 & 0.0 & 0.1 & 0.0 & 89 & M \\
\hline RB119-126 & 72.59 & 98.7 & 0.5 & 0.1 & 0.0 & 0.0 & 107 & $\mathrm{~K}$ \\
\hline RB119-127 & 68.69 & 99.1 & 0.3 & 0.0 & 0.1 & 0.0 & 77 & M \\
\hline RB119-128 & 68.63 & 98.6 & 0.4 & 0.0 & 0.1 & 0.0 & 106 & $\mathrm{~K}$ \\
\hline RB119-129 & 65.38 & 99.4 & 0.6 & 0.0 & 0.0 & 0.0 & 92 & M \\
\hline RB119-130 & 65.26 & 98.4 & 1.9 & 0.0 & 0.1 & 0.0 & 99 & $\mathrm{~K}$ \\
\hline RB119-131 & 62.10 & 99.7 & 0.9 & 0.0 & 0.0 & 0.0 & 101 & M \\
\hline RB119-132 & 62.00 & 99.1 & 0.4 & 0.0 & 0.0 & 0.0 & 124 & M \\
\hline RB119-133 & 59.03 & 98.9 & 0.6 & 0.0 & 0.0 & 0.0 & 105 & M \\
\hline RB119-134 & 58.96 & 99.1 & 0.1 & 0.0 & 0.0 & 0.0 & 103 & M \\
\hline RB119-135 & 55.56 & 99.1 & 0.4 & 0.0 & 0.0 & 0.0 & 116 & M \\
\hline RB119-136 & 52.17 & 98.1 & 0.6 & 0.0 & 0.0 & 0.0 & 112 & M \\
\hline RB119-137 & 52.12 & 98.4 & 0.6 & 0.0 & 0.0 & 0.0 & 123 & $\mathrm{~K}$ \\
\hline RB119-138 & 47.04 & 98.1 & 1.0 & 0.0 & 0.0 & 0.0 & 167 & $\mathrm{~K}$ \\
\hline RB119-139 & 46.96 & 99.4 & 0.4 & 0.0 & 0.1 & 0.0 & 159 & $\mathrm{~K}$ \\
\hline RB119-140 & 46.91 & 100.2 & 0.3 & 0.0 & 0.0 & 0.0 & 163 & $\mathrm{M}$ \\
\hline RB119-141 & 46.83 & 100.2 & 0.5 & 0.0 & 0.0 & 0.0 & 139 & $\mathrm{~K}$ \\
\hline RB119-142 & 43.36 & 99.4 & 0.0 & 0.1 & 0.0 & 0.0 & 141 & M \\
\hline RB119-143 & 40.07 & 94.3 & 5.7 & 0.0 & 0.1 & 0.0 & 141 & $\mathrm{~K}$ \\
\hline RB119-144 & 40.03 & 99.7 & 0.5 & 0.0 & 0.0 & 0.0 & 124 & $\mathrm{M}$ \\
\hline
\end{tabular}


Table A.3 (continued): Bromide data Gorleben (drilling core RB119)

\begin{tabular}{|c|c|c|c|c|c|c|c|c|}
\hline $\begin{array}{l}\text { Sample } \\
\text { name }\end{array}$ & $\begin{array}{c}\text { Hauptsalz } \\
\text { thickness } \\
(\mathrm{m})\end{array}$ & $\begin{array}{l}\text { Halite } \\
\text { wt } \%\end{array}$ & $\begin{array}{c}\text { Anhydrite } \\
\text { wt } \%\end{array}$ & $\begin{array}{c}\text { Polyhalite } \\
\text { wt } \%\end{array}$ & $\begin{array}{c}\text { Kieserite } \\
\text { wt } \%\end{array}$ & $\begin{array}{c}\text { Sylvine } \\
\text { wt } \%\end{array}$ & $\begin{array}{c}\text { Br / } \\
\text { Halite } \\
\text { ppm } \\
\end{array}$ & $\begin{array}{c}\text { Sample } \\
\text { type }\end{array}$ \\
\hline RB119-145 & 39.97 & 98.1 & 1.7 & 0.1 & 0.1 & 0.0 & 191 & $\mathrm{~K}$ \\
\hline RB119-146 & 36.67 & 100.1 & 0.0 & 0.0 & 0.0 & 0.0 & 155 & $\mathrm{M}$ \\
\hline RB119-147 & 36.59 & 99.4 & 0.2 & 0.1 & 0.0 & 0.0 & 133 & $\mathrm{M}$ \\
\hline RB119-148 & 36.55 & 99.6 & 0.2 & 0.1 & 0.0 & 0.0 & 162 & $\mathrm{~K}$ \\
\hline RB119-149 & 33.06 & 98.2 & 0.7 & 0.1 & 0.0 & 0.0 & 190 & $\mathrm{~K}$ \\
\hline RB119-150 & 33.05 & 98.4 & 0.8 & 0.0 & 0.0 & 0.0 & 143 & $\mathrm{M}$ \\
\hline RB119-151 & 29.93 & 98.6 & 0.3 & 0.2 & 0.1 & 0.0 & 124 & $\mathrm{~K}$ \\
\hline RB119-152 & 29.82 & 98.7 & 1.4 & 0.1 & 0.0 & 0.0 & 138 & $\mathrm{M}$ \\
\hline RB119-153 & 26.42 & 99.6 & 0.0 & 0.1 & 0.0 & 0.0 & 152 & $\mathrm{M}$ \\
\hline RB119-154 & 26.36 & 98.6 & 0.8 & 0.0 & 0.1 & 0.0 & 146 & M \\
\hline RB119-155 & 26.31 & 98.1 & 0.8 & 0.1 & 0.0 & 0.0 & 201 & $\mathrm{~K}$ \\
\hline RB119-156 & 23.38 & 99.1 & 0.1 & 0.0 & 0.1 & 0.0 & 133 & $\mathrm{~K}$ \\
\hline RB119-157 & 23.32 & 98.6 & 1.1 & 0.2 & 0.1 & 0.0 & 214 & $\mathrm{~K}$ \\
\hline RB119-158 & 23.27 & 99.7 & 0.5 & 0.0 & 0.0 & 0.0 & 132 & $\mathrm{M}$ \\
\hline RB119-159 & 20.23 & 99.1 & 0.2 & 0.0 & 0.1 & 0.1 & 161 & $\mathrm{~K}$ \\
\hline RB119-160 & 20.20 & 99.1 & 0.1 & 0.0 & 0.1 & 0.0 & 145 & $\mathrm{~K}$ \\
\hline RB119-161 & 20.12 & 99.1 & 0.0 & 0.2 & 0.0 & 0.0 & 114 & $\mathrm{~K}$ \\
\hline RB119-162 & 20.09 & 98.9 & 0.2 & 0.0 & 0.1 & 0.1 & 174 & $\mathrm{~K}$ \\
\hline RB119-163 & 20.06 & 99.2 & 0.1 & 0.1 & 0.0 & 0.0 & 143 & $\mathrm{M}$ \\
\hline RB119-164 & 16.57 & 99.7 & 0.7 & 0.0 & 0.1 & 0.0 & 140 & $\mathrm{M}$ \\
\hline RB119-165 & 16.51 & 100.7 & 0.1 & 0.0 & 0.1 & 0.1 & 119 & $\mathrm{~K}$ \\
\hline RB119-166 & 16.43 & 99.4 & 0.0 & 0.2 & 0.0 & 0.0 & 135 & $\mathrm{~K}$ \\
\hline RB119-167 & 13.47 & 99.2 & 0.0 & 0.4 & 0.1 & 0.0 & 143 & $\mathrm{~K}$ \\
\hline RB119-168 & 13.44 & 98.4 & 1.1 & 0.1 & 0.0 & 0.0 & 135 & $\mathrm{M}$ \\
\hline RB119-169 & 10.38 & 99.6 & 0.0 & 0.0 & 0.0 & 0.0 & 157 & $\mathrm{M}$ \\
\hline RB119-170 & 10.32 & 97.9 & 0.7 & 0.0 & 0.3 & 0.2 & 185 & $\mathrm{~K}$ \\
\hline RB119-171 & 10.23 & 99.1 & 0.1 & 0.3 & 0.0 & 0.0 & 175 & M \\
\hline RB119-172 & 5.81 & 98.4 & 0.0 & 0.4 & 0.0 & 0.0 & 127 & K \\
\hline RB119-173 & 5.75 & 98.2 & 0.0 & 1.0 & 0.0 & 0.0 & 165 & $\mathrm{M}$ \\
\hline RB119-174 & 3.62 & 98.4 & 0.0 & 1.1 & 0.0 & 0.0 & 172 & M \\
\hline RB119-175 & 3.56 & 98.7 & 0.0 & 0.6 & 0.0 & 0.0 & 164 & $\mathrm{~K}$ \\
\hline RB119-176 & 1.38 & 99.1 & 0.0 & 0.2 & 0.0 & 0.0 & 164 & $\mathrm{~K}$ \\
\hline RB119-177 & 1.34 & 99.2 & 0.2 & 0.1 & 0.0 & 0.0 & 194 & $\mathrm{M}$ \\
\hline
\end{tabular}


Table A.4: Bromide data Kristallbrocken (Teutschenthal) - detailed sampling

\begin{tabular}{|c|c|c|c|c|c|c|}
\hline $\begin{array}{l}\text { Sample } \\
\text { number }\end{array}$ & $\begin{array}{c}\text { Hauptsalz } \\
\text { thickness (m) }\end{array}$ & $\begin{array}{l}\text { Halite } \\
\text { wt } \%\end{array}$ & $\begin{array}{c}\text { Anhydrite } \\
\text { wt } \%\end{array}$ & $\begin{array}{l}\mathrm{Br} / \text { Halite } \\
\text { ppm }\end{array}$ & $\begin{array}{c}\text { Average } \\
\text { Br / Halite } \\
\text { (ppm) }\end{array}$ & $\begin{array}{c}\text { Drilling } \\
\text { core slab }\end{array}$ \\
\hline $\bar{~} 1$ & 30.86 & 98.7 & 0.9 & 64 & \multirow{10}{*}{92} & \multirow{10}{*}{ Lt60-11-85 } \\
\hline 2 & 30.87 & 98.4 & 1.3 & 93 & & \\
\hline 3 & 30.90 & 99.3 & 1.2 & 92 & & \\
\hline 4 & 30.92 & 99.4 & 0.4 & 87 & & \\
\hline 5 & 30.93 & 99.7 & 0.4 & 94 & & \\
\hline 6 & 30.99 & 99.1 & 0.6 & 114 & & \\
\hline 7 & 31.00 & 99.7 & 0.5 & 105 & & \\
\hline 8 & 31.02 & 98.6 & 0.8 & 91 & & \\
\hline 9 & 31.03 & 98.6 & 2.1 & 96 & & \\
\hline 10 & 30.98 & 98.9 & 0.4 & 84 & & \\
\hline 11 & 43.39 & 97.4 & 1.4 & 93 & \multirow{9}{*}{73} & \multirow{9}{*}{ Lt60-12-93 } \\
\hline 12 & 43.42 & 98.4 & 0.3 & 63 & & \\
\hline 13 & 43.43 & 98.9 & 0.3 & 73 & & \\
\hline 14 & 43.43 & 99.4 & 0.1 & 77 & & \\
\hline 15 & 43.43 & 99.4 & 0.3 & 70 & & \\
\hline 16 & 43.43 & 99.4 & 0.5 & 83 & & \\
\hline 17 & 43.44 & 98.7 & 0.3 & 59 & & \\
\hline 18 & 43.48 & 98.6 & 0.8 & 78 & & \\
\hline 19 & 43.49 & 98.6 & 0.7 & 63 & & \\
\hline 20 & 54.21 & 98.4 & 1.0 & 71 & \multirow{16}{*}{71} & \multirow{16}{*}{ Lt60-12-102 } \\
\hline 21 & 54.21 & 99.1 & 0.2 & 91 & & \\
\hline 22 & 54.21 & 96.8 & 1.3 & 99 & & \\
\hline 23 & 54.21 & 98.9 & 0.5 & 70 & & \\
\hline 24 & 54.21 & 98.5 & 0.4 & 70 & & \\
\hline 25 & 54.22 & 98.1 & 0.8 & 84 & & \\
\hline 26 & 54.23 & 98.1 & 0.5 & 68 & & \\
\hline 27 & 54.23 & 97.8 & 1.7 & 85 & & \\
\hline 28 & 54.24 & 98.9 & 0.6 & 57 & & \\
\hline 29 & 54.24 & 98.1 & 1.0 & 59 & & \\
\hline 30 & 54.28 & 98.4 & 0.5 & 64 & & \\
\hline 31 & 54.29 & 97.4 & 1.0 & 64 & & \\
\hline 32 & 54.30 & 98.1 & 0.5 & 65 & & \\
\hline 33 & 54.30 & 96.4 & 2.3 & 63 & & \\
\hline 34 & 54.30 & 98.1 & 0.8 & 74 & & \\
\hline 35 & 54.32 & 99.0 & 0.2 & 46 & & \\
\hline 36 & 70.07 & 97.9 & 1.5 & 120 & \multirow{6}{*}{86} & \multirow{6}{*}{ Lt60-13-115 } \\
\hline 37 & 70.11 & 96.9 & 2.3 & 110 & & \\
\hline 38 & 70.12 & 97.6 & 0.8 & 87 & & \\
\hline 39 & 70.14 & 98.9 & 0.8 & 60 & & \\
\hline 40 & 70.15 & 97.9 & 1.3 & 83 & & \\
\hline 41 & 70.16 & 98.1 & 1.0 & 57 & & \\
\hline
\end{tabular}


Table A.4 (continued): Bromide data Kristallbrocken (Teutschenthal) - detailed sampling

\begin{tabular}{|c|c|c|c|c|c|c|}
\hline $\begin{array}{l}\text { Sample } \\
\text { number }\end{array}$ & $\begin{array}{c}\text { Hauptsalz } \\
\text { thickness (m) }\end{array}$ & $\begin{array}{l}\text { Halite } \\
\text { wt } \%\end{array}$ & $\begin{array}{c}\text { Anhydrite } \\
\text { wt } \%\end{array}$ & $\begin{array}{l}\mathrm{Br} / \text { Halite } \\
\text { ppm }\end{array}$ & $\begin{array}{l}\text { Average } \\
\mathrm{Br} / \text { Halite } \\
\text { (ppm) }\end{array}$ & $\begin{array}{c}\text { Drilling } \\
\text { core slab }\end{array}$ \\
\hline$\overline{42}$ & 100.67 & 97.8 & 1.2 & 87 & \multirow{12}{*}{61} & \multirow{12}{*}{ Lt60-15-136 } \\
\hline 43 & 100.68 & 98.6 & 1.2 & 67 & & \\
\hline 44 & 100.68 & 98.9 & 0.8 & 87 & & \\
\hline 45 & 100.73 & 99.4 & 0.2 & 50 & & \\
\hline 46 & 100.73 & 99.9 & 0.2 & 35 & & \\
\hline 47 & 100.74 & 98.9 & 0.2 & 38 & & \\
\hline 48 & 100.75 & 97.4 & 2.1 & 43 & & \\
\hline 49 & 100.75 & 99.1 & 0.4 & 55 & & \\
\hline 50 & 100.75 & 98.4 & 0.6 & 41 & & \\
\hline 51 & 100.75 & 97.9 & 1.8 & 57 & & \\
\hline 52 & 100.78 & 98.4 & 0.8 & 92 & & \\
\hline 53 & 100.79 & 98.6 & 0.8 & 84 & & \\
\hline 54 & 121.41 & 98.9 & 1.0 & 126 & \multirow{25}{*}{91} & \multirow{25}{*}{ Lt60-16-154 } \\
\hline 55 & 121.41 & 98.7 & 1.3 & 99 & & \\
\hline 56 & 121.42 & 98.4 & 1.3 & 126 & & \\
\hline 57 & 121.43 & 98.9 & 0.9 & 80 & & \\
\hline 58 & 121.43 & 98.4 & 0.5 & 79 & & \\
\hline 59 & 121.44 & 99.9 & 0.4 & 79 & & \\
\hline 60 & 121.44 & 100.4 & 0.4 & 79 & & \\
\hline 61 & 121.44 & 99.1 & 0.4 & 81 & & \\
\hline 62 & 121.45 & 98.4 & 1.1 & 85 & & \\
\hline 63 & 121.45 & 98.1 & 0.9 & 83 & & \\
\hline 64 & 121.45 & 98.4 & 1.6 & 86 & & \\
\hline 65 & 121.48 & 99.3 & 0.2 & 56 & & \\
\hline 66 & 121.48 & 98.9 & 0.2 & 52 & & \\
\hline 67 & 121.48 & 99.4 & 0.3 & 51 & & \\
\hline 68 & 121.50 & 99.4 & 1.3 & 109 & & \\
\hline 69 & 121.51 & 98.7 & 2.0 & 107 & & \\
\hline 70 & 121.51 & 97.3 & 1.2 & 102 & & \\
\hline 71 & 121.52 & 98.3 & 2.1 & 110 & & \\
\hline 72 & 121.52 & 97.8 & 1.4 & 104 & & \\
\hline 73 & 121.53 & 97.8 & 1.2 & 98 & & \\
\hline 74 & 121.54 & 96.8 & 2.3 & 104 & & \\
\hline 75 & 121.55 & 99.1 & 1.2 & 105 & & \\
\hline 76 & 121.56 & 99.4 & 1.1 & 88 & & \\
\hline 77 & 121.57 & 100.4 & 0.3 & 83 & & \\
\hline 78 & 121.58 & 99.1 & 1.4 & 106 & & \\
\hline
\end{tabular}


Table A.4 (continued): Bromide data Kristallbrocken (Teutschenthal) - detailed sampling

\begin{tabular}{|c|c|c|c|c|c|c|}
\hline $\begin{array}{l}\text { Sample } \\
\text { number }\end{array}$ & $\begin{array}{c}\text { Hauptsalz } \\
\text { thickness (m) }\end{array}$ & $\begin{array}{l}\text { Halite } \\
\text { wt } \%\end{array}$ & $\begin{array}{c}\text { Anhydrite } \\
\text { wt } \%\end{array}$ & $\begin{array}{l}\mathrm{Br} / \text { Halite } \\
\text { ppm }\end{array}$ & $\begin{array}{c}\text { Average } \\
\mathrm{Br} / \text { Halite } \\
\text { (ppm) }\end{array}$ & $\begin{array}{l}\text { Drilling } \\
\text { core slab }\end{array}$ \\
\hline 79 & 200.51 & 999.1 & $\bar{~} 0.8$ & 51 & \multirow{18}{*}{65} & \multirow{18}{*}{ Lt60-21-210 } \\
\hline 80 & 200.51 & 98.9 & 0.4 & 75 & & \\
\hline 81 & 200.51 & 98.6 & 0.6 & 77 & & \\
\hline 82 & 200.51 & 99.1 & 0.7 & 76 & & \\
\hline 83 & 200.55 & 96.3 & 2.9 & 77 & & \\
\hline 84 & 200.55 & 98.6 & 0.8 & 60 & & \\
\hline 85 & 200.56 & 96.9 & 2.4 & 68 & & \\
\hline 86 & 200.56 & 98.6 & 1.1 & 56 & & \\
\hline 87 & 200.56 & 97.6 & 2.0 & 64 & & \\
\hline 88 & 200.57 & 97.6 & 1.7 & 56 & & \\
\hline 89 & 200.57 & 97.9 & 1.4 & 74 & & \\
\hline 90 & 200.57 & 98.6 & 0.9 & 53 & & \\
\hline 91 & 200.57 & 98.9 & 0.8 & 73 & & \\
\hline 92 & 200.57 & 98.9 & 0.4 & 72 & & \\
\hline 93 & 200.57 & 98.1 & 1.0 & 54 & & \\
\hline 94 & 200.59 & 98.1 & 1.4 & 69 & & \\
\hline 95 & 200.60 & 97.9 & 1.0 & 65 & & \\
\hline 96 & 200.60 & 96.9 & 2.2 & 49 & & \\
\hline 97 & 298.97 & 95.4 & 3.4 & 74 & \multirow{11}{*}{74} & \multirow{11}{*}{ Lt62-5-135 } \\
\hline 98 & 298.96 & 93.6 & 4.8 & 97 & & \\
\hline 99 & 298.98 & 94.1 & 4.8 & 95 & & \\
\hline 100 & 298.99 & 94.3 & 4.9 & 90 & & \\
\hline 101 & 299.06 & 94.8 & 4.3 & 78 & & \\
\hline 102 & 299.06 & 97.3 & 1.9 & 72 & & \\
\hline 103 & 299.07 & 98.1 & 0.8 & 68 & & \\
\hline 104 & 299.06 & 96.9 & 2.4 & 78 & & \\
\hline 105 & 299.07 & 96.8 & 2.9 & 48 & & \\
\hline 106 & 299.07 & 97.8 & 1.1 & 61 & & \\
\hline 107 & 299.09 & 92.5 & 5.8 & 55 & & \\
\hline 108 & 410.97 & 98.6 & 1.1 & 55 & \multirow{11}{*}{46} & \multirow{11}{*}{ Lt62-12-66 } \\
\hline 109 & 410.98 & 99.7 & 0.6 & 52 & & \\
\hline 110 & 410.98 & 98.4 & 0.5 & 41 & & \\
\hline 111 & 410.99 & 99.4 & 0.7 & 36 & & \\
\hline 112 & 410.99 & 99.4 & 0.5 & 46 & & \\
\hline 113 & 410.99 & 99.7 & 0.3 & 52 & & \\
\hline 114 & 411.00 & 98.4 & 0.6 & 36 & & \\
\hline 115 & 411.00 & 98.6 & 0.5 & 52 & & \\
\hline 116 & 411.02 & 99.6 & 0.5 & 30 & & \\
\hline 117 & 411.02 & 98.6 & 0.5 & 47 & & \\
\hline 118 & 411.03 & 97.1 & 2.5 & 61 & & \\
\hline
\end{tabular}


Table A.5: Bulk composition of the Hauptsalz of Teutschenthal

\begin{tabular}{|c|c|c|c|c|c|c|c|c|}
\hline $\begin{array}{l}\text { Sample } \\
\text { name }\end{array}$ & $\begin{array}{l}\text { Depth } \\
\text { of drill } \\
\text { core } \\
\text { slab }(\mathrm{m})\end{array}$ & $\begin{array}{l}\text { Halite } \\
\text { wt } \%\end{array}$ & $\begin{array}{c}\text { Anhydrite } \\
\text { wt } \%\end{array}$ & $\begin{array}{c}\text { Polyhalite } \\
\text { wt } \%\end{array}$ & $\begin{array}{c}\text { Kieserite } \\
\text { wt } \%\end{array}$ & $\begin{array}{c}\mathrm{Br} / \\
\text { Halite } \\
\text { ppm }\end{array}$ & $\begin{array}{c}\varnothing \mathrm{Br} / \\
\text { Halite } \\
\text { ppm }\end{array}$ & $\begin{array}{l}\text { Strati- } \\
\text { graphic } \\
\text { section }\end{array}$ \\
\hline TeuGes1 & \multirow{3}{*}{0.5} & 92.8 & 6.7 & 0.0 & 0.3 & 215 & \multirow{3}{*}{217} & \multirow{9}{*}{$\begin{array}{l}\text { upper part } \\
\text { of the } \\
\text { Hauptsalz } \\
\text { (z2HS) }\end{array}$} \\
\hline TeuGes2 & & 93.0 & 6.7 & 0.0 & 0.3 & 211 & & \\
\hline TeuGes 3 & & 93.0 & 6.7 & 0.0 & 0.3 & 227 & & \\
\hline TeuGes4 & \multirow{3}{*}{59.5} & 89.2 & 11.2 & 0.0 & 0.0 & 114 & \multirow{3}{*}{115} & \\
\hline TeuGes5 & & 89.2 & 11.1 & 0.0 & 0.0 & 120 & & \\
\hline TeuGes6 & & 89.0 & 11.5 & 0.0 & 0.0 & 112 & & \\
\hline TeuGes 7 & \multirow{3}{*}{117.5} & 89.8 & 10.2 & 0.0 & 0.0 & 117 & \multirow{3}{*}{113} & \\
\hline TeuGes 8 & & 89.5 & 10.4 & 0.0 & 0.0 & 113 & & \\
\hline TeuGes9 & & 89.5 & 10.4 & 0.0 & 0.0 & 109 & & \\
\hline TeuGes 10 & \multirow{3}{*}{241.5} & 90.5 & 9.0 & 0.0 & 0.0 & 79 & \multirow{3}{*}{78} & \multirow{9}{*}{$\begin{array}{l}\text { lower par } \\
\text { of the } \\
\text { Hauptsalz } \\
\text { (z2HS) }\end{array}$} \\
\hline TeuGes 11 & & 90.2 & 8.9 & 0.0 & 0.0 & 73 & & \\
\hline TeuGes 12 & & 90.5 & 8.9 & 0.0 & 0.0 & 81 & & \\
\hline TeuGes13 & \multirow{3}{*}{327.5} & 80.8 & 18.2 & 0.0 & 0.0 & 78 & \multirow{3}{*}{79} & \\
\hline TeuGes 14 & & 81.3 & 18.3 & 0.0 & 0.0 & 81 & & \\
\hline TeuGes 15 & & 80.6 & 18.2 & 0.0 & 0.0 & 79 & & \\
\hline TeuGes 16 & \multirow{3}{*}{392.5} & 80.8 & 18.9 & 0.0 & 0.0 & 73 & \multirow{3}{*}{75} & \\
\hline TeuGes 17 & & 80.3 & 19.0 & 0.0 & 0.0 & 76 & & \\
\hline TeuGes 18 & & 79.8 & 18.4 & 0.0 & 0.0 & 75 & & \\
\hline
\end{tabular}

Table A.6: Bulk composition of the Hauptsalz of Morsleben

\begin{tabular}{|c|c|c|c|c|c|c|c|c|}
\hline $\begin{array}{l}\text { Sample } \\
\text { name }\end{array}$ & $\begin{array}{l}\text { Average } \\
\text { depth (m) }\end{array}$ & $\begin{array}{l}\text { Halite } \\
\text { wt } \%\end{array}$ & $\begin{array}{c}\text { Anhydrite } \\
\text { wt } \%\end{array}$ & $\begin{array}{c}\text { Polyhalite } \\
\text { wt } \%\end{array}$ & $\begin{array}{c}\text { Kieserite } \\
\text { wt } \%\end{array}$ & $\begin{array}{l}\mathrm{Br} / \text { Halite } \\
\text { ppm }\end{array}$ & $\begin{array}{c}\emptyset \mathrm{Br} / \\
\text { Halite } \\
\mathrm{ppm} \\
\end{array}$ & $\begin{array}{l}\text { Stratigraphic } \\
\text { section }\end{array}$ \\
\hline MoGes9 & \multirow{5}{*}{63.7} & 94.6 & 4.3 & 0.0 & 0.0 & 55 & \multirow{5}{*}{55} & \multirow{5}{*}{$\begin{array}{c}\text { lower } \\
\text { Hauptsalz } \\
\text { (z2HS1) }\end{array}$} \\
\hline MoGes10 & & 94.6 & 4.3 & 0.1 & 0.0 & 55 & & \\
\hline MoGes11 & & 95.1 & 4.4 & 0.0 & 0.0 & 54 & & \\
\hline MoGes 12 & & 94.1 & 4.3 & 0.0 & 0.0 & 56 & & \\
\hline MoGes13 & & 94.8 & 4.3 & 0.0 & 0.1 & 55 & & \\
\hline MoGes14 & \multirow{5}{*}{40.5} & 94.8 & 4.6 & 0.1 & 0.0 & 58 & \multirow{5}{*}{58.1} & \multirow{5}{*}{$\begin{array}{c}\text { middle } \\
\text { Hauptsalz } \\
\text { (z2HS2) }\end{array}$} \\
\hline MoGes15 & & 95.1 & 4.6 & 0.1 & 0.0 & 57 & & \\
\hline MoGes16 & & 95.1 & 4.6 & 0.0 & 0.0 & 59 & & \\
\hline MoGes17 & & 95.4 & 4.5 & 0.1 & 0.0 & 59 & & \\
\hline MoGes18 & & 94.8 & 4.5 & 0.0 & 0.0 & 58 & & \\
\hline MoGes19 & \multirow{5}{*}{11.5} & 94.8 & 4.1 & 0.8 & 0.0 & 148 & \multirow{5}{*}{151} & \multirow{5}{*}{$\begin{array}{c}\text { upper } \\
\text { Hauptsalz } \\
\text { (z2HS3) }\end{array}$} \\
\hline MoGes20 & & 94.6 & 4.1 & 0.7 & 0.0 & 150 & & \\
\hline MoGes21 & & 95.1 & 4.1 & 0.8 & 0.0 & 151 & & \\
\hline MoGes22 & & 95.1 & 4.2 & 0.6 & 0.1 & 151 & & \\
\hline MoGes23 & & 95.4 & 4.1 & 0.8 & 0.0 & 155 & & \\
\hline
\end{tabular}


Table A.7: Bulk composition of the Hauptsalz of Gorleben

\begin{tabular}{|c|c|c|c|c|c|c|c|c|}
\hline $\begin{array}{l}\text { Sample } \\
\text { name }\end{array}$ & $\begin{array}{l}\text { Average } \\
\text { depth (m) }\end{array}$ & $\begin{array}{c}\text { Halite } \\
\text { wt } \%\end{array}$ & $\begin{array}{c}\text { Anhydrite } \\
\text { wt } \%\end{array}$ & $\begin{array}{c}\text { Polyhalite } \\
\text { wt } \%\end{array}$ & $\begin{array}{c}\text { Kieserite } \\
\text { wt } \%\end{array}$ & $\begin{array}{c}\mathrm{Br} / \text { Halite } \\
\text { ppm }\end{array}$ & $\begin{array}{c}\varnothing \mathrm{Br} / \\
\text { Halite } \\
\text { ppm }\end{array}$ & $\begin{array}{l}\text { Stratigraphic } \\
\text { section }\end{array}$ \\
\hline GoGes1 & \multirow{8}{*}{384.7} & 95.1 & 5.5 & 0.0 & 0.0 & 55 & \multirow{8}{*}{59} & \multirow{8}{*}{$\begin{array}{c}\text { lower } \\
\text { Hauptsalz } \\
\text { (z2HS1) }\end{array}$} \\
\hline GoGes2 & & 94.8 & 4.8 & 0.0 & 0.0 & 58 & & \\
\hline GoGes3 & & 95.3 & 5.5 & 0.0 & 0.0 & 59 & & \\
\hline GoGes4 & & 94.8 & 5.6 & 0.0 & 0.0 & 56 & & \\
\hline GoGes5 & & 93.3 & 6.4 & 0.0 & 0.0 & 59 & & \\
\hline GoGes6 & & 93.5 & 6.4 & 0.0 & 0.0 & 68 & & \\
\hline GoGes7 & & 94.1 & 6.4 & 0.0 & 0.0 & 57 & & \\
\hline GoGes8 & & 93.5 & 6.4 & 0.0 & 0.0 & 63 & & \\
\hline GoGes9 & \multirow{12}{*}{201.7} & 95.4 & 4.8 & 0.0 & 0.0 & 61 & \multirow{12}{*}{62} & \multirow{12}{*}{$\begin{array}{c}\text { middle } \\
\text { Hauptsalz } \\
\text { (z2HS2) }\end{array}$} \\
\hline GoGes 10 & & 95.1 & 4.8 & 0.0 & 0.0 & 59 & & \\
\hline GoGes11 & & 94.8 & 4.7 & 0.0 & 0.0 & 66 & & \\
\hline GoGes12 & & 94.8 & 4.8 & 0.0 & 0.0 & 64 & & \\
\hline GoGes13 & & 95.3 & 4.1 & 0.0 & 0.0 & 51 & & \\
\hline GoGes14 & & 95.4 & 4.1 & 0.0 & 0.0 & 57 & & \\
\hline GoGes 15 & & 95.6 & 4.0 & 0.0 & 0.0 & 55 & & \\
\hline GoGes16 & & 96.3 & 4.1 & 0.0 & 0.0 & 52 & & \\
\hline GoGes17 & & 96.6 & 2.8 & 0.0 & 0.0 & 68 & & \\
\hline GoGes18 & & 97.4 & 2.8 & 0.0 & 0.0 & 71 & & \\
\hline GoGes19 & & 96.6 & 2.7 & 0.0 & 0.0 & 72 & & \\
\hline GoGes20 & & 97.1 & 2.8 & 0.1 & 0.0 & 68 & & \\
\hline GoGes21 & \multirow{8}{*}{16.2} & 97.6 & 2.4 & 0.1 & 0.1 & 131 & \multirow{8}{*}{152} & \multirow{8}{*}{$\begin{array}{c}\text { upper } \\
\text { Hauptsalz } \\
\text { (z2HS3) }\end{array}$} \\
\hline GoGes22 & & 96.8 & 2.4 & 0.1 & 0.1 & 141 & & \\
\hline GoGes 23 & & 97.1 & 2.4 & 0.1 & 0.1 & 135 & & \\
\hline GoGes24 & & 97.6 & 2.5 & 0.0 & 0.1 & 135 & & \\
\hline GoGes 25 & & 97.6 & 1.9 & 0.0 & 0.2 & 169 & & \\
\hline GoGes26 & & 97.6 & 1.9 & 0.0 & 0.2 & 170 & & \\
\hline GoGes27 & & 97.9 & 1.9 & 0.0 & 0.2 & 168 & & \\
\hline GoGes28 & & 96.6 & 1.9 & 0.0 & 0.2 & 171 & & \\
\hline
\end{tabular}




\section{Electron microprobe}

The electron microprobe is an instrument for high-resolution and non-destructive analyses of major and trace elements in a wide variety of solid materials as for instance minerals, glasses, metals, and ceramics. During analysis, a stable electron beam is focused on a certain point on a well polished sample surface. The high energy electrons interact with the atoms in the sample insofar as they remove inner orbital electrons. The electron vacancies are replaced by outer orbital electrons, thereby releasing energy in form of characteristic X-rays. The emitted $\mathrm{X}$-ray spectrum is characteristic for each element and can be measured by either wavelength dispersive spectrometer (WDS) or energy dispersive spectrometer (EDS) (Reed 1996). By comparison of these spectra with that of samples with known elements and known concentration of these elements (=standards), it is possible to quantify element concentrations.

Table A.8: Bromide contents of Kristallbrocken (electron microprobe)

\begin{tabular}{lcc}
\hline \hline $\begin{array}{l}\text { Sample } \\
\text { number }\end{array}$ & $\begin{array}{c}\text { Bromide in } \\
\text { halite }(\mathrm{ppm})\end{array}$ & $\begin{array}{c}\text { Detection } \\
\text { limit }\end{array}$ \\
\hline \hline 1 & 118 & 57 \\
2 & 83 & 57 \\
3 & 90 & 57 \\
4 & 115 & 57 \\
5 & 120 & 57 \\
6 & 123 & 57 \\
7 & 63 & 57 \\
8 & 66 & 57 \\
9 & 85 & 57 \\
10 & 68 & 57 \\
11 & 104 & 57 \\
12 & 116 & 57 \\
13 & 74 & 57 \\
14 & 88 & 57 \\
15 & 76 & 57 \\
16 & 88 & 56 \\
17 & 72 & 57 \\
18 & 71 & 57 \\
\hline
\end{tabular}


Table A.9: Strontium contents of anhydrite inclusions in Kristallbrocken (electron microprobe)

\begin{tabular}{|c|c|c|c|}
\hline $\begin{array}{l}\text { Sample } \\
\text { name }\end{array}$ & $\begin{array}{l}\text { Strontium content } \\
\text { of anhydrite } \\
\left(\mu \mathrm{g} \mathrm{Sr} / \mathrm{g} \mathrm{CaSO}_{4}\right)\end{array}$ & $\begin{array}{l}\text { Sample type ( } \mathrm{D}=\text { directly } \\
\text { included in halite; } \\
\mathrm{F}=\text { enclosed by fluids) }\end{array}$ & Location \\
\hline 1_2-169_BSE2a & 852 & $\mathrm{~F}$ & \multirow{46}{*}{ Teutschenthal } \\
\hline 2_2-169_BSE2a & 1502 & $\mathrm{~F}$ & \\
\hline 3_2-169_BSE2a & 1745 & $\mathrm{~F}$ & \\
\hline 4_2-169_BSE2a & 964 & $\mathrm{~F}$ & \\
\hline 5_2-169_BSE10a & 953 & $\mathrm{~F}$ & \\
\hline 6_2-169_BSE10a & 1009 & $\mathrm{~F}$ & \\
\hline 7_2-169_BSE10a & 1146 & $\mathrm{~F}$ & \\
\hline 8_2-169_BSE1a & 1754 & $\mathrm{~F}$ & \\
\hline 9_2-169_BSE1a & 1603 & $\mathrm{~F}$ & \\
\hline 10_2-169_BSE1a & 903 & $\mathrm{~F}$ & \\
\hline 11_2-169_BSE1a & 2375 & $\mathrm{~F}$ & \\
\hline 11b_2-169_BSE1a & 2517 & $\mathrm{~F}$ & \\
\hline 12_2-169_BSE1a & 1613 & $\mathrm{~F}$ & \\
\hline 12) & 1600 & $\mathrm{~F}$ & \\
\hline 13_2-169_BSE4a & 1113 & $\mathrm{~F}$ & \\
\hline 14_2-169_BSE5b & 940 & $\mathrm{D}$ & \\
\hline 15_2-169_BSE8a & 1764 & $\mathrm{~F}$ & \\
\hline 15b_2-169_BSE8a & 2114 & $\mathrm{~F}$ & \\
\hline 16_2-169_BSE9a & 1011 & $\mathrm{~F}$ & \\
\hline 17-36_2-169_BSE2a_1 & 1196 & $\mathrm{D}$ & \\
\hline 17-36_2-169_BSE2a_2 & 1358 & $\mathrm{D}$ & \\
\hline 17-36_2-169_BSE2a_3 & 1341 & $\mathrm{D}$ & \\
\hline 17-36_2-169_BSE2a_4 & 1074 & $\mathrm{D}$ & \\
\hline 17-36_2-169_BSE2a_5 & 993 & $\mathrm{D}$ & \\
\hline 17-36_2-169_BSE2a_6 & 1179 & $\mathrm{D}$ & \\
\hline 17-36_2-169_BSE2a_7 & 1017 & $\mathrm{D}$ & \\
\hline 17-36_2-169_BSE2a_8 & 824 & $\mathrm{D}$ & \\
\hline 17-36_2-169_BSE2a_9 & 939 & $\mathrm{D}$ & \\
\hline 17-36_2-169_BSE2a_10 & 853 & $\mathrm{D}$ & \\
\hline 17-36_2-169_BSE2a_11 & 926 & $\mathrm{D}$ & \\
\hline 17-36_2-169_BSE2a_12 & 1327 & $\mathrm{D}$ & \\
\hline 17-36_2-169_BSE2a_13 & 1578 & $\mathrm{D}$ & \\
\hline 17-36_2-169_BSE2a_14 & 1105 & $\mathrm{D}$ & \\
\hline 17-36_2-169_BSE2a_15 & 1797 & $\mathrm{D}$ & \\
\hline 17-36_2-169_BSE2a_16 & 1721 & $\mathrm{D}$ & \\
\hline 17-36_2-169_BSE2a_17 & 2132 & $\mathrm{D}$ & \\
\hline 17-36_2-169_BSE2a_18 & 2344 & $\mathrm{D}$ & \\
\hline 17-36_2-169_BSE2a_19 & 2024 & $\mathrm{D}$ & \\
\hline 17-36_2-169_BSE2a_20 & 2118 & $\mathrm{D}$ & \\
\hline 37_2-169_BSE3a & 2489 & $\mathrm{D}$ & \\
\hline 38_2-169_BSE3a & 1435 & $\mathrm{D}$ & \\
\hline 39_2-169_BSE3a & 2847 & $\mathrm{D}$ & \\
\hline 40_2-169_BSE5a & 1210 & $\mathrm{D}$ & \\
\hline 41_2-169_BSE5a & 1293 & $\mathrm{D}$ & \\
\hline 42_2-169_BSE5a & 1841 & $\mathrm{D}$ & \\
\hline 43_2-169_BSE5a & 1307 & $\mathrm{D}$ & \\
\hline
\end{tabular}


Table A.9 (continued): Strontium contents of anhydrite inclusions in Kristallbrocken (microprobe)

\begin{tabular}{|c|c|c|c|}
\hline $\begin{array}{l}\text { Sample } \\
\text { name }\end{array}$ & $\begin{array}{c}\text { Strontium content } \\
\text { of anhydrite } \\
\left(\mu \mathrm{g} \mathrm{Sr} / \mathrm{g} \mathrm{CaSO}_{4}\right)\end{array}$ & $\begin{array}{l}\text { Sample type ( } \mathrm{D}=\text { directly } \\
\text { included in halite; } \\
\mathrm{F}=\text { enclosed by fluids })\end{array}$ & Location \\
\hline 44_2-169_BSE5a & 1750 & $\mathrm{D}$ & \multirow{29}{*}{ Teutschenthal } \\
\hline 45_2-169_BSE5a & 1522 & $\mathrm{D}$ & \\
\hline 46_2-169_BSE6a & 1610 & $\mathrm{D}$ & \\
\hline 47_2-169_BSE6a & 2581 & $\mathrm{D}$ & \\
\hline 48_2-169_BSE6a & 2106 & $\mathrm{D}$ & \\
\hline 49_2-169_BSE6a & 1457 & $\mathrm{D}$ & \\
\hline 50_2-169_BSE6a & 1455 & $\mathrm{D}$ & \\
\hline 51-70_2-169_BSE7a_1 & 1292 & $\mathrm{D}$ & \\
\hline 51-70_2-169_BSE7a_2 & 1164 & $\mathrm{D}$ & \\
\hline 51-70_2-169_BSE7a_3 & 1293 & $\mathrm{D}$ & \\
\hline 51-70_2-169_BSE7a_4 & 1526 & $\mathrm{D}$ & \\
\hline 51-70_2-169_BSE7a_5 & 1139 & $\mathrm{D}$ & \\
\hline 51-70_2-169_BSE7a_6 & 1256 & $\mathrm{D}$ & \\
\hline 51-70_2-169_BSE7a_7 & 1238 & $\mathrm{D}$ & \\
\hline 51-70_2-169_BSE7a_8 & 1379 & $\mathrm{D}$ & \\
\hline 51-70_2-169_BSE7a_9 & 1736 & $\mathrm{D}$ & \\
\hline 51-70_2-169_BSE7a_10 & 855 & $\mathrm{D}$ & \\
\hline 51-70_2-169_BSE7a_11 & 1655 & $\mathrm{D}$ & \\
\hline 51-70_2-169_BSE7a_12 & 948 & $\mathrm{D}$ & \\
\hline 51-70_2-169_BSE7a_13 & 2189 & $\mathrm{D}$ & \\
\hline 51-70_2-169_BSE7a_14 & 2148 & $\mathrm{D}$ & \\
\hline 51-70_2-169_BSE7a_15 & 1952 & $\mathrm{D}$ & \\
\hline 51-70_2-169_BSE7a_16 & 2240 & $\mathrm{D}$ & \\
\hline 51-70_2-169_BSE7a_17 & 2150 & $\mathrm{D}$ & \\
\hline 51-70_2-169_BSE7a_18 & 2644 & $\mathrm{D}$ & \\
\hline 51-70_2-169_BSE7a_19 & 1424 & $\mathrm{D}$ & \\
\hline 51-70_2-169_BSE7a_20 & 1816 & $\mathrm{D}$ & \\
\hline 71_2-169_BSE7a & 1325 & $\mathrm{D}$ & \\
\hline 72_2-169_BSE7a & 1320 & $\mathrm{D}$ & \\
\hline 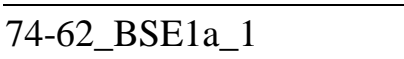 & 2118 & $\mathrm{D}$ & \multirow{16}{*}{ Morsleben } \\
\hline 74-62_BSE1a_2 & 1632 & $\mathrm{D}$ & \\
\hline 74-62_BSE1a_3 & 1530 & $\mathrm{D}$ & \\
\hline 74-62_BSE1a_4 & 1809 & $\mathrm{D}$ & \\
\hline 74-62_BSE2a_5 & 1117 & $\mathrm{D}$ & \\
\hline 74-62_BSE2a_6 & 1628 & $\mathrm{D}$ & \\
\hline 74-62_BSE2a_7 & 2534 & $\mathrm{D}$ & \\
\hline 74-62_BSE2a_8 & 1858 & $\mathrm{D}$ & \\
\hline 74-62_BSE3a_9 & 1187 & $\mathrm{D}$ & \\
\hline 74-62_BSE3a_10 & 1371 & $\mathrm{D}$ & \\
\hline 74-62_BSE3a_11 & 1830 & $\mathrm{D}$ & \\
\hline 74-62_BSE3a_12 & 2001 & $\mathrm{D}$ & \\
\hline 74-62_BSE3a_13 & 2113 & $\mathrm{D}$ & \\
\hline 74-62_BSE4a_14 & 1829 & $\mathrm{D}$ & \\
\hline 74-62_BSE4a_15 & 1136 & $\mathrm{D}$ & \\
\hline 74-62_BSE4a_16 & 2303 & $\mathrm{D}$ & \\
\hline
\end{tabular}


Table A.9 (continued): Strontium contents of anhydrite inclusions in Kristallbrocken (microprobe)

\begin{tabular}{|c|c|c|c|}
\hline $\begin{array}{l}\text { Sample } \\
\text { name }\end{array}$ & $\begin{array}{l}\text { Strontium content } \\
\text { of anhydrite } \\
\left(\mu \mathrm{g} \mathrm{Sr} / \mathrm{g} \mathrm{CaSO}_{4}\right)\end{array}$ & $\begin{array}{l}\text { Sample type }(\mathrm{D}=\text { directly } \\
\text { included in halite; } \\
\mathrm{F}=\text { enclosed by fluids })\end{array}$ & Location \\
\hline 74-62_BSE5a_17 & 1514 & $\mathrm{D}$ & \multirow{15}{*}{ Morsleben } \\
\hline 74-62_BSE5a_18 & 1647 & $\mathrm{D}$ & \\
\hline 74-62_BSE5a_19 & 2281 & $\mathrm{D}$ & \\
\hline 74-62_BSE6a_20 & 2300 & $\mathrm{~F}$ & \\
\hline 74-62_BSE6a_21 & 1170 & $\mathrm{~F}$ & \\
\hline 74-62_BSE7a_22 & 1884 & $\mathrm{~F}$ & \\
\hline 74-62_BSE7a_23 & 2024 & $\mathrm{~F}$ & \\
\hline 74-62_BSE7a_24 & 1836 & $\mathrm{~F}$ & \\
\hline 74-62_BSE8a_25 & 2008 & $\mathrm{~F}$ & \\
\hline 74-62_BSE8a_26 & 1105 & $\mathrm{~F}$ & \\
\hline 74-62_BSE9a_27 & 1658 & $\mathrm{~F}$ & \\
\hline 74-62_BSE9a_28 & 1460 & $\mathrm{~F}$ & \\
\hline 74-62_BSE9a_29 & 1453 & $\mathrm{~F}$ & \\
\hline 74-62_BSE10a_30 & 2374 & $\mathrm{~F}$ & \\
\hline 74-62_BSE11a_31 & 1054 & $\mathrm{~F}$ & \\
\hline 88-159-BSE1a_1 & 2095 & $\mathrm{D}$ & \multirow{20}{*}{ Gorleben } \\
\hline 88-159-BSE1a_2 & 2405 & $\mathrm{D}$ & \\
\hline 88-159-BSE1a_3 & 2042 & $\mathrm{D}$ & \\
\hline 88-159-BSE2a_4 & 1951 & $\mathrm{D}$ & \\
\hline 88-159-BSE2a_5 & 1840 & $\mathrm{D}$ & \\
\hline 88-159-BSE3a_6 & 3329 & $\mathrm{D}$ & \\
\hline 88-159-BSE3a_7 & 3232 & $\mathrm{D}$ & \\
\hline 88-159-BSE4a_8 & 1776 & $\mathrm{D}$ & \\
\hline 88-159-BSE5a_9 & 1051 & $\mathrm{~F}$ & \\
\hline 88-159-BSE6a_10 & 2507 & $\mathrm{~F}$ & \\
\hline 88-159-BSE7a_11 & 1499 & $\mathrm{~F}$ & \\
\hline 88-159-BSE7a_12 & 1394 & $\mathrm{~F}$ & \\
\hline 88-159-BSE9a_13 & 1484 & $\mathrm{~F}$ & \\
\hline 88-159-BSE9a_14 & 1435 & $\mathrm{~F}$ & \\
\hline 88-159-BSE10a_15 & 1727 & $\mathrm{~F}$ & \\
\hline 88-159-BSE10a_16 & 1585 & $\mathrm{~F}$ & \\
\hline 88-159-BSE7b_17 & 1984 & $\mathrm{D}$ & \\
\hline 88-159-BSE7b_18 & 1245 & $\mathrm{~F}$ & \\
\hline 88-159-BSE8a_19 & 1570 & $\mathrm{~F}$ & \\
\hline 88-159-BSE10a_20 & 1444 & $\mathrm{D}$ & \\
\hline
\end{tabular}


Table A.10: Water contents of rock salt samples from Teutschenthal

\begin{tabular}{|c|c|c|c|c|}
\hline Location & $\begin{array}{l}\text { Stratigraphic } \\
\text { section }\end{array}$ & $\begin{array}{l}\text { Sample } \\
\text { name }\end{array}$ & $\begin{array}{l}\text { Total water } \\
\text { content }(\%)\end{array}$ & $\begin{array}{l}\text { Average water } \\
\text { content }(\%)\end{array}$ \\
\hline \multirow{6}{*}{ Teutschenthal } & \multirow{5}{*}{$\begin{array}{l}\text { Hauptsalz } \\
\text { (z2HS) }\end{array}$} & Teu WG 1 & $\begin{array}{l}0.67 \\
0.64 \\
0.72 \\
0.65 \\
0.80 \\
\end{array}$ & 0.69 \\
\hline & & Teu WG 2 & $\begin{array}{l}1.04 \\
0.90 \\
1.04 \\
0.78 \\
0.70\end{array}$ & 0.89 \\
\hline & & Teu WG 3 & $\begin{array}{l}0.61 \\
0.69 \\
1.76 \\
5.46 \\
0.79\end{array}$ & 1.86 \\
\hline & & Teu WG 4 & $\begin{array}{l}0.76 \\
0.84 \\
0.77 \\
0.79 \\
0.55\end{array}$ & 0.74 \\
\hline & & Teu WG 5 & $\begin{array}{l}0.48 \\
2.87 \\
0.61 \\
0.63 \\
0.54\end{array}$ & 1.02 \\
\hline & $\begin{array}{l}\text { Basissalz } \\
\text { (z2BS) }\end{array}$ & Teu WG 6 & $\begin{array}{l}0.62 \\
0.69 \\
0.61 \\
0.98 \\
0.72\end{array}$ & 0.72 \\
\hline
\end{tabular}


Table A.11: Water contents of rock salt samples from Morsleben

\begin{tabular}{|c|c|c|c|c|}
\hline Location & $\begin{array}{l}\text { Stratigraphic } \\
\text { section }\end{array}$ & $\begin{array}{l}\text { Sample } \\
\text { name }\end{array}$ & $\begin{array}{l}\text { Total water } \\
\text { content }(\%)\end{array}$ & $\begin{array}{c}\text { Average water } \\
\text { content }(\%)\end{array}$ \\
\hline \multirow{30}{*}{ Morsleben } & \multirow{10}{*}{$\begin{array}{c}\text { lower part of } \\
\text { the Hauptsalz } \\
\text { (z2HS1) }\end{array}$} & & 0.63 & \multirow{5}{*}{0.67} \\
\hline & & & 0.55 & \\
\hline & & Mo WG 1 & 0.73 & \\
\hline & & & 0.68 & \\
\hline & & & 0.74 & \\
\hline & & \multirow{5}{*}{ Mo WG 2} & 0.51 & \multirow{5}{*}{0.57} \\
\hline & & & 0.53 & \\
\hline & & & 0.66 & \\
\hline & & & 0.55 & \\
\hline & & & 0.59 & \\
\hline & \multirow{10}{*}{$\begin{array}{c}\text { middle part of } \\
\text { the Hauptsalz } \\
\text { (z2HS2) }\end{array}$} & & 0.61 & \multirow{5}{*}{0.58} \\
\hline & & & 0.58 & \\
\hline & & Mo WG 3 & 0.66 & \\
\hline & & & 0.47 & \\
\hline & & & 0.58 & \\
\hline & & \multirow{5}{*}{ Mo WG 4} & 0.57 & \multirow{5}{*}{0.51} \\
\hline & & & 0.51 & \\
\hline & & & 0.54 & \\
\hline & & & 0.43 & \\
\hline & & & 0.49 & \\
\hline & \multirow{10}{*}{$\begin{array}{c}\text { upper part of } \\
\text { the Hauptsalz } \\
\text { (z2HS3) }\end{array}$} & & 1.26 & \multirow{5}{*}{1.04} \\
\hline & & & 0.48 & \\
\hline & & Mo WG 5 & 2.01 & \\
\hline & & & 0.60 & \\
\hline & & & 0.87 & \\
\hline & & \multirow{5}{*}{ Mo WG 6} & 0.61 & \multirow{5}{*}{1.02} \\
\hline & & & 0.48 & \\
\hline & & & 0.56 & \\
\hline & & & 2.75 & \\
\hline & & & 0.69 & \\
\hline
\end{tabular}


Table A.12: Water contents of rock salt samples from Gorleben

\begin{tabular}{|c|c|c|c|c|}
\hline Location & $\begin{array}{l}\text { Stratigraphic } \\
\text { section }\end{array}$ & $\begin{array}{l}\text { Sample } \\
\text { name }\end{array}$ & $\begin{array}{l}\text { Total water } \\
\text { content }(\%)\end{array}$ & $\begin{array}{c}\text { Average water } \\
\text { content }(\%)\end{array}$ \\
\hline \multirow{6}{*}{ Gorleben } & \multirow{2}{*}{$\begin{array}{l}\text { lower part of } \\
\text { the Hauptsalz } \\
\text { (z2HS1) }\end{array}$} & Go WG 1 & $\begin{array}{l}0.29 \\
0.29 \\
0.23\end{array}$ & 0.27 \\
\hline & & Go WG 2 & $\begin{array}{l}0.25 \\
0.27 \\
0.29 \\
\end{array}$ & 0.27 \\
\hline & \multirow{2}{*}{$\begin{array}{l}\text { middle part of } \\
\text { the Hauptsalz } \\
\text { (z2HS2) }\end{array}$} & Go WG 3 & $\begin{array}{l}0.27 \\
0.28 \\
0.30\end{array}$ & 0.28 \\
\hline & & Go WG 4 & $\begin{array}{l}0.23 \\
0.22 \\
0.20 \\
\end{array}$ & 0.22 \\
\hline & \multirow{2}{*}{$\begin{array}{l}\text { upper part of } \\
\text { the Hauptsalz } \\
\text { (z2HS3) }\end{array}$} & Go WG 5 & $\begin{array}{l}0.20 \\
0.23 \\
0.21\end{array}$ & 0.21 \\
\hline & & Go WG 6 & $\begin{array}{l}0.22 \\
0.22 \\
0.22\end{array}$ & 0.22 \\
\hline
\end{tabular}




\section{APPENDIX B RESULTS OF KRISTALLBROCKEN SAMPLING}

The following photographs of the drilling core slabs show Kristallbrocken with exact sampling positions. Black arrows in photographs point to stratigraphically older Hauptsalz sections. Partially, only small relics of Kristallbrocken have been preserved that can be better identified under the microscope than in the photographs below. Next to the sampled drilling core slabs, the results of the bromide analyses are presented in diagrams, with the bromide contents plotted versus the depth in the corresponding drilling core slab. All profiles are plotted in the same horizontal and vertical scale. The approximate position of the anhydrite layers (A) is indicated by dashed lines in the diagrams. The red curve represents the running average of 3 points, and the straight line is a linear fit through the bromide data that provides some indication for the general trend of the bromide curve within each drilling core slab. The results are described in chapter 3.2.1.

\section{- Sample Lt60-11-85}
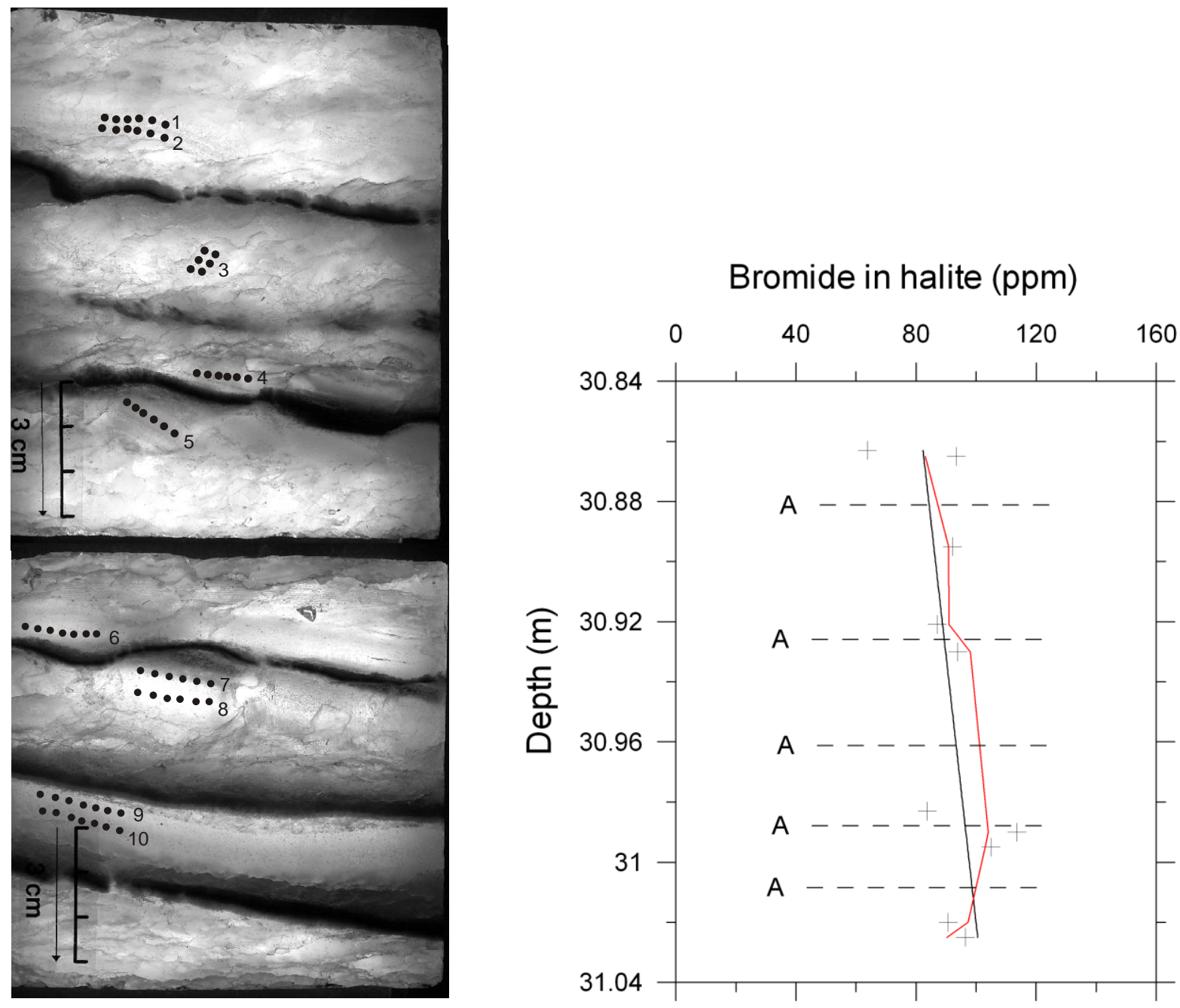
- Sample Lt60-12-93

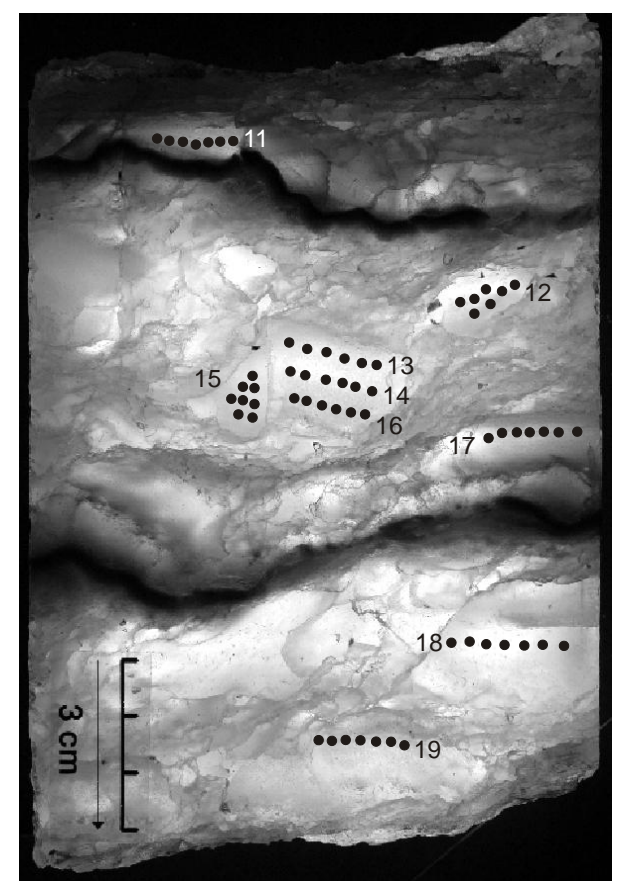

Bromide in halite (ppm)

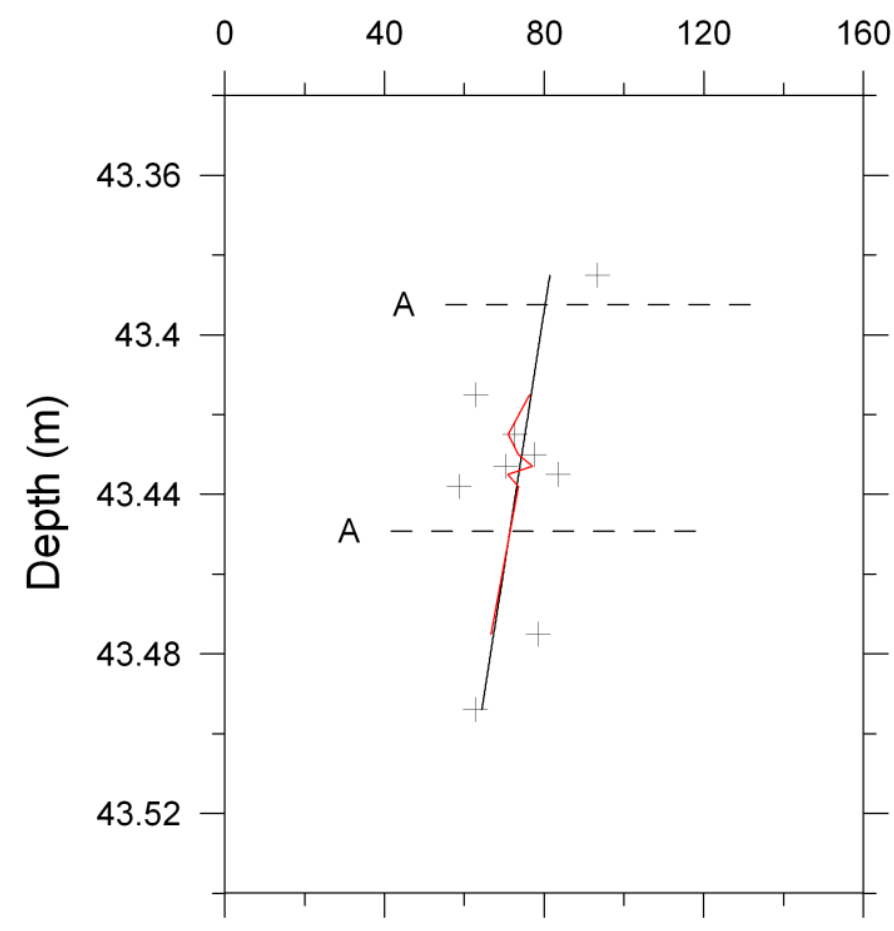

- Sample Lt60-12-102

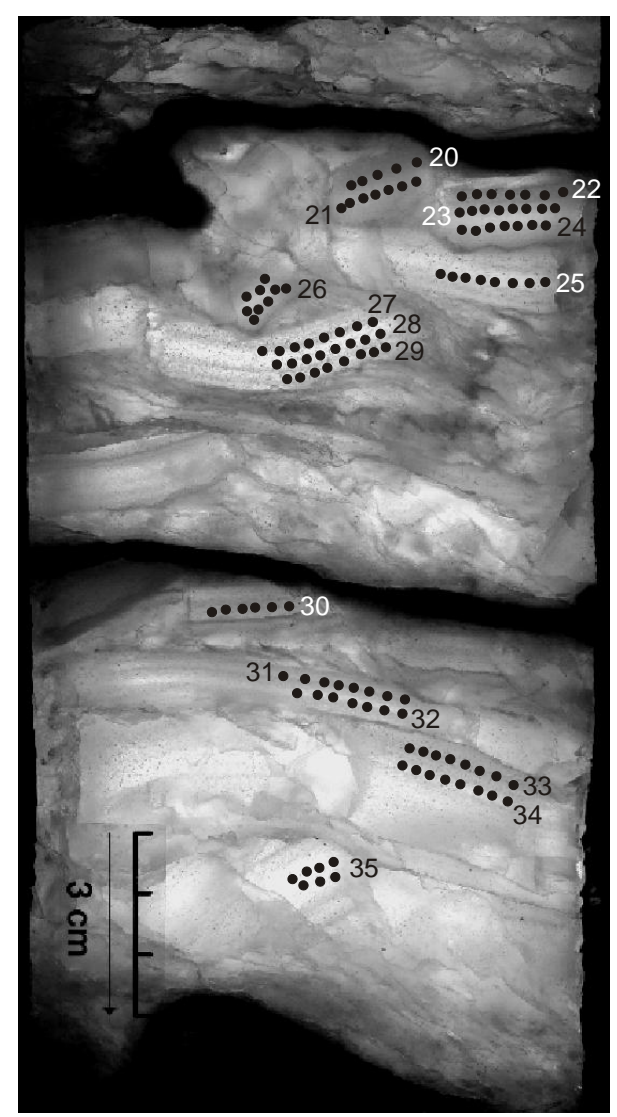

Bromide in halite (ppm)

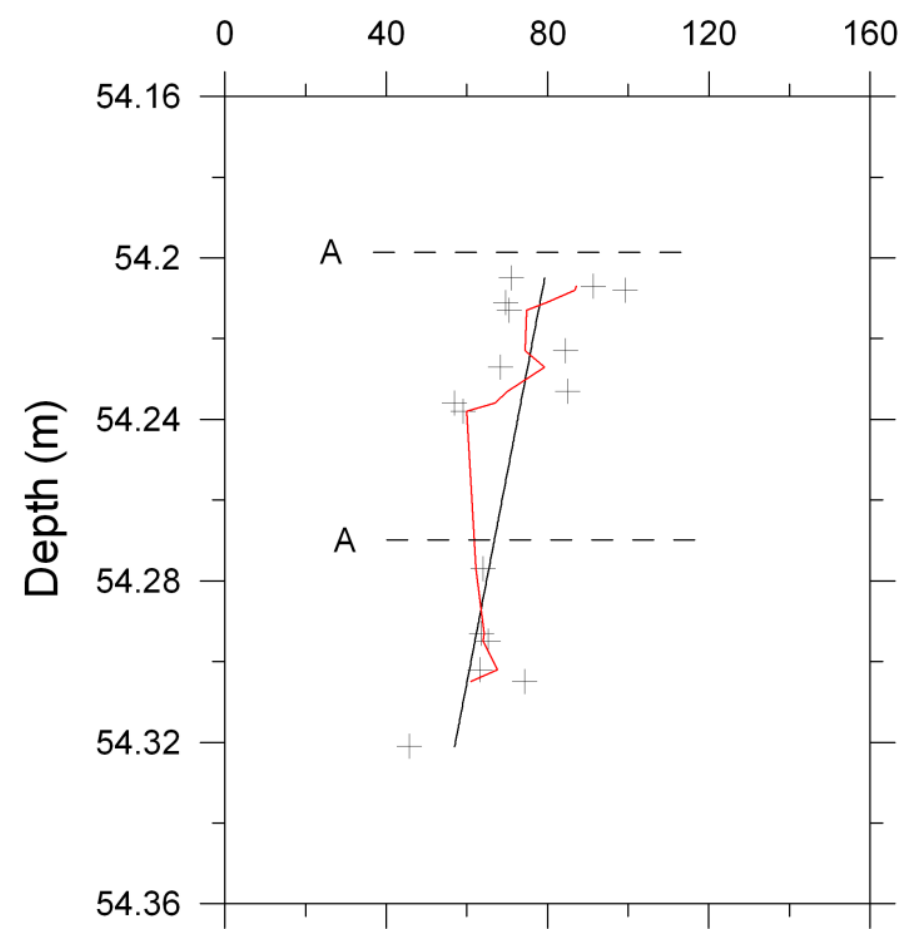


- Sample Lt60-13-115
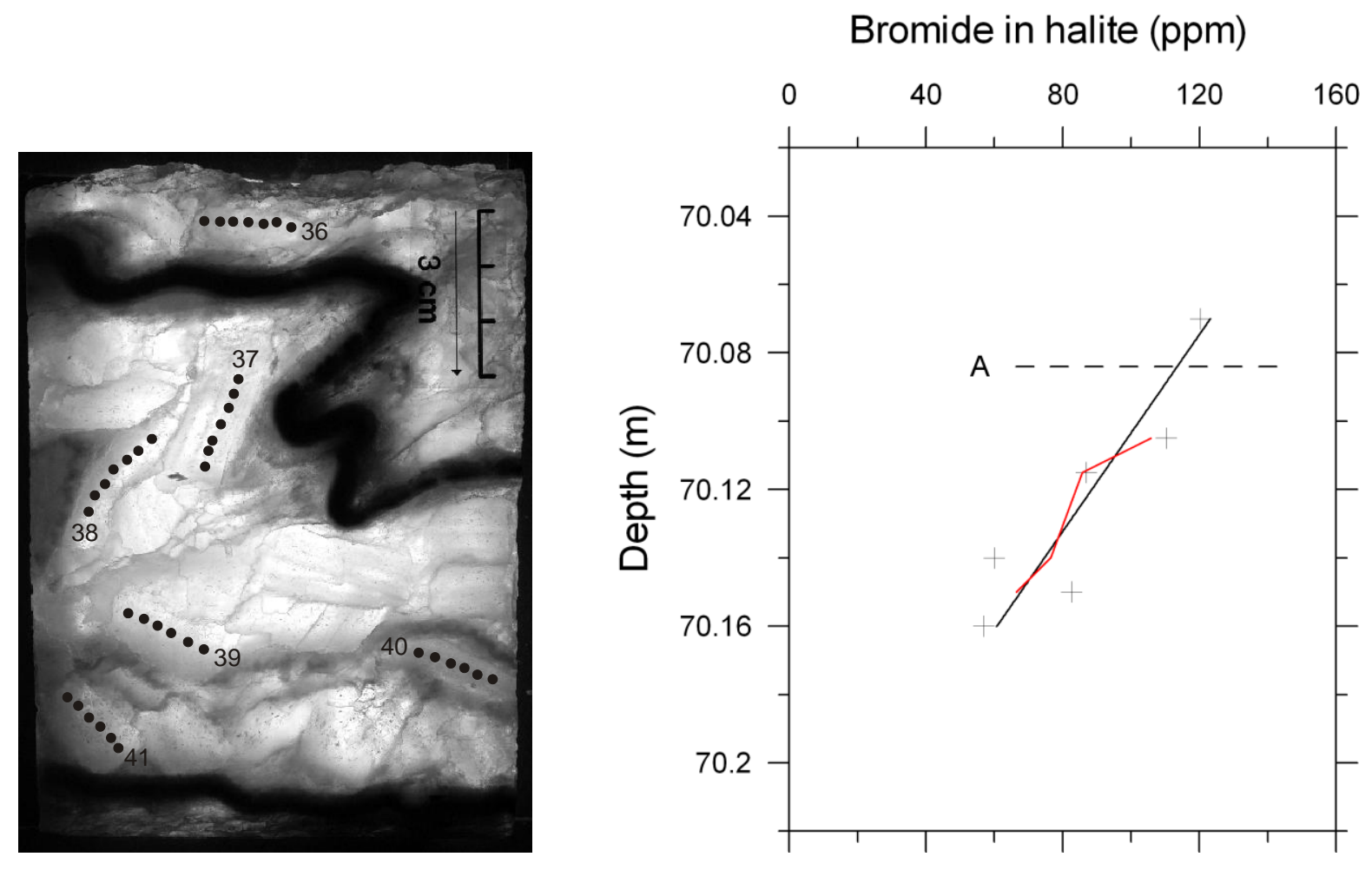

- Sample Lt60-15-136
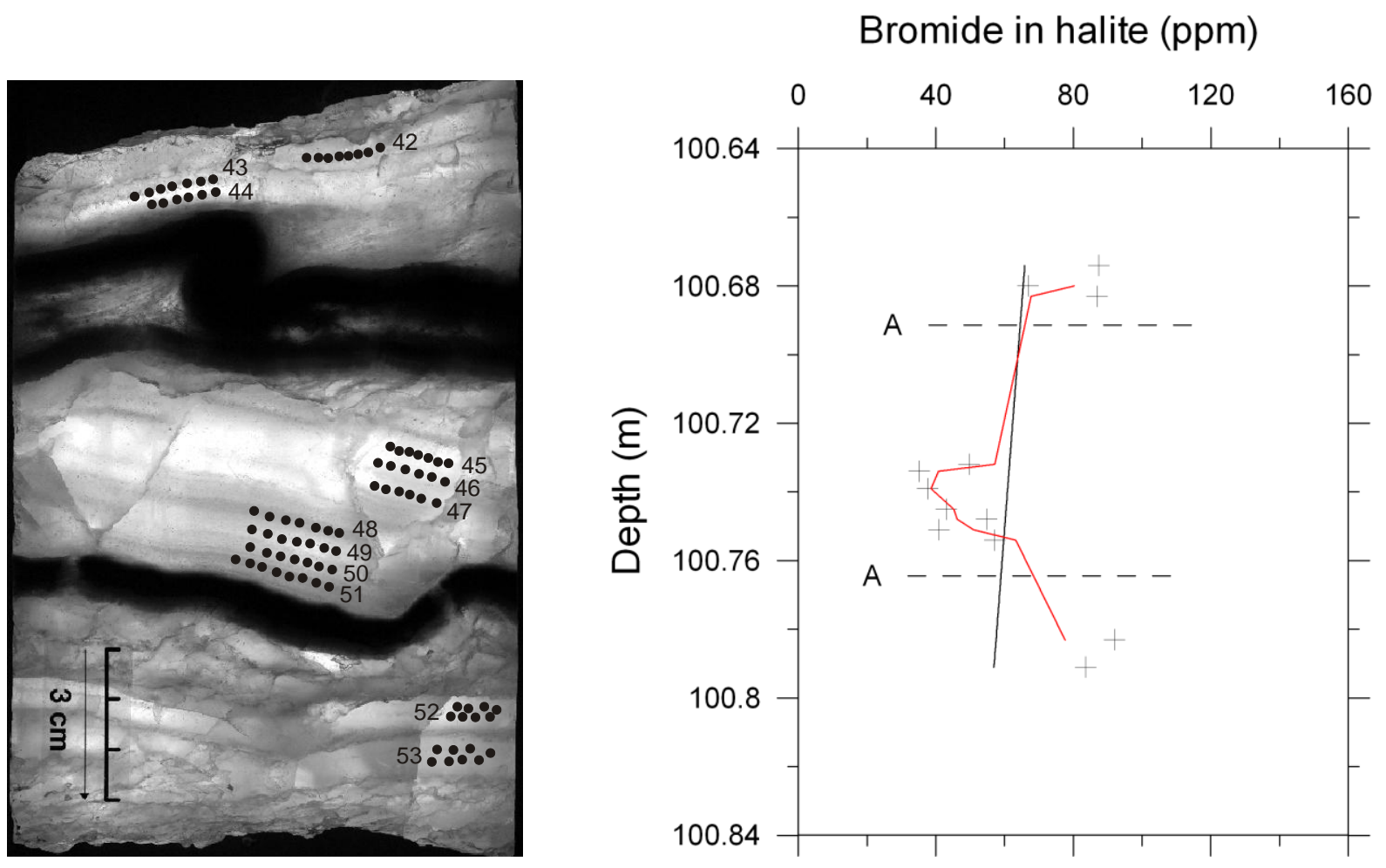
- Sample Lt60-16-154
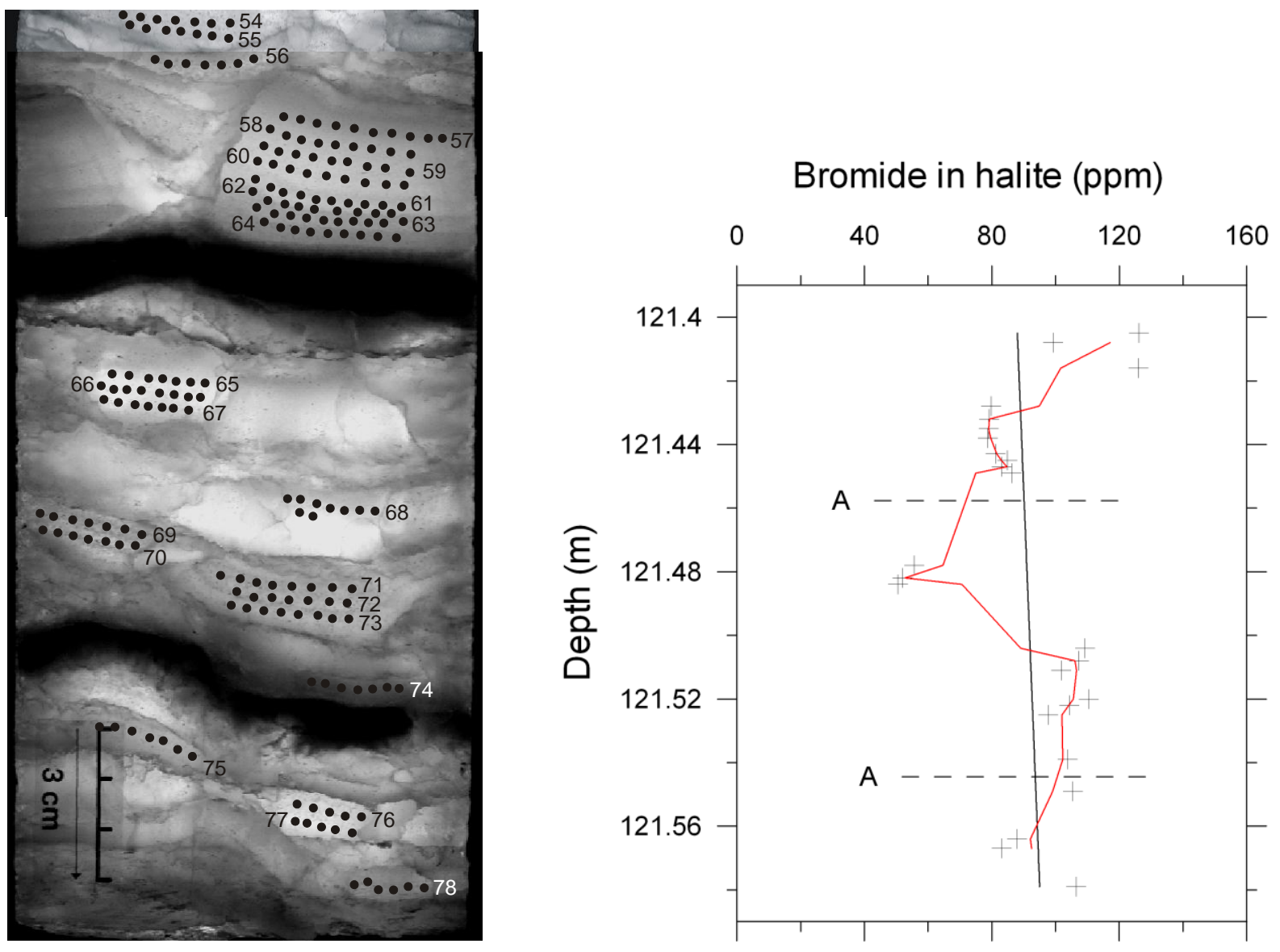

- Sample Lt60-21-210

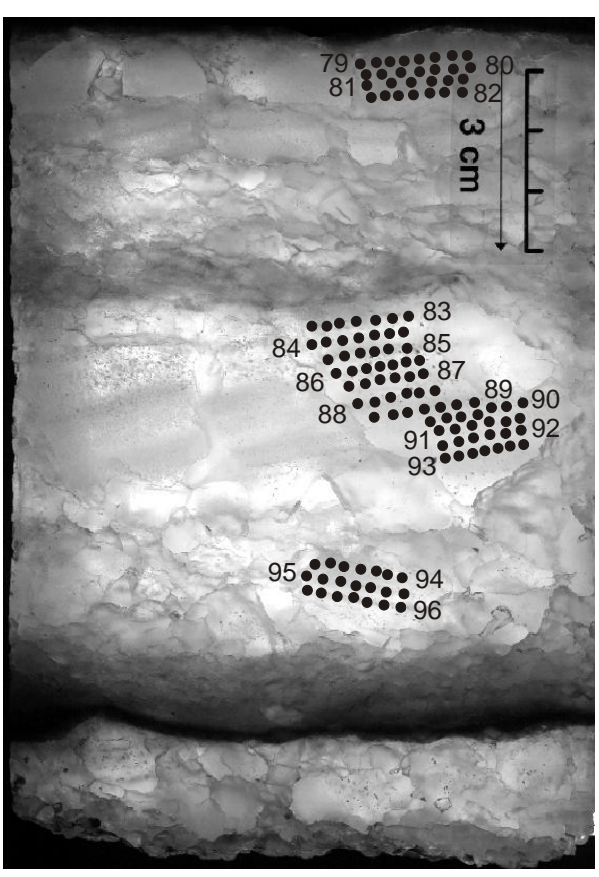

Bromide in halite (ppm)

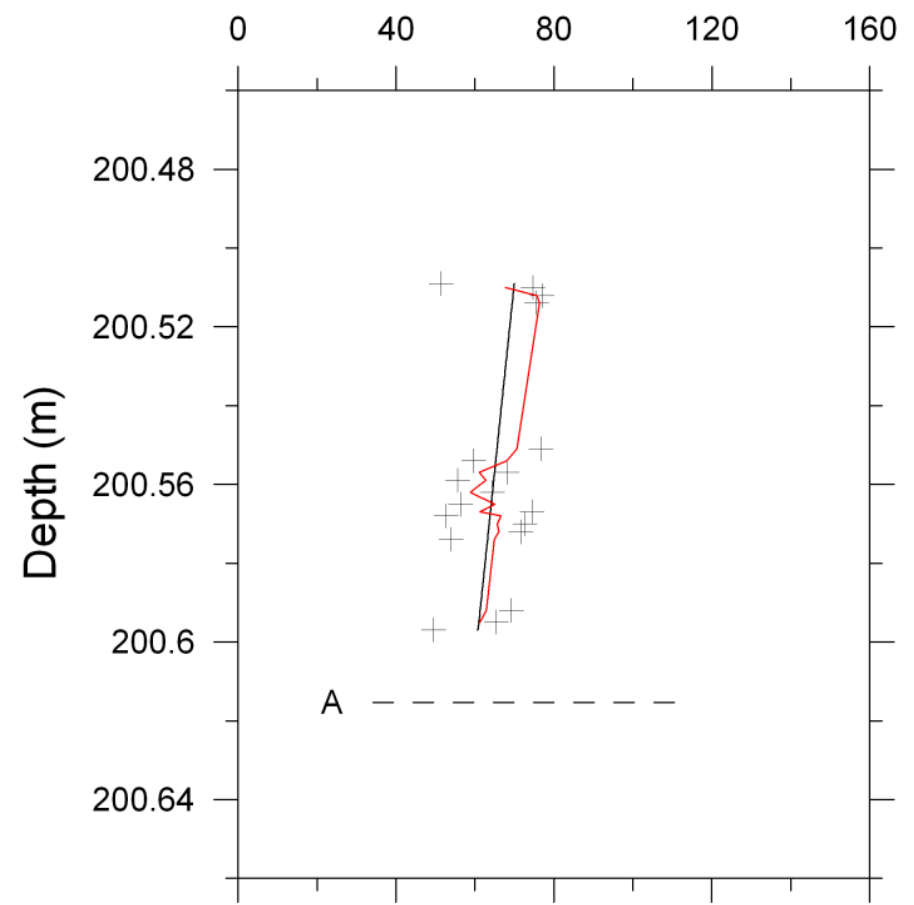


- Sample Lt62-5-135
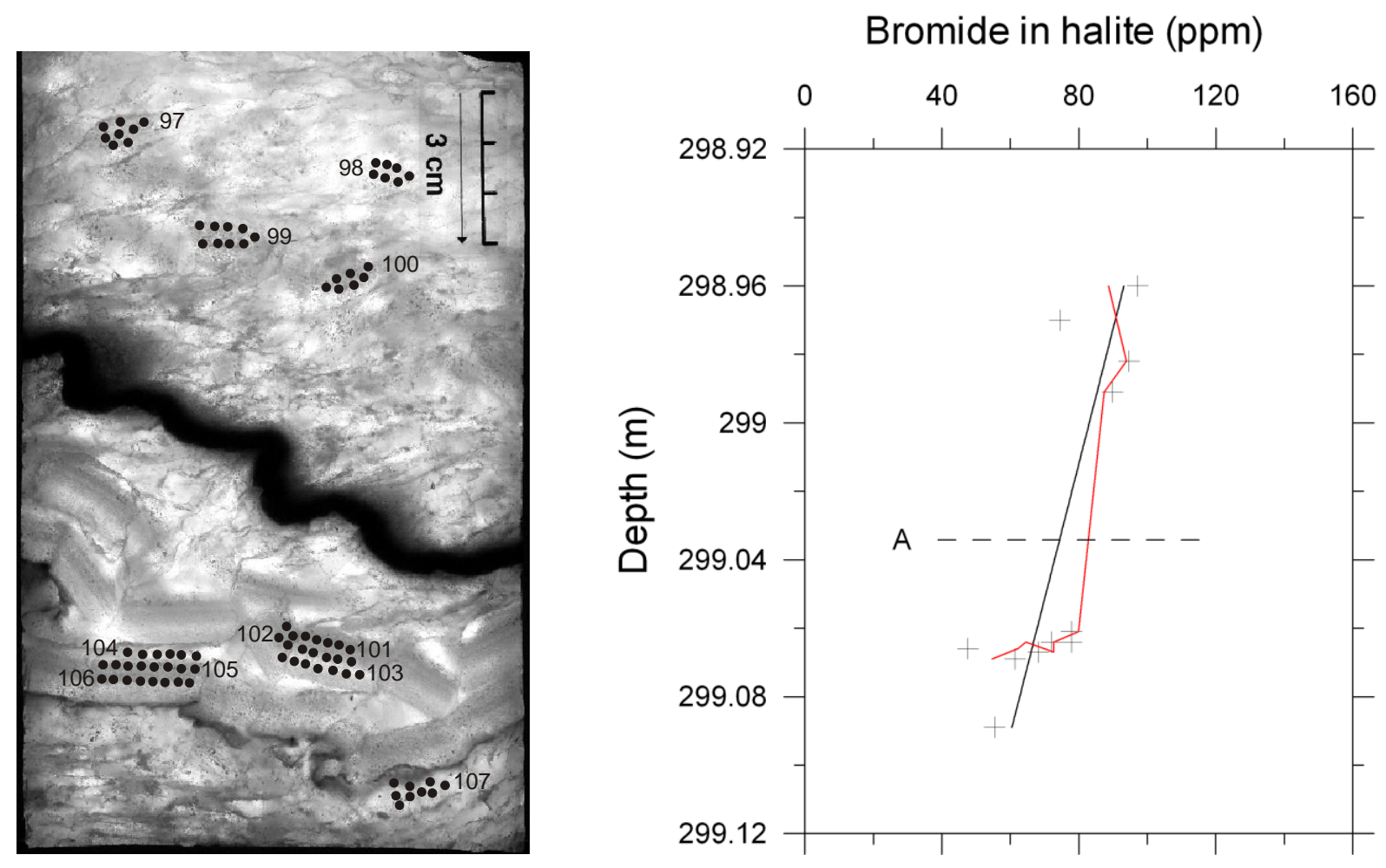

- Sample Lt62-12-66
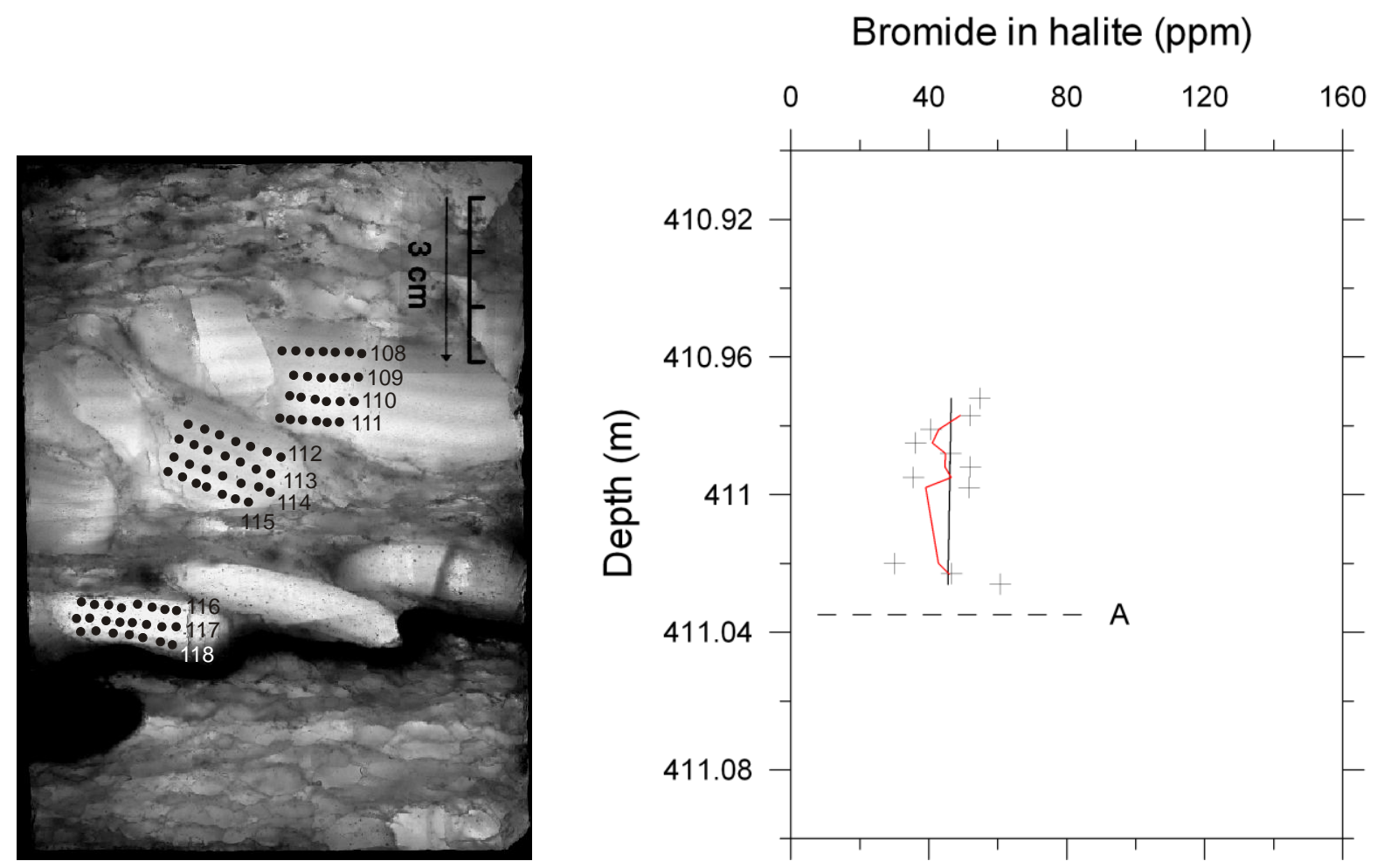


\section{APPENDIX C RESULTS OF X-RAY TEXTURE GONIOMETRY}

The results of the X-ray texture goniometry of the investigated samples Lt62-6-125, Lt60-18174, Lt62-3-151, and Lt60-12-89 are presented as experimental pole figures of the reflections $\{111\},\{220\},\{400\}$, and $\{420\}$. Lowest contour lines (gray) are equal to 1 and 5 m.r.d. From contour line 10 m.r.d. (black), the contour interval is 20 m.r.d. The results are described in detail in chapters 4.1 and 4.3 .

Plot C.1: Pole figures of sample Lt62-6-125_M1

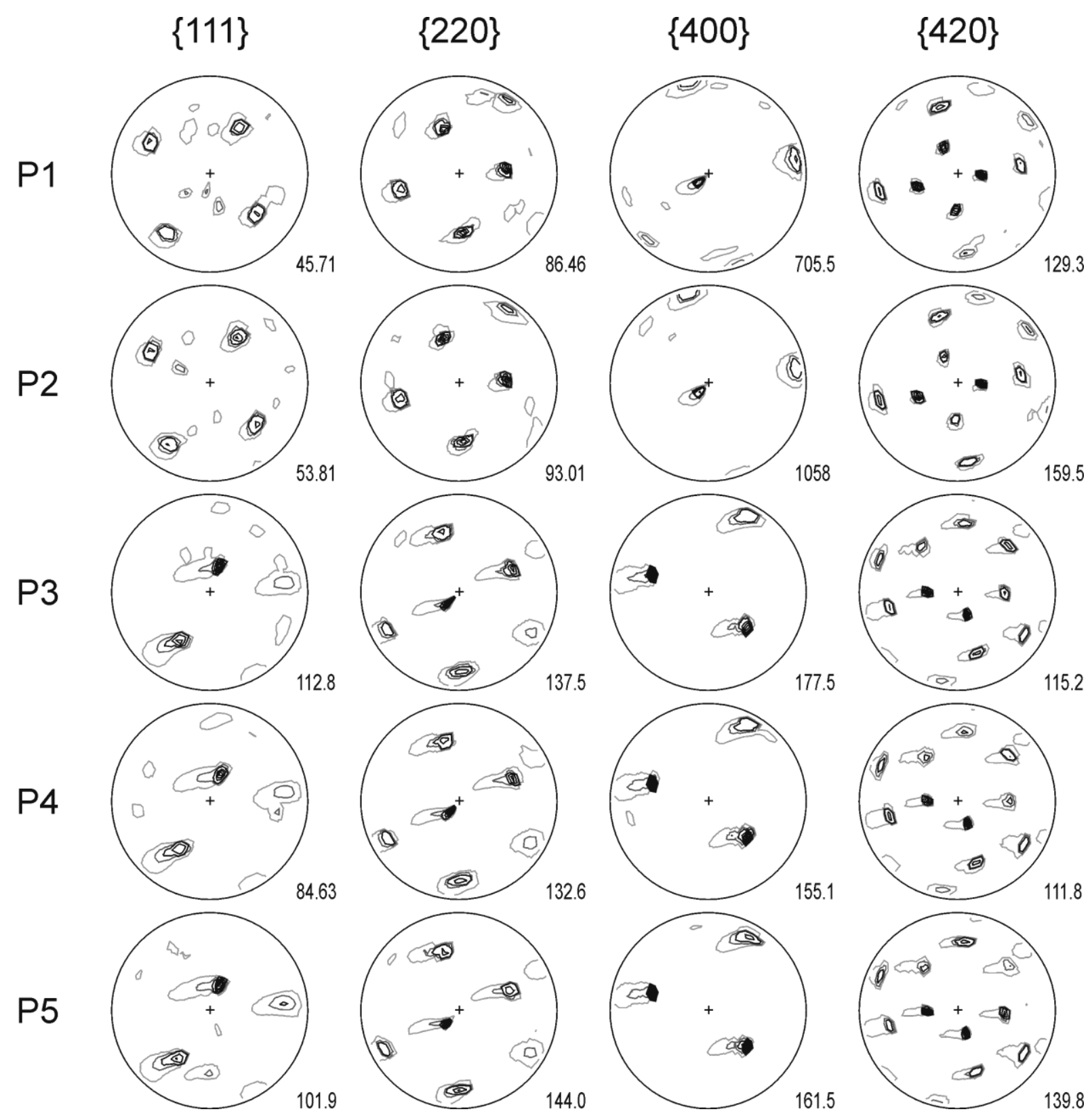


Plot C.1 (continued): Pole figures of sample Lt62-6-125_M1

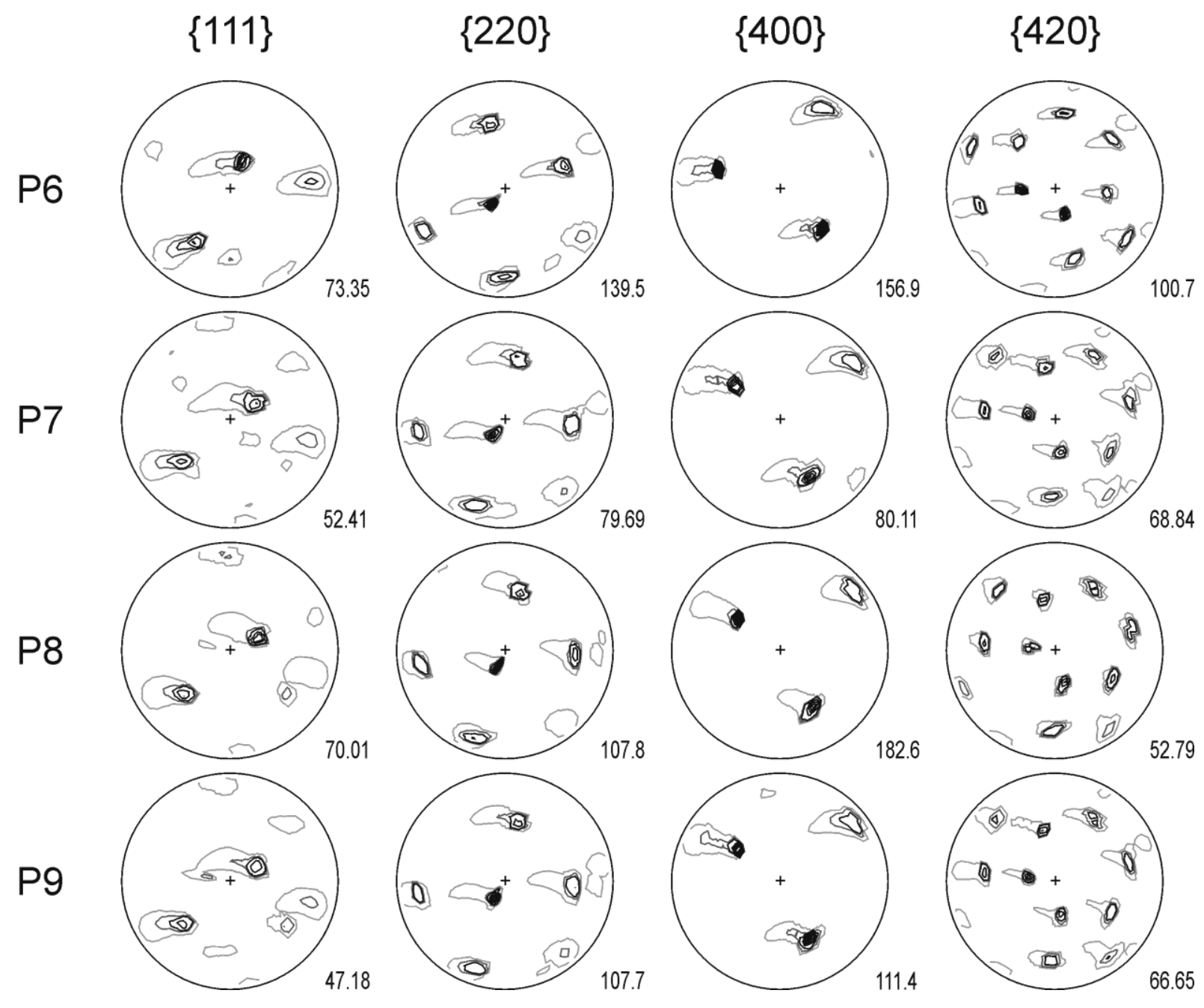


Plot C.2: Pole figures of sample Lt62-6-125_M2

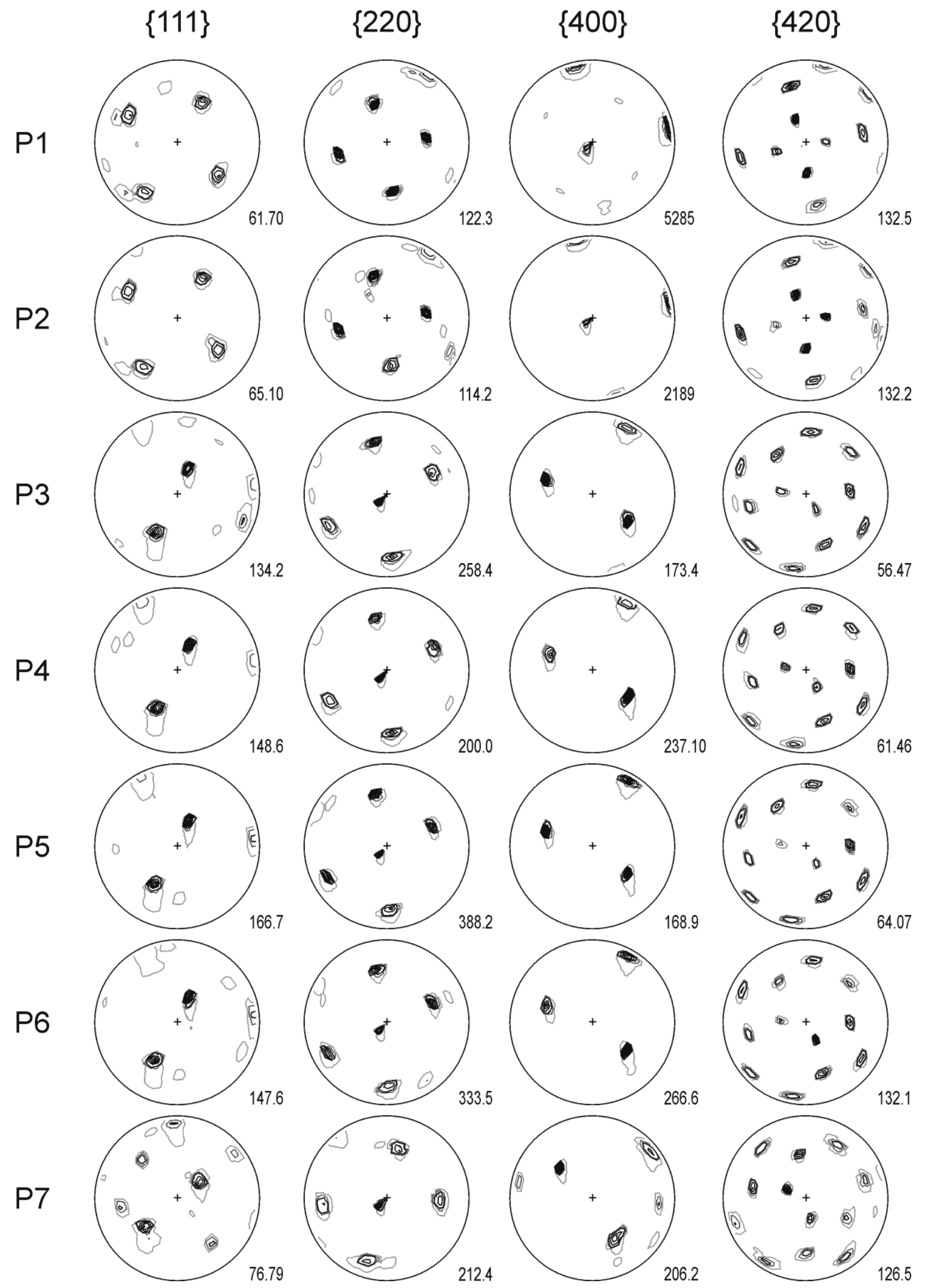


Plot C.2 (continued): Pole figures of sample Lt62-6-125_M2
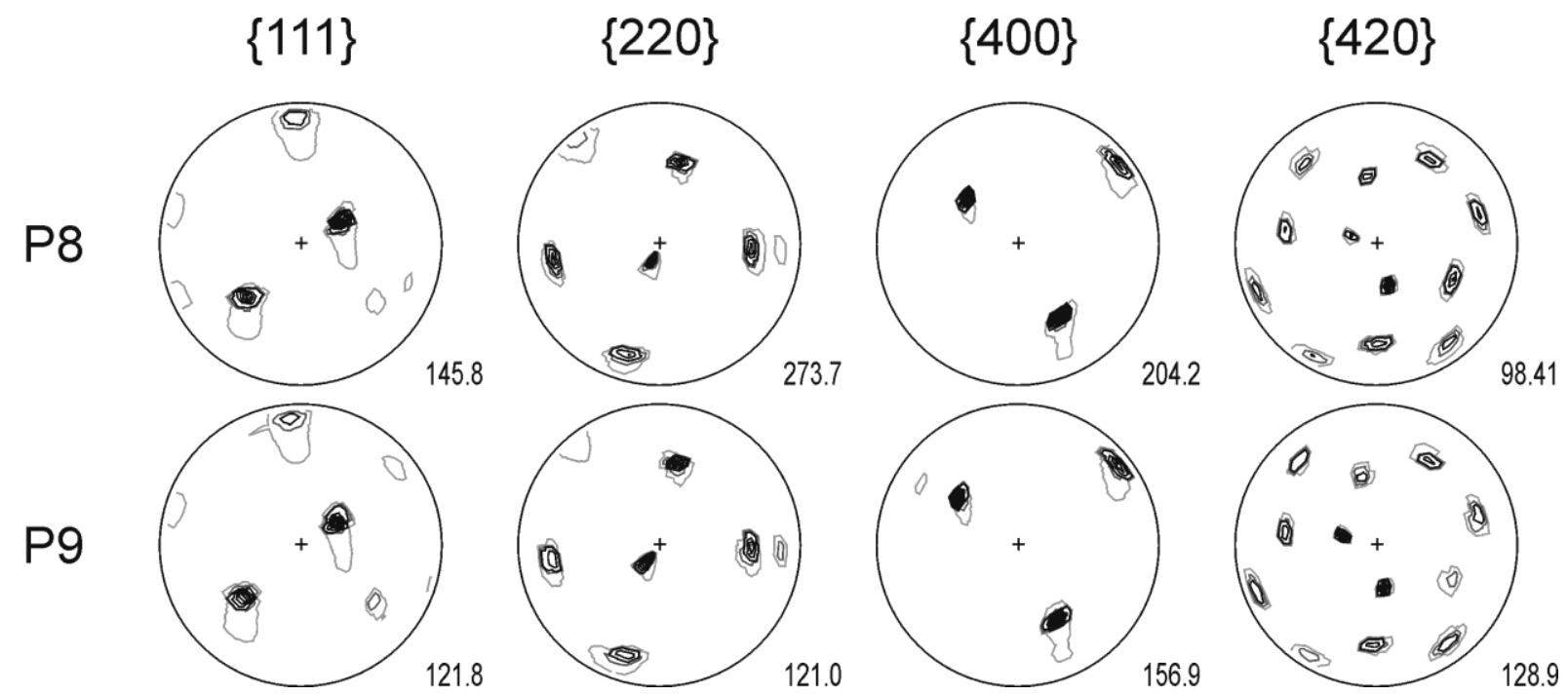
Plot C.3: Pole figures of sample Lt62-6-125_M3

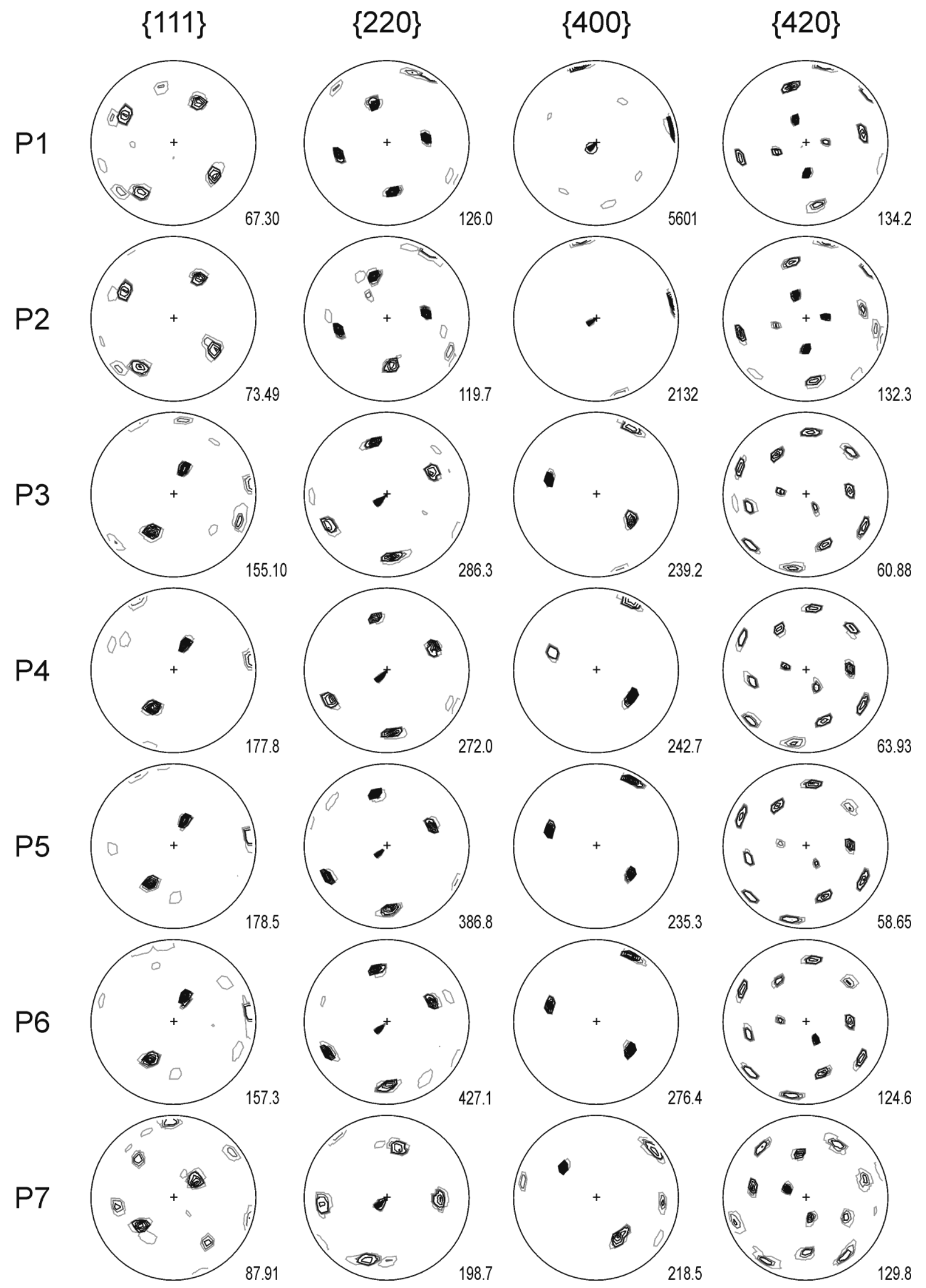


Plot C.3 (continued): Pole figures of sample Lt62-6-125_M3
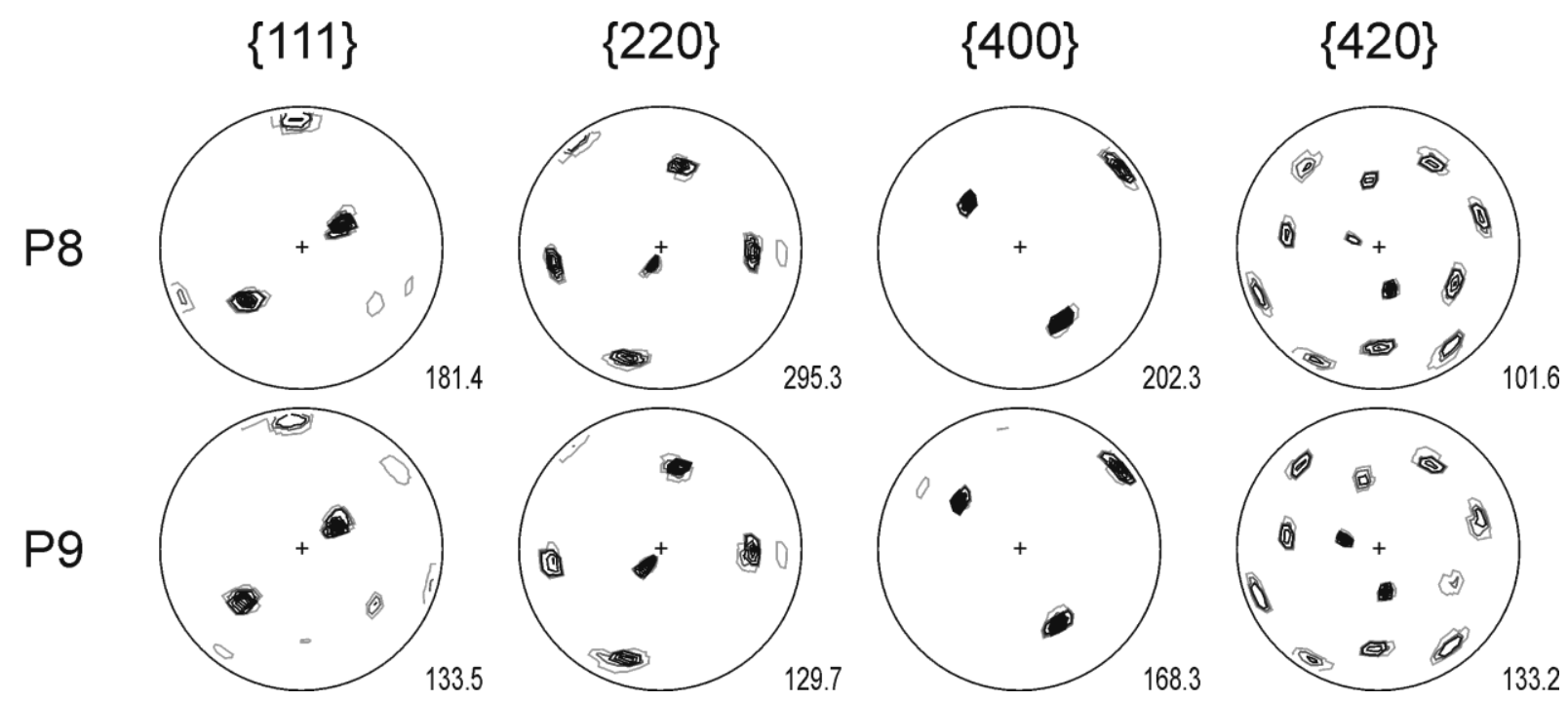
Plot C.4: Pole figures of sample Lt60-18-174

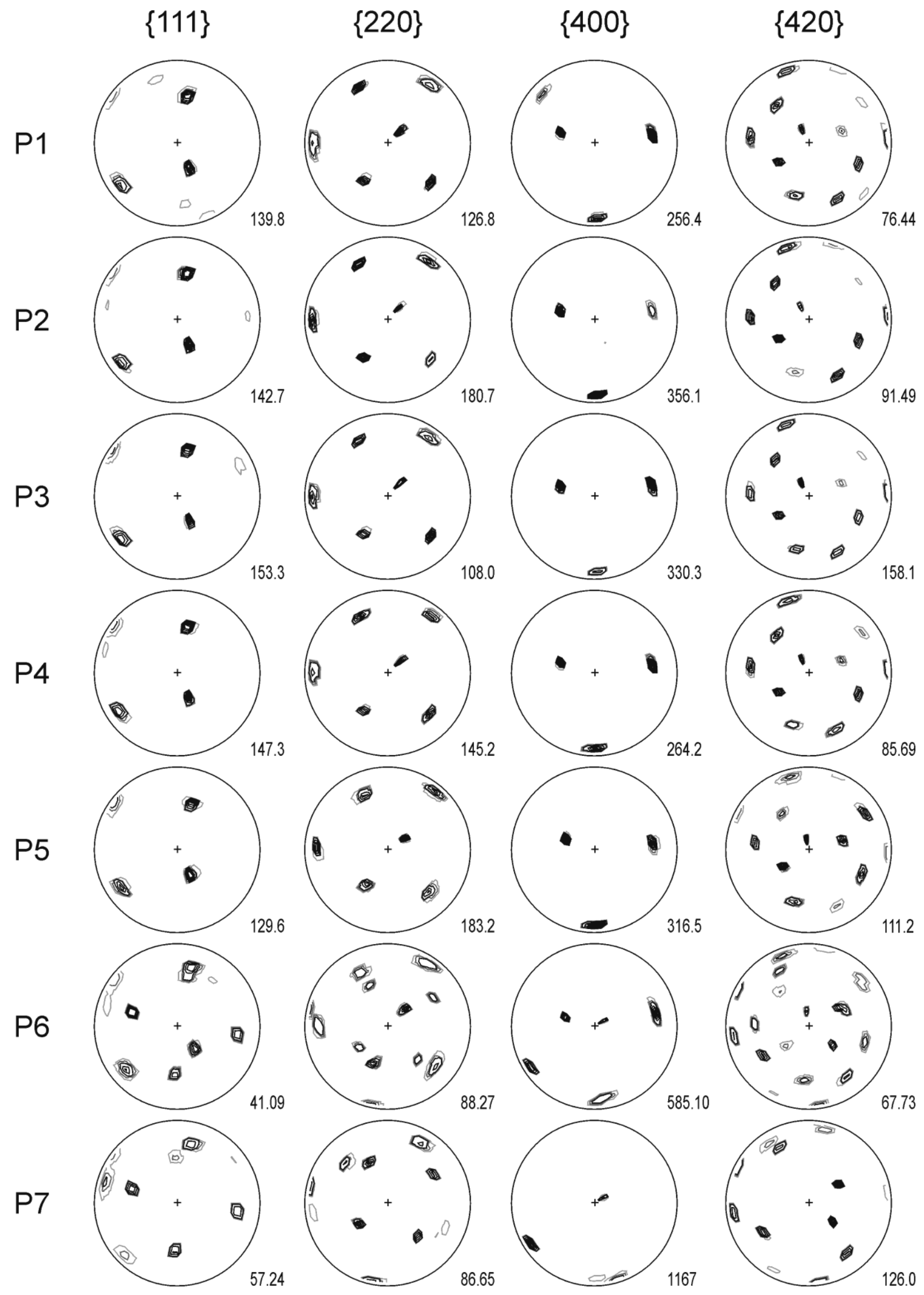


Plot C.4 (continued): Pole figures of sample Lt60-18-174

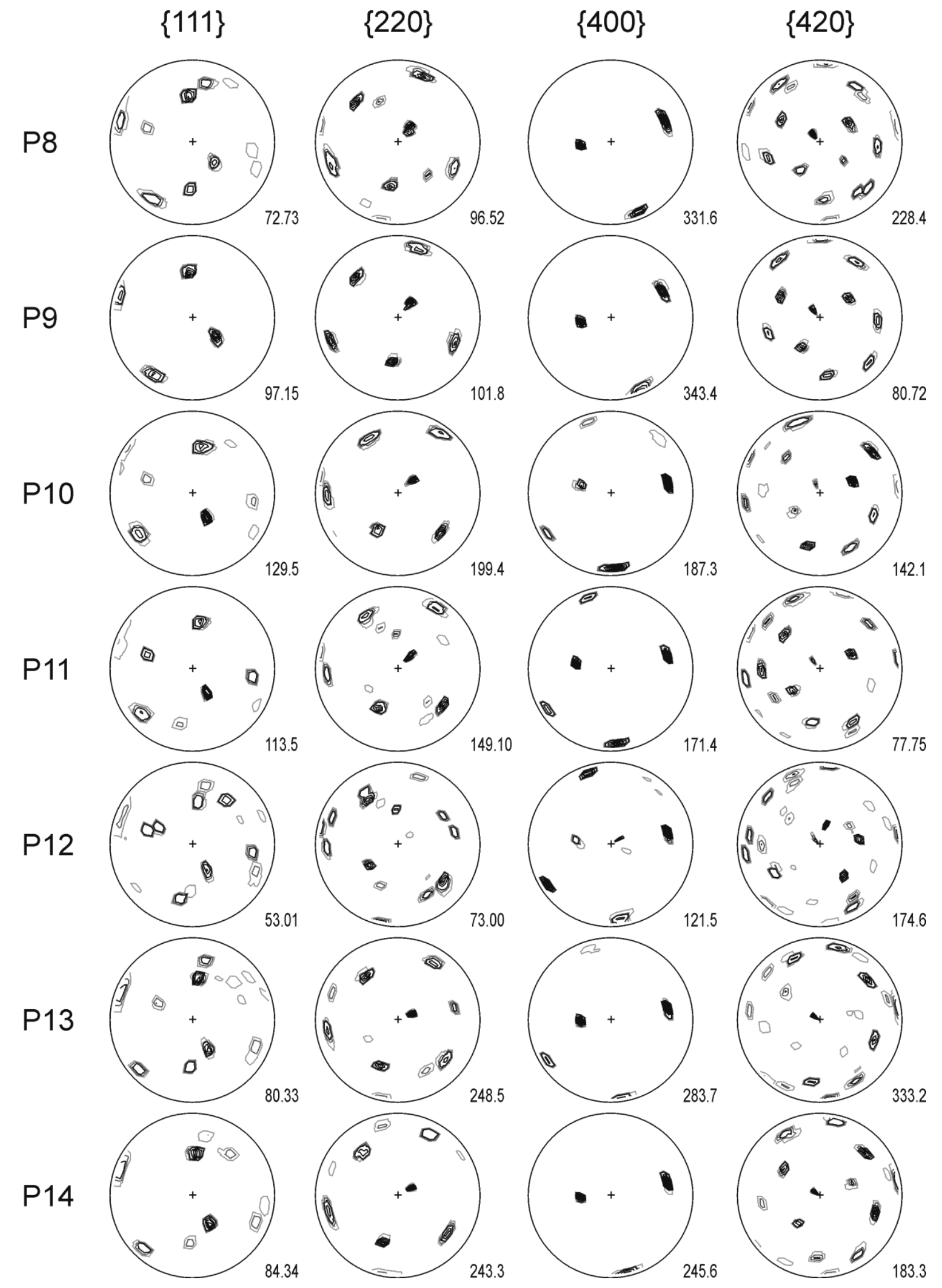


Plot C.4 (continued): Pole figures of sample Lt60-18-174
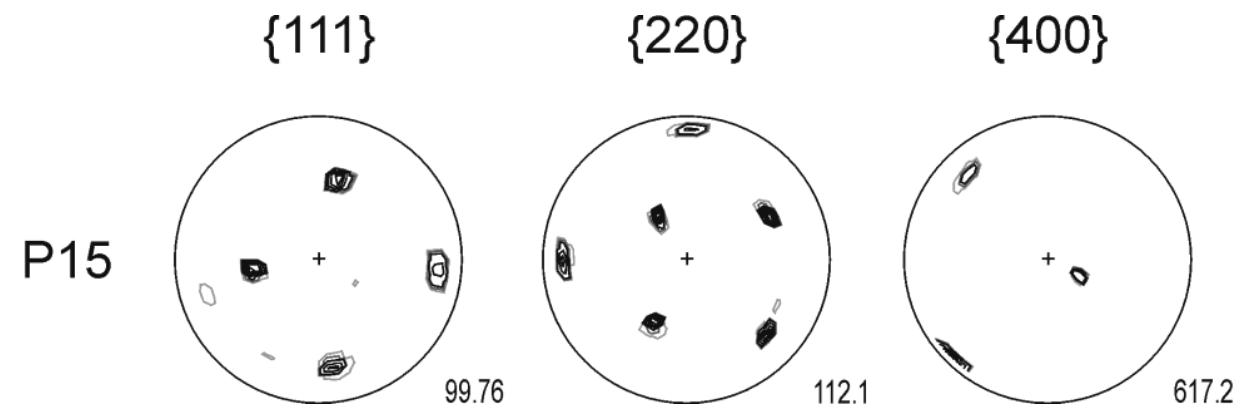

\{420\}

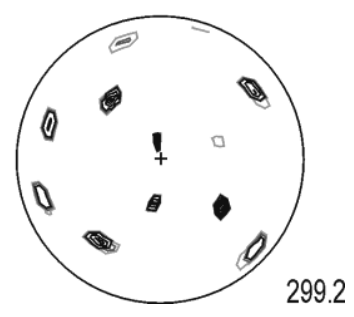


Plot C.5: Pole figures of sample Lt62-3-151

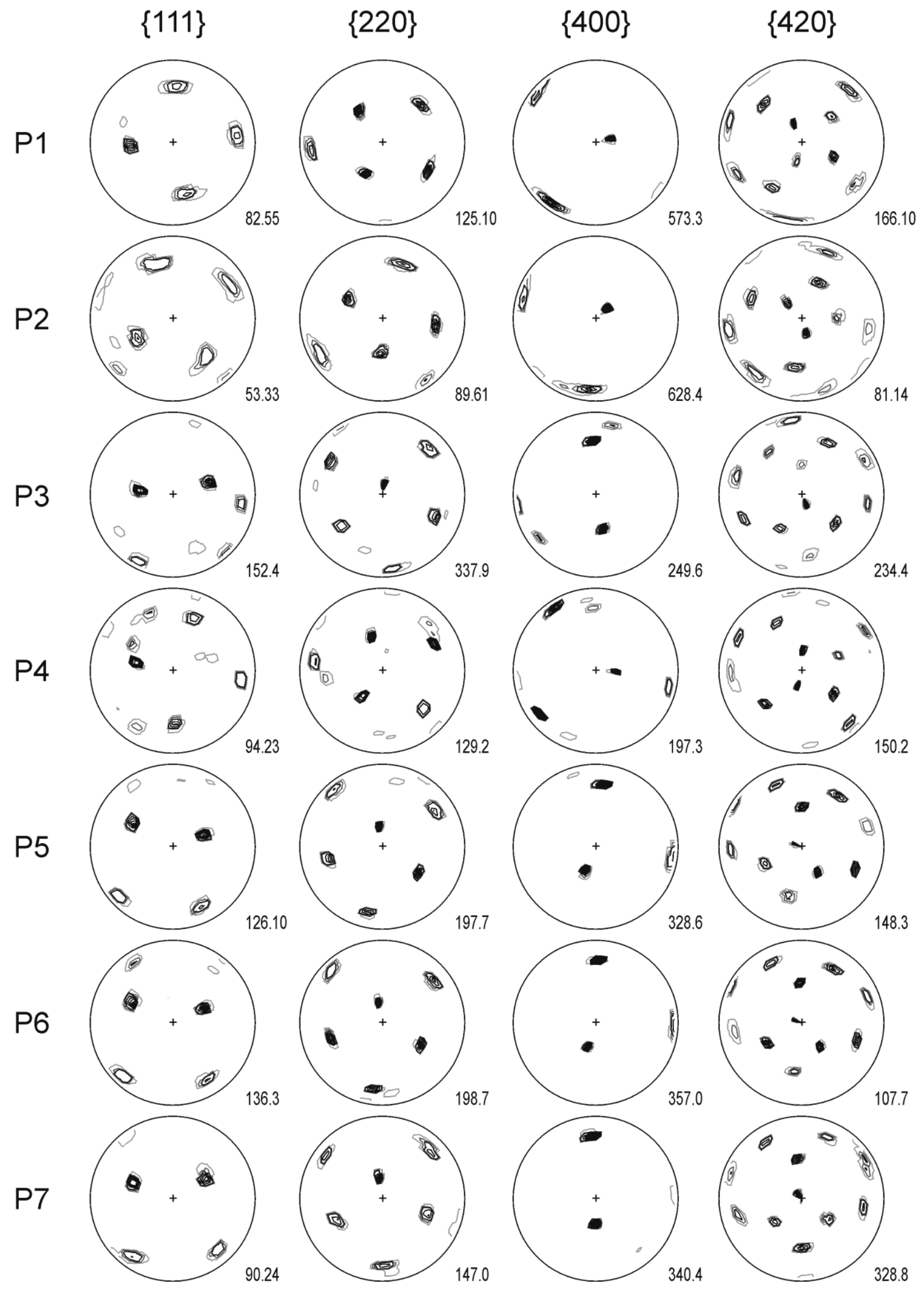


Plot C.5 (continued): Pole figures of sample Lt62-3-151

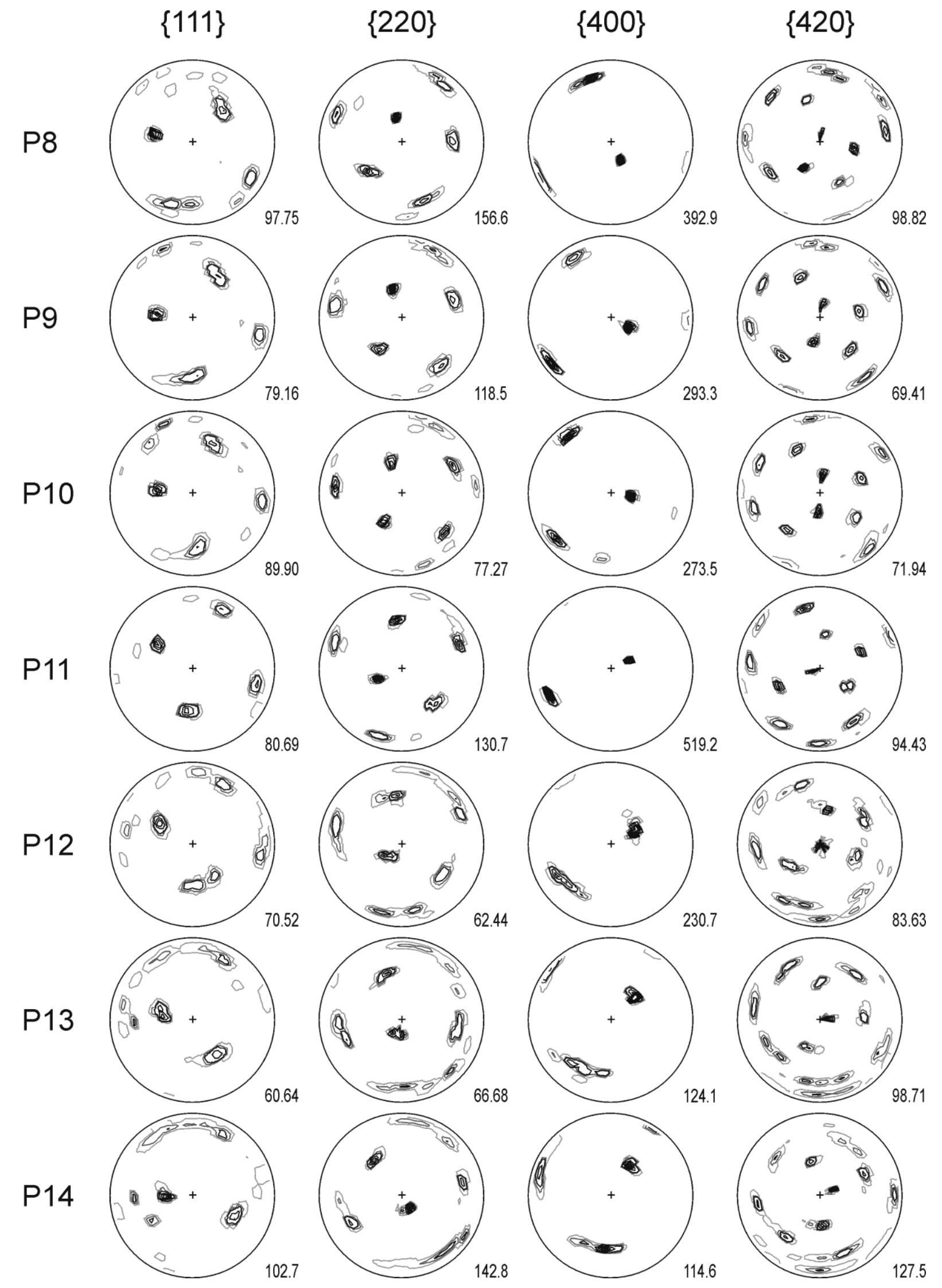


Plot C.5 (continued): Pole figures of sample Lt62-3-151

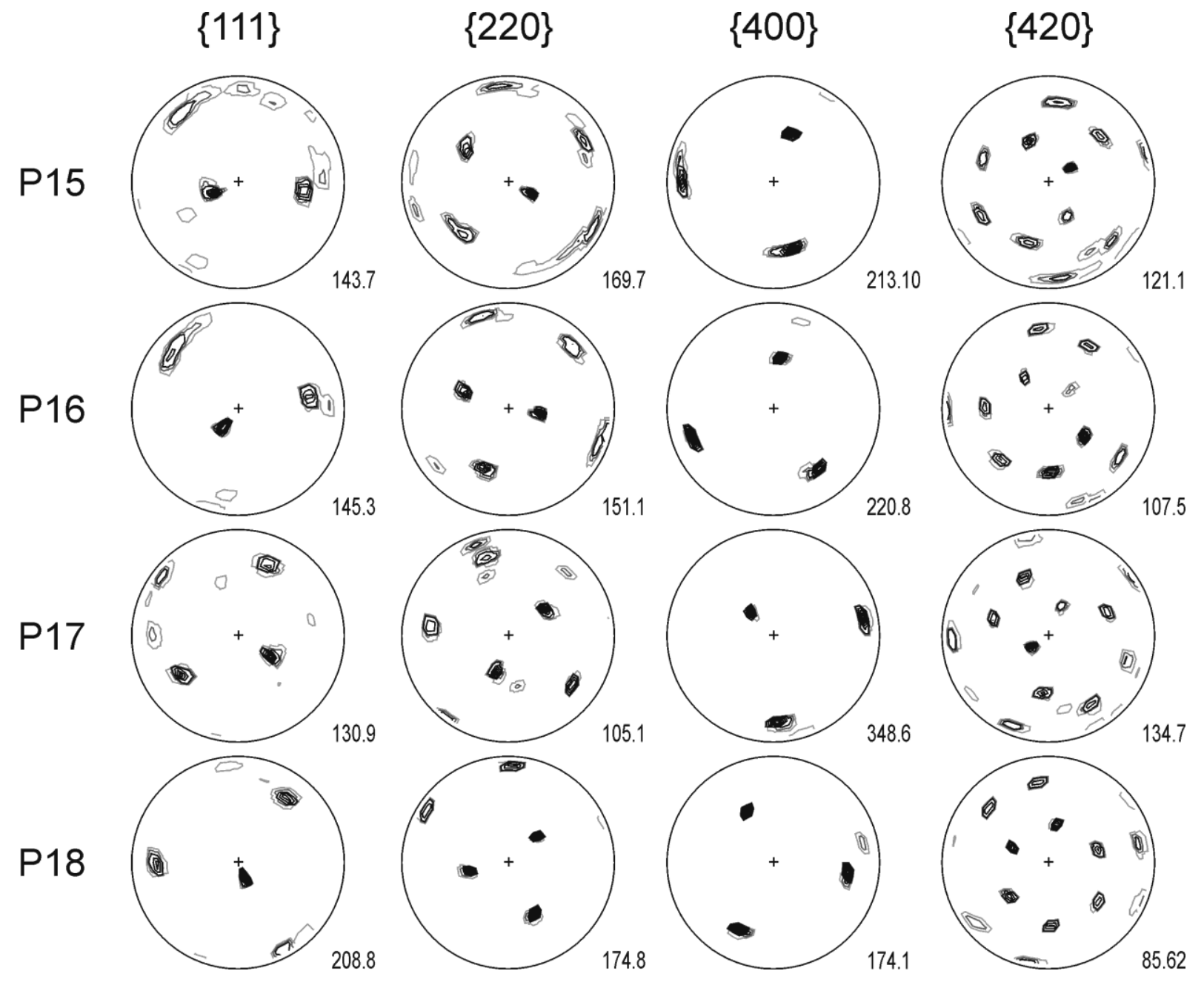


Plot C.6: Pole figures of sample Lt60-12-89

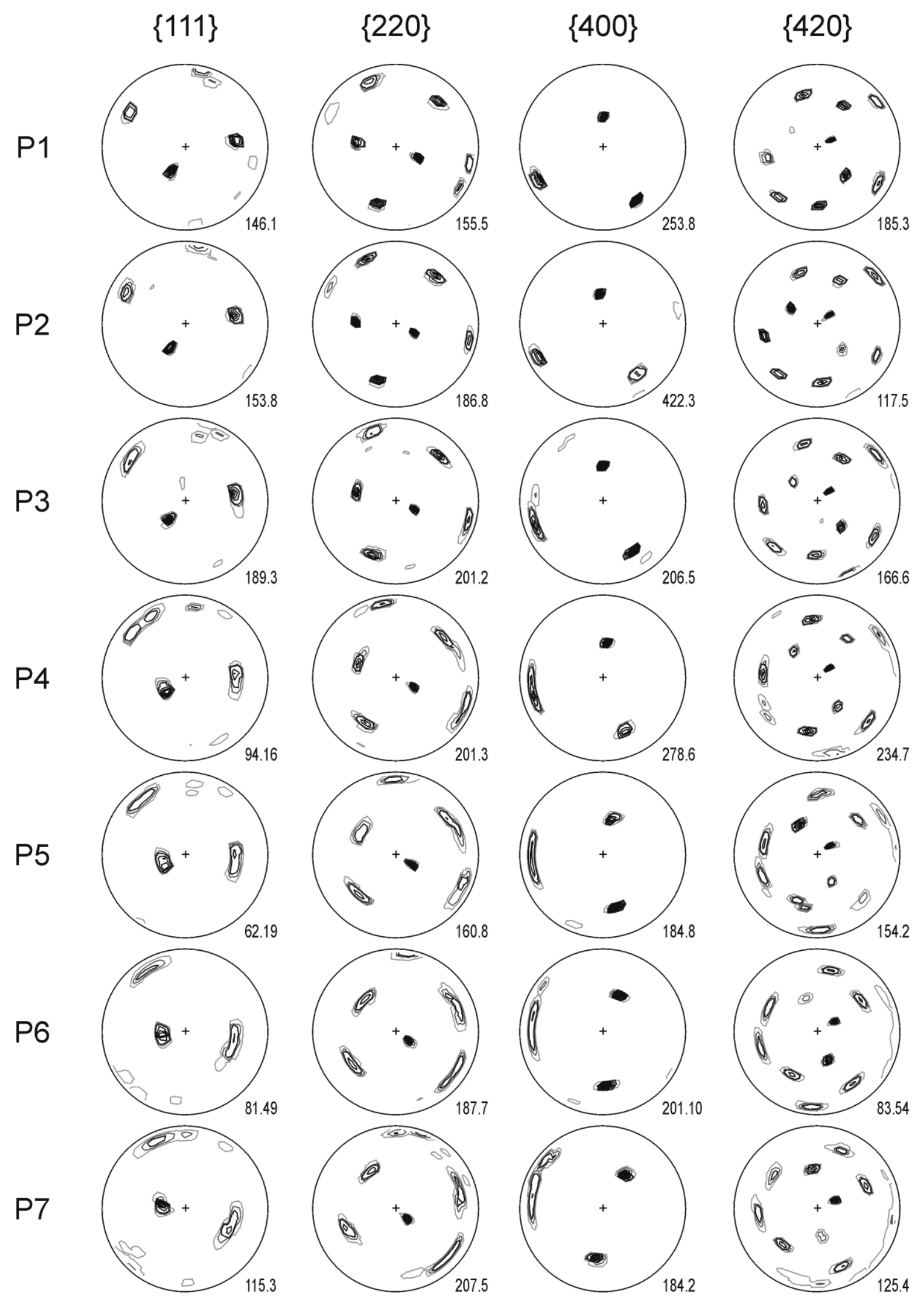


Plot C.6 (continued): Pole figures of sample Lt60-12-89

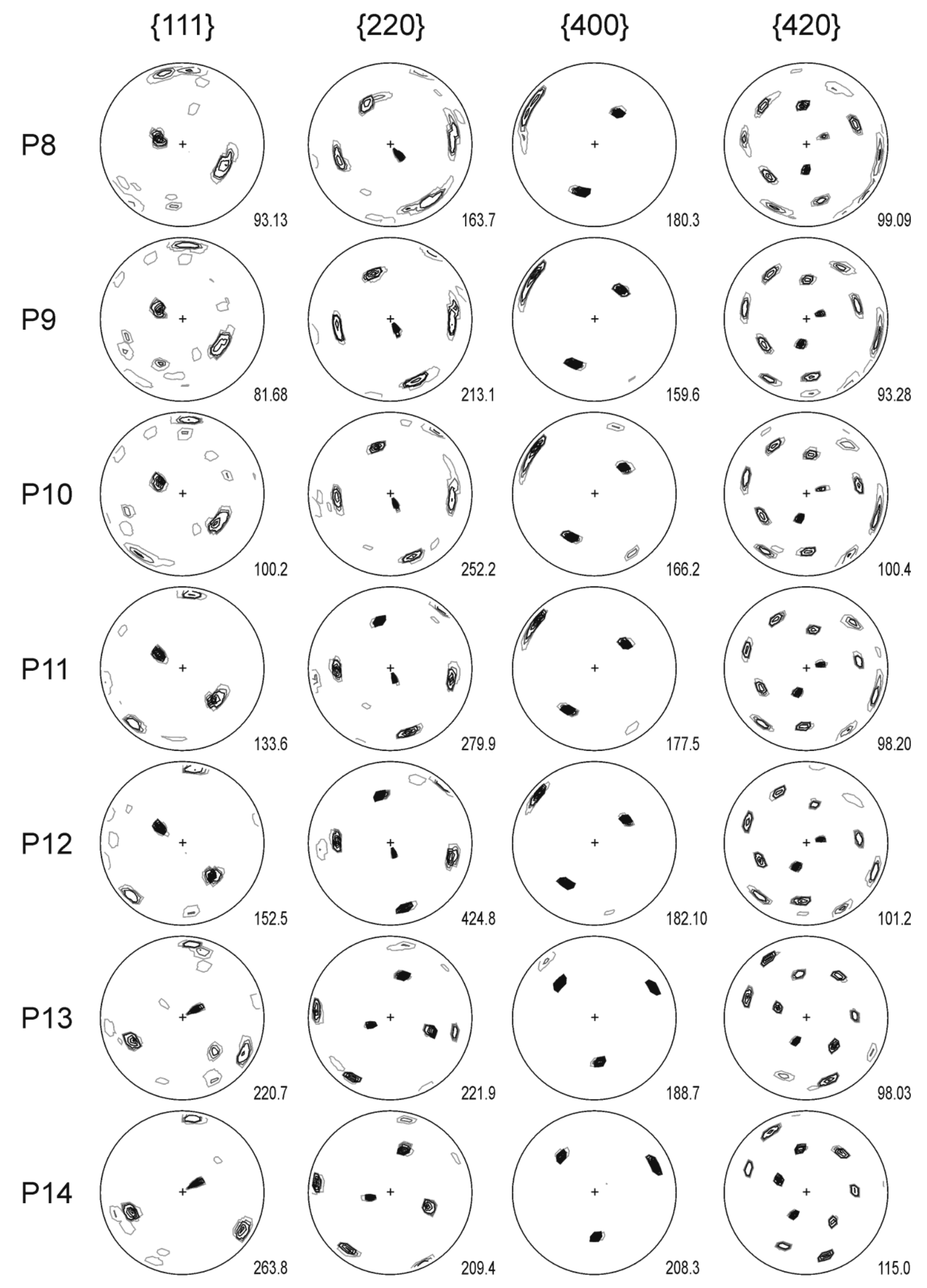





\section{Acknowledgements}

I would like to thank all persons that contributed to this work with their experience, practical help, advice, and encouragement.

First of all, I am especially grateful to my supervisors Dr. Bernd Leiss and Dr. Michael Schramm for their supervision, invaluable input to many discussions, advice regarding the concept of the studies, the technical procedures, the chemical analyses, and the publications, as well as for their general encouragement and support. I thank Dr. Bernd Leiss additionally for introducing me to texture analysis and teaching me the operation of an X-ray texture goniometer.

I thank PD Dr. Helmut Klein and Prof. Dr. Bent Hansen who kindly agreed to be the first and second examiner of this dissertation, respectively. I further thank Prof. Dr. Hans Ruppert and Dr. Axel Vollbrecht for being part of the examination committee.

Many thanks go to Detlev Klosa for technical support and helpful discussion on SEM analyses. I further thank Wolfgang Glatte for analytical measurements and Jerzy Lodziak for microprobe analyses. Adolf Hofmann, Ralf Götze, Maik Gern, and many other technicians in the drill core storage facility were always very helpful. I am grateful for their technical and photographic support as well as for the good working atmosphere. I thank Udo Ziesche for water content analyses. Otto Schulze is thanked for his interest and for helpful discussion on the deformational behavior of the Kristallbrocken. I also want to thank Dr. Jörg Hammer for helpful comments on parts of the dissertation.

This thesis has been carried out within the framework of the project no. 9 Y3215020000 financed by the Federal Institute for Geosciences and Natural Resources (BGR), and I would like to thank Dr. Otto Bornemann for giving me the opportunity to take part in this project.

Special thanks go to my family. Dennis - thank you for being part of my life, for your love, understanding, support and continuous patience during the process of writing my dissertation. I thank Larissa and Lionel for being the wonderful children they are and for challenging me every day in a "non-scientific" way. 



\section{Lebenslauf}

Vor- und Zuname: $\quad$ Yvonne Küster

Geburtsdatum und -ort: $\quad$ 30.03.1979 in Görlitz

Familienstand: verheiratet, 2 Kinder

Staatsangehörigkeit: deutsch

$\underline{\text { Ausbildung }}$

2006-2011 Promotion mit dem Thema: „Bromide characteristics and deformation mechanisms of naturally deformed rock salt of the German Zechstein Basin“, Universität Göttingen

2004-2007 Wissenschaftliche Angestellte an der Bundesanstalt für Geowissenschaften und Rohstoffe (BGR), Hannover

09/2003 Diplom Geologie/Paläontologie; Diplomarbeit mit dem Thema: „Lumineszenz-Datierung an äolischen Deckschichten von tektonischen Flussterrassen am Nordrand von Tibet"

10/1997-09/2003 Studium der Geologie/Paläontologie an der TU Bergakademie Freiberg

$07 / 1997$

Abitur am "Frederic-Joliot-Curie-Gymnasium” in Görlitz

Ort, Datum

Unterschrift 